
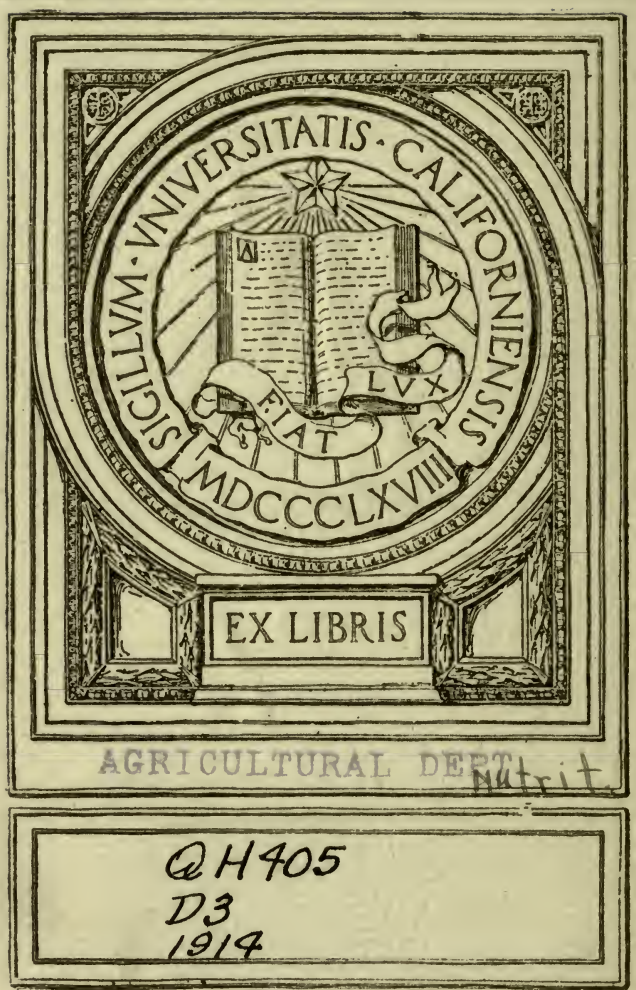

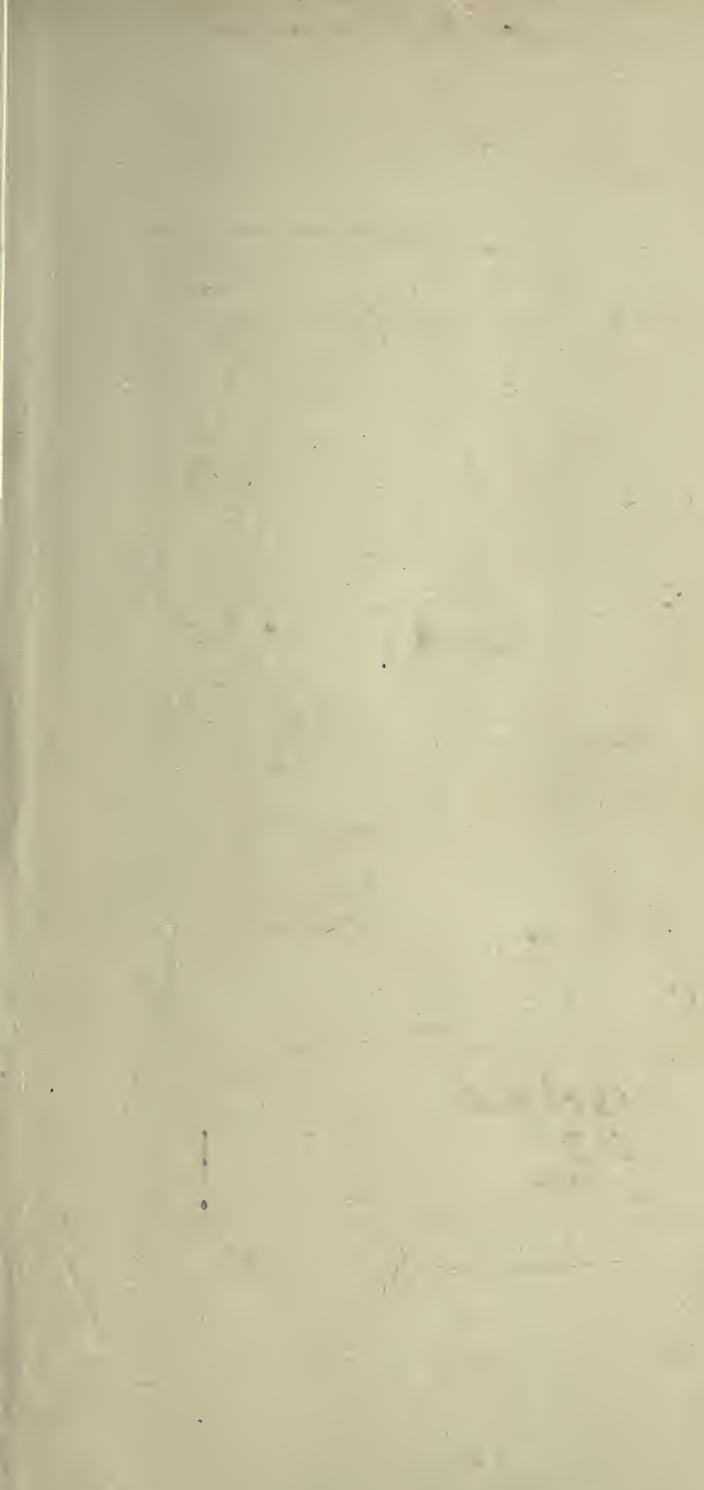

w 
Digitized by the Internet Archive in 2007 with funding from Microsoft Corporation 




\title{
STATISTICAL METHODS
}

WITH SPECIAL REFERENCE TO

\section{BIOLOGICAL VARIATION.}

\author{
BY \\ C. B. DAVENPORT, \\ Director of Department of Experimental Evolution, \\ Carnegie Institution of Washington.
}

THIRD, REVISED EDITION. FIRST THOUSANA :

NEW YORK

JOHN WILEY \& SONS, INC.

LONDON: CHAPMAN \& HALL, LIMITED 
Copyright, 1899, 1904,

BI

C. B. DAVENPOR?。

Qgric, hutrition

PRESS OF

BRAUNWORTH \& CO. BROOKLYN, N. Y. 


\section{PREFACE.}

THIs book has been issued in answer to a repeated call for a simple presentation of the newer statistical methods in their application to biology. The immediate need which has called it forth is that of a handbook containing the working formulæ for use at summer laboratories where material for variation. study abounds. In order that the book should not be too bulky the text has been condensed as much as is consistent with clearness.

This book was already in rough draft when the work of Duncker appeared in Roux's Archiv. I have made much use of Duncker's paper, especially in Chapter IV. I am indebted to Dr. Frederick H. Safford, Assistant Professor of Mathematics at the University of Cincinnati and formerly Instructor at Harvard University. for kindly reading the proofs and for valuable advice. To Messrs. Keuffel and Esser, of New York, I am indebted for the use of the electrotypes of Figures 1 and 2. Finally, I cannot fail to acknowledge the cordial coöperation which the publishers have given in making the book serviceable.

C. B. Davenport.

Biological Laboratory of the Brooklyn Institute, Cold Spring Harbor, LoNg Island, June 29, 1899. 


\section{PREFACE TO THE SECOND EDITION. -}

THE first edition of this book having been favorably received, the publishers have authorized a revised edition embodying many of the new statistical methods elaborated chiefly by Professor Karl Pearson and his students and associates, and presenting a summary of the results gained by these methods. These, while increasing somewhat the bulk of the book, have, it is hoped, rendered it more serviceable to investigators. Too much emphasis can hardly be laid on the debt that Biometricians owe to Professor Pearson's indefatigable researches in the new science of Biometry - especially in the development of Statistical Theory.

The publishers, also, of this book are deserving of credit for the courage they have shown in reproducing expensive tables for the use of a still very limited body of statistical workers. Especial attention is called to Table IV, which is an extension of Table IV of the first edition that was calculated by Professor Frederick H. Safford, and appears to have been the first published table of the normal probability integrals based on the standard deviation. More recently Mr. W. F. Sheppard has published in Biometrika a similar table in which, however, the tabular entries are given to seven places of decimals, while the arguments are given to two decimal places only. In the present table the arguments are subdivided to three places of decimals and with the aid of the table of proportional parts interpolation is easily effected.

Especial acknowledgment must be made of assistance received from my friend Mr. F. E. Lutz, who read over the entire manuscript and contributed certain of the numerical examples.

Station for Experimental Evolution Carnegie institution of Washington.

Cold Spring Harbor,

March 27, 1904. 


\section{CON'TENTS.}

\section{CHAPTER I. \\ On Methods of Measuring Organisms.}

Preliminary definitions . . . . . . . . . . . . . . . 1

Methods of collecting individuals for measurement. . . . . . . . 2

Processes preliminary to measuring characters ............ 2

The determination of integral variates-Methods of counting. . . . 3

The determination of graduated variates-Method of measurement. 4

Straight lines on a plane surface. .............. 4

Distances t:rough solid bodies or cavities. . . . . . . . . 4

Area of plane surfaces. . . . . . . . . . . . . . . . .

Area of a curved surface. . . . . . . . . . . . . 5

Characters occupying three dimensions of space........ 6

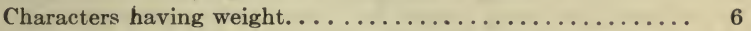

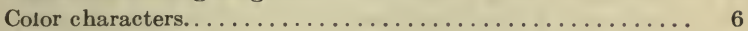

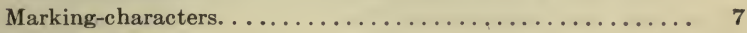

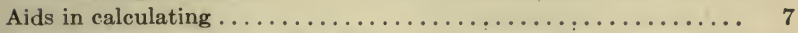

Precautions in arithmetical work. ................. 8

CHAPTER II.

On the Seriation and Plotting of Data and the Frequency Polygon.

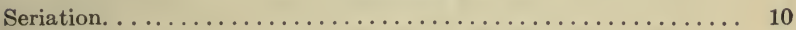

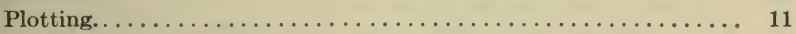

Method of rectangles. ........................ 11

Method of loaded ordinates. .................. 12

The rejection of extreme variates................ 12

Certain constants of the frequency polygon ............. 13

The average or mean. . . . . . . . . . . . . . . . 13

The mode. . . . . . . . . . . . . . . . . . . . 13

The median magnitude. . . . . . . . . . . . . . . . . 14

The probable error of the determination.............. 14

The probable difference between two averages. . . . . . . . 15

The probable error of the mean. . . . . . . . . . . . . 15

The probable error of the median. . . . . . . . . . . . 15

The geometric mean. . . . . . . . . . . . . . . . . 15

The index of variability. . . . . . . . . . . 15

The probable error of the standard deviation. . . . . . . . . 16

Average deviation and probable departure........... 16 
Coefficient of variability................... 16

The probable error of the coefficient of variahility........ 16

Quick methods of roughly determining average and variability.... 17

\section{CHAPTER III.}

The Classez of Frequency Polygons.

Classification. ............................... 19

To classify a simple frequency polygon. ................ 19

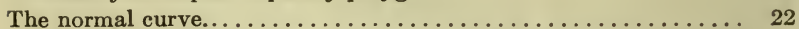

To compare any observed curve with the theoretical normal

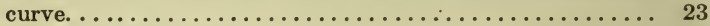

The index of abmodality ..................... 23

To determine the closeness of fit of a theoretical polygon to the

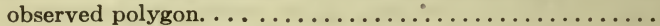

To determine the probability of a given distribution being normal............................. 24

The probable range of abscissæ................ 25

The normal curve as a binomial curve. . . . . . . . . . . 25

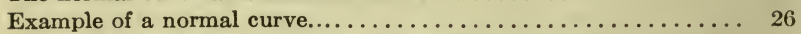

To find the average difference between the $p$ th and the $(p+1)$ th

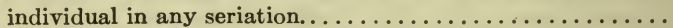

To find the best fitting normal frequency distribution when only a portion of an empirical distribution is given. . . . . . . . .

Other unimodal frequency polygons. . . . . . . . . . . . . . .

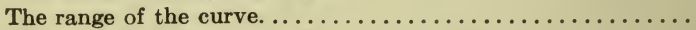

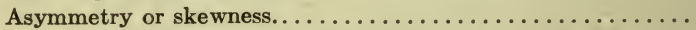

To compare any observed frequency polygon of Type I with its

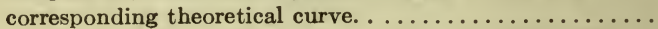

To compare any observed frequency polygon of Type II with

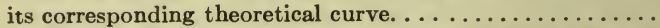

To compare any observed frequency polygon of Type III with its corresponding theoretical curve. . . . . . . . . . . .

To compare any observed frequency curve of Type IV with its

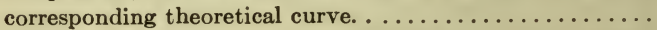

To compare any observed frequency polygon of Type $\mathrm{V}$ with

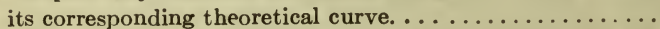

To compare any observed frequency polygon of Type VI with

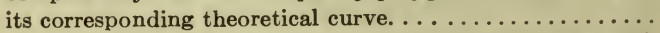
Example of calculating the theoretical curve corresponding with

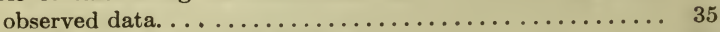

The use of logarithms in curve fitting. . . . . . . . . . . . 36

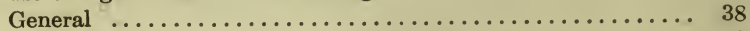

Type IV . . . . . . . . . . . . . . 39

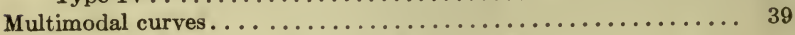

\section{CHAPTER IV.}

Correlated Variability.

General principles .......................... 42

Methocis of determining coefficient of correlation. . . . . . . . . 44 
PAGE

Galton's graphic method. ...................... 44

Pearson's method. ............................ 44

Brief method. ............................ 45

Probable error of $r \ldots \ldots \ldots \ldots \ldots \ldots \ldots \ldots \ldots \ldots \ldots \ldots \ldots \ldots \ldots \ldots, \quad 45$

Example............................... 45

Coefficient of regression...................... 47

The quantitative treatment of characters not quantitatively measurable............................... 47

The correlation of non-quantitative qualities............. 49

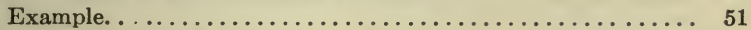

Quick methods of roughly determining the coefficient of correlation. 54 Spurious correlation in indices..................... 54

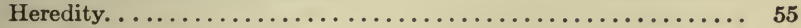

Uniparental inheritance..................... 55

Biparental inheritance....................... 55

To find the coefficient of correlation between brethren from the means of the arrays....................... 56

Galton's law of ancestral heredity. ............... 57

Mendel's law of inheritance in hybrids. . . . . . . . . . 57

A dissymmetry index.......................... 60

CHAPTER V.

Some Regults of Statistical Biological Study.

General..................................62

Variability................................... 62

General ............................... 62

Man...................................... 63

Mammalia................................ 65

Aves................................. 65

Amphibia. .............................. 66

Pisces.................................... 66

Tracheata................................ 66

Crustacea. . . . . . . . . . . . . . . . . . 66

Annelida................................. 67

Brachiopoda................................ $\quad \dot{6} 7$

Bryozoa................................. 67

Mollusea............................... 67

Echinodermata............................ 68

Colenterata. ............................... 68

Protista.................................... 69

Plants. ....................................... 69

Some types of biological distributions. . . . . . . . . . . . 71

Type I.................................... 71

Type IV. . . . . . . . . . . .

Type V......................................... 72

Normal. .............................. 72

Skewness.................................... 72

Complex distributions........................ 73 
PAGE

Correlation.............................. 73

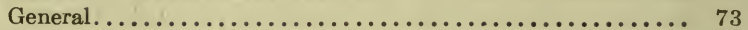

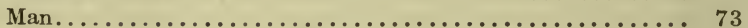

Lower animals.......................... 76

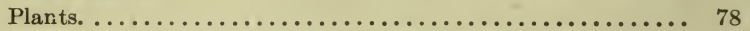

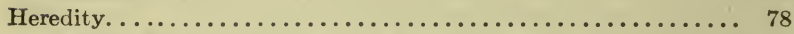

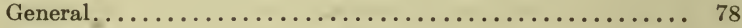

Parentel. ............................... 79

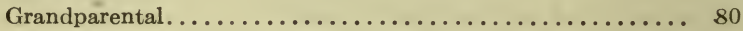

Fraternal. ............................. 80

Theoretical coefficient of heredity between relatives....... 81

Homotyposis........................... 81

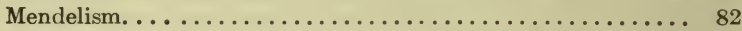

Telegony.............................. 82

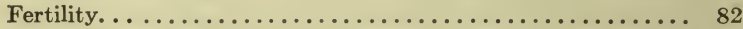

Selection. .............................. 82

Dissymmetry ............................... 82

Direct effect of environment. .................... 83

Local races. .............................. 83

Useful tables. ................................. 84

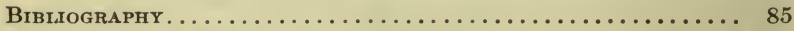

Explanation of Tables. ... . . . . . . . . . . . . . . 105

\section{List OF TABLES.}

The Greek alphabet. . . . . . . . . . . . . . . . . . 114

Index to the principal letters used in the formulæ of this book... 115

Table I. Formulas. . . . . . . . . . . 116

“ II. Certain constants and their logarithms.......... 117

، III. Table of ordinates of normal curve, or values of $\frac{y}{y_{0}}$ corresponding to values of $\frac{x}{\sigma} \ldots \ldots \ldots \ldots \ldots \ldots \ldots$

- IV. Table of half-class index values $\left(\frac{1}{2} a\right)$ or the values of the normal probability integral corresponding to values of $\frac{x}{\sigma}$; or the fraction of the area of the curve between the limits 0 and $+\frac{x}{\sigma}$ or 0 and $-\frac{x}{\sigma} \ldots \ldots 119$

* $\quad$ V. Table of $\log \Gamma$ functions of $p \ldots \ldots \ldots \ldots \ldots \ldots \ldots$

- VI. Table of reduction of linear dimensions from common to metric system.................... 128

.6 VII. Minutes and seconds in decimals of a degree....... 128

“VIII. First to sixth powers of integers from 1 to $50 \ldots \ldots \ldots 129$

“ IX. Probable errors of the coefficient of correlation...... 130

- X. Squares, cubes, square-roots, cube-roots, and reciprocals............................ 131

XI. Logarithms of numbers. ................. 149

.. XII. Logarithmic sines, cosines, tangents, and cotangents. 176 


\section{STATISTICAL METHODS}

WITH SPECIAL REFERENCE TO

\section{BIOLOGICAL VARIATION.}

\section{CHAPTER I.}

\section{On Methods of Measuring Organisms. .}

\section{Preliminary Definitions.}

An individual is a segregated mass of living matter, capable of independent existence. Individuals are either simple or compound, i.e., stocks or corms. In the case of a compound individual the morphological unit may be called a person.

A multiple organ is one that is repeated many times on the same individual. Example, the leaves on a tree, the scales on a fish.

A character is any quality common to a number of individuals or to a number of multiple organs of one individual.

A variate is a single magnitude-determination of a character.

Integral variates are magnitude-determinations of characters which from their nature are expressed in integers. Such magnitudes are expressed by counting; e.g., the number of teeth in the porpoise. These are also called discontinuous.

Graduated variates are magnitude-determinations of characters which do not exist as integers and which may consequently differ in different variates by any degree of magnitude however small; e.g., the stature of man.

A variant, among integral variates, is a single number-condition, e.g., 5 (flowers), 13 (ray-flowers), etc.

A class, among graduated variates, includes variates of the same or nearly the same magnitude. The class range gives the limits between which the variates of any class fall.

Individual variation deals with diversity in the characters of individuals.

Organ variation, or partial variation, deals with diversity in multiple organs in single individuals. 


\section{Metlodo of Collecting Individuals for Meas- urement.}

In collecting a lot of individuals for the study of the variability of any character undue selection must be avoided. The rule is:

Having settled upon the general conditions, of race, sex, locality, age, which the individuals to be measured must fulfil, take the individuals methodically at random and without possible selection of individuals on the basis of the magnitude of the character to be measured. If the individuals are simply not consciously selected on the basis of magnitude of the character they will often be taken sufticieutly at random.

The number of variates to be obtanned should be large; if possible from 200 to 2000, depending on abundance and variability of the material.

\section{Processes Preliminary to Measuring Characters.}

Some characters can best be measured directly; e.g., the stature of a race of men. Often the character can be better studied by reproducing it on paper. The two principal methods of reproducing are by photography and by camera drawings.

For photographic reproductions the organs to be measured will be differently treated according as they are opaque or trausparent. Opaque organs should be arranged if possible in large series on a suitable opaque or transparent background. The prints should be made on a rough paper so that they can be written on; blue-print paper is excellent. This method is applicable to hard parts which may be studied dry; e.g., mollusc shells, echinoderms, various large arthro: pods, epidermal markings of vertebrates and parts of the vertebrate skeleton. Shadow photographs may be made of the outlines of opaque objects, such as birds' bills, birds' eggs, and butterfly wings, by using parallel rays of light and interposing the object between the source of light * and the photo.

* A Welsbach burner or an electric light are especially good. Minute 
graphic paper. More or less transparent organs, such as leaves, petals, insect-wings, and appendages of the smaller Crustacea, may be reproduced either directly on blue-print paper or by "solar prints," either of natural size or greatly enlarged. For solar printing the objects should be mounted in series on glass plates. They may be fixed on the plate by means of balsam or albumen and mounted between plates either dry or in Canada balsam or other permanent mounting media. Wings of flies, orthoptera, neuroptera, etc., may be prepared for study in this way; twenty-five to one hundred sets of wings being photographed on one sheet of paper, say $16 \times 20$ inches in size. Microphotographs will sometimes be found serviceable in studying small organisms or organs, such as shells of Protozoa or cytological details.

Camera dravoings are a convenient although slow method of reproducing on paper greatly enlarged outlines of microscopic characters, such as the form and markings of worms and lower Crustacea, sponge spicules, bristles, scales and scutes, plant-hairs, cells and other microscopic objects. In making such camera drawings a low-power objective, such as Zeiss A*, will often be found very useful.

\section{The Determination of Integral Variates.- Methods of Counting.}

While the counting of small numbers offers no special diffculty, the counting becomes more difficult with an increase of numbers. To count large numbers the general rule is to divide the field occupied by the numerous organs into many small fields each containing only a few organs. Counting under the microscope, e.g., the number of spines, scales or plant-hairs per square millimetre, may be aided by cross-hair rectangles in the eyepiece. The number of blood-corpuscles in a drop of blood, or of organisms in a cubic centimetre of water, have long been counted on glass slides ruled in small squares.

electric lamps such as are fed by a single cell give sharp shadows of small objects. 


\section{The Determination of Graduated Variates.- Methods of Measurement.}

Straight lines on a plane surface are easily measured by means of a measuring-scale of some sort. The meas-

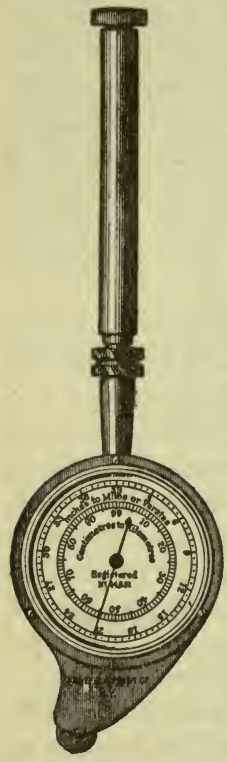

Fig. 1. urement should always be metric because this is the universal scientific system. Various kinds of scales may be obtained of optical companies and hardware dealers,such as steel measuring-tapes, graduated to millimetres (about $\$ 1.00$ ), and steel rules $\left(6 \mathrm{~cm}\right.$. to $15 \mathrm{~cm}$.) graduated to $\frac{1}{5}$ of a millimetre. Steel "spring-bow" dividers with milled-head screw are useful for getting distances which may be laid off on a scale. Tortuous lines, e.g., the contour of the serrated margin of a leaf or the outer margin of the wing of a sphinx moth, may be measured by a map-measurer ("Entfernungsmesser," Fig. 1), supplied at artist's and engineer's supply stores at about $\$ 3.50$.

Distances through solid bodies or cavities are measured by calipers of some sort. Calipers for measuring diameters of solid bodies are made in various styles. Micrometer screw calipers ("speeded") reading to one-hundredths of a millimetre and sold by dealers in physical apparatus for about $\$ 5.00$ are excellent for determining diameters of bones, birds' eggs, gastropod shells, etc. Leg calipers for rougher work can be obtained for from 30 cents to $\$ 4.00$. The micrometer "caliper-square," available for inside or outside measurements and measuring to hundredths of a millimetre, is a useful instrument.*

The area of plane surfaces, as, e.g., of a wing or leaf, is easily determined by means of a sheet of colloidin scratched in millimetre squares. By rubbing in a little carmine the

* Many of the instruments described in this section are made by the Starrett Co., Athol, Mass., and by Brown and Sharpe, Providence, tool cutters. 
scratches may be made clearer. The number of squares covered by the surface is counted (fractional squares being mentally summated) and the required area is at once obtained. If the area has been traced on paper it may be measured by the planimeter (Fig. 2). This instrument may be obtained at

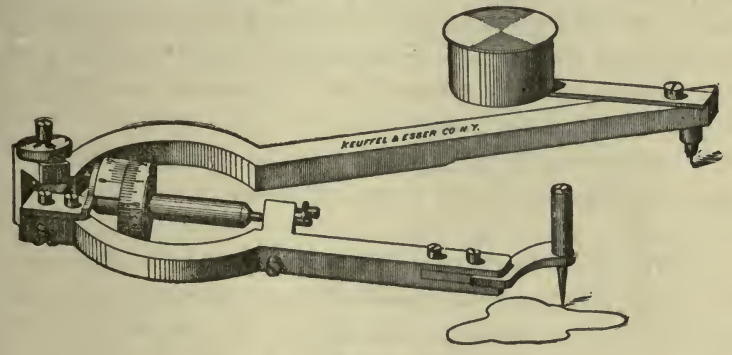

Fig. 2.

engineer's supply shops. It consists of two steel arms hinged together at one end; the other end of one arm is fixed by a pin into the paper, the end of the second arm is provided with a tracer. By merely tracing the periphery of the figure whose area is to be determined the area may be read off from a drum which moves with the second arm. This method is less wearisome than the method of counting squares.

The area of a curved surface, like that of the elytra of a beetle or the shell of a clam, is not always easy to find. To get the area approximately, project the curved surface on a plane by making a camera drawing or photograph of its outline. By means of parallel lines divide the outline drawing into strips such that the corresponding parts of the curved surface are only slightly curved across the strips, but greatly curved lengthwise of the strips. Measure the length of each plane strip and divide the magnitude by the magnification of the drawing. Measure also, with a flexible scale, the length of the corresponding strip on the curved surface. Then, the area of any strip of the object is to the area of the projection as the length of the strip on the object is to the length of its projection. The sum of the areas of the strips will give the total area of the surface. 
Characters occupying three dimensions of space may be quantitatively expressed by volume. The volume of water or sand displaced may be used to measure volume in the case of solids. The volume of water or sand contained will measure a cavity. Irregular form is best measured by getting, either by means of photography or drawings, projections of the object on one or more of the three rectangular fundamental planes of the organ, and then measuring these plane figures as already described. Or two or more axes may be measured and their ratio found.

Characters having weight are easily measured; the only precautions being those observed by physicists and chemists.

Color Characters. Color may be qualitatively expressed by reference to named standard color samples. Such standard color samples are given in Ridgeway's book, "Nomenclature of Color," and also in a set of samples manufactured by the Milton Bradley Co., Springfield, Mass., costing 6 cents. The best way of designating a color character is by means of the color wheel, a cheap form of which (costing 6 cents) is made by the Milton Bradley Co. 'The colors of this "top" are standard and are of known wave-length as follows:

$\begin{array}{ll}\text { Red, } 656 \text { to } 661 & \text { Green, } 514 \text { to } 519 \\ \text { Orange, } 606 \text { to } 611 & \text { Blue, } 467 \text { to } 472 \\ \text { Yellow, } 577 \text { to } 582 & \text { Violet, } 419 \text { to } 424 .\end{array}$

It is desirable to use Milton Bradley's color top as a standard. Any color character can be matched by using the elementary colors and white and black in certain proportions. The proportions are given in percents. In practice the fewest possible colors necessary to give the color character should be employed and two or three independent determinations of each should be made at different times and the results averaged. So far as my experience goes any color character is given by only one least combination of elementary colors. (See Science, July 16, 1897.)

When there is a complex color pattern the color of the different patches must be determined separately. In case of a close intermingling of colors, the colored area may be rapidly rotated on a turntable so that the colors blend and the result- 
ant may then be compared with the color wheel. By this means also the total melanism or albinism, viridescence, etc., may be measured.

Marking-characters. The quantitative expression of markings or color patterns will often call for the greatest ingenuity of the naturalist. Only the most general rules can here be laid down. Study the markings comparatively in a large number of the individuals, reduce the pattern to its simplest elements, and find the law of the qualitative variation of these elements. The variation of the elements can usually be treated under one of the preceding categories. Find in how far the variation of the color pattern is due to the variation of some number or other magnitude, and express the variation in terms of that magnitude. Remember that it is rarely a question whether the variation of the character can be expressed quantitatively but rather what is the best method of expressing it quantitatively.

Aids in Calculating. An indispensable aid in multiplying and dividing is a book of reckoning tables of which Crelle's Rechnungstafeln (Berlin: Geo. Reimer) is the best. This work enables us to get directly any product to $999 \times 999$ and indirectly, but with great rapidity, any higher product or any quotient.

The tables of Barlow ("Tables of Squares, Cubes, Square Roots, Cube Roots, and Reciprocals of all Integer Numbers up to 10,000") are like our Table X, but more extended.

The tedious work of adding columns of numbers is greatly simplified by the use of some one of the better adding machines. There are many forms; of which the best are made in the United States. The author has used the "Comptometer" made by the Felt and Tarrent Manufacturing Co., Chicago (\$225), and found it perfectly satisfactory. This machine is manipulated by touching keys, as in a typewriter, but it does not print the numbers touched off. In this respect it is inferior to the Burroughs Adding Machine of the American Arithometer Co., St. Louis, Mo., which costs $\$ 250$ to $\$ 350$, or to the Standard Adding Machine, St. Louis (\$185).

For the multiplication and division of large numbers the Baldwin Calculator is well spoken of (Science, xvir, 706). It is sold by the Spectator Company, 95 William Street, New York, price $\$ 250$. The same firm is agent for Tate's Im- 
proved Arithometer ( $\$ 300$ to $\$ 400$ ). The "Brunsviga" calculating machine (Herrn Grimme, Natalis \& Co., Brunswick, Germány, Manu'acturers; price $\$ 140$ to 75 ) is highly recommended by Pearson.

To draw logarithmic curves and for the mechanical solution of arithmetical problems the instrument of Brooks (Science, xvir, 690, not yet marketed) should be found useful.

Precautions in Arithmetical Work. Even the most careful computers make mistakes in arithmetical work. It is absolutely necessary to take such precautions that errors may be detected. The best method is for statistical workers to compute in pairs, but absolutely independently, comparing results as the work progresses, so that time shall not be wasted by elaborate work done with erroneous values. In case of disagreement both workers should recompute, starting from that point of the work where their results check. In cases where it is not feasible for the work to be done by twa people, it should be calculated on distinct pages of the notebook-proceeding through several steps on the one page and then independently through the same steps on another page; checking the work as it progresses. It will be found useful as the work progresses to make rough checks by comparing the results with the original data to see that the results are probable.

Neatness in arrangement of work and in the making of figures is essential. It is best to make all calculations in a book with pages about $20 \mathrm{~cm}$. by $30 \mathrm{~cm}$., quadruple ruled, with about three squares to the centimetre, so that each figure may occupy a distinct square. I like to work with a pencil, of $2 \mathrm{H}$ grade, so that slight errors may be erased and rectified. In case of larger errors running through several steps of the work, the erroneous calculations should not be erased but cancelled.

In using logarithms with the six-place table given in this book, it is ordinarily necessary to write the entire mantissa to six places, and to determine the number corresponding to any logarithm to at least six places by use of the table of proportional parts given at the bottom of the page. Upon the completion of the calculation the number of decimal places to be recorded will depend upon the probable error of 
each constant. It will ordinarily suffice if the probable error contain two significant figures, e.g., \pm 0.17 or \pm 0.0059 ; then the constant will be carried out to the same number of places and not farther. 


\section{CHAPTER II.}

\section{On the Seriation and Plotting of Data and the Frequency Polygon.}

The data obtained by measuring any character in a lot of individuals consists either of a mass of numbers for the character in each individual; or, perhaps, two numbers which are to be united to form a ratio ; or, finally, a series of numbers such as are obtained by the color wheel, of the order : $W 40 \%, N$ (Black) $38 \%, Y 12 \%, G 10 \%$. The first operation is the simplification of data. Each variate must be represented by one number only. Consequently, quotients of ratios must be determined and that single color of a series of colors which shows most variability in the species must be selected, e.g., $N$.

The process of seriation, which comes next, consists of the grouping of similar magnitudes into the same magnitude class. The classes being arranged in order of magnitude, the number of variates occurring in each class is determined. The number of variates in the class determines the frequency of the class. Each class has a central value, an inner and an outer limiting value, and a certain range of values.

The method of seriation may be illustrated by two examples; one of integral variates, and the other of graduated variates.

Example 1. The magnitude of 21 integral variates are found to be as follows : $12,14,11,13,12,12,14,13,12,11,12,12,11,12,10,11,12,13,13$, $13,12,12$. In seriation they are arranged as follows :

$$
\begin{aligned}
& \text { Classes: } \quad 10,11,12,13,14 . \\
& \text { Frequency : } 1,4,11,4,2 .
\end{aligned}
$$

Example 2. In the more frequent case of graduated variates our mag. nitudes might be more as follows :

$\begin{array}{lllll}3.2 & 4.5 & 5.2 & 5.6 & 6.0 \\ 3.8 & 4.7 & 5.2 & 5.7 & 6.2 \\ 4.1 & 4.9 & 5.3 & 5.8 & 6.4 \\ 4.3 & 5.0 & 5.3 & 5.8 & 6.7 \\ 4.3 & 5.1 & 5.4 & 5.9 & 7.3\end{array}$

In this case it is clear that our magnitudes are not exact, but are merely approximations of the real (forever unknowable) value. The question 
arises concerning the inclusiveuess of a class-the class range. An approximate rule is: Make the classes oniy just large enough to have no or very few vacant classes in the series. Following this rule we get

\begin{tabular}{|c|c|c|c|c|c|}
\hline \multirow{3}{*}{ Classes.... } & $3.0-3.4$; & 3.5-3.9; & $4.0-4.4 ;$ & $4.5-4.9$ & $5.0-5.4 ;$ \\
\hline & 3.2 & 3.7 & 4.2 & 4.7 & 5.2 \\
\hline & 1 & 2 & 3 & 4 & 5 \\
\hline \multirow[t]{2}{*}{ Frequency } & 1 & 1 & 3 & 3 & 7 \\
\hline & 5.5-5.9; & 6.0-6.4; & 6.5-6.9; & $\because .0-7.4$; & \\
\hline \multirow[t]{2}{*}{ Classes.... } & 5.7 & 6.2 & 6.7 & 7.2 & \\
\hline & 6 & 7 & 8 & 9 & \\
\hline Frequency & 5 & - 3 & 1 & 1 & \\
\hline
\end{tabular}

The classes are named from their middle value, or better, for ease of subsequent calculations, by a series of small integers (1 to 9).

In case the data show a tendency of the observer towards estimating to the nearest round number, like 5 or 10 , each class should include one and only one of these round numbers.

As Fechner ('9\%) has pointed out, the frequency of the classes and all the data to be calculated from the series will vary according to the point at which we begin our seriation. Thus if, instead of beginning the series with 3.0 as in our example, we begin with 3.1 we get the series:

\begin{tabular}{|c|c|c|c|c|c|}
\hline Classes & $\begin{array}{c}3.1-3.5 \\
3.3\end{array}$ & $\begin{array}{c}3.6-4.0 \\
3.8\end{array}$ & $\begin{array}{l}4.1-4.5 \\
4.3\end{array}$ & $\begin{array}{c}4.6-5.0 \\
4.8\end{array}$ & $\begin{array}{c}5.1-5.5 \\
3.5\end{array}$ \\
\hline Frequency & 1 & 1 & 4 & 3 & 6 \\
\hline $\mathrm{Cla}$ & $\begin{array}{c}5.6-6.0 \\
5.8\end{array}$ & $\begin{array}{c}6.1-6.5 \\
6.3\end{array}$ & $\begin{array}{c}6.6-\tau .0 \\
6.8\end{array}$ & $\begin{array}{c}7.1-7.5 \\
7.3\end{array}$ & \\
\hline Frequency & 6 & 2 & 1 & 1 & \\
\hline
\end{tabular}

which is quite a different series. Fechner suggests the rule: Choose such a position of the classes as will give a most normal distribution of frequencies. According to this rule the first distribution proposed above is to be preferred to the second.

In order to give a more vivid picture of the frequency of the classes it is important to plot the frequency polygon. This is done on coordinate paper.*

The best method, especially when the number of classes is less than 20 , is to represent the frequencies by rectangles of equal base and of altitude proportional to the frequencies. Lay off along a horizontal line equal contiguous spaces each of which shall represent one class, number the spaces in order from left to right with the class magnitudes in succession, and erect upon these bases rectangles proportionate in height to the frequency of the respective classes (Fig. 3).

* This paper may be obtained at any artists' supply store. 
This method of drawing the frequency polygon is known as the method of rectangles.

When the number of classes is large the frequencies may be represented by ordinates as follows: At equal intervals along

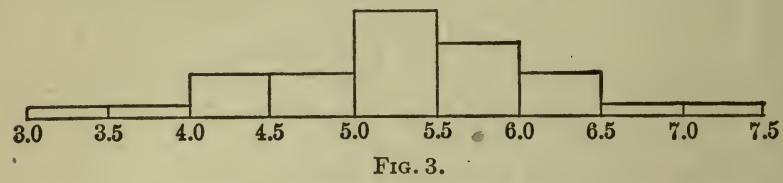

a horizontal line (axis of $X$ ) draw a series of (vertical) ordinates whose successive heights shall be proportional to the frequency of the classes. Join the tops of the ordinates as shown in Fig. 4. This method of drawing the frequency polygon is known as the method of loaded ordinates.

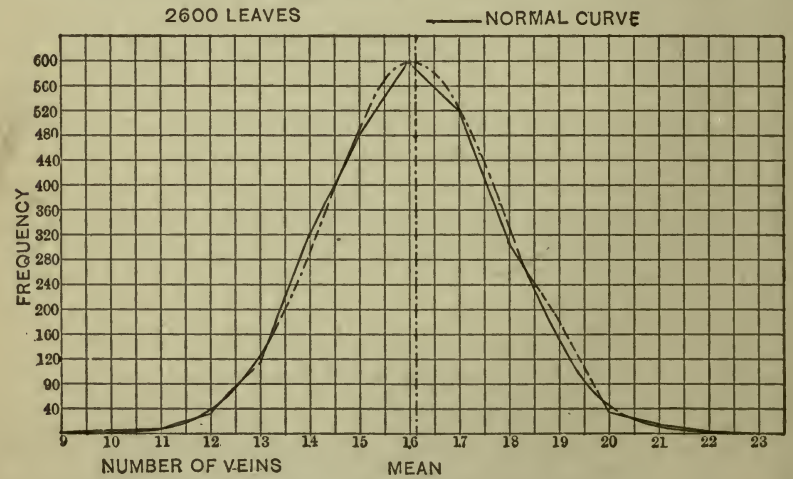

Fig. 4.-Veins in Beech Leaves, after Pearson, '02i.

The rejection of extreme variates in calculating the constants of a distribution polygon is to be done only rarely and with caution. In many physical measurements Chauvenet's criterion is used to test the suspicion that a single extreme variant should be rejected. A limiting deviation $(\kappa \sigma)$ is calculated. $\quad \kappa$ is the argument in Table IV corresponding to a tabular entry equal to $\frac{2 n-1}{4 n}$. 
Example.-In 1000 minnows from one lake there are found the following frequencies of anal fin-rays:

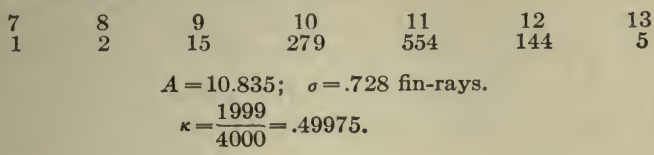

Looking in Table IV we find 3.48 corresponding to the entry 49975. Then the limiting deviation $=3.48 \times .728=2.5334$ and the limiting class is $10.835-2.533=8.302$; hence the observation at 7 might be excluded in calculating the constants of the seriation; but it should not be suppressed in publishing the data.

\section{Certain Constants of the Frequency Polygon.}

After the data have been gathered and arranged it is necessary to determine the law of distribution of the variates. To get at this law we must first determine certain constants.

The average or mean $(A)$ is the abscissa of the centre of gravity of the frequency polygon. It is found by the formula

$$
A=\frac{\Sigma(V \cdot f)}{n},
$$

in which $V$ is the magnitude of any class; $f$ its frequency; $\Sigma$ indicates that the sum of the products for all classes into frequency is to be got, and $n$ is the number of variates.

Thus in the example on p. 10:

$$
\begin{aligned}
& A=(3.2 \times 1+3.7 \times 1+4.2 \times 3+4.7 \times 3+5.2 \times 7+5.7 \times 5+6.2 \times 3 \\
& \text { or } \quad+6.7 \times 1+7.2 \times 1) \div 25=5.24, \\
& A_{1}=(1 \times 1+2 \times 1+3 \times 3+4 \times 3+5 \times 7+6 \times 5+7 \times 3+8 \times 1+9 \times 1)
\end{aligned}
$$

$A=5.2 *+.08(5.7-5.2)=5.24$.

A still shorter method of finding $A$ is given on page 20 .

The mode $(M)$ is the class with the greatest frequency. It is necessary to distinguish sharply between the empirical and the theoretical mode. The empirical mode is that mode which is found on inspection of the seriated data. In the example, the empirical mode is 5.2. The theoretical mode is the mode of the theoretical curve most closely agreeing with the observed distribution. Pearson $1902^{\mathrm{b}}$, p. 261) gives this

* 5.2 is the true class magnitude corresponding to the integer 5 . 
rule for roughly determining the theoretical mode. The mode lies on the opposite side of the median from the mean; and the abscissal distance from the median to the mode is double the distance from the median to the mean; or, mode $=$ mean $-3 \times($ mean - median $)$. More precise directions for finding the mode in the different types of frequency polygons are given in the discussion of the types.

The median magnitude is one above which and below which $50 \%$ of the variates occur. It is such a point on the axis of $X$ of the frequency polygon that an ordinate drawn from it bisects the polygon of rectangles or the continuous curve, but not the polygon of loaded ordinates.

To find its position: Divide the variates into three lots: those less than the middle class, i.e., the one that contains the median magnitude, of which the total number is a; those of the middle class, $b$; and those greater, c. Then $a+b+c=n=$ the total number of variates: Let $l^{\prime}=$ the lower limiting value of the middle class, and $l^{\prime \prime}=$ the upper limiting value, and let $x=$ the abscissal distance of the median ordinate above the lower limit or below the upper limit of the median class according as $x$ is positive or negative. Then $\frac{1}{2} n-a: b=x: l^{\prime \prime}-l^{\prime}$ when $x$ is positive, or $\frac{1}{2} n-c: b=x: l^{\prime \prime}-l^{\prime}$ when $x$ is negative.

Thus in the last example: $(12.5-8): 7=x: 0.5 ; x=.32$; the median magnitude $=5.0+.32=5.32$. Or $(12.5-10): 7=-x: 0.5 ; \quad x=-.18$; the median magnitude $=5.5-.18=5.32$. (Cf. p. 10.)

\section{The probable error $(E)$ of the determination of} any value gives the measure of unreliability of the determination; and it should always be found. For, any determination of a constant of a frequency polygon is only an approximation to the truth. The probable error $(E)$ is a pair of values lying one above and the other below the value determined. We can say that there is an even chance that the true value lies between these limits. The chances that the true value lies within:*

$$
\begin{array}{cc} 
\pm 2 E \text { are } 4.5: 1 & \pm 5 E \text { are } 1,310: 1 \\
\pm 3 E \text { are } 21: 1 & \pm 6 E \text { are } 19,200: 1 \\
\pm 4 E \text { are } 142: 1 & \pm 7 E \text { are } 420,000: 1 \\
& \pm 8 E \text { are } 17,000,000: 1 \\
& \pm 9 E \text { are about a billion to } 1 .
\end{array}
$$

The probable error should be found to two significant

\footnotetext{
* These values are easily deduced from Table IV.
} 
figures. The determination of which it is the error should be carried out to the same number of places as the probable error and no more.

The probable differen ce between two averages $\left(A_{1}\right.$ and $A_{2}$ ) of which the probable errors $\left(E_{1}\right.$ and $\left.E_{2}\right)$ are known is the square root of the sum of the squared probable errors, or (Pearson, '02):

Probable Difference of $A_{1}-A_{2}$ is $\sqrt{E_{1}{ }^{2}+E_{2}{ }^{2}}$.

The probable error of the mean is given by, the formula

$$
\pm 0.6745 \times \frac{\text { standard deviation [see below] }}{\sqrt{\text { number of variates }}}= \pm 0.6745 \frac{\sigma}{\sqrt{n}} .
$$

It will be seen that the probable error is less, that is, that the result is more accurate, the greater the number of variates measured, but the accuracy does not increase in the same ratio as the number of individuals measured, but as the square root of the number. The probable error of the mean decreases as the standard deviation decreases.

The probable error of the median is $\pm .84535 \sigma$ $\div \sqrt{n}$ (Sheppard, '98).

The geometric mean of a series of values $(v)$ is the number corresponding to the average of the logarithms of the values. Thus,

$$
G=N \frac{\sum(\log v)}{n}
$$

The index of the variability, $\sigma$, of the variates when they group themselves about one mode is found by adding the products of the squared deviation-from-the-mean of each class multiplied by its frequency, dividing by the total number of variates, and extracting the square root of the quotient, thus:

$$
\begin{aligned}
& \sigma=\sqrt{\frac{\begin{array}{c}
\text { sum of }\left[(\text { deviation of class from mean })^{2}\right. \\
\times \text { frequency of class }]
\end{array}}{\text { number of variates }}} \times \lambda \\
& =\sqrt{\frac{\sum\left(x^{2} \cdot f\right)}{n}} \times \lambda ;
\end{aligned}
$$

where $\lambda$ is the number of units in the class range, frequently unity. 
This measure is known as the standard deviation. It is a concrete number expressed in the units of the classes. This, the best measure of variability, is expressed geometrically as the half parameter, or the abscissa of the point on the frequency curve where the change of curvature (from concave to convex toward the centre) occurs.

The probable error of the standard deviation is

$$
\pm 0.6745 \frac{\text { standard deviation }}{\sqrt{2 \times \text { number of variates }}}= \pm 0.6745 \frac{\sigma}{\sqrt{2 n}} .
$$

Other Indices of Variation. The average deviation, or average departure, is found thus:

$$
\text { A.D. }=\frac{\text { sum of }[\text { deviations of class from mean } \times \text { frequency }]}{\text { number of variates }} .
$$

The average deviation is equal to $.7979 \times$ standard deviation, or $=0.7979 \sigma$.

The probable (or mid) departure is the distance from the mode of that ordinate which exactly bisects the half curve $0 M X$ or $0 M X^{1}$, Fig. 5, it is equal to $0.6745 \times$ standard deviation $=0.6745 \sigma$. Neither of these last two indices of variation is as good as the standard deviation when $n$ is rather small.

The standard deviation, like the other indices of variation, is a concrete number, being expressed in the same units as the magnitudes of the classes. The standard deviation of one lot of variates is consequently not comparable with the $\mathrm{S}$. D. of variates measured in other units. It has been proposed to reduce the index of variation to an abstract number, independent of any particular unit, by dividing the index of variation of any variates by the mean; the quotient multiplied by 100 is called the coefficient of variability. In a formula, $C=\frac{\sigma}{A} \times 100 \%$ (Pearson, '96; Brewster, '97).

The probable error of the coefficient of variability is given by Pearson as:

$$
E_{C}=.6745 \frac{C}{\sqrt{2 n}}\left[1+2\left(\frac{C}{100}\right)^{2}\right]^{\frac{1}{2}} .
$$


When $C$ is small, say less than $10 \%$, the factor in brackets may be omitted, especially as only two significant figures of the probable error need be recorded.

The average, standard deviation, coefficient of correlation, and their probable errors may be conveniently calculated altogether by logarithms, as shown in the paradigm on page 38 .

Quick Methods of Roughly Determining Average and VARIABILITY.*

1. Arrange the specimens in a series according to the magnitude of the character, simply judging the order by the eye. Then pick out those two that will divide the series into thirds and measure them. Their average will be the average of the whole series. Then,

$$
\frac{\text { Mean - the smaller of the two measures }}{.43}=\sigma \text {. }
$$

(.43 is the value of $\pm \frac{x}{\sigma}$, at which the area of the curve included between these limits of $x$ equals one-third of the whole).

Or, 2. Select roughly two specimens that seem to be about one-third of the distance from the two extremes and group all others as larger than the larger one, smaller than the smaller one, or between the two. Measure the two specimens. Count the number in each group and determine $\sigma$ by aid of Table IV (p. 120) as follows: Taking as origin the middle of the whole series, call the numbcr of leaves from the middle to the smaller $n_{2}^{\prime}$, and the number from the middle to the larger $n_{2}{ }^{\prime \prime}$. Also, the $x$ distance to the lower division point $h_{1}$ and to the upper division point $h_{2}$. Then $\left(h_{1}+h_{2}\right)=$ the range covered by the middle division or the difference between the upper and lower value. As we know the areas of the curve between the origin and $h_{1}$ on the one hand and $h_{2}$ on the other (percentage of individuals between the middle and $h_{1}$ and $h_{2}$ ), we can find $\frac{h_{1}}{\sigma}$ and $\frac{h_{2}}{\sigma}$ from Table IV, since they are the values $\frac{x}{\sigma}$ corresponding to the percentage 
areas determined. But $\frac{h_{1}}{\sigma}+\frac{h_{2}}{\sigma}=\frac{\left(h_{1}+h_{2}\right)}{\sigma}$; thus $\sigma$ is determined. Knowing $\sigma$ we can get $h_{1}$ or $h_{2}$, and hence the mean. Or the value of the character of the middle specimen may be taken as the mean value.

Example.-Seventy-six beech-leaves which had fallen from one tree were picked up. They were sorted out as in the second method. It was found that 22 were smaller than the smaller type leaf, which was 1.78 inches in length; and 23 were larger than the larger type leaf (2.22 inches in length). The 38 th leaf is the middle of the series, and so the smaller type leaf was distant 16 laaves from the middle, and the larger 15.

$$
\frac{n_{2}^{\prime}}{n}=\frac{16}{76}=.2105 ; \quad \frac{n_{2}^{\prime \prime}}{n}=\frac{15}{76}=.1974 .
$$

From Table IV:

$$
\begin{array}{c|l}
\frac{h_{1}}{\sigma} & \% \text { area. } \\
\hline .56 & .21226 \\
.55 & .20884 \\
\hline
\end{array}
$$

Similarly $\frac{h_{2}}{\sigma}=.517$;

$$
\begin{gathered}
\frac{h_{1}+h_{2}}{\sigma}=1.072=\frac{2.22-1.78}{\sigma} . \\
\therefore \sigma=\frac{.44}{1.072}=.4105 ; \\
\frac{h_{1}}{.4105}=.555 ; \quad \frac{h_{2}}{.4105}=.517 ; \\
h_{1}=.2278, \quad h_{2}=.2122 .
\end{gathered}
$$

Mean is at $1.78+.2278=2.01$. 


\section{CHAPTER III.}

The Classes of Frequency Polygons.

The plotted curve may fall into one of the following classes : A. Unimodal.

I. Simple.

1. Range unlimited in both directions:

a. Symmetrical. The normal curve.

b. Unsymmetrical (Pearson's Type IV).

2. Range limited in one direction, together with skewness (Types III, V, and VI).

3. Range limited in both directions :

a. Symmetrical, Type II.

b. Unsymmetrical, Type I.

II. Complex.

B. Multimodal.

The classification of any given curve is not always an easy task. Whether the curve is unimodal or multimodal can be told by inspection. Whether any unimodal curve is simple or complex cannot be told by any existing methods without great labor and uncertainty in the result.

Complex curves may be classified as follows :

1. Composed of two curves, whose modes are different but so near that the component curves blend into one; such curves are usually unsym. metrical.

2. The sum of two curves having the same mode but differing variability.

3. The difference of two curves having the same mode but differing variability.

If the material is believed to be homogeneous and the curve is unimodal it is probably simple and its classification may be carried further.

For classification the rule is as follows: Determine the mean of the magnitudes. Take a class near the mean (call it $V_{0}$ ) 
as a zero point; then the departure of all the other classes will be $-1,-2,-3$, etc., and $+1,+2,+3$, etc.

Add the products of all these departures multiplied by the frequency of the corresponding class and divide by $n$; call the quotient $v_{1}$.

Add the products of the squares of all the departures multiplied by the frequency of the corresponding class and divide by $n$; call the quotient $\nu_{2}$.

Add the products of the cubes of all the departures multiplied by the frequency of the corresponding class and divide by $n$; call the quotient $\dot{\nu}_{3}$.

Add the products of the fourth povers of all the departures multiplied by the frequency of the corresponding class and divide by $n$; call the quotient $\nu_{4}$. Or,

$$
\begin{aligned}
& v_{1}=\frac{\Sigma\left(V-V_{0}\right)}{n}=\begin{array}{c}
\text { departure of } V_{0} \text { from mean. } V_{0} \text { being } \\
\text { known, } A \text { may be found }\left[A=V_{0}+v_{1}\right] ; *
\end{array} \\
& v_{2}=\frac{\Sigma\left(V-V_{0}\right)^{2}}{n} ; \\
& v_{3}=\frac{\Sigma\left(V-V_{0}\right)^{3}}{n} ; \\
& v_{4}=\frac{\Sigma\left(V-V_{0}\right)^{4}}{n}
\end{aligned}
$$

The values $v_{1}, v_{2}, v_{3}, v_{4}$, are called respectively the first, second, third, and fourth moments of the curve about $V_{0}$.

To get the moments of the curve about the mean, either of two methods ( $\mathrm{A}$ or $\mathrm{B}$ ) will be employed. Method $\mathrm{A}$ is used when integral variates are under consideration; method $B$ when we deal with graduated variates.

(A) To find moments in case of integral variates:

$$
\begin{aligned}
& \mu_{1}=0 ; \\
& \mu_{2}=\nu_{2}-\nu_{1}^{2} ; E_{\mu_{2}}=.67449 \sqrt{\frac{\mu_{4}-\mu_{2}^{2}}{n} ;}
\end{aligned}
$$

* This is the short method of finding $A$ referred to on page 13. 
$\mu_{3}=\nu_{3}-3 \nu_{1} \nu_{2}+2 \nu_{1}^{3} ; \quad E_{\mu_{3}}=T \sqrt{\frac{\mu_{6}-\mu_{3}^{2}-6 \mu_{4} \mu_{2}+9 \mu_{2}^{2}}{n}} ;$

$\mu_{4}=\nu_{4}-4 \nu_{1} \nu_{3}+6 \nu_{1}{ }^{2} \nu_{2}-3 \nu_{1}{ }^{4} ; E_{\mu_{4}}=T \sqrt{\frac{\mu_{8}-\mu_{4}{ }^{2}-8 \mu_{5} \mu_{3}+16 \mu_{2} \mu_{3}{ }^{2}}{n}} ;$

$\mu_{5}=\nu_{5}-5 \nu_{1} \nu_{4}+10 \nu_{1}^{2} \nu_{3}-10 \nu_{1}^{3} \nu_{2}+4 \nu_{1}^{5}$;

$\mu_{6}=\nu_{6}-6 \nu_{1} \nu_{5}+15 \nu_{1}^{2} \nu_{4}-20 \nu_{1}^{3} \nu_{3}+15 \nu_{1}{ }^{4} \nu_{2}-5 \nu_{1}{ }^{0}$.

(B) To find moments in case of graduated variates:

$\mu_{1}^{\prime}=0$;

$\mu_{2}^{\prime}=\left[\nu_{2}-\nu_{1}^{2}-\frac{1}{12}\right] \lambda^{2}$;

$\mu_{3}^{\prime}=\left[\nu_{3}-3 \nu_{1} \nu_{2}+2 \nu_{1}^{3}\right] \lambda^{3}$

$\mu_{4}^{\prime}=\left[\nu_{4}-4 \nu_{1} \nu_{3}+6 \nu_{1}^{2} \nu_{2}-3 \nu_{1}^{4}-\frac{1}{2}\left(\nu_{2}-\nu_{1}^{2}\right)+\frac{7}{24}\right] \lambda^{4} ;$.

$\mu_{5}^{\prime}=\left[\nu_{5}-5 \nu_{1} \nu_{4}+10 \nu_{1}^{2} \nu_{3}-10 \nu_{1}^{3} \nu_{2}+4 \nu_{1}^{5}-\frac{5}{6} \mu_{3}\right] \lambda^{5}$;

in which $\lambda$ is the class range expressed in the same unit as the average.

$$
\text { Also, } \beta_{1}=\frac{\mu_{3}^{2}}{\mu_{2}^{3}} ; \quad \beta_{2}=\frac{\mu_{4}}{\mu_{2}^{2}} \text {. }
$$

The probable error of the preceding constants in the special case of the normal curve is as follows:

$$
\begin{array}{lc}
E \mu_{2}=.67449 \sigma^{2} \sqrt{\frac{2}{n}} ; & E_{\beta_{2}}=.67449 \sqrt{\frac{24}{n}} ; \\
E \mu_{3}=.67449 \sigma^{3} \sqrt{\frac{6}{n}} ; & E \sqrt{\beta_{1}}=.67449 \sqrt{\frac{6}{n}} ; \\
E \mu_{4}=.67449 \sigma^{4} \sqrt{\frac{96}{n}} ; & E_{D}^{-}=.67449 \sqrt{\frac{3}{2 n}} \sigma(\text { p. 31) }
\end{array}
$$

$$
E \text { of Skewness }=.67449 \sqrt{\frac{3}{2 n}} . \quad(\text { See page 30.) }
$$

(From Pearson, 1903 ${ }^{\mathrm{c}}$ ).

The classification of any empirical frequency polygon depends upon the value of its "critical function," $F *$ (Pearson, $1901^{\mathrm{d}}$ ).

$$
F=\frac{\beta_{1}\left(\beta_{2}+3\right)^{2}}{4\left(4 \beta_{2}-3 \beta_{1}\right)\left(2 \beta_{2}-3 \beta_{1}-6\right)} .
$$

* This value of $F$ is general. For the special case of Types I-IV the following critical function was given by Pearson and has been 


\begin{tabular}{l|l}
\hline \multicolumn{1}{c|}{ Value of $F}$. & \multicolumn{1}{c}{ Corresponding Frequency Curve. } \\
\hline$F=\infty$ & $\begin{array}{l}\text { Type III. Transitional between Type } \\
\text { I and Type VI. } \\
\text { Type VI. } \\
F>1 \text { and }<\infty\end{array}$ \\
$\begin{array}{l}\text { Type V. Transitional between Type } \\
\text { IV and Type II. } \\
F>0 \text { and }<1 \\
F=0, \beta_{1}=0, \beta_{2}=3 \\
F=0, \beta_{1}=0, \beta_{2} \text { not }=3 \\
F<0\end{array}$ & $\begin{array}{l}\text { Type IV. } \\
\text { Normal curve. } \\
\text { Type II. } \\
\text { Type I. }\end{array}$ \\
\hline
\end{tabular}

An important relation to be referred to later is -

$$
s=\frac{6\left(\beta_{2}-\beta_{1}-1\right)}{3 \beta_{1}-2 \beta_{2}+6} \text {. }
$$

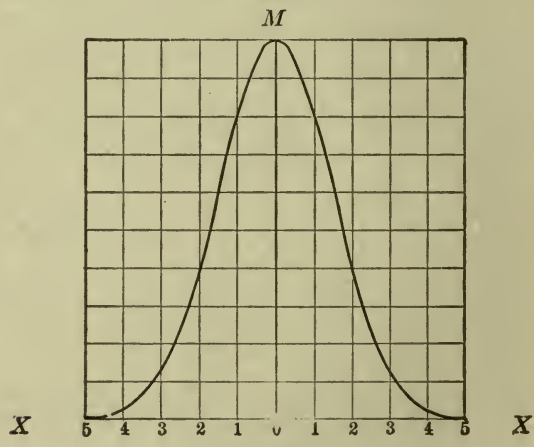

FIG. 5.

\section{The Normal Curve.}

The normal curve is symmetrical about the mode; consequently the mode and the median and mean coincide.

The mathematical formula of the normal curve, a formula

much used. $\quad F_{1}=2 \beta_{2}-3 \beta_{1}-6$. The classification was given as follows: When $F$ is negative and $\left\{\beta_{1}>0\right.$, curve is of Type I.

When $F=0$ and $\quad\left\{\begin{array}{l}\beta_{1}>0, \beta_{2}>3 \text {, curve is of Type III. } \\ \beta_{1}=0, \beta_{2}=3, \text { curve is }\end{array}\right.$

When $F$ is positive and $\beta_{1}>0, \beta_{2}>3$, curve is of Type IV. 
of which one does not have to understand the development in order to make use of it, is

$$
y=\frac{n}{\sigma \sqrt{2 \pi}} \cdot \frac{1}{e^{x^{2} / 2 \sigma^{2}}}
$$

This formula gives the value of any ordinate $y$ (or any class) at any distance $x$ (measured along the base, $X, X^{\prime}$, of Fig. 5) from the mode. $e$ is a constant number, 2.71828, the base of the Naperian system of logarithms. $n$ is the total area of the curve or number of variates, and $\sigma$ is the Standard Deviation, which is constant for any curve and measures the variability of the curve, or the steepness of its slope.

To compare any observed curve with the theoretical normal curve we can make use of tables. For the case of a polygon of loaded ordinates the theoretical frequency of any class at a deviation $\frac{x}{\sigma}$ from the mean can be taken directly from Table III. Here $\frac{x}{\sigma}$ is the actual deviation from the mean expressed in units of the standard deviation, and $\frac{y}{y_{0}}$ the corresponding ordinate, $y_{0}$ being taken as equal to 1 , and $\sigma$ is the standard deviation.

For the case of a polygon built up of rectangles representing the relative frequency of the variates, Table IV gives immediately the theoretical number of individuals occurring between the values $x=0$ and $x= \pm \frac{x}{\sigma}$. By looking up the given values of $\frac{x}{\sigma}$ the corresponding theoretical percentage of variates between the limits $x=0$ and $x= \pm \frac{x}{\sigma}$ will be found directly. The ratio $\frac{x}{\sigma}$ may be called the Index of Abmodality.

The normal curve may preferably be employed even when $\beta_{1}$ is not exactly equal to 0 , nor $\beta_{2}$ exactly equal to 3 , nor $F$ exactly equal to 0 . Use the normal curve when

$$
F \times \mu_{2}^{3}< \pm 1 \text { and } \frac{3 \nu_{2}^{2}-2 \nu_{1}^{4}}{\nu_{1}}=1 \pm .2
$$


also the skewness (p. 30) should be less than twice the value $.67449 \sqrt{\frac{3}{2 n}}$.

\section{To determine the closeness of fit of a theoreti-} cal polygon to the observed polygon. Find for each class the difference $\left(\delta_{1}\right)$ between the theoretical value $(y)$ and the observed frequency $(f)$. Divide the square of this difference in each case by $y$. The square root of the sum of the quotients is the index of closeness of fit $(\Delta)$. Or, $\Delta=\sqrt{\Sigma \frac{\delta_{1}^{2}}{y}}$. The probability $(P: 1)$ that the observed distribution is truly represented by the theoretical polygon may be calculated from the following formula, to use which the number of classes (A) must be odd or must be made odd by the addition of a class with 0 frequency.

$$
P=e^{-\frac{1}{2} \Delta^{2}}\left(1+\frac{\Delta^{2}}{2}+\frac{\Delta^{4}}{2.4}+\frac{\Delta^{6}}{2 \cdot 4 \cdot 6}+\ldots+\frac{\Delta^{A-3}}{2 \cdot 4 \cdot 6 \ldots A-3}\right)
$$

This is the method of Pearson, $1900^{b}$.

To determine the probability of a given distribution being normal. Having found, in units of the standard deviation, the deviation $(\chi)$ of the inner limiting value $(L)$ of each class from the average, look up the corresponding class-index $a$ from Table IV. Or, better, find $a$ directly for each class by dividing the half of the total number of variates minus all those lying beyond the inner limiting value of the class in question by the half of the total number of variates; or, in a formula, $\frac{\Sigma_{0} x_{f}}{\frac{1}{2} n}$; where $\Sigma_{0} x_{f}$ means add all the frequencies from the median value to $\chi$, and $n$ is the number of variates. Next find for each class the sum of $A+\sigma \chi$. This should equal $L$. The difference is the actual discrepancy. The probable discrepancy should next be calculated for all but the extreme values. It is calculated by use of the formula

$$
0.6745 \sigma\left\{\frac{\pi\left(1-a^{2}\right)}{2 z^{2}}-\left(1+\frac{\chi^{2}}{2}\right)\right\}^{\frac{1}{2}} \div \sqrt{n}
$$


where the value of $z$ corresponding to $\chi$ is got from Table III, or from the formula

$$
e^{-\frac{1}{2} \chi^{2}}=\frac{1}{e^{\frac{1}{2} \chi^{2}}}
$$

The ratio of actual to prohable discrepancy is next to be calculated for each class. The probable limit (P.L.) of the ratios varies with the number $(\Lambda)$ of ratios found, according to the following table:

\begin{tabular}{c|c||c|c||c|c||c|c}
\hline$\Lambda_{1}$ & P.L. & $\Lambda_{1}$ & P.L. & $\Lambda_{1}$ & P.L & $\Lambda_{1}$ & P.L. \\
\hline 1 & 1.000 & 6 & 2.375 & 11 & 2.777 & 16 & 3.009 \\
2 & 1.559 & 7 & 2.481 & 12 & 2.832 & 17 & 3.046 \\
3 & 1.874 & 8 & 2.570 & 13 & 2.882 & 18 & 3.080 \\
4 & 2.088 & 9 & 2.648 & 14 & 2928 & 19 & 3.112 \\
5 & 2.248 & 10 & 2.716 & 15 & 2970 & 20 & 3.142 \\
\hline
\end{tabular}

The foregoing method is from Sheppard (1898).

The probable range of abscissæ $\left(2 x_{l}\right)$ of a normal distribution, or that beyond which the theoretical frequency $(y)$ is less than 1 , varies with the number of variates $(n)$ as well as with $\sigma$, in accordance with the following formula derived by the transposition of $y=\frac{n}{\sigma \sqrt{2 \pi}} e^{-x^{2} / 2 \sigma^{2}}$ by putting $y=1$ :

$$
2 x_{l}=2 \sigma \sqrt{\frac{2}{\log e} \log \frac{n}{\sigma \sqrt{2 \pi}}} .
$$

Example. For the ventricosity of 1000 shells of Littornea littorea from Tenby, Wales, $A=90.964 \%$ and $\sigma=$ $2.3775 \%$. What is the probable range of ventricosity expressed in per cent.?

$$
2 x_{l}=2 \times 2.3775 \sqrt{.460517 \times \log \frac{1000}{2.506628 \times 2.3775}}=15.2 \text {. }
$$

The observed range was 15 (Duncker, '98). See also the criterion of Chauvenet. ('88) for the rejection of extreme variates (page 12).

The Normal Curve of Frequency as a Binomial Curve.

The normal curve may also be expressed by the binomial formula $(p \times q)^{A}$, where $p=\frac{1}{2}, q=\frac{1}{2}$, and $A$ is the number of 
terms, less 1 , in the expansion of the binomial; hence approximately the number of classes into which the magnitudes of the variates should fall. If the standard deviation be known, $\Lambda$ may be found by the equation

$$
\Lambda=4 \times(\text { Standard Deviation })^{2}=4 \sigma^{2} \text {. }
$$

Example of Normal Curve. - Number of rays in lower valve of Pecten opercularis from Firth of Forth:

\begin{tabular}{rrrrrrr}
$V$ & \multicolumn{1}{c}{$f$} & $V-V_{0}$ & $f\left(V-V_{0}\right)$ & $f\left(V-V_{0}\right)^{2}$ & $f\left(V-V_{0}\right)^{3}$ & $f\left(V-V_{0}\right)^{4}$ \\
14 & 1 & -3 & -3 & 9 & -27 & 81 \\
15 & 8 & -2 & -16 & 32 & -64 & 128 \\
16 & 63 & -1 & -63 & 63 & 63 & 63 \\
17 & 154 & 0 & 0 & 0 & 0 & 0 \\
18 & 164 & -1 & 164 & 164 & 164 & 164 \\
19 & 96 & 2 & 192 & 384 & 768 & 1535 \\
20 & 20 & 3 & 60 & 180 & 540 & 1620 \\
21 & 2 & 4 & $\underline{8}$ & $\underline{32}$ & $\underline{128}$ & $\underline{512}$ \\
& $n=508$ & & $\underline{342}$ & 864 & 1446 & 4104
\end{tabular}

$\nu_{1}=\frac{342}{508}=.6732 ; \nu_{2}=\frac{864}{508}=1.7008 ; \nu_{3}=\frac{1446}{508}=2.8465 ; \nu_{4}=\frac{4104}{508}=8.0787$.

$A=V_{0}+\nu_{1}=17+.6732=17.6732$.

$\mu_{2}=1.7008-0.6732^{2}=1.2475 ; \sigma=\sqrt{\mu_{2}}=1.1169$.

$\mu_{3}=2.8465-3 \times 0.6732 \times 1.7008+2 \times 0.6732^{3}=0.0217$.

$\mu_{4}=8.0787-4 \times 0.6732 \times 2.8465+6 \times 0.6732^{2} \times 1.7008-3 \times 0.6732^{4}$

$\beta_{1}=\frac{0.0217^{2}}{1.1169^{3}}=0.0002 ; \beta_{2}=\frac{4.4223}{1.1169^{2}}=2.8414$.

$F=\frac{0.0002 \times 5.8414^{2}}{4 \times 11.3650 \times(-0.3178)}=-0.00047 ; \quad F \mu_{2}^{3}=0.0009$.

$\frac{3 \nu_{2}^{2}-2 \nu_{1}^{4}}{\nu_{4}}=\frac{3(1.7008)^{2}-2 \times .7059^{4}}{8.0787}=1.011$.

Theoretical maximum frequency, $y_{0}=\frac{n}{\sigma \sqrt{2 \pi}}=\frac{508}{1.1169 \sqrt{2 \pi}}=181.5$.

The probable discrepancy, based on the five larger values of $y$, is found as follows, the $\chi_{1}$ values being taken from a table like Table IV:

$\begin{array}{rcccccc}L & a & \chi_{1} & A+\sigma \chi_{1} & \begin{array}{c}\text { Actual } \\ \text { Dis- } \\ \text { crepancy. }\end{array} & \begin{array}{c}\text { Probable } \\ \text { Dis- } \\ \text { crepancy. }\end{array} & \begin{array}{c}\text { Ratio of } \\ \text { Actual to } \\ \text { Probable } \\ \text { Dis- } \\ \text { crepancy. }\end{array} \\ 14.5 & -0.99606 & & & & & \\ 15.5 & -0.96457 & -2.11 & 15.34 & +0.17 & .083 & 2.05 \\ 16.5 & -0.71654 & -1.07 & 16.51 & -0.01 & .032 & 0.31 \\ 17.5 & -0.11023 & -0.138 & 17.55 & -0.05 & .025 & 2.00 \\ 18.5 & +0.53543 & 0.73 & 18.51 & -0.01 & .027 & 0.37 \\ 19.5 & +0.91439 & 1.72 & 19.62 & -0.12 & .054 & 2.22 \\ 20.5 & +0.99213 & & & & & \end{array}$


The extreme values are not calculated for the relations indicated by the formula do not hold well there where the frequencies are small and the proportionate values of $y$ are changing rapidly for small changes of $x$. For the five values considered the actual discrepancy is less than the probable discrepancy in three cases and less than the probable limit in all.

To find the average difference between the $p$ th and the $(p+1)$ th individual in any seriation (Galton's difference problem). Let $x_{p}$ be the average interval between the $p$ th and $(p+1)$ th individual; $n$ the total number of variates; and $\sigma$ their standard deviation.

Then, (1) when $n$ is large and $p$ small:

$$
i_{p}=\sigma \frac{\sqrt{2 \pi p} p^{p} e^{-p}}{\mid \underline{p}} \cdot \frac{1}{n y_{m}}\left\{1+c_{1}+c_{2}+c_{3}+\ldots\right\}
$$

where $y_{m}=\frac{1}{\sqrt{2 \pi}} e^{-\frac{1}{2} m^{2}}$.

$m$ can be found from Table IV by the use of the formula

$$
\frac{n-2 p}{n}=\sqrt{\frac{2}{\pi}} \int_{0}^{m} e^{-\frac{1}{2} \chi^{2}} d \chi,
$$

where the value of $m$ sought is the argument corresponding to the tabular entry $\left(\frac{n-2 p}{n}\right)$.

$$
\begin{aligned}
c_{1}= & .83 \dot{3} \frac{(n-2 p)^{2}}{n(n-p) p}-2.5 \frac{n-2 p}{n^{2}} \frac{m}{y_{m}} \\
& +1.875 \frac{(n-p) p}{n^{3}} \cdot\left(\frac{m}{y_{m}}\right)^{2} ; \\
c_{2}=-.75 \frac{(n-p)^{3}+p^{3}}{n^{2}(n-p) p}+1.5 \frac{n-2 p}{n^{2}} & \frac{m}{y_{m}} \\
& -.125 \frac{(n-p) p}{n^{3}}\left(7-\frac{4}{m^{2}}\right)\left(\frac{m}{y_{m}}\right)^{2} ;
\end{aligned}
$$




$$
\begin{aligned}
c_{3}=-2.5 \frac{(n-p)^{5}+p^{5}}{n^{3}(n-p)^{2} p^{2}} & +7.5 \frac{(n-p)^{4}-p^{4}}{n^{4}(n-p) p} \cdot \frac{m}{y_{m}} \\
& -.625 \frac{(n-p)^{3}+p^{3}}{n^{5}}\left(13-\frac{4}{m^{2}}\right)\left(\frac{m}{y_{m}}\right)^{2} \\
& -.625 \frac{(n-2 p)(n-p) p}{n^{5}}\left(6-\frac{7}{m^{2}}\right)\left(\frac{m}{y_{m}}\right)^{3} \\
& +.02083\left[\frac{(n-p) p^{2}}{n^{3}}\right] \frac{31 m^{4}-101 m^{2}+28}{y_{m}^{4}} .
\end{aligned}
$$

The solution of the equations for $c_{1}, c_{2}$, and $c_{3}$ will be facilitated by finding, once for all, the logarithms of $n,(n-p)$, $(n-2 p),(n-p) p$, and $\frac{m}{y_{m}}$.

(2). When $n$ and $p$ are both large and not nearly equal:

$$
i_{p}=\frac{\sigma}{n y_{m}}\left(1+c_{1}+c_{2}+c_{3}+\ldots\right) \text {. }
$$

(3). When $n$ is small the unsimplified form of the equattion must be used.

$$
\begin{aligned}
& i_{p}=\sigma \frac{\mid \underline{n}}{|\underline{n-p}| \underline{p}} \frac{(n-p)^{n-p} p^{p}}{n^{n}} \sqrt{2 \pi} \sqrt{\frac{(n-p) p}{n^{3}}} \\
& \times \frac{1}{y_{m}}\left(1+c_{1}+c_{2}+c_{3}+\ldots\right) \text {. }
\end{aligned}
$$

$n$ means the products of all integers from 1 to $n$. The series $c_{1}, c_{2}, c_{3}$ is not complete, but the values of $c$ with higher subscripts are so small that they may be neglected.

Let $I_{p^{\prime} p^{\prime \prime}}$ be the difference measured in units of $\sigma$ between the $p^{\prime}$ th and the $p^{\prime \prime}$ th individual, then

$$
I_{p^{\prime} p^{\prime \prime}}=\left(i_{p^{\prime}}+i_{p^{\prime}+1}+i_{p^{\prime}+2}+\ldots+i_{p^{\prime \prime}-1}\right) \sigma .
$$

The foregoing method is that of Pearson (1902k) based upon some considerations of Galton (1902).

To find the best fitting normal frequency distribution when only a portion of an empirical distribution is given.

First apply the following parabola of the second order: 
(1)

$$
y=y_{0}\left\{\varepsilon_{0}+\varepsilon_{1} \frac{x}{l}+\varepsilon_{2}\left(\frac{x}{l}\right)^{2}\right\},
$$

where $l$ is the half range and

also,

$$
\begin{aligned}
& \varepsilon_{0}=\frac{3}{4}\left(3 \lambda_{0}-5 \lambda_{2}\right)=3\left(\lambda_{2}-.2 \varepsilon_{2}\right) ; \\
& \varepsilon_{1}=3 \lambda_{1} ; \\
& \varepsilon_{2}=3.75\left(3 \lambda_{2}-\lambda_{0}\right) ;
\end{aligned}
$$

$$
y_{0}=\frac{m_{0}}{2 l} ; \quad \lambda_{0}=3 \lambda_{2}-\frac{4}{15} \varepsilon_{2} ; \quad \lambda_{1}=\frac{m_{1}}{m_{0} l} ; \quad \lambda_{2}=\frac{m_{2}}{m_{0} l^{2}} .
$$

To find $m_{0}$ arrange the frequencies in the usual manner (p. 26) and find the logarithm of each; their sum is equal to $m_{0}$. Making the class situated at the middle of the range 0 , find the deviation of each of the other classes from this class. The algebraic sum of the product of the logarithms by the deviations gives $m_{1}$. The second moment about the same zero point gives $m_{2}$. Or, $m_{0}=\Sigma \log f=\Sigma Y ; \quad m_{1}=\Sigma\left[Y\left(V-V_{\infty}\right)\right] ; \quad m_{2}=\Sigma\left[Y\left(V-V_{0}\right)^{2}\right]$.

Substituting in (1) we get a numerical quadratic equation which can be put in the form

$$
\text { (2) } \begin{aligned}
\boldsymbol{Y} & =y_{0}\left\{\varepsilon_{2}\left[\left(\frac{x}{l}\right)^{2}+\frac{\varepsilon_{1}}{\varepsilon_{2}} \frac{x}{l}+\left(\frac{\varepsilon_{1}}{2 \varepsilon_{2}}\right)^{2}\right]+\varepsilon_{0}-\varepsilon_{2}\left(\frac{\varepsilon_{1}}{2 \varepsilon_{2}}\right)^{2}\right\} \\
& =y_{0}\left\{\varepsilon_{2}\left(\frac{x+\frac{\varepsilon_{1} l}{2 \varepsilon_{2}}}{l}\right)^{2}+\varepsilon_{0}-\frac{\varepsilon_{1}^{2}}{4 \varepsilon_{2}}\right\} .
\end{aligned}
$$

If the normal curve be $y=z_{0} e^{-\frac{(x+h)^{2}}{2 \sigma^{2}}}$,

$$
Y=\log y=\log z_{0}-\frac{(x+h)^{2}}{2 \sigma^{2}} \log e ;
$$

whence, by comparison of right-hand expressions in equations (2) and (3),

$$
\begin{aligned}
\log z_{0} & =y_{0} \times\left(\varepsilon_{0}-\frac{\varepsilon_{1}^{2}}{4 \varepsilon_{2}}\right) ; \\
2 \sigma^{2} & =\frac{l^{2} \log e}{y_{0} \times \varepsilon_{2}} .
\end{aligned}
$$

Then the required normal curve is

(Pearson, 1902 ${ }^{\mathrm{m}}$.)

$$
y=z_{0} e^{-x^{2} / 2 \sigma^{2}} .
$$




\section{Other Unimodal Frequency Polygons.}

The formulas of Pearson's Types I to VI are as follows:

Type I. $y=y_{\mathrm{i}}\left(1+\frac{x}{l_{1}}\right)^{m_{1}}\left(1-\frac{x}{l_{2}}\right)^{m_{2}}$.

Type II. $y=y_{0}\left(1-\frac{x^{2}}{l^{2}}\right)^{m}$.

Type III. $y=y_{0}\left(1+\frac{x}{l}\right)^{p} e^{-x / d}$.

Type IV. $y=y_{0} \cos \theta^{2 m} e^{-\tau \theta}$, where $\tan \theta=\frac{x}{l^{\circ}}$.

Type V. $y=y_{0} x^{-p} e^{-r / x}$.

Type VI. $y=y_{0}(x-l)^{q_{2}} / x^{q_{1}}$.

In these formulas:

$x$, abscissæ;

$y_{0}$, the ordinate at the origin, to be especially reckoned for each type;

$y$, the height of the ordinate (or rectangle) located at the distance $x$ from $y_{0}$;

$l$, a part of the abscissa-axis $X X^{\prime}$ expressed in units of the classes;

$e$, the base of the Naperian system of logarithms, 2.71828.

The other letters stand for relations that are explained in the sections below treating of each type separately.

The range of the curve is limited in both directions in Types I and II, is limited in one direction only in Types III, $\mathrm{V}$, and VI, and is unlimited in both directions in Type IV and the normal curve. The normal curve may give the best fit, however, notwithstanding the fact that in biological statistics the range is ordinarily limited at both extremes. Thus the range of carapace length to total length of the lobster is limited between 0 and 1 . The ratio of carapace length to abdominal length in various crustaceans may, however, conceivably take any value from $+\infty$ to 0 . In the ratio of dorsoventral to antero-posterior diameter the forms of the molluscan genera Pinna or Malleus on the one hand and Solen on the other approach such extremes.

Asymmetry or Skewness $(\alpha)$ is tound in Types I, III, IV, V, and VI. In skew curves the mode and the mean are 
separated from each other by a certain distance $D$; or $D=$ mean-mode. Asymmetry is measured by the ratio $\alpha=\frac{D}{\sigma}$. If the mean is greater than the mode, skewness is positive; if the mean is less than the mode, skewness is negative. $D$, and hence skewness, may be calculated when the theoretical mode is known (see pages 13, 14, and below).

In Types I and III skewness is measured also by the ratio $\quad \alpha=\frac{1}{2} \sqrt{\beta_{1}} \frac{s \pm 2}{s \mp 2}, \quad$ where $\quad s=\frac{6\left(\beta_{2}-\beta_{1}-1\right)}{3 \beta_{1}-2 \beta_{2}+6}$. When $5 \beta_{2}-6 \beta_{1}-9$ is positive, $\alpha$ has the sign of $\mu_{3}$; if negative, $\alpha$ has the opposite sign to $\mu_{3}$ (Duncker, ' $00^{\mathrm{b}}$ ).

In Type I, $\alpha=\frac{1}{2} \sqrt{\beta_{1}} \frac{s+2}{s-2}\left(=\frac{1}{2} \sqrt{\beta_{1}} \frac{5 \beta^{2}-6 \beta_{1}-9}{\beta_{2}+3}\right)$.

“ "IIII, $\alpha=\frac{1}{2} \sqrt{\bar{\beta}_{1}}=\frac{ \pm \mu_{3}}{+2 \sqrt{\mu_{2}{ }^{3}}}$, where the sign is the

“ " IV,$\alpha=\frac{1}{2} \sqrt{\beta_{1}} \frac{s-2}{s+2}$.

“ " $\mathrm{V}, \alpha=\frac{2 \sqrt{p-3}}{p}$,

since $p-4$ is the positive root of the quadratic:

$$
(p-4)^{2}-\frac{16}{\beta_{1}}(p-4)-\frac{16}{\beta_{1}}=0,
$$

$p$ is readily found.

$$
\text { i. Type VI, } \alpha=\frac{\left(q_{1}+q_{2}\right) \sqrt{ }\left(q_{1}-q_{2}-3\right)}{\left(q_{1}-q_{2}\right) \sqrt{ }\left\{\left(q_{1}-1\right)\left(q_{2}+1\right)\right\}} \text {, }
$$

where $\left(1-q_{1}\right)$ and $\left(q_{2}+1\right)$ are the two roots of the equation

$$
z^{2}-s z+\frac{s^{2}}{4+1 \beta_{1}(s+2)^{2} /(s+1)}=0 .
$$

To compare any observed frequency polygon of Type I with its corresponding theoretical curve.

$$
y=y_{0}\left(1+\frac{x}{l_{1}}\right)^{m_{1}}\left(1-\frac{x}{l_{2}}\right)^{m_{2}} \text {. }
$$


To find $l_{1}, l_{2}, m_{1}, m_{2}, \dddot{y}_{0}$.

The total range, $l$, of the curve (along the abscissa axis) is found by the equation

$$
l=\frac{\sigma}{2} \sqrt{\beta_{1}(s+2)^{2}+16(s+1)} ;
$$

$l_{1}$ and $l_{2}$ are the ranges to the one side and the other of $y_{0}$;

$$
\begin{array}{rlrl}
l_{1} & =\frac{1}{2}(l-D s) ; & D=\sigma \alpha=\sqrt{\mu_{2}} \cdot \alpha ; \\
l_{2}=l-l_{1} ; & m_{1}+m_{2}=s-2 ; \\
m_{1}=\frac{l_{1}}{l}(s-2) ; & \\
y_{0}=\frac{n}{l} \cdot \frac{m_{1}^{m_{1}} \cdot m_{2}{ }^{m_{2}}}{\left(m_{1}+m_{2}\right)^{m_{1}+m_{2}}} \cdot \frac{\Gamma\left(m_{1}+m_{2}+2\right)}{\Gamma\left(m_{1}+1\right) \Gamma\left(m_{2}+1\right)} .
\end{array}
$$

To solve this equation it will be necessary to determine the value of each parenthetical quantity following the $\Gamma$ sign and find the corresponding value of $\Gamma$ from Table V. It is, however, sometimes easier to calculate the value of $y_{0}$ from the following approximate formula:

$$
y_{0}=\frac{n}{l} \cdot \frac{\left(m_{1}+m_{2}+1\right) \sqrt{m_{1}+m_{2}}}{\sqrt{2 \pi m_{1} m_{2}}} e^{\frac{1}{12}}\left(\frac{1}{m_{1}+m_{2}}-\frac{1}{m_{1}}-\frac{1}{m_{2}}\right) .
$$

With these data the theoretical curve of Type I may be drawn. Frequency polygons of Type $I$ are often found in biological measurements.

To compare any observed frequency polygon of Type II with its corresponding theoretical curve.

$$
y=y_{0}\left(1-\frac{x^{2}}{\frac{1}{2} l^{2}}\right)^{m}
$$

This equation is only a special form of the equation of Type I in which $l_{1}=l_{2}$ and $m_{1}=m_{2}$.

As from page $22, \beta_{1}=0$ in Type II, $l=2 \sigma \sqrt{s+1}$; since the curve is symmetrical, $D=0$, and

$$
m=\frac{1}{2}(s-2) ; \quad y_{0}=\frac{n}{\frac{1}{2} l} \frac{\Gamma(m+1.5)}{\sqrt{\pi} \Gamma(m+1)} .
$$

The $\Gamma$ values will be found from Table V. 
An approximate formula for $y_{0}$ is given by Duncker as follows:

$$
y_{0}=\frac{n}{\sigma \sqrt{2 \pi}} \frac{s-1}{\sqrt{(s+1)(s-2)}} e^{-\frac{1}{4(s-2)}} .
$$

To compare any observed frequency polygon of Type III with its corresponding theoretical curve.

$$
y=y_{0}\left(1+\frac{x}{l_{1}}\right)^{p} e^{-x / d} .
$$

The range at one side of the mode is infinite; at the other is found by the formula

$$
l_{1}=\sigma \frac{4-\beta_{1}}{2 \sqrt{\beta_{1}}}=\sigma \frac{1-\alpha^{2}}{\alpha} \text { (for Type III). }
$$

Also, $\quad p=\frac{l_{1}}{D}=\frac{l_{1}}{\sigma \alpha} ; \quad y_{0}=\frac{n}{l_{1}} \cdot \frac{p^{p+1}}{e^{p} \Gamma(p+1)}$.

The value of $\Gamma$ corresponding to $p+1$ can be got from Table V, Appendix.

To compare any observed frequency polygon of Type IV with its corresponding theoretical curve.

This is the commonest type of biological skew curves.

$$
y=y_{0}(\cos \theta)^{2 m} \cdot e^{-\tau \theta} .
$$

$\theta$ is a variable, dependent upon $x$ as shown in the equation

$$
x=l \tan \theta \text {. }
$$

The factor $(\cos \theta)^{2 m}$ following $y_{0}$ indicates that the curve is not calculated from the mean ordinate $(A)$, or the mode $(A-D)$, but that the zero ordinate is at $A-m D$; or at a distance $m \times D$ from the mean.

$$
\begin{array}{ll}
l=\frac{\sqrt{\mu_{2}}}{4} \sqrt{16(s-1)-\beta_{1}(s-2)^{2}} ; & m=\frac{1}{2}(s+2) ; \\
D & =\frac{\sigma}{2} \sqrt{\beta_{1}} \frac{s-2}{s+2} ; \quad m D=\frac{\sigma}{4} \sqrt{\beta}(s-2) ; \\
\tau & =\frac{\sqrt{\mu_{2}} s(s-2) \sqrt{\beta_{1}}}{4 l}, \text { with the opposite sign to } \mu_{3} ;
\end{array}
$$


$\theta($ arc of circle $)=\frac{\pi \theta^{\circ}}{180^{\circ}}$

$y_{0}=\frac{n}{l} \sqrt{\frac{s}{2 \pi}} \frac{e^{\frac{(\cos \phi)^{2}}{3 s}-\frac{1}{12 s}-\tau \phi *}}{(\cos \phi)^{s+1}}$.

$\phi=$ angle whose tangent is $\frac{\tau}{s}$.

To compare any observed frequency polygon of Type $V$ with its corresponding theoretical curve.

$$
y=y_{0} x^{-p} e^{-r / x}
$$

To find $p$ solve the quadratic equation

$$
(p-4)^{2}-\frac{16}{\beta_{1}}(p-4)-\frac{16}{\beta_{1}}=0,
$$

and take the positive root.

$$
\gamma=\sigma(p-2) \sqrt{p-3} ; \quad y_{0}=\frac{n \cdot r^{p-1}}{\Gamma(p-1)} ; \quad D=\frac{2 \gamma}{p(p-2)} .
$$

To compare any observed frequency polygon of Type VI with its corresponding theoretical curve.

$$
y=y_{0}\left(x-l_{1}\right)^{q_{2} / x^{q_{1}}} .
$$

$1-q_{1}$ and $q_{2}+1$ are the two roots of the equation

$$
z^{2}-s z+\frac{s^{2}}{4+\frac{1}{4} \beta_{1}(s+2)^{2} /(s+1)}=0 ;
$$

$l_{1}=s \sqrt{\frac{\mu_{2}(s+1) s^{2}}{\left(1-q_{1}\right)\left(1+q_{2}\right)}}$, where $\left(1-q_{1}\right)$ and $s$ are negative;

$$
\begin{aligned}
& y_{0}=\frac{n l_{1}^{q_{1}-q_{2}-1} \Gamma\left(q_{1}\right)}{\Gamma\left(q_{1}-q_{2}-1\right) \Gamma\left(q_{2}+1\right)}: \\
& D=\frac{l\left(q_{1}+q_{2}\right)}{\left(q_{1}-q_{2}\right)\left(q_{1}-q_{2}-2\right)} .
\end{aligned}
$$

* The foregoing value is approximate and is applicable when, as is usually the case, 8 is greater than 2 . The exact value is given by Pearson as

$$
y_{0}=\frac{n}{l} \cdot \frac{e^{\frac{1}{\tau} \tau \pi}}{\int_{0}^{\pi}(\sin \theta)^{8} e^{\tau \theta} d \theta},
$$

the formula for reducing which is to be gained from the integral calculus. 
Example of calculating the theoretical curve corresponding with observed data. (Fig. 6.)

Distribution of frequency of glands in the right fore leg of 2000 female swine (integral variates):

$\begin{array}{llllllllllll}\text { Number of glands } & 0 & 1 & 2 & 3 & 4 & 5 & 6 & 7 & 8 & 9 & 10\end{array}$ $\begin{array}{llllllllllll}\text { Frequency........ } & 15 & 209 & 365 & 482 & 414 & 277 & 134 & 72 & 22 & 8 & 2\end{array}$

Assume the axis $y y^{\prime}(V m)$ to pass through ordinate 4, then:

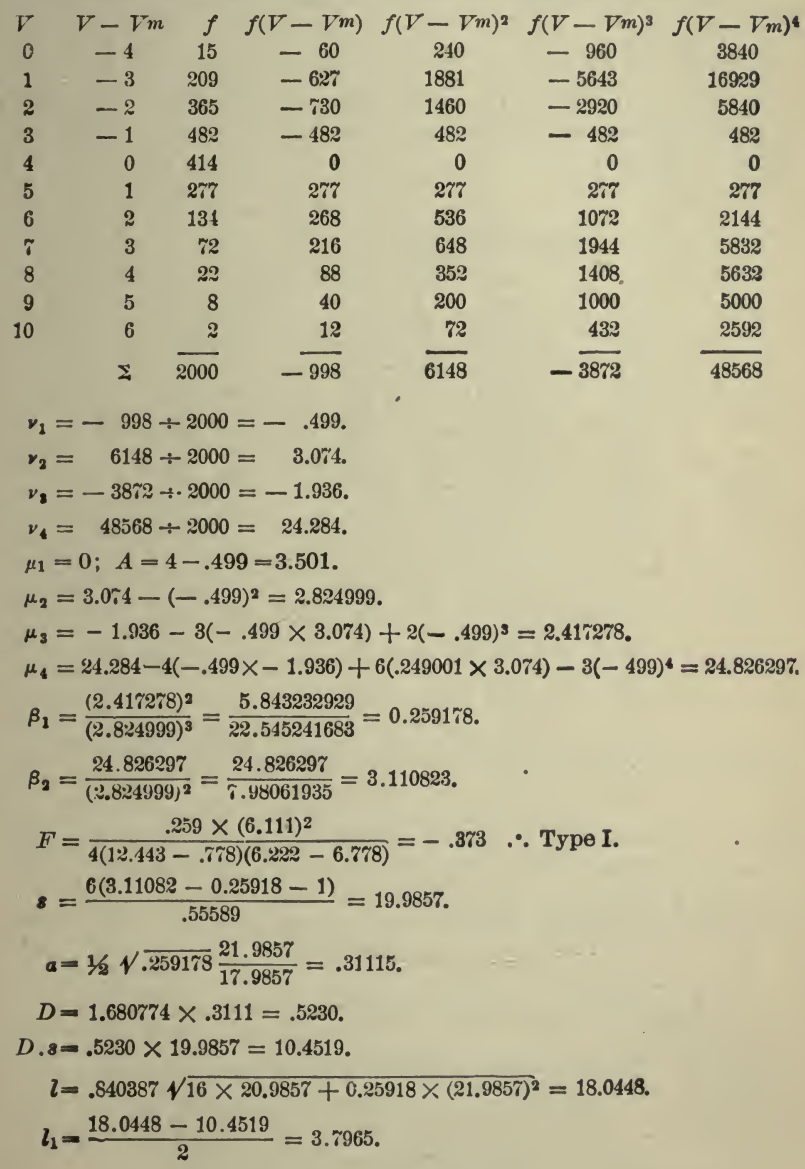




$$
\begin{aligned}
l_{2} & =18.0448-3.7965=14.2483 ; \\
m_{1} & =\frac{3.7965 \times 17.9857}{18.0448}=3.78401 ; \\
m_{2} & =\frac{14.2483 \times 17.9857}{18.0448}=14.2006 ; \\
y_{0} & =\frac{2000}{18.0448} \frac{(18.9846) \sqrt{17.9846}}{\sqrt{2 \pi \times 3.7840 \times 14.2006}} \times 2.17182 \delta^{.0833(.0556-.2643-.0704)}
\end{aligned}
$$

$=475.24$, the frequency of the modal class.

\begin{tabular}{|c|c|c|c|c|c|}
\hline $\boldsymbol{V}$ & $t$ & Theoretical $(y)$ & $\delta$ & $\delta^{2}$ & $\frac{\hat{o}^{2}}{u}$ \\
\hline-1 & 0 & 0.0 & 0.0 & & \\
\hline 0 & 15 & 21.1 & -6.1 & 37.21 & 1.76 \\
\hline 1 & 209 & 185.8 & +23.2 & 538.24 & 2.90 \\
\hline 2 & 365 & 395.1 & -30.1 & 906.01 & 2.30 \\
\hline 3 & 482 & 475.2 & +6.8 & 46.24 & .10 \\
\hline 4 & 414 & 405.6 & +8.4 & 70.56 & .17 \\
\hline 5 & 277 & 272.1 & +4.9 & 24.01 & .09 \\
\hline 6 & 134 & 147.6 & -13.6 & 184.96 & 1.25 \\
\hline 7 & 72 & 65.9 & +6.1 & 37.21 & .57 \\
\hline 8 & 22 & 24.1 & -2.1 & 4.41 & .18 \\
\hline 9 & 8 & 7.0 & +1.0 & 1.00 & .14 \\
\hline 10 & 2 & 1.6 & +0.4 & .16 & .10 \\
\hline 11 & 0 & 0.2 & -0.2 & .04 & \\
\hline \multirow[t]{2}{*}{12} & & 0.0 & & & \\
\hline & & & & \multicolumn{2}{|c|}{$\Sigma \frac{\delta^{2}}{y}=9.5$} \\
\hline
\end{tabular}

Position of the mode, $y_{0}=A-D=3.501-.523=2.978$. The closeness of fit to the theoretical curve is calculated below by Pearson's method (page 24).

That is, the probability is that in one out of every two random series belonging to Type I we should expect a fit not essentially closer than that given by our series, which, of course, assures us that this distribution is properly classified under Type I.

\section{The Use of Logarithis in Curve-fitting.}

Most of the statistical operations can be greatly facilitated by the use of logarithms. In curve-fitting their use becomes 
necessary. The following paradigm will be found of assistance:

\section{GENERAL.}

$\log \nu_{1}=\log \Sigma\left(V-V_{0}\right)-\log n$. $A=V_{m}+\nu_{1}$.

$\log \nu_{2}=\log \Sigma\left(V-V_{0}\right)^{2}-\log n$. $\log \sigma=\frac{1}{2} \log \mu_{2}$

$\log \nu_{3}=\log \Sigma\left(V-V_{0}\right)^{3}-\log n$. $\log C=\frac{1}{2} \log \mu_{2}-\log A$.

$\log \nu_{4}=\log \nu^{\prime}\left(V-V_{0}\right)^{4}-\log n$.

$\log \mathrm{E} \cdot A=9.828982+\log \sigma-\frac{1}{2} \log n$.

$\log \mathrm{E}_{\cdot \sigma}=\log \mathrm{E} . A-0.150515$.

$\log$ E. $C=\log$ E.o $_{\bullet}-\log A$.

$\log 2=0.301030$

$\log 3=0.477121$

$\log 4=0.602060$

$\log 6=0.778151$$$
\text { . }
$$

$\mu_{2}=N\left(\log \nu_{2}\right)-N\left(2 \log \nu_{1}\right)-[.0833] . \quad$ Find: $\log \mu_{2} ; 2 \log \mu_{2} ;$

$3 \log \mu_{2}$.

$\mu_{3}=N\left(\log \nu_{3}\right)-N\left(\log 3+\log \nu_{1}+\log \nu_{2}\right)+N\left(\log 2+3 \log \nu_{1}\right)$

Find: $\log \mu_{3} ; 2 \log \mu_{3}$.

$\mu_{4}=N\left(\log \nu_{4}\right)-N\left(\log 4+\log \nu_{1}+\log \nu_{3}\right)$

$+N\left(\log 6+2 \log \nu_{1}+\log \nu_{2}\right)-N\left(\log 3+4 \log \nu_{1}\right)$

$-N\left[9.698970+\log \mu_{2}\right]-\frac{7}{240}$. Find $\log \mu_{4}$. $\log \beta_{1}=2 \log \mu_{3}-3 \log \mu_{2}$.

$\log \beta_{2}=\log \mu_{4}-2 \log \mu_{2}$. $w=5 \beta_{2}-6 \beta_{1}-9$ (Types I, IV).

Skewness:

Type I: $\log \alpha=\frac{1}{2} \cdot \operatorname{og} \beta_{1}+\log w-\log \left(\beta_{2}+3\right)-0.301030$ 。

Type III: $\log \alpha=\frac{1}{2} \log \beta_{1}-0.301030$. 
Type IV: $\log \alpha=\frac{1}{2} \log \beta_{1}+\log \left(\beta_{2}+3\right)-\log w-0.301030$.

Type V: $\log \alpha=\log 2+\frac{1}{2} \log (p-3)-\log p$.

Type VI: $\log \alpha=\log \left(q_{1}+q_{2}\right)+\frac{1}{2} \log \left(q_{1}-q_{2}-3\right)-\log \left(q_{1}-q_{2}\right)$ $-\frac{1}{2} \log \left(q_{1}-1\right)-\frac{1}{2} \log \left(q_{2}+1\right)$.

\section{TYPE IV.}

This is the most difficult of all the types to be fitted. The work of fitting is carried out by the use of logarithms, as follows:

$\log j=\frac{1}{2} \log \beta_{1}+\log (s-2) . \quad \log k=\log j+\frac{1}{2} \log \mu_{2}$. $\log \alpha=\log j-\log (s+2)-0.301030$.

$\log l=\frac{1}{2} \log \mu_{2}+\frac{1}{2} \log \{N[\log (s-1)+1.204120]$

$$
\left.-N\left[\log \beta_{1}+2 \log (s-2)\right]\right\}-0.602060 \text {. }
$$

$\log D=\log \alpha+\frac{1}{2} \log \mu_{2} ; \quad m=\frac{s+2}{2}$.

$\log m D=\log k-0.602060$.

$\log \tau=\log k+\log s-0.602060-\log l$.

$\log \tan \phi=\log \tau-\log s$.

$\log \theta=8.241877+\log \theta^{\circ}$.*

$\log y_{0}=\log n+\frac{1}{2} \log s+N\{\log [N(2 \log \cos \phi-\log 3 s)$

$-N(8.920819-\log s)-N(\log \tau+\log \phi)]+9.637784\}$ $-0.399090-\log l-(s+1) \log \cos \phi$.

$\log y=\log y_{0}+N[\log (s+2)+\log \log \cos \theta]$

$$
\mp N\left[7.8796612+\log \theta^{\circ *}+\log \tau\right] \text {. }
$$

\section{Multimodal Curves.}

Multimodal curves are given when the frequency in the different classes exhibits more than one mode. False multimodal curves result from too few observations, or when the classes are too numerous for the variates. By increasing the number of variates or by making the classes more inclusive some of the modes disappear.

* In degrees and fractions of a degree; see Table VII. 
Multimodal curves differ in degree. The modes may be so close that only a single mode (usually in an asymmetrical curve) appears in the result; or one of the modes may appear as a hump on the other; or the two modes may even be far apart and separated by a deep sinus (Figs. 7 to 10).

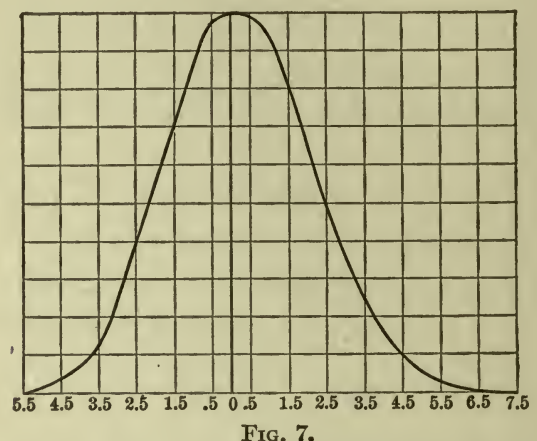

Pearson has offered a menns of breaking up a compound curve with apparently only one mode into two curves having distinct modes; but this method is very tedious and rarely applicable.

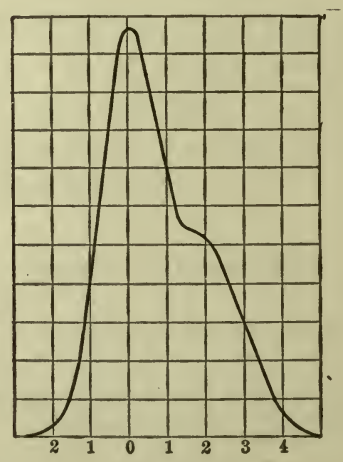

FIG. 8.

The index of divergence of two modes of a multi. modal curve is the distance between the modes expressed in 
terms of the standard deviation of the more variable of the components.*

The index of isolation of two masses of variates grouped about adjacent modes is the ratio of the depression between the modes to the height of the shorter mode.

, The meaning of multimodal curves is diverse. Sometimes

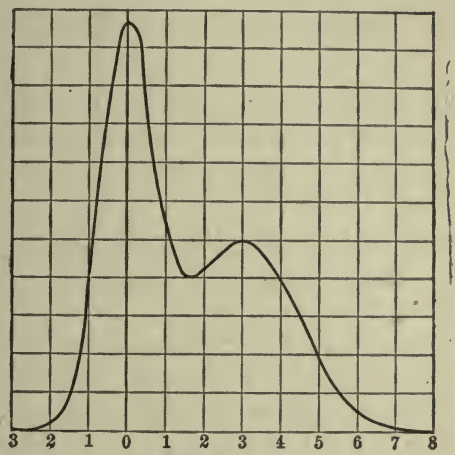

FIG. 9.

they indicate a polymorphic condition of the species, the modes representing the different type forms. This is the case with

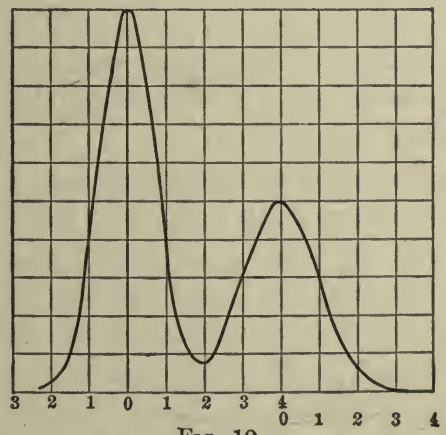

Fig. 10.

the number of ray flowers of the white daisy which has modes at $8,13,21,34$, etc. Sometimes they indicate a splitting of a species into two or more varieties.

* I have proposed (Science, VII, 685) to measure the divergence in a unit $=3 \times$ Standard Deviation, which has certain advantages in species study. 


\section{CHAPTER IV.}

\section{Correlated Variability.}

Correlated variation is such a relation between the magnitudes of two or more characters that any abmodality of the one is accompanied by a corresponding abmodality of the other or others.

The methods of measuring correlation given below are applicable to cases where the distribution of variates is either symmetrical or skew.

The principles upon which the measure of correlated variation rests are these. When we take individuals at random we find that the mean magnitude of any character is equal to the mean magnitude of this character in the whole population. Deviation from the mean of the whole population in any lot of individuals implies a selection. If we select individuals on the basis of one character $(A$, called the subject) we select also any closely correlated character ( $B$, called the relative) (e.g., leg-length and stature). If perfectly correlated, the index of abmodality (p.23) of any class of $B$ will be as great as that of the corresponding class of $A$, or

$$
\frac{\text { Index abmodality of relative class }}{\text { Index abmodality of subject class }}=1 \text {. }
$$

If there is no correlation, then whatever the value of the index of abmodality of the subject, that of the relative will be zero and the coefficient of correlation will be

$$
\text { Index of abmodality of relative class }=\frac{0}{m}=0 \text {. }
$$

The coefficient of correlation is represented in formulas by the letter $r$. We cannot find the degree of correlation between two organs by measuring a single pair only; it is the correlation "in the long run" which we must consider. Hence we must deal with masses and with averages. 


\begin{tabular}{|c|c|c|c|c|c|c|c|c|c|c|c|c|c|c|}
\hline & 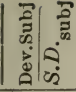 & & $\begin{array}{l}28 \\
6 i \\
1\end{array}$ & $\frac{5}{i}$ & $\begin{array}{l}8 \\
0 \\
1\end{array}$ & 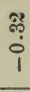 & $\begin{array}{l}\ddot{Q} \\
\dot{0}\end{array}$ & $\infty$ & $\nabla$ & & is & ก) & & \multirow{17}{*}{ 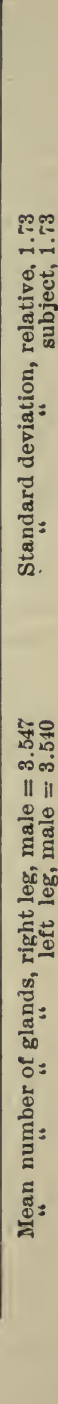 } \\
\hline & 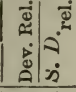 & & $\frac{0}{1}$ & $\frac{\mathscr{2}}{1}$ & i & $\begin{array}{l}\text { \& } \\
0 \\
1\end{array}$ & \&? & is & + & & 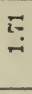 & $\stackrel{O}{\circ}$ & & \\
\hline & 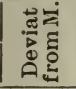 & & $\begin{array}{l}\text { 웅 } \\
\text { مi } \\
1\end{array}$ & $\begin{array}{c}8 \\
\dddot{1} \\
\text { oi } \\
1\end{array}$ & $\begin{array}{l}\text { शै? } \\
\text { ?े } \\
1\end{array}$ & $\begin{array}{l}m \\
0 \\
0\end{array}$ & $\stackrel{\infty}{\stackrel{\infty}{\sharp ! ~}}$ & ने & : & & $\begin{array}{l}\text { o } \\
\text { oे } \\
\text { iं }\end{array}$ & 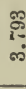 & & \\
\hline & | & & $\begin{array}{l}8 \\
8 \\
0\end{array}$ & $\begin{array}{l}80 \\
\text { ก } \\
-1\end{array}$ & 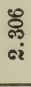 & 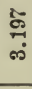 & $\begin{array}{l}\infty \\
\infty \\
\infty \\
\infty\end{array}$ & वै: & if & & $\begin{array}{l}8 \\
\qquad \\
0\end{array}$ & ๙ุ & & \\
\hline$\stackrel{ }{\circ}$ & ڤ & & $:$ & $\vdots$ & $\vdots$ & $\vdots$ & $\vdots$ & $\vdots$ & $\sigma$ & & $\vdots$ & $\leadsto$ & & \\
\hline$\infty$ & $\underset{20}{\circ}$ & & $:$ & : & $\vdots$ & $\vdots$ & $\vdots$ & : & 0 & & Q2 & 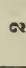 & 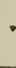 & \\
\hline$\infty$ & $\underset{7}{*}$ & & $:$ & : & : & $\vdots$ & $r$ & $\infty$ & $r$ & & ax & O2 & & \\
\hline I- & $\underset{\text { ஸे }}{\stackrel{0}{0}}$ & & $\vdots$ & $\vdots$ & $\vdots$ & $\vdots$ & $\infty$ & $=$ & 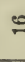 & & $\infty$ & $\infty$ & & \\
\hline$\infty$ & $\stackrel{\infty}{\stackrel{0}{2}}$ & & $\vdots$ & $\vdots$ & -1 & $\infty$ & $\stackrel{e s}{x}$ & 암 & $\stackrel{\infty}{q}$ & & مه & $\infty$ & & \\
\hline 20 & $\stackrel{0}{\check{1}}$ & & $:$ & $\vdots$ & is & $\begin{array}{l}\infty \\
\text { K }\end{array}$ & i & 음 & 冓 & & $\infty$ & - & & \\
\hline ד & : & & $:$ & $\infty$ & 品 & 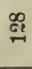 & กี & $\delta$ & 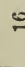 & & 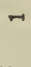 & : & & \\
\hline$\infty$ & मी & & $:$ & $\sigma$ & 8 & 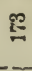 & $\underset{\sim}{\stackrel{2}{二}}$ & a & $\infty$ & & $\vdots$ & : & & \\
\hline$Q 0$ & İं & 1 & C2 & $\infty$ & स्र & $\infty$ & कर & $x$ & . & & $\vdots$ & : & & \\
\hline$\pi$ & $\begin{array}{l}\text { at } \\
\text { ei } \\
1\end{array}$ & & 20 & 돔 & อ8 & $\rightleftarrows$ & 10 & $n$ & & & $\vdots$ & : & & \\
\hline 0 & वृ? & & $\infty$ & $\nabla$ & $\infty$ & : & : & & & & $\vdots$ & : & & \\
\hline $\begin{array}{l}\dot{\theta} \\
\frac{\theta}{0} \\
\frac{0}{0}\end{array}$ & $\mid \begin{array}{l}\frac{0}{0} \\
\frac{\pi}{0} \\
0\end{array}$ & 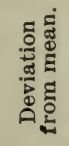 & के & $\frac{10}{10}$ & एव & $\begin{array}{l}2 \\
0 \\
0\end{array}$ & $\frac{\text { in }}{2}$ & กี้ & if & & $\frac{15}{4}$ & हึ & & \\
\hline 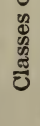 & 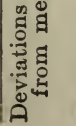 & 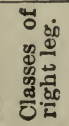 & 0 & 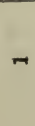 & CP & $\infty$ & + & 20 & $c$ & & $\infty$ & $\mathscr{R}$ & & \\
\hline
\end{tabular}


In studying correlation one (either one) of the characters is regarded as subject and the other as relative. A correlation table is then arranged as in the example on page 43 , which gives data for determining the correlation between the number of Müllerian glands on the right (subject) and left (relative) legs of male swine. The selected subject class is called the type; the corresponding distribution of the relative magnitudes is called the array.

Methods of Determining Coefficient of Correlation.

Galton's graphic method. On co-ordinate paper draw perpendicular axes $X$ and $Y$; locate a series of points from the pairs of indices of abmodality of the relative and subject corresponding to each subject class. The indices of the subjects are laid off as abscissæ; the indices of the relatives as ordinates, regarding signs. Get another set of points by making a second correlation table, regarding character $B$ as subject and character $A$ as relative. Then draw a straight line through these points so as to divide the region occupied by them into halves. The tangent of the angle made by the last line with the horizontal axis $\mathrm{XX}$ (any distance $y p$, divided by $x p$ ) is the index of correlation.

A more precise method is given by Pearson as follows: Sum of products (deviation subj. class $\times$ deviation each assoc. rel. class $X$ no. of cases in both)

total no. of indivs. $\times$ Stand. Dev. of subject $\times$ Stand. Dev. of relative;

or, expressed in a formula :

$$
r=\frac{\Sigma(\operatorname{dev} . x \times \operatorname{dev} . y \times f)}{n \sigma_{1} \sigma_{2}} .
$$

This method requires finding many products in the numeralor, as many sets of products as there are entries in the body of the correlation table. A portion of the products to be found in correlation table, p. 43 , is indicated below:

$$
\begin{gathered}
-3.547 \times\left\{\begin{array}{l}
-3.540 \times 8 \\
-2.540 \times 5 \\
-1.540 \times 2
\end{array}\right. \\
-2.547 \times\left\{\begin{array}{l}
-3.540 \times 4 \\
-2.540 \times 151 \\
-1.540 \times 58
\end{array}\right. \\
\text { etc. }
\end{gathered}
$$


The handling of long decimal fractions may be avoided by the use of a method similar to that used at page 26 for finding the average and standard deviation. The formula for $r$ may be written

$$
r=\left(\frac{\Sigma\left(x^{\prime} y^{\prime}\right)}{n}-\nu_{1}^{\prime} \nu_{1}^{\prime \prime}\right) \frac{1}{\sigma_{1} \sigma_{2}}
$$

Assuming the class including or nearest to the true mean of the subject values as the mean of the subjects, and the class including or nearest to the true mean of the relative values as the mean of the relatives, find for each variate the product of its deviations $x^{\prime}$ and $y^{\prime}$ from the respective assumed means, and (having regard for signs) find the algebraic sum of these products. Divide this sum by the number of variates; the quotient is the average of the deviation products about the assumed axes. To refer to the true axes, passing through the true means, find the average moments, $\nu_{1}$ (as on page 26), both for the subject and the relative distributions about their respective assumed means, and subtract the product of the two values of $\nu_{1}$ from the average of the approximate deviation products already found. Divide the difference by the product of the standard deviations of the two frequency distributions. (Compare Yule, '97b, pp. 12-17.)

The probable error of the determination of $r$ is

$$
E_{r}=\frac{0.6745\left(1-r^{2}\right)}{\sqrt{n}}
$$

(Pearson and Filon, '98, p. 242.)

Example. Correlation in number of Müllerian glands on right and left legs of 2000 male swine. (See table on next page.)

For + quadrants $\Sigma\left(x^{\prime} y^{\prime}\right)=5243$

$$
\text { “ “ } \quad \Sigma\left(x^{\prime} y^{\prime}\right)=\frac{-118}{\frac{5125}{2000}}=2.5625=\frac{\Sigma\left(x^{\prime} y^{\prime}\right)}{n} .
$$




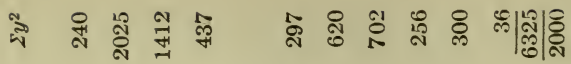

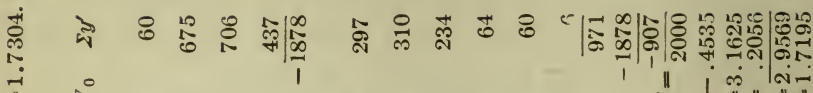
i

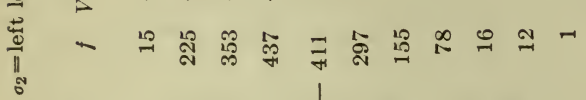

10

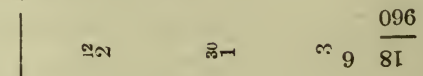

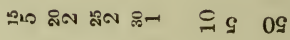$$
\text { ThO }
$$

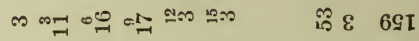

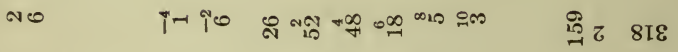

1ิ

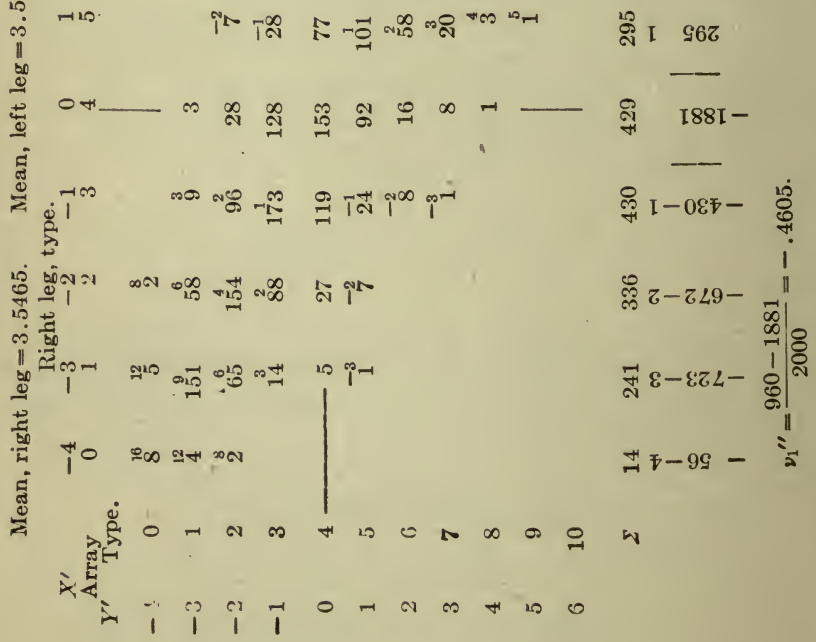


$r=\left(\frac{\Sigma\left(x^{\prime} y^{\prime}\right)}{n}-\nu_{1}^{\prime} \nu_{1}^{\prime \prime}\right) \frac{1}{\sigma_{1} \sigma_{2}}=(2.5625-.4535 \times .4605)$

$$
\begin{gathered}
\times \frac{1}{1.7195 \times 1.730}=0.7911 . \\
\mathrm{E}_{\cdot r}=\frac{.6745\left[1-(.7919)^{2}\right]}{\sqrt{2000}}= \pm .0056 .
\end{gathered}
$$

The average variability of an array is $=\sigma \sqrt{1-r^{2}}$.

The coeflicient of regression marks the proportional change of the relative organ for a unit's change of the subject organ. It is given by the equation $\rho=r \frac{\sigma_{1}}{\sigma_{2}}$, where $\sigma_{1}$ is the standard deviation of the subject, $\sigma_{2}$ that of the relative.

The Quantitative Treatment of Characters not Quan- . titatively Measurable.

Even qualities that do not lend themselves to a quantitative expression may be expressed in a roughly quantitative fashion. The fundamental assumption is made that the frequencies would obey the normal law of frequency more or less closely, provided a quantitative scale could be found. This assumption will not, in most biological data, lead us far astray.

Divide the data into three classes (e.g., in eye-color we may have black, brown and gray, and blue), and let the frequency of these classes be $n_{1}, n_{2}, n_{3}$, in which $n_{1}$ and $n_{3}$ are each less than $\frac{1}{2} n$, so that $n_{\varepsilon}$ contains the median. Let $L_{1}, L_{*}$ be the (unknown) distances of the mean from the two boundaries of $n_{2}$. Call $L_{1} / \sigma=h_{1}$ and $L_{3} / \sigma=h_{3}$, then

$$
\frac{n_{1}-n_{2}-n_{3}}{n}=\sqrt{\frac{2}{\pi}} \int_{0}^{h_{1}} e^{-\frac{1}{2} \chi^{2}} d \chi
$$

and

$$
\frac{n_{1}+n_{2}-n_{3}}{n}=\sqrt{\frac{2}{\pi}} \int_{0}^{h_{3}} e^{-\frac{1}{2} \chi^{2}} d \chi .
$$


Now the left-hand side in these equations is known; it is $\frac{1}{2} a$ of Table IV. From this table the right-hand value of the

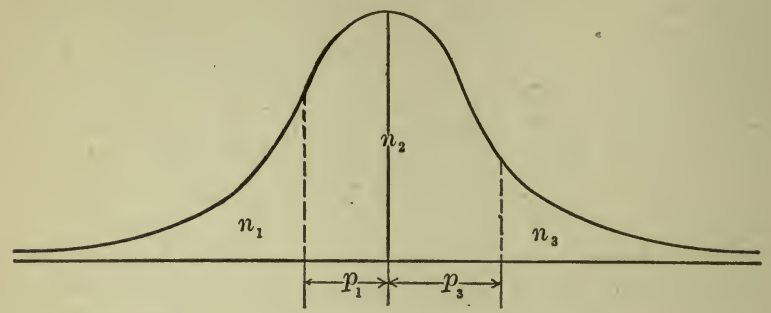

FIG. 11.

equations is found; it is the entry corresponding to the argixment $\frac{1}{2} a$. Thus $h_{1}$ and $h_{3}\left(=\frac{x}{\sigma}\right)$ are found, and hence $L_{1} / \sigma$ and $L_{3} / \sigma$ and the entire range $\frac{L_{3}+L_{1}}{\sigma}$ of the middle class, in terms of $\sigma$, is known. Call the range in absolute units $l$. Then $l=L_{3}+L_{1}$ and $l / \sigma$ is known and for a second series $l / \sigma^{\prime}$ can be similarly determined. Hence $\sigma / \sigma^{\prime}$, the ratio of the variabilities of the two series, is determined.

Again, since $L_{1} / \sigma$ and $\frac{L_{3}+L_{1}}{\sigma}$ are known, $L_{1} /\left(L_{3}+L_{1}\right)$ is known, and this gives us the ratio in which the mean divides the true range of the central class. (Pearson and Lee, 1900.)

The foregoing method may sometimes be advantageously employed where the data are quantitative. In this case the numerical value of $l$ is known. (Macdonell, 1902.) Consequently $h_{1}+h_{2}=\frac{L_{1}+L_{3}}{\sigma}$ is known and hence $\sigma=\frac{L_{1}+L_{3}}{h_{1}+h_{3}}$, the standard deviation, is found. Since $L_{\iota_{1}}=h_{1} \sigma=$ the distance of the mean from the left-hand boundary of $n_{2}$, the position of the mean is known.

The probable error of $\sigma$ is

$$
\mathrm{E}_{\cdot \sigma}=.67449 \frac{L_{1}+L_{3}}{\left(h_{1}+h_{3}\right)^{2}}\left\{\frac{n_{1}\left(n-n_{1}\right)}{n^{3} H_{1}{ }^{2}}+\frac{n_{3}\left(n-n_{3}\right)}{n^{3} H_{3}{ }^{2}}-\frac{2 n_{1} n_{3}}{n^{3} H_{1} H_{3}}\right\}^{\frac{1}{2}} \text {, }
$$

where

$$
H_{1}=\frac{1}{\sqrt{2 \pi}} e^{-\frac{1}{2} h_{1}^{2}} \text { and } H_{3}=\frac{1}{\sqrt{2 \pi}} e^{-\frac{1}{2} h_{3}^{2}} \text {. }
$$


The values of the last two equations may be obtained directly from Table III.

The probable error of $L_{1}$, or of the mean, is

$$
\mathrm{E} \cdot A=.67449\left\{\frac{\sigma^{2}\left(h_{1} \Sigma_{h_{3}}^{2}+h_{3} \Sigma_{h_{1}}^{2}\right.}{h_{1}+h_{3}}-\Sigma_{o}^{2} h_{1} h_{3}\right\}^{\frac{1}{2}},
$$

where $\Sigma_{\sigma}^{2}=\left(\frac{E \sigma}{.67749}\right)^{2}, \Sigma{ }_{h_{1}}^{2}=\frac{n_{1}\left(n-n_{1}\right)}{n^{3} H_{1}{ }^{2}}$, and $\Sigma_{h_{3}}^{2}=\frac{n_{3}\left(n-n_{3}\right)}{n^{3} H_{3}{ }^{2}}$.

\section{The Correlation of Non-Quantitative Qualities.}

Pearson $\left(1900^{c}\right)$ has ingeniously discovered a method of expressing correlation quantitatively when the variables cannot be so expressed, as, for example, in the case of effectiveness of vaccination. Strictly, this method assumes normal variation in variables, but it can be employed generally, in default of a better method, with fairly accurate results.

The prime requisite is that the qualities to be compared shall be separable into two grades, an upper and a lower. For example, in the case of the result of vaccination: on the one hand, either presence or absence of a scar; on the other, either recovery or death. As either of the second pair may occur with either of the first pair, four classes, $a, b, c, d$, will be formed altogether and a correlation surface like the following may be made:

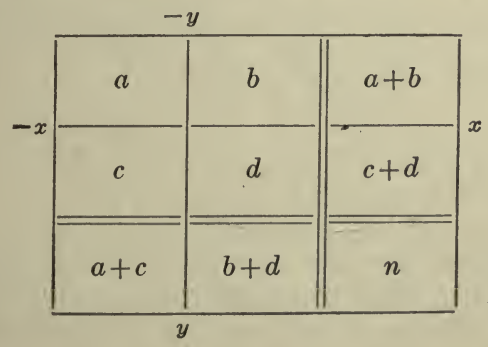

The axes $y,-y$ and $x,-x$ probably do not coincide with the axes $y$ and $x$ passing through the "origin" of the correlation 
surface, but may be regarded as situated from those axes at the respective distances $h$ and $k$. These values may be found from the formulæ

$$
\begin{aligned}
& \frac{(a+c)-(b+d)}{n}=\sqrt{\frac{2}{\pi}} \int_{0}^{h} e^{-\frac{1}{2} \chi^{2} d \chi ;} \\
& \frac{(a+b)-(c+d)}{n}=\sqrt{\frac{2}{\pi}} \int_{0}^{k} e^{-\frac{1}{2} y^{2} d y .}
\end{aligned}
$$

$a, b, c$, and $d$ being known, $h$ and $k$ are found from Table IV. Then

$$
H=\frac{1}{\sqrt{2 \pi}} e^{-\frac{1}{2} h^{2}} \text { and } \quad K=\frac{1}{\sqrt{2 \pi}} e^{-\frac{1}{2} k^{2}}
$$

of which the values may be looked up in Table III, or, better, their product may be calculated by logarithms as follows:

$$
\log H K=9.201820-N\left[\log \frac{h^{2}+k^{2}}{2}+9.637784\right] .
$$

Find also log $h k, h^{2}$, and $k^{2}$. To find $r$ solve the following equation to as many terms as may be necessary:

$$
\begin{aligned}
\frac{a d-b c}{n^{2} H K}=r & +\frac{h k}{2} r^{2}+\frac{1}{6}\left(h^{2}-1\right)\left(k^{2}-1\right) r^{3}+\frac{1}{24} h k\left(h^{2}-3\right)\left(k^{2}-3\right) r^{4} \\
& +\frac{1}{120}\left(h^{4}-6 h^{2}+3\right)\left(k^{4}-6 k^{2}+3\right) r^{5} \\
& +\frac{1}{720} h k\left(h^{4}-10 h^{2}+15\right)\left(k^{4}-10 k^{2}+15\right) r^{6}+\text { etc. }
\end{aligned}
$$

This gives us a numerical equation of the $n$th degree which can be solved by ordinary algebraic methods, using Sturm's functions and Horner's method. Or it can be solved by successive approximations as follows: The first approximation is made by neglecting all powers of $r$ above the second and solving the quadratic (remembering, that if $a x^{2}+b x+c=0$, 
$\left.x=\frac{-b \pm \sqrt{b^{2}-4 a c}}{2 a}\right)$, and taking the positive root. Substitute this value in the whole equation to the 4 th power for $f(r)$, and in the first derivative of the same equation for $f^{\prime}(r)$ (remembering that the first derivative of $f(x)$ is obtained by multiplying each term in $f(x)$ by the exponent of $x$ in that term and diminishing the exponent of $x$ by 1 ). The correction $\frac{f(r)}{f^{\prime}(r)}$ should be added to the value of $r$ used in substituting. Repeat this process as often as the correction affects the fourth place of decimals, and go to $r^{5}$ if necessary.

The probable error of $\boldsymbol{r}$ as thus determined is found as follows: First calculate the relations $\beta_{1}=\frac{h-r k}{\sqrt{1-r^{2}}}$ and $\beta_{2}=\frac{k-r h}{\sqrt{1-r^{2}}}$. Also find

$$
\psi_{1}=\frac{1}{\sqrt{2 \pi}} \int_{0}^{\beta_{1}} e^{-\frac{1}{2} \chi^{2}} d \chi \quad \text { and } \quad \phi_{2}=\frac{1}{\sqrt{2 \pi}} \int_{0}^{\beta_{1}} e^{-\frac{1}{2} \chi^{2}} d \chi
$$

from Table IV. Moreover,

$$
\omega_{0}=\frac{1}{2 \pi} \frac{1}{\sqrt{1-r^{2}}} e^{-\frac{1}{2(1-r)}\left(h^{2}+k^{2}-2 r h k\right)} .
$$

Then,

Prob. error of $r=\frac{.67449}{n^{\frac{3}{2}} \sqrt{\omega_{0}}}\left[\frac{1}{4}(a+d)(c+b)+(a+c)(d+b) \psi_{2}{ }^{2}\right.$

$$
\begin{aligned}
& +(a+b)(d+c) \psi_{1}{ }^{2}+2(a d-b c) \psi_{1} \psi_{2} \\
& \left.-(a b-c d) \psi_{2}-(a c-b d) \psi_{1}\right]^{\frac{1}{2}},
\end{aligned}
$$

which can be easily solved by substitution. In using the foregoing formula, it must be noted that " $a$ is the quadrant in which the mean falls. so that $h$ and $k$ are both positive." In other words, $a+c>b+d$ and $a+b>c+d$. (Pearson, '00 ${ }^{\mathrm{c}}$.)

Example. The eye-colors of a certain set of people (see Biometrika, II, 2, pp. 237-240) and of their great-grandparents were found to be distributed as follows 
Offspring.

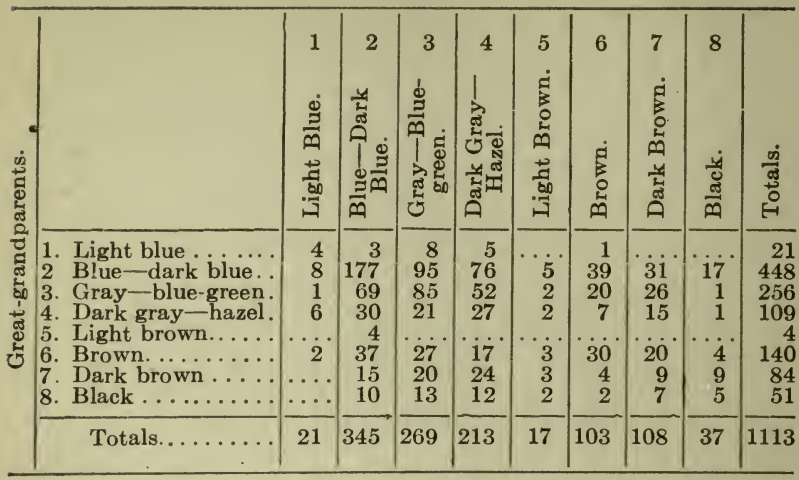

It was desired to determine the correlation between the eye-color of the offspring and that of their great-grandparents. Clearly the ranges of the classes given above are not quantitatively equal nor determinable. Consequently a fourfold table was formed by dividing the population into those having eyes whose color was gray blue-green, or lighter, and those having dark gray, hazel, or darker eyes. This gives a good basis for calculation If the dark gray and hazel eyes had been grouped with the lighter eyes it would have made quadrant $a$ entirely too large; and there is nothing in the nature of the data that strongly favors one division more than another.

\begin{tabular}{|c|c|c|c|c|c|}
\hline \multirow{3}{*}{$a_{1}=\frac{725-388}{1113}=.302785$} & \multirow{5}{*}{ 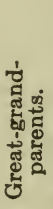 } & \multicolumn{4}{|c|}{ Offspring } \\
\hline & & & $1-3$ & $4-8$ & Totals. \\
\hline & & & 450 & 275 & 725 \\
\hline$=\frac{000-480}{1113}=.141060$ & & $4-8$ & 185 & 203 & 388 \\
\hline From the tables: & & Totals. & 635 & 478 & 1113 \\
\hline
\end{tabular}

\begin{tabular}{c|c}
$a_{1}$ & $h$ \\
\hline .31 & .39886 \\
.30 & .38532 \\
\hline .01 & .01354
\end{tabular}

\begin{tabular}{c|c}
$a_{2}$ & $k$ \\
\hline .15 & .18912 \\
.14 & .17637 \\
\hline .01 & .01275
\end{tabular}

$h=.38532+(1.354 \times .002785)=.389091$

$k=.17637+(1.275 \times .001060)=.177722$ 
Log $h=9.5900512$

Log $k=9.2497412$

Log $h k=8.8397924$

$$
h k=.069150
$$$$
\frac{1}{2} h k=.034575
$$

$h^{2}=.151392$

$k^{2}=.031585$

$h^{2}+k^{2} .182977$ $\frac{h^{2}+k^{2}}{2}=.091489$

$\log (450 \times 203-275 \times 185)=4.6071869$

$\log H K=-\log 2 \pi-.091489 \log e$

$$
\begin{aligned}
& =9.2018201-N[8.9613689+9.63778428] \\
& =9.2018201-0.0397332=9.1620869
\end{aligned}
$$

$\log \frac{a d-b c}{n^{2} H K}=4.6071869-(9.1620869+2 \log 1113)=9.3521096$ $.224962=r+.034755 r^{2}+\frac{1}{6}\left(h^{2}-1\right)\left(k^{2}-1\right) r^{3}+\frac{1}{2} h k\left(h^{2}-3\right)\left(k^{2}-3\right) r^{4}+$ etc.

Solving $.034575 r^{2}+r-.224962 \doteq 0$, $r=\frac{1 \pm \sqrt{1+4(.034575 \times .224962)}}{2(.034575)}=.223225$ to 1 st approx.

$h^{2}-1=-.848608 \quad . \quad k^{2}-1=-.968415 \quad$ Coeff. $r^{3}=.136967$

Coeff. $r^{4}=\frac{+.069150 \times 2.848608 \times 2.968415}{24}=.024363$.

$$
.024363 r^{4}+.136967 r^{3}+.034575 r^{2}+r-.224962=0 .
$$

Applying Newton's approximation, we reach the result

$$
r=.2217 \text {. }
$$

E. $r=\frac{.67449}{n^{\frac{3}{2} \omega_{0}}}\left(75095+303530 \psi_{2}^{2}+281300 \psi_{1}^{2}+80950 \psi_{1} \psi_{2}\right.$

$\log \omega_{0}=\log \frac{1}{2} \pi-\frac{1}{2} \log \left(1-r^{2}\right)-N\left[\log \log \epsilon+\log \left(h^{2}+k^{2}-2 r h k\right)\right.$

$\left.-86195 \psi_{2}-27425 \psi_{1}\right) . \frac{1}{2}$

$$
h^{2}+k^{2}-2 r h k=0.152315,
$$$$
\left.-\log \left(1-r^{2}\right)-\log 2\right]
$$

$1-r^{2}=0.950850$.

$\log \omega_{0}=9.20182-9.989056-N[9.637784+9.18274-9.978112-0.30103]$

$$
=9.1779797
$$

$$
\log \frac{.67449}{n^{\frac{3}{2}} \omega_{0}}=9.828975-4.569743-9.177980=4.081253 \text {. }
$$

$$
\beta_{1}=0.358614
$$

$$
\beta_{2}=0.093794
$$

From Table IV:

$\begin{array}{rcrc}\beta_{1} & \psi_{1} & \beta_{2} & \psi_{2} \\ .358 & .13983 & .093 & .03705 \\ & 22.2 & .4 & 27.3 \\ \psi_{1}= & =\frac{3.5}{.14006} & \psi_{2}=-.03736\end{array}$

Log E. $r=\overline{4} .0812530+\frac{1}{2} \log 74426.858$

E. $r=0.03289$ 
Quick Methods of Roughly Determining the CoeffiCient of Correlation.

The method just described may be used in lieu of the relation $r=\frac{\sum x_{1} y_{1}}{n \sigma_{1} \sigma_{2}}$ whenever the distributions of frequencies of the two correlated organs are normal. An exceedingly simple relation that is independent of the assumption of a normal distribution has been given by' Yule (' $\left.00^{\mathrm{b}}\right)$ as

$$
r_{2}=\frac{a d-b c}{a d+b c},
$$

and this may be used as a rough approximation to the coefficient of correlation.

But Pearson ('00c) has shown that this simple relation is not nearly as close to the true $r$ as the following:

where

$$
r_{3}=\sin \frac{\pi}{2} \frac{1}{\sqrt{1+k_{2}}},
$$

$$
k_{2}=\frac{4 a b c d \cdot n^{2}}{(a d-b c)^{2}(a+d)(b+c)} .
$$

The superiority of the value $r_{3}$ as an approximation to $r_{4}$ justifies the additional work its determination demands.

\section{Spurious Correlation in Indices.}

When two characters $a$ and $b$ are measured in each individual of a series of individuals, and each absolute magnitude is transformed into an index by dividing it by the magnitude of a third character $c$ as found in the same individuals, a spurious correlation will be found to exist between the indices of $\frac{a}{c}$ and $\frac{b}{c}$ (Pearson, '97).

Let $C_{1}=$ the coefficient of variability of $a$;

$$
\begin{aligned}
& C_{2}=\text { " " " " " "b; } \\
& C_{3}=\text { " " " " " " } " c \text {; } \\
& r_{0}=\text { " " " "spurious correlation. }
\end{aligned}
$$

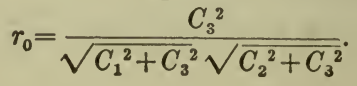


The precise method of using $r_{0}$ in modifying any determination of $r$ is uncertain. Pearson recommends using $\dot{r}-r_{0}$ as the true measure of "organic correlation" in the case of indices.

\section{HeREDity.}

Heredity is a certain degree of correlation between the abmodality of parent and offspring. The statistical laws of heredity deal not with relations between one descendant and its parent or parents, but only with mean progeny of parents. Any group of selected parents is called a parentage, the progeny of a parentage is called a fraternity.

Three categories of inheritance have long been recognized (Galton, 1888, p. 12). These are: (1) blending heritage illustrated by stature in man; (2) alternative heritage, illustrated by human eye-color; and (3) mixed heritage, illustrated by the piebald condition of the progeny of mice of different colors. The immediately following statistical laws of inheritance hold especially for blending heritage.

In uniparental inheritance, as in budding or asexual generation, heredity of any character is measured by the coefficient of correlation between the abmodality in a parentage and the abmodality of the corresponding fraternity. More strictly, since the variability of the character in the second generation, $\sigma_{2}$, may (as a result of selection or of environmental change) be different from the variability of the character in the first generation, $\sigma_{1}$, the index should be taken as $r \frac{\sigma_{1}}{\sigma_{2}}$, called the coefficient of regression.

The probable error of this determination is $\frac{.6745 \sigma_{1}}{\sigma_{2}} \sqrt{\frac{1-r_{12}{ }^{2}}{n}}$, in which $r_{12}$ means the correlation coefficient between the filial character and that of the single parent under consideration.

The variability of the fraternity is to variability of offspring in general as $\sqrt{1-r^{2}}$ is to 1 .

In biparental inheritance, if there is no evidence of assortative mating, or correlation between the two parents in the character in question, the mean abmodality of any frater- 
nity will be

$$
h_{1}=r_{3} \frac{\sigma_{1}}{\sigma_{2}} h_{2}+r_{2} \frac{\sigma_{1}}{\sigma_{3}} h_{3},
$$

where $h_{1}=$ average abmodality of fraternity;

$h_{2}=$ average abmodality of male parent;

$h_{3}=$ average abmodality of female parent;

$r_{2}=$ correlation coefficient between fraternity and female parent;

$r_{3}=$ correlation coefficient between fraternity and male parent;

$\sigma_{1}=$ standard deviation of fraternity;

$\sigma_{2}=$ standard deviation of male parent;

$\sigma_{3}=$ standard deviation of female parent.

When assortative mating occurs, as is usually the case, the abmodality of a fraternity is given by

$$
h_{1}=\frac{r_{3}-r_{1} r_{2}}{1-r_{1}^{2}} \cdot \frac{\sigma_{1}}{\sigma_{2}} h_{2}+\frac{r_{2}-r_{1} r_{3}}{1-r_{1}^{2}} \cdot \frac{\sigma_{1}}{\sigma_{2}} \cdot h_{3},
$$

where $r_{1}=$ correlation between male and female parents. The other letters have the same signification as before.

The strength of heredity in assortative mating is measured by the formula

$$
\frac{r_{3}-r_{1} r_{2}}{1-r_{1}^{2}} \cdot \frac{\sigma_{1}}{\sigma_{2}}
$$

To find the coefficient of correlation between brethren from the means of the arrays.

This is given by the formula

$$
r=\frac{\sum\left[\frac{1}{2} n_{1}\left(n_{1}-1\right) A_{1}\right] / n-A_{2}^{2}}{\sigma^{2}},
$$

where $n_{1}$ is the number of the brethren in an array [and therefore $\frac{1}{2} n_{1}\left(n_{1}-1\right)$ is the number of possible pairs of brothers in that array]; $A_{1}$ is the mean value of the array; $\sigma$ is the standard deviation of the character in the brethren taiken all together, $n$ is the total number of variates, and $A_{2}$ is the average of the brethren. This method will be found useful where to take all possible pairs of brethren would be found a work of too great magnitude (Pearson, Lee, etc.,'99, p. 271). 
Galton ('97) has shown that an individual inherits not only from his parents, but also from his grandparents, great-grand. parents, and so on. The heritage from his 2 parents together is, on the average, $50 \%$ or $\frac{1}{2}$ of the whole; from the 4 grand. parents $25 \%$ or $\frac{1}{4}$; from the 8 great-grandparents $12.5 \%$ or $\frac{1}{8}$; from the $n$th ancestral generation $\frac{1}{2^{n}}$ of the whole; the total heritage adding up 100\%. This law has been generalized by Pearson ('98) as follows:

$$
h_{1}=\frac{1}{2} \frac{\sigma_{0}}{\sigma_{1}} k_{1}+\frac{1}{4} \frac{\sigma_{0}}{\sigma_{2}} k_{2}+\frac{1}{8} \frac{\sigma_{0}}{\sigma_{3}} k_{3}+\frac{1}{16} \frac{\sigma_{0}}{\sigma_{4}} k_{4}+\ldots .
$$

where $h_{1}=$ average abmodality of fraternity.

$\sigma_{0}=$ standard deviation of fraternity.

$\sigma_{1}, \sigma_{2} \ldots \sigma_{s}=$ standard deviation of mid-parent of 1st, $2 \mathrm{~d}$.... sth ancestral generation.

$k_{1}=$ abmodality of mid-parent of 1 st ancestral generation.

$k_{2}, k_{3} \ldots k_{s}=$ abmodality of mid-parent of $2 \mathrm{~d}, 3 \mathrm{~d}$ ... sth ancestral generation.

The abmodality of the mid-parent of any degree of ancestry may be taken as the average abmodality of all the contributory ancestors of that generation.

\section{Mendel's Law of Alternative Inheritance.}

In 1865 Gregor Merdel published an account of his experiments in Plant Hybridization and reached the following laws, which have been abundantly confirmed in certain experiments.

First Case. The two parents differ in one character (the antagonistic peculiarity)-case of monohybrids.

Of the two antagonistic peculiarities the cross exhibits only one; and it exhibits it completely, so as not to be distinguishable in this regard from one of the parents. Intermediate conditions do not occur [in alternative heritage].

2. In the formation of the pollen and the egg-cell the two antagonistic peculiarities are segregated; so that each ripe germ-cell carries only one of these peculiarities. 
Of the two antagonistic peculiarities united in the cross, that which becomes visible in the soma is called by Mendel the dominating, that which lies latent is called the recessive character. What determines which character shall be dominating is still unknown, and the determination of this point offers an enticing field of inquiry. In some cases the dominating form is the systematically higher, in others it is the older or ancestral form.

The law of dichotomy may now be developed. When a mongrel (monohybrid) fertilization takes place the zygote contains both the dominant quality (abbreviated $d$ ) and the recessive quality $(r)$. In the early cleavages $d$ and $r$ are both passed over into both the daughter-cells; but apparently, at the time of segregation of the germ-cells, the somatic cells are provided with $d$ only, while the germ-cells retain both qualities. In the ripening of these germ-cells, probably in ther reduction division, $d$ and $r$ come to reside in distinct cells, so that we have

$$
\begin{aligned}
& \text { of the female cells } 50 \% d+50 \% r \text {, and } \\
& \text { of the male cells } 50 \% d+50 \% r \text {. }
\end{aligned}
$$

If now mongrels are crossed haphazard, a male $d$ cell may unite with either a female $d$ cell or with a female $r$ cell; likewise a male $r$ cell may unite with a female $d$ or a female $r$ cell. Consequently in the long run we shall have of all the zygotes

$$
25 \% d, d+50 \% d, r+25 \% r, r,
$$

or $50 \%$ of the zygotes hybrid and $50 \%$ of pure blood, and of the latter half exclusively maternal and half paternal. But since the soma developed from the hybrid germ-cell has the dominant character, we shall have

$75 \%$ of the cases with the dominant character;

$25 \%$ " " " " recessive "

and this agrees with various empirical results, of which the following from Correns is instructive. A cross was obtained between a variety of pea with a green $(g)$ germ and one having a yellow $(y)$ germ. Yellow is dominating. 


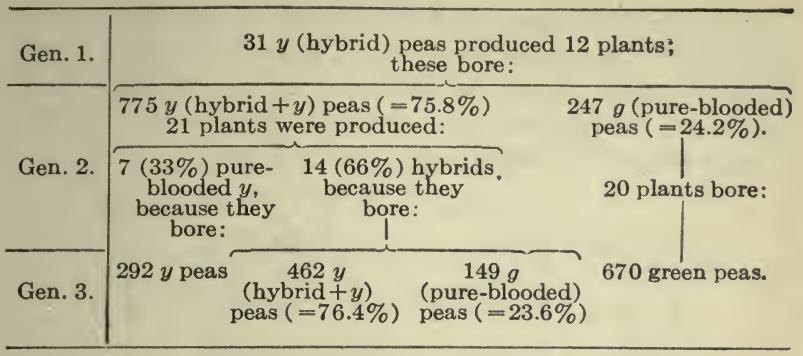

It is clear that if this process of crossing of the hybrids continues, the proportion of hybrids to the whole population will diminish; for the share of pure-blooded forms breeds true; while the originally equal share of hybrids is repeatedly halved.

If the hybrid is crossed with one of the parents instead of with another hybrid, we will get

(1) $(d+r) d=d, d+d, r$, and

(2) $(d+r) r=d, r+r, r$.

In (1) all of the progeny will appear of the dominant type. In (2) one-half will appear of that type. This again agrees with experiment.

Second Case. The two parents differ in respect to two characters - case of dihybrids. Imagine a lot of ripe germcells with the antagonistic qualities of any pair separated according to the second principle stated at the outset. $A$ indicates the one pair of qualities and $B$ the other; then we shall have nine classes of zygotes, the proportion of each of which is as follows:

$$
\begin{array}{lc}
\text { A. } & 25 \% d, d \\
\text { B. } & \overbrace{6.25 \% d, d ; 12.5 \% d, r ; 6.25 \% r, r} . \\
\text { A. } & \overbrace{12.5 \% d, d ; 25 \% d, r ; 12.5 \% r, r}^{50 \% d, r} \\
\text { B. } & 25 \% r, r \\
\text { A. } & \overbrace{6.25 \% d, d ; 12.5 \% d, r ; 6.25 \% r, r} .
\end{array}
$$


Thus the first class has $6.25 \%$ purely dominant in both characters; the second class, $12.5 \%$ purely dominant in one character and hybrid in the other, and so on. Recalling that hybrid zygotes produce somas with the dominant character, it follows that the progeny appear as follows:
$A$. dom. + B. rec. . . . . $18.75 \%$
Ratios
A. rec. $+B$. dom. . . . . $18.75 \%$
3
A. dom. + B. dom. . . . . . 56.25\%
3
A. rec.
$6.25 \%$
9
1

This result again agrees with experiment. The resulting mixture of characters in tri- to polyhybrids may be likewise predicted, by extending the principles already laid down.

\section{Measure of Dissymmetry in Organisms.}

A Dissymmetry-Index, $\Xi$, measuring the average degree of asymmetry in the right and left organs of bilateral organisms, has been proposed by Duncker (1903).

First a series of integral differences $-3,-2,-1,0,1,2$, 3,4 , etc., between the right- and left-side measurements of the organ in question is made, and the frequencies of each integral difference (reckoning to the nearest integer) is found. The average of the difference series is the difference of the averages of the right- and left-side measurements, and the standard deviation of the difference is given by

$$
\sigma_{d}=\sqrt{\sigma_{\mathrm{I}}^{2}+\sigma_{\mathrm{II}}^{2}-2 r \sigma_{\mathrm{I}} \sigma_{\mathrm{II}}}
$$

in which the subscripts refer to the bilateral series of which the asymmetry is to be found, and $r$ is the coefficient of correlation between the two sides.

Let $d^{\prime}$ represent any positive differences in the series, and $d^{\prime \prime}$ any negative differences; and let $f_{1}^{\prime}, f_{2}^{\prime}$, etc., represent the frequencies of the negative-difference classes, and $f_{1}^{\prime \prime}$, $f_{2}^{\prime \prime}$, etc., the frequencies of the positive-difference classes. Then the asymmetry-index

$$
\Xi=\frac{\Sigma\left(f^{\prime}\right) \times \Sigma\left(d^{\prime}\right)-\Sigma\left(f^{\prime \prime}\right) \times \Sigma\left(d^{\prime \prime}\right)}{n\left[\Sigma\left(d^{\prime}\right)+\Sigma\left(d^{\prime \prime}\right)\right]}=0 .
$$


Example. Absolute difference between dextral $(d)$ and sinistral $(s)$ lateral edges $(L)$ of carapace of right-handed fiddler-crabs-Gelasimus pugilator (Yerkes, 1901; Duncker, 1903):

$$
\begin{aligned}
& d=L_{d}-L_{s}:-1 \quad 0 \quad 1 \quad 2 \quad 3 \\
& f: \quad \begin{array}{lllll}
f & 63 & 310 & 23 & 3
\end{array} \\
& \Sigma\left(d^{\prime}\right)=310 \times 1+23 \times 2+3 \times 3=365, \quad \Sigma\left(f^{\prime}\right)=336 \text {. } \\
& \Sigma\left(d^{\prime \prime}\right)=1, \quad \Sigma\left(f^{\prime \prime}\right)=1, \quad n=400 \text {. } \\
& \Xi=\frac{336 \times 365-1 \times 1}{400 \times 366}=\frac{122639}{146400}=0.83770 .
\end{aligned}
$$




\section{CHAPTER V.}

Some Results of Statistical Biological Study.

It is hoped that the following analysis of the literature, although not complete, will prove suggestive and otherwise useful. Numerical results are occasionally given. These are intended to be used in making comparisons with numerical results obtained in the same field and thus to assist in the interpretation of such results. The literature references are to the Bibliography which follows this chapter, in which the titles are arranged by author and date.

\section{GENERAL.}

Expositions, Addresses, etc.: Amann, '96; Ammon, '99; Camerano, '00 ${ }^{\mathrm{b}}$ '01, '02; Davenport, '00, '00 d, 01 ${ }^{\mathrm{b}}$; Duncker, '99 ${ }^{\mathrm{b}}$; Eigenmann, '96; Galton, '01; Gallardo, '00, '01, '01 b; Ludwig, '00, '03; Redeke, '00; Volterre, '01.

Texт-воокs: Galton, '89; Bateson, '94; Duncker, '00; Pearson, '00; Vernon, '03.

Method: Camerano, '00; Engberg, '03; Fechner, '97;

Galton, '89, '02; Heinckè, '97; Johannsen, '03; Pear-

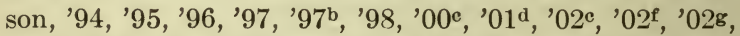
'02m, '02n, 03 ; Pearson and Lee, '00; Sheppard, '98, '98 b' '03; Verschaffelt, '95; Wasteels, '99, '00; Yule, '97, '97b, '00, '00', '03.

\section{General.}

\section{VARIABILITY.}

Frequency polygon, its significance; its dependence on time, place, and conditions: Burkill, '95; Kellerman, '01; Tower, '02; Shull, '02; Yule, '02; Johannsen, '03.

Proper value of ratio of first to second prizes: Galton, '02; Pearson, ' $02^{k}$. 
Coefficient of variability; significance: Pearson, '96; Brewster, '97; Duncker, '00 ${ }^{\mathrm{b}}$; Davenport, '00'.

Mutations: Bateson, '94; Howe, '98; deVries, '01-'03; Weldon, '02c.

Individual vs. specific variation: Brewster, '97, '99; Field, '98; Mayer, '02; Davenport '03b.

Variability independent of sexual reproduction: Warren, '99, '02; Pearson and others, '01', pp. 359-362.

Relative variability of the sexes:-in man, Pearson, '97'; Brewster, '99; Pearl, '03; in crabs, Schuster, '03.

Relative variability of primitive and modern races:-in man, primitive races less variable: Pearson, '96, p. 281; Pearson (and others), ' $01^{\mathrm{c}}$, p. 362 .

\section{Man.}

Stature.-Seriation for adults of different races: Bavarians, Ammon, '99; United States, recruits, Bąxter, '75, Pearson, '95, p. 385; various, Macdonell, '02; English middle upper classes, Galton, '£9, Pearson, '96, p. 270; Germans, Pearson, '96, p. 278; French, Pearson, '96, p. 281; Cambridge University students, Pearson, '99.

Lot.

Engl. upper middle class \& do. husbands .

Cambridge Univ. students

English fathers........ 1078

English sons. ........ 1078

U. S. recruits ........ 25878

N. S. Wales, criminals. ... 2862

Frenchmen .......... 284

English criminals...... 3000

French, Lyons ..............

Germans........... 390

Engl. upper middle class ? do. wives....

Cambridge Un. students $q$

French, Lyons \& ........
$A$

$683 \quad 69.215^{\prime \prime} \pm .066 \quad 2.592^{\prime \prime} \pm .047$

$\begin{array}{lll}200 & 69.135^{\prime \prime} \pm .126 & 2.628^{\prime \prime} \pm .089\end{array}$

$68.863^{\prime \prime} \pm .054 \quad 2522^{\prime \prime} \pm .048$

$\begin{array}{ll}652 & 64.043 \pm .061\end{array}$

200 cm.

171.95

174.40

170.94

169.88

166.80

166.46

$166.26 \pm .53$

156.93

in.

cm.

$\begin{array}{ll}6.81 & 3.99\end{array}$

6.94

6.56

3.80

$\begin{array}{ll}6.47 & 3.88 \\ 6.45 & 3.88\end{array}$

$5.50 \pm .37$

6.68 in.

4.02

$2.325 \pm .043$

$\begin{array}{rr}63.869 \pm .110 & 2.303 \pm .078 \\ 63.883 \pm .130 & 2.361 \pm .092\end{array}$

3.69

Seriation at different ages: British infant at birth, Pearson, '99; school children, Bowditch, '91; St. Louis schoolgirls, Porter, '94, Pearson, '95, p. 386; Australian adult whites, Powys, '01. 


\section{Lot. \\ Average.}

New-born infant, British ơ. $20.503 \pm .028$ in.

$$
\text { " " क. } 20.124 \pm .025 \text { “ }
$$

St. Louis schoolgirls. . . . . 118.271 cm.

Australian whites:

\begin{tabular}{|c|c|c|c|c|c|c|}
\hline \multirow{2}{*}{$\begin{array}{l}\text { Age, } \\
\text { Years }\end{array}$} & \multicolumn{2}{|c|}{ Average. } & \multicolumn{2}{|c|}{0} & \multicolumn{2}{|c|}{$C$} \\
\hline & $\delta$ & q & t & $q$ & s & q \\
\hline $20-25$ & 66.95 & 62.50 & 2.475 & 2.365 & 3.70 & 3.79 \\
\hline $25-30$ & 67.30 & 62.76 & 2.562 & 2.432 & 3.81 & 3.87 \\
\hline $30-40$ & 67.15 & 62.44 & 2.587 & 2.303 & 3.86 & 3.69 \\
\hline $40-50$ & 66.91 & 62.96 & 2.618 & 2.555 & 3.91 & 4.06 \\
\hline $50-60$ & 66.74 & 62.22 & 2.633 & 2.591 & 3.95 & 4.16 \\
\hline $60 \&$ over & 66.26 & 61.31 & 2.682 & 2.300 & 4.04 & 3.75 \\
\hline
\end{tabular}

Weight.-Seriations at different ages, British: Infants, Pearson, '99; University students, Pearson, '99; 5552 Englishmen, Sheppard, '98.

$$
\text { Lot. Average. }
$$

New-born infants, 古 .....7.301 $\pm .024 \mathrm{lb}$.

$$
\text { “ } \quad \text { \&....7.073 } \pm .021
$$

Cambridge Univ. students, o $152.783 \pm .35$

$$
\text { } 125.605 \pm .77
$$

\begin{tabular}{cl}
$\sigma$ & \multicolumn{1}{c}{$C$} \\
$1.144 \pm .017$ & $15.66 \%$ \\
$1.006 \pm .015$ & 14.23 \\
$16.547 \pm .25$ & 10.83 \\
$14.030 \pm .57$ & 11.17
\end{tabular}

15. $66 \%$ 14.23 11.17
$1.117 \pm .018 \quad 5.849$ 2.776

Skull.-Cephalic index: Bavarians, Ranke, '83; 680020 year old Badeners, working class, Ammon, '99, p. 85; various races, Pearson, '96, p. 20 , Màcdonell, '02.

Lot.

Bavarian peasants . ........... 100

Baden recruits.............. 6748

Modern Parisians .................

French peasants . ............ 56

Cambridge students ............. 1000

Criminals (British) ............. 100

Brahmans of Bengal. ........... 100

Whitechapel English. ........... 107

Maquada race $. . . \ldots \ldots \ldots \ldots \ldots . . . .$.
A

$\begin{array}{lll}83.41 & 3.58 & 4.29 \\ 81.15 & 3.63 & 4.48 \\ 79.82 & 3.79 & 4.74 \\ 79.79 & 3.84 & 4.81 \\ 78.33 & 2.90 & 3.70 \\ 76.86 & 3.65 & 4.75 \\ 75.77 & 3.37 & 4.44 \\ 74.73 & 3.31 & 4.43 \\ 72.94 & 2.98 & 3.95\end{array}$

Skull capacity: coefficients of variability. Fawcett and Lee, '02.'

Lot.

Andamanese...... 5.04

Ainos........... 6.89

Negroes.......... 7.07

Low-caste Punjabs . . 7.24

Parisian French .... 7.36

Kanakas .......... 7.37

17th Century English. 7.68

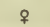

5.59

6.82

6.90

8.99

7.10

6.68

8.15
Lot.

$\begin{array}{llll}\text { Naquadas . ......... } & 7.72 \quad 6.92\end{array}$

Germans ......... $7.74 \quad 8.19$

Egyptian mummies. . $8.13 \quad 8.29$

Polynesians ....... $8.20 \quad 5.55$

Italians . . . . . . . $8.34 \quad 8.99$

Modern Egyptians... $8.59 \quad 7.17$

$\begin{array}{llll}\text { Etruscans ......... } & 9.58 \quad 8.54\end{array}$ 
Various cranial dimensions, Lee and Pearson, '01.

Other Organs.-Coefficient of variability of bones of skeleton of French and Naquada ( $C$. of limb-bones, 4.53-5.57), Warren, '97; appendicular skeleton, Pearson, '96; fingerbones, Lewenz and Whiteley, '02; seriation of position of spinal nerves, Bardeen and Elting, '01; various organs in diverse races, Brewster, '97, '99.

\section{Mammalia.}

Relative variability of specific and generic characters in various mammals the former being greater, Brewster, '97; seriation of number of Müllerian glands in Sus scrofa, $n, 2000$; $A, 3.501 \pm .025 ; \sigma, 1.6 \subseteq 0 \pm .018 ; C, 48.0$, Davenport and Bullard, '96.

\section{Aves.}

Seriations of various proportions of N. A. birds, Allen, '71; characters of Lanius ("shrike") and its races, Strong, '01;

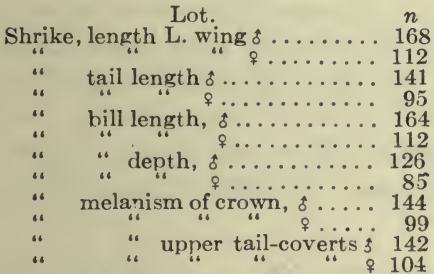

Curvature of culimen ............

$A$
$99.06 \mathrm{~mm}$.
97.98
101.57
99.55
12.01
11.71
9.27
8.95
$83.57 \%$
83.66
53.13
47.98
$29.94^{\circ}$

${ }^{\circ}$
$2.74 \mathrm{~mm}$.
2.64
3.48
3.63
0.71
0.63
0.42
0.41
$3.0 \%$
3.19
15.42
18.99
2.74

C

2.81

2.69

3.43

3.65

5.89

5.35

4.57

4.61

3.58

3.81

29.02

39.58

9.15

Eggs, proportions: Passer domesticus, Bumpus, '97, Pearson, '02e; various species, Latter, '02.

$$
\begin{gathered}
\text { Av. } \\
\text { Length, } \\
\text { Species. }
\end{gathered} \quad A \begin{gathered}
\text { iength, mm. } \\
C
\end{gathered} \quad \begin{gathered}
\text { Breadth, mm. } \\
\dot{C}
\end{gathered}
$$

Cuckoo . . . . in. $14 \quad 243$

Blackbird .... 10

Song-thrush .... 9 9 151

Starling ....... 8-8.5 27

$\begin{array}{lll}\text { Yellowhammer. } & 7 & 32 \\ \text { Tree-pipit } & 6.5 & 27\end{array}$

$\begin{array}{lll}\text { Tree-pipit..... } & 6.5 & 27 \\ \text { Meadow-pipet . . } & 6 & 74\end{array}$

Headow-pipet . (English).... 6

House-sparrow

(American)...

Hedge-sparrow. .

Robin ..........

Linnet....... 5.5-6
$22.40 \quad 1.059$

$29.44 \quad 1.357$

$\begin{array}{ll}27.44 & 0.999\end{array}$

$29.78 \quad 1.097$

$\begin{array}{ll}21.55 & 0.682\end{array}$

$\begin{array}{ll}20.01 & 0.698\end{array}$

19.721 .250

$\begin{array}{lll}687 & 21.82 & 1.195\end{array}$

868

26

57

65

\section{$21.32 \quad 1.05$}

$\begin{array}{ll}20.12 & 0.810\end{array}$

$\begin{array}{lll}20.22 & 0.857\end{array}$

$\begin{array}{ll}17.14 & 0.598\end{array}$
4.72

4.61

3.64

3.68

3.17

3.49

6.37

$\begin{array}{lll}69 & .516 & 2.50\end{array}$

$\begin{array}{llll}6.04 & .405 \quad 253\end{array}$

$\begin{array}{lll}15.09 & .449 & 2.97\end{array}$

2.97
3.84

3.38

$4.92 \quad 15.34$

$\begin{array}{llll}4.02 & 14.73 & .415 & 2.81\end{array}$

$\begin{array}{lllll}4.24 & 15.43 & .477 & 3.09\end{array}$

$\begin{array}{llll}3.49 & 13.33 & .358 & 2.69\end{array}$
$16.54 \quad .650$ 


\section{Amphibia.}

Seriations of variations in position of pelvic girdle in Necturus, Bumpus, '97.

\section{Pisces.}

Geographical races: in Leuciscus, Eigenmann, '95; in adjacent lakes, Moenkhaus, '96; in schools of herring, Heincke, '97; in flounders, Bumpus, '98; in mackerel, Williamson, '00. See under Local Races.

Various species: Pimephales fin-rays and scales of lateral line, Voris, '99; Zeus faber, an ancestral Pleuronectid, has its plates symmetrical in only $23.6 \%$ of the individuals, Byrne, '02; dimensions of 141 Petromyzon', Lönnberg, '93.

\section{Tracheata.}

Lepidoptera.-Seriations of wing dimensions of Thyreus abbotti. Field, '98; number of "eye-spots" on wing of Epinephele, Bachmetjew, '03; number of spots on different species of the genus Papilio, Mayer, '02; breadth of wing, 98 \& Strenia clathrata $C=4.57$, Warren, '02.

Aphido.-Asexually produced offspring show an average variability of $60 \%$ that of the race, Warren, '02, p. 144; seriation of fertility, empirical mode $=7$ young, Warren, '02, p. 133; reduced variability of the earlier generations, because they include only such as can produce fertile offspring,Warren, '02.

\section{Dimension.}

Grandmothers.

$\begin{array}{lll}\sigma & C\end{array}$

Frontal breadth .......... 2.28 mm. $6.07 \%$

Children.

Length R. antenna......... 7.36

8.77

$2.96 \mathrm{~mm}$.

C

Ratio: $\frac{\text { Length antenna }}{\text { Frontal breadth }} \times 10 . .1 .23 \%$

5.67

10.94

12.97

Myriapoda.-Lithobius: seriations of length of adults, $C$, for ${ }^{\prime}$ 's $=10.97$; ' 's $=11.25$; number of prosternal teeth; of antennal joints; of coxal pores in which $C$ varies from 9.9 to 15.4 , Williams, '03.

\section{Crustacea.}

Podophthalmata.-Seriations of 12 dimensions of righthanded and left-handed "fiddler-crabs," Gelasimus pugilator, $C$ varies from 7.0 to 11.1 , Yerkes, '01; relative variability of male and female Eupagurus prideauxi from deep and from shallow water. Schuster. '03; forehead breadths of Carcinus 
mœnas, Weldon, '93, Pearson, '94; various dimensions, Crangon, Weldon, '90; length of rostrum, Palæmon serratus, Thompson, '94, Pearson, '94; number of rostral teeth of Palæmonetes, Weldon, '92 ${ }^{\mathrm{b}}$, Pearson, '95, Duncker, '00.

\section{Lot.}

Eupagurus, short edge of R. chela:

$\delta$ deep water ................

o shallow water............ 10.272 \pm .075

\& deep water ............ $7.400 \pm .033$

\& shallow water........... $7.485 \pm .029$

Eupagurus, long edge of R. chela:

$\delta$ deep water...............

o shallow water.............

\& deep water ..............

i shallow water.............

Eupagurus, carapace length:

s deep water ..............

$\delta$ shallow water..............

\& deep water ...............

Palæmonetes vulgaris, dorsal spines .

“ " ventral spines.

Palæmonetes, varians, dorsal spines .

“ ventral spines.

$\begin{array}{ccc}17.97 \pm .14 & 4.73 & 27.8 \\ 18.68+.13 & 4.38 & 23.5 \\ 14.14 \pm .06 & 1.67 & 11.9 \\ 13.97 \pm .05 & 1.82 & 13.0 \\ & & \\ 8.59 \pm .05 & 1.67 & 19.4 \\ 7.54 \pm .03 & 0.94 & 12.5 \\ 7.12 \pm .03 & 0.86 & 12.1 \\ 8.28 & 0.81 & 9.83 \\ 2.98 & 0.45 & 15.03 \\ 4.31 & 0.86 & 20.00 \\ 1.70 & 0.48 & 28.26\end{array}$

Amphipoda.-Seriations of lengths of body, of second antennæ, and of ratio of second antennæ to body-length, Smallwood, '03.

\section{Annelida.}

Choctopoda.-Teeth on jaws of Nereis virens. Right: $A=$ $10.055 \pm .045, \sigma=1.339 \pm .032, C=13.3 \%$; Left: $A=10.00 \pm$ $.044, \sigma=1.306 \pm .031, C=13.1 \%$, Hefferan, '00.

\section{Brachiopoda.}

Seriation of width $\div$ breadth, width of sinus $\div$ depth, number of plications on ventral and dorsal valves in sinus and on fold, Cummings and Mauck, '02.

\section{Bryozoa.}

Number of spines on statoblasts of Pectinatella magnifica. $A=13.782 \pm .031, \sigma=1.318 \pm .022, C=9.57 \pm .16$, Davenport, ${ }^{\prime} 00^{\circ}$.

\section{Mollusca.}

Gastropoda.-Frequency polygons of ventricosity, weight, and index of Littorina littorea for 3 British and 10 American localities-greater variability in America. Index: $\sigma_{B}=2.3 \%$, 
$\sigma_{A}=2.7 \%, C_{B}=2.6 \%, C_{A}=3.0 \%$, Bumpus, '98, Duncker, '98; critical, Bigelow and Rathbun, '03; seriations of length, ratio of diameter to length, ratio of aperture to length, apical angle, number of whorls, color of aperture lip, and depth of suture between whorls in Nassa, Dimon, '02; seriations of shell-index and spinosity of Io in different parts of a river system, Adams, '00; variability of adult Clausilia laminata less than that of young, 15:13, ascribed to periodic selection, although average size not altered, Weldon, '01; variability of bands of Helix nemoralis in one spot of America, Howe, '98; in different localities near Strasburg, Hensgen, '02.

Lamellibranchiata.-Seriation of number of ribs of Cardium, Baker, '03; Pecten; ray-frequency, Lutz, '00, Davenport, '00, '03, '03 ; change in proportions with age, acquisition of new symmetry about transverse axis; definition of form units from different localities, Davenport, '03, ' $03^{\mathrm{b}}$.

Lot.

Pecten irradians

Cold Spring Har., L. I., R.valve $17.353 \pm .018$

Cutchogue, L. I., R. valve . . . $16.534 \pm .034$

Cold Spring Har., L. valve . . . 16.790 \pm .022

Cutchogue, L. valve . ....... 15.954 \pm .105

Pecten opercularis:

Eddystone, R.valve . . . . 17.478 1.029

Irish Sea, R. valve . ........ 18.101 \pm .029

Firth of Forth, R. valve .... 17.673 \pm .027

Pecten gibbus.

Tampa, Fla, $\mathrm{R}$ valve ....... $20.512 \pm .030 \quad 0.991 \pm .021 \quad 4.83 \pm .10$ Pecten ventricosus:

San Diego, Cal., R. valve . . . $19.495 \pm .087 \quad 0.885 \pm .019 \quad 4.55 \pm .10$

\section{Echinodermata.}

Seriation of ray-frequency in starfish, Crossaster papposus: $A=12.391, C=0.788, v=6.36 \%$, Ludwig, '9 b $^{\mathrm{b}}$.

\section{Coelenterata.}

Scyphomedusa.-Seriation of number of tentaculocysts of Aurelia aurita: $n=3000$, empirical range 4-15; empirical mode $=8$, genital sacs, $M^{\prime}=4$, range, 2-10, Browne, '95, '01.

Hydromedusa. - Seriation of number of radial canals, gonads, gastric lobes, and tentacles of Gonionemus, Hargitt, '01; radial canals and lips of Pseudoclytia pentata, Mayer, '01, Davenport, '02; radial canals, etc., of Eucope, Agassiz and Woodworth, '96. 
Lot.

A

Pseudocyltia, num. radial canals .....5.004 \pm .094

lips ............... $468 \pm .012$

$\begin{array}{cc}\circ & C \\ 0.441 & 8.81 \\ 0.556 & 11.4\end{array}$

\section{Protista.}

Paramecium recently divided, Simpson, '02; seriation of diameter of Actinospherium and number of cysts and nuclei in body, Smith, '03; outer and inner diameters of shell of 502 Arcella vulgaris, Pearl and Dunbar, '03; various diatoms, Schröter and Vogler, '01.

\section{Lot.}

Paramecium, length $\mu . . .$. .

" $\quad$ breadth.......

Arcella, outer diameter..... 55.79 \pm .17

.. inner diameter.... $15.91 \pm .07$

\section{A}

229.05

68.13

29.91

$\begin{array}{cc}\sigma & C \\ 19.15 & 8.36 \% \\ 9.16 & 13.44 \\ 4.03 & \\ 5.73 \pm .12 & 10.27 \pm .22 \\ 2.17 \pm .05 & 13.66 \pm .30\end{array}$

\section{Plants.}

General.-Multimodal polygons especially frequent in plants, Ludwig, '97; critical, Lee, '02; Pears $\_n$, '02 ${ }^{\text {h}}$.

RAY-FLOWERS IN Composite.--Seriation of ray-frequency of Coreopsis, de Vries, '94; of Senecio nemorensis, S. fuchsii, Centurea cyanus, C. jacea, Solidago virga aurea, Achilla millefolium, Ludwig, '96; ray-frequency in Chrysanthemum, Ludwig, '97c, Lucas, '98, Tower, '02, Pearson and Yule, '02; Helianthus, Wilcox, '02; Bellis perennis, Ludwig, '95b; Solidago serotina, Ludwig, ' $00^{\mathrm{b}}$; Arnica montana, Ludwig, '01; Aster, Shull, '02.

Num. Ray-flowers.

$A$ Aster shortii ............. 14.000土.068 A. novæ-angliæ . . . . . . . 42.874 \pm .302 A. punicens........... 36.672 \pm .107 A. prenanthoides ......... 28.080 \pm .107

$\begin{array}{cc}\sigma & C \\ 1.526 \pm .048 & 10.90 \\ 6.308 \pm .213 & 14.71 \\ 4.480 \pm .076 & 12.22 \\ 4.070 \pm .077 & 14.52\end{array}$

Other Seriations of Floral Organs: Ranunculacece.Petals, Ranunculus bulbosus, de Vries, '94, Pearson, '95; calyx, coralla, stamens, and pistils of Ficaria verna, Ludwig, '01; number of Ficaria pistils, early flowers, $A=17.448, \sigma=$ 3.89; late flowers, $A=12.147, \sigma=3.88$; number of stamens, early, $A=26.731, \sigma=3.761$ and late, $A=17.863, \sigma=3.298$, 
MacLeod, '99, Weldon, '01; number of petals of Caltha palustris, de Vries, '94; number of calyx parts and petals of Trollius europæus and number of fruits per head of Ranunculus acris, Ludwig, ' $95^{\mathrm{b}}$, ' $00^{\mathrm{b}}$; number of seeds per capsulecompartment of Helleborus fœtidus, Ludwig, '97.

Cruciferc.-Number of flowers, Cardamine pratensis, empirical modes at 2, 5, 8, 11, 13, 16, 19, 22, not in Fibonacci series, Vogler, '03.

Papaveracex.-Number of floral organs in Papaver, MacLeod, '00; number of sepals and petals in the lesser Celandine, various species, Pearson and others, '03.

Caryophyllacece.-Number of stamens in Stellaria media, varies with season and Fosition on plant, Burkill, '95; number of anthers in 44,542 flowers of Stellaria media-a complex polygon due to effect of age and environment, Reinöhl, '03.

Sapidacece.-Number of compartments in fruit of Acer pseudoplatanus, de Vries, '94.

Leguminosœ.-Number of blossoms in clover plants, Type I: $\sigma=2.788$, de Vries, '94, Pearson, '95, p. 402; number of elevated flowers in blossoms of Trifolium repens perumbellatum, de Vries, '94; floral organs of Lotus uliginosus, L. corniculatus, Medicago saliva, M. falcata, Ludwig, '97; flowers per head of Lathyrus, Ludwig, ' $00^{\mathrm{b}}$.

Rosacex.-Number of stamens of Prunus spinora and Cratægus, Ludwig, '01; sepals of 1000 Potentilla 1ormentilla and petals of 4097 Potentilla anserina, de Vries, '94.

Cornacece.-Number of flowers in head of Cornus mas and C. sanguinea, not in Fibonacci series, Vogler, '03.

Caprifoliacex.-Number of petals of 1167 Weigelea amabilis, de Vries, '94: number of flowers in inflorescence and number of petals on flower of Adoxa moschatellina, Whitehead, ' 02 .

Dipsacc.-Number of flowers per head in Knautia arvensis, maximum at 64, Vogler, '03.

Compositce.-Number of male and female flowers in umbel of Homogyne, Ludwig, '01.

Primulacece.-Number of flowers per umbel, Primula, multimodal, Ludwig, '97, '98 ${ }^{\mathrm{b}}$, '00; rays in Primula farinosa, Vogler, '01. 
Scrophulariacex.-Number of parts in peloria of Lenaria spuria, Yost, '99; number of stamens, Digitalis, Gallardo, '00.

Orchidacece.-Extremes in variability of number of spots on flower, Chodat, ' 01.

Leaves. - Seriation of numbers of paired leaflets of Pirus aucuparia, Fraxinus excelsior, Senecio nemorencis, and Polemonium, Ludwig, '97, '98 . Length and breadth of leaves of Fagus silvatica and Carpinus betulus, Ludwig, '99. Leafdimiensions, Sanguinaria, Liriodendron, Ampelopsis, and Ailanthis ( $n$, small), Harshberger, '01. Number of side ribs on leaves of Fagus silvatica, Carpinus betulus, and Quercus monticola, Ludwig, '99; on leaves of beech, Pearson, '00; leaves of mulberry, Fry, '02; dimensions of Typha leaves, Davenport and Blankinship, '95; pine needles. Ludwig, '01; from various branches of Pinus silvestris, Lee, ' 02 .

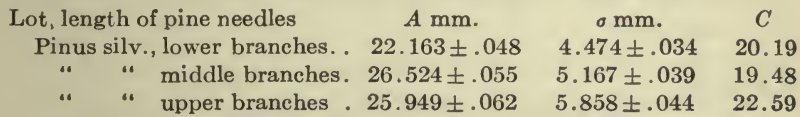

Fruit.-Number of ears in head of Agropyrum repens and Brachypodium, Ludwig, '01; of the grass Lolium, Ludwig, ' $00^{\mathrm{b}}$; fruits per head of Ranunculus acris Ludwig, ' $00^{\mathrm{b}}$; number of seeds per capsule-compartment, Helleborus, Ludwig, '97; fruit length, Oenothera Lamarckiana, and Helianthus, de Vries, '94; dimensions of beans in masses and in successive generations of same family, Johannsen, ' 03 .

Bryophyta.-Seriations of length of capsule-stalk, Bryum cirratum, Amann, '96; parts in sexual organs of Marchantea and Lonicera, Ludwig, ' $00^{\mathrm{b}}$.

\section{SOME TYPES OF BIOLOGICAL DISTRIBUTIONS.}

General.-Pearson, '95 '01d. $\alpha$ modified by selection, Reinöhl, '03.

\section{Type I.}

Petals of 222 flowers of Ranunculus bulbosus, de Vries, '94, Pearson, '95, p. 401.

Number of glands of fore legs of swine, Davenport and Bullard, '96, Pearson, '96, p. 291: $\alpha=.311 \pm .016$. 
Fertility (percentage of births with one year of marriage) of wives at different ages, Powys, '01.

Rays in dorsal fin of Pleuronectes s, Duncker, '00.

666 anal 66666066

\section{Type IV.}

Stature of St. Louis schoolgirls, Fearson, '95, p. 386. $\alpha=-0.489$.

Number of teeth, Palæmonetes varians Plymouth, Pearson, '95, p. $404 . \quad \alpha=0.134$.

Stature of Australian whites, Powys, '01.

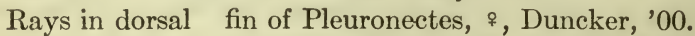

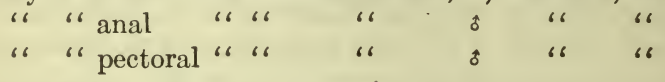

\section{Type V.}

Number of lips of medusa, P. pentata, Mayer, '01, Pearson, '01d. $\alpha=.549$.

\section{Normal.}

Stature, U. S. recruits, Baxter, 75, Pearson, 95, p. 385.

Ray frequency, Pectens, Davenport, '00, '03 ${ }^{\mathrm{b}}$.

\section{Skewness.}

General.-Mathematical Analysis.-Pearson, '95, '01 d, '02', '02 $2^{\mathrm{g}}, 2^{\mathrm{m}}$. Biological Interpretation.-Davenport, ' $01^{\mathrm{b}}, \mathrm{\prime}^{\prime} 01^{\mathrm{c}}$.

\section{Quantitative Results.}

Numerous cranial characters, Naquada race, Fawcett, '02.

Nearly always + .

Num. lips of medusa, P. pentata (Mayer, '01; Pearson, '01 d) . . . +.549

Num. Müllerian glands, legs of swine (Pearson and Filon, '98) . . + . 311

Num. dorsal teeth, Palæmonetes varians (Pearson, '95). . . . . . . 130

Num. rays, Pecten opercularis, Irish Sea (Davenport, ' $03^{\mathrm{h}}$ ). . . . +. 087

“ " " " Eddystone (Davenport, ' $03^{\mathrm{b}}$ ) $\ldots+.080$

“ hooks on statoblasts, Pectinatella (Davenport, ' $\left.00^{\mathrm{e}}\right) \ldots \ldots . .077$

Weldon's crab measurements, "No. 4 " (Pearson, '95) . . . . . . +.077

Num. rays lower valve, Pecten irradians, L. I (Davenport, ' $00^{\mathrm{c}}$ ) +.023

" " " " P.opercularis, F. of Forth........... 007

“ “ upper valve, P. irradians (Davenport, $\left.00^{\circ}\right) \ldots \ldots \ldots \ldots \pm .000$

Height, British eriminals (Macdonell, '02) ................ 023

Baxter's height of U.S. recruits (Pearson, '95) . . . . . . . . . 038

Porter's height of 2192 St. Louis schoolgirls (Pearson, '95). . . . . - .049

Head breadth, British criminals (Macdonell, '02) ........... 051 
Index of Littorina, Casco Bay (Bumpus, '98) . . . . . . . . . 13

Index of Littorina: Newport (Bumpus, '98) . . . . . . . . . . . 25

" " " Humber " " . . . . . . . . . . . 048

“ “ $"$ So. Kincardineshire (Bumpus '98). . . . . +.068

21-rayed Chrysanthemum (de Vries, '99) ............... 13

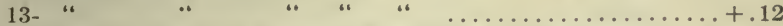

Selected 12-(and 13-) rayed Chrysanthemum (de Vries, '99) $\ldots+1.9$

Rays of Pecten irradians, fossil, Va oldest (Davenport, '01 b) . . - .22

" " " " " " youngest.............. 16

" " " " "

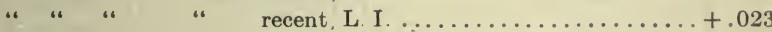

Length of wings of long-winged chinch-bug (Davenport, '01b) $\ldots-.43$

" " " short-winged chinch-bug " " ... .44

Length horns rhinoceros-beetle, long-horned (Davenport, '01 b) . . - .03

" " " $"$ " short-horned " $\quad \ldots+.48$

\section{Complex Distributions.}

Bimodal Polygons.-Discontinuity in hairiness of Biscutella, Saunders, '97; of Iyychnis, Bateson and Saunders, '02, Weldon, '02'.

Length of cephalic horns of rhinoceros-beetle, and forceps length of male earwigs, Bateson, '94; explanation of dimorphism, Giard, '94.

Multimodal Polygons.-Modes fall in Fibonacci series, Ludwig, '96, '96 ${ }^{\mathrm{b}}, ' 96^{\mathrm{c}},{ }^{\prime} 97,{ }^{\prime} 97^{\mathrm{b}},{ }^{\prime} 97^{\mathrm{c}}$

Modes of Chrysanthemum segetum at 13, 21, de Vries,'95.

Opposed to Fibonacci series, complex polygon due to lack of homogeneity, Lucas, '93, Shull, '02, Pearson, '02h, Lee, '02, Reinöhl, '03, Vogler, '03.

\section{CORRELATION.}

General and Method.-Galton, '88, '89, Pearson, '96, Yule, '97, '97b; spurious correlation, Pearson,'97; nonquantitative characters, Pearson, ' $00^{\mathrm{c}}$, Pearson and Lee, '00, Yule, '00, '00' '02; index not constant in related races, Weldon, '92, Pearson, '96, '98 ${ }^{\mathrm{b}}$ p. 175 , '02 $^{\mathrm{n}}$ p. 2, Davenport, ' $03^{\mathrm{b}}$.

\section{Man.}

General.-Galton, '8.; British criminals, various dimensions, $r=.13$ to .84 , Macdonell, ' 02 .

Skull.-Correlated with eranial capacity in living persons, Lee and Pearson, '01; breadth and length, Naquada, Bavarians, French, Pearson, '96, p. 280; N. A. Indians, Boas, '99; 
various dimensions, Aino and German, Lee and Pearson, '01; Naquadas, Fawcett and Lee, '02. With civilization woman's correlation tends to gain nn man's, Lee and Pearson, '01, Pearson, '02n.

Lot.

Breadth and Length:

German, $+\ldots \ldots \ldots \ldots \ldots \ldots \ldots \ldots \ldots \ldots .49 \pm .05$

Smith Sound Eskimo................47

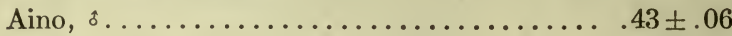

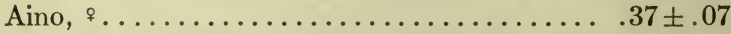

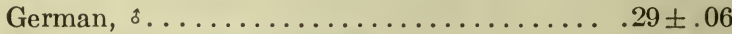

Modern Bavarian peasants. .............28 . 06

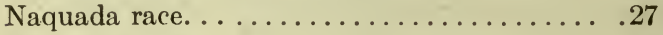

Sioux Indians. . . . . . . . . . . . . . 24

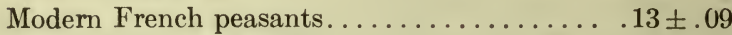

British Columbian Indians $\delta$............ . 08

Modern Frensh (Parisians)............. .05 \pm .06

Shuswap Indians. ................. .04

$$
\text { Lot. } \quad r \delta \quad r \text { \% }
$$

Aino:

Capacity and length..... . .89 $\pm .01 \quad .66 \pm .05$

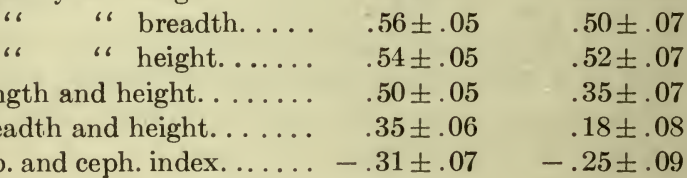

German:

Cap. and ceph. index..... $-.31 \pm .07 \quad-.25 \pm .09$

Capacity and breadth. .... $.67 \pm .04 \quad .70 \pm .03$

"، " length...... .51 $\pm .05 \quad .69 \pm .04$

" " height...... .24 $4.06 \quad .45 \pm .05$

Cap. and ceph. index...... $\quad .20 \pm .06 \quad-.03 \pm .07$

Breadth and height. ..... $\quad .07 \pm .06 \quad .28 \pm .06$

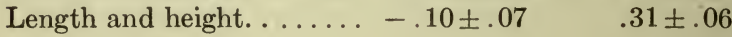

Skeletal.-Rollet, '89; stature correlated with length of long bones, reconstruction of stature of extinct races, Pearson, ' $98^{\text {b }}$; various coefficients of correlation, Pearson, '99, '00, p. 402; in hand-bones, Whiteley and Pearson, '99, Lewenz and Whiteley, '02. 
Lot.

Right and left femur. ........... $\quad .96$

Metacarpals, ii and iii digits right. . . . . . .94

First joints, iv digit, R. and L. hands. ... $\quad .93$

First joints, ii and iii, right. ........ $\quad .90$

Metacarpals, ii and $\mathrm{v}$ digits, right. .... $\quad .89$

Femur and humerus............. .84 to .87

Femur and tibia.............. . 81 to .89

First joints, ii and v, right. . ....... $\quad .82$

Stature and femur.............. $80\left(^{\circ}\right)$ to $.81\left(^{(}\right)$

Stature and humerus..............77( $\left.{ }^{\circ}\right)$ to $.81\left({ }^{\circ}\right)$

Stature and tibia..............78( $\left.{ }^{\wedge}\right)$ to $.80(\%)$

Humerus and ulna............... .75 to .86

Humerus and radius............. .74 to .84

Radius and stature..............67 $\left(^{(}\right)$to $70\left({ }^{(}\right)$

Clavicle and humeruse........... .44 to .63

Forearm and stature.............................

Clavicle and scapula............. .12 to .16

Stature and cephalic index.......... 08

Various: Pearson, '99; intelligence not correlated with size or shape of head, Pearson, '02.

Weight and length of new-born infant $\$$............ $.644 \pm .012$

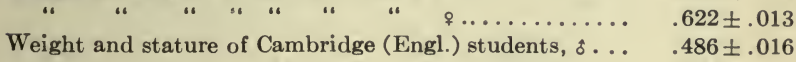

Breadth of head (reduced to 12th yr.) and intelligence, youth.............................. .084 \pm .024

Length of head (reduced to 12th yr.) and intelligence, youth ........................... .044 \pm .024

Cephalic index and intelligence, youth ........... .005 \pm .024

Breadth of head and ability, adults ............. $.045 \pm .032$

Cephalic index and ability, University men......... .031 \pm .035

" " " length of head, University men .... - -.086 \pm .033

Vaccination and Recovery.-Pearson, '00'; Macdonell, '02, '03. $r=.23$ to .91 .

Assortative Mating.-Pearson, '96, '99 ${ }^{\mathrm{b}}$, '00, Pearson and Lee, '00.

Stature of husbands and wives.......... r $r=.093 \pm .047$

ditto, another determination....... $r=.28 \pm .02$

Eye-color, husbands and wives.......... r $=.100 \pm .038$ Age at death of consorts............ $r=.22$ 


\section{Lower Animals.}

ANTIMERICALLY SYMMETRICAL ORGANS:

Paired organs.-Number of Müllerian glands on R. and L. fore legs of swine, Davenport and Bullard, '96; R. and L. fins of fishes, Duncker, '97, '00; number of coxal pores on R. and L. legs of the centipede Lithobius, Williams, '03; R. and L. dimensions of Gelasimus, Yerkes, '01, Duncker, '03; number of teeth on R. and L. jaws of Nereis, Hefferan, '00; breadth of R. and L. valves of Pecten, Davenport, '03b; skeletal spicules on R. and L. half of Echinus larva.

\section{Subject and Relative.}

Length R. and L. sides of carapace, Gelasimus. . . . . . .947 \pm .003

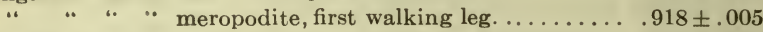

Breadth R. and L. valve of Pecten opercularis, Irish Sea. . . .858 \pm .006

Num. of teeth R. and $L$ jaws of Nereis. . ........... . $820 \pm .008$

". "fin-rays R. and L pectoral, Acerina.......... .710

“ coxal pores R. and L. 14th pair legs, Lithobius. . . . . . .69 \pm .02

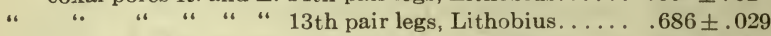

" " " " " " 12 th pair legs, Lithobius.... . . $.58 \pm .04$

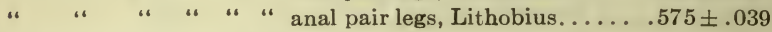

\section{Other antimeric organs:}

Num of dorsal and ventral spines, Palæmonetes vulgaris

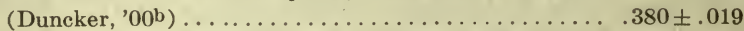

Num. of lips and canals of the medusa, Pseudoclytia

(Mayer, '01; Davenport, '02) ......................... 019

Secondarily ANTIMERIC organs.-Median organs in animals that lie on one side.)

Num. of dorsal.and anal fin-rays in flounder, $\delta \ldots \ldots \ldots \ldots .651$

" " " " " " “

Length antero-posterior and dorso-ventral diameters, Pecten $.970 \pm .001$

Unsymmetrical paired organs. - Pleuronectes, Duncker, '00; Gelasimus, the fiddler-crab, Yerkes, '01, Duncker, '03.

Length of meropodite, R. and L. chelæ of Galasimus. . . . . . .754 \pm .014

" " carpopodite, R. and L. chelæ of Gelasimus..... . .698 \pm .017

“ " " propodite, R. and L. chelæ of Gelasimus. . . . . . .473 \pm .026

Num. rays R. and L. pectoral fin, flounder, Pleuronectes, o . . .594

" " " " " " " " . . . 582

“ of dorsal fin-rays at which lateral line ends, R. and L.

Pleuronectes, of . ....................467

Num. rays $R$. and $L$. ventral fin, Pleuronectes, s....... .243 
Metamerically repeated organs.-Fin-rays of fishes, Duncker, '97; coxal pores centipede, Williams, '03; segments of shrimp Crangon, Weldon, '92.

Num. dorsal spines and soft fin-rays, Acerina . . . . . . . . . 379

" " " " " " Cottus .......... .11C

“ coxal pores R. anal and 14th segment, Lithobius . . .... .440

“ " " R. 13th and 14th segments, Lithobius ..... $\quad .722$

“ “ “ R. 13th and 12th segments, Lithobius ..... . .464

Length carapace and post-spinous portion rostrum, Crangon... .81

“ “ " tergum VI abd. seg., Crangon......... . . 09

“ tergum VI and telson, Crangon.................11

Mixed ANd Cross CORRELAtion.-Length of wing and tail of Lanius “shrike," Strong, '01; in fishes, Duncker, '97, '99; proportions of aphids, "plant-lice," Warren, '02; coxal pores of centipede, Williams, '03; length of carapace and of chelæ in Eupagurus, “hermit-crab," Schuster, '02; diameter of cell and body length, Daphnia, Warren, '03; cross correlation in teeth on jaws of Nereis, Hefferan, '00; various characters of the mud-snail, Nassa, Dimon, '02; circumference to number of spines, statoblast of Bryozoa, Davenport, ' $00^{\mathrm{e}}$; diameter of body of the Heliozoan Actinosphærium Echorni and the number of cysts and of nuclei, Smith, '03; inner and outer diameters and color of the shell of Arcella, Pearl and Dunbar, '03.

\section{Organs.}

Carapace length and chela length, Eupagurus, $\delta$.....

\&......

Diameter of body of Actinospherian and num. of nuclei

Inner and outer diameter shell of Arcella...........

Diam. of body of Actinosphærium and num. of cysts. .

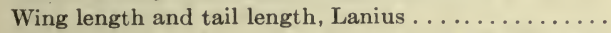

Diam. of cell and body length, Daphnia, hatching to

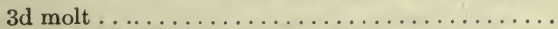

Diam, of cell and body length, Daphnia, $3 t^{\text {to }} 4$ th

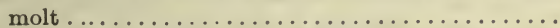

Diam. of cell and body length, Daphnia, after 4 th molt.. Num. coxal pores, R. anal and L. 12th seg., Lithobius... Frontal breadth and antennal length (Warren, '02).... Ccxal pores, R. 14th leg and body length, Lithobius...

Num. rays dorsal fin and end-point of L. lateral line,

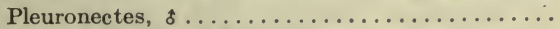

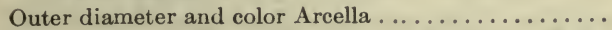
Num. dorsal spines and L. pectoral rays, Pleuronectes.

$$
\begin{aligned}
& .9389 \pm 0036 \\
& .8626 \pm .0080 \\
& .854 \pm .017 \\
& .836 \pm .007 \\
& .769 \pm .026 \\
& .569
\end{aligned}
$$




\section{Organs.}

Body length and number antennal joints.......... $\quad-.013 \pm .067$ Cireumference of statoblast and number spines,

Pectinatella . ..................... - .092 \pm .006

Num. R. definite teeth and L. indefinite, Nereis..... $\quad-.524 \pm .023$

Carapree length and chela index, Eupagurus....... $\quad-.522 \pm .022$

Num. of cysts and their diam., Actinosphærium. . . . $\quad-.669 \pm .040$

\section{Plants.}

Between various parts of flowers, Ludwig, '01.

Floral parts.-Stamens and pistils of Ficaria, MacLeod, '98, '99, Ludwig, '01, Weldon, '01, Lee, '02; rays and bracts and rays and disc florets of Aster, Shull, '02; various organs on Lesser Celandine, Pearson and others, '03.

\section{Organs.}

Num. rays and bracts. Aster . . . . . . . . . . 856 to .799

.. stamens and pistils Ficaria ranunculoides, early... $\quad .507 \pm .031$

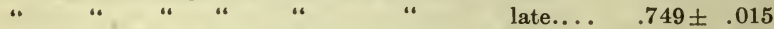

. rays and disc florets, Aster .............. .574 to .353

“ petals and sepals Ficaria verna ............ +.34 to -.18

.. stamens and pistils, Celandine............ .43 to .75

" " " petals, Celandine ........... . 38 to .22

“ pistils and petals, Celandine............. . 35 to .19

“ . " sepals, Celandine.............. .25 to .03

" stamens and sepals, Celandine............ .06 to .02

Other parts. - Size of leaves of same rosette of Bellis perennis, Verschaffelt, '99; various pairs of dimensions of fruits and leaves, Harshberger, '01; parts of Syndesmon, Kellerman, '01.

\section{General.}

Treatises.-Galton, '89, Pearson, '00.

Classification.-Galton, '89, pp. 7, 12, Pearson and Lee, '00, pp. 89, 91, 98 .

Law of ancestral heredity.-Galton, '97, Pearson, '98; estimate of heredity from a single ancestral generation, Pearson, '96, p. 306.

Inequality in parental transmission.-Father prepotent in sons; mother in daughters, Pearson and Lee, '00, p. 115; heredity weakened by change of sex, Pearson and Lee, '00, p. 115, Lutz, '03. 
Inheritance of Eye-color, Homo. $s$, son; $d$, daughter; $f$, father; $m$, mother.

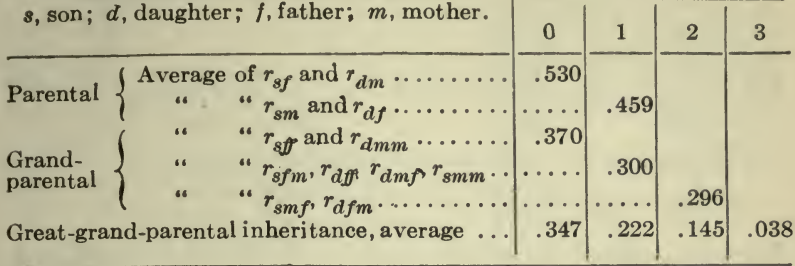

\section{Parental.}

Exceptional fathers produce exceptional sons at a rate three to six times that of non-exceptional fathers and exceptional pairs at ten times the rate of non-exceptional pairs, Pearson, ' $00^{\mathrm{c}}$, pp. $38,47$.

\section{$\stackrel{x}{\text { Longevity: }}$}

Father and son (Beeton and Pearson, '99).

Nc. of Changes of Sex.

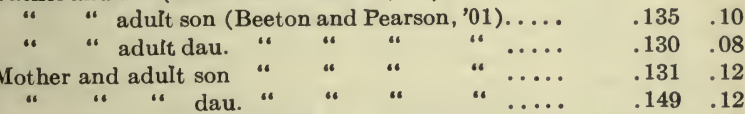

Eye-color (Pearson and Lee, '00) .............. .55 to .44

Stature, English middle class:

Father and son (Pearson, '96, p. 270) .......... .396 $\quad .352$

$$
\text { " " dau. " " " }
$$

Mother and son " " dau.

“ “

$.302 \quad .269$

$.284 \quad .275$

Head index, N. Amer. Indian:

Mother and son (Pearson, '00, p. 458) .......... . .370

$$
\text { " " dau. " " " ......... } 300
$$

Coat-color, thoroughbred horses:

Sire, foal (Pearson. '00, p. 458) .............. $\quad .517$

Dam, foal " " " $\ldots \ldots \ldots \ldots \ldots \ldots . . .527$

Fertility:

Mother and daughter, British upper class ..........

Father and son, " " "

Mother and daughter, British peerage...........

Father and son, " "

Mother and daughter, landed gentry............

Father and son

Frontal breadth, Hyalopterus (Warren, '02) .........

Length R. antenna, Hyalopterus “ " Ratio: R. antenna $\div$ frontal breadth (Warren, '02) ... $.439 \quad .539$

Ratio: Length protopodite $\div$ length body, Daphnia

(Warren, 02$) \ldots \ldots \ldots \ldots \ldots \ldots \ldots \ldots \ldots$ 


\section{Grandparental.}

Coat color, thoroughbred race-horses . . . . . . . . . . ${ }_{339}^{r}$

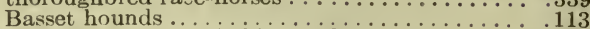

Frontal breadth, Hyalopterus, A phidæ (Warren, 02) ........ 321

Length, R. antenna, Aphidx (Warren, '02) ................

Ratio R. antenna $\div$ fronta breadth, Aphidæ (Warren, '02) . 231

Ratio Length protopodite $\div$ length body. Daphnia (War-

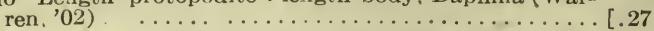

Stature.

Gr'dson and gr'df.. h?mo male line (Pearson, '96) ......... . 199

" ". female line (Pearson, '96)........ .089

frtgr'dson and grtgr'df. homo of line “

Eye-color, homo, f., grandfather, and son (Blanchard, '03) ." .421
Coat ".

Eye “ homo, “ $\quad$ “ $\quad$ “ dau. “

Coat " horse, " "

Eye " homo, m., " " $"$ son "

Coat " horse, " $"$ "

Eye " homo," " " " dau. " " " 297

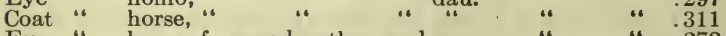

Eye " homo, f, grandmother, and son " " $\quad .272$

Coat " horse, ", grand "

$\begin{array}{llllll}\text { Eye "“ homo, “ } & \text { "“ } & \text { " dau. } & \text { " } & \text { " } & .221 \\ \text { Coat " } & \text { horse, " } & & \text { " } & .204\end{array}$

Eye " homo, m., " " "

Coat " horse, ". " " " $"$ "

Eye " homo, " “

Coat " horse, " "

\section{Fraternal.}

Daphnia, length of spine (Warren, '99; Pearson, '01 $) \ldots \ldots \ldots \ldots .693$

Aphis, antennal length (Warren, '02).................. .679

" frontal breadth (Warren, '02)..................666

Paramecium, index of just separated fission pairs (Simpson, '02). .664

Horse, coat-color (Pearson, Lee, and Moore), average of 3 sets.. . 633

Man, forearm, English (Pearson, ' $01^{\mathrm{c}}$ )................. 542

Hound, coat-color, Bassett (Pearson and Lee, '00). .......... .526

Man, eye-color, English (Pearson, '01 ${ }^{c}$ ). Average of 2 sets . . . . . 475

Pectinatella, statoblast hooks (Pearson, '01c) . ............ .430

Man, stature " " "Average of 3 sets.. .403

" cephalic index, N. A. Ind. " " Average of 3 sets.. .403

“ longevity, Quakers (Beeton and Pearson, '01).......... . 332

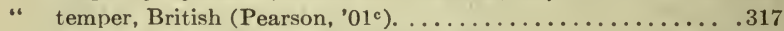

“ longevity, British peerage (Pearson, '01) ............ 260

" " Quakers " " " ............. 197

Average of 23 sets. . ................... $\overline{.476}$

Mean of 42 fraternal correlations (Pearson, ' $02^{\mathrm{k}}$ )....... 495

Some mental characteristics, inherited exactly like physical characters (Pearson, '01 ${ }^{\mathrm{e}}$ ):

Conscientiousness ....... .593 Popularity............504

Self-consciousness....... .592 Vivacity............ .470

Shyness. ............528 Intelligence..........456

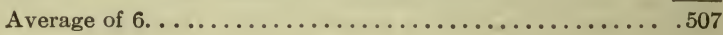




\section{Theoretical coefficient of correlation be-} tween relatives.-Pearson, '00, Pearson and Lee, '00.

Blended

Inheritance.

Off̈spring and Parent........... .3000 " " grandparent......... .1500

" " " great-grandparent.... .0750

" " "gt.-gt.-grandparent... .0375

" " $n$th order grandparent $.6 \times\left(\frac{1}{2}\right)^{n}$

Brothers. .................. .4000

Half-brothers. ............... .2000

Uncle and nephew . . .......... 1500

First cousins. . . . . . . . . . . . 0750

First cousins once removed ....... 0344

Second cousins . ............ 0172

Third cousins................ .0041
Alternative Inheritance.

.5000

.4 to 1.0

.2 to 0.5

.250

\section{Homotyposis.}

Correlation in non-sexual reproduction, as in production of homologous undifferentiated physiologically independent parts, Pearson, '01c; criticism, Bateson, '01; reply, Pearson, '02i' rejoinder, Bateson, '03; correlation between differentiated homologous organs, Pearson, '02e.

\section{Lot.} \% Var. to
Character.
Vace.
Race

Ceteract, Somersetshire $\%$ Var.
Var. of
Race
.... 78

Hartstongue, Somersetshire........... Sori on fronds...... 78

Shirley poppy, Chelsea............. Stigmatic bands.....79

English onion. Hampden......... . Veins in tunics . . . . . 79

Holly Dorsetshire ........................ 80

Spanish chest nut, mixed. . . . . . . . Veins in leaves .... 81

Beech, Buckinghamshire ......... Veins in leaves ...... 82

Papaver rhoeas, Hampden... . . . . . . . Stigmatic bands..... 83

Mushroom, Hampden........... Gill indices ....... 84

Papaver rhocas, Quantocks. .......... Stigmatic bands..... 85

Shirley poppy. Hampden ... . . . . . Stigmatic bands.... . 85

Spanish chestnut, Buckinghamshire. Veins in leaves . . . . . 89

Broom. Yorkshire ............. Seeds in pods . . .... 91

Ash. Monmouthshire . . . . . . . . . . Leaflets on leaves.... 91

Papaver rhxas, Lower Chilterns. . . . . Stigmatic bands. . . . . 92

Ash. Dorsetshire ............. Leaflets on leaves. ... 92

Ash Buckinghamshire ............... Leaflets on leaves.... 93

Holly Somersetshire ............. Prickles on leaves.... 93

Wild ivy, mixed localities. . . . . . . . . . Leaf indices........ 96

Nigella hispanica. Slough ............ Seg of seed-capsules. 98

Malva rotundifolia, Hampden. .........Seg. of seed-vessels... 98

Woodruff, Buckinghamshire ..........Members of whorls ... 98

Correlation. 


\section{Mendelism.}

General Statement.-Mendel, '66, de Vries, '00, '00 b, '00c '03, Correns, '00, Davenport, '01, Bateson, '02, Castle, '03; critical, Weldon, '02, '03, Pearson, '03' .

Plants. - Correns, '00, '00 b' '01, '02-'02c , '03-'03' , de Vries, '02, '01-'03, Bateson and Saunders, '02.

Animals.-Echinoids, Doncaster, '03; poultry, Bateson and Saunders, '02; mice, Darbishire, '02,' 03 , ' $03^{\text {b }}$, Castle, ' $03^{\mathrm{b}}$, Bateson, ' $03^{\text {b}}$; rabbits, Woods, ' 03.

\section{Telegony.}

No evidence of, in human statures, Pearson and Lee, '96.

\section{Fertility.}

Inherited in man and race-horses, Pearson, Lee, and Bramley-Moore, '99; greater fertility in poppy of seeds from capsules with a high number of stigmatic bands, Pearson, '02; fertility of medusæ with symmetrical bands exceeds that of the unsymmetrical as 3 to 4 , Mayer, '01.

\section{SELECTION.}

General.-Intensity of selection connotes a lessening of correlation, Pearson, '02 $2^{\mathrm{d}}$, p. 23 ; mediocre individuals not the fittest to survive, Pearson, ' $02^{\mathrm{n}}$, p. 50 .

Man. $-50 \%$ to $80 \%$ of human death-rate selective, Beeton and Pearson, '01.

Other Animals.-Annihilation of the extremes in the.sparrow, Bumpus, '99; percentage death-rate of families of Aphids has inverse correlation with length of antenna of mother $(r=-.201 \pm .084)$, with frontal breadth of mother $(r=-.184 \pm .084)$, and with number in newly born brood $(r=-.188 \pm .084)$; in Carcinus mœnas, Weldon, '95, '99; in Clausilia, Weldon, '01.

Plants. - Transformation of skew frequency curve to a symmetrical one by selection, de Vries, '94, '98; shifting of the mode by selection, de Vries, '99.

Sexual.-Pearson, '96:

Stature of husbands, inches. . . . . 69.136 . 126

“ males in general ........6. 69.215 .066

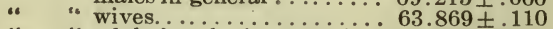

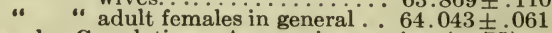

See also Correlation: Assortative mating (p. 75 ).

$2.628 \pm .089$

$2.592 \pm .047$

$2.303 \pm .078$

$2.325 \pm .043$

\section{DISSYMMETRY.}

The following values for $\Xi$ have been determined by Duncker, '00 and '03: 
Pleuronectes flesus L., 1060 R.-eyed and 60 L.-eyed: Right- Lefteyed. eyed.

Num. of pectoral divided rays . . . . . . . . . . .997 $\quad-.983$

Total num. pectoral rays................. .604 -.583

Num. of ventral divided rays. . ..............326 $\quad-.374$

Total num. of ventral fin-rays. . . . . . . . . . $019 \quad-.083$

Gelasimus pugilator Latr. (fiddler-crib).

Right- Left-

Lateral edge of carapace ................. $838 \quad .793$

Length of meropodite, first ambulacral appendage. $\quad .813 \quad .872$

Length of meropodite, of carpopodite, and of propodite of chelæ, all ................. $1.00 \quad 1.00$

Num. of rays on R. and L. pectoral fins, Acerina ......

" " glands on wrists of swine...............

\section{DIRECT EFFECT OF ENVIRONMENT.}

Animals.-Aphids reared in successive generations in increasingly unfavorable conditions have reduced dimensions, Warren, '02:

Grandmother. Grandchildren.

Frontal breadth, Aphid. . $A=37.56 \quad 33.93$

Length of R. antenna. ... $A=83.91 \quad 76.59$

Ratio $\frac{\text { F. B. }}{\text { R. A. ..........A A }=22.46 \quad 22.57}$

Depauperization of mud-snail, Nassa, in diluted sea-water, Dimon, '02.

Plants.-Conditions of life affect number of floral parts in poppy, de Vrias, '99, MacLeod, '00, Pearson and others, '03; number of ray-flowers of Primula farinosa increases with moisture, Vogler, '01; empirical mode in number of anthers in Stellaria in poor environment is 3 ; in good environment 5, Reinöhl, '03; leaf-blade smaller in light than in shade, MacLeod, '98.

\section{LOCAL RACES.}

General.-Davenport and Blankenship, '98, Davenport, '99. Pisces.-Leuciscus from different altitudes, Eigenmann, '95; herring from diñerent sea-areas distinguishable, Heincke, '97, 98; mackerel from three Scotch localities differ, Williamson, '00; fin-rays of Pleuronectes from New England shore, Bumpus, '98:

Wood Holl. Waquoit. Bristol, R. I.

$\begin{array}{lllll}\text { Dorsal fin-rays. . . } & A=66.1 & 65.2 & 64.9 \\ \text { Anal } & \ldots & A=49.7 & 48.6 & 48.7\end{array}$


Number of fin-rays of Pleuronectes flesus from Western Baltic, $M^{\prime}=39$, southern North Sea $41 \frac{1}{2}$, Plymouth 44, Duncker, '99.

Fish in similar and adjacent lakes belonging to different drainage-basins have marked difference in scales on nape, number of fin-rays and of dorsal spines, Moenkhaus, '96.

Invertebrata.-Mean and variability of deep- and shallow. water Eupagurus differ, Schuster, '03; proportions, variability, and correlation coefficients of Pecten opercularis differ at Eddystone, Irish Sea, and Firth of Forth, Davenport, ' $03^{\text {b }}$.

Plants.-Iesser celandine, Pearson and others, ' 03.

\section{USEFUL TABLES.}

Probability Integral.-Area and ordinate of normal curve in terms of abscissa, Sheppard, '93, '03; abscissa of normal curve in terms of ordinate, Sheppard, '93; abscissa and ordinate in terms of difference of area, Sheppard, '03; abscissa of normal curve in terms of class index, Sheppard, '98.

Probability of fitted curve being the true one:

$$
P=e^{-\frac{1}{2} \chi^{2}}\left(1+\frac{\chi^{2}}{2}+\frac{\chi^{4}}{2.4}+\frac{\chi^{6}}{2.4 .6}+\cdots+\frac{\chi^{n^{\prime}-3}}{2.4 .6 \ldots\left(n^{\prime}-3\right)}\right),
$$

Values of $\log \left\{\chi \sqrt{\frac{2}{\pi}} e^{-\frac{1}{2} \chi^{2}}\right\}$ for various values of $\chi^{2}$.

Table of $\log \frac{1}{n(n-2)(n-4) \ldots}$. Elderton, '02.

Table of $\sqrt{\frac{2}{\pi}} \int_{\chi}^{\infty} e^{-\frac{1}{2} \chi^{2}} d \chi$, for different values of $\chi$, Elderton, '02.

Table of $\log _{10}(1+x)-x \log _{10} e$ for various values of $x$, for use with curves of Type III.

Tables for calculating probable error, Sheppard, '9s.

Table of values of $1-r^{2}$ and $\sqrt{1-r^{2}}$ for all values of $r$ from 0 to 1 proceeding by hundredths, Yule, '97.

Probable errors of $r$ for all values of $n$, Yule, '97. 


\section{BIBLIOGRAPHY.}

Note.-An effort has been made to include all recent works containing usable quantitative data in botany and zoology; but the literature on the mathematical treatment of statistics and that affording data in anthropology are by no means completely listed.

\section{ABBREVIATIONS.}

The following names of journals often referred to have been much abbreviated:

Amer. Nat. = American Naturalist.

Ber. d. deutsch. bot. Ges.= Berichte der deutschen botanischen Gesellschaft.

Biom. = Biometrika .

Bot. Centralbl. = Botanisches Centralblatt.

Phil. Trans. $=$ Philosophical Transactions of the Royal Society of London.

Proc. Roy. Soc. $=$ Proceedings of the Royal Society of London.

The references are scattered through fifty-seven periodicals.

Adams, C. C. '00. Variation in Io. Proc. Amer. Assoc. for the Adv. of Sci., XIIX, 18 pp., 27 plates.

Agassiz, A., and W. McM. Woodworth, '96. Some variations in the Genus Eucope. Bull. Mus. Comp. Zool., XXX, 123-150. Plates I-IX. Nov.

Allen, J. A., '71. On the Mammals and Winter Birds of East Florida, etc. Bull. Mus. Comp. Zool., II, 161-450. Plates IV-VIII.

Amann, J., '96. Application du calcul des probabilités à l'étude de la variation d'un type végétal. Bull. de

l'Herb. Bossier. IV, 578-590.

Амmon, Отто, '99. Zur Anthropologie der Badener. Jena:

G. Fischer, $707 \mathrm{pp}, 15 \mathrm{Tab}$.

Bachmetjew, P., '03. Ueber die Anzahl der Augen auf der Unterseite der Hinterflügel von Epinephele jurtina L.

Allgemeine Zeitschr. f. Entomologie, VIII, 253-256.

BAKer, F. C., '03. Rib Variation in Cardium. Amer Nat., XXXVII, 481-488, July.

Ballowitz, E., '99. Ueber Hypomerie und Hypermerie bei Aurelia aurita. Arch. f. Entw. Mech. d. Organismen, VIII, 239-252. 
Bardeen, C. R., and A. W. Elting, '01. A Statistical Study of the Variations in the Formation and Position of the Lumbo-sacral Plexus in Man. Anatom. Anz., XIX, 124135, 209-238, Mar., Apr.

Bateson, W., '89. On some Variations of Cardium edule apparently Correlated to the Conditions of Life. Phil. Trans., 1889 B., 297-330, Pl. 26.

Bateson, W., '94. Materials for the Study of Variation. London and New York. xvi+598 pp.

Bateson, W., '01. Heredity, Differentiation, and Other Conceptions of Biology: a consideration of Professor Karl Pearson's paper "On the Principle of Homotyposis.” Proc. Roy. Soc., LXIX, 193-205.

Bateson, W., and E. R. Saunders, '02. Reports to the Evolution Committee-Report I. Royal Society. London: Harrison \& Sons. $160 \mathrm{pp}$.

Bateson, W., '02. Mendel's Principles of Heredity. Cambridge [Engl.]: Univ. Press. $212 \mathrm{pp}$.

Bateson, W., '03. Variation and Differentiation in Parts and Brethren. Cambridge [Engl.]: J. and C. F. Clay. Bateson, W., '03 ${ }^{b}$. The Present State of our Knowledge of Colour-heredity in Mice and Rats. Proc. Zool. Soc., London, 1903, II, 71-99, Oct. 1.

BAxter, J. H., '75. Statistics, Medical and Anthropological, of the Provost-Marshal-General's Bureau. 2 vols. Washington: Gov't Printing Office. $569+767 \mathrm{pp}$.

Beeton, Mary, and K. Pearson, '99. Data for the Problem, etc. II. A First Study of the Inheritance of Longevity, and the Selective Death-rate in Man. Proc. Roy. Soc., LXV, 290-305.

Beeton, Mary, and Karl Pearson, '01. On the Inheritance of the Duration of Life, and on the Intensity of Natural Selection in Man. Biom., I, 50-89, Oct.

Beeton, M., G. U. Yule, and K. Pearson, '00. Data for the Problem of Evolution in Man. V. On the Correlation between Duration of Life and the Number of Offspring. Proc. Roy. Soc., LXVII, 159-179, Oct. 31.

Bigelow, R. P., and Eleanor P. Rathbun, '03. On the Shell of Littorina littorea as Material for the Study of Variation. Amer. Nat., XXXVII, 171-183, Mar. 
Blanchard, N., '02. On the Inheritance of Coat-colour of Thoroughbred Horses (Grandsire and Grandchildren). Biom., I, 361-364, April.

Blanchard, Norman, '03. On Inheritance (Grandparent and Offspring) in Thoroughbred Horses. Biom., II, 229-234, Feb.

Boaz, Franz, '99. The Cephalic Index. American Anthropologist, N. S., I, 448-461, July.

Bowditch, H. P., '01. The Growth of Children, Studied by Galton's Method of Percentile Grades. Twenty-second Annual Report of the State Board of Health of Massachusetts (for 1890).

Brewster, E. T., '97. A Measure of Variability and the Relation of Individual Variations to Specific Differences. Proc. Amer. Acad. Arts and Sc., XXXII, 268-280.

Brewster, E. T., '99. Variation and Sexual Selection in Man. Proc. Boston Soc. Nat. Hist., XXIX, 45-61, July, '99.

Browne, E. T., '95. On the Variation of the Tentaculocysts of Aurelia aurita. Quart. Jour. Micros. Soc., XXXVII, 245-251.

Browne, E. T., '01. Variation in Aurelia aurita. Biom., I, 90-108, Oct.

Bumpus, H. C., '97. The Variations and Mutations of the Introduced Sparrow. Biol. Lect. Woods Holl, 1896, 1-15. Bumpus, H. C., ' $97^{\text {b }}$. A Contribution to the Study of Variation. Jour. of Morphol., XII, 455-480. Pls. A-C.

Bumpus, H. C., '98. The Variations and Mutations of the Introduced Littorina. Zool. Bull., I, 247-259.

Bumpus, H. C., ' $98^{\text {b }}$. On the Identification of Fish Artificially Hatched. Amer. Nat., XXXII, 407-412.

Bumpus, H. C., '99. The Elimination of the Unfit, as Illustrated by the Introduced Sparrow, Passer domesticus.

Biol. Lects. Woods Holl for '97 and '93, pp. 209-226.

Burkill, I. H., '95. On some Variations in the Number of Stamens and Carpels. Proc. Linn. Soc., Botany, XXXI, 216-245.

Byrne, L. W., '02. On the Number and Arrangement of the Bony Plates of the Young John Dory. Biom., II, 113-120. Nov. 
Camerano, L., '00. Lo studio quantitativo degli organismi ed il coefficiente somatico. Atti d. R. Accademia delle sci. di Torino, XXXV, 22 pp.

Camerano, L., ' $00^{\text {b. }}$ Lo studio quantitativo degli organismi e gli indici di variabilità, di variazione, di frequenza, di deviazione e di isolamento. Atti d. $R$. Accademia delle sci. di Torino, XXXV, 19 pp.

Camerano, L., '01. Lo studio quantitativo degli organismi e gli indici di mancanza, di correlazione e di asimmetria. Atti d. R. Accademia delle sci. di Torino, XXXVI, $8 \mathrm{pp}$.

Camerano, L., '02. Ricerche somatometriche in zoologia. Boll. dei Musei de Zool. e Anat. Comp. di Torino, XVII, $18 \mathrm{pp}$.

Castle, W. E., '03. Mendel's Law of Heredity. Proc. Amer. Acad. Arts and Sci., XXXVIII, 533-548, Jan. Castle, W. E., '03 ${ }^{\text {b }}$ The Heredity of Albinism. Proc. Amer. Acad. Arts and Sci., XXXVIII, 601-622, Apr.

Chauvenet, W., 1888. A Treatise on the Method of Least Squares, etc., being the appendix to the Author's Manual of Spherical and Practical Astronomy. Philadelphia, pp. 469-599.

Chodat, R., '01. Note sur la variation numérique dans l'Orchis morio. Bull. de l'herb. Boissier, (2) I, 652686.

Correns, C., '00. G. Mendel's Regeln über das Verhalten der Nachkommenschaft der Rassenbastarde. Ber。d. deutsch. bot. Ges., XVIII, 158-168.

Correns, C., '00b. Ueber Levkojenbastarde. Zur Kenntniss der Grenzen der Mendel'schen Regeln. Bot. Centralbl., LXXXIV, 97-113, Oct. 17.

Correns, C., '01. Bastarde zwischen Maisrassen, mit besonderer Berücksichtigung der Xenien. Bibliotheca Botanica. Bd. X, Hft. 53, xii +161 pp., 2 Taf.

Correns, C., '02. Ueber den Modus und den Zeitpunkt der Spaltung der Anlagen bei den Bastarden vom ErbsenTypus. Bot. Zeitung, LX, 66-82.

Correns, C., '02b. Die Ergebnisse der neuesten Bastardforschungen tür die Vererbungslehre. Ber. d. deutsch. Bot. Ges , XIX, 71-94. 
Correns, C., '02c. Scheinbare Ausnahmen von der Mendel'schen Spaltungsregel für Bastarde. Ber d. deutsch. Bot. Ges., XX, 159-172.

Correns, C., '03. Ueber Bastardirungsversuche mit Mirabilis-Sippen. Ber. d. deutsch. Bot. Ges., XX, 594-609.

Correns, C., '03b. Ueber die dominierenden Merkmale der Bastarde. Ber d. deutsch. Bot. Ges., XXI, 133-147, Mar. 25.

Correns, C., '03c. Weitere Beiträge zur Kenntnis der dominierenden Merkmale und der Mosaikbildung der Bastarde. Ber. d. deutsch Bot. Ges., XXI, 195-201, April 23.

Cú́not, L., '02. Le loi de Mendel et l'hérédité de la pigmentation chez les souris. Arch. Zool. exp. et gén, '02, p. xxvii.

CuEnot, L., '03. L'hérédité de la pigmentation chez les Souris (2 $2^{\text {me }}$ note). Arch. de Zool, expér. et gén., (4) I, xxxiii-xli.

Cummings, E. R., and A. V. Mauck, '02. A Quantitative Study of Variation in the Fossil Brachiopod, Platystrophia lynx. Amer. Jour. of Science, XIV, 9-16, July, '02. Darbishire, A. D., '02. Note on the Results of Crossing Japanese Waltzing Mice with European Albino Races. Biom., II, 101-109, Nov.

Darbishire, A. D., '03. Second Report on the Result of Crossing Japanese Waltzing Mice with European Albino Races. Biom., II, 165-173, Feb.

Darbishire, A. D., '03 ${ }^{\text {b }}$ Third Report on Hybrids between Waltzing Mice and Albino Races. On the Result of Crossing Japanese Waltzing Mice with "Extracted" Recessive Albinos. Biom., II, 282-285, June.

DAvenPorT, C. B., '99. The Importance of Establishing Place Modes. Science, N. S., IX, 415-416, Mar. 17. Davenport, C. B., '00. The Aims of the Quantitative Study of Variation. Biol. Lect. Woods Holl for '99, 267-272.

DAvenport, C. B., '00 ${ }^{\text {. }}$ Review of von Guaita's Experiments in Breeding Mice. Biol. Bull., II, 121-128.

DAVENPORT, C. B., '00'. On the Variation of the Shell of Pecten irradians Lamarck from Long Island. Amer. Nat., XXXIV, \&63-877, Nov. 
Davenport, C. B., '00 d. A History of the Development of the Quantitative Study of Variation. Science, N.S., XII, 864-870, Dec. 7.

Davenport, C. B., '00'. On the Variation of the Statoblasts of Pectinatella Magnifica from Lake Michigan at Chicago. Amer. Nat., XXXIV, 959-968, Dec.

Davenport, C. B., '01. Mendel's Law of Dichotomy in Hybrids. Biol. Bulletin, II, 307-310.

Davenport, C. B., '01 . Zoology of the Twentieth Century. Science, XIV, 315-324, Aug. 30.

Davenport, C. B., '01c. The Statistical Study of Evolution. Popular Science Monthly, LIX, 447-460, Sept. Davenport, C. B., '02. Variability, Symmetry, and Fertility in an Abnormal Species. Biom., I, 255, 256, Jan.

Davenport, C. B., '03. A Comparison of the Variability of Some Pectens from the East and West Coasts of the United States. Mark Anniversary Volume.

Davenport, C. B., '03 ${ }^{\text {b }}$ Quantitative Studies in the Evolution of Pecten. III. Comparison of Pecten opercularis from three localities of the British Isles. Proc. Amer. Acad. Arts and Sci., XXXIX, 123-159, Nov.

Davenport, C. B., and J. W. Blankinship, '98. A Precise Criterion of Species. Science, VII, 685-695.

Davenport, C. B., and C. Bullard, '96. Studies in Morphogenesis, VI. A Contribution to the Quantitative Study of Correlated Variation and the Comparative Variability of the Sexes. Proc. Amer. Acad. Arts and Sci., XXXII, 85-97.

DE VRIES, H., '94. Ueber halbe Galton-Kurven als Zeichnen diskontinuirlichen Variation. Ber. deutsch. Bot. Ges., XII, 197-207, Taf. X.

DE Vries, H., '95. Eine zweigipfelige Variations-Kurve. Arch. f. Entwickelungsmechanik, II, 52-65, 1 Taf.

DE Vries, H., '98. Over het omkeeren van halve GaltonCurven. [Résumé in French.] Bot. Jaarboek, X, 27-61.

de Vries, H., '99. Alimentation et Sélection. Cinquantenaire de la Société de Biologie, Volume jubilaire, 22 pp. . 
dE VRies, H., '99. Ueber Curvenselection bei Chrysanthemum segetum. Ber. d. deutsch. Bot Ges., XVII, 86-98.

de Vries, H., '00. Das Spaltungsgesetz der Bastarde Ber. d. deutsch. Bot. Ges., XVIII, ₹3-90.

DE VRIES, H., '00 b. Sur la loi de disjonction des hybrids. Compt. Rend. de l'Acad. des Sci., CXXX, 845-847.

DE VRIES, H., '00'. Ueber erbungleiche Kreuzungen. Ber. d. deutsch. Bot. Ges., XVIII, 435-443.

DE Vries, H., '02. Ueber tricolyte Rassen. Ber. d. deutsch. bot. Ges., XX, 45-54.

DE Vries, H., '01-'03. Die Mutationstheorie. Versuche und Beobochtungen über die Entstehung der Arten im Pflanzenreich. 2 Bde. Leipzig: Veit \&.Comp.

DE VRIEs, H., '03. La loi de Mendel et les correcteurs constantes des hybrides. C. R. de l'Acad. des Sci., Feb. 2, 1903.

Dimon, Abigall Camp, '02. Quantitative Study of the Effect of Environment upon the Forms of Nassa obsoleta and Nassa trivittata from Cold Spring Harbor, Long Island. Biom., II, 24-43, Nov.

Doncaster, L., '03. Experiments in Hybridization with Special Reference to the Effect of Conditions on Dominance. Phil. Trans., B. CXCVI, 119-173, Oct. 3.

Duncker, G., '97. Correlation-Studien an den Strahlzahlen einiger Flossen von Acerina cernua L. Biol. Centralbl., XVII, 785-794; 815-831.

Duncker, G., '98. Bemerkung zu dem Aufsatz von H. C. Bumpus "The Variations and Mutations of the Introduced Littorina." Biol. Centralbl., XVIII, 569-573.

Duncker, G., '99. Die Methode der Variations-Statistik. Arch. f. Entwickelungs-Mechan. d. Organismen, VIII, 112-183. [The most important elementary presentation of the subject; extensive, nearly complete bibliography.] Duncker, G., '99 . Wesen und Ergebnisse der Variationsstatistischen Methode in der Zoologie Verh. d. deutsch. Zool. Ges., IX, 209-226.

Duncker, G., '00. Variation und Asymmetrie bei Pleuronectes flesus L. Wiss. Meeresuntersuch., N. F., III, 335-404, Taf. XI-XIII. 
Duncker, Georg, ' $00^{b}$. On Variation of the Rostrum in Palæmonetes vulgaris Herbst. Amer. Nat., XXXIV, 621-633, Aug.

Duncker, Georg, '03. Ueber Asymmetrie bei "Gelasimus pugilator" Latr. Biom., II, 307-320, June.

EigenmanN, C. H., '95. Leuciscus balteatus (Richardson): a Study in Variation. Amer. Naturalist, XXIX, 10-25, Pls. 1-5.

Eigenmann, C. H., '96. The Study of Variation. Proc. Indiana Acad. Sci., V. 265-278. [Extensive bibliography.]

Elderton, W. Palin, '02. Tables for Testing the Goodness of Fit of Theory to Observation. Biom., I, 155-163, Jan. Elderton, W. Palin, '02 ${ }^{\mathrm{b}}$. Graduation and Analysis of a Sickness Table. Biom., II, 260-272, June.

Elderton, W. Palin, '02c. Interpolation by Finite Differences. Biom., II, 105-108, Nov.

Engberg, Carl C., '03. The Degree of Accuracy of Statistical Data. University Studies, University of Nebraska, III, 87-100.

Fawcett, Cicely D., and Alice Lee, '02. A. Second Study of the Variation and Correlation of the Human Skull, with Special Reference to the Naquada.Crania. Biom., I, 408-467, Tables I-VIII, Aug.

Fawcetr, Cicely D., and Karl Pearson, '98. Mathematical Contributions to the Theory of Evolution. On the Inheritance of the Cephalic Index. Proc. Roy. Soc., LXII, 413-417.

Fechner, G. T., '97. Kollektivmasslehre. Im Auftrage der Königlich-Sächsischen Gesellschaft der Wissenschaften herausgegeben von Gottl. Friedr. Lipps. Leipzig: Engelmann. 483 pp.

Field, W. L. W., '98. A Contribution to the Study of Individual Variation in the Wings of Lepidoptera. Proc. Amer. Acad. Arts and Sci., XXXIII, 389-395.

Fry, Agnes, '02. Note on Variation in Leaves of Mulberry Trees. Biom. I., 258, Jan.

Galton, F., '88. Correlations and their Measurement, chiefly from Anthropometric Data. Proc. Roy. Soc. London, XLV, 136-145. 
Galton, F., '89. Natural 'Inheritance. London: Macmillan.

Galton, F., '97. The Average Contribution of each several Ancestor to the Total Heritage of the Offspring. Proc. Roy. Soc. London LXI, 401-413.

Galton, Francis, '97. Note to the Memoir by Professor Karl Pearson, F.R.S., on Spurious Correlation. Proc. Roy. Soc., LX, 498-502.

Galton, Francis, '01. Biometry. Biom., I, 7-10, Oct. Galton, Francis, '02. The Most Suitable Proportion between the Values of First and Second Prizes. Biom., I, 385-390, Aug.

Gallardo, A., '00. Observaciones morfológicas y estadísticas sobre algunas anomalías de digitalis purpurea $\mathrm{L}$. Anales del Museo Nac. de Buenos Aires, VII, 37-72, June 12.

Gallardo, A., '00. Les mathématiques et la biologie. Deuxième Congrès internat. des mathématiques. Paris. 395-403.

Gallardo, A., '01. Las matématicas y la biología. Anales de la Sociedad Cientifica Argentiná, LI., 112-122.

Gallardo, A., '01 b. Concordancia entre los polígonos empíricos de variación y las correspondientes curvas teóricas. Anales de la Sociedad Cientifica Argentiná, LII, 61-68.

Giard, A., '94. Sur certains cas de dédoublement des courbes de Galton dus au parasitisme et sur le dimorphisme d'origine parasitaire. Compt. Rend. de l'Acad. des Sci., 16 Apl., '94.

Guaita, Georg von, '98-'00. Versuche mit Kreuzungen von verschiedenen Rassen der Hausmaus. Ber. naturf.

Ges. Freiburg-i.-B., X, 317-332; XI, 131-138.

HargitT, C. W., '01. Variation among Hydromedusæ. Biol. Bull., II, 221-255, Feb.

Harshberger, J. W., '01. The Limits of Variation in

Plants. Proc. Acad. Nat. Sci., Philadelphia, LIII, 303-319, April.

Hefferan, Mary, '00. Variation in the Teeth of Nereis Biol. Bulletin, II, 129-143. 
Heincke, F., '97. Naturgeschichte des Herings. T'eil I. Die Lokalformen und die Wanderungen des Herings in den Europäischen Meeren. Abbandl. des deutschen Seefischerei, Vereins, II, 128 pp., 26 Tab.

Heincke, F., '9S. Ditto. Teil II, 223 pp. Tabellen +2 ; Tafeln.

Hensgen, C., '02. Biometrische Untersuchungen über die Spielarten von Helix nemoralis. Biom., I., 468-492, Aug. Howe, J. L., '98. Variation in the Shell of Helix nemoralis in the Lexington, Va., Colony.. Amer. Nat., XXXII, 913-923, Dec.

Jacob, S., A. Lee, and Karl Pearson, '03. Preliminary Note on Interracial Characters and their Correlation in Man. Biom., II, 347-356, June.

Jонаnnsen, W., '03. Ueber Erblichkeit in Populationen und in reinen. Linien. Ein Beitrag zur Beleuchtung schwebender Selektionsfragen. Jena: Fischer. 68 pp. Kellerman, W. A., '01. Variation in Syndesmon thalictroides. Ohio Naturalist, I, 107-111, Pl. 9, May.

KökösI, ., '96. An Estimate of the Degrees of Legitimate Natality as derived from a Table of Natality compiled by the Author from his Observations made at Budapest. Phil. Trans., B. CLXXXVI, Pt. II, pp. 781-876.

Latter, Oswald H, '02. The Egg of Cuculus canorus. An Enquiry into the Dimensions of the Cuckoo's Egg and the Relation of the Variations to the Size of the Eggs of the Foster-parent, with Notes on Coloration, etc. Biom., I, 164-176, Jan.

Lee, A., and K. Pfarson, '00. Data for the Problem of Evolution in Man. VI. A First Study of the Correlation of the Human Skull (abstract). Proc. Roy. Soc., LXVII, 333-337.

Lee, Alice, and K. Pearson, '01. Data for the Problem of Evolution in Man. VI. A First Study of the Correlation of the Human Skull. Phil. Trans., A. CXCVI, 225264, Mar. 29.

Iiee, Alice, '02. Dr. Ludwig on Variation and Correlation in Plants. Biom., I, 316-319, April.

Lee, Alice, '03. On Inheritance (Great-grandparents and Great-great-grandparents and Offspring) in Thoroughbred Race-horses. Biom., II, 234-236, Feb. 
Lewenz, M. A., and M. A. Whiteley, '02. Data for the Problem of Evolution in Man. A Second Study of the Variability and Correlation of the Hand. Biom., I, 345-360, April.

LönnberG, E., '93. Ichthyologische Notizen. Bihangh til K. Svenska Vet. Akad. Handl., XVIII, Afd. IV, No. 2. $13 \mathrm{pp}$.

LuCAS, F. C., '99. Variation in the Number of Ray-flowers in the White Daisy. Amer. Naturalist, XXXII, 509511,2 figs.

Ludwig, F., '95. Ueber Variationskurven und Variationsflächen der Pflanzen. Bot. Centralbl., LXIV, 1-8 et folg, 2 Tafn.

Ludwig, F., '96. Weiteres über Fibonacci-Kourven und die numerische Variation der gesammten Rlüthenstände der Kompositen. Bot. Centralbl., LXVIII, 1 et folg., 1 Taf.

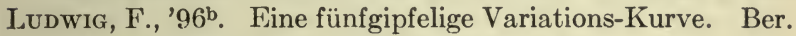
deutsch. bot. Ges., XIV, 204-207, 1 fig.

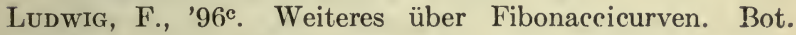

Centralbl., LXVIII, 1-8.

LudwiG, F., '97. Das Gesetz der Variabilität der Zahl der Zungenblüthen von Chrysanthemum leucanthemum. Mitth. des Thür. bot. Vereins, N. F., X, 20-22.

Ludwig, F., '97'b Beiträge zur Phytarithmetik. Bot. Centralbl., LXXI, 257-265.

Ludwig, F., '97c. Nachträgliche Bemerkungen über die Multipla der Fibonaccizahlen und die Coëxistenz kleiner Bewegungen hei der Variation der Pflanzen. Bot. Centralbl., LXXI, 2\$9-291.

Ludwig, F., '97'. Variationskurven von Lotus, Trifolium, Medicago. Deutsch. botan. Monatsschrift, Heft 11, 294296, Nov.

Ludwig, F., '98. Die pflanzlichen Variationscurven und die Gauss'sche Wahrscheinlichkeitscurve. Bot. Centralbl., LXXIII, 241-250 et folg., 1 Taf.

Lunwig, F., '98 ${ }^{\text {b. }}$ Ueber Variationscurven. Bot. Centralbl., LXXV, 97-107; 178-183, 1 Taf. July 29, Aug. 10.

Ludwig, F., '99. Ein fundamentaler Unterschied in der Variation bei Tier und Pflanze. Botanisch Jaarboek, XI, 103-121. 
Ludwig, F., '00. Ueber neuere Ergebnisse der VariationsStatistik. 39. bis 42. Jahresber. Ges. von Freunden der Naturwiss. in Gera (Reus3). 1896-1899. 22 pp.

LUDwiG, F., ' $00^{\text {b }}$. Ueber Variationspolygone und Wahrscheinlichkeitscurven Bot. Centralbl. Beiheft, IX, $24 \mathrm{pp}$.

Ludwig, F., '01. Variationsstatistische Probleme und Materialien. Biom., I, 11-29, Oct.

Ludwig, F., '03. Neuere Literatur über das Grenzgebiet der Biometrie. Zeitschr. f. Mathematik u. Physik, XLIX, 269-277.

Lutz, F. F., '00. A Study of the Variation in the Number of Grooves upon the Shells of Pecten irradians Lam. Science, N. F., XII, 372.

Lutz, Frank E., '03. Note on the Influence of Change in Sex on the Intensity of Heredity. Biom., II, 237-240, Feb.

Macdonell, W. R., '02. On Criminal Anthropometry and the Identification of Criminals. Biom., I, 177-227, Jan. Macdonell, W. R., ' $02^{\mathrm{b}}$. On the Influence of Previous Vaccination in Cases of Smallpox. Biom., I, 375-383, April.

Macdonell, W. R., '03. A Further Study of Statistics relating to Vaccination and Smallpox. Biom., II, 135144, Feb.

MacLeod, J., '98. Over de correlatie tusschen lengte en breedte van licht- en schaduwbladen bij den groenen en den bruinen beuk. Handl II. Vlaamsch Natuur- en Geneesk. Congres, Gent, pp. 29-41.

MacLeod, J., '98. Over correlatieve variatie bij de Rogge en de Gerst. Handl. II, Vlaamsch Natuur-en Geneesk. Congres, Gent, pp. 42-56.

MacLeod, Julius, '99. Over de correlatie tusschen het aantal meeldraden en het aantal stampers bij het Speenkruid (Ficaria ranunculoides). Botan. Jaarboek, XI, 91-107.

MACLEOD, J., '00. Over de veranderlijkheid van het aantal Stempelstralen bij Papaver. Handl. IV, Vlaamsch Natuur-en Geneesk. Congres. Brussel, 30 Sept. II, pp. 11, 12. 
Mayer, A. G. '01. The Variations of a newly-arisen Species of Medusa. Science Bulletin, Museum Brooklyn Inst. Arts and Sci., I, 1-22, 2 pls., April.

Mayer, A. G., '02. Effects of Natural Selection and Race Tendency upon the Color-patterns of Lepidoptera. Science Bulletin, Museum Brooklyn Inst. Arts and Sciences, I, 31-86, Pls. I, II, Oct.

Mendel, G., '66. Versuche über Pflanzen-Hybriden. Verhandlungen des Naturforscher-Vereines, Brünn, IV, $47 \mathrm{pp}$.

Moenkhaus, W. J., '96. The Variation of Etheostoma caprodes Rafinesque in Turkey Lake and Tippecanoe Lake.

Proc. Indiana Acad. Sci., V, 278-296.

Pearl, R.. '03. On the Mortality Due to Congenital Malformations, with Especial Reference to the Problem of the Relative Variability of the Sexes. Medicine, Nov. Pearl, Raymond, and Frances J. Dunbar, '03. Variation and Correlation in Arcella. Biom., II, 321-337, June. Pearson, K., '94 Contributions to the Mathematical Theory of Evolution. [I. On the Dissection of Frequency Curves.] Phil. Trans. Roy. Soc. London, CIXXXV, A, 71-110, Pls. 1-5.

Pearson, K., '95. Contributions, etc., II. Skew Variation in Homogeneous Material Phil Trans. Roy. Soc. London, CLXXXVI, A, 343-414, 10 Pls.

Pearson, K., '96. Mathematical Contributions to the Theory of Evolution, III. Regression, Heredity, and Panmixia. Phil. Trans. Roy. Soc. London, CLXXXVII, A, 253318

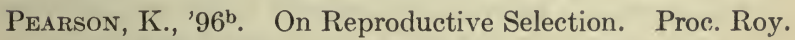
Soc., IIX, 301.

Pearson, K., and Alice Lee, '96c. Mathematical Contributions to the Theory of Evolution. On Telegony in Man, etc. Proc. Roy. Soc., LX, 273-2£3.

Pearson, K., '97. Mathematical Contributions, etc. On a Form of Spurious Correlation, which may Arise when Indices are used in the Measurement of Organs. Proc. Roy. Soc. London, LX, 4£9-498

Pearson, K., '97 b On the Scientific Measure of Variability.

Nat, Science., XI, 115-118. 
Pearson, K., '97c. The Chances of Death and Other Studies in Evolution. 2 vols., London

Pearson, K., '98. Mathematical Contributions, etc. On the Law of Ancestral Heredity. Proc. Roy. Soc. London LXII, 386-412.

Pearson, K., and L. N. G. Filon, '99. Mathematical Contributions etc., IV. On the Probable Errors of Frequency Constants and on the Influence of Random Selection on Variation and Correlation. Phil Trans Roy. Soc. London, CXCI, A, 229-311

Pearson, K., '98 ${ }^{\mathrm{b}}$. Mathematical Contributions, etc, V On the Reconstruction of the Stature of Prehistoric Races. Phil Trans., A. CXCII, 169-244, Dec 30, '98.

Pearson K., '99. Data for the Problem of Evolution in Man, III. On the Magnitude of Certain Coefficients of Correlation in Man, etc. Proc. Roy Soc.: IXVI, 23-32.

Pearson, K., '99b. Data, etc., IV. Note on the Effect of Fertility Depending on Homogamy. Proc. Roy. Soc, LXVI, 316-323, May 12, '00.

Pearson, K., Alice Lee, and L. Bramley Moore, '99. Mathematical Contributions, etc., VI. Genetic (Reproductive) Selection: Inheritance of Fertility in Man, and of Fecundity in Thorough-bred Race-horses. Phil. Trans., A. CXCII 257-330, Mar 29, '99.

Pearson, K., '00. The Grammar of Science. 2d Edition. London: A. \& C. Black.

Pearson, K., '00 ${ }^{\mathrm{b}}$. On the Criterion that a Given System of Deviations from the Probable in the Case of a Correlated System of Variables is such that it can be reasonably supposed to have arisen from Random Sampling Philosoph. Mag., 157-174, July.

Pearson, K., '00. Mathematical Contributions, etc., VII. On the Correlation of Characters not Quantitatively Measurable. Phil. Trans., A. CXCV, 1-47. Aug. 16.

Pearson, K., and Alice Lee, '00. Mathematical Contributions, etc., VIII. On the Inheritance of Characters not Capable of Exact Quantitative Measurement. Phil. Trans., A. CXCV, 79-150, Oct. 29. 
Pearson, K., '01. On some Applications of the Theory of Chance to Racial Differentiation. Philosophical Mag., 110-124, Jan., '01.

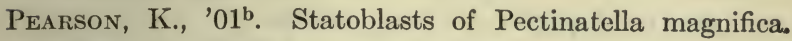
Biom., I, 128, Oct.

Pearson, K., [and others,] '01 ${ }^{\mathrm{c}}$. Mathematical Contributions, etc., IX. On the Principle of Homotyposis and its Relation to Heredity, to the Variability of the Individual, and to that of the Race. Phil. Trans., A. CXCVII, 285-379 Dec. 12.

Pearson, K., '01 ${ }^{\text {d. }}$ Mathematical Contributions, etc., X.

Supplement to a Memoir on Skew Variation. Phil.

Trans., A. CXCVII, 443-459, Dec. 29.

Pearson, K., '01'. On the Inheritance of the Mental Characters of Man. Proc. Roy. Soc., ILXIX, 153155.

Pearson, K., '02. On the Correlation of Intellectual Ability with the Size and Shape of the Head. Proc. Roy. Soc., LXIX, 333-342.

Pearson, K., '02 ${ }^{\mathrm{b}}$. Variation of the Egg of the Sparrow (Passer domesticus). Biom., I, 256-257, Jan.

Pearson, K., '02c. On the Modal Value of an Organ or Character. Biom., I, 260-261, Jan.

Pearson, K., '02d - On the Change in Expectation of Life in Man during a period of circa 2000 years. Biom., I, 261-264, Jan.

Pearson, K., '02e. Mathematical Contributions, etc. On Homotyposis in Homologous but Differentiated Organs Proc. Roy. Soc., LXXI, 288-313.

Pearson, K., '02'. On the Mathematical Theory of Errors of Judgment, with Special Reference to the Personal Equation. Phil. Trans., A. CXCVIII, 235-299, Mar 14.

Pearson, K., '02 ${ }^{\mathrm{g}}$. On the Systematic Fitting of Curves to Observations and Measurements. Biom., I, 265-303, April.

Pearson, K., ' $02^{\mathrm{h}}$. On the Sources of Apparent Polymorphism in Plants. Biom., I, 304-306, April.

Pearson, K., '02i. On the Fundamental Conceptions of Biology. Biom., I, 320-344, April. 
Pearson, K., '02k . Notes on Francis Galton's Problem. Biom., I, 390-399, Aug.

Pearson, K., '021. Note on Dr. Simpson's Memoir on Paramoecium caudatum. Biom., I, 404-407, Aug.

Pearson, K., '02 ${ }^{\mathrm{m}}$. On the Systematic Fitting of Curves to

Observations and Measurements. Biom., II, 1-23, Nov.

Pearson, K., '02n. Mathematical Contributions, etc., XI. On the Influence of Natural Selection on the Variability and Correlation of Organs. Phil. Trans., A. CC, 1-66, Dec. 21, '02.

Pearson, K., [and others,] '03. Cooperative Investigations on Plants. I. On Inheritance in the Shirlcy Poppy. Biom., II, 56-100, Nov. II. Variation and Correlation in Lesser Celandine from Diverse Localities. Biom., II, 145-164, Feb.

Pearson, K., '03 ${ }^{\text {b }}$ The Law of Ancestral Heredity. Biom., II, 211-228, Feb.

Pearson, K., '03'. On the Probable Errors of Frequency Constants. Biom., II, 273-281, June.

Pearson, K., '03 d. Craniological Notes. I. Professor Aurel von Török's Attack on the Arithmetical Mean. Biom., II, 339-345. II. Homogeneity and Heterogeneity in Collections of Crania. Biom., II, 345-347, June.

Pearson, K., and G. U. Yule, '02. Variation in Rayflowers of Chrysanthemum leucanthemum, 1133 heads gathered at Keswick during July, '95. Biom., I, 319, April.

Porter, W. T., '94. The Growth of St. Louis Children. Trans. Acad. Science, St. Louis, VI, 279.

Powys, A. O., '01. Data for the Problem of Evolution in Man. Anthropometric Data from Australia. Biom., I, 30-49, Oct.

REDEKe, H. C., '02. Variationsstatistische Untersuchungen über Fischrassen. Zool. Centralbl., IX, 645-670.

Reinöhl, F., '03. Die Variation im Andröceum der Stellaria media Cyr. Bot. Zeitung, LXI.

Rorlet, E., '89. De la mensuration des Os Longs des membres. Lyons. 
Saunders, E. R., '97. On a Discontinuous Variation Occurring in Biscutella lævigata. Proc. Roy. Soc., LXII, $11-26$.

Schröter, C., and P. Vogler, '01. Variationsstatistische Untersuchungen über Fragilaria crotonensis (Edw.) Kitton im Plankton des Zürichsees in den Jahren 18961901. Vieteljahrsschrift der Naturf. Gesellsch. Zürich, XLVI, 1ᄃ5-206.

Schuster, E. H. J., '03. Variation in "Eupagurus prideauxi" (Heller). Biom., II, 191-210, Feb.

Sheppard, W. F., '98. On the Application of the Theory of Error to Cases of Normal Distribution and Normal Correlation. Phil. Trans., A. CXCII, 101-167, Dec. 15.

Sheppard, W. F., '98'. On the Calculation of the Most Probable Values of the Frequency-constants for Data arranged according to Equidistant Divisions of a Scale. Proc. London Mathematical Soc., XXIX, 353-380, March 10.

Sheppard, W. F., '03. New Tables of the Probability Integral. Biom., II, 174-190, Feb.

Shull, G. H., '02. A Quantitative Study of Variation in the Bracts, Rays, and Disk Florets of Aster shortii Hook. A. novæ-angleæ L., A. puniceus L., and A. prenanthoides Muhl., from Yellow Springs, Ohio. Amer. Nat., XXXVI, 111-152.

Simpson, J. Y., '02. The Relation of Binary Fission to Variation. Biom., I, 400-404, Aug.

Smallwood, Mabel E., '03. The Beach Flea: Talorchestia longicornis. Cold Spring Harbor Monographs, I, 27 pp., 3 pls.

Sмith, Geofrrey, '03. Actinosphærium eichorni. A Biometrical Study in the Mass Relations of Nucleus and Cytoplasm. Biom., II, 241-254, June.

Strong, R. M., '01. A Quantitative Study of Variation in the Smaller North-American Shrikes. Amer. Nat., XXXV, 271-293, April.

Thомpson, H., '94. On Correlations of Certain External Parts of Palcemon serratus. Proc. Roy. Soc. London. LV, 234-240. 
Tower, W. L., '02. Variation in the Ray-flowers of Chrysanthemum leucanthemum L. at Yellow Springs, Green Co., O., with remarks upon the Determination of Modes. Biom., I, 309-315, April.

Verschaffelt, E., '04. Ueber graduelle Variabilität von pflanzlichen Eigenschaften. Ber. d. deutsch. bot. Ges., XII, 350-355.

Verschaffelt, E., '95. Ueber Asymmetrische Variationskurven. Ber. d. deutsch. bot. Ges., XIII, 34S-356, 1 Taf. Verschaffelt, E., '99. Galton's Regression to Mediocrity bij ongeslachtelijke verplanting. Livre jubilaire dédié à Charles Van Bambeke. (Bruxelles: H. Lamerton.) pp. 1-5.

Vogler, P., '01. Ueber die Variationskurven von Primula farinosa L. Vierteljahrsschrift der Naturf. Gesellsch. Zürich, XLVI, 264-274.

Vogler, P., '03. Variationskurven bei Pflanzen mit tetrameren Blüten. Vieteljahrsschr. d. Naturf. Gesellsch. Zürich, XLVII, 429-436, April 11.

Voris, J. H., '99. Material for the Study of the Variation of Pomephales notatus (Raf.) in Turkey Lake and in Shoe, and Tippecanoe Lakes. Proc. Indiana Acad. of Sci., 233-239.

Volterra, V., '01. Sui tentativi di applicazione delle matematiche alle scienze biologiche e sociali. Discorso letto 1 per la solenne inaugurazione dell' anno scolastico '01'02 nella R. Università di Roma. Roma, 26 pp.

Warren, E., '96. Variation in Portunus depurator. Proc. Roy. Soc. London, LX, 221-243.

WARREN, E., '97 An Investigation on the Variability of the Human Skeleton with Especial Reference to the Naquada Race. Phil. Trans. Roy. Soc. London, CLXXXIX, B. 135-227, PI. 22.

Warren, E., '99. An Observation on Inheritance in Parthenogenesis. Proc. Roy. Soc., LXV, 154-158.

Warren, ERnest, '02. Variation and inheritance in the Parthenogenetic Generations of the Aphis "Hyalopterus triphodus" (Walker). Biom., I, 129-154, Jan.

Warren, Ernest, '03. A Preliminary Attempt to Ascertain the Relationship between the Size of Cell and the 
Size of Body in Daphnia Magna Straus. Biom., II, 255-259, June.

Wasteeris, C. E., '99. Over de Fibonaccigetallen. Handelengen van het derde Vlaamsch Natuur-en Geneeskundig Congres geh. te Antwerpen d. 24 Sept., '99, pp. 25-37. Wasteels, C. E., '00. De Variatiecurven met betrekbing tot de polynomiale Waarschijnlijk heidswet. Handl. IV, Vlaamsch Natuur-en Geneesk. Congres. Brussel., pp. $33-45$.

Weldon, W. F. R., '90. The Variations occurring in Certain

Decapod Crustacea, I. Crangon vulgaris. Proc. Roy.

Soc. London, XLVII, 445-453.

Weldon, W. F. R., '92. Certain Correlated Variations in

Crangon vulgaris. Proc. Roy. Soc. London, LI, 2-21.

Weldon, W. F. R., '92b. Palæmonetes varians in Plymouth.

Jour. Marine Biol. Assoc., U. K. N. S., I, 459-461.

WeLdon, W. F. R., '93. On Certain Correlated Variations

in Carcinus monas. Proc. Roy. Soc. London, LIV, 318-329.

Weldon, W. F. R., '95. Report of the Committee for Conducting Statistical Inquiries into the measurable Characteristics of Plants and Animals. Part I. An Attempt to Measure the Death-rate due to Selective Destruction of Carcinus manas with respect to a Particular Dimension. Proc. Roy. Soc. London, LVII, 360-379.

Weldon, W. F. R., '01. A First Study of Natural Selection in Clausilia laminata (Montagu). Biom., I, 109-124, Oct.

Weldon, W. F. R., '01. Change in Organic Correlation of Ficaria ranunculoides during the Flowering Season. Biom. I, 125-128, Oct.

Weldon, W. F. R., '02. Mendel's Laws of Alternative Inheritance in Peas. Biom., I, 228-254, Jan.

Weldon, W. F. R., '02b. Professor De Vries On the Origin of Species. Biom., I. 365-374, April.

Weldon, W. F. R., '02. ${ }^{\text {e }}$ On the Ambiguity of Mendel's Categories. Biom., II, 44-55, Nov.

WeLdon, W. F. R., '02 ${ }^{d}$. Seasonal Change in the Characters of Aster prenanthoides Muhl. Biom., II, 113, 114, Nov. 
Weldon, W. F. R., '03. Mr. Bateson's Revisions of Mendel's

Theory of Heredity. Biom., II, 286-298, June.

Whitehead, Henry, '02. Variation in the Moscatel

(Adoxa moschatellina L.) Biom., II, 108-113, Nov.

Whiteley, M. A., and K. Pearson, '99. Data for the

Problem of Evolution in Man, I. A First Study of the

Variability and Correlation of the Hand. Proc. Roy.

Soc., LXV, 126-151.

Wilcox, E. M., '02. Numerical Variation of the Rayflowers of Compositæ. Bot. Gazette, XXXIII, 463465 , June.

Williams, S. R., '03. Variation in Lithobius forficatlis. Amer. Nat., XXXVII, 299-312.

Williamson, H. C., '00. On the Mackerel of the East and

-West Coasts of Scotland. Report Scottish Fisheries Board, XVIII, 294-329.

Woods, Frederick Adans, '03. Mendel's Laws and Some

Records in Rabbit Breeding. Biom, II, 299-306, June.

YeRKes, R. M., '01. A Study of Variation in the Fiddlercrab, Gelasimus pugilator Latr. Proc. Amer. Acad. Arts and Sciences, XXXVI, 417-442. March, 1901.

Yost, L., '99. Ueber Blüten-Anomalien bei Linaria spuria.

Biol. Centralbl., XIX, 145-153, 185-195, March, 1, 15.

Yule, G. U., '97. On the Significance of Bravais' Formulæ

for Regression, etc. Proc. Roy. Soc., LX, 477-489.

Yule, G. U., '97b. On the Theory of Correlation. Jour. Roy. Statistical Society, LX, 1-44, Dec.

Yule, G. U., '00. On the Association of Attributes in Statistics, with Examples from the Material of the Childhood Society, etc. Proc. Roy. Soc., LXVI, 22-23, Feb. 4, 1900.

Yule, G. U., ' $00^{\mathrm{b}}$. On the Association of Attributes in Statistics: with Illustrations from the Material of the Childhood Society, etc. Phil. Trans., A. CXCIV, 257-319.

Yule, G. U., '02. Variation of the Number of Sepals in Anemone nemorosa, Biom., I, 307-309, April.

Yule, G. U., '02b. Local Death Rates. Biom., I, 384, April. Yule, G. Udny, '03. Notes on the Theory of Association of Attributes in Statistics. Biom., II, 123-134, Feb. 


\section{EXPLANATION OF TABLES.}

I. Formulas. In this table the principal formulas used in the calculation of curves are brought together for convenient reference. The meanings of the letters are explained in the text. This table is preceded by an index to the principal letters used in the formulæ of this book.

\section{Certain constants and their logarithms.} This table includes the constants most frequently employed in the calculations of this book.

III. Table of ordinates of normal curve. Th's table is for comparison of a normal frequency polygon consisting of weighted or dinates with the theoretical curve.

Example: $A=17.673 ; \quad \sigma=1.117 ; \quad y_{0}=181.4$.

(See page 26.)

$\begin{array}{rrrrcrr}V & V-M & \frac{V-M}{\sigma} & \begin{array}{c}\text { Entries in Table } \\ \text { corresponding to } \\ \frac{V-M}{\sigma}\end{array} & y_{0} & y & \boldsymbol{t} \\ 14 & -3.673 & 3.29 & .00449 & \times 181.4= & & \\ 15 & -2.673 & 2.39 & .05750 & \times 181.4=10.4 & 1 \\ 16 & -1.673 & 1.50 & .32465 & \times 181.4=58.9 & 63\end{array}$

IV. Table of values of probability integral. This table is for comparison of a normal frequency polygon consisting of rectangles with the theoretical curve.

Example: $A=17.673 ; \sigma=1.1169$. (See page 26.)

\begin{tabular}{rrrrrrc} 
Class. & \multicolumn{1}{c}{$\frac{x}{\sigma}$} & $\begin{array}{c}\text { Per } \\
\text { cent. }\end{array}$ & $\begin{array}{c}\text { Class } \\
\text { Limits. }\end{array}$ & $\begin{array}{c}\text { Deviation } \\
\text { from } \\
A=x_{1}\end{array}$ & \multicolumn{1}{c}{$\frac{x_{1}}{\sigma}$} & $\begin{array}{c}\left(\frac{1}{2}-\frac{1}{2} a\right) \times 100 \\
\text { less } \sum_{x_{1}}^{\infty} \div \sigma\end{array}$ \\
14 & -3.29 & .2 & 14.5 & -3.173 & -2.841 & .225 \\
15 & -2.39 & 1.6 & 15.5 & -2.173 & -1.945 & 2.364 \\
16 & -1.50 & 12.4 & 16.5 & -1.173 & -1.050 & 12.097 \\
17 & -.60 & 30.3 & 17.5 & -0.173 & -0.155 & 29.155 \\
18 & .29 & 32.3 & 18.5 & 0.827 & 0.740 & 33.194 \\
19 & 1.19 & 18.9 & 19.5 & 1.827 & 1.636 & 17.873 \\
20 & 2.08 & 3.9 & 20.5 & 2.827 & 2.531 & 4.524 \\
21 & 2.98 & 0.4 & & & & .568 \\
& & 100.0 & & & & 100.000
\end{tabular}


In the example, the data of which are given on p. 26, the frequency between the limits is given in $\%$ column. The $\frac{x}{\sigma}$ of each limit (as an inner class limit) is found and the entries in Table IV corresponding to the limits are taken. Each such entry is subtracted from 0,50000 , is multiplied by 100 , and from the product is subtracted the total theoretical percentage of variates lying between the outer limit of the class and the corresponding extremity of the half curve. This gives the theoretical frequency of the class in question. The closeness of agreement of the last column with the "Per cent." column indicates the closeness of the observed frequency to the theoretical.

V. Table of $\log \Gamma$ functions of $p$. This table will enable one to solve the equations for $y_{0}$ given on page 32 . The table gives the logarithms of the values of $\Gamma$ functions only within the range $p=1$ to 2 . As all values of the function within these limits are less than 1 , the mantissa of the logarithms is -1 ; but it is given in the table as $10-1=9$, as is usually done in logarithmic tables.

Supposing the quantity of which we wish to find the value reduced to the form $\Gamma(4.273)$. The value cannot be found directly because the value of $p$ is larger than the numbers in the table (1 to 2$)$. The solution is made by aid of the equation $\Gamma(p+1)=p \Gamma(p)$, thus:

$$
\begin{aligned}
& \log \Gamma(1.273)=9.955185 \\
& \log 1.273=0.104828 \\
& \log \Gamma(2.273)=\overline{0.060013} \\
& \log 2.273=0.356599 \\
& \log \Gamma(3.273)=\overline{0.416612} \\
& \log 3.273=0.514946 \\
& \log \Gamma(4.273)=\overline{0.931558}
\end{aligned}
$$

or, more briefly, $\quad \log \Gamma(1.273)=9.955185$

$$
\begin{aligned}
& \log 1.273=.104828 \\
& \log 2.273=.356599 \\
& \log 3.273=.514946 \\
& \log \Gamma(4.273)=\overline{0.931558}=\log 8.542
\end{aligned}
$$




\section{Table of reduction from the common to} the metric system. This is given first for whole inches from 1 to 99 excepting even tens, which may be got from the first line of figures by shifting the decimal point one place to the right. The table may be used for hundredths of an inch by shifting the decimal point two places to the left. Other fractious than decimals are given in the lower tables.

VII. Table of minutes and seconds of arc in decimals of a degree. This table will be found of use in the fitting of curves of Type IV (p. 33).

VIII. First to sixth powers of integers from 1 to 30. This table is useful in calculating moments.

IX. Table of the probable errors of the coefficient of correlation for various numbers of observations or variates $(n)$ and for various values of $r$. The probable error of the coefficient of correlation being $\frac{0.6745\left(1-r^{2}\right)}{\sqrt{n}}$, a table for the varying values of $n$ and $r$ is easily constructed, and for large values of $n$ is accurate with interpolation by inspection to two significant figures, which are all that are required.

$\mathrm{X}$. Squares, cubes, square roots, and reciprocals of numbers from 1 to 1054. The use of this table can be extended by using the principle that if any number be multiplied by $n$, its square is multiplied by $n^{2}$, its cube by $n^{3}$, and its reciprocal by $\frac{1}{n}$.

XI. Logarithms of numbers to six places. The following explanation of the use of the logarithmic tables is taken from Searles' ${ }^{\prime}$ Field Engineering, pp. 257-263 [ed. 1887].

The logarithm of a number consists of two parts, a whole number, called the characteristic, and a decimal, called the mantissa. All numbers which consist of the same figures standing in the same order have the same mantissa, regardless of the position of the decimal point in the number, or of the number of ciphers which precede or follow the significant figures of the number. The value of the characteristic depends entirely on the position of the decimal point 
in the number. It is always one less than the number of figures in the number to the left of the decimal point. The value is therefore diminishcd by one every time the decimal point of the number is removed one place to the left, and vice versa. Thus

Number.
13840.
1384.0
138.40
13.84
1.384
.1384
.01384
.001384
etc.

Logarithm.

4.141136

3.141136

2.141136

1.141136

0.141136

$-1.141136$

$-2.141136$

$-3.141136$

etc.

The mantissa is always positive even when the characteristic is negative. We may avoid the use of a negative characteristic by arbitrarily adding 10 , which may be neglected at the closf of the calculation. By this rule we have

Number.
1.384
.1384
.01384
.001384
etc.

Logarithm.

0.141136

9.141136

8.141136

7.141136

etc.

No confusion need arise from this method in finding a number from its logarithm; for although the logarithm 6.141136 represents either the number $1,384,000$, or the decimal .0001384 , yet these are so diverse in their values that we can never be uncertain in a given problem which to adopt.

TA B L XI, contains the mantissas of logarithms, carried to six places of decimals, for numbers between 1 and 9999 , inclusive. The first three figures of a-number are given in the first column, the fourth at the top of the other columns. The first two figures of the mantissa are given only in the second column, but these are understood to apply to the remaining four figures in either column following, which are comprised between the same horizontal lines with the two.

If a number (after cutting off the ciphers at either end) consists of not more than four figures, the mantissa may be taken direct from the table; but by interpolation the logarithm of a number having six figures may be obtained. The last column contains the average difference of consecutive logarithms on 
the same line, but for a given case the difference needs to be verified by actual subtraction, at least so far as the last figure is concerned. The lower part of the page contains a complete list of differences, with their multiples divided by 10 .

To find the logarithm of a number having six figures:-Take out the mantissa for the four superior places directly from the table, and find the difference between this mantissa and the next greater in the table. Add to the mantissa taken out the quantity found in the table of proportional parts, opposite the difference, and in the column headed by the fifth figure of the number; also add $\frac{1}{10}$ the quantity in the column headed by the sixth figure. The sum is the mantissa required, to which must be prefixed a decimal point and the proper characteristic.

Example.-Find the log of 23.4275 .

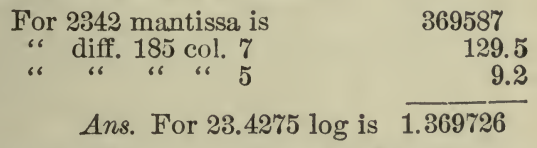

The decimals of the corrections are added together to determine the nearest value of the sixth figure of the mantissa.

\section{To find the number corresponding to a given} logarithm. - If the given mantissa is not in the table find the one next less, and take out the four figures corresponding to it; divide the difference between the two mantissas by the tabular difference in that part of the table, and annex the figures of the quotient to the four figures already taken out. Finally, place the decimal point according to the rule for characteristics, prefixing or annexing ciphers if necessary. The division required is facilitated by the table of proportional parts, which furnishes by inspection the figures of the quotient.

Example.-Find the number of whish the logarithm is 8.263927

First 4 figures 1836 from

$8: 263927$

263873

\begin{tabular}{|c|c|c|}
\hline \multirow{2}{*}{ Tabular diff. $=236$} & & \\
\hline & $\begin{array}{r}\text { Diff. } \\
\therefore \text { 5th fig. }=2\end{array}$ & $\begin{array}{l}54.0 \\
47.2\end{array}$ \\
\hline & 6th fig. $=3$ & $\begin{array}{r}6.80 \\
7.08 \\
\end{array}$ \\
\hline
\end{tabular}

Ans. No. $=.0183623$ or $183,623,000$. 
The number derived from a six-place logarithm is not reliable beyond the sixth figure.

At the end of Table XI is a small table of logarithms of numbers from 1 to 100 , with the characteristic prefixed, for easy reference when the given number does not exceed two digits. But the same mantissas may be found in the larger table.

TABLE XII.-The logarithmic sine, tangent, etc., of an arc is the logarithm of the natural sine, tangent, etc., of the same arc, but with 10 added to the characteristic to avoid negatives. This table gives log sines, tangents, cosines, and cotangents for every minute of the quadrant. With the number of degrees at the left side of the page are to be read the minutes in the left-hand column; with the degrees on the right-hand side are to be read the minutes in the right-hand column. When the degrees appear at the top of the page the top headings must be observed, when at the bottom those at the bottom. Since the values found for ares in the first quadrant are duplicated in the second, the degrees are given from $0^{\circ}$ to $180^{\circ}$. The differences in the logarithms due to a change of one second in the arc are given in adjoining columns.

To find the log.sin, cos, tan, or cot of a given arc.: Take out from the proper column of the table the logarithm corresponding to the given number of degrees and minutes. If there be any seconds multiply them by the adjoining tabular difference, and apply their product as a correction to the logarithm already taken out. The correction is to be added if the logarithms of the table are increasing with the angle, or subtracted if they are decreasing as the angle increases. In the first quadrant the $\log$ sines and tangents increase, and the log. cosines and cotangents decrease as the angle increases.

Example.-Find the $\log \sin$ of $9^{\circ} 28^{\prime} 20^{\prime \prime}$.

$\log \sin$ of $9^{\circ} 28^{\prime}$ is

Add correction $20 \times 12.62$

9.216097

252

Ans. $\overline{9.216349}$

Froxample.-Find the $\log \cot$ of $9^{\circ} 28^{\prime} 20^{\prime \prime}$.

$\log \operatorname{cotan}$ of $9^{\circ} 28^{\prime}$ is

Subtract correction $20 \times 12.97$

10.777948

259

Ans. $\overline{10.777689}$ 
To find the angle or arc corresponding to a given logarithmic sine, tangent, cosine, or cotangent. - If the given logarithm is found in the proper column take out the degrees and minutes directly; if not, find the two consecutive logarithms between which the given logarithm would fall, and adopt that one which corresponds to the least number of minutes; which minutes take out with the degrees, and divide the difference between this logarithm and the given one by the adjoining tabular difference for a quotient, which will be the required number of seconds.

With logarithms to six places of decimals the quotient is not reliable beyond the tenth of a second.

Example. -9.383731 is the $\log$ tan of what angle?

Next less 9.383682 gives $13^{\circ} 36^{\prime}$

Diff.

$$
49.00 \div 9.20=
$$

$05^{\prime \prime} .3$

$$
\text { Ans. } \overline{13^{\circ} 36^{\prime} 05^{\prime \prime} .3}
$$

Example. -9.249348 is the log cos of what angle? Next greater 583 gives $79^{\circ} 46^{\prime}$

Diff.

$$
235 \div 11.67=
$$

Ans. $\overline{79^{\circ} 46^{\prime} 20^{\prime \prime} .1}$

The above rules do not apply to the first two pages of this table (except for the column headed cosine at top) because here the differences vary so rapidly that interpolation made by them in the usual way will not give exact results.

On the first two pages, the first column contains the number of seconds for every minute from $1^{\prime}$ to $2^{\circ}$; the minutes are given in the second, the log. sin. in the third, and in the fourth are the last three figures of a logarithm which is the difference between the log sin and the logarithm of the number of seconds in the first column. The first three figures and the characteristic of this logarithm are placed, once for all, at the head of the column.

To find the $\log \sin$ of an arc less than $2^{\circ}$ given to seconds. - Reduce the given arc to seconds, and take the logarithm of the number of seconds from the table of logarithms, and add to this the logarithm from the fourth column opposite the same number of seconds. The sum is the log sin required. 
The logarithm in the fourth column may need a slight interpolation of the last figure, to make it correspond closely to the given number of seconds.

Example.-Find the $\log \sin$ of $1^{\circ} 39^{\prime} 14^{\prime \prime} .4$.

$1^{\circ} 39^{\prime} 14^{\prime \prime} .4=5954^{\prime \prime} .4$

$$
\begin{aligned}
& \log 3.774838 \\
& \text { add }(q-l) 4.685515 \\
& \text { Ans. } \log \sin \overline{8.460353}
\end{aligned}
$$

Log tangents of small arcs are found in the same way, only taking the last four figures of $(q-l)$ from the fifth column.

Example.-Find the $\log \tan$ of $0^{\circ} 52^{\prime} 35^{\prime \prime}$.

$$
\begin{aligned}
& 52^{\prime} 35^{\prime \prime}=\left(3120^{\prime \prime}+35^{\prime \prime}\right)=3155^{\prime \prime} \quad \log 3.498999 \\
& \text { add }(q-i) \quad 4.685609 \\
& \text { Ans. } \log \tan \overline{8.184608}
\end{aligned}
$$

\section{To find the log cotangent of an angle less than} $\mathbf{2}^{\circ}$ given to seconds. - Take from the column headed $(q+\imath)$ the logarithm corresponding to the given angle, interpolating for the last figure if necessary, and from this subtract the logarithm of the number of seconds in the given angle.

Example.-Find the $\log \operatorname{cotan}$ of $1^{\circ} 44^{\prime} 22^{\prime \prime} .5$.

$$
6240^{\prime \prime}+22^{\prime \prime} .5=6262.5
$$

$$
\begin{array}{cr}
q+l & 15.314292 \\
\log & 3.796748 \\
\text { Ans. } & 11.517544
\end{array}
$$

These two pages may be used in the same way when the given angle lies between $88^{\circ}$ and $92^{\circ}$, or between $178^{\circ}$ and $180^{\circ}$; but if the number of degrees be found at the bottom of the page, the title of each column will be found there also; and if the number of degrees be found on the right hand side of the page, the number of minutes must be found in the right hand column, and since here the minutes increase upward, the number of seconds on the same line in the first column must be diminished by the odd seconds in the given angle to obtain the number whose logarithm is to be used with $(q \pm l)$ taken from the table.

Example.-Find the $\log \cos$ of $88^{\circ} 41^{\prime} 12^{\prime \prime} .5$

$$
4740^{n}-12^{n} .5=4727.5
$$$$
(q-\ell) 4.685537
$$$$
\log 3.674631
$$ 
Example.-Find the $\log \tan$ of $90^{\circ} 30^{\prime} 50^{\prime \prime}$.

$$
1800^{\prime \prime}+50^{\prime \prime}=1850^{\prime \prime}
$$

$q+l \quad 15.314413$

Ans. 12.047241

To find the arc corresponding to a given $\log$ sin, cos, tan, or cotan which falls within the limits of the first two pages of Table $x$.

Find in the proper column two consecutive logarithms between which the given logarithm falls. If the title of the given function is found at the top of that column read the degrees from the top of the page; if at the bottom read from the bottom.

Find the value of $(q-\imath)$ or $(q+\imath)$, as the case may require, corresponding to the given $\log$ (interpolating for the last figure if necessary). Then if $q=$ given $\log$ and $l=\log$ of number of seconds, $n$, in the required arc, we have at once $l=q-(q-l)$ or $l=(q+l)-q$, whence $n$ is easily found.

Find in the first column two consecutive quantities between which the number $n$ falls, and if the degrees are read from the left hand side of the page, adopt the less, take out the minutes from the second column, and take for the seconds the difference between the quantity adopted and the number n. But if the degrees are read from the right hand side of the page, adopt the greater quantity, take out the minutes on the same line from the right-hand column, and for the seconds take the difference between the number adopted and the number $n$.

Example. -11.734268 is the log cot of what arc?

$q+l$

$q$

$\therefore n=$

3802.8

Fo: $1^{\circ}$ adopt 3780 .

giving $03^{\prime}$
15.314376

11.734268

3.580108

\section{Difference $22^{\prime \prime} .8$}

Ans. $1^{\circ} 03^{\prime} 22^{\prime \prime} .8$ or $178^{\circ} 56^{\prime} 37^{\prime \prime} .2$.

Hxample. -8.201795 is the log cos of what arc?

$$
\begin{aligned}
& q-l \\
& q \\
& \therefore \quad n= \\
& \text { For } 89^{\circ} \text { adopt } \\
& 3282^{\prime \prime} .8 \\
& \text { 3300. giving } 05^{\prime} \\
& \text { Difference } \\
& 17^{\prime \prime} .2
\end{aligned}
$$

4.685556

8.201795

Ans. $89^{\circ} 05^{\prime} 17^{\prime \prime} .2$ or $90^{\circ} 54^{\prime} 42^{\prime \prime} .8$. 
THE GREEK ALPHABET.

$\begin{array}{llllll}A \alpha & \text { Alpha } & I \tau & \text { Iota } & P \rho \text { Rho } \\ B \beta & \text { Beta } & K \kappa & \text { Kappa } & \Sigma \sigma \varsigma \text { Sigma } \\ \Gamma \gamma \text { Gamma } & A \lambda \text { Lamba } & T \tau \text { Tau } \\ \Delta \delta \text { Delta } & M \mu & \mathrm{Mu} & \gamma v \text { Upsilon } \\ E \epsilon \text { Epsilon } & N \nu \text { Nu } & \Phi \phi \text { Phi } \\ Z \zeta \text { Zeta } & \Xi \xi & \mathrm{Xi} & X \chi & \mathrm{Chi} \\ H \eta \text { Eta } & O \sigma & \text { Omicron } & \Psi \psi \text { Psi } \\ \Theta \theta \vartheta & \text { Theta } & \Pi \pi \mathrm{Pi} & \Omega \omega \text { Omega }\end{array}$




\section{INDEX TO THE PRINCIPAL LETTERS USED IN THE}

\section{FORMULÆ OF THIS BOOK.}

$A$, average, mean.

$a$, class index (p. 24); also upper left-hand quadrant (p. 49).

$\alpha$, skewness index.

$b$, the frequency of the upper right quadrant (p. 49).

$\beta$, ratio of moments.

$C$, coefficient of variability.

$c$, the frequency of the lower left quadrant (p. 49).

$D$, distance from mean to mode.

$d$, a difference; differential; the frequency of lower right quadrant (p. 49).

$\Delta$, index of closeness of fit.

$\delta$, difference between $y$ and $f$.

$E$, probable error.

$e$, base of Naperian logarithms,

$\because=2.718282$.

$F$, critical function.

$f$, class frequency.

$G$, geometric mean.

$H$, a function of $h$.

$h$, a fixed value of $x$; also, index of heredity.

$I$, interval between the $p^{\prime}$ th and $p^{\prime \prime}$ th individual.

$i$, interval between the $p$ th and $(p+1)$ th individual (p. 27).

$K$, a function of $k$.

$k$, a fixed value of $x$.

$L$, limiting value of class.

$l$, range of curve along $x$.

$l_{1}, l_{2}$, portions of the curve range.

$\Lambda$, number of classes.

$\lambda$, class range.

$M$, abseissal value of the mode (theoretical).

$M^{\prime}$, abscissal value of the mode (empirical).

$\mu$, moment about $A$.

$N$, the number corresponding to a $\log$. $n$, number of variates; area of polygon; any, not specified, number.

$\underline{n}$, product of all integers from 1 to $n$.

$\nu$, average moment about $V_{0}$.

$\Xi$, index of dissymmetry. .

$P$, probability.

$p$, ordinal rank of a particular individual or case (p. 27); a root or power.

$\pi$, circumference in units of diameter, 3.14159 .

$q$, a root or power.

$r$, coefficient of correlation.

$\rho$, coefficient of regression.

$s$, a relation of $\beta$ 's (p. 22).

$\Sigma$, summation sign.

$\sigma$, standard deviation; index of variability.

$T$, transmuting factor, $a$ into $E$, .67449 .

$\tau$, in Type IV.

$\theta, \quad\}$ angles.

$V$, magnitude of any class.

$V_{0}$, magnitude of central class.

$v$, any variate or value.

$w=5 \beta_{2}-6 \beta_{1}-9$ (p. 31).

$X$, the horizontal axis or base of polygon.

$x$, a varying abscissal value.

$x_{1}, x_{2}$, etc., definite values of $x$.

$\chi, \frac{x}{a}$.

$Y$, the vertical axis of polygons;

also the $\log$ of $f$ (p. 29).

$y$, a varying ordinate value.

$y_{0}$, value of the ordinate at the origin.

$\boldsymbol{z}$, ordinate value. 


\section{FORMULAS.}

$$
\begin{aligned}
& A=\frac{\Sigma(V \cdot f)}{n}=V_{0}+\nu_{1} \text {. } \\
& E_{A}= \pm 0.5745 \frac{\sigma}{\sqrt{n}} \cdot \quad x=V-A \\
& \sigma=\sqrt{\frac{\sum\left(x^{2} \cdot f\right)}{n}}=\sqrt{\nu_{2}-\nu_{1}^{2}}=\sqrt{\overline{\mu_{2}}} . \quad E_{\sigma}=0.6745 \frac{\sigma}{\sqrt{2 n}} . \\
& C=\frac{o}{A} \times 100 \% \text {. } \\
& E_{c}=0.6745 \frac{C}{\sqrt{2 n}}\left[1+2\left(\frac{C}{100}\right)^{2}\right]^{\frac{1}{2}} . \\
& \text { A. D. }=\frac{\Sigma(x . f)}{n}=0.7979 \sigma . \\
& E_{\text {A. D. }}=0.6745 \text {. } \\
& \nu_{1}=\frac{\Sigma\left(V-V_{0}\right)}{n}=A-V_{0} . \\
& \nu_{2}=\frac{\Sigma\left(V-V_{0}\right)^{2}}{n} \text {. } \\
& \nu_{3}=\frac{\Sigma\left(V-V_{0}\right)^{3}}{n} \text {. } \\
& \nu_{4}=\frac{\Sigma\left(V-V_{0}\right)^{4}}{n} . \\
& \mu_{2}=\nu_{2}-\nu_{1}^{2}+\left\{\frac{1}{12}\right\}=\frac{\Sigma\left(x^{2} \cdot f\right)}{n}+\left\{\frac{1}{12}\right\} . \\
& \mu_{3}=\nu_{3}-3 \nu_{1} \nu_{2}+2 \nu_{1}^{3}=\frac{\sum\left(x^{3} \cdot f\right)}{n} \text {. } \\
& \mu_{4}=\nu_{4}-4 \nu_{1} \nu_{3}+6 \nu_{1}^{2} \nu_{2}-3 \nu_{1}^{4}+\left\{\frac{1}{2}\left(\nu_{2}-\nu_{1}^{2}\right)+\frac{7}{240}\right\}= \\
& =\frac{\Sigma\left(x^{4} \cdot f\right)}{n}+\left\{\frac{\Sigma\left(x^{2} \cdot f\right)}{2 n}+\frac{7}{240}\right\} \text {. } \\
& \beta_{1}=\frac{\mu_{3}^{2}}{\mu_{2}{ }^{3}} . \\
& \beta_{2}=\frac{\mu_{4}}{\mu_{2}^{2}} . \\
& s=\frac{6\left(\beta_{2}-\beta_{1}-1\right)}{3 \beta_{1}-2 \beta_{2}+6} \text {. } \\
& F=\frac{\beta_{1}\left(\beta_{2}+3\right)^{2}}{4\left(4 \beta_{2}-3 \beta_{1}\right)\left(2 \beta_{2}-3 \beta_{1}-6\right)^{\circ}} \\
& D=\sigma . A . \\
& \alpha=\frac{1}{2} \sqrt{\beta_{1}} \frac{8 \pm 2}{8 \mp 2} \text { (Types I, IV). } \\
& \alpha=\frac{2 \sqrt{p-3}}{p} \text { (Type V). } \\
& \text { Probable discrepancy, } \frac{0.6745 a}{\sqrt{n}}\left\{\frac{\pi}{2} \cdot \frac{\left(1-a^{2}\right)}{y^{2}}-\left(1+\frac{x^{2}}{2}\right)\right\}^{\frac{1}{2}} \text {. } \\
& r=\frac{\Sigma(\text { dev. } x \times \text { dev }, y \times f)}{n \cdot \sigma_{1}, \sigma_{2}}=\frac{\Sigma\left(x_{1} x_{2} f\right)}{n \sigma_{1} \sigma_{2}} . \quad E_{r}=\frac{0.6745\left(1-r^{2}\right)}{\sqrt{n}} .
\end{aligned}
$$

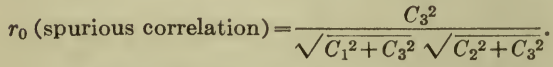

$$
\begin{aligned}
& h(\text { uniparental })=r \frac{\sigma_{1}}{\sigma_{2}} ; \quad h_{1}(\text { biparental })=r_{3} \frac{\sigma_{1}}{\sigma_{2}} h_{2}+r_{2} \frac{\sigma_{1}}{\sigma_{3}} h_{3} \text {. } \\
& E_{h}=\frac{6745 \sigma_{1}}{\sigma_{2}} \sqrt{\frac{1-r_{12}}{n}} \text {. }
\end{aligned}
$$

To solve any equation of the second degree,

$$
a x^{2}+b x+c=0 ; \quad x=\frac{-b \pm \sqrt{b^{2}-4 a c}}{2 a} .
$$


CERTAIN CONSTANTS AND THEIR LOGARITHMS. 117

II.-CERTAIN CONSTANTS AND THEIR LOGARITHMS.

\begin{tabular}{|c|c|c|c|}
\hline Title. & Symbol. & Number. & Log. \\
\hline Ratio of circumference to diamete & $\pi$ & 3.1415927 & 0.4971499 \\
\hline Reciprocal of same & $\frac{1}{\pi}$ & 0.3183099 & $9.502 £ \Sigma C 1$ \\
\hline Square root of same. & $\sqrt{\pi}$ & 1.7724538 & $0.248574 \varepsilon$ \\
\hline Reciprocal of square root of same & $\frac{1}{\sqrt{\pi}}$ & 0.5641896 & $9.751 \_2 E 1$ \\
\hline Square $\mathrm{rcot}$ of $2 \pi \ldots$ & $\sqrt{2 \pi}$ & 2.506628 & $0.3 \varepsilon 9090$ \\
\hline Reciprocal of same. & $\frac{1}{\sqrt{2 \pi}}$ & 0.3989422 & 9.6009101 \\
\hline Reciprocal of $2 \pi$. & $\frac{1}{2 \pi}$ & 0.159155 & 9.201820 \\
\hline Square root of $2 \ldots$ & $\sqrt{2}$ & 1.4142136 & 0.150515 \\
\hline Reciprocal of same . & $\frac{1}{\sqrt{2}}$ & 0.707105 & 9.8494849 \\
\hline Square root of $\frac{2}{\pi}$. & $\sqrt{\frac{2}{\pi}}$ & 0.797816 & 9.9019401 \\
\hline Base of hyperbolic logarithms. & $e$ & 2.7182818 & 0.4342945 \\
\hline Reciprocal of square root of same & $\frac{1}{\sqrt{e}}$ & 0.606530 & 9.7828528 \\
\hline Modulus of common system of $\log s=\log e$ & $m$ & 0.4342945 & 9.6377843 \\
\hline Reciprocal of same $=$ hyp $\cdot \log 10$ & $\frac{1}{m}$ & 2.3025851 & 0.3622157 \\
\hline Factor to reduce $\sigma$ to probable error. .... & $T$ & 0.67449 & 9.828976 \\
\hline $\begin{array}{l}\text { Com. } \log x=m \times \text { hyp. } \log x \text {, or } \\
\text { Com. } \log (\text { com. } \log x) \\
\quad=9.6377843+\text { com. } \log \text { (hyp. } \log x)\end{array}$ & & & \\
\hline Hyp. $\log x=$ com. $\log x \times \frac{1}{m}$, or & & & \\
\hline $\begin{aligned} \text { Com. } \log (\text { hyp. } \log x) \\
=\text { com. } \log (\operatorname{com} . \log ) x+0.3622157\end{aligned}$ & & & \\
\hline Circumference of circle...$\ldots$. & $2 \pi r$ & & \\
\hline Area of circle.$\ldots \ldots \ldots \ldots \ldots$ & $\begin{array}{l}\pi r^{2} \\
1 / 6 l r\end{array}$ & & \\
\hline $\begin{array}{l}\text { Area of sector (length of arc }=l \text { ). } \\
\text { Area of sector (angle of } \operatorname{arc}=a^{\circ} \text { ). }\end{array}$ & $\begin{array}{l}\frac{a}{360} \pi r^{2} \\
36 r\end{array}$ & & \\
\hline \multicolumn{4}{|c|}{$\begin{array}{c}\text { Eccentricity of an ellipse, } \varepsilon=\sqrt{\frac{a^{2}-b^{2}}{a^{2}}} \text {, where } a=\text { semi-major axis; } b= \\
\text { semi-minor axis of ellipse. }\end{array}$} \\
\hline
\end{tabular}


TABLE III.-TABLE OF ORDINATES $(z)$ OF NORMAL CURVE, OR VALUES OF $\frac{y}{y_{0}}$ CORRESFONDING TO VALUES OF $\frac{x}{a}$. $x=$ deviation from mean. $\quad y=$ frequency. $\sigma=$ standard deviation. $\quad y_{0}=\frac{n}{\sigma \sqrt{2 \pi}}=$ maximum frequency.

\begin{tabular}{|c|c|c|c|c|c|c|c|c|c|c|}
\hline$x / o$ & 0 & 1 & 2 & 3 & 4 & 5 & 6 & 7 & 8 & 9 \\
\hline $\begin{array}{l}0.0 \\
0.1 \\
0.2 \\
0.3 \\
0.4\end{array}$ & $\begin{array}{r}100000 \\
99501 \\
98020 \\
95600 \\
92312\end{array}$ & $\begin{array}{l}99995 \\
99396 \\
97819 \\
95309 \\
91939\end{array}$ & $\begin{array}{l}99980 \\
99283 \\
97609 \\
95010 \\
91558\end{array}$ & $\begin{array}{l}99955 \\
99158 \\
97390 \\
94702 \\
91169\end{array}$ & $\begin{array}{l}99920 \\
99025 \\
97161 \\
94387 \\
90774\end{array}$ & $\begin{array}{l}99875 \\
98881 \\
96923 \\
94055 \\
90371\end{array}$ & $\begin{array}{l}99820 \\
98728 \\
96676 \\
93723 \\
89961\end{array}$ & $\begin{array}{l}99755 \\
98565 \\
96420 \\
93382 \\
89543\end{array}$ & $\begin{array}{l}99685 \\
98393 \\
96156 \\
93034 \\
89119\end{array}$ & $\begin{array}{l}99596 \\
98211 \\
95882 \\
92677 \\
88688\end{array}$ \\
\hline $\begin{array}{l}0.5 \\
0.6 \\
0.7 \\
0.8 \\
0.9\end{array}$ & $\begin{array}{l}88250 \\
83527 \\
78270 \\
72615 \\
66698\end{array}$ & $\begin{array}{l}87805 \\
83023 \\
77721 \\
72033 \\
66097\end{array}$ & & $\begin{array}{l}86896 \\
82010 \\
76610 \\
70861 \\
64891\end{array}$ & $\begin{array}{l}86432 \\
81481 \\
76048 \\
70272 \\
64287\end{array}$ & $\begin{array}{l}85962 \\
80957 \\
75484 \\
69681 \\
63683\end{array}$ & $\begin{array}{l}85488 \\
80429 \\
74916 \\
69087 \\
63077\end{array}$ & $\begin{array}{r}85006 \\
79896 \\
74342 \\
748493 \\
62472\end{array}$ & $\begin{array}{l}84519 \\
79359 \\
73769 \\
67896 \\
61865\end{array}$ & $\begin{array}{l}84060 \\
78817 \\
73193 \\
67298 \\
61259\end{array}$ \\
\hline $\begin{array}{l}1.0 \\
1.1 \\
1.2 \\
1.3 \\
1.4\end{array}$ & $\begin{array}{l}60653 \\
54607 \\
48675 \\
42956 \\
37531\end{array}$ & $\begin{array}{l}60047 \\
54007 \\
48092 \\
42399 \\
37007\end{array}$ & $\begin{array}{l}59440 \\
53409 \\
47511 \\
41845 \\
36487\end{array}$ & $\begin{array}{l}58834 \\
52812 \\
46933 \\
41294 \\
35971\end{array}$ & $\begin{array}{l}58228 \\
52214 \\
46357 \\
40747 \\
35459\end{array}$ & $\begin{array}{l}57623 \\
51620 \\
45783 \\
40202 \\
34950\end{array}$ & $\begin{array}{l}57017 \\
51027 \\
45212 \\
39661 \\
34445\end{array}$ & $\begin{array}{l}56414 \\
50437 \\
44644 \\
39123 \\
33944\end{array}$ & $\begin{array}{l}55810 \\
49848 \\
44078 \\
38589 \\
33447\end{array}$ & $\begin{array}{l}55209 \\
49260 \\
43516 \\
38058 \\
32954\end{array}$ \\
\hline $\begin{array}{l}1.5 \\
1.6 \\
1.7 \\
1.8 \\
1.9\end{array}$ & $\begin{array}{l}32465 \\
27804 \\
23575 \\
19790 \\
16448\end{array}$ & $\begin{array}{l}31980 \\
27361 \\
23176 \\
1936 \\
16137\end{array}$ & $\begin{array}{l}31500 \\
26923 \\
22782 \\
19086 \\
15831\end{array}$ & $\begin{array}{l}31023 \\
26489 \\
22392 \\
18741 \\
15530\end{array}$ & $\begin{array}{l}30550 \\
26059 \\
22008 \\
18400 \\
15232\end{array}$ & $\begin{array}{l}30082 \\
25634 \\
21627 \\
18064 \\
14939\end{array}$ & $\begin{array}{l}29618 \\
25213 \\
21251 \\
17732 \\
14650\end{array}$ & $\begin{array}{l}29158 \\
24797 \\
20879 \\
17404 \\
14364\end{array}$ & $\begin{array}{l}28702 \\
24385 \\
20511 \\
17081 \\
14083\end{array}$ & $\left\{\begin{array}{l}28251 \\
23978 \\
20148 \\
16762 \\
13806\end{array}\right.$ \\
\hline $\begin{array}{l}2.0 \\
2.1 \\
2.2 \\
2.3 \\
2.4\end{array}$ & $\begin{array}{l}13534 \\
11025 \\
08892 \\
07100 \\
05614\end{array}$ & $\begin{array}{l}13265 \\
10795 \\
08698 \\
06939 \\
05481\end{array}$ & $\begin{array}{l}13000 \\
10570 \\
08507 \\
06780 \\
05350\end{array}$ & $\begin{array}{l}12740 \\
10347 \\
08320 \\
06624 \\
05222\end{array}$ & $\begin{array}{l}12483 \\
10129 \\
08136 \\
06471 \\
05096\end{array}$ & & $\begin{array}{l}11981 \\
09702 \\
07778 \\
06174 \\
04852\end{array}$ & $\begin{array}{l}11737 \\
09495 \\
07604 \\
06029 \\
04734\end{array}$ & $\begin{array}{l}11496 \\
09290 \\
07433 \\
05888 \\
04618\end{array}$ & $\begin{array}{l}11259 \\
09090 \\
07265 \\
305750 \\
04505\end{array}$ \\
\hline $\begin{array}{l}2.5 \\
2.6 \\
2.7 \\
2.8 \\
2.9\end{array}$ & $\begin{array}{l}04394 \\
03405 \\
02612 \\
01984 \\
01492\end{array}$ & $\begin{array}{l}03317 \\
02542 \\
01929 \\
01449\end{array}$ & 01408 & $\begin{array}{l}01823 \\
01367\end{array}$ & $\begin{array}{l}02343 \\
01772 \\
01328\end{array}$ & $\begin{array}{l}01723 \\
01289\end{array}$ & $\begin{array}{l}03775 \\
02908 \\
02218 \\
01674 \\
01252\end{array}$ & $\begin{array}{l}02157 \\
01627 \\
01215\end{array}$ & $\begin{array}{l}03586 \\
02757 \\
02098 \\
01581 \\
01179\end{array}$ & $\begin{array}{l}03494 \\
02684 \\
02040 \\
01536 \\
01145\end{array}$ \\
\hline $\begin{array}{l}3 \\
4 \\
5\end{array}$ & $\begin{array}{l}01111 \\
00034 \\
00000\end{array}$ & 02 & $\begin{array}{l}59 \\
01\end{array}$ & 00432 & 003 & $\begin{array}{l}00219 \\
00004\end{array}$ & $\begin{array}{l}00153 \\
00003\end{array}$ & $\begin{array}{l}00106 \\
00002\end{array}$ & $\begin{array}{l}00073 \\
00001\end{array}$ & $\begin{array}{l}00050 \\
00001\end{array}$ \\
\hline
\end{tabular}


VALUES OF NORMAL PROBABILITY INTEGRAL. 119

TABLE IV.-TABLE OF THE HALF CLASS INDEX ( $\left.\frac{1}{2} a\right)$ VALUES OF THE NORMAL PROBABILITY INTEGRAL CORRESPOND. ING TO VALUES OF $\frac{x}{\sigma}$; OR THE FRACTION OF THE AREA OF THE CURVE BETWEEN THE LIMITS 0 AND $+\frac{x}{\sigma}$, OR 0 AND $-\frac{x}{\sigma}$.

Total area of curve assumed to be 100,000 . $x=$ deviation from mean.

$\sigma=$ standard deviation.

\begin{tabular}{|c|c|c|c|c|c|c|c|c|c|c|c|}
\hline$x / \sigma$ & 0 & 1 & 2 & 3 & 4 & 5 & 6 & 7 & 8 & $\begin{array}{lll}9 & \end{array}$ & $\Delta$ \\
\hline 0.00 & 00 & & 80 & 120 & 159 & 199 & 239 & 279 & 319 & \multirow{2}{*}{$\begin{array}{l}359 \\
758\end{array}$} & 40 \\
\hline .02 & \begin{tabular}{|l|}
0399 \\
0798
\end{tabular} & $\begin{array}{l}439 \\
838\end{array}$ & $\begin{array}{l}479 \\
878 \\
\end{array}$ & $\begin{array}{l}519 \\
917\end{array}$ & \begin{tabular}{c|c}
959 \\
7 & 559
\end{tabular} & 598 & $\begin{array}{r}638 \\
1037\end{array}$ & $\begin{array}{r}678 \\
1077\end{array}$ & $\begin{array}{r}718 \\
117\end{array}$ & & \\
\hline 0.03 & $\begin{array}{l}07 \\
1197 \\
\end{array}$ & 1237 & $\begin{array}{r}878 \\
1276\end{array}$ & 1316 & $\begin{array}{r}957 \\
6 \quad 1356\end{array}$ & $\begin{array}{rr}9996 \\
6\end{array}$ & \begin{tabular}{|l|}
1037 \\
1436
\end{tabular} & $\begin{array}{l}1077 \\
1476\end{array}$ & $\begin{array}{l}1117 \\
1516\end{array}$ & \multirow{2}{*}{\multicolumn{2}{|c|}{$\begin{array}{l}1555 \\
1954\end{array}$}} \\
\hline 0.04 & 1595 & 1635 & 1675 & \multirow{2}{*}{$\begin{array}{l}1715 \\
2113\end{array}$} & 51755 & $5 \quad 1795$ & 1834 & 1874 & 1914 & & \\
\hline 0.05 & 1994 & 2034 & 2074 & & $\begin{array}{ll}3 & 2153\end{array}$ & $\begin{array}{ll}3 & 2193\end{array}$ & 2233 & 2273 & 2313 & \multirow{2}{*}{\multicolumn{2}{|c|}{$\begin{array}{l}2352 \\
2751\end{array}$}} \\
\hline 0.06 & 2392 & 2432 & 2472 & \multirow{2}{*}{$\begin{array}{l}2512 \\
2910\end{array}$} & 22551 & $1 \quad 2591$ & 2631 & 2671 & 2711 & & \\
\hline 0.07 & 2790 & 2830 & 2870 & & $\begin{array}{ll}0 \quad 2949 \\
\end{array}$ & $\begin{array}{l}9 \\
9\end{array}$ & 3029 & 3069 & 3109 & \multirow{2}{*}{\multicolumn{2}{|c|}{$\begin{array}{l}3148 \\
3546\end{array}$}} \\
\hline 08 & 3188 & 3228 & 3268 & 3307 & 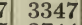 & \begin{tabular}{ll|l}
7 & 3387
\end{tabular} & 3427 & 3466 & 3506 & & \\
\hline 09 & 3586 & 3625 & 3665 & \multirow{2}{*}{$\begin{array}{l}3705 \\
4102\end{array}$} & $\begin{array}{l}5374 \\
\end{array}$ & $\begin{array}{l}4 \quad 3784 \\
\end{array}$ & 3824 & 3864 & 3903 & \multirow{2}{*}{\multicolumn{2}{|c|}{3943}} \\
\hline 10 & 3983 & 4022 & 4062 & & $\begin{array}{ll}2 & 4141\end{array}$ & $1 \quad 4181$ & 4221 & 4261 & 4300 & \multirow{2}{*}{\multicolumn{2}{|c|}{$\begin{array}{l}4340 \\
4736\end{array}$}} \\
\hline 11 & 4380 & \begin{tabular}{|l|}
4419 \\
\end{tabular} & 4459 & \multirow{2}{*}{$\begin{array}{l}4498 \\
4895\end{array}$} & 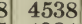 & \begin{tabular}{l|l|}
3 & 4578
\end{tabular} & 4617 & 4657 & 4697 & & \\
\hline 12 & 4776 & 4815 & 4855 & & $\begin{array}{l}5 \\
5\end{array}$ & $\begin{array}{l}4974 \\
\end{array}$ & 5013 & 5053 & 5093 & \multirow{2}{*}{\multicolumn{2}{|c|}{$\begin{array}{l}5132 \\
5527\end{array}$}} \\
\hline 13 & 5172 & 5211 & 5251 & \multirow{2}{*}{$\begin{array}{l}5290 \\
5685\end{array}$} & $\begin{array}{ll}0 & 5330\end{array}$ & 5369 & 5409 & 5448 & 5488 & & \\
\hline & 5567 & 5606 & 5646 & & $\begin{array}{l}5725 \\
\end{array}$ & $5 \quad 5764$ & 5804 & 5843 & 5883 & \multirow{2}{*}{\multicolumn{2}{|c|}{$\begin{array}{l}5922 \\
6317\end{array}$}} \\
\hline & 5962 & 6001 & 6041 & 6080 & $\begin{array}{l}0 \\
0\end{array}$ & 6159 & 6198 & 6238 & 6277 & & \\
\hline & 6356 & 6395 & 6435 & \multirow{2}{*}{$\begin{array}{l}6474 \\
6867\end{array}$} & $\begin{array}{l}4 \quad 6513 \\
\end{array}$ & 6553 & 6592 & 6631 & 6671 & \multicolumn{2}{|c|}{6710} \\
\hline & 6750 & 6789 & 6828 & & $7 \quad 6907$ & 6946 & 6985 & 7025 & 7064 & \multirow{2}{*}{\multicolumn{2}{|c|}{$\begin{array}{l}7103 \\
7495\end{array}$}} \\
\hline & 7142 & 7182 & 7221 & 7260 & $\begin{array}{l}0 \\
0\end{array}$ & 733 & 7378 & 7417 & 7456 & & \\
\hline & 7535 & 7574 & 7613 & 7652 & 27691 & 17730 & 7769 & 7809 & 7848 & 7887 & \\
\hline & 7926 & 7965 & 8004 & 8043 & $\begin{array}{ll}3 & 8082 \\
\end{array}$ & 8121 & 8160 & 8199 & 8238 & 8278 & \\
\hline & 8317 & 8356 & 8395 & 8434 & 48473 & 8512 & 8551 & 8590 & 8628 & 8667 & 39 \\
\hline & 8706 & 8745 & 8784 & 8823 & $\begin{array}{lll}3 & 8862\end{array}$ & 8901 & 8940 & 8979 & 9018 & 9057 & \\
\hline & $\begin{array}{l}9095 \\
9483\end{array}$ & $\begin{array}{l}9134 \\
9522\end{array}$ & $\begin{array}{l}9173 \\
0561\end{array}$ & 9212 & \begin{tabular}{l|l|}
2 & 9250 \\
& 9638
\end{tabular} & $\begin{array}{l}9 \\
0\end{array}$ & \begin{tabular}{|l|}
9328 \\
9716
\end{tabular} & 9367 & \begin{tabular}{|c|}
9406 \\
0702
\end{tabular} & 9445 & \\
\hline $\begin{array}{l}24 \\
25\end{array}$ & $\begin{array}{l}9483 \\
9871\end{array}$ & $\begin{array}{c}9522 \\
9909\end{array}$ & $\begin{array}{l}9561 \\
9948\end{array}$ & $\begin{array}{l}9600 \\
9986\end{array}$ & $\begin{array}{r}0 \\
6 \\
6\end{array}$ & \begin{tabular}{|c|c|}
96777 \\
10064
\end{tabular} & $\left|\begin{array}{|}9716 \\
10102\end{array}\right|$ & $\begin{array}{r}9754 \\
10141\end{array}$ & $\begin{array}{r}90183 \\
\text {. }\end{array}$ & & \\
\hline 0.26 & 10257 & 10295 & 10334 & 10372 & $\begin{array}{lll}2 & 10411\end{array}$ & $\begin{array}{l}\mathbf{1} \\
10449\end{array}$ & 10488 & 10526 & 10565 & 106 & \\
\hline 0.27 & 10642 & 10680 & 10719 & 10757 & 7107 & 10834 & 10872 & 10911 & 10949 & 1098 & \\
\hline 29 & $\begin{array}{l}11026 \\
11409\end{array}$ & & & 11 & $\begin{array}{l}1 \\
4 \\
4\end{array}$ & 11217 & 56 & $\begin{array}{l}11294 \\
1676\end{array}$ & 11715 & & \\
\hline 29 & $\begin{array}{l}11409 \\
11791\end{array}$ & $\begin{array}{l}11849 \\
11829\end{array}$ & $\begin{array}{l}11485 \\
11867\end{array}$ & 11905 & $\begin{array}{l}4 \\
5 \\
5\end{array}$ & $\begin{array}{l}1100 \\
1191\end{array}$ & $\begin{array}{l}11038 \\
12019\end{array}$ & $\begin{array}{l}12058 \\
1\end{array}$ & 12096 & 12134 & \\
\hline 31 & 12172 & 12210 & 12248 & 1228 & 12324 & 12362 & 12400 & 124381 & 2476 & 12 & \\
\hline 32 & $\begin{array}{l}12552 \\
12930\end{array}$ & $\begin{array}{l}12589 \\
12968\end{array}$ & $12627 \mid$ & 1266 & $\begin{array}{l}12703 \\
13081\end{array}$ & $\begin{array}{l}12741 \\
1318\end{array}$ & $\begin{array}{l}12778 \\
13156\end{array}$ & 12816 & $\begin{array}{lll}54 & 1 \\
32 & \end{array}$ & 12 & \\
\hline 0.3 & 13307 & 13344 & & 1342 & $\begin{array}{lll}0 & 13457\end{array}$ & 13495 & & 13570 & & 13645 & \\
\hline 0.35 & 13683 & 13720 & 13758 & 137 & $\begin{array}{lll}513833 \\
\end{array}$ & 13870 & 13908 & 13945 & & 14020 & \\
\hline & & & & Pro & гіо & L $P$ & & & & & \\
\hline$\Delta$ & 1 & 2 & 3 & & 4 & 5 & 6 & 7 & 8 & & 9 \\
\hline 40 & 4.0 & 8.0 & 12. & & 16.0 & 20.0 & 24.0 & 28.0 & 32.0 & & 6.0 \\
\hline & & & 11. & & $\begin{array}{l}15 \\
15\end{array}$ & & 23 & 27 & 30 & & 4.2 \\
\hline & 7 & & & & & 18.5 & 22.2 & 25.9 & 29 . & & 3.3 \\
\hline
\end{tabular}


TABIE IV.-Continued.

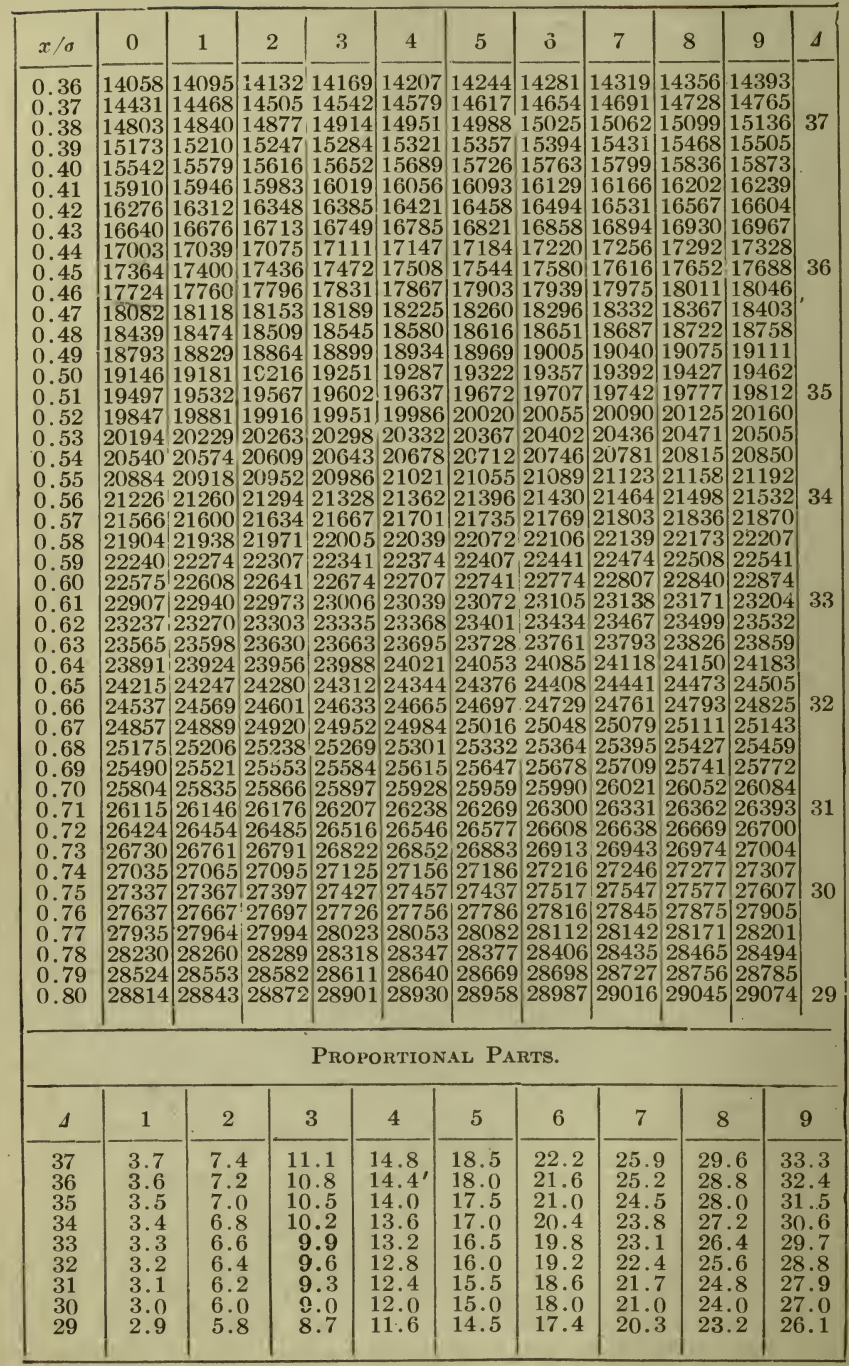


VALUES OF NORMAL PROBABILITY INTEGRAL. 121

TABLE IV.-Continued.

\begin{tabular}{|c|c|c|c|c|c|c|c|c|c|c|c|}
\hline$x / \sigma$ & 0 & 1 & 2 & 3 & 4 & 5 & 6 & 7 & 8 & 9 & $\Delta$ \\
\hline 0.81 & 9103 & 29132 & 29160 & 29189 & 29217 |2 & 29246 & 29274 & 29303 & 29332 & 29360 & \\
\hline 0.82 & 29389 & 29417 & 29446 & & \begin{tabular}{l|l}
502 & 2 \\
\end{tabular} & 29531 & 29559 & 29588 & 29616 & 29645 & \multirow{5}{*}{28} \\
\hline 0.83 & $\mid 29673$ & 29701 & 29729 & 29757 & $\left.29785\right|^{2}$ & {$[29814]$} & 29842 & 29870 & 29898 & 23926 & \\
\hline $\begin{array}{l}0.84 \\
0.85\end{array}$ & $\begin{array}{l}29954 \\
30234\end{array}$ & $\begin{array}{l}29982 \\
30261\end{array}$ & $\begin{array}{l}30010 \\
30289\end{array}$ & $\begin{array}{l}30038 \mid \\
30317\end{array}$ & $\begin{array}{l}30066 \\
30344\end{array}$ & $\begin{array}{l}30094 \\
30372\end{array}$ & $\begin{array}{l}30122 \\
30400\end{array}$ & $\begin{array}{l}30150 \\
30427\end{array}$ & $\begin{array}{l}30178 \\
30455\end{array}$ & $\begin{array}{l}30206 \\
30483\end{array}$ & \\
\hline 0.86 & 30510 & 30538 & 30565 & 30593 & 306203 & 30648 & 30675 & 30702 & 30730 & 30757 & \\
\hline 0.87 & 30785 & 30812 & 30839 & 30866 & 30894 & 30921 & 30948 & 30975 & 31002 & 31030 & \\
\hline 0.88 & 31057 & 31084 & 31111 & 31138 & $|3 i 165|^{3}$ & 31192 & 31219 & 31246 & 31273 & 31300 & \multirow[t]{3}{*}{27} \\
\hline 0.89 & 31327 & 31353 & 31380 & 31407 & 31433|3 & 31460 & 31487 & 31514 & 31540 & 31567 & \\
\hline 0.90 & \begin{tabular}{|l|}
31594 \\
31859
\end{tabular} & $\begin{array}{l}31620 \\
31885\end{array}$ & $\begin{array}{l}31647 \\
31911\end{array} \mid$ & $\begin{array}{l}31673 \\
31937\end{array}$ & \begin{tabular}{l|l}
31700 \\
31964
\end{tabular} & $\begin{array}{l}31726 \\
31990\end{array}$ & $\left|\begin{array}{l}31753 \\
32016\end{array}\right|$ & $\begin{array}{l}31780 \\
32042\end{array}$ & $\begin{array}{l}31806 \\
32069\end{array}$ & $\begin{array}{l}31832 \\
32095\end{array}$ & \\
\hline $0: 92$ & 32121 & 32147 & 32173 & 32199 & 32225 & 32251 & 32277 & 32303 & 32329 & 32355 & \multirow[t]{3}{*}{26} \\
\hline 0.93 & 32381 & 32407 & 32433 & 32459 & 324843 & 32510 & 32536 & $|32562|$ & 32587 & 32613 & \\
\hline 0.94 & 32639 & 32665 & 32690 & 32715 & $32741 \mid 3$ & 32766 & 32792 & 32818 & 32843 & 32869 & \\
\hline 0.95 & 32894 & 32919 & 32945 & 32970 & 329953 & 33021 & 33046 & $3307 \mathrm{~J} \mid$ & 33096 & 33122 & \multirow{3}{*}{25} \\
\hline 0.96 & 33147 & 33172 & 33197 & 33222 & $\left.33247\right|^{3}$ & 33272 & 33297 & 33322 & 33347 & 33373 & \\
\hline 0.97 & 33398 & 33422 & 33447 & 33472 & 334973 & 33521: & 33546 & 33571 & 33596 & 33621 & \\
\hline 0.98 & 33646 & 33670 & 33695 & 33719 & 33744 & 33768 & 33793 & 33817 & 33842 & 33867 & \\
\hline 0.99 & $\begin{array}{l}33891 \\
34134\end{array}$ & 33915 & 33940 & $\begin{array}{l}33964 \\
34206\end{array}$ & $\begin{array}{l}33988 \\
34230\end{array}$ & 34013 & $\begin{array}{l}34037 \\
34979\end{array}$ & 34061 & $\begin{array}{l}34086 \\
34327\end{array}$ & $\begin{array}{l}34110 \\
34351\end{array}$ & \multirow{2}{*}{24} \\
\hline $\begin{array}{l}1.00 \\
1.01\end{array}$ & \begin{tabular}{|}
34134 \\
34375
\end{tabular} & $\begin{array}{l}34158 \\
34399\end{array}$ & $\begin{array}{l}34182 \\
34423\end{array}$ & $\begin{array}{l}34206 \\
34446\end{array}$ & $\begin{array}{l}34230 \\
34470\end{array}$ & $\begin{array}{l}34255 \\
34494\end{array}$ & $\begin{array}{l}34279 \\
34518\end{array}$ & $\begin{array}{l}34303 \\
34542\end{array}$ & $\begin{array}{l}3432 \\
34566\end{array}$ & $\begin{array}{l}04501 \\
34590\end{array}$ & \\
\hline 1.02 & 34613 & 34637 & 34661 & 34684 & 34708 & 34731 & 34755 & 34778 & 34802 & 34826 & \\
\hline 1.03. & 34849 & 34873 & 96 & 34919 & & 66 & 34989 & 35013 & 35036 & 35059 & \multirow{5}{*}{23} \\
\hline 1.04 & 35083 & 35106 & 35129 & 35152 & 35175 & 35198 & 35221 & 35245 & 35268 & 35291 & \\
\hline 1.05 & 35314 & 35337 & $35360 \mid$ & 35 & 35405 & 3. & 35451 & 35474 & 35497 & 35520 & \\
\hline $\begin{array}{l}1.06 \\
1.07\end{array}$ & $\begin{array}{l}355 \\
357\end{array}$ & 5655 & $\begin{array}{l}35588 \\
35814\end{array}$ & $\mid \begin{array}{l}35610 \\
35836\end{array}$ & $\begin{array}{l}35633 \\
35858\end{array}$ & $\begin{array}{l}35656 \\
35881\end{array}$ & $\mid$\begin{tabular}{|}
35678 \\
35903
\end{tabular} & $\mid 35701$ & $\mid \begin{array}{l}35724 \\
35948\end{array}$ & $\begin{array}{l}35746 \\
35970\end{array}$ & \\
\hline 1.08 & $2500 ?$ & & & & 30000 & & & & & & \\
\hline 100 & & 015 & 037 & 059 & 081 & 103 & 125 & 148 & 170 & 192 & \multirow[t]{4}{*}{22} \\
\hline 1.09 & 36214 & 236 & 258 & 280 & 302 & 324 & $34:$ & 36 & 38 & 41 & \\
\hline 1.10 & & 455 & 47 & 498 & 520 & 541 & 563 & 585 & 607 & 628 & \\
\hline 1.11 & $\begin{array}{l}650 \\
864\end{array}$ & $\begin{array}{l}671 \\
885\end{array}$ & $\begin{array}{l}693 \\
906\end{array}$ & $\begin{array}{l}714 \\
928\end{array}$ & $\begin{array}{l}735 \\
949\end{array}$ & $\begin{array}{l}757 \\
970\end{array}$ & $\begin{array}{l}778 \\
991\end{array}$ & 800 & 821 & 843 & \\
\hline & & & & & & & & 012 & 034 & 055 & \multirow{5}{*}{21} \\
\hline 1.13 & 37176 & 097 & 118 & 139 & 160 & 181 & 202 & & 244 & 26 & \\
\hline & 286 & 306 & 327 & 348 & 368 & 38 & 410 & 430 & 451 | & 472 & \\
\hline 1.15 & 493 & 513 & 534 & 554 & 574 & 595 & 615 & 636 & 656 & 677 & \\
\hline 1. & 697 & 718 & 738 & $\begin{array}{l}758 \\
960\end{array}$ & 778 & 798 & 819 & 839 & & 880 & \\
\hline & & 920 & 0.0 & & & 000 & 020 & 040 & 060 & 080 & \multirow[t]{4}{*}{20} \\
\hline 1.18 & 38100 & 120 & 139 & 159 & 179 & 199 & 218 & 23 & 258 & 27 & \\
\hline 1.19 & 298 & 317 & & 356 & 376 & 395 & 415 & 434 & 454 & 473 & \\
\hline 1.20 & 493 . & 51 & 531 & 55 & 570 & 58 & 609 & 62 & & 667 & \\
\hline
\end{tabular}

Proportional Parts.

\begin{tabular}{|c|c|c|c|c|c|c|c|c|c|}
\hline \multicolumn{1}{c|}{$\Delta$} & 1 & 2 & 3 & 4 & 5 & 6 & 7 & 8 & 9 \\
\hline 29 & 2.9 & 5.8 & 8.7 & 11.6 & 14.5 & 17.4 & 20.3 & 23.2 & 26.1 \\
28 & 2.8 & 5.6 & 8.4 & 11.2 & 14.0 & 16.8 & 19.6 & 22.4 & 25.2 \\
27 & 2.7 & 5.4 & 8.1 & 10.8 & 13.5 & 16.2 & 18.9 & 21.6 & 24.3 \\
26 & 2.6 & 5.2 & 7.8 & 10.4 & 13.0 & 15.6 & 18.2 & 20.8 & 23.4 \\
25 & 2.5 & 5.0 & 7.5 & 10.0 & 12.5 & 15.0 & 17.5 & 20.0 & 22.5 \\
24 & 2.4 & 4.8 & 7.2 & 9.6 & 12.0 & 14.4 & 16.8 & 19.2 & 21.6 \\
23 & 2.3 & 4.6 & 6.9 & 9.2 & 11.5 & 13.8 & 16.1 & 18.4 & 20.7 \\
22 & 2.2 & 4.4 & 6.6 & 8.8 & 11.0 & 13.2 & 15.4 & 17.6 & 19.8 \\
21 & 2.1 & 4.2 & 6.3 & 8.4 & 10.5 & 12.6 & 14.7 & 16.8 & 18.9 \\
20 & 2.0 & 4.0 & 6.0 & 8.0 & 10.0 & 12.0 & 14.0 & 16.0 & 18.0 \\
19 & 1.9 & 3.8 & 5.7 & 7.6 & 9.5 & 11.4 & 13.3 & 15.2 & 17.1 \\
\hline
\end{tabular}


TABLE IV.-Continued

\begin{tabular}{|c|c|c|c|c|c|c|c|c|c|c|c|}
\hline$x / \sigma$ & 0 & 1 & 2 & 3 & 4 & 5 & 6 & 7 & 8 & 9 & $\Delta$ \\
\hline \multirow{2}{*}{$\begin{array}{l}1.21 \\
1.22\end{array}$} & \multirow{2}{*}{$\begin{array}{r}38686 \\
876 \\
\end{array}$} & \multirow{2}{*}{$\begin{array}{l}705 \\
895\end{array}$} & \multirow{2}{*}{$\begin{array}{l}724 \\
914 \\
\end{array}$} & \multirow{2}{*}{$\begin{array}{l}743 \\
933 \\
\end{array}$} & \multirow{2}{*}{$\begin{array}{l}762 \\
952\end{array}$} & \multirow{2}{*}{$\begin{array}{l}\mathbf{7 8 1} \\
\mathbf{9 7 1}\end{array}$} & \multirow{2}{*}{$\begin{array}{l}800 \\
990 \\
\end{array}$} & 819 & 838 & 857 & \multirow[t]{7}{*}{19} \\
\hline & & & & & & & & & \multirow{6}{*}{$\begin{array}{l}027 \\
214 \\
398 \\
580 \\
760 \\
937\end{array}$} & \multirow{6}{*}{\begin{tabular}{l|}
046 \\
232 \\
417 \\
598 \\
778 \\
955
\end{tabular}} & \\
\hline 1. 23 & 39065 & 084 & 102 & 121 & 139 & 158 & 177 & & & & \\
\hline 4 & & & & & 324 & & & & & & \\
\hline .25 & 435 & 453 & 471 & 489 & 507 & 525 & 544 & 562 & & & \\
\hline .26 & 617 & 634 & 652 & 670 & 688 & 706 & 724 & 742 & & & \\
\hline \multirow{2}{*}{$\begin{array}{l}1.27 \\
1.28\end{array}$} & $\begin{array}{l}796 \\
973\end{array}$ & 813 & 831 & 849 & 866 & 884 & 902 & 920 & & & \\
\hline & 973 & 990 & 008 & 025 & \multirow{6}{*}{$\begin{array}{l}042 \\
216 \\
388 \\
557 \\
725 \\
889\end{array}$} & 060 & 077 & 95 & \multirow{6}{*}{$\begin{array}{l}112 \\
285 \\
456 \\
625 \\
792 \\
955\end{array}$} & \multirow{6}{*}{\begin{tabular}{l|}
130 \\
303 \\
473 \\
641 \\
808 \\
971 \\
\end{tabular}} & \\
\hline 1. 29 & 147 & 165 & & 199 & & & & & & & \\
\hline 1.30 & 320 & 337 & 354 & 371 & & 405 & 422 & 439 & & & 17 \\
\hline 1. 31 & 490 & 507 & 524 & 540 & & 574 & 591 & 608 & & & \\
\hline 1.32 & 658 & 675 & 692 & 709 & & 742 & 758 & 775 & & & \\
\hline \multirow{2}{*}{$\begin{array}{l}1.33 \\
1.34\end{array}$} & 825 & 841 & $85 \overline{7}$ & 873 & & 906 & 922 & 938 & & & \\
\hline & & 004 & 020 & 036 & 052 & 063 & 084 & 101 & 117 & 133 & \\
\hline 1.35 & 41149 & 165 & 181 & 197 & 213 & 229 & 245 & & 77 & 92 & 16 \\
\hline 1. 36 & & 324 & 340 & 355 & 371 & 387 & 40. & 418 & 434 & 450 & \\
\hline 1.37 & 466 & 481 & 497 & 512 & 527 & 543 & 55 & 574 & 590 & 605 & \\
\hline 1.38 & 621 & 637 & 652 & 667 & 683 & 698 & $71:$ & 728 & 744 & 59 & \\
\hline $\begin{array}{l}1.39 \\
1.40\end{array}$ & $\begin{array}{l}774 \\
924\end{array}$ & $\begin{array}{l}789 \\
939\end{array}$ & $\begin{array}{l}804 \\
954\end{array}$ & $\begin{array}{l}819 \\
969\end{array}$ & 834 & $\begin{array}{l}849 \\
098\end{array}$ & 864 & 879 & 894 & 909 & 15 \\
\hline & & & & & 64 & 90 & 013 & 28 & 43 & 58 & \\
\hline 1.41 & 42073 & 088 & 102 & 117 & 131 & 16 & & & & 205 & \\
\hline 42 & 220 & 234 & 248 & 263 & 277 & 292 & & & & 350 & \\
\hline 1.43 & 364 & 378 & 393 & 407 & 421 & 435 & & 464 & 478 & 492 & \\
\hline 1.44 & 507 & 521 & 535 & 549 & 563 & 577 & 5 & & 619 & 633 & 14 \\
\hline 1.45 & 647 & 661 & 675 & 688 & 702 & 716 & 7 & 744 & 758 & 772 & \\
\hline 1.4 & 785 & 799 & 813 & 826 & 840 & 854 & 867 & 881 & 895 & 308 & \\
\hline 1.47 & & 935 & 949 & 962 & 975 & 89 & & & & & \\
\hline 1.48 & 43056 & 069 & 083 & 096 & 109 & 22 & & & & 175 & \\
\hline .49 & 189 & 202 & 215 & 228 & 241 & 254 & & & 293 & 306 & 13 \\
\hline .50 & 319 & 332 & 345 & 358 & 371 & 383 & 396 & 409 & 422 & 435 & \\
\hline .51 & 448 & 460 & 473 & 486 & 498 & 511 & 5 & & 549 & 562 & \\
\hline $5 ?$ & 574 & 587 & 599 & 612 & 624 & 637 & 6 & 6 & 674 & 687 & \\
\hline 1.53 & 69 & 711 & 724 & 736 & 748 & 760 & 7 & 78 & 797 & 810 & \\
\hline 1.54 & 822. & 834 & 846 & 858 & 870 & 882 & 894 & 906 & 919 & 931 & 12 \\
\hline & & & & & & 002 & 01 & 0 & 38 & 950 & \\
\hline 56 & a & 074 & 085 & 097 & 109 & & & 14 & 156 & 167 & \\
\hline & & & & & & 2 & & & 271 & 283 & \\
\hline 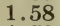 & 29 & 306 & 317 & 329 & 340 & 351 & & 374 & 385 & 397 & \\
\hline 1.59 & 40 & 419 & 430 & 442 & 453 & 464 & 475 & 486 & 498 & 509 & \\
\hline & & & & & & & & & & & \\
\hline$\Delta$ & 1 & 2 & & & & 5 & 6 & 7 & 8 & & 9 \\
\hline 1 & 1 & 3.8 & & & & 9.5 & & & 15 & & 7.1 \\
\hline & & & & & & & & & & & \\
\hline 17 & 7 & & & & & 8.5 & 10 & & & & 5.3 \\
\hline 1 & & & & & & & & & & & \\
\hline 1. & & & & & & 7.5 & 9 & & & & 3.5 \\
\hline & & & & & & 7. & & & & & \\
\hline 13 & & & & & & 6 & & $y$ & 10 & & 1.7 \\
\hline 1. & & & & & & 6. & 7 & 8. & 9 & & 0.8 \\
\hline 11 & 1.1 & 2.2 & & & & 5.5 & 6.6 & 7.7 & 0.0 & & 9.9 \\
\hline
\end{tabular}


VALUES OF NORMAL PROBABILITY INTEGRAL. 123

TABLE IV.-Continued.

\begin{tabular}{|c|c|c|c|c|c|c|c|c|c|c|c|}
\hline$x / \sigma$ & 0 & 1 & 2 & 3 & 4 & 5 & 6 & 7 & 8 & 9 & $\Delta$ \\
\hline 1.60 & 4520 & 531 & 542 & 553 & 564 & 575 & 586 & 597 & 608 & 619 & 11 \\
\hline 1.61 & 630 & & & 662 & 673 & 684 & 695 & 706 & 717 & 727 & \\
\hline $\begin{array}{l}1.62 \\
1.63\end{array}$ & $\begin{array}{l}73 \\
84\end{array}$ & 7 & 0 & $\begin{array}{l}770 \\
876\end{array}$ & 781 & $\begin{array}{l}791 \\
897\end{array}$ & 802 & 813 & 823 & 834 & \\
\hline 1.64 & 950 & 960 & 970 & 980 & $\begin{array}{l}881 \\
991\end{array}$ & 891 & 908 & & 929 & 939 & \\
\hline 1.65 & 5053 & 063 & 073 & 083 & & 001 & 011 & 022 & 032 & 042 & \\
\hline 1.66 & 年 & & 174 & 1 & $\begin{array}{l}093 \\
194\end{array}$ & & & & & 144 & \\
\hline 1.67 & 25 & 264 & 274 & 283 & $\begin{array}{l}194 \\
293\end{array}$ & $\begin{array}{l}204 \\
303\end{array}$ & $\begin{array}{l}214 \\
313\end{array}$ & $\begin{array}{l}224 \\
323\end{array}$ & 34 & $\begin{array}{l}244 \\
342\end{array}$ & 10 \\
\hline 1.68 & 35 & 36 & 371 & 38 & 391 & 400 & 410 & 419 & 429 & $\begin{array}{l}342 \\
439\end{array}$ & \\
\hline 1.69 & 44 & 45 & 467 & 47 & 486 & 496 & 505 & 5 & 4 & 34 & \\
\hline 1.70 & 543 & 553 & 562 & 571 & 581 & 590 & 599 & 609 & 618 & 627 & \\
\hline 1.71 & 637 & 646 & 655 & 664 & 673 & 682 & 692 & 701 & 710 & 719 & \\
\hline 1.72 & 728 & 73 & 746 & 75 & 764 & 773 & 782 & 791 & 800 & 809 & 9 \\
\hline $\begin{array}{l}1.73 \\
1.74\end{array}$ & 818 & 82 & 836 & 84 & 854 & 86 & 871 & 00 & & 98 & \\
\hline $\begin{array}{l}1.74 \\
1.75\end{array}$ & 90 & 916 & 924 & 933 & 942 & 950 & 959 & 968 & 977 & 985 & \\
\hline & & & 011 & 020 & 028 & 037 & 045 & 05 & 062 & 071 & \\
\hline 1.76 & 46080 & & 0 & 105 & 113 & 121 & 130 & & 7 & 155 & \\
\hline 1.77 & 1 & 17 & 180 & 188 & 196 & 205 & 213 & 221 & 230 & 238 & \\
\hline 1.78 & 16 & 254 & 262 & 270 & 279 & 287 & 295 & 303 & 311 & 319 & \\
\hline 1.79 & 327 & 33 & 343 & 351 & 359 & 367 & 375 & 383 & 391 & 399 & 8 \\
\hline 1.80 & 407 & 415 & 423 & 430 & 438 & 446 & 454 & 462 & 469 & 477 & \\
\hline $\begin{array}{l}1.81 \\
1.82\end{array}$ & 85 & 49 & 500 & 50 & 516 & 52 & 531 & 539 & 5 & 554 & \\
\hline 1.83 & 638 & $\begin{array}{l}57 \\
64\end{array}$ & $\begin{array}{l}577 \\
652\end{array}$ & $\begin{array}{l}58 \\
660\end{array}$ & $\begin{array}{l}592 \\
667\end{array}$ & $\begin{array}{l}600 \\
674\end{array}$ & $\begin{array}{l}607 \\
682\end{array}$ & $\begin{array}{l}61 \\
68\end{array}$ & & $\begin{array}{l}630 \\
704\end{array}$ & \\
\hline 1.84 & 71 & 71 & 726 & 73 & 741 & 74 & 755 & 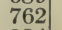 & 7 & 777 & \\
\hline 1.8 & 78 & 79 & 798 & 80 & 813 & 82 & 827 & 8 & 8 & 849 & \\
\hline 1.86 & 85 & 8 & 870 & 8 & 8 & 8 & 898 & 9 & 2 & 919 & 7 \\
\hline $\begin{array}{l}1.8 \\
1.8\end{array}$ & 926 & 938 & 939 & 946 & 953 & 960 & 967 & 9 & 98 & 988 & \\
\hline & & & 008 & 0 & 021 & 028 & 035 & 042 & & 05 & \\
\hline 1.89 & 47062 & & 0 & & 0 & 0 & 102 & 1 & & 12 & \\
\hline 1.9 & 93 & 13 & 141 & 14 & 154 & 16 & 167 & 17 & & 187 & \\
\hline $\begin{array}{l}1.91 \\
1.92\end{array}$ & 93 & 200 & 206 & 212 & 219 & 225 & 231 & 2 & 24 & 251 & \\
\hline 1.93 & $0<$ & $\begin{array}{l}2 t \\
32\end{array}$ & $\begin{array}{l}270 \\
332\end{array}$ & $\begin{array}{l}27 \\
33\end{array}$ & $\begin{array}{l}28 \\
34\end{array}$ & $\begin{array}{l}28 \\
35\end{array}$ & $\begin{array}{l}294 \\
356\end{array}$ & & & $\begin{array}{l}313 \\
375\end{array}$ & \\
\hline 1.94 & 38 & 38 & 393 & 39 & 40 & 41 & 417 & 42 & & 43 & 6 \\
\hline 1.9 & 44 & 44 & 45 & 45 & 46 & 47 & 47 & 4 & & 49 & \\
\hline 1.9 & 50 & 50 & 51 & 51 & 5 & 5 & & & & 552 & \\
\hline 1,9 & 5 & & $5 €$ & 57 & 5 & 5 & 5 & 5 & & 609 & \\
\hline 1.98 & 6 & & 6 & 6 & & 6 & & & & 665 & \\
\hline 1.99 & & & & 6 & 6 & & & & & 71 & \\
\hline 2.0 & 72 & 73 & 73 & 74 & 7 & 7 & 7 & 78 & & 772 & \\
\hline 2.0 & 77 & 78 & 78 & 79 & 7 & 8 & & 8 & & 826 & \\
\hline 2.0 & 83 & & 8 & 84 & 8 & 8 & & 8 & 8 & 877 & \\
\hline 2.0 & 8 & 88 & 80 & 89 & 90 & 9 & 9 & 91 & 9 & 927 & 5 \\
\hline & & 9 & 942 & 947 & 95 & 957 & 962 & 967 & 972 & 977 & \\
\hline
\end{tabular}

Proportional Parts.

\begin{tabular}{|r|c|c|c|c|c|c|c|c|c|}
\hline \multicolumn{1}{r|}{$\boldsymbol{y}$} & 1 & 2 & 3 & 4 & 5 & 6 & 7 & 8 & 9 \\
\hline 11 & 1.1 & 2.2 & 3.3 & 4.4 & 5.5 & 6.6 & 7.7 & 8.8 & 9.9 \\
10 & 1.0 & 2.0 & 3.0 & 4.0 & 5.0 & 6.0 & 7.0 & 8.0 & 9.0 \\
9 & 0.9 & 1.8 & 2.7 & 3.6 & 4.5 & 5.4 & 6.3 & 7.2 & 8.1 \\
8 & 0.8 & 1.6 & 2.4 & 3.2 & 4.0 & 4.8 & 5.6 & 6.4 & 7.2 \\
7 & 0.7 & 1.4 & 2.1 & 2.8 & 3.5 & 4.2 & 4.9 & 5.6 & 6.3 \\
6 & 0.6 & 1.2 & 1.8 & 2.4 & 3.0 & 3.6 & 4.2 & 4.8 & 5.4 \\
\hline
\end{tabular}


TABLE IV.-Continued.

\begin{tabular}{|c|c|c|c|c|c|c|c|c|c|c|c|}
\hline$x / \sigma$ & 0 & 1 & 2 & 3 & 4 & 5 & 6 & 7 & 8 & 9 & $\Delta$ \\
\hline 2.05 & 47982 & 987 & 991 & 996 & & & & & & & \\
\hline 2.06 & 48030 & 035 & 039 & 044 & $\begin{array}{l}001 \\
049\end{array}$ & $\begin{array}{l}006 \\
054\end{array}$ & $\begin{array}{l}011 \\
058\end{array}$ & $\begin{array}{l}015 \\
063\end{array}$ & $\begin{array}{l}020 \\
068\end{array}$ & $\begin{array}{l}025 \\
073\end{array}$ & \\
\hline 2.07 & 077 & 082 & 087 & 091 & 096 & 100 & 105 & 110 & 114 & 119 & \\
\hline 2.08 & 124 & 128 & 133 & 137 & 142 & 14 & 151 & 155 & 160 & 165 & \\
\hline 2.09 & 169 & 173 & 178 & 182 & 187 & 191 & 196 & 200 & 205 & 209 & \\
\hline 2.10 & 214 & 218 & 222 & 227 & 231 & 235 & 240 & 244 & 248 & 253 & \\
\hline 2.11 & 257 & 261 & 266 & 270 & 274 & 278 & 283 & 287 & 291 & 295 & \\
\hline 2.12 & 300 & 304 & 308 & 312 & 316 & 320 & 325 & 329 & 333 & 337 & \\
\hline 2.13 & 341 & 345 & 350 & 354 & 358 & 362 & 366 & 370 & 374 & 378 & \\
\hline 2.14 & 382 & 386 & 390 & 394 & 398 & 402 & 406 & 410 & 414 & 418 & 4 \\
\hline 2.15 & 422 & 426 & 430 & 434 & 438 & 442 & 446 & 450 & 453 & 457 & \\
\hline 2.16 & 461 & 465 & 469 & 473 & 477 & 480 & 484 & 488 & 492 & 496 & \\
\hline 2.17 & 500 & 503 & 507 & 511 & 515 & 518 & 522 & 526 & 533 & 533 & \\
\hline 2.18 & 537 & 541 & 544 & 548 & 552 & 55 & 559 & 563 & 56 & 570 & \\
\hline 2.19 & 574 & 577 & 581 & 584 & 588 & 592 & 595 & 599 & 602 & 306 & \\
\hline 2.20 & 6 & 613 & 617 & 620 & 624 & 627 & 63 & 63 & 6 & 641 & \\
\hline 2.21 & 6 & 648 & 652 & 655 & 658 & 662 & 665 & 669 & 672 & 676 & \\
\hline 2.2 & 6 & & 686 & 689 & 692 & 696 & 69 & 70 & 706 & 709 & \\
\hline 2.2 & 713 & 71 & 719 & 722 & 726 & 729 & 73 & 736 & $\begin{array}{l}739 \\
771\end{array}$ & $\begin{array}{l}742 \\
774\end{array}$ & \\
\hline $\begin{array}{l}2.24 \\
2.25\end{array}$ & 5 & $\begin{array}{l}74 \\
78\end{array}$ & 7 & $\begin{array}{l}755 \\
787\end{array}$ & $\begin{array}{l}758 \\
790\end{array}$ & $\begin{array}{l}761 \\
793\end{array}$ & $\begin{array}{l}765 \\
796\end{array}$ & $\begin{array}{l}768 \\
799\end{array}$ & $\begin{array}{l}771 \\
803\end{array}$ & $\begin{array}{l}774 \\
806\end{array}$ & \\
\hline 2.26 & 809 & 812 & 8 & 8. & 821 & 824 & & & & 837 & \\
\hline 2.27 & 40 & 843 & 8 & 849 & 852 & 855 & 858 & 861 & 864 & 867 & 3 \\
\hline 2.28 & 0 & 8 & & 78 & 881 & 884 & 887 & 8 & & 896 & \\
\hline 2.29 & 899 & 9 & 9 & $\left.907\right|^{\circ}$ & 910। & 913 & 916 & 9 & 922 & 925 & \\
\hline 2.30 & & 93 & 9 & 936 & 939 & 942 & 944 & 91 & 950 & 953 & \\
\hline 2.31 & 6 & 9 & 961 & 964 & 966 & 9 & 972 & 975 & 977 & 980 & \\
\hline 2.3 & & & & & 994 & 996 & 999 & & & & \\
\hline 2.33 & 9010 & 012 & 015 & 017 & 020 & 023 & 025 & 028 & 031 & 033 & \\
\hline 2.34 & & & & & 046 & 0 & 051 & 054 & 056 & 059 & \\
\hline 35 & & & & & & 0 & 076 & 07 & 081 & 084 & \\
\hline & & & 0 & & 0 & 0 & 10 & 10 & 106 & 108 & \\
\hline & & & & & & 122 & & 12 & & 132 & \\
\hline & 134 & 1 & 13 & 141 & 1 & 146 & 1. & 15 & 153 & 155 & \\
\hline 2 & & & 1 & 164 & & 16 & 17 & 17 & 17 & 178 & \\
\hline & & & 1 & 1 & 1 & 19 & 19 & 19 & 19 & 200 & \\
\hline & & & & & & & & & & 222 & \\
\hline 2.42 & & & & & & 2 & ? & 22 & 241 & 243 & \\
\hline & 5 & & 249 & & 253 & 2 & & 2 & & 264 & \\
\hline 2.44 & & & 270 & 272 & 274 & 276 & 278 & 28 & 28 & 284 & 2 \\
\hline 2.45 & & & 29 & 292 & 294 & 29 & 297 & 29 & 3 & 303 & \\
\hline 2.46 & & & 30 & 311 & 31 & 31 & 31 & 31 & 3 & 323 & \\
\hline & & & & & & 33 & 336 & 32 & 339 & 341 & \\
\hline 2.48 & & & 3 & 34 & 350 & 352 & 354 & 356 & 358 & 359 & \\
\hline 2.49 & & & 36 & 3 & 36 & 37 & 372 & 37 & 3 & 377 & \\
\hline & & & 4 & 48 & 4 & 46 & 47 & 45 & 5 & 520 & 16 \\
\hline 2.6 & & & 56 & 57 & 58 & 5 & 60 & 62 & 6 & 643 & 12 \\
\hline 2.7 & & & & & 69 & 70 & 711 & 72 & 72 & 736 & 9 \\
\hline 2.8 & -1 & 7.52 & 760 & 767 & 774 & 781 & 788 & 795 & 801 & 807 & \\
\hline
\end{tabular}

Proportional Parts.

\begin{tabular}{r|r|r|r|r|r|r|r|r|r|}
\hline \multicolumn{1}{r|}{$\Delta$} & 1 & 2 & 3 & 4 & 5 & 6 & 7 & 9 & \multicolumn{1}{c|}{9} \\
\hline 16 & 1.6 & 3.2 & 4.8 & 6.4 & 8.0 & 9.6 & 11.2 & 12.8 & 14.4 \\
12 & 1.2 & 2.4 & 3.6 & 4.8 & 6.0 & 7.2 & 8.4 & 9.6 & 10.8 \\
9 & 0.9 & 1.8 & 2.7 & 3.6 & 4.5 & 5.4 & 6.3 & 7.2 & 8.1 \\
7 & 0.7 & 1.4 & 2.1 & 2.8 & 3.5 & 4.2 & 4.9 & 5.6 & 6.3 \\
\hline
\end{tabular}


VALUES OF NORMAL PROBABILITY INTEGRAL. 125

TABLE IV.-Continued.

\begin{tabular}{|c|c|c|c|c|c|c|c|c|c|c|c|}
\hline$x / 0$ & 0 & 1 & 2 & 3 & 4 & 5 & 6 & 7 & 8 & 9 & $\Delta$ \\
\hline 2.9 & 49813 & 819 & 825 & 831 & 836 & 841 & 846 & 851 & 856 & 861 & 5 \\
\hline 3.0 & 865 & 869 & 873 & 878 & 882 & 886 & 889 & 893 & 897 & 900 & 4 \\
\hline 3.1 & 903 & 906 & 910 & 913 & 916 & 918 & 921 & 924 & 926 & 929 & 3 \\
\hline 3.2 & 931 & 934 & 936 & 938 & 940 & 942 & 944 & 946 & 948 & 950 & 2 \\
\hline 3.3 & 952 & 953 & 955 & 957 & 958 & 960 & 961 & 962 & 964 & 965 & 1 \\
\hline 3.4 & 966 & 968 & 969 & 970 & 971 & 972 & 973 & 974 & 975 & 976 & 1 \\
\hline 3.5 & 977 & 978 & 978 & 979 & 980 & 981 & 981 & 982 & $98 ?$ & 983 & 1 \\
\hline 3.6 & 984 & 985 & 985 & 986 & 986 & 987 & 987 & 988 & $98 \varepsilon$ & 989 & 1 \\
\hline 3.7 & 989 & 990 & 990 & 990 & 991 & 991 & 992 & 992 & 992 & 992 & 0 \\
\hline 3.8 & 993 & 993 & 993 & 994 & 994 & 994 & 994 & 995 & 995 & 995 & 0 \\
\hline 3.9 & 995 & 995 & 996 & 996 & 996 & 996 & 996 & 996 & 997 & 997 & 0 \\
\hline 4 & 997 & 998 & 999 & 999 & 999 & 000 & 000 & 000 & 00. & 000 & 0 \\
\hline \multicolumn{12}{|c|}{ Proportional Parts. } \\
\hline$\Delta$ & 1 & 2 & 3 & & & 5 & 6 & 7 & 8 & & 9 \\
\hline 5 & 0.5 & 1.0 & 1. & & & 2.5 & 3.0 & 3.5 & 4.0 & & 4.5 \\
\hline 4 & 0.4 & 0.8 & 1. & & & 2.0 & 2.4 & 2.8 & 3.2 & & 3.6 \\
\hline 3 & 0.3 & 0.6 & 0 . & & & 1.5 & 1.8 & 2.1 & 2.4 & & 2.7 \\
\hline 2 & 0.2 & 0.4 & 0. & & & 1.0 & 1.2 & 1.4 & 1.6 & & 1.8 \\
\hline 1 & 0.1 & 0.2 & 0. & & & 0.5 & 0.6 & 0.7 & 0.8 & & 0.9 \\
\hline
\end{tabular}


V.-TABLE OF LOG $\boldsymbol{\Gamma}$ FUNCTIONS OF $p$ (see pages 32-34).

\begin{tabular}{|c|c|c|c|c|c|c|c|c|c|c|}
\hline$p$ & 0 & 1 & 2 & 3 & 4 & 5 & 6 & 7 & 8 & 9 \\
\hline $\begin{array}{l}1.00 \\
1.01 \\
1.02 \\
1.03 \\
1.04\end{array}$ & $\begin{array}{r}9.9975: 29 \\
51: 8 \\
2796 \\
0533\end{array}$ & $\begin{array}{l}9750 \\
7285 \\
489: 2 \\
2567 \\
0311\end{array}$ & $\begin{array}{l}9500 \\
7043 \\
4656 \\
2: 3: 38 \\
0089\end{array}$ & $\begin{array}{l}9251 \\
6801 \\
1421 \\
2110 \\
9868\end{array}$ & $\begin{array}{l}9003 \\
6560 \\
4187 \\
1883 \\
9647\end{array}$ & $\begin{array}{l}8 \% 55 \\
63 \div 0 \\
3953 \\
1656 \\
94 \div 6\end{array}$ & $\begin{array}{l}8: 09 \\
6080 \\
3721 \\
1430 \\
9: 308\end{array}$ & $\begin{array}{l}8: 63 \\
5841 \\
3489 \\
1205 \\
8989\end{array}$ & $\begin{array}{l}8017 \\
5602 \\
3: 57 \\
0981 \\
\hat{8} \div 7:\end{array}$ & $\begin{array}{l}\tilde{r r 3} \\
5365 \\
3026 \\
0757 \\
\hat{8} 554\end{array}$ \\
\hline $\begin{array}{l}1.05 \\
1.06 \\
1.07 \\
1.08 \\
1.09\end{array}$ & $\begin{array}{r}9.988338 \\
6209 \\
4145 \\
2147 \\
0212\end{array}$ & $\begin{array}{l}8122 \\
6000 \\
3943 \\
1951 \\
0022\end{array}$ & $\begin{array}{l}7907 \\
5 \div 91 \\
3: 41 \\
1755 \\
95: 33\end{array}$ & $\begin{array}{l}\tau 692 \\
5583 \\
3539 \\
1560 \\
\hat{9} 644\end{array}$ & $\begin{array}{l}7478 \\
5376 \\
3338 \\
1365 \\
\hat{9} 456\end{array}$ & $\begin{array}{l}7265 \\
5169 \\
3138 \\
1172 \\
9269\end{array}$ & $\begin{array}{l}\tilde{1} 052 \\
4963 \\
2939 \\
0978 \\
9082\end{array}$ & $\begin{array}{l}6841 \\
4758 \\
2 \pi 40 \\
0786 \\
\hat{8} 896\end{array}$ & $\begin{array}{l}6629 \\
4553 \\
2541 \\
0591 \\
8 \hat{8} 110\end{array}$ & $\begin{array}{l}6419 \\
4349 \\
2: 44 \\
0403 \\
8525\end{array}$ \\
\hline $\begin{array}{l}1.10 \\
1.11 \\
1.12 \\
1.13 \\
1.14\end{array}$ & $\begin{array}{r}9.978341 \\
6531 \\
4783 \\
3096 \\
1469\end{array}$ & $\begin{array}{l}8157 \\
6351 \\
4612 \\
2931 \\
1309\end{array}$ & $\begin{array}{l}7974 \\
6177 \\
4441 \\
2766 \\
1150\end{array}$ & $\begin{array}{l}\tau 791 \\
6000 \\
42 \pi 1 \\
2602 \\
0992\end{array}$ & $\begin{array}{l}7610 \\
5825 \\
4101 \\
2438 \\
0835\end{array}$ & $\begin{array}{l}7428 \\
5650 \\
3932 \\
2275 \\
06 \%\end{array}$ & $\begin{array}{l}7248 \\
5+75 \\
3764 \\
2113 \\
0521\end{array}$ & $\begin{array}{l}7068 \\
5301 \\
3596 \\
1951 \\
0365\end{array}$ & $\begin{array}{l}6888 \\
5128 \\
31: 9 \\
1790 \\
0: 10\end{array}$ & $\begin{array}{l}6: 09 \\
4955 \\
326: 2 \\
1629 \\
0055\end{array}$ \\
\hline $\begin{array}{l}1.15 \\
1.16 \\
1.17 \\
1.18 \\
1.19\end{array}$ & $\begin{array}{r}9.969901 \\
8390 \\
6939 \\
5544 \\
4205\end{array}$ & $\begin{array}{l}9747 \\
8243 \\
6 \% 97 \\
5108 \\
4075\end{array}$ & $\begin{array}{l}9594 \\
8096 \\
6655 \\
52 \% 2 \\
3944\end{array}$ & $\begin{array}{l}9442 \\
7949 \\
6514 \\
5137 \\
3815\end{array}$ & $\begin{array}{l}9290 \\
7803 \\
63 \pi 4 \\
500: 3 \\
3686\end{array}$ & $\begin{array}{l}9139 \\
7658 \\
6234 \\
4868 \\
3557\end{array}$ & $\begin{array}{l}8988 \\
7513 \\
6095 \\
4734 \\
3429\end{array}$ & $\begin{array}{l}8838 \\
7369 \\
5957 \\
4601 \\
3302\end{array}$ & $\begin{array}{l}8688 \\
7: 225 \\
5818 \\
4469 \\
3175\end{array}$ & $\begin{array}{l}8539 \\
7082 \\
5681 \\
4337 \\
3048\end{array}$ \\
\hline $\begin{array}{l}1.2 \\
1.2 \\
1.2 \\
1.2 \\
1.2\end{array}$ & $\begin{array}{r}2922 \\
1695 \\
0521 \\
9.959401 \\
8335\end{array}$ & $\begin{array}{l}2 \% 97 \\
1575 \\
0407 \\
9: 9 \% \\
8231\end{array}$ & $\begin{array}{l}2672 \\
1456 \\
0: 29: 3 \\
9181 \\
81: 8\end{array}$ & $\begin{array}{l}2548 \\
1337 \\
0180 \\
9076 \\
8025\end{array}$ & $\begin{array}{l}2425 \\
1219 \\
0067 \\
8968 \\
\tau 923\end{array}$ & $\begin{array}{l}2302 \\
1101 \\
9955 \\
8861 \\
r 821\end{array}$ & $\begin{array}{l}2179 \\
0984 \\
8843 \\
8755 \\
7 \% 20\end{array}$ & $\begin{array}{l}2057 \\
086 \% \\
9 \tau 3: \\
8619 \\
\tau 6 \approx 0\end{array}$ & $\begin{array}{l}1936 \\
0751 \\
9621 \\
8544 \\
7520\end{array}$ & $\begin{array}{l}1815 \\
0636 \\
9511 \\
8439 \\
74: 0\end{array}$ \\
\hline $\begin{array}{l}1.25 \\
1.26 \\
1.27 \\
1.28 \\
1.28\end{array}$ & $\begin{array}{l}r 321 \\
6359 \\
5449 \\
4589 \\
3780\end{array}$ & $\begin{array}{l}7223 \\
626 \tau \\
5360 \\
4506 \\
3702\end{array}$ & $\begin{array}{l}7125 \\
6173 \\
5273 \\
4423 \\
3621\end{array}$ & $\begin{array}{l}7027 \\
6081 \\
5185 \\
4341 \\
\mathbf{3 5 4 7}\end{array}$ & $\begin{array}{l}6930 \\
5989 \\
5099 \\
4: 259 \\
34 \% 0\end{array}$ & $\begin{array}{l}6834 \\
5898 \\
5013 \\
41 \% 8 \\
3394\end{array}$ & $\begin{array}{l}6738 \\
5807 \\
4927 \\
4097 \\
3318\end{array}$ & $\begin{array}{l}6642 \\
5716 \\
4842 \\
4017 \\
3 \approx 43\end{array}$ & $\begin{array}{l}6547 \\
5627 \\
4757 \\
3938 \\
3168\end{array}$ & $\begin{array}{l}6453 \\
5537 \\
4673 \\
3858 \\
3094\end{array}$ \\
\hline $\begin{array}{l}1.3 \\
1.3 \\
1.3 \\
1.3 \\
1.3\end{array}$ & $\begin{array}{l}3020 \\
2310 \\
1648 \\
1035 \\
0470\end{array}$ & $\begin{array}{l}2947 \\
2242 \\
1585 \\
09 \pi 7 \\
0416\end{array}$ & $\begin{array}{l}28 \pi 4 \\
2174 \\
15: 22 \\
0918 \\
0362\end{array}$ & $\begin{array}{l}2802 \\
: 106 \\
1459 \\
0861 \\
0309\end{array}$ & $\begin{array}{l}2730 \\
2040 \\
1397 \\
0803 \\
0257\end{array}$ & $\begin{array}{l}2659 \\
1973 \\
13336 \\
0 \approx 47 \\
0205\end{array}$ & $\begin{array}{l}2589 \\
1907 \\
1275 \\
0690 \\
0153\end{array}$ & $\begin{array}{l}1214 \\
0634 \\
0102\end{array}$ & $\begin{array}{l}2448 \\
17 \% 7 \\
1154 \\
0.579 \\
0051\end{array}$ & $\begin{array}{l}23 \% 9 \\
1 \approx 12 \\
1094 \\
0.524 \\
0001\end{array}$ \\
\hline $\begin{array}{l}1.3 \\
1.3 \\
1.3 \\
1.3 \\
1.3\end{array}$ & $\begin{array}{r}9.919951 \\
9490 \\
9054 \\
8676 \\
8342\end{array}$ & $\begin{array}{l}9902 \\
9435 \\
9015 \\
8640 \\
8311\end{array}$ & $\begin{array}{l}9853 \\
9391 \\
89 \pi 5 \\
8605 \\
8280\end{array}$ & $\begin{array}{l}9805 \\
9348 \\
8936 \\
8571 \\
8250 .\end{array}$ & $\begin{array}{l}9757 \\
9304 \\
8898 \\
8537 \\
8221\end{array}$ & $\begin{array}{l}9710 \\
9: 622 \\
8859 \\
8503 \\
8192\end{array}$ & $\begin{array}{l}9663 \\
9219 \\
88: 22 \\
8470 \\
8163\end{array}$ & $\begin{array}{l}8437 \\
8135\end{array}$ & $\begin{array}{l}9571 \\
9136 \\
8748 \\
8405 \\
8107\end{array}$ & $\begin{array}{l}9.525 \\
9095 \\
8 \% 11 \\
8: 73 \\
8080\end{array}$ \\
\hline $\begin{array}{l}1.40 \\
1.41 \\
1.42 \\
1.43 \\
1.44\end{array}$ & $\begin{array}{l}7608 \\
7451 \\
7338\end{array}$ & $\begin{array}{l}8026 \\
\tau \% 86 \\
\tau 590 \\
7438 \\
73: 9\end{array}$ & $\begin{array}{l}8000 \\
7 \% 65 \\
75 \% 3 \\
7425 \\
7321\end{array}$ & $\begin{array}{l}\tau 9 \tau 5 \\
\tau \pi 44 \\
7556 \\
7413 \\
\tau 312\end{array}$ & $\begin{array}{l}7950 \\
7 \% 23 \\
7540 \\
7401 \\
7305\end{array}$ & $\begin{array}{l}7925 \\
7 \% 03 \\
7524 \\
7389 \\
7298\end{array}$ & $\begin{array}{l}7901 \\
7683 \\
7509 \\
73 ; 78 \\
7291\end{array}$ & $\begin{array}{l}78 \% 7 \\
7664 \\
7494 \\
7368 \\
7284\end{array}$ & $\begin{array}{l}7854 \\
7645 \\
74 \div 9 \\
7358 \\
72 \% 8\end{array}$ & $\begin{array}{l}\tau 831 \\
\tau 626 \\
7465 \\
\tau 348 \\
\tau 2 \tau 3\end{array}$ \\
\hline $\begin{array}{l}1.45 \\
1.46 \\
1.47 \\
1.48 \\
1.49\end{array}$ & $\begin{array}{l}7268 \\
7240 \\
7254 \\
7310 \\
7407\end{array}$ & $\begin{array}{l}7263 \\
7239 \\
7258 \\
7317 \\
7419\end{array}$ & $\begin{array}{l}\tilde{r}_{259} 259 \\
7239 \\
\tau 262 \\
\tau 326 \\
7431\end{array}$ & $\begin{array}{l}\tau 255 \\
\tau 240 \\
\tau 266 \\
\tau 234 \\
\tau 444\end{array}$ & $\begin{array}{l}\tau 251 \\
7 \approx 41 \\
\tau 271 \\
7343 \\
745 \%\end{array}$ & $\begin{array}{l}\tau 248 \\
724: \\
\tau 2 \% \\
7353 \\
7471\end{array}$ & $\begin{array}{l}\tau 246 \\
7243 \\
7 \approx 8: \\
7363 \\
7485\end{array}$ & $\begin{array}{l}r 244 \\
7245 \\
72 \backsim 9 \\
7373 \\
7499\end{array}$ & $\begin{array}{l}7242 \\
7248 \\
7: 95 \\
7384 \\
7515\end{array}$ & $\begin{array}{l}7241 \\
7251 \\
7302 \\
7395 \\
7529\end{array}$ \\
\hline
\end{tabular}


TABLE OF LOG $\mathrm{\Gamma}$ FUNCTIONS.

V.-TABLE OF LOG $\Gamma$ FUNCTIONS OF $p$ (see pages 32-34).

\begin{tabular}{|c|c|c|c|c|c|c|c|c|c|c|}
\hline$p$ & 0 & 1 & 2 & 3 & 4 & 5 & 6 & 7 & 8 & 9 \\
\hline $\begin{array}{l}1.50 \\
1.51 \\
1.52 \\
1.53 \\
1.54\end{array}$ & $\begin{array}{r}9.947545 \\
7724 \\
7943 \\
8201 \\
8500\end{array}$ & $\begin{array}{l}7561 \\
7744 \\
7967 \\
8229 \\
8532\end{array}$ & $\begin{array}{l}7577 \\
7764 \\
7991 \\
8258 \\
8564\end{array}$ & $\begin{array}{l}7594 \\
7785 \\
8016 \\
8987 \\
8597\end{array}$ & $\begin{array}{l}7612 \\
7806 \\
8011 \\
8316 \\
8630\end{array}$ & $\begin{array}{l}7629 \\
7829 \\
8067 \\
8346 \\
8664\end{array}$ & $\begin{array}{l}7647 \\
7850 \\
8093 \\
8376 \\
8698\end{array}$ & $\begin{array}{l}7666 \\
7873 \\
8120 \\
8406 \\
8732\end{array}$ & $\begin{array}{l}76.5 \\
7896 \\
8146 \\
8437 \\
8 \% 67\end{array}$ & $\begin{array}{l}7 \% 04 \\
7919 \\
8174 \\
8468 \\
8802\end{array}$ \\
\hline $\begin{array}{l}1.55 \\
1.56 \\
1.57 \\
1.58 \\
1.59\end{array}$ & $\begin{array}{r}8837 \\
9211 \\
9329 \\
9.950082 \\
05 \% 3\end{array}$ & $\begin{array}{l}88 \% 3 \\
9254 \\
96 \% 2 \\
0130 \\
0624\end{array}$ & $\begin{array}{l}8910 \\
9294 \\
9716 \\
0177 \\
06 \% 6\end{array}$ & $\begin{array}{l}8946 \\
9334 \\
9761 \\
0225 \\
0728\end{array}$ & $\begin{array}{l}8983 \\
9375 \\
9806 \\
02 \pi 4 \\
0780\end{array}$ & $\begin{array}{l}9021 \\
9417 \\
9851 \\
0323 \\
0833\end{array}$ & $\begin{array}{l}9059 \\
9158 \\
9896 \\
03 \% 2 \\
0886\end{array}$ & $\begin{array}{l}9097 \\
9500 \\
9942 \\
0422 \\
0939\end{array}$ & $\begin{array}{l}9135 \\
9543 \\
9989 \\
0472 \\
0993\end{array}$ & $\begin{array}{l}9174 \\
9586 \\
6035 \\
0522 \\
1047\end{array}$ \\
\hline $\begin{array}{l}1.60 \\
1.61 \\
1.62 \\
1.63 \\
1.64\end{array}$ & $\begin{array}{l}1102 \\
1668 \\
2271 \\
2911 \\
3587\end{array}$ & $\begin{array}{l}1157 \\
1727 \\
2333 \\
2977 \\
3656\end{array}$ & $\begin{array}{l}1212 \\
1786 \\
2396 \\
3043 \\
3726\end{array}$ & $\begin{array}{l}1268 \\
1845 \\
2459 \\
3110 \\
3797\end{array}$ & $\begin{array}{l}1324 \\
1905 \\
2522 \\
3177 \\
3867\end{array}$ & $\begin{array}{l}1380 \\
1965 \\
2586 \\
3244 \\
3938\end{array}$ & $\begin{array}{l}1437 \\
2025 \\
2650 \\
3312 \\
4010\end{array}$ & $\begin{array}{l}1494 \\
2086 \\
2715 \\
3380 \\
4081\end{array}$ & $\begin{array}{l}1552 \\
2147 \\
2780 \\
3449 \\
4154\end{array}$ & $\begin{array}{l}1610 \\
2209 \\
2845 \\
3517 \\
4226\end{array}$ \\
\hline $\begin{array}{l}1.65 \\
1.66 \\
1.67 \\
1.69 \\
1.69\end{array}$ & $\begin{array}{l}4299 \\
5047 \\
5830\end{array}$ & $\begin{array}{l}4372 \\
5124 \\
5911 \\
6733 \\
7590\end{array}$ & $\begin{array}{l}4446 \\
5201 \\
5991 \\
6817 \\
7678\end{array}$ & $\begin{array}{l}4519 \\
5: 78 \\
60 \% 2 \\
6901 \\
7 \% 66\end{array}$ & $\begin{array}{l}4594 \\
5356 \\
6154 \\
6986 \\
7854\end{array}$ & $\begin{array}{l}4668 \\
5434 \\
6235 \\
7072 \\
7943\end{array}$ & $\begin{array}{l}4743 \\
5513 \\
6317 \\
7157 \\
8032\end{array}$ & $\begin{array}{l}4819 \\
5592 \\
6400 \\
7243 \\
8122\end{array}$ & $\begin{array}{l}4894 \\
5671 \\
6482 \\
7329 \\
8211\end{array}$ & $\begin{array}{l}4970 \\
5750 \\
6566 \\
7416 \\
8301\end{array}$ \\
\hline $\begin{array}{l}1.70 \\
1.71 \\
1.72 \\
1.73 \\
1.74\end{array}$ & $\begin{array}{r}8391 \\
9314 \\
9.960271 \\
1262 \\
2287\end{array}$ & $\begin{array}{l}8482 \\
9409 \\
0369 \\
1363 \\
2391\end{array}$ & $\begin{array}{l}8573 \\
9502 \\
0467 \\
1464 \\
2496\end{array}$ & $\begin{array}{l}8664 \\
9598 \\
0565 \\
1566 \\
2601\end{array}$ & $\begin{array}{l}8756 \\
9: ; 93 \\
0664 \\
1668 \\
2706\end{array}$ & $\begin{array}{l}8848 \\
9788 \\
0 \% 63 \\
1 \% 0 \\
2812\end{array}$ & $\begin{array}{l}8941 \\
9884 \\
0862 \\
1873 \\
2918\end{array}$ & $\begin{array}{l}9034 \\
9980 \\
0961 \\
19 \% 6 \\
30: 4\end{array}$ & $\begin{array}{l}9127 \\
6077 \\
1061 \\
2079 \\
3131\end{array}$ & $\begin{array}{l}9220 \\
\text { ô174 } \\
1162 \\
2183 \\
3238\end{array}$ \\
\hline $\begin{array}{l}1.75 \\
1.76 \\
1.77 \\
1.78 \\
1.79\end{array}$ & $\begin{array}{l}3345 \\
4436 \\
5561\end{array}$ & $\begin{array}{l}3453 \\
4547 \\
5675 \\
6835 \\
8028\end{array}$ & $\begin{array}{l}3561 \\
4659 \\
5789 \\
6953 \\
8149\end{array}$ & $\begin{array}{l}3669 \\
4770 \\
5904 \\
7071 \\
82 \% 0\end{array}$ & $\begin{array}{l}3 \% 78 \\
4882 \\
6019 \\
7189 \\
8392\end{array}$ & $\begin{array}{l}3887 \\
4994 \\
6135 \\
7308 \\
8514\end{array}$ & $\begin{array}{l}3996 \\
5107 \\
6251 \\
7427 \\
8636\end{array}$ & $\begin{array}{l}4105 \\
5220 \\
6367 \\
7547 \\
8759\end{array}$ & $\begin{array}{l}4215 \\
5333 \\
6484 \\
7666 \\
8882\end{array}$ & $\begin{array}{l}4326 \\
5447 \\
6600 \\
7787 \\
9005\end{array}$ \\
\hline $\begin{array}{l}1.80 \\
1.81 \\
1.82 \\
1.83 \\
1.84\end{array}$ & $\begin{array}{r}9129 \\
9.970383 \\
1668 \\
2985 \\
4333\end{array}$ & $\begin{array}{l}9253 \\
0509 \\
1798 \\
3118 \\
4470\end{array}$ & $\begin{array}{l}9377 \\
0637 \\
19: 29 \\
3252 \\
4606\end{array}$ & $\begin{array}{l}9501 \\
0765 \\
2060 \\
3386 \\
\mathbf{4 7 4 4}\end{array}$ & $\begin{array}{l}9626 \\
0898 \\
2191 \\
3520 \\
4881\end{array}$ & $\begin{array}{l}9751 \\
1021 \\
2322 \\
3655 \\
5019\end{array}$ & $\begin{array}{l}9877 \\
1150 \\
2454 \\
3790 \\
5157\end{array}$ & $\begin{array}{l}2586 \\
3925 \\
5295\end{array}$ & $\begin{array}{l}\text { o129 } \\
1408 \\
2719 \\
4061 \\
5434\end{array}$ & $\begin{array}{l}6255 \\
1535 \\
2852 \\
4197 \\
5573\end{array}$ \\
\hline $\begin{array}{l}1.85 \\
1.86 \\
1.87 \\
1.88 \\
1.89\end{array}$ & $\begin{array}{r}5712 \\
7123 \\
8564 \\
9.980036 \\
1537\end{array}$ & $\begin{array}{l}5852 \\
7266 \\
8710 \\
0184 \\
1689\end{array}$ & $\begin{array}{l}5992 \\
7408 \\
8856 \\
0333 \\
1841\end{array}$ & $\begin{array}{l}6132 \\
7552 \\
9002 \\
0483 \\
1994\end{array}$ & $\begin{array}{l}6273 \\
7696 \\
9149 \\
0633 \\
2147\end{array}$ & $\begin{array}{l}6414 \\
7840 \\
9296 \\
0 \% 83 \\
2299\end{array}$ & $\begin{array}{l}6555 \\
7984 \\
9443 \\
0933 \\
2453\end{array}$ & $\begin{array}{l}6697 \\
8128 \\
9591 \\
1084 \\
2607\end{array}$ & $\begin{array}{l}6838 \\
82 \pi 3 \\
9739 \\
1234 \\
2761\end{array}$ & $\begin{array}{l}6980 \\
8419 \\
9887 \\
1386 \\
2915\end{array}$ \\
\hline $\begin{array}{l}1.90 \\
1.91 \\
1.92 \\
1.93 \\
1.94\end{array}$ & 30 & $\begin{array}{l}3224 \\
4789 \\
6383 \\
8007 \\
9660\end{array}$ & $\begin{array}{l}3379 \\
4947 \\
6544 \\
8171 \\
9827\end{array}$ & $\begin{array}{l}3535 \\
5105 \\
6706 \\
8336 \\
9995\end{array}$ & $\begin{array}{l}3690 \\
5264 \\
6867 \\
8500 \\
6162\end{array}$ & $\begin{array}{l}3846 \\
5423 \\
7029 \\
8665 \\
6330\end{array}$ & $\begin{array}{l}4003 \\
5582 \\
7192 \\
8830 \\
6198\end{array}$ & $\begin{array}{l}4159 \\
5 \% 42 \\
7354 \\
8996 \\
6666\end{array}$ & $\begin{array}{l}4316 \\
5902 \\
7517 \\
9161 \\
6835\end{array}$ & $\begin{array}{l}44 \pi 4 \\
6062 \\
7680 \\
9327 \\
1004\end{array}$ \\
\hline $\begin{array}{l}1.95 \\
1.96 \\
1.97 \\
1.98 \\
1.99\end{array}$ & $\begin{array}{r}9.991173 \\
2881 \\
4618 \\
6384 \\
8178\end{array}$ & $\begin{array}{l}3054 \\
4794 \\
6562 \\
8359\end{array}$ & $\begin{array}{l}1512 \\
32: 27 \\
4969 \\
6740 \\
8540\end{array}$ & $\begin{array}{l}1683 \\
3399 \\
5145 \\
6919 \\
8722\end{array}$ & $\begin{array}{l}1853 \\
3573 \\
5321 \\
7098 \\
8903\end{array}$ & $\begin{array}{l}2024 \\
3746 \\
5498 \\
72 \% 7 \\
9085\end{array}$ & $\begin{array}{l}2195 \\
3920 \\
56 \% 4 \\
7457 \\
9268\end{array}$ & $\begin{array}{l}2366 \\
4094 \\
5851 \\
7637 \\
9450\end{array}$ & $\begin{array}{l}2537 \\
4269 \\
6029 \\
7817 \\
9633\end{array}$ & $\begin{array}{l}2709 \\
4443 \\
6206 \\
7997 \\
9816\end{array}$ \\
\hline
\end{tabular}


VI.-TABLE OF REDUCTION FROM COMMON TO METRIC SYSTEM. -

\begin{tabular}{|c|c|c|c|c|c|c|c|c|c|}
\hline & \multicolumn{9}{|c|}{ Inches to Millimeters. } \\
\hline & 1 & 2 & 3 & 4 & 5 & 6 & 7 & 8 & 9 \\
\hline & 25.40 & 50.80 & $\approx 6.20$ & 101.60 & 127.00 & 152.40 & $17 \% .80$ & 203.20 & 228.60 \\
\hline i0 & 279.40 & 304.80 & 330.19 & 355.59 & 380.99 & 406.39 & 431.79 & 457.19 & $48 \div .59$ \\
\hline 20 & 533.39 & 558.79 & 584.19 & 609.59 & 634.99 & 660.39 & 685.79 & \%11.19 & 736.59 \\
\hline 30 & 787.39 & 812.79 & $\begin{array}{lll}838 & 19\end{array}$ & 863.59 & 888.99 & 914.39 & 939.78 & 965.18 & 990.58 \\
\hline 40 & 1041.4 & 1066.8 & 1092.2 & 1117.6 & 1143.0 & 1168.4 & 1193.8 & 1219.2 & 1244.6 \\
\hline 50 & 1295.4 & 1320.8 & 1346.2 & 1371.6 & 1397.0 & 1422.4 & 1447.8 & $14 \pi 3.2$ & 1498.6 \\
\hline 60 & 1549.4 & 1574.8 & 1600.2 & $16: 25.6$ & 1651.0 & $16,6.4$ & 1701.8 & 1727.2 & 1752.6 \\
\hline 70 & 1803.4 & 1828.8 & 1854.2 & 1879.6 & 1905.0 & 1930.4 & 1955.8 & 1981.2 & 2006.6 \\
\hline 80 & 2057.4 & 2082.8 & 2108.2 & 2133.6 & 2159.0 & 2181.4 & $2: 209.8$ & 2235.2 & 2260.6 \\
\hline 90 & 2311.4 & 2336.8 & 2362.2 & 2387.6 & 2413.0 & 2438.4 & 2463.8 & 2489.2 & .2514 .6 \\
\hline
\end{tabular}

Twelfths.

\begin{tabular}{r|r||r|r}
\hline $1 / 12$ & 2.12 & $7 / 12$ & 14.82 \\
$2 / 12$ & 4.23 & $8 / 12$ & 16.93 \\
$3 / 12$ & 6.35 & $9 / 12$ & 19.05 \\
$4 / 12$ & 8.47 & $10 / 12$ & 21.17 \\
$5 / 12$ & 10.58 & $11 / 12$ & 23.28 \\
$6 / 12$ & 12.70 & $12 / 12$ & 25.40 \\
\hline
\end{tabular}

Sixteenths.

\begin{tabular}{|l|l||r|r||r|r||r|r|r|}
\hline $1 / 16$ & 1.59 & $5 / 16$ & 7.94 & $9 / 16$ & 14.29 & $13 / 16$ & 20.64 \\
$1 / 8$ & 3.17 & $3 / 8$ & 9.52 & $5 / 8$ & 15.80 & $7 / 8$ & 22.22 \\
$3 / 16$ & 4.76 & $7 / 16$ & 11.11 & $11 / 16$ & 17.46 & $15 / 16$ & 23.81 \\
$1 / 4$ & 6.35 & $1 / 2$ & 12.70 & $3 / 4$ & 19.05 & 1 & 25.40 \\
& & & & & & & \\
\hline
\end{tabular}

TABLE VII.-MINUTES AND SECONDS IN DECIMALS OF A DEGREE.

\begin{tabular}{|c|c|c|c|c|c|c|c|c|c|c|c|}
\hline 1 & $\circ$ & ' & 0 & ' & $\circ$ & " & 。 & " & $\circ$ & " & $\circ$ \\
\hline 1 & .016666 & 21 & .350000 & 41 & .683333 & 1 & $.000278 *$ & 21 & .005833 & 41 & .011389 \\
\hline 2 & .033333 & 22 & .366666 & 42 & .700000 & 2 & .00055 & 22 & .006111 & 42 & .011667 \\
\hline 3 & .050000 & 23 & .383333 & 43 & .716666 & 3 & .000833 & 23 & .006389 & 43 & .011944 \\
\hline 4 & .066666 & 24 & .400000 & 44 & 33333 & 4 & .001111 & 24 & .006667 & 44 & .012222 \\
\hline 5 & .083333 & 25 & .416666 & 45 & .750000 & 5 & .001389 & 25 & .006944 & 45 & .012500 \\
\hline 6 & .100000 & 26 & .433333 & 46 & .766666 & 6 & .001667 & 26 & .007222 & 46 & .012778 \\
\hline 7 & .116666 & 27 & .450000 & 47 & 333 & 7 & .001 & 27 & .007500 & 47 & .013056 \\
\hline & .13 & 28 & .466666 & 48 & .80 & 8 & .002 & 28 & .007 & 48 & .01333 \\
\hline 9 & .150000 & 29 & .483333 & 49 & .816666 & 9 & .002500 & 29 & .008056 & 49 & .013611 \\
\hline 10 & .166666 & 30 & .500000 & 50 & .833333 & 10 & .002778 & 30 & .008333 & 50 & .013889 \\
\hline 11 & .18 & 31 & .516666 & 51 & .850000 & 11 & .0030 & 31 & .00 & 51 & .01 \\
\hline 12 & 000 & 32 & .5 & 52 & .866666 & 12 & .003333 & 32 & .0 & 52 & .0 \\
\hline 13 & 216666 & 33 & 000 & 53 & 3333 & 13 & .003611 & 33 & .0 & 53 & .0 \\
\hline 14 & 233333 & 34 & .566666 & 54 & .900000 & 14 & .003889 & 34 & .009444 & 54 & .015000 \\
\hline 15 & .250000 & 35 & .583333 & 55 & .916666 & 15 & .004167 & 35 & .009722 & 55 & .015278 \\
\hline 16 & 266666 & 36 & .600000 & 56 & .933333 & 16 & .004 & 36 & .010 & 56 & .01 \\
\hline 17 & 283333 & 37 & .616 & 57 & .950000 & 17 & .00 & 37 & .010278 & 57 & .01 \\
\hline & 300000 & 38 & 3 & 58 & 966666 & 18 & .005 & 38 & .010556 & 58 & .0 \\
\hline 19 & .316666 & 39 & .650000 & 59 & .983333 & 19 & .005278 & 39 & .010833 & 59 & .016389 \\
\hline 20 & .333333 & 40 & .666666 & 60 & 1.000000 & 20 & .005556 & 40 & .011111 & 60 & .016667 \\
\hline
\end{tabular}

$* .0002777778$. 
FIRST TO SIXTH POWERS OF INTEGERS.

TABLE VIII.-FIRST TO SIXTH POWERS OF INTEGERS FROM 1 TO 50.

\begin{tabular}{|c|c|c|c|c|c|}
\hline First. & Second. & Third. & Fourth. & Fifth. & Sixth. \\
\hline $\begin{array}{l}1 \\
2 \\
3 \\
4 \\
5\end{array}$ & $\begin{array}{r}1 \\
4 \\
9 \\
16 \\
25\end{array}$ & $\begin{array}{r}1 \\
8 \\
27 \\
64 \\
125\end{array}$ & $\begin{array}{r}1 \\
16 \\
81 \\
256 \\
625\end{array}$ & $\begin{array}{r}1 \\
33 \\
243 \\
1024 \\
3125\end{array}$ & $\begin{array}{r}1 \\
61 \\
729 \\
4096 \\
15625\end{array}$ \\
\hline $\begin{array}{r}6 \\
7 \\
8 \\
9 \\
10\end{array}$ & $\begin{array}{r}36 \\
49 \\
64 \\
81 \\
100\end{array}$ & $\begin{array}{r}216 \\
343 \\
512 \\
729 \\
1000\end{array}$ & $\begin{array}{r}1296 \\
2401 \\
4096 \\
6561 \\
10000\end{array}$ & $\begin{array}{r}7776 \\
16807 \\
32768 \\
59049 \\
100000\end{array}$ & $\begin{array}{r}46656 \\
117649 \\
262144 \\
531441 \\
1000000\end{array}$ \\
\hline $\begin{array}{l}11 \\
12 \\
13 \\
14 \\
15\end{array}$ & $\begin{array}{l}121 \\
144 \\
169 \\
196 \\
225\end{array}$ & $\begin{array}{l}1331 \\
1728 \\
2197 \\
2744 \\
3375\end{array}$ & $\begin{array}{l}14641 \\
20736 \\
28561 \\
33416 \\
50625\end{array}$ & $\begin{array}{l}161051 \\
24883: \\
371: 993 \\
5378 \% 4 \\
759375\end{array}$ & $\begin{array}{r}1771561 \\
2985984 \\
48: 6809 \\
75: 95336 \\
113906: 5\end{array}$ \\
\hline $\begin{array}{l}16 \\
17 \\
18 \\
19 \\
20\end{array}$ & $\begin{array}{l}256 \\
289 \\
321 \\
361 \\
400\end{array}$ & $\begin{array}{l}4096 \\
4913 \\
5832 \\
6859 \\
8000\end{array}$ & $\begin{array}{r}65536 \\
83521 \\
1049.6 \\
1303: 1 \\
160000\end{array}$ & $\begin{array}{l}10485 \% 6 \\
1419857 \\
1889568 \\
24 \tau 6099 \\
3200000\end{array}$ & $\begin{array}{l}1677 \% 216 \\
24137569 \\
34012: 24 \\
47045881 \\
64000000\end{array}$ \\
\hline $\begin{array}{l}21 \\
22 \\
23 \\
24 \\
25\end{array}$ & $\begin{array}{l}441 \\
484 \\
529 \\
5 \% 6 \\
6: 5\end{array}$ & $\begin{array}{r}9261 \\
10648 \\
1216 \pi \\
13824 \\
156: 5\end{array}$ & $\begin{array}{l}194481 \\
234256 \\
279841 \\
331776 \\
390625\end{array}$ & $\begin{array}{l}4084101 \\
5153632 \\
6436343 \\
7962624 \\
9765625\end{array}$ & $\begin{array}{r}85 \% 66121 \\
1133 \div 9904 \\
1480: 35889 \\
1911029 \% 6 \\
241140625\end{array}$ \\
\hline $\begin{array}{l}26 \\
27 \\
28 \\
29 \\
30\end{array}$ & $\begin{array}{l}676 \\
7 \% 9 \\
784 \\
841 \\
900\end{array}$ & $\begin{array}{l}17576 \\
19683 \\
21952 \\
24389 \\
27000\end{array}$ & $\begin{array}{c}456976 \\
531441 \\
614656 \\
707281 \\
810000\end{array}$ & $\begin{array}{l}118813 \pi 6 \\
14348907 \\
17210368 \\
20511149 \\
24300000\end{array}$ & $\begin{array}{l}308915 i ; 6 \\
38: 420489 \\
481890304 \\
594823321 \\
729900000\end{array}$ \\
\hline $\begin{array}{l}31 \\
32 \\
33 \\
34 \\
35\end{array}$ & $\begin{array}{r}961 \\
1024 \\
1089 \\
1156 \\
1225\end{array}$ & $\begin{array}{l}29791 \\
32768 \\
35937 \\
39304 \\
42875\end{array}$ & $\begin{array}{r}923521 \\
1048576 \\
1185921 \\
13363336 \\
1500625\end{array}$ & $\begin{array}{l}28629151 \\
33554432 \\
391353393 \\
45135494 \\
52521875\end{array}$ & $\begin{array}{r}887503681 \\
10737418 \% 4 \\
1291467969 \\
1544804416 \\
1838 \% 65625\end{array}$ \\
\hline $\begin{array}{l}36 \\
37 \\
38 \\
39 \\
40\end{array}$ & $\begin{array}{l}1296 \\
1369 \\
1444 \\
1521 \\
1600\end{array}$ & $\begin{array}{l}46656 \\
50653 \\
54872 \\
59319 \\
64000\end{array}$ & $\begin{array}{l}1679616 \\
1874161 \\
2085136 \\
2313441 \\
2560000\end{array}$ & $\begin{array}{r}60464176 \\
69343957 \\
79235168 \\
90224199 \\
102400000\end{array}$ & $\begin{array}{l}2176782336 \\
2565726409 \\
30109363384 \\
3518 \% 43761 \\
4096000000\end{array}$ \\
\hline $\begin{array}{l}41 \\
42 \\
43 \\
44 \\
45\end{array}$ & $\begin{array}{l}1681 \\
1764 \\
1849 \\
1936 \\
2025\end{array}$ & $\begin{array}{l}68921 \\
74088 \\
79507 \\
85184 \\
91125\end{array}$ & $\begin{array}{l}2825761 \\
3111696 \\
3418801 \\
3748096 \\
4100625\end{array}$ & $\begin{array}{l}115956201 \\
1306912: 32 \\
14700 \times 443 \\
1649162824 \\
184528125\end{array}$ & $\begin{array}{l}4750104241 \\
54-9031744 \\
6321363049 \\
7256313-56 \\
8303765625\end{array}$ \\
\hline $\begin{array}{l}46 \\
47 \\
49 \\
49 \\
50\end{array}$ & $\begin{array}{l}2116 \\
2: 209 \\
2304 \\
2401 \\
2500\end{array}$ & $\begin{array}{r}97336 \\
1033 \% 3 \\
110592 \\
117649 \\
125000\end{array}$ & $\begin{array}{l}4477456 \\
4879681 \\
5308416 \\
5764801 \\
6250000\end{array}$ & $\begin{array}{l}20: 96 \% 996 \\
229: 34500 \% \\
254803969 \\
242475949 \\
312500000\end{array}$ & 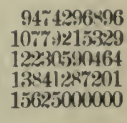 \\
\hline
\end{tabular}


TABLE IX.-PROBABLE ERRORS OF THE COEFFICIENT OF CORRELATION FOR VARIOUS NUMBERS OF OBSERVATIONS OR VARIATES $(n)$ AND FOR VARIOUS VALUES OF $r$.

Decimal point, properly preceding each entry, is omitted. (Specially Calculated.)

\begin{tabular}{|c|c|c|c|c|c|c|c|}
\hline \multirow{2}{*}{$\begin{array}{l}\text { Number } \\
\text { of Obser- } \\
\text { vations- }\end{array}$} & \multicolumn{7}{|c|}{ Correlation Coefficient $r$. } \\
\hline & 0.0 & 0.1 & 0.2 & 0.3 & 0.4 & 0.5 & 0.6 \\
\hline $\begin{array}{l}20 \\
30 \\
40 \\
50 \\
60\end{array}$ & $\begin{array}{l}1508 \\
1231 \\
1067 \\
0954 \\
0871\end{array}$ & $\begin{array}{l}1493 \\
1219 \\
1056 \\
0944 \\
0862\end{array}$ & $\begin{array}{l}1448 \\
1182 \\
1024 \\
0915 \\
0836\end{array}$ & $\begin{array}{l}1373 \\
1121 \\
0971 \\
0868 \\
0793\end{array}$ & $\begin{array}{l}1267 \\
1035 \\
0896 \\
0801 \\
0731\end{array}$ & $\begin{array}{l}1131 \\
0924 \\
0800 \\
0715 \\
0653\end{array}$ & $\begin{array}{l}0965 \\
0788 \\
0683 \\
0610 \\
0557\end{array}$ \\
\hline $\begin{array}{r}70 \\
80 \\
90 \\
100 \\
150\end{array}$ & $\begin{array}{l}0806 \\
0754 \\
0711 \\
0674 \\
0551\end{array}$ & $\begin{array}{l}0798 \\
0747 \\
0704 \\
0668 \\
0546\end{array}$ & $\begin{array}{l}0774 \\
0724 \\
0683 \\
0648 \\
0529\end{array}$ & $\begin{array}{l}0734 \\
0686 \\
0647 \\
0614 \\
0501\end{array}$ & $\begin{array}{l}0677 \\
0633 \\
0597 \\
0567 \\
0463\end{array}$ & $\begin{array}{l}0605 \\
0566 \\
0533 \\
0506 \\
0413\end{array}$ & $\begin{array}{l}0516 \\
0483 \\
0455 \\
0432 \\
0352\end{array}$ \\
\hline $\begin{array}{l}200 \\
250 \\
300 \\
400 \\
500\end{array}$ & $\begin{array}{l}0477 \\
0426 \\
0389 \\
0337 \\
0302\end{array}$ & $\begin{array}{l}0472 \\
0421 \\
0386 \\
0334 \\
0299\end{array}$ & $\begin{array}{l}0458 \\
0409 \\
0374 \\
0324 \\
0290\end{array}$ & $\begin{array}{l}0434 \\
0387 \\
0354 \\
0307 \\
0274\end{array}$ & $\begin{array}{l}0401 \\
0358 \\
0327 \\
0283 \\
0253\end{array}$ & $\begin{array}{l}0358 \\
0319 \\
0292 \\
0253 \\
0226\end{array}$ & $\begin{array}{l}0305 \\
0272 \\
0249 \\
0216 \\
0193\end{array}$ \\
\hline $\begin{array}{r}600 \\
700 \\
800 \\
900 \\
1000\end{array}$ & $\begin{array}{l}0275 \\
0255 \\
0239 \\
0225 \\
0213\end{array}$ & $\begin{array}{l}0272 \\
0252 \\
0236 \\
0222 \\
0211\end{array}$ & $\begin{array}{l}0264 \\
0245 \\
0229 \\
0216 \\
0205\end{array}$ & $\begin{array}{l}0251 \\
0232 \\
0217 \\
0205 \\
0194\end{array}$ & $\begin{array}{l}0232 \\
0214 \\
0200 \\
0189 \\
0179\end{array}$ & $\begin{array}{l}0207 \\
0191 \\
0179 \\
0169 \\
0160\end{array}$ & $\begin{array}{l}0176 \\
0163 \\
0153 \\
0144 \\
0137\end{array}$ \\
\hline \multirow[t]{2}{*}{$\begin{array}{l}2000 \\
5000\end{array}$} & $\begin{array}{l}0151 \\
0095\end{array}$ & $\begin{array}{l}0149 \\
0094\end{array}$ & $\begin{array}{l}0145 \\
0092\end{array}$ & $\begin{array}{l}0137 \\
00 S 7\end{array}$ & $\begin{array}{l}0127 \\
0080\end{array}$ & $\begin{array}{l}0113 \\
0072\end{array}$ & $\begin{array}{l}0097 \\
0061\end{array}$ \\
\hline & 0.65 & 0.7 & 0.75 & 0.8 & 0.85 & 0.9 & 0.95 \\
\hline $\begin{array}{l}20 \\
30 \\
40 \\
50 \\
60\end{array}$ & $\begin{array}{l}0871 \\
0711 \\
0616 \\
0551 \\
0503\end{array}$ & $\begin{array}{l}0769 \\
0628 \\
0544 \\
0486 \\
0444\end{array}$ & $\begin{array}{l}0660 \\
0539 \\
0467 \\
0417 \\
0381\end{array}$ & $\begin{array}{l}0543 \\
0444 \\
0384 \\
0343 \\
0313\end{array}$ & $\begin{array}{l}0419 \\
0342 \\
0296 \\
0265 \\
0241\end{array}$ & $\begin{array}{l}0287 \\
0234 \\
0203 \\
0181 \\
0165\end{array}$ & $\begin{array}{l}0147 \\
0120 \\
0104 \\
0093 \\
0085\end{array}$ \\
\hline $\begin{array}{r}70 \\
80 \\
90 \\
100 \\
150\end{array}$ & $\begin{array}{l}0466 \\
0436 \\
0411 \\
0391 \\
0318\end{array}$ & $\begin{array}{l}0411 \\
0385 \\
0363 \\
0345 \\
0281\end{array}$ & $\begin{array}{l}0353 \\
0330 \\
0311 \\
0294 \\
0241\end{array}$ & $\begin{array}{l}0290 \\
0271 \\
0256 \\
0242 \\
0198\end{array}$ & $\begin{array}{l}0224 \\
0209 \\
0197 \\
0187 \\
0153\end{array}$ & $\begin{array}{l}0153 \\
0143 \\
0135 \\
0128 \\
010.5\end{array}$ & $\begin{array}{l}0079 \\
0074 \\
0069 \\
0066 \\
0054\end{array}$ \\
\hline $\begin{array}{l}200 \\
250 \\
300 \\
400 \\
500\end{array}$ & $\begin{array}{l}0275 \\
0246 \\
0225 \\
0195 \\
0174\end{array}$ & $\begin{array}{l}0243 \\
0218 \\
0199 \\
0172 \\
0154\end{array}$ & $\begin{array}{l}0209 \\
0187 \\
0170 \\
0148 \\
0132\end{array}$ & $\begin{array}{l}0172 \\
0154 \\
0140 \\
0122 \\
0109\end{array}$ & $\begin{array}{l}0133 \\
0118 \\
0108 \\
0094 \\
0084\end{array}$ & $\begin{array}{r}0091 \\
0081 \\
0074 \\
0064 \\
0057\end{array}$ & $\begin{array}{l}0047 \\
0042 \\
0038 \\
0033 \\
0029\end{array}$ \\
\hline $\begin{array}{r}600 \\
700 \\
800 \\
900 \\
1000\end{array}$ & $\begin{array}{l}0159 \\
0147 \\
0138 \\
0130 \\
0123\end{array}$ & $\begin{array}{l}0140 \\
0130 \\
0122 \\
0114 \\
0109\end{array}$ & $\begin{array}{l}0121 \\
0112 \\
0105 \\
0098 \\
0093\end{array}$ & $\begin{array}{l}0099 \\
0092 \\
0086 \\
0081 \\
0077\end{array}$ & $\begin{array}{l}0076 \\
0071 \\
0066 \\
0062 \\
0059\end{array}$ & $\begin{array}{l}0052 \\
0049 \\
0045 \\
0043 \\
0041\end{array}$ & $\begin{array}{l}0027 \\
0025 \\
0023 \\
0022 \\
0021\end{array}$ \\
\hline $\begin{array}{l}2000 \\
5000\end{array}$ & $\begin{array}{l}0087 \\
0055\end{array}$ & $\begin{array}{l}0077 \\
0049\end{array}$ & $\begin{array}{l}0066 \\
0042\end{array}$ & $\begin{array}{l}0054 \\
0034\end{array}$ & $\begin{array}{l}0042 \\
0026\end{array}$ & $\begin{array}{l}0029 \\
0018\end{array}$ & $\begin{array}{l}0014 \\
0009\end{array}$ \\
\hline
\end{tabular}


TABLE X.-SQUARES, CUBES, ETC.

\begin{tabular}{|c|c|c|c|c|c|}
\hline No. & Squares. & Cubes. & $\begin{array}{c}\text { Square } \\
\text { Roots. }\end{array}$ & Cube Roots. & Reciprocals. \\
\hline $\begin{array}{l}1 \\
2 \\
3 \\
4 \\
5 \\
6 \\
7 \\
8 \\
9\end{array}$ & $\begin{array}{r}1 \\
4 \\
9 \\
16 \\
25 \\
36 \\
49 \\
64 \\
81\end{array}$ & $\begin{array}{r}1 \\
8 \\
27 \\
64 \\
125 \\
216 \\
343 \\
512 \\
729\end{array}$ & $\begin{array}{l}1.0000000 \\
1.4142136 \\
1.7320508 \\
2.0000000 \\
2.2360680 \\
24491897 \\
2.6457513 \\
2.8281271 \\
3.0000000\end{array}$ & $\begin{array}{l}1.0000000 \\
1.2599210 \\
1.4422496 \\
1.5874011 \\
1.7099759 \\
1.8171206 \\
1.9129812 \\
2.0000000 \\
2.0800837\end{array}$ & $\begin{array}{r}1.000000000 \\
.500000000 \\
.3333333333333 \\
.250000000 \\
.200000000 \\
.166666667 \\
.142857143 \\
.125000000 \\
.111111111\end{array}$ \\
\hline $\begin{array}{l}10 \\
11 \\
12 \\
13 \\
14 \\
15 \\
16 \\
17 \\
18 \\
19\end{array}$ & $\begin{array}{l}100 \\
121 \\
144 \\
169 \\
196 \\
225 \\
256 \\
289 \\
324 \\
361\end{array}$ & $\begin{array}{l}1000 \\
1331 \\
1728 \\
219 \tau \\
2744 \\
3375 \\
4096 \\
4913 \\
5832 \\
6859\end{array}$ & $\begin{array}{l}3.1622777 \\
3.3166248 \\
3.4641016 \\
3.6055513 \\
3.7416574 \\
3.8729833 \\
4.0000000 \\
4.1231056 \\
4.2426107 \\
4.3588989\end{array}$ & $\begin{array}{l}2.1544347 \\
2.2239801 \\
2.2894286 \\
2.3513347 \\
2.4101422 \\
2.4662121 \\
2.5198421 \\
2.5712816 \\
2.620 \% 414 \\
2.6684016\end{array}$ & $\begin{array}{l}.100000000 \\
.090909091 \\
.08333333333 \\
.076923077 \\
.071428571 \\
.0666666667 \\
.062500000 \\
.058823529 \\
.055555556 \\
.052631579\end{array}$ \\
\hline $\begin{array}{l}20 \\
21 \\
22 \\
23 \\
24 \\
25 \\
26 \\
27 \\
28 \\
29\end{array}$ & $\begin{array}{l}400 \\
441 \\
484 \\
529 \\
576 \\
625 \\
6 \% 6 \\
729 \\
784 \\
841\end{array}$ & $\begin{array}{r}8000 \\
9261 \\
10613 \\
12167 \\
13824 \\
15625 \\
17576 \\
19683 \\
21952 \\
24389\end{array}$ & $\begin{array}{l}4.4721360 \\
4.582575 \% \\
4.6904158 \\
4.7958315 \\
4.8989 \% 95 \\
5.0000000 \\
5.0990195 \\
5.1961524 \\
5.2915026 \\
5.3851648\end{array}$ & $\begin{array}{l}2.7144177 \\
2.7589243 \\
2.8020393 \\
2.8438670 \\
2.8844991 \\
2.9240177 \\
2.9624960 \\
3.0000000 \\
3.0365889 \\
3.0723168\end{array}$ & $\begin{array}{l}.050000000 \\
.047619048 \\
.045454545 \\
.043478261 \\
.041666667 \\
.040000000 \\
.038461538 \\
.037037037 \\
.035714286 \\
.034482759\end{array}$ \\
\hline $\begin{array}{l}30 \\
31 \\
32 \\
33 \\
34 \\
35 \\
36 \\
37 \\
38 \\
39\end{array}$ & $\begin{array}{r}900 \\
961 \\
1024 \\
1089 \\
1156 \\
1225 \\
1296 \\
1369 \\
1444 \\
1521\end{array}$ & $\begin{array}{l}27000 \\
29791 \\
32768 \\
35937 \\
39304 \\
42875 \\
46656 \\
50653 \\
548 \% 2 \\
59319\end{array}$ & $\begin{array}{l}5.472256 \\
5.56 \% 644 \\
5.6568542 \\
5.7445626 \\
5.8309519 \\
5.9160798 \\
6.0000000 \\
6.082 \% 625 \\
6.1644140 \\
6.2449980\end{array}$ & $\begin{array}{l}3.1072325 \\
3.1413806 \\
3.1748021 \\
3.2075243 \\
3.2306118 \\
3.2710663 \\
3.3019272 \\
3.3322218 \\
3.3619754 \\
3.3912114\end{array}$ & $\begin{array}{r}.033333333 \\
.032258065 \\
.031250000 \\
030303030 \\
.029411765 \\
.0285714: 29 \\
.02 \% 77 \% 8 \\
.027027027 \\
.026315 \% 89 \\
.025641026\end{array}$ \\
\hline $\begin{array}{l}40 \\
41 \\
42 \\
43 \\
44 \\
4.5 \\
46 \\
47 \\
48 \\
49\end{array}$ & $\begin{array}{l}1600 \\
1681 \\
1764 \\
1849 \\
1936 \\
2025 \\
2116 \\
2209 \\
2304 \\
2401\end{array}$ & $\begin{array}{r}64000 \\
68921 \\
74088 \\
79507 \\
85184 \\
91125 \\
97336 \\
103823 \\
110592 \\
11 \% 649\end{array}$ & $\begin{array}{l}6.3245553 \\
6.4031242 \\
6.480 \pi 407 \\
6.5574385 \\
6.6332406 \\
6.7082039 \\
6.7823300 \\
6.8556546 \\
6.9282032 \\
7.0000000\end{array}$ & $\begin{array}{l}3.4199519 \\
3.44821 \% 2 \\
3.4760266 \\
3.5033981 \\
3.5303483 \\
3.5568933 \\
3.5830479 \\
3.6088261 \\
3.6312411 \\
3.6593057\end{array}$ & $\begin{array}{l}.025000000 \\
.024390244 \\
.023809524 \\
.023255814 \\
.022 \% 27273 \\
.022222222 \\
.021739130 \\
.021276600 \\
.020833333 \\
.020408163\end{array}$ \\
\hline $\begin{array}{l}50 \\
51 \\
52 \\
53 \\
54 \\
55 \\
56 \\
57 \\
58 \\
59\end{array}$ & $\begin{array}{l}2500 \\
2601 \\
2704 \\
2809 \\
2916 \\
3025 \\
3136 \\
3249 \\
3364 \\
3481\end{array}$ & $\begin{array}{l}125000 \\
132651 \\
140608 \\
148877 \\
15 \% 464 \\
166375 \\
175616 \\
185193 \\
195112 \\
205379\end{array}$ & $\begin{array}{l}7.0710678 \\
7.1414284 \\
7.2111026 \\
7.2801099 \\
7.3484692 \\
7.4161985 \\
7.4833148 \\
7.5498344 \\
7.615 \% \\
7.6811457\end{array}$ & $\begin{array}{l}\text { 3. } 6810314 \\
\text { 3. } 7081298 \\
3.7325111 \\
3.7562858 \\
3.797631 \\
3.8029525 \\
3.8258624 \\
3.8185011 \\
3.8708766 \\
3.8929965\end{array}$ & $\begin{array}{l}.020000000 \\
.019607813 \\
.019230 \% 69 \\
.018867925 \\
.018518519 \\
.018181818 \\
.01 \% 85 \% 143 \\
.017543860 \\
.017241379 \\
.016949153\end{array}$ \\
\hline $\begin{array}{l}60 \\
61 \\
62\end{array}$ & $\begin{array}{l}3600 \\
3721 \\
3844\end{array}$ & $\begin{array}{l}216000 \\
226981 \\
2383 \pm 8\end{array}$ & $\begin{array}{l}7.7459667 \\
7.8102497 \\
7.8 \div 40079\end{array}$ & $\begin{array}{l}3.9148676 \\
3.9364972 \\
3.9575915\end{array}$ & $\begin{array}{l}.016666667 \\
.016393443 \\
.016129032\end{array}$ \\
\hline
\end{tabular}


TABLE X.-SQUARES, CUBES, SQUARE ROOTS,

\begin{tabular}{|c|c|c|c|c|c|}
\hline No. & Squares. & Cubes. & $\begin{array}{c}\text { Square } \\
\text { Roots. }\end{array}$ & Cube Roots. & Reciprocals. \\
\hline $\begin{array}{l}63 \\
64 \\
65 \\
66 \\
6 \% \\
68 \\
69\end{array}$ & $\begin{array}{l}3969 \\
4096 \\
4225 \\
4356 \\
4489 \\
4624 \\
4 \div 61\end{array}$ & $\begin{array}{l}250047 \\
262144 \\
2 \tau 4625 \\
287496 \\
300763 \\
314432 \\
328509\end{array}$ & $\begin{array}{l}7.03 \% 2539 \\
8.0000000 \\
8.06225 \% 7 \\
8.1240384 \\
8.1853528 \\
8.2462113 \\
8.3066239\end{array}$ & $\begin{array}{l}3.9790571 \\
4.0000000 \\
4.0207256 \\
4.0412401 \\
4.0615480 \\
4.0816551 \\
4.1015661\end{array}$ & $\begin{array}{l}.015873016 \\
.015625000 \\
.015384615 \\
.015151515 \\
.014925373 \\
.014705882 \\
.014192 \% 54\end{array}$ \\
\hline $\begin{array}{l}70 \\
71 \\
72 \\
73 \\
74 \\
74 \\
75 \\
76 \\
77 \\
78 \\
79\end{array}$ & $\begin{array}{l}4900 \\
5041 \\
5184 \\
5329 \\
54 \% 6 \\
5625 \\
57 \% 6 \\
5929 \\
6084 \\
6211\end{array}$ & $\begin{array}{l}313000 \\
35 \% 911 \\
3 \% 3248 \\
389017 \\
405224 \\
4218 \pi 5 \\
4389 \% 6 \\
456533 \\
4 \pi 4552 \\
493039\end{array}$ & $\begin{array}{l}8.3666003 \\
8.4261498 \\
8.4852814 \\
8.540037 \\
8.6023253 \\
8.6602540 \\
8.717 \% 979 \\
8.7149644 \\
8.831 \% 609 \\
8.8881944\end{array}$ & $\begin{array}{l}4.1212853 \\
4.1408178 \\
4.1601676 \\
4.1793390 \\
4.1983364 \\
4.2171633 \\
4.2358236 \\
4.2513210 \\
4.2726586 \\
4.2908404\end{array}$ & $\begin{array}{l}.014285714 \\
.014084507 \\
.013888889 \\
013698630 \\
.013513514 \\
.0133333333 \\
.013157895 \\
.01248 \% 013 \\
.012820513 \\
.012658828\end{array}$ \\
\hline $\begin{array}{l}80 \\
81 \\
82 \\
83 \\
81 \\
85 \\
86 \\
87 \\
88 \\
89\end{array}$ & $\begin{array}{l}6400 \\
6561 \\
67221 \\
6889 \\
r 056 \\
r 225 \\
7396 \\
r 569 \\
r 744 \\
r 921\end{array}$ & $\begin{array}{l}512000 \\
531441 \\
551368 \\
57178 \% \\
592 \% 01 \\
614125 \\
636056 \\
658503 \\
681472 \\
704969\end{array}$ & $\begin{array}{l}8.9442 \% 19 \\
9.0000000 \\
9.0553851 \\
9.1104336 \\
9.1651514 \\
9.2195445 \\
9.2736185 \\
9.3273791 \\
9.3808315 \\
9.4339811\end{array}$ & $\begin{array}{l}4.3088695 \\
4.3267487 \\
4.3444815 \\
4.3620707 \\
4.3795191 \\
4.3968296 \\
4.4140049 \\
4.4310476 \\
4.4479602 \\
4.4647451\end{array}$ & $\begin{array}{l}.012500000 \\
.0123456 \% 9 \\
.012195122 \\
.012048193 \\
.011901 \% 62 \\
.011764706 \\
.011627907 \\
.011491253 \\
.011363636 \\
.011235955\end{array}$ \\
\hline $\begin{array}{l}90 \\
91 \\
92 \\
93 \\
94 \\
95 \\
96 \\
9 \pi \\
98 \\
99\end{array}$ & $\begin{array}{l}8100 \\
8281 \\
8464 \\
8649 \\
8836 \\
9025 \\
9216 \\
9409 \\
9604 \\
9801\end{array}$ & $\begin{array}{l}729000 \\
7535 \% 1 \\
7 \% 8688 \\
804357 \\
830581 \\
85 \% 3 \% 5 \\
881736 \\
9126 \% 3 \\
941192 \\
9 \% 0299\end{array}$ & $\begin{array}{l}9.4868330 \\
9.5393920 \\
9.5916630 \\
9.6436508 \\
9.6953597 \\
9.746 \tau 943 \\
9.7979590 \\
9.84885 \% 8 \\
9.8994949 \\
9.9498 \% 44\end{array}$ & $\begin{array}{l}4.4814047 \\
4.49 \% 9414 \\
4.51435 \pi 4 \\
4.5306549 \\
4.5468359 \\
4.5629026 \\
4.5788570 \\
4.5947009 \\
4.6104363 \\
4.6260650\end{array}$ & $\begin{array}{l}.011111111 \\
.010989011 \\
.010809565 \\
.010752688 \\
.010638298 \\
.010526316 \\
.010416667 \\
.010309278 \\
.010204082 \\
.010101010\end{array}$ \\
\hline $\begin{array}{l}100 \\
101 \\
102 \\
103 \\
104 \\
105 \\
106 \\
107 \\
108 \\
109\end{array}$ & $\begin{array}{l}10000 \\
10: 201 \\
10404 \\
10609 \\
10816 \\
110: 25 \\
11236 \\
11449 \\
11664 \\
11881\end{array}$ & $\begin{array}{l}1000000 \\
1030301 \\
1061208 \\
1092727 \\
1124864 \\
1157625 \\
1191016 \\
1225013 \\
1259712 \\
1295029\end{array}$ & $\begin{array}{l}10.0000000 \\
10.0498756 \\
10.0995049 \\
10.1488916 \\
10.1980390 \\
10.2469508 \\
10.2956301 \\
10.3440804 \\
10.3923048 \\
10.4403065\end{array}$ & 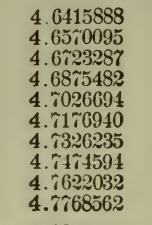 & $\begin{array}{l}.010000000 \\
.009900990 \\
.009803922 \\
.009708738 \\
.009615385 \\
.009523810 \\
.009433962 \\
.009345 \% 94 \\
.007259259 \\
.0091 \div 4312\end{array}$ \\
\hline $\begin{array}{l}110 \\
111 \\
112 \\
113 \\
114 \\
115 \\
116 \\
117 \\
118 \\
119\end{array}$ & $\begin{array}{l}12100 \\
12321 \\
12541 \\
12769 \\
12996 \\
13225 \\
13456 \\
13689 \\
13924 \\
14161\end{array}$ & $\begin{array}{l}1331000 \\
1367631 \\
1404928 \\
1442897 \\
1481544 \\
15208 \% 5 \\
1560896 \\
1601613 \\
1643032 \\
1685159\end{array}$ & $\begin{array}{l}10.4880885 \\
10.5356538 \\
10.5830052 \\
10.6301458 \\
10 .(770783 \\
10.7238053 \\
10.703296 \\
10.8166538 \\
10.862780 .5 \\
10.908 \% 121\end{array}$ & $\begin{array}{l}4.7914199 \\
4.8058955 \\
4.8202845 \\
4.8345881 \\
4.81880 \% 6 \\
4.8629442 \\
4.8769990 \\
4.8909732 \\
4.9048681 \\
4.9186847\end{array}$ & $\begin{array}{l}.009090909 \\
.009009009 \\
.0089285 ; 1 \\
.008849558 \\
.008 \% 1930 \\
.008695652 \\
.008620690 \\
.008547009 \\
.00847456 \\
.008403361\end{array}$ \\
\hline $\begin{array}{l}120 \\
121 \\
122 \\
123 \\
124\end{array}$ & $\begin{array}{l}14400 \\
14641 \\
14881 \\
15129 \\
153 \% 6\end{array}$ & $\begin{array}{l}1728000 \\
171561 \\
1815848 \\
1860867 \\
1906624\end{array}$ & $\begin{array}{l}10.9544512 \\
11.000000 \\
11.0153610 \\
11.0905365 \\
11.1355287\end{array}$ & $\begin{array}{l}4.9324242 \\
4.9460874 \\
4.9596757 \\
4.9731898 \\
4.9866310\end{array}$ & $\begin{array}{l}.008333333 \\
.008264463 \\
.008196721 \\
.008130081 \\
.008064516\end{array}$ \\
\hline
\end{tabular}


CUBE ROOTS, AND RECIPROCALS.

\begin{tabular}{|c|c|c|c|c|c|}
\hline No. & Squares. & Cubes. & $\begin{array}{l}\text { Square } \\
\text { Roots. }\end{array}$ & Cube Roots. & Reciprocals. \\
\hline $\begin{array}{l}125 \\
1: 26 \\
1: 2 \\
128 \\
129\end{array}$ & $\begin{array}{l}15625 \\
158 \pi 6 \\
16129 \\
16384 \\
16641\end{array}$ & $\begin{array}{l}1953125 \\
20003 \% 6 \\
2048383 \\
2097152 \\
2146689\end{array}$ & $\begin{array}{l}11.1803399 \\
11.2249722 \\
11.26942 \% 7 \\
11.313 \% 085 \\
11.3578167\end{array}$ & $\begin{array}{l}5.0000000 \\
5.0132979 \\
5.0265: 57 \\
5.0396842 \\
5.052 \% 74\end{array}$ & $\begin{array}{l}.008000000 \\
.00 \% 936508 \\
.00 \% 8 \% 4016 \\
.00 \% 812500 \\
.00 \% 751938\end{array}$ \\
\hline $\begin{array}{l}130 \\
131 \\
132 \\
133 \\
134 \\
135 \\
136 \\
137 \\
138 \\
139\end{array}$ & $\begin{array}{l}16900 \\
1 \% 161 \\
1 \% 424 \\
1 \% 689 \\
17956 \\
18225 \\
18496 \\
18 \% 69 \\
19044 \\
19321\end{array}$ & $\begin{array}{l}219 \pi 000 \\
2248091 \\
2299968 \\
2352637 \\
2406104 \\
24603 \pi 5 \\
2515456 \\
25 \pi 1353 \\
26280 \pi 2 \\
2685619\end{array}$ & $\begin{array}{l}11.401 \% 543 \\
11.4455231 \\
11.4891253 \\
11.53225626 \\
11.5 \% 58369 \\
11.6189500 \\
11.66190338 \\
11.7046999 \\
11 . \% 473401 \\
11.7898261\end{array}$ & $\begin{array}{l}5.065 \% 970 \\
5.0 \% 8 \% 531 \\
5.0916434 \\
5.1044687 \\
5.11 \% 2299 \\
5.1299278 \\
5.1425632 \\
5.1551367 \\
5.16 \% 6493 \\
5.1801015\end{array}$ & $\begin{array}{l}.007692308 \\
.007633 .588 \\
.007575 \% 78 \\
.007518 \% 97 \\
.00 \% 462687 \\
.00740 \% 407 \\
.007352941 \\
.007299270 \\
.007246 \% 77 \\
.007194245\end{array}$ \\
\hline $\begin{array}{l}140 \\
141 \\
142 \\
143 \\
144 \\
145 \\
146 \\
147 \\
148 \\
149\end{array}$ & $\begin{array}{l}19600 \\
19881 \\
20164 \\
20449 \\
20 \% 36 \\
21025 \\
21316 \\
21609 \\
21904 \\
22201\end{array}$ & $\begin{array}{l}2744000 \\
2803221 \\
2863288 \\
2924207 \\
2985984 \\
3018625 \\
3112136 \\
31 \sim 6523 \\
3241792 \\
3307949\end{array}$ & $\begin{array}{l}11.8321596 \\
11.8 \sim 43421 \\
11.9163753 \\
11.958260 \% \\
12.0000000 \\
12.0415946 \\
12.0830460 \\
12.124355 \% \\
12.1655251 \\
12.2065556\end{array}$ & $\begin{array}{l}5.1924941 \\
5.2048279 \\
5.2171034 \\
5.2293215 \\
5.2414828 \\
5.2535879 \\
5.26563 \% 4 \\
5.27 \% 6321 \\
5.2895 \pi 25 \\
5.3014592\end{array}$ & $\begin{array}{l}.00 \% 142857 \\
.007092199 \\
.007042254 \\
.006993007 \\
.006944144 \\
.006896552 \\
.006849315 \\
.006802 \% 21 \\
.006 \pi 5 \% 57 \\
.006 \pi 11409\end{array}$ \\
\hline $\begin{array}{l}150 \\
151 \\
152 \\
153 \\
154 \\
155 \\
156 \\
157 \\
158 \\
159\end{array}$ & $\begin{array}{l}22500 \\
22801 \\
23104 \\
23409 \\
23 \% 16 \\
24025 \\
24336 \\
24649 \\
24964 \\
25281\end{array}$ & $\begin{array}{l}3375000 \\
3442951 \\
3511808 \\
35815 \pi 7 \\
3652264 \\
37238 \pi 5 \\
3796416 \\
3869893 \\
3944312 \\
4019679\end{array}$ & $\begin{array}{l}12.4474487 \\
12.2882057 \\
12.3288280 \\
12.3693169 \\
12.4096736 \\
12.4198996 \\
12.4899960 \\
12.5299641 \\
12.5698051 \\
12.6095202\end{array}$ & 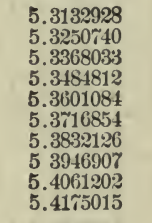 & $\begin{array}{l}.006666667 \\
.006622517 \\
.0065 \% 8947 \\
.0065355948 \\
.006493506 \\
.006451613 \\
.006410256 \\
.006369427 \\
.006329114 \\
.006289308\end{array}$ \\
\hline $\begin{array}{l}160 \\
161 \\
162 \\
163 \\
164 \\
165 \\
166 \\
167 \\
168 \\
169\end{array}$ & $\begin{array}{l}25600 \\
25921 \\
26244 \\
26569 \\
26896 \\
27225 \\
27556 \\
27889 \\
28224 \\
28561\end{array}$ & $\begin{array}{l}4096000 \\
41 \sim 3281 \\
4251528 \\
4330 \% 47 \\
4410944 \\
4492125 \\
45 \approx 4296 \\
465 \approx 463 \\
4 \pi 41632 \\
4826809\end{array}$ & $\begin{array}{l}12.6491106 \\
12.6885 \% 75 \\
12.7279221 \\
12.7671453 \\
12.8062485 \\
12.8452326 \\
12.8840987 \\
12.9228480 \\
12.9614814 \\
13.0000000\end{array}$ & $\begin{array}{l}5.4288352 \\
5.4401218 \\
5.4513618 \\
5.4625556 \\
5.473 \% 037 \\
5.4848066 \\
5.4958647 \\
5.5068 \% 84 \\
5.5178484 \\
5.5287 \% 48\end{array}$ & $\begin{array}{l}.006250000 \\
.006211180 \\
.0061 \% 2810 \\
.006134969 \\
.006097561 \\
.006060606 \\
.006021096 \\
.005983024 \\
.005952381 \\
.00591 \approx 160\end{array}$ \\
\hline $\begin{array}{l}170 \\
171 \\
172 \\
173 \\
174 \\
175 \\
176 \\
176 \\
178 \\
179\end{array}$ & $\begin{array}{l}28900 \\
29241 \\
29584 \\
29929 \\
302 \% 6 \\
30625 \\
309 \% 6 \\
31329 \\
31684 \\
32041\end{array}$ & $\begin{array}{l}4913000 \\
5000211 \\
5088148 \\
5177 \% 17 \\
5268024 \\
53593 \% 5 \\
545176 \\
5545233 \\
5639 \% 52 \\
5 \pi 35339\end{array}$ & $\begin{array}{l}13.0394048 \\
13.0766968 \\
13.1148 \% 70 \\
13.1529464 \\
13.1909060 \\
13.2287566 \\
13.2664992 \\
13.3041347 \\
13.3416641 \\
13.3790882\end{array}$ & $\begin{array}{l}5.5396583 \\
5.5504991 \\
5.56129 \% 8 \\
5.5720546 \\
5.582702 \\
5.5934447 \\
5.6040 \% 97 \\
5.6146 \% 24 \\
5.6252263 \\
5.635 \% 408\end{array}$ & $\begin{array}{l}.005882353 \\
.005817953 \\
.005813953 \\
.005780347 \\
.005 \pi 47126 \\
.005714286 \\
.005681818 \\
.005649718 \\
.005617978 \\
.00558659:\end{array}$ \\
\hline $\begin{array}{l}180 \\
181 \\
182 \\
183 \\
184 \\
185 \\
186\end{array}$ & $\begin{array}{l}32400 \\
32 \tau 61 \\
33124 \\
3: 3489 \\
33856 \\
34225 \\
34596\end{array}$ & $\begin{array}{l}5832000 \\
5929 \% 41 \\
6028568 \\
6128487 \\
6229504 \\
6331625 \\
6434856\end{array}$ & $\begin{array}{l}13.4164079 \\
13.4536240 \\
13.49073 \% 6 \\
13.527493 \\
13.5646600 \\
13.6014705 \\
13.6381817\end{array}$ & $\begin{array}{l}5.6462162 \\
5.65665: 8 \\
5.66 \% 0511 \\
5.67 \% 4114 \\
5.68 \% 7340 \\
5.6980192 \\
5.7082675\end{array}$ & $\begin{array}{l}.0055555556 \\
.005524862 \\
.005494505 \\
.005464481 \\
.005434783 \\
.005405405 \\
.005376344\end{array}$ \\
\hline
\end{tabular}


TABLE X. -SQUARES, CUBES, SQUARE ROOTS,

\begin{tabular}{|c|c|c|c|c|c|}
\hline No. & Squares. & Cubes. & $\begin{array}{l}\text { Square } \\
\text { Roots. }\end{array}$ & Cube Roots. & Reciprocals. \\
\hline $\begin{array}{l}187 \\
188 \\
189\end{array}$ & $\begin{array}{l}34969 \\
35344 \\
35 \% 21\end{array}$ & $\begin{array}{l}6539203 \\
66446 \% 2 \\
6 \% 51269\end{array}$ & $\begin{array}{l}13.6 \% 47943 \\
13.7113092 \\
13.74 \% 271\end{array}$ & $\begin{array}{l}\text { 5. } 7184791 \\
\text { 5.7286543 } \\
\text { 5.7387936 }\end{array}$ & $\begin{array}{l}.005347594 \\
.005319149 \\
.005291005\end{array}$ \\
\hline $\begin{array}{l}190 \\
191 \\
192 \\
193 \\
194 \\
195 \\
196 \\
197 \\
198 \\
199\end{array}$ & $\begin{array}{l}36100 \\
36481 \\
36864 \\
37249 \\
37636 \\
38025 \\
38416 \\
38809 \\
39204 \\
39601\end{array}$ & $\begin{array}{l}6859000 \\
6967871 \\
70 \% 7888 \\
7189057 \\
7301384 \\
7414875 \\
7529536 \\
7645373 \\
r 762392 \\
r 880599\end{array}$ & $\begin{array}{l}13.7840488 \\
13.8202750 \\
13.8564065 \\
13.8924440 \\
13.9283883 \\
13.9642400 \\
14.0000000 \\
14.0356688 \\
14.0 \% 12473 \\
14.1067360\end{array}$ & $\begin{array}{l}\text { 5. } .48899 \% 1 \\
5.7589652 \\
5.7689982 \\
5.1789966 \\
5.7889604 \\
5.7988900 \\
5.8087857 \\
5.8186479 \\
5.8284767 \\
5.8382725\end{array}$ & $\begin{array}{r}.005263158 \\
.005235602 \\
.005208333 \\
.005181347 \\
.005154639 \\
.005128205 \\
.005102041 \\
.005076142 \\
.005050505 \\
.005025126\end{array}$ \\
\hline $\begin{array}{l}200 \\
201 \\
202 \\
203 \\
204 \\
205 \\
206 \\
207 \\
208 \\
209\end{array}$ & $\begin{array}{l}40000 \\
40401 \\
40804 \\
41209 \\
41616 \\
42025 \\
42436 \\
42849 \\
43264 \\
43681\end{array}$ & $\begin{array}{l}8000000 \\
8120601 \\
8242408 \\
8365427 \\
8189664 \\
8615125 \\
8741816 \\
8869743 \\
8998912 \\
9129329\end{array}$ & $\begin{array}{l}14.1421356 \\
14.17 \% 4469 \\
14.2126 \% 04 \\
14.24 \% 8068 \\
14.2828569 \\
14.31 \% 8211 \\
14.352 \% 001 \\
14.38 \% 4946 \\
14.4222051 \\
14.4568323\end{array}$ & $\begin{array}{l}5.8480355 \\
5.85 \% 660 \\
5.86 \% 4643 \\
5.8 \% 1130 \% \\
5.8867653 \\
5.8963685 \\
5.9059406 \\
5.9154817 \\
5.9249921 \\
5.934421\end{array}$ & $\begin{array}{r}.005000000 \\
.004975124 \\
.004950495 \\
.004926108 \\
.004901961 \\
.0048 ; 8049 \\
.004854369 \\
.0048 \% 0918 \\
.004805692 \\
.004784689\end{array}$ \\
\hline $\begin{array}{l}210 \\
211 \\
212 \\
213 \\
214 \\
215 \\
216 \\
217 \\
218 \\
219\end{array}$ & $\begin{array}{l}44100 \\
44521 \\
44944 \\
45369 \\
45796 \\
46225 \\
46656 \\
4: 089 \\
47524 \\
47961\end{array}$ & $\begin{array}{r}9261000 \\
9393931 \\
9528128 \\
9663597 \\
9800344 \\
9938375 \\
100 \% 696 \\
10218313 \\
10360232 \\
10503459\end{array}$ & $\begin{array}{l}14.4913 \% 67 \\
14.5258390 \\
14.5602198 \\
14.5945195 \\
14.6287388 \\
14.6628783 \\
14.6969385 \\
14.7309199 \\
14.7648231 \\
14.7986486\end{array}$ & $\begin{array}{l}5.9439220 \\
5.9533418 \\
5.9627320 \\
5.9720926 \\
5.9814240 \\
5.9907264 \\
6.0000000 \\
6.0092450 \\
6.0184617 \\
6.0276502\end{array}$ & $\begin{array}{l}.004761905 \\
.004739336 \\
.004716981 \\
.004694836 \\
.0046 i 2897 \\
.004651163 \\
.004629630 \\
.004608295 \\
.004587156 \\
.004566210\end{array}$ \\
\hline $\begin{array}{l}220 \\
221 \\
222 \\
223 \\
224 \\
225 \\
226 \\
227 \\
228 \\
229\end{array}$ & $\begin{array}{l}48400 \\
48841 \\
49284 \\
49 \% \approx 9 \\
501 \% 6 \\
50625 \\
510 \% 6 \\
51529 \\
51984 \\
52441\end{array}$ & $\begin{array}{l}10648000 \\
10 \div 93861 \\
10941048 \\
11089567 \\
11239424 \\
11390625 \\
11543176 \\
11697083 \\
11852352 \\
12008989\end{array}$ & $\begin{array}{l}14.8323970 \\
14.8660687 \\
14.8996644 \\
14.9331845 \\
14.9666295 \\
15.0000000 \\
15.0332964 \\
15.0665192 \\
15.0996689 \\
15.1327460\end{array}$ & $\begin{array}{l}6.0368107 \\
6.0459435 \\
6.0550489 \\
6.0641270 \\
6.0731779 \\
6.0822020 \\
6.0911994 \\
6.1001702 \\
6.1091147 \\
6.1180332\end{array}$ & $\begin{array}{l}.004545455 \\
.004524887 \\
.004504505 \\
.004484305 \\
.004464286 \\
.004444444 \\
.004424779 \\
.004405286 \\
.004385965 \\
.004366812\end{array}$ \\
\hline $\begin{array}{l}230 \\
231 \\
232 \\
233 \\
234 \\
235 \\
2: 36 \\
237 \\
238 \\
239\end{array}$ & $\begin{array}{l}52900 \\
53361 \\
53824 \\
54289 \\
54756 \\
55225 \\
55696 \\
56169 \\
56644 \\
57121\end{array}$ & $\begin{array}{l}1216 \% 000 \\
12326391 \\
12487168 \\
12649337 \\
12812904 \\
1297875 \\
13144256 \\
13312053 \\
13481272 \\
13651919\end{array}$ & $\begin{array}{l}15.1657509 \\
15.1986842 \\
15.231546 \approx \\
15.2643375 \\
15.2970585 \\
15.3297097 \\
15.3622915 \\
15.3948043 \\
15.4272486 \\
15.4596248\end{array}$ & $\begin{array}{l}6.1269257 \\
6.135 r 924 \\
6.1446337 \\
6.1534495 \\
6.1622401 \\
6.1710058 \\
6.1797466 \\
6.1884628 \\
6.1971544 \\
6.2058218\end{array}$ & $\begin{array}{l}.004347826 \\
.004329004 \\
.004310345 \\
.004291845 \\
.0042 ; 3504 \\
.004255319 \\
.004237288 \\
.004219409 \\
.004201681 \\
.004184100\end{array}$ \\
\hline $\begin{array}{l}240 \\
241 \\
242 \\
243 \\
244 \\
245 \\
246 \\
247 \\
248\end{array}$ & $\begin{array}{l}57600 \\
58081 \\
58564 \\
59049 \\
595336 \\
60025 \\
60516 \\
61009 \\
61504\end{array}$ & $\begin{array}{l}13824000 \\
13997521 \\
1417 \% 488 \\
14348907 \\
14526 \% 84 \\
14706125 \\
14886936 \\
15069223 \\
15252992\end{array}$ & $\begin{array}{l}15.4919334 \\
15.5841747 \\
15.5563492 \\
15.5884573 \\
15.6204994 \\
15.6524758 \\
15.6843871 \\
15.7162336 \\
15.7480157\end{array}$ & $\begin{array}{l}6.2144650 \\
6.2230843 \\
6.2316 \pi 97 \\
6.2402515 \\
6.248 \pi 998 \\
6.2573248 \\
6.2658266 \\
6.2743054 \\
6.2827613\end{array}$ & $\begin{array}{l}.004166667 \\
.004149378 \\
.004132231 \\
.004115226 \\
.004098561 \\
.004081633 \\
.004065041 \\
.004048583 \\
.004032258\end{array}$ \\
\hline
\end{tabular}


CURE ROO'TS, AND RECIPROCALS.

\begin{tabular}{|c|c|c|c|c|c|}
\hline No. & Squares. & Cubes. & $\begin{array}{l}\text { Square } \\
\text { Roots. }\end{array}$ & Cube Roots. & Reciprocals. \\
\hline 249 & 62001 & 15438249 & 15. 7797338 & 6.2911946 & .001016064 \\
\hline 250 & 62500 & 15625000 & 15.8113883 & 6.2996053 & .004000000 \\
\hline 251 & 63001 & 15813251 & 15.8429795 & 6. $30 \div 9935$ & $.00: 3 y 840464$ \\
\hline $25 \%$ & 63504 & 16003008 & $15.8 \div 450 \% 9$ & 6.3163546 & $.003968: 551$ \\
\hline 253 & 64009 & 16194277 & $15.9059 \div 37$ & 6.32470:35 & $.00: 3: 5 \div 2569$ \\
\hline 254 & 61516 & 16387064 & $15.93 \% 3 \% 75$ & $6.3330: 556$ & .003937008 \\
\hline 255 & 65025 & 16581375 & $15.968 \div 194$ & 6.3413257 & .003921569 \\
\hline 256 & 65536 & $167 \% 7216$ & 16.0000000 & 6.3196042 & .003906250 \\
\hline 257 & 66049 & 16974593 & 16.0312195 & $6.35 \% 8611$ & .003891051 \\
\hline 258 & $6656 t$ & 17173512 & $16.06: 3784$ & 6.3660968 & .003875969 \\
\hline 259 & 67081 & 17373979 & 16.0931769 & 6.3743111 & .003861004 \\
\hline 260 & 67600 & $175 \% 6000$ & 16.1245155 & 6.3825043 & $.00384615 t$ \\
\hline 261 & 68121 & $177 \% 9581$ & 16.1554944 & $6.3906 \div 65$ & .003831413 \\
\hline 262 & 68644 & 17984723 & 16.1864141 & $6.39882 \div 9$ & .003816794 \\
\hline 263 & 69169 & 18191447 & 16.2172747 & 6.4069585 & .003802281 \\
\hline 264 & 69696 & $18399 \pi 44$ & $16.2480 \div 68$ & 6.4150687 & $.00378 \% 879$ \\
\hline 265 & 70225 & $186096: 5.5$ & $16.2 \% 88206$ & 6.4231583 & .0037 .7585 \\
\hline 266 & $70 \% 56$ & 18821096 & $16.309506 t$ & 6.43122\%6 & .003759398 \\
\hline 267 & 71289 & 19034163 & 16.3401346 & $6.4392 \% 67$ & .003745318 \\
\hline 268 & $\tau 18: 4$ & $19: 218332$ & $16.370 \% 055$ & $6.44 \div 305 \%$ & .003731343 \\
\hline 269 & 72361 & 19465103 & 16.4012195 & 6.4553148 & .003717472 \\
\hline 270 & 72900 & 19683000 & $16.4316 \% 67$ & 6.4633041 & .003703704 \\
\hline $2 \pi 1$ & 73141 & 19902511 & $16.4620 \% 6$ & 6.4712736 & .003690037 \\
\hline $2 \pi 2$ & $7398 t$ & 20123618 & 16.4924225 & $6.4 \div 92236$ & .0036 .6471 \\
\hline $2 \div 3$ & 74523 & 20346417 & 16.5227116 & $6.48 \pi 1541$ & .003663004 \\
\hline $2 \pi 4$ & 75076 & 20570824 & 16.5529451 & 6.4950653 & .003649635 \\
\hline 2,5 & 75625 & $20 \% 968 \% 5$ & 16.5831240 & $6.50295 \approx 2$ & .003636364 \\
\hline $2 \% 6$ & $761 \% 6$ & $210245 \% 6$ & 16.6132477 & 6.5108300 & .003623188 \\
\hline 277 & r6729 & 21253933 & 16.6433170 & 6.5186839 & .003610108 \\
\hline $2 \pi 8$ & 77284 & 21481952 & 16.6733320 & 6.5265189 & .003597122 \\
\hline $2 \% 9$ & 77811 & 21717639 & 16.7032931 & 6.5343351 & $.0035812 \% 9$ \\
\hline 280 & 78400 & 21952000 & 16. 7332005 & 6.5421326 & $.0035 \div 1429$ \\
\hline 281 & 78961 & 22188041 & 16.7680546 & 6.5499116 & $.003558 \pi 19$ \\
\hline 282 & 79524 & 22425668 & 16. 7928556 & $6.55 \% 6 \% 22$ & .003546099 \\
\hline 283 & 80089 & 22665187 & 16.8226038 & 6.5654144 & $.00: 35333569$ \\
\hline 281 & 80656 & 22906301 & 16.8522995 & 6.5731385 & .003521127 \\
\hline 285 & 81225 & 23149125 & 16.8819430 & 6.5808143 & $.003508 \% 72$ \\
\hline 286 & 81796 & 23393656 & 16.9115345 & 6.5885393 & .003496503 \\
\hline 287 & 82369 & 2:3639903 & $16.9410 \div 43$ & 6.5962023 & .003184321 \\
\hline 288 & 82944 & $2388 \div 872$ & 16.9705627 & 6. 6038545 & .0034722222 \\
\hline 289 & 83521 & 21137569 & 17.0000000 & 6.6114890 & $.003160: 08$ \\
\hline 290 & 84100 & 24389000 & 17.0293864 & 6.6191060 & $.0031482 \% 6$ \\
\hline 291 & 81681 & $216121 \div 1$ & 17.058 .221 & 6. 6267054 & $.0034: 36426$ \\
\hline 292 & 85264 & 24897088 & $17.08800 \%$ & $6.63428 \pi 4$ & .003124658 \\
\hline 293 & 85849 & $25153 i 57$ & 17.1172428 & 6.6418522 & .003412969 \\
\hline 294 & 86133 & 25412184 & 17.1464282 & 6. 6493998 & .003401361 \\
\hline 295 & $8 \pi 025$ & 25672375 & 17.1755640 & 6. 6569302 & .0033389831 \\
\hline 296 & 87616 & 25931336 & 17.2046505 & 6.6644437 & .0033383378 \\
\hline 297 & 88209 & $261980 \div 3$ & $17.23368 \% 9$ & $6.6 \% 19403$ & .003367003 \\
\hline 298 & 88801 & 26463592 & $17.2626 \% 65$ & 6.6794200 & $.003335 \% 05$ \\
\hline 293 & 89401 & $26 \% 30899$ & 17.2916165 & 6.6868831 & .003344182 \\
\hline 300 & 90000 & $2 \% 000000$ & 17.3205081 & 6. 6913295 & .00833333333 \\
\hline 301 & 90601 & $2 \tau 2 \% 0901$ & 17.3493516 & 6. 017593 & .00333222559 \\
\hline 302 & 91201 & $2 \% 543608$ & 17.3781472 & 6. 091729 & .003311258 \\
\hline 303 & 91809 & 27818127 & 17.4068952 & 6.7165\%00 & .0033300330 \\
\hline 304 & 92416 & 28094461 & 17.4355958 & 6.7239508 & $.0032894 \pi 4$ \\
\hline 305 & 93025 & 25372625 & 17.4642492 & 6. 7313155 & $.00: 32 r 8689$ \\
\hline 306 & 93636 & $2865: 2616$ & 17.4928557 & 6.7386641 & .003267974 \\
\hline 307 & 94249 & 28934143 & 17.5214155 & 6.7459967 & .003257329 \\
\hline 308 & 94864 & 29218112 & 17.5499288 & 6.7533134 & $.003246 \div 53$ \\
\hline 309 & 95481 & $2950: 36 \geq 9$ & $17.5 \div 83958$ & 6.7606143 & .003236246 \\
\hline 310 & 96100 & 29791000 & 17.6068169 & 6.7678995 & .003 .25806 \\
\hline
\end{tabular}


TABLE X.-SQUARES, CUBES, SQUARE ROOTS,

\begin{tabular}{|c|c|c|c|c|c|}
\hline No. & Squares. & Cubes. & $\begin{array}{l}\text { Square } \\
\text { Kuots. }\end{array}$ & Cube Roots. & Reciprocals. \\
\hline $\begin{array}{l}311 \\
312 \\
313 \\
314 \\
315 \\
316 \\
317 \\
318 \\
319\end{array}$ & $\begin{array}{r}96 \%: 21 \\
97344 \\
97969 \\
98596 \\
99225 \\
99856 \\
100489 \\
101124 \\
101 \% 61\end{array}$ & $\begin{array}{l}30080231 \\
30371328 \\
30664297 \\
30959144 \\
31255875 \\
31554496 \\
31855013 \\
3215 \% 432 \\
32461 \% 59\end{array}$ & $\begin{array}{l}17.6351921 \\
17.6635217 \\
17.6918060 \\
17.7200451 \\
17.7482393 \\
17.7 \% 63888 \\
17.8044938 \\
17.8325545 \\
17.8605711\end{array}$ & $\begin{array}{l}6.751690 \\
6.78 \% 4229 \\
6.7896613 \\
6.7968844 \\
6.8040921 \\
6.8112847 \\
6.8184620 \\
6.8256242 \\
6.832 \% 714\end{array}$ & $\begin{array}{l}.003215434 \\
.003205128 \\
.003194888 \\
.003184713 \\
.003174603 \\
.003164557 \\
.003154574 \\
.003144654 \\
.003134796\end{array}$ \\
\hline $\begin{array}{l}320 \\
321 \\
322 \\
323 \\
324 \\
325 \\
326 \\
327 \\
328 \\
529\end{array}$ & $\begin{array}{l}102400 \\
103041 \\
103684 \\
104329 \\
104976 \\
105625 \\
106276 \\
106929 \\
107581 \\
108241\end{array}$ & $\begin{array}{l}32768000 \\
33076161 \\
33386248 \\
33698267 \\
34012224 \\
34328125 \\
34645976 \\
34965783 \\
35287552 \\
35611289\end{array}$ & $\begin{array}{l}17.8885438 \\
17.9164729 \\
17.9443584 \\
17.9722008 \\
18.0000000 \\
18.0277564 \\
18.0554701 \\
18.0831413 \\
18.110703 \\
18.1383571\end{array}$ & $\begin{array}{l}6.8399037 \\
6.8470213 \\
6.8541240 \\
6.8612120 \\
6.8682855 \\
6.8753443 \\
6.8823888 \\
6.8894188 \\
6.8964345 \\
6.9034359\end{array}$ & $\begin{array}{l}.003125000 \\
.003115265 \\
.003105590 \\
.003095975 \\
.003086420 \\
.003076923 \\
.003067485 \\
.003058104 \\
.003018780 \\
.003039514\end{array}$ \\
\hline $\begin{array}{l}330 \\
331 \\
3332 \\
333 \\
334 \\
335 \\
336 \\
337 \\
338 \\
339\end{array}$ & $\begin{array}{l}108900 \\
109561 \\
110224 \\
110889 \\
111556 \\
112225 \\
112896 \\
113569 \\
114244 \\
114921\end{array}$ & $\begin{array}{l}35937000 \\
36264691 \\
36594368 \\
36926037 \\
37259704 \\
37595375 \\
37933056 \\
38272753 \\
38614472 \\
38958219\end{array}$ & $\begin{array}{l}18.1659021 \\
18.1934054 \\
18.22086 \pi \approx \\
18.24828 \pi 6 \\
18.2756669 \\
18.3030052 \\
18.3303028 \\
18.3575598 \\
18.384 \pi 63 \\
18.4119526\end{array}$ & $\begin{array}{l}6.9104232 \\
6.9173964 \\
6.9243556 \\
6.9313008 \\
6.9382321 \\
6.9451496 \\
6.9520533 \\
6.9589434 \\
6.9658198 \\
6.9726826\end{array}$ & $\begin{array}{l}.003030303 \\
.003021148 \\
.003012048 \\
.003003003 \\
.002994012 \\
.002985075 \\
.002976190 \\
.00296 \pi 359 \\
.002958580 \\
.002949853\end{array}$ \\
\hline $\begin{array}{l}340 \\
341 \\
342 \\
343 \\
344 \\
345 \\
346 \\
347 \\
348 \\
349\end{array}$ & $\begin{array}{l}115600 \\
116281 \\
116964 \\
117649 \\
118336 \\
119025 \\
119716 \\
120409 \\
121104 \\
121801\end{array}$ & $\begin{array}{l}39304000 \\
39651821 \\
40001688 \\
40353607 \\
40 \% 07584 \\
41063625 \\
41421 \% 36 \\
41 \% 81923 \\
42144192 \\
42508549\end{array}$ & $\begin{array}{l}18.4390889 \\
18.4661853 \\
18.4932420 \\
18.5202592 \\
18.5472370 \\
18.5 \% 41756 \\
18.6010752 \\
18.6279360 \\
18.6547581 \\
18.6815417\end{array}$ & $\begin{array}{l}6.9795321 \\
6.9863681 \\
6.9931906 \\
7.0000000 \\
7.006 \% 962 \\
7.0135 \% 91 \\
7.0203490 \\
7.0271058 \\
7.0338497 \\
7.0405806\end{array}$ & $\begin{array}{l}.002941176 \\
.002932551 \\
.0029239 \% \\
.002915452 \\
.0029069 \% \\
.002898551 \\
.002890173 \\
.002881844 \\
.002873563 \\
.002865330\end{array}$ \\
\hline $\begin{array}{l}350 \\
351 \\
352 \\
353 \\
354 \\
355 \\
356 \\
357 \\
358 \\
359\end{array}$ & $\begin{array}{l}122500 \\
123201 \\
123904 \\
124609 \\
125316 \\
126025 \\
126 \% 36 \\
12 \approx 449 \\
128164 \\
128881\end{array}$ & $\begin{array}{l}42875000 \\
43243551 \\
43614208 \\
43986977 \\
44361864 \\
44738875 \\
45118016 \\
45499293 \\
45882 \pi 12 \\
46268279\end{array}$ & $\begin{array}{l}18.7082869 \\
18.7349940 \\
18.7616630 \\
18.7882942 \\
18.814887 \\
18.8114437 \\
18.8679623 \\
18.8944436 \\
18.92088 \% 9 \\
18.9472953\end{array}$ & $\begin{array}{l}7.0472987 \\
7.0540041 \\
7.0606967 \\
7.0673767 \\
7.0740440 \\
7.0806988 \\
7.08 \% 3411 \\
7.0939709 \\
7.1005885 \\
7.10 \% 1937\end{array}$ & $\begin{array}{l}.002857143 \\
.002849003 \\
.002840909 \\
.002832861 \\
.002821859 \\
.002816901 \\
.002808989 \\
.002801120 \\
.002793296 \\
.002785515\end{array}$ \\
\hline $\begin{array}{l}360 \\
361 \\
362 \\
363 \\
364 \\
365 \\
366 \\
367 \\
368 \\
369\end{array}$ & $\begin{array}{l}129600 \\
130321 \\
131044 \\
131 \% 69 \\
132496 \\
133225 \\
133956 \\
134689 \\
135424 \\
136161\end{array}$ & $\begin{array}{l}46656000 \\
4 \pi 045881 \\
47437928 \\
47832147 \\
48228544 \\
4862 \pi 125 \\
4902 \% 896 \\
49430863 \\
49836032 \\
50243409\end{array}$ & $\begin{array}{l}18.9736660 \\
19.0000000 \\
19.0262976 \\
19.0525589 \\
19.0787840 \\
19.1049732 \\
19.1311265 \\
19.1572141 \\
19.1833261 \\
19.2093727\end{array}$ & $\begin{array}{l}7.1137866 \\
7.12036 \% 4 \\
7.1269360 \\
7.1334925 \\
7.14003 \% 0 \\
7.1465695 \\
7.1530901 \\
\tau .1595988 \\
7.1660957 \\
7.1725809\end{array}$ & 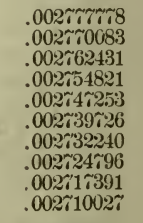 \\
\hline $\begin{array}{l}3 \% 0 \\
3 \% 1 \\
3 \% 2\end{array}$ & $\begin{array}{l}136900 \\
137641 \\
138381\end{array}$ & $\begin{array}{l}50653000 \\
51064811 \\
\mathbf{5 1 4 7 8 8 4 8}\end{array}$ & $\begin{array}{l}19.2353841 \\
19.2613603 \\
19.2873015\end{array}$ & $\begin{array}{l}7.1790544 \\
7.1855162 \\
7.1919663\end{array}$ & $\begin{array}{l}.002702703 \\
.002695418 \\
.002688172\end{array}$ \\
\hline
\end{tabular}


CUBE ROOTS, AND RECIPROCALS.

\begin{tabular}{|c|c|c|c|c|c|}
\hline No. & Squares. & Cubes. & $\begin{array}{l}\text { Square } \\
\text { Roots. }\end{array}$ & Cube Roots. & Reciprocals. \\
\hline $\begin{array}{l}373 \\
374 \\
375 \\
376 \\
377 \\
378 \\
379\end{array}$ & $\begin{array}{l}139129 \\
1398 \% 6 \\
140625 \\
1413 \% 6 \\
142129 \\
142884 \\
143641\end{array}$ & $\begin{array}{l}51895117 \\
52313624 \\
52734375 \\
53157376 \\
53582633 \\
54010152 \\
54439939\end{array}$ & $\begin{array}{l}19.3132079 \\
19.3390796 \\
19.3649167 \\
19.3907194 \\
19.4164878 \\
19.4422221 \\
19.4679223\end{array}$ & $\begin{array}{l}7.1984050 \\
7.2048322 \\
7.2112479 \\
7.2176522 \\
7.2240450 \\
7.2304268 \\
7.2367972\end{array}$ & $\begin{array}{l}.002680965 \\
.002673797 \\
.002666667 \\
.002659574 \\
.002652520 \\
.002645503 \\
.0022638522\end{array}$ \\
\hline $\begin{array}{l}380 \\
381 \\
382 \\
383 \\
384 \\
385 \\
386 \\
387 \\
388 \\
389\end{array}$ & $\begin{array}{l}144400 \\
145161 \\
145924 \\
146689 \\
14: 456 \\
148225 \\
148996 \\
149769 \\
150544 \\
151321\end{array}$ & $\begin{array}{l}54872000 \\
55306341 \\
55742968 \\
56181887 \\
56623104 \\
57066625 \\
57512456 \\
57960603 \\
58411072 \\
58863869\end{array}$ & $\begin{array}{l}19.4935887 \\
19.5192213 \\
19.5448203 \\
19.5703858 \\
19.5959179 \\
19.6214169 \\
19.6468827 \\
19.6723156 \\
19.6977156 \\
19.7230829\end{array}$ & $\begin{array}{l}7.2431565 \\
7.2495045 \\
7.2558415 \\
7.2621675 \\
7.2684824 \\
7.2747864 \\
7.2810794 \\
7.2873617 \\
7.2936330 \\
7.2998936\end{array}$ & $\begin{array}{l}.002631579 \\
.0026246 \% 2 \\
.002617801 \\
.002610966 \\
.002604167 \\
.002597403 \\
.002590674 \\
.002583979 \\
.002577320 \\
.002570694\end{array}$ \\
\hline $\begin{array}{l}390 \\
391 \\
392 \\
393 \\
394 \\
395 \\
396 \\
397 \\
398 \\
399\end{array}$ & $\begin{array}{l}152100 \\
15: 2881 \\
153664 \\
154449 \\
155236 \\
156025 \\
156816 \\
157609 \\
158404 \\
159201\end{array}$ & $\begin{array}{l}59319000 \\
597 \% 6171 \\
60236288 \\
60698157 \\
61162984 \\
61629875 \\
62099136 \\
62570773 \\
63044792 \\
63521199\end{array}$ & $\begin{array}{l}19.7484177 \\
19.7737199 \\
19.7989899 \\
19.8242276 \\
19.8494332 \\
19.8746069 \\
19.8997487 \\
19.9248588 \\
19.9499373 \\
19.9749844\end{array}$ & $\begin{array}{l}7.3061436 \\
7.3123828 \\
7.3186114 \\
7.3248295 \\
7.3310369 \\
7.3372339 \\
7.3434205 \\
7.3495966 \\
7.3557624 \\
7.3619178\end{array}$ & $\begin{array}{l}.002564103 \\
.002557545 \\
.002551020 \\
.002544529 \\
.002538071 \\
.002531646 \\
.002525253 \\
.002518892 \\
.002512563 \\
.002506266\end{array}$ \\
\hline $\begin{array}{l}400 \\
401 \\
402 \\
403 \\
404 \\
405 \\
406 \\
407 \\
408 \\
409\end{array}$ & $\begin{array}{l}160000 \\
160801 \\
161604 \\
162409 \\
163216 \\
164025 \\
164836 \\
165649 \\
166464 \\
167281\end{array}$ & $\begin{array}{l}64000000 \\
64481201 \\
64964808 \\
65450827 \\
65939264 \\
66430125 \\
66923416 \\
67419143 \\
67917312 \\
68417929\end{array}$ & $\begin{array}{l}20.0000000 \\
20.0249844 \\
20.0499377 \\
20.0748599 \\
20.0997512 \\
20.1246118 \\
20.1494417 \\
20.1742410 \\
20.1990099 \\
20.2237484\end{array}$ & $\begin{array}{l}7.3680630 \\
7.3741979 \\
7.3803227 \\
7.3864373 \\
7.3925418 \\
7.3986363 \\
7.4047206 \\
7.4107950 \\
7.4168595 \\
7.4229142\end{array}$ & $\begin{array}{l}.002500000 \\
.002493766 \\
.002487562 \\
.002481390 \\
.002475248 \\
.002469136 \\
.002463054 \\
.002457002 \\
.002450980 \\
.002444988\end{array}$ \\
\hline $\begin{array}{l}410 \\
411 \\
412 \\
413 \\
414 \\
415 \\
416 \\
417 \\
418 \\
419\end{array}$ & $\begin{array}{l}168100 \\
168921 \\
169744 \\
170569 \\
171396 \\
172225 \\
173056 \\
173889 \\
174724 \\
175561\end{array}$ & $\begin{array}{l}68921000 \\
69426531 \\
69934528 \\
70444997 \\
7095 \% 944 \\
71473375 \\
71991296 \\
72511713 \\
73034632 \\
73560059\end{array}$ & $\begin{array}{l}20.2484567 \\
20.2731349 \\
20.2977831 \\
20.3224014 \\
20.3469899 \\
20.3715488 \\
20.3960781 \\
20.4205779 \\
20.4450483 \\
20.4694895\end{array}$ & $\begin{array}{l}7.4289589 \\
7.4349938 \\
7.4410189 \\
7.4470342 \\
7.4530399 \\
7.4590359 \\
7.4650223 \\
7.4709991 \\
7.4769664 \\
7.4829242\end{array}$ & $\begin{array}{l}.002439024 \\
.002433090 \\
.002427184 \\
.002421308 \\
.002415459 \\
.002409639 \\
.002403846 \\
.002398082 \\
.002392344 \\
.002386635\end{array}$ \\
\hline $\begin{array}{l}420 \\
421 \\
422 \\
423 \\
424 \\
425 \\
426 \\
427 \\
428 \\
429\end{array}$ & $\begin{array}{l}176400 \\
17241 \\
178084 \\
178929 \\
179 \% 66 \\
180625 \\
1814 \% 6 \\
182329 \\
183184 \\
181041\end{array}$ & $\begin{array}{l}74088000 \\
74618461 \\
75151448 \\
75686967 \\
76225024 \\
76 \% 65625 \\
730876 \\
7854483 \\
78402752 \\
78953589\end{array}$ & $\begin{array}{l}20.4939015 \\
20.5182845 \\
20.5426386 \\
20.5669638 \\
20.5912603 \\
20.6155281 \\
20.63976 \pi 4 \\
20.6639783 \\
20.6881609 \\
20.7123152\end{array}$ & $\begin{array}{l}7.4888 \% 24 \\
7.4948113 \\
7.5007406 \\
7.5066607 \\
7.5125 \% 15 \\
7.5184730 \\
7.5243652 \\
7.5302482 \\
7.5361221 \\
7.5419867\end{array}$ & $\begin{array}{l}.002380952 \\
.002375297 \\
.002369668 \\
.002364066 \\
.002358491 \\
.002352941 \\
.002347418 \\
.002341920 \\
.002336449 \\
.002331002\end{array}$ \\
\hline $\begin{array}{l}430 \\
431 \\
432 \\
433 \\
434\end{array}$ & $\begin{array}{l}181900 \\
185 \div 61 \\
186624 \\
18 \div 489 \\
188356\end{array}$ & $\begin{array}{l}7950 \% 000 \\
80062991 \\
80621568 \\
81182 \% 37 \\
81 \% 46504\end{array}$ & $\begin{array}{l}20.7364414 \\
20.7605395 \\
20.7846097 \\
20.8086520 \\
20.8326667\end{array}$ & $\begin{array}{l}7.5478123 \\
7.5536888 \\
7.5595263 \\
7.5653548 \\
7.5711743\end{array}$ & $\begin{array}{l}.002325581 \\
.002320186 \\
.002314815 \\
.002309469 \\
.002304147\end{array}$ \\
\hline
\end{tabular}


TABLE X.-SQUARES, CUBES, SQUARE ROOTS,

\begin{tabular}{|c|c|c|c|c|c|}
\hline No. & Squares. & Cubes. & $\begin{array}{l}\text { Square } \\
\text { Kuots. }\end{array}$ & Cube Roots. & Reciprocals. \\
\hline $\begin{array}{l}435 \\
436 \\
437 \\
438 \\
439\end{array}$ & $\begin{array}{l}189225 \\
190096 \\
190969 \\
191844 \\
192721\end{array}$ & $\begin{array}{l}823128 \% 5 \\
82881856 \\
83453153 \\
84026672 \\
84604519\end{array}$ & $\begin{array}{l}20.8566536 \\
20.8806130 \\
20.9045450 \\
20.9284495 \\
20.9523268\end{array}$ & $\begin{array}{l}7.5769849 \\
7.5827865 \\
7.5885793 \\
7.5943633 \\
7.6001385\end{array}$ & $\begin{array}{l}.002298851 \\
.002293578 \\
.002238330 \\
.002283105 \\
.0022 \div \% 904\end{array}$ \\
\hline $\begin{array}{l}440 \\
441 \\
442 \\
443 \\
444 \\
445 \\
446 \\
447 \\
448 \\
449\end{array}$ & $\begin{array}{l}193600 \\
194481 \\
195364 \\
196249 \\
197136 \\
198025 \\
198916 \\
199809 \\
200704 \\
201601\end{array}$ & $\begin{array}{l}85184000 \\
85766121 \\
86350868 \\
86938307 \\
875238384 \\
881211: 25 \\
88716536 \\
89314623 \\
89915392 \\
90518849\end{array}$ & $\begin{array}{l}20.97617 \% 0 \\
21.0000000 \\
21.0237960 \\
21.0475652 \\
21.07130 \% 5 \\
21.0950231 \\
21.118 \% 121 \\
21.1423 \% 45 \\
21.1660105 \\
21.1896201\end{array}$ & $\begin{array}{l}7.6059019 \\
7.6116626 \\
7.6174116 \\
7.6231519 \\
7.0288837 \\
7.63+6067 \\
7.6403213 \\
7.6460272 \\
7.6517247 \\
7.657+133\end{array}$ & $\begin{array}{l}.002272 \pi 27 \\
.00226 \% 5 \% 4 \\
.002262443 \\
.002257336 \\
.002252252 \\
.002247191 \\
.002242152 \\
.00223 \pi 136 \\
.002232143 \\
.002227171\end{array}$ \\
\hline $\begin{array}{l}450 \\
451 \\
452 \\
453 \\
454 \\
455 \\
456 \\
457 \\
458 \\
459\end{array}$ & $\begin{array}{l}202500 \\
203101 \\
201304 \\
205209 \\
206116 \\
207025 \\
207936 \\
208819 \\
209764 \\
210681\end{array}$ & $\begin{array}{l}91125000 \\
91733851 \\
92345438 \\
92959677 \\
93576664 \\
941963 \% 5 \\
94818816 \\
95443993 \\
960 \% 1912 \\
967025 \% 9\end{array}$ & $\begin{array}{l}21.2132034 \\
21.2367606 \\
21.2602916 \\
21.2837967 \\
21.3072758 \\
21.3307290 \\
21.3541565 \\
21.3775583 \\
21.4009316 \\
21.4212853\end{array}$ & $\begin{array}{l}7.6630943 \\
7.6687665 \\
7.6744303 \\
7.5800857 \\
7.6857328 \\
7.6913717 \\
7.6970023 \\
7.7026216 \\
7.7082388 \\
7.7138448\end{array}$ & $\begin{array}{l}.002222222 \\
.002217295 \\
.002212389 \\
.002207506 \\
.002202643 \\
.002197802 \\
.002192982 \\
.002188184 \\
.002183406 \\
.002178619\end{array}$ \\
\hline $\begin{array}{l}460 \\
461 \\
462 \\
463 \\
464 \\
465 \\
466 \\
467 \\
468 \\
469\end{array}$ & $\begin{array}{l}211600 \\
212521 \\
213444 \\
214369 \\
215296 \\
216225 \\
217156 \\
218089 \\
219024 \\
219961\end{array}$ & $\begin{array}{r}97336000 \\
97972181 \\
98611128 \\
99252847 \\
99897344 \\
100514625 \\
101194606 \\
101847563 \\
102503: 332 \\
103161709\end{array}$ & $\begin{array}{l}21.4476106 \\
21.4709106 \\
21.4941853 \\
21.5174348 \\
21.5106592 \\
21.5638587 \\
21.5870331 \\
21.61018 \% 8 \\
21.63330 \% 7 \\
21.6564078\end{array}$ & $\begin{array}{l}7.7194426 \\
7.7250325 \\
7.7306141 \\
7.7361877 \\
7.7417532 \\
7.7473109 \\
7.7528606 \\
7.7584023 \\
7.7639361 \\
7.7691620\end{array}$ & $\begin{array}{l}.002173913 \\
.002169197 \\
.002164502 \\
.002159827 \\
.002155172 \\
.002150538 \\
.002145923 \\
.002141328 \\
.002136752 \\
.002132196\end{array}$ \\
\hline $\begin{array}{l}470 \\
471 \\
472 \\
473 \\
474 \\
475 \\
476 \\
477 \\
478 \\
479\end{array}$ & $\begin{array}{l}220900 \\
221841 \\
222784 \\
223729 \\
221676 \\
225625 \\
226576 \\
227529 \\
228184 \\
229411\end{array}$ & $\begin{array}{l}103823000 \\
10148 \% 111 \\
105154048 \\
105823817 \\
106496424 \\
1071718 \% 5 \\
107850176 \\
108531333 \\
109215352 \\
109902239\end{array}$ & $\begin{array}{l}21.6194834 \\
21.7025344 \\
21.7255610 \\
21.7485632 \\
21.7715411 \\
21.7944947 \\
21.8174242 \\
21.8103297 \\
218632111 \\
21.8860686\end{array}$ & $\begin{array}{l}7.7749801 \\
7.7804904 \\
7.7859928 \\
7.7914875 \\
7.7969745 \\
7.8024538 \\
7.80 \% 9254 \\
7.8133892 \\
7.8188456 \\
7.8242912\end{array}$ & $\begin{array}{l}.00212660 \\
.002123142 \\
.002118641 \\
.002114165 \\
.002109705 \\
.002105263 \\
.002100810 \\
.002096436 \\
.002092050 \\
.002087683\end{array}$ \\
\hline $\begin{array}{l}480 \\
481 \\
482 \\
483 \\
484 \\
485 \\
486 \\
487 \\
488 \\
489\end{array}$ & $\begin{array}{l}230400 \\
231361 \\
232324 \\
233289 \\
231256 \\
233225 \\
236196 \\
237169 \\
238144 \\
239121\end{array}$ & $\begin{array}{l}110592000 \\
111281611 \\
111980163 \\
112678587 \\
113379904 \\
114084125 \\
114791256 \\
115501303 \\
116214272 \\
116930169\end{array}$ & $\begin{array}{l}21.9089023 \\
21.9317122 \\
21.9544984 \\
21.9772610 \\
22.0000000 \\
22.022 \% 155 \\
22.0454077 \\
22.0680 \% 65 \\
22.090 \% 220 \\
22.1133444\end{array}$ & $\begin{array}{l}7.8297353 \\
7.8351688 \\
7.8405949 \\
7.8460131 \\
7.8514241 \\
7.8568281 \\
7.8622242 \\
7.8676130 \\
7.8729941 \\
78783681\end{array}$ & $\begin{array}{l}.002083333 \\
.0020 \% 9002 \\
.0020 \% 4689 \\
.0020 \% 0393 \\
.002066116 \\
.002001856 \\
.00205 \pi 613 \\
.002053388 \\
.002049180 \\
.002044990\end{array}$ \\
\hline $\begin{array}{l}490 \\
491 \\
492 \\
493 \\
494 \\
495 \\
496\end{array}$ & $\begin{array}{l}240100 \\
241081 \\
212064 \\
243049 \\
244036 \\
245025 \\
246016\end{array}$ & $\begin{array}{l}117649000 \\
1183707 \% 1 \\
119095488 \\
119823157 \\
120553784 \\
121287375 \\
122023936\end{array}$ & $\begin{array}{l}22.1359436 \\
22.1585198 \\
22.1810730 \\
22.2036033 \\
22.2261108 \\
22.2185955 \\
22.2 \pi 105 \% 5\end{array}$ & $\begin{array}{l}7.8837352 \\
7.8890916 \\
7.8911468 \\
7.899 \% 917 \\
7.9051291 \\
7.9104599 \\
7.915 \% 832\end{array}$ & $\begin{array}{l}.002040816 \\
.002036660 \\
.002032520 \\
.002028398 \\
.002024291 \\
.002020202 \\
.002016129\end{array}$ \\
\hline
\end{tabular}


CUBE ROOTS, AND RECIPROCALS.

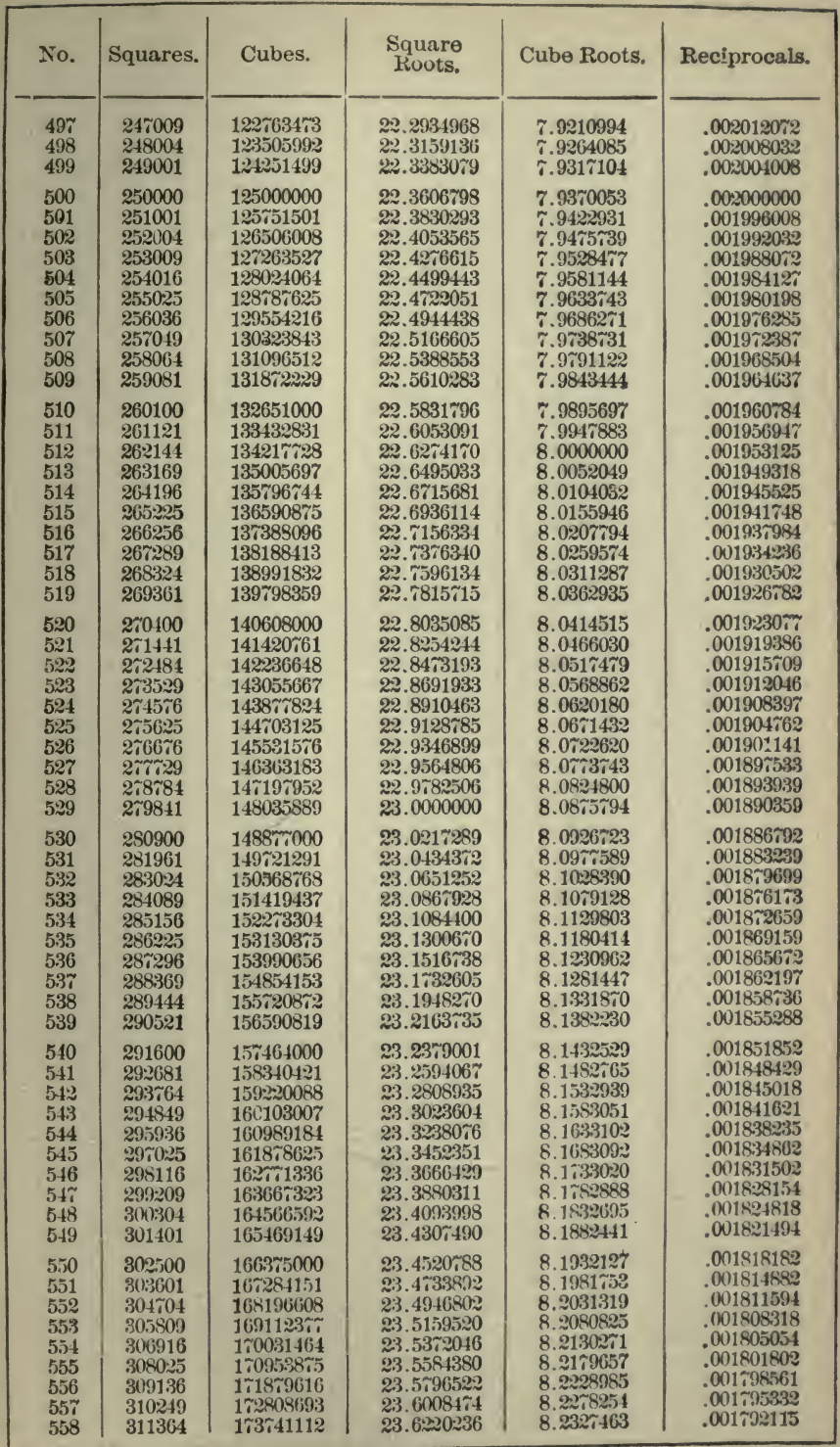


TABLE X.-SQUARES, CUBES, SQUARE ROOTS,

\begin{tabular}{|c|c|c|c|c|c|}
\hline No. & Squares. & Cubes. & $\begin{array}{c}\text { Square } \\
\text { Roots. }\end{array}$ & Cube Roots. & Reciprocals. \\
\hline 559 & 312481 & $1746 \% 6879$ & 23.6431808 & 8.2376614 & .001788909 \\
\hline $\begin{array}{l}560 \\
561 \\
562 \\
563 \\
564 \\
565 \\
566 \\
567 \\
568 \\
569\end{array}$ & $\begin{array}{l}313600 \\
314721 \\
315844 \\
316969 \\
318096 \\
319225 \\
320356 \\
321489 \\
322624 \\
323761\end{array}$ & $\begin{array}{l}175616000 \\
176558481 \\
177504328 \\
178453547 \\
179406144 \\
180362125 \\
181321490 \\
182284263 \\
183250432 \\
184220000\end{array}$ & $\begin{array}{l}23.6643191 \\
23.6854386 \\
23.7065392 \\
23.7276210 \\
23.7486842 \\
23.7697286 \\
23.7907545 \\
23.8117618 \\
23.8327506 \\
23.8537209\end{array}$ & $\begin{array}{l}8.2425706 \\
8.24 r 4 r 40 \\
8.2523715 \\
8.2572633 \\
8.2621492 \\
8.26 r 0294 \\
8.2719039 \\
8.2767726 \\
8.2816355 \\
8.2664928\end{array}$ & $\begin{array}{r}.001785714 \\
.001782531 \\
0017 \% 9359 \\
001776199 \\
.001773050 \\
.001769912 \\
.001766784 \\
.001763668 \\
.001760563 \\
.001757469\end{array}$ \\
\hline $\begin{array}{l}5 \% 0 \\
5 \% 1 \\
5 \tau 2 \\
573 \\
5 \pi 4 \\
575 \\
5 \% 6 \\
5 \% 7 \\
578 \\
579\end{array}$ & $\begin{array}{l}321900 \\
326041 \\
32 \pi 184 \\
328329 \\
329476 \\
330625 \\
3317 \% 6 \\
332929 \\
334084 \\
335241\end{array}$ & $\begin{array}{l}185193000 \\
186169411 \\
18 \pi 149248 \\
188132517 \\
189119224 \\
190109375 \\
191102976 \\
192100033 \\
193100552 \\
194104529\end{array}$ & $\begin{array}{l}23.8146728 \\
23.8956063 \\
23.9165215 \\
23.9374184 \\
23.9582971 \\
23.97915 \pi 6 \\
24.0000000 \\
24.0208243 \\
24.0416306 \\
24.0624188\end{array}$ & $\begin{array}{l}8.2913444 \\
8.2961903 \\
8.3010304 \\
8.3058651 \\
8.3106941 \\
8.3155175 \\
8.3203353 \\
8.3251475 \\
8.3299542 \\
8.3347553\end{array}$ & $\begin{array}{l}.001754386 \\
.001751313 \\
.001 \% 48252 \\
.001745201 \\
.001742160 \\
.001739130 \\
.001736111 \\
.001733102 \\
.001730104 \\
.00172 \pi 116\end{array}$ \\
\hline $\begin{array}{l}580 \\
581 \\
582 \\
583 \\
584 \\
585 \\
586 \\
58 \pi \\
588 \\
589\end{array}$ & $\begin{array}{l}336400 \\
337561 \\
338 \% 24 \\
339889 \\
341056 \\
342225 \\
343396 \\
344569 \\
345 \% 44 \\
346921\end{array}$ & $\begin{array}{l}195112000 \\
196122941 \\
197137368 \\
198155287 \\
199176704 \\
200201625 \\
201230056 \\
202262003 \\
203297472 \\
204336469\end{array}$ & $\begin{array}{l}24.0831891 \\
24.1039416 \\
24.1246762 \\
24.1453929 \\
24.1660919 \\
24.1867 \% 32 \\
24.20 \% 4369 \\
24.2280829 \\
24.2487113 \\
24.2693222\end{array}$ & $\begin{array}{l}8.3395509 \\
8.3443410 \\
8.3491256 \\
8.3539047 \\
8.3586784 \\
8.3634466 \\
8.3682095 \\
8.3729668 \\
8.371188 \\
8.3824653\end{array}$ & $\begin{array}{l}.001724138 \\
.001721170 \\
.001718213 \\
.001715266 \\
.001712329 \\
.001709402 \\
.001706485 \\
.001703578 \\
.001700680 \\
.001697793\end{array}$ \\
\hline $\begin{array}{l}590 \\
591 \\
592 \\
593 \\
594 \\
595 \\
596 \\
597 \\
598 \\
599\end{array}$ & $\begin{array}{l}348100 \\
349281 \\
350464 \\
351649 \\
352836 \\
354025 \\
355216 \\
356409 \\
357604 \\
358801\end{array}$ & $\begin{array}{l}205379000 \\
206425071 \\
207474688 \\
208527857 \\
209584584 \\
210644875 \\
211708736 \\
21276173 \\
213847192 \\
214921799\end{array}$ & $\begin{array}{l}24.2899156 \\
24.3104916 \\
24.3310501 \\
24.3515913 \\
24.3721152 \\
24.3926218 \\
24.4131112 \\
24.4335834 \\
24.4540385 \\
24.4744765\end{array}$ & $\begin{array}{l}8.3872065 \\
8.3919423 \\
8.3966729 \\
8.4013981 \\
8.4061180 \\
8.4108326 \\
8.4155419 \\
8.4202460 \\
8.4249448 \\
8.4296383\end{array}$ & $\begin{array}{r}.001694915 \\
.001692047 \\
.001689189 \\
.001686341 \\
.001683502 \\
001680672 \\
.0016 \div 1852 \\
.001675042 \\
.001672241 \\
.001669449\end{array}$ \\
\hline $\begin{array}{l}600 \\
601 \\
602 \\
603 \\
604 \\
605 \\
606 \\
607 \\
608 \\
609\end{array}$ & $\begin{array}{l}360000 \\
361201 \\
362404 \\
363609 \\
364816 \\
366025 \\
367236 \\
368449 \\
369664 \\
370881\end{array}$ & $\begin{array}{l}216000000 \\
217081801 \\
218167203 \\
219256227 \\
220348864 \\
221445125 \\
222545016 \\
223648543 \\
224755712 \\
225866529\end{array}$ & $\begin{array}{l}24.4948974 \\
24.5153013 \\
24.5356883 \\
24.5560583 \\
24.5764115 \\
24.596 \% 478 \\
24.6170673 \\
24.6373 i 00 \\
24.6576560 \\
24.6779254\end{array}$ & $\begin{array}{l}8.4343267 \\
8.4390098 \\
8.4436877 \\
8.4483605 \\
8.4530281 \\
8.45 \pi 6906 \\
8.4623479 \\
8.4670001 \\
8.4716471 \\
8.4662892\end{array}$ & $\begin{array}{l}.001666667 \\
.001663894 \\
.001661130 \\
.001658375 \\
.001655629 \\
.001652893 \\
.001650165 \\
.00164 \pi 446 \\
.001644737 \\
.001642036\end{array}$ \\
\hline $\begin{array}{l}610 \\
611 \\
612 \\
613 \\
614 \\
615 \\
616 \\
617 \\
618 \\
619 \\
620\end{array}$ & $\begin{array}{l}372100 \\
373321 \\
374544 \\
375769 \\
376996 \\
378225 \\
379456 \\
380689 \\
381924 \\
383161 \\
384400\end{array}$ & $\begin{array}{l}226981000 \\
228099131 \\
229220928 \\
230346397 \\
231475544 \\
232608375 \\
233744896 \\
234885113 \\
236029032 \\
237176659 \\
238328000\end{array}$ & $\begin{array}{l}24.6981781 \\
24.7184142 \\
24.7386338 \\
24.7588368 \\
24.7790234 \\
24.7991935 \\
24.8193473 \\
24.8394847 \\
24.8596058 \\
24.8797106 \\
24.8997992\end{array}$ & $\begin{array}{l}8.4809261 \\
8.4855579 \\
8.4901848 \\
8.4948065 \\
8.4994233 \\
8.5040350 \\
8.5086417 \\
8.5132135 \\
8.5178403 \\
8.5224321 \\
8.5270189\end{array}$ & $\begin{array}{l}.001639344 \\
.001636661 \\
001633987 \\
001631321 \\
.001628664 \\
.001626016 \\
.001623377 \\
.001620746 \\
.001618123 \\
.001615509 \\
.001612903\end{array}$ \\
\hline
\end{tabular}


CUBE ROOTS, AND RECIPROCALS.

\begin{tabular}{|c|c|c|c|c|c|}
\hline No. & Squares. & Cubes. & $\begin{array}{c}\text { Square } \\
\text { Koots. }\end{array}$ & Cube Roots. & Reciprocals. \\
\hline $\begin{array}{l}621 \\
6: 2 \\
623 \\
624 \\
625 \\
626 \\
627 \\
628 \\
629\end{array}$ & $\begin{array}{l}385641 \\
386884 \\
388129 \\
389376 \\
390625 \\
391876 \\
393129 \\
394384 \\
395641\end{array}$ & $\begin{array}{l}239483061 \\
240641848 \\
241804367 \\
242970624 \\
244140625 \\
245314376 \\
246491883 \\
247673152 \\
248858189\end{array}$ & $\begin{array}{l}24.9198 \% 16 \\
24.9399278 \\
24.9599679 \\
24.9799920 \\
25.0000000 \\
25.0199920 \\
25.0399681 \\
25.0599282 \\
25.0798 \% 24\end{array}$ & $\begin{array}{l}8.5316009 \\
8.5361780 \\
8.5407501 \\
8.5453173 \\
8.5498797 \\
8.5544372 \\
8.5589893 \\
8.563537 \% \\
8.5680807\end{array}$ & $\begin{array}{l}.001610306 \\
.00160 \% 71 \tau \\
.001605136 \\
.001602564 \\
.001600000 \\
.001597444 \\
.001594896 \\
.00159235 \tilde{7} \\
.001589825\end{array}$ \\
\hline $\begin{array}{l}630 \\
631 \\
632 \\
633 \\
634 \\
635 \\
635 \\
637 \\
638 \\
639 \\
\end{array}$ & $\begin{array}{l}396900 \\
398161 \\
399424 \\
400689 \\
401956 \\
403225 \\
404496 \\
405 \% 69 \\
407044 \\
408321\end{array}$ & $\begin{array}{l}250047000 \\
251239591 \\
252435968 \\
253636137 \\
254840104 \\
256047875 \\
257259456 \\
258474853 \\
259694072 \\
260917119\end{array}$ & $\begin{array}{l}25.0998008 \\
25.1197134 \\
25.1396102 \\
25.1594913 \\
25.1793566 \\
25.1992063 \\
25.2190404 \\
25.2388589 \\
25.2586619 \\
25.2784493\end{array}$ & $\begin{array}{l}8.5 \% 26189 \\
8.571523 \\
8.5816809 \\
8.5862047 \\
8.590 \% 238 \\
8.5952380 \\
8.5997476 \\
8.6042525 \\
8.6087526 \\
8.6132480\end{array}$ & $\begin{array}{l}.00158 \% 302 \\
.001581786 \\
.001582278 \\
.0015 \% 97 \% 9 \\
.0015 \% 7287 \\
.0015 \% 4803 \\
.0015 \% 2327 \\
.001569859 \\
.001567398 \\
.001564945\end{array}$ \\
\hline $\begin{array}{l}640 \\
641 \\
642 \\
643 \\
644 \\
645 \\
646 \\
647 \\
648 \\
649\end{array}$ & $\begin{array}{l}409600 \\
410881 \\
412164 \\
413149 \\
414736 \\
416025 \\
417316 \\
418609 \\
419904 \\
421201\end{array}$ & $\begin{array}{l}262144000 \\
263374721 \\
264609288 \\
265847707 \\
267089984 \\
268336125 \\
269586136 \\
2 \% 0810023 \\
272097792 \\
273359449\end{array}$ & $\begin{array}{l}25.2982213 \\
25.3179778 \\
25.3377189 \\
25.3574447 \\
25.3771551 \\
25.3968502 \\
25.4165301 \\
25.4361947 \\
25.4558441 \\
25.4754781\end{array}$ & $\begin{array}{l}8.617 r 388 \\
8.6222248 \\
8.6267063 \\
8.6311830 \\
8.6356551 \\
8.6401226 \\
8.6445855 \\
8.6490437 \\
8.6534974 \\
8.6579465\end{array}$ & $\begin{array}{l}.001562500 \\
.001560062 \\
.00155 \pi 632 \\
.001555210 \\
.001552795 \\
.001550388 \\
.001547988 \\
.001545595 \\
.001543210 \\
.001540832\end{array}$ \\
\hline $\begin{array}{l}650 \\
651 \\
652 \\
653 \\
654 \\
655 \\
656 \\
657 \\
658 \\
659\end{array}$ & $\begin{array}{l}422500 \\
423801 \\
425104 \\
426109 \\
427716 \\
429025 \\
430336 \\
431649 \\
432961 \\
434281\end{array}$ & $\begin{array}{l}2 \% 4625000 \\
275894451 \\
2 \tau 716 \pi 808 \\
278445077 \\
2 \tau 9726264 \\
281011375 \\
282300416 \\
283593393 \\
281890312 \\
2861911 \% 9\end{array}$ & $\begin{array}{l}25.4950976 \\
25.5147016 \\
25.5342907 \\
25.5538647 \\
25.5734237 \\
25.5929678 \\
25.6124969 \\
25.6320112 \\
25.6515107 \\
25.6 \% 09953\end{array}$ & $\begin{array}{l}8.6623911 \\
8.6668310 \\
8.6712665 \\
8.6756974 \\
8.6801237 \\
8.6845456 \\
8.6889630 \\
8.6933759 \\
8.6977843 \\
8.7021882\end{array}$ & $\begin{array}{l}.001538462 \\
.001536098 \\
.001533 \% 42 \\
.001531394 \\
.001529052 \\
.001526718 \\
.001524390 \\
.0015220 \% 0 \\
.001519 \% 5 \% \\
.00151 \% 451\end{array}$ \\
\hline $\begin{array}{l}660 \\
661 \\
662 \\
663 \\
664 \\
665 \\
666 \\
667 \\
668 \\
669\end{array}$ & $\begin{array}{l}435600 \\
436921 \\
438244 \\
439569 \\
440896 \\
442225 \\
443556 \\
444889 \\
446224 \\
447561\end{array}$ & $\begin{array}{l}287496000 \\
288804 \pi 81 \\
290117528 \\
291434247 \\
292754944 \\
294079625 \\
295408296 \\
296740963 \\
298077632 \\
299418309\end{array}$ & $\begin{array}{l}25.6904652 \\
25.7099203 \\
25.7293607 \\
25.7487864 \\
25.7681975 \\
25.7875939 \\
25.8069758 \\
25.8263431 \\
25.8456960 \\
25.8650343\end{array}$ & $\begin{array}{l}\text { 8. } 7065877 \\
8.710982 \% \\
8.7153734 \\
8.7197596 \\
8.7241414 \\
8.7285187 \\
\text { 8. } 7328918 \\
8.7372604 \\
8.7416246 \\
8.7459846\end{array}$ & $\begin{array}{l}.001515152 \\
.001512859 \\
.0015105 \% 4 \\
.001508296 \\
.001506024 \\
.001503 \% 59 \\
.001501502 \\
.001499250 \\
.001497006 \\
.001494 \% 68\end{array}$ \\
\hline $\begin{array}{l}6 \% 0 \\
671 \\
672 \\
673 \\
674 \\
675 \\
676 \\
677 \\
678 \\
679\end{array}$ & $\begin{array}{l}448900 \\
450211 \\
451581 \\
452929 \\
454276 \\
455625 \\
456976 \\
458329 \\
459691 \\
461011\end{array}$ & $\begin{array}{l}300763000 \\
302111711 \\
303464448 \\
304821217 \\
306182024 \\
30 \% 5468 \% 5 \\
308915 \% 76 \\
310288733 \\
311665 \% 52 \\
313046839\end{array}$ & $\begin{array}{l}25.8813582 \\
25.9036677 \\
25.9229628 \\
25.9422435 \\
25.9615100 \\
25.980 \% 621 \\
26.0000000 \\
26.0192237 \\
26.0384331 \\
26.05 \% 6284\end{array}$ & $\begin{array}{l}\text { 8. } 7503401 \\
8.7546913 \\
8.7590383 \\
8.7633809 \\
8.767192 \\
8.760532 \\
8.763830 \\
8.7807084 \\
8.7850296 \\
8.7893166\end{array}$ & $\begin{array}{l}.001492537 \\
.001490313 \\
.001488095 \\
.001485884 \\
.001483680 \\
.001481481 \\
.001479290 \\
.001477105 \\
.001474926 \\
.001472754\end{array}$ \\
\hline $\begin{array}{l}680 \\
681 \\
682\end{array}$ & $\begin{array}{l}462400 \\
463761 \\
465121\end{array}$ & $\begin{array}{l}314432000 \\
315821241 \\
317214568\end{array}$ & $\begin{array}{l}26.0 \% 68096 \\
26.0959767 \\
26.1151297\end{array}$ & $\begin{array}{l}\text { 8. } \% 936593 \\
8.79796 \% 9 \\
8.8022721\end{array}$ & $\begin{array}{l}.001470588 \\
.001468429 \\
.001466276\end{array}$ \\
\hline
\end{tabular}


TABLE X.-SQUARES, CUBES, SQUARE ROOTS,

\begin{tabular}{|c|c|c|c|c|c|}
\hline No. & Squares. & Cubes. & $\begin{array}{l}\text { Square } \\
\text { Roots. }\end{array}$ & Cube Roots. & Reciprocals. \\
\hline 683 & 466489 & 318611987 & $26.13426 \& 7$ & 8.8065722 & .001464129 \\
\hline 684 & 467856 & 320013504 & 26.1533937 & 8.8108681 & .001461988 \\
\hline 685 & 469225 & 321419125 & 26.1725047 & 8.8151598 & .001459854 \\
\hline 686 & 470596 & 322828856 & 26.1916017 & $8.81944 \pi 4$ & .001457726 \\
\hline 687 & 471969 & 324242703 & 26.2106848 & 8.8237307 & .001455604 \\
\hline 688 & 473344 & $3256606 \% 2$ & 26.2297541 & 8.8280099 & .001453488 \\
\hline 689 & $4 \pi 4 \pi 21$ & 327082769 & 26.2488095 & 8.8322850 & .001451379 \\
\hline 690 & 476100 & 328509000 & 26.2678511 & 8.8365559 & .001449275 \\
\hline 691 & 477481 & $3299393 \pi 1$ & 26.2868789 & 8.8408227 & $.00144 \pi 178$ \\
\hline 692 & 478864 & 331373888 & 26.3058929 & 8.8450854 & .001445087 \\
\hline 693 & 480249 & 332812557 & 26.3248932 & 8.8493440 & .001443001 \\
\hline 694 & 481636 & 334255384 & 26.3438797 & 8.8535985 & .001440922 \\
\hline 695 & 483025 & $335 \pi 023 \pi 5$ & 26.3628527 . & 8.8578489 & .001438849 \\
\hline 696 & 484416 & 337153536 & 26.3818119 & 8.8620952 & .001436782 \\
\hline 697 & 485809 & 338608873 & $26.40075 \% 6$ & $8.86633 \pi 5$ & .001434720 \\
\hline 698 & 487204 & 340068392 & 26.4196896 & $8.8 \% 05757$ & .001432665 \\
\hline 699 & 488601 & 341532099 & 26.4386081 & $8.8 \widetilde{r} 48099$ & .001430615 \\
\hline 700 & 490000 & 343000000 & 26.4575131 & 8.8790400 & $.0014285 \% 1$ \\
\hline 701 & 491401 & 344472101 & 26.4764046 & 8.8832661 & .001426534 \\
\hline 702 & 492804 & 345948108 & 26.4952826 & 8.8874882 & .001424501 \\
\hline 703 & 494209 & $34742892 \pi$ & 26.5141472 & 8.8917063 & .001422475 \\
\hline 704 & 495616 & 348913664 & 26.5329983 & 8.8959204 & .001420455 \\
\hline 705 & 497025 & 350402625 & 26.5518361 & 8.9001304 & .001418440 \\
\hline 706 & 498436 & 351895816 & 26.5706605 & 8.9043366 & .001416431 \\
\hline 707 & 499849 & 353393243 & 26.5894716 & 8.9085387 & .001414427 \\
\hline 708 & 501264 & 354894912 & 26.6082694 & 8.9127369 & .001412429 \\
\hline$\tau 09$ & 502681 & 356400829 & $26 \quad 62 \% 0539$ & 8.9169311 & .001410437 \\
\hline 710 & 504100 & 357911000 & 26.6458252 & 8.9211214 & .001408451 \\
\hline$\tau 11$ & 505521 & 359425431 & 26.6645833 & 8.9253078 & .001406470 \\
\hline$\pi 12$ & 506944 & 360944128 & 26.6833281 & 8.9294902 & .001404494 \\
\hline$\tau 13$ & $508: 369$ & $36246 \% 097$ & 26. 7020598 & 8.9336687 & .001402525 \\
\hline$\tau: 4$ & 509796 & 363994344 & 26.7207784 & 8.9378433 & .001400560 \\
\hline 715 & 511225 & $3655258 \pi 5$ & 26.7394839 & 8.9420140 & .001398601 \\
\hline 716 & 512656 & 367061696 & 26.7581763 & 8.9461809 & .001396648 \\
\hline 717 & 514089 & 368601813 & 26.7768557 & 8.9503438 & .001394700 \\
\hline 718 & 515524 & 370146232 & 26.7955220 & 8.9545029 & .001392758 \\
\hline 719 & 516961 & 371694959 & 26.8141754 & 8.9586581 & .001390821 \\
\hline 720 & 518400 & 373248000 & 26.8328157 & 8.9628095 & .001388889 \\
\hline 721 & 519841 & $3 \pi 4805361$ & 26.8514432 & $8.96695 \% 0$ & .001386963 \\
\hline 722 & 521284 & $37636 r 048$ & $26.87005 \%$ & 8.9711007 & .001385042 \\
\hline 723 & 522729 & 377933067 & 26.8886593 & $8.9 \pi 52406$ & .001383126 \\
\hline 724 & 524176 & 379503424 & $26.90 \approx 2481$ & 8.9793766 & .001381215 \\
\hline 725 & 525625 & 381078125 & 26.9258240 & 8.9835089 & .001379310 \\
\hline 726 & 527076 & 382657176 & 26.9443872 & $8.98 \% 63 \% 3$ & .001377410 \\
\hline 727 & 528529 & 384240583 & 26.9629375 & 8.9917620 & .001375516 \\
\hline 728 & 529984 & 385828352 & 26.9814751 & 8.9958829 & .001373626 \\
\hline 729 & 531441 & $38 \approx 420489$ & $2 \tau .0000000$ & 9.0000000 & .001371742 \\
\hline 730 & 532900 & 389017000 & 27.0185122 & 9.0041134 & .001369863 \\
\hline 731 & 534361 & 390617891 & 27.0370117 & 9.00822229 & .001367989 \\
\hline$\pi 32$ & 535824 & 392223168 & 27.0554985 & 9.0123288 & .001366120 \\
\hline 733 & 537289 & 393832837 & $27.0739 \pi 2 ?$ & 9.0164309 & .001364256 \\
\hline 734 & 538756 & 395446904 & 27.0924344 & 9.0205293 & .001362398 \\
\hline 735 & $540: 225$ & 397065375 & 27.1108834 & 9.0246239 & .001360544 \\
\hline 736 & 541696 & 398688256 & 27.1293199 & $9.028 \pi 149$ & .001358696 \\
\hline 737 & 543169 & 400315553 & 27.1477439 & 9.0328021 & .001356852 \\
\hline 738 & 544644 & $4019172 \% 2$ & 27.1661554 & 9.0368857 & .001355014 \\
\hline 739 & 546121 & 403583419 & 27.1845544 & 0.0409655 & .001353180 \\
\hline 740 & $54 \% 600$ & 405224000 & 27.2029410 & 9.0450419 & .001351351 \\
\hline 741 & 549081 & 406869021 & $2 \% .2213152$ & 9.0491142 & .001349528 \\
\hline 742 & 550564 & 408518488 & 27.2396769 & 9.0531831 & $.001347 \% 09$ \\
\hline$\lceil 43$ & 552049 & 410172407 & $27.2580^{2} 66^{3}$ & 9.0572482 & .001345895 \\
\hline$\tau 44$ & 553536 & 411830784 & 27.2763634 & 9.0613098 & .001344086 \\
\hline
\end{tabular}


CUBE ROOTS, AND RECIPROCALS.

\begin{tabular}{|c|c|c|c|c|c|}
\hline No. & Squares. & Cubes. & $\begin{array}{l}\text { Square } \\
\text { Roots. }\end{array}$ & Cube Roots. & Reciprocals. \\
\hline $\begin{array}{l}745 \\
746 \\
747 \\
748 \\
749\end{array}$ & $\begin{array}{l}555025 \\
556516 \\
558009 \\
559504 \\
561001\end{array}$ & $\begin{array}{l}413493625 \\
415160936 \\
416832723 \\
418508992 \\
420189749\end{array}$ & $\begin{array}{l}2 \pi .2946881 \\
2 \pi .3130006 \\
2 \pi .3313007 \\
27.3495887 \\
27.3678644\end{array}$ & $\begin{array}{l}9.0653677 \\
9.0694220 \\
9.0734726 \\
9.0 \% 75197 \\
9.0815631\end{array}$ & $\begin{array}{l}.001342282 \\
.001340483 \\
.001338688 \\
.001336898 \\
.001335113\end{array}$ \\
\hline $\begin{array}{l}750 \\
751 \\
752 \\
753 \\
754 \\
755 \\
756 \\
757 \\
758 \\
759\end{array}$ & $\begin{array}{l}562500 \\
564001 \\
565504 \\
567009 \\
568516 \\
570025 \\
571536 \\
573049 \\
571564 \\
5 \% 6081\end{array}$ & $\begin{array}{l}421875000 \\
423564751 \\
425259008 \\
42695 \% 7 \% 7 \\
428661064 \\
430368875 \\
432081216 \\
433798093 \\
435519512 \\
437245479\end{array}$ & $\begin{array}{l}27.3861279 \\
27.4043792 \\
27.4226184 \\
27.4408455 \\
27.4590604 \\
27.4772632 \\
27.4954542 \\
27.5136330 \\
27.5317998 \\
27.5499546\end{array}$ & $\begin{array}{l}9.0856030 \\
9.0896392 \\
9.0936719 \\
9.097 \% 010 \\
9.1017265 \\
9.1057485 \\
9.1097669 \\
9.1137818 \\
9.1177931 \\
9.1218010\end{array}$ & $\begin{array}{l}.001333333 \\
.001331558 \\
.001329787 \\
.001328021 \\
.001326260 \\
.001324503 \\
.001322751 \\
.001321004 \\
.001319261 \\
.001317523\end{array}$ \\
\hline $\begin{array}{l}r 60 \\
r 61 \\
r 62 \\
r 63 \\
764 \\
r 65 \\
766 \\
767 \\
r 68 \\
r 69\end{array}$ & $\begin{array}{l}577600 \\
579121 \\
580644 \\
582169 \\
583696 \\
585225 \\
586756 \\
588289 \\
589824 \\
591361\end{array}$ & $\begin{array}{l}438976000 \\
440711081 \\
442450728 \\
444194947 \\
445943744 \\
447697125 \\
449455096 \\
451217663 \\
452984832 \\
454756609\end{array}$ & $\begin{array}{l}27.5680975 \\
27.5862284 \\
27.6043475 \\
27.62 .4546 \\
27.6105499 \\
27.6586334 \\
27.6767050 \\
27.6947648 \\
27.7128129 \\
27.7308492\end{array}$ & $\begin{array}{r}9.1258053 \\
9.1298061 \\
9.1338034 \\
9.1377971 \\
9.1417874 \\
9.1457 \% 42 \\
9.14975 \% 6 \\
9.1537375 \\
9.1577139 \\
9.1616863\end{array}$ & $\begin{array}{l}.001315 r 89 \\
.001314060 \\
.001312336 \\
.001310616 \\
.001308901 \\
.001307190 \\
.001305483 \\
.001303781 \\
.001302083 \\
.001300390\end{array}$ \\
\hline 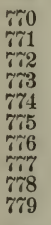 & $\begin{array}{l}592900 \\
594441 \\
595984 \\
597529 \\
599076 \\
600625 \\
602176 \\
603729 \\
605281 \\
606841\end{array}$ & $\begin{array}{l}4565333000 \\
458314011 \\
460099648 \\
461889917 \\
463684824 \\
465484375 \\
467288576 \\
469097433 \\
470910952 \\
472729139\end{array}$ & $\begin{array}{l}27.7488739 \\
27.7668808 \\
27.7848880 \\
27.8028775 \\
27.8208555 \\
27.8388218 \\
27.8567666 \\
27.8747197 \\
27.8926514 \\
27.9105715\end{array}$ & $\begin{array}{l}9.1656565 \\
9.1696225 \\
9.1735852 \\
9.1775445 \\
9.1815003 \\
9.1854527 \\
9.1894018 \\
9.1933474 \\
9.1972897 \\
9.2012286\end{array}$ & $\begin{array}{l}.001298701 \\
.00129701 \% \\
.001295337 \\
.001293661 \\
.001291990 \\
.001290323 \\
.001288660 \\
.001287001 \\
.001285347 \\
.001283697\end{array}$ \\
\hline $\begin{array}{l}780 \\
781 \\
782 \\
783 \\
784 \\
785 \\
786 \\
787 \\
788 \\
789\end{array}$ & $\begin{array}{l}608400 \\
609961 \\
611524 \\
613089 \\
614656 \\
616225 \\
617796 \\
619369 \\
620944 \\
622521\end{array}$ & $\begin{array}{l}474552000 \\
476379541 \\
478211768 \\
480048687 \\
481890304 \\
483736625 \\
485587656 \\
4874434 C 3 \\
489303872 \\
491169069\end{array}$ & $\begin{array}{l}27.9284801 \\
27.94637 \% 2 \\
27.9642629 \\
27.98213 \% 2 \\
28.0000000 \\
28.01 \% 8515 \\
28.0356915 \\
28.0535203 \\
28.0713377 \\
28.0891438\end{array}$ & $\begin{array}{l}9.2051641 \\
9.2090962 \\
9.2130250 \\
9.2169505 \\
9.2208726 \\
9.2247914 \\
9.228 \% 068 \\
9.2326189 \\
9.23652 r 7 \\
9.2404333\end{array}$ & $\begin{array}{l}.001282051 \\
.001280410 \\
.0012787 \% 2 \\
.0012 \% 139 \\
.001275510 \\
.001273885 \\
.0012 \% 2265 \\
.001270648 \\
.001269036 \\
.00126 \% 427\end{array}$ \\
\hline $\begin{array}{l}790 \\
791 \\
792 \\
793 \\
794 \\
795 \\
796 \\
797 \\
798 \\
799\end{array}$ & $\begin{array}{l}624100 \\
625681 \\
627264 \\
628849 \\
630436 \\
632025 \\
633616 \\
635209 \\
636804 \\
638401\end{array}$ & $\begin{array}{l}493039000 \\
494913671 \\
496793088 \\
498677257 \\
500566184 \\
502459875 \\
504358336 \\
506261573 \\
508169592 \\
510082399\end{array}$ & $\begin{array}{l}28.1069386 \\
28.1247222 \\
28.1424946 \\
28.1602557 \\
28.1780056 \\
28.1957444 \\
28.2134720 \\
28.2311884 \\
28.2488938 \\
28.2665881\end{array}$ & $\begin{array}{l}9.2443355 \\
9.2482344 \\
9.2521300 \\
9.2560224 \\
9.2599114 \\
9.2637973 \\
9.26 r 6 r 98 \\
9.2715592 \\
9.2754352 \\
9.2793081\end{array}$ & $\begin{array}{l}.001265823 \\
.001264223 \\
.001262626 \\
.001261034 \\
.001259446 \\
.001257862 \\
.001256281 \\
.001254705 \\
.001253133 \\
.001251564\end{array}$ \\
\hline $\begin{array}{l}800 \\
801 \\
802 \\
803 \\
804 \\
805 \\
806\end{array}$ & $\begin{array}{l}640000 \\
641601 \\
643201 \\
644809 \\
646416 \\
648025 \\
649636\end{array}$ & $\begin{array}{l}512000000 \\
513922401 \\
515819608 \\
517781627 \\
519718464 \\
521660125 \\
523606616\end{array}$ & $\begin{array}{l}28.2842712 \\
28.3019434 \\
28.3196045 \\
28.3972546 \\
28.3548938 \\
28.3 r 25219 \\
28.3901391\end{array}$ & $\begin{array}{l}9.2831777 \\
9.2870440 \\
9.2909072 \\
9.2947671 \\
9.2986239 \\
9.3024775 \\
9.3063278\end{array}$ & $\begin{array}{l}.001250000 \\
.001248439 \\
.001246883 \\
.001245330 \\
.001243781 \\
.001242236 \\
.001240695\end{array}$ \\
\hline
\end{tabular}


TABLE X.-SQUARES, CUBES, SQUARE ROOTS,

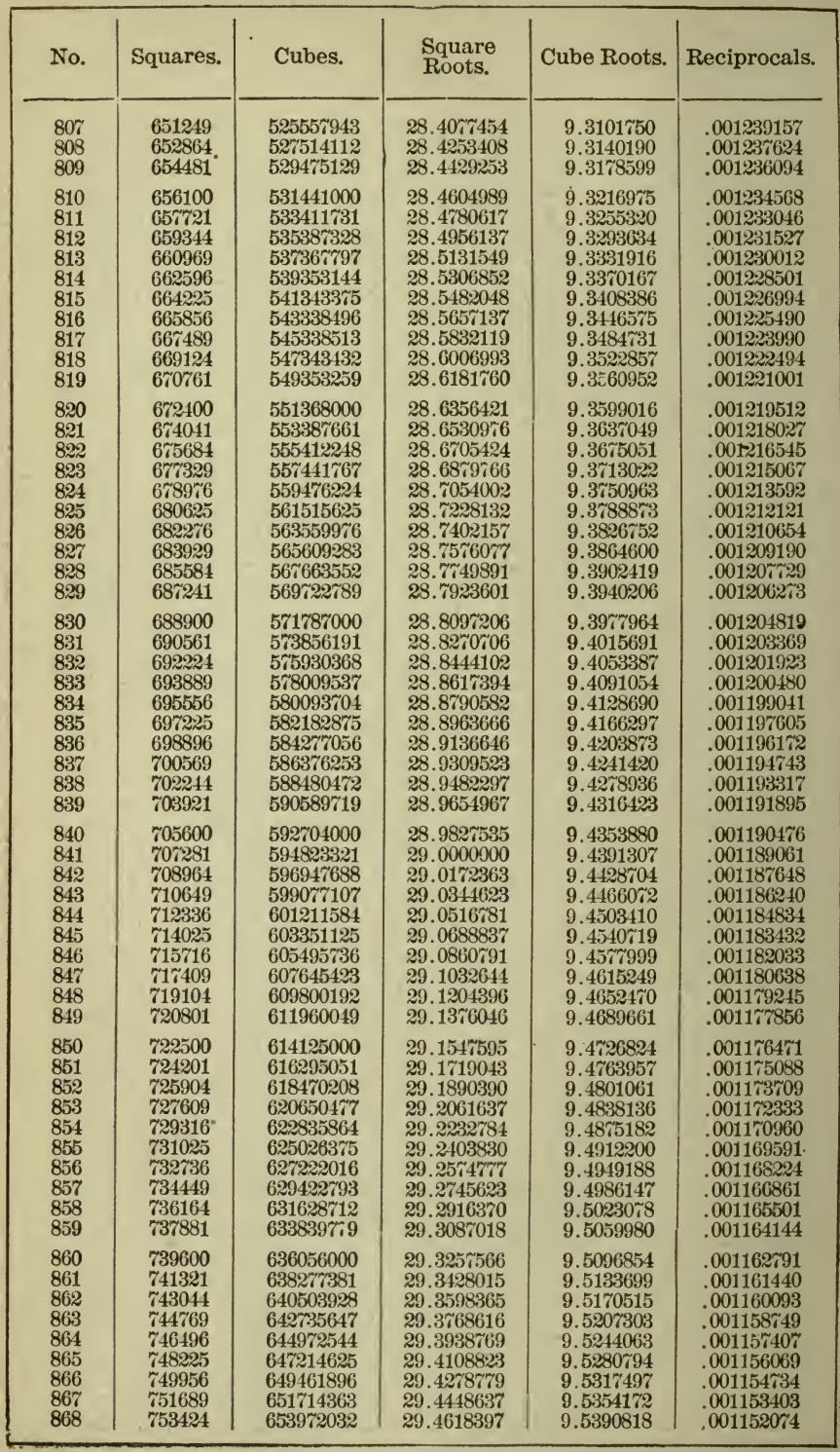


CUBE ROOTS, AND RECIPROCALS.

\begin{tabular}{|c|c|c|c|c|c|}
\hline No. & Squares. & Cubes. & $\begin{array}{l}\text { Square } \\
\text { Roots. }\end{array}$ & Cube Roots. & Reciprocals. \\
\hline 869 & \%ั5ั161 & 656234909 & 29.4788059 & 9.5427437 & .001150748 \\
\hline $8 \% 0$ & 756900 & 658503000 & 29.4957624 & 9.5464027 & .001149425 \\
\hline 871 & 758641 & 660776311 & $29.512 \gamma 091$ & 9.5500589 & .001148106 \\
\hline $8 \% 2$ & 760384 & 663054848 & 29.5296461 & 9.5537123 & .001146789 \\
\hline 873 & 762129 & 665338617 & 29.5465734 & 9.5573630 & .001145475 \\
\hline 874 & 763876 & 667627624 & 29.5634910 & 9.5610108 & .001144165 \\
\hline $8 \% 5$ & 765625 & 669921875 & 29.5803989 & 9.5646559 & .001142857 \\
\hline 876 & 767376 & $6722213 \% 6$ & 29.5972972 & 9.5682982 & .001141553 \\
\hline 877 & 769129 & 674526133 & 29.6141858 & $9.57193 \% 7$ & .001140251 \\
\hline 878 & 70884 & 676836152 & 29.6310648 & 9.5755745 & .001138952 \\
\hline $879^{\circ}$ & 72641 & 679151439 & 29.6479342 & 9.5792085 & .001137656 \\
\hline 880 & 774400 & 681472000 & 29.6647939 & 9.5828397 & .001136364 \\
\hline 881 & 776161 & 683797841 & 29.6816442 & 9.5864682 & .001135074 \\
\hline 882 & 77924 & 686128968 & 29.6984848 & 9.5900939 & .001133787 \\
\hline 883 & 779689 & 688465387 & 29.7153159 & 9.5937169 & .001132503 \\
\hline 884 & 781456 & 690807104 & 29.7321375 & 9.5973373 & .001131222 \\
\hline 885 & 783225 & 693154125 & 29.7489496 & 9.6009548 & .001129944 \\
\hline 886 & 784996 & 695506456 & 29.7657521 & 9.6045696 & .001128668 \\
\hline 887 & 786769 & 697864103 & 29.7825452 & 9.6081817 & .001127396 \\
\hline 888 & 788544 & 7002270\% & 29.7993289 & 9.6117911 & .001126126 \\
\hline 889 & 790321 & 702595369 & 29.8161030 & 9.6153977 & .001124859 \\
\hline 890 & $\tau 92100$ & 704969000 & 29.8328678 & 9.6190017 & .001123596 \\
\hline 891 & 793881 & 707347971 & 29.8496231 & 9.6226030 & .001122334 \\
\hline 892 & 795664 & \%09732288 & 29.8663690 & 9.6262016 & .001121076 \\
\hline 893 & 797449 & ซ12121957 & 29.8831056 & 9.6297975 & .001119821 \\
\hline 894 & 799236 & 714516984 & 29.8998328 & 9.6333907 & .001118568 \\
\hline 895 & 801025 & $7169173 \% 5$ & 29.9165506 & 9.6369812 & .001117318 \\
\hline 896 & 802816 & 719323136 & 29.9332591 & 9.6405690 & .001116071 \\
\hline 897 & 804609 & ซ21734273 & 29.9499583 & 9.6441542 & $.00111482 \gamma$ \\
\hline 898 & 806404 & 724150792 & 29.9666481 & 9.6477367 & .001113586 \\
\hline 899 & 808201 & $7265 \% 2699$ & 29.9833287 & 9.6513166 & .001112347 \\
\hline 900 & 810000 & 729000000 & 30.0000000 & 9.6548938 & .001111111 \\
\hline 901 & 811801 & 731432701 & 30.0166620 & 9.6584684 & .001109878 \\
\hline 902 & 813604 & 733870808 & 30.0333148 & 9.6620403 & .001108647 \\
\hline 903 & 815409 & 736314327 & 30.0499584 & 9.6656096 & $.00110 \pi 420$ \\
\hline 904 & $81 \% 216$ & 738763264 & 30.0665928 & 9.6691762 & .001106195 \\
\hline 905 & 819025 & 741217625 & 30.0832179 & $9.6 \% 2 \% 403$ & .001104972 \\
\hline 906 & 820836 & \%43677416 & 30.0998339 & 9.6763017 & $.001103 \pi 53$ \\
\hline 907 & 822649 & 746142643 & 30.1164407 & 9.6798604 & .001102536 \\
\hline 908 & 824464 & 748613312 & 30.1330383 & 9.6834166 & .001101322 \\
\hline 909 & 826281 & 751089429 & 30.1496269 & 9.6869701 & .001100110 \\
\hline 910 & 828100 & 753571000 & 30.1662063 & 9.6905211 & .001098901 \\
\hline 911 & 829921 & 756058031 & 30.182765 & 9.6940694 & .001097695 \\
\hline 912 & 831744 & 758550528 & $30.19933 \pi 7$ & 9.6976151 & .001096491 \\
\hline 913 & 833569 & 761048497 & 30.2158899 & 9.7011583 & .001095290 \\
\hline 914 & 835396 & 763551944 & 30.2324329 & 9.7046989 & .001094092 \\
\hline 915 & $83 \% 225$ & 766060875 & 30.2489669 & 9.7082369 & .001092896 \\
\hline 916 & - 839056 & 768575296 & 30.2654919 & 9.7117ซ23 & .001091703 \\
\hline 917 & 840889 & 771095213 & 30.2820079 & 9.7153051 & .001090513 \\
\hline 918 & 842724 & 773620632 & 30.2985148 & 9.7188354 & .001089335 \\
\hline 919 & 844561 & 776151559 & 30.3150128 & 9.7223631 & .001088139 \\
\hline 920 & 846400 & 78688000 & 30.3315018 & 9.7258883 & .001086957 \\
\hline 921 & 848241 & r81229961 & 30.3479818 & 9.7294109 & .00108576 \\
\hline 922 & 850084 & 883777448 & 30.3644529 & 9.7329309 & .001084599 \\
\hline 923 & 851929 & $8633046 \%$ & 30.3809151 & 9.7364484 & .001083423 \\
\hline 924 & 853776 & 788889024 & 30.3973683 & 9.7399634 & .001082251 \\
\hline 925 & 855625 & \%91453125 & 30.4138127 & 9.7434758 & .001081081 \\
\hline 926 & $85 \pi 4 \% 6$ & $7940227 \% 6$ & 30.4302481 & 9.7469857 & .001079914 \\
\hline 927 & 859329 & ๆ96597983 & 30.4466747 & 9.7504930 & .001078749 \\
\hline 928 & 861184 & 799178752 & 30.4630924 & 9.7539979 & .00107586 \\
\hline 929 & 863041 & 801765089 & 30.4795013 & $9.75 \% 5002$ & .001076426 \\
\hline 930 & 864900 & 804357000 & 30.4959014 & 9.7610001 & $.0010 \div 5269$ \\
\hline
\end{tabular}


TABLE X.-SQUARES, CUBES, SQUARE ROOTS,

\begin{tabular}{|c|c|c|c|c|c|}
\hline No. & Squares. & Cubes. & $\begin{array}{l}\text { Square } \\
\text { Roots. }\end{array}$ & Cube Roots. & Reciprocals. \\
\hline $\begin{array}{l}931 \\
932 \\
933 \\
934 \\
935 \\
936 \\
937 \\
938 \\
839\end{array}$ & $\begin{array}{l}866761 \\
868624 \\
870489 \\
872356 \\
874225 \\
876096 \\
877969 \\
879844 \\
881721\end{array}$ & $\begin{array}{l}806954491 \\
80955 \pi 568 \\
812166237 \\
814780504 \\
81 \% 4003 \pi 5 \\
820025856 \\
822656953 \\
8252936 \% 2 \\
827936019\end{array}$ & $\begin{array}{l}30.5122926 \\
30.5286750 \\
30.5450487 \\
30.5614136 \\
30.5777697 \\
30.5941171 \\
30.6104557 \\
30.6267857 \\
30.6431069\end{array}$ & $\begin{array}{l}9.76449 \% 4 \\
9.7679922 \\
9.7714845 \\
9.7749 \pi 43 \\
9.7 \% 4616 \\
9.7819466 \\
9.7854288 \\
9.7889087 \\
9.7923861\end{array}$ & $\begin{array}{l}.0010 \% 4114 \\
.0010 \tau 2961 \\
.0010 \tau 1811 \\
.0010 \% 0664 \\
.001069519 \\
.0010683 \% 6 \\
.00106 \tau 236 \\
.001066098 \\
.001064963\end{array}$ \\
\hline $\begin{array}{l}940 \\
941 \\
942 \\
943 \\
944 \\
945 \\
946 \\
947 \\
948 \\
949\end{array}$ & $\begin{array}{l}883600 \\
885481 \\
887364 \\
889249 \\
891136 \\
893025 \\
894916 \\
896809 \\
898704 \\
900601\end{array}$ & $\begin{array}{l}830584000 \\
83323 r 621 \\
835896888 \\
838561807 \\
841232384 \\
843908625 \\
846590536 \\
849278123 \\
851971392 \\
854670349\end{array}$ & $\begin{array}{l}30.6594194 \\
30.6757233 \\
30.6920185 \\
20.7083051 \\
\vdots 0.7245830 \\
30.7408523 \\
30.7571130 \\
30.7733651 \\
30.7896086 \\
30.8058436\end{array}$ & $\begin{array}{l}9.7958611 \\
9.7993336 \\
9.8028036 \\
9.8062711 \\
9.8097362 \\
9.8131989 \\
9.8166591 \\
9.8201169 \\
9.8235723 \\
9.82 .0252\end{array}$ & $\begin{array}{l}.001063830 \\
.001062699 \\
.001061571 \\
.001060445 \\
.001059322 \\
.001058201 \\
.00105 \% 082 \\
.001055966 \\
.001054852 \\
.001053 r 41\end{array}$ \\
\hline $\begin{array}{l}950 \\
951 \\
952 \\
953 \\
954 \\
955 \\
956 \\
957 \\
958 \\
959\end{array}$ & $\begin{array}{l}902500 \\
904401 \\
906304 \\
908209 \\
910116 \\
912025 \\
913936 \\
915849 \\
911664 \\
919681\end{array}$ & $\begin{array}{l}85 \% 3 \% 5000 \\
860085351 \\
862801408 \\
865523177 \\
868250664 \\
8 \% 09838 \% 5 \\
873722816 \\
87646 \% 493 \\
87921 \% 912 \\
8819740 \% 9\end{array}$ & $\begin{array}{l}30.8220700 \\
30.8382879 \\
30.8544972 \\
30.8706981 \\
30.8868904 \\
20.9030 \% 43 \\
20.9192497 \\
30.9354166 \\
30.9515 \% 51 \\
30.96 \% 251\end{array}$ & $\begin{array}{l}9.8304757 \\
9.8339238 \\
9.8373695 \\
9.8408127 \\
9.8442536 \\
9.8476920 \\
9.8511280 \\
9.8545617 \\
9.85 \% 9929 \\
9.8614218\end{array}$ & $\begin{array}{l}.001052632 \\
.001051525 \\
.001050420 \\
.001049318 \\
.001048218 \\
.001047120 \\
.001046025 \\
.001044932 \\
.001043841 \\
.001042753\end{array}$ \\
\hline $\begin{array}{l}960 \\
961 \\
962 \\
963 \\
964 \\
965 \\
966 \\
967 \\
968 \\
969\end{array}$ & $\begin{array}{l}921600 \\
923521 \\
925444 \\
927369 \\
929296 \\
931225 \\
933156 \\
935089 \\
937024 \\
938961\end{array}$ & $\begin{array}{l}884736000 \\
88 \pi 503681 \\
8902 ; \tau 128 \\
893056347 \\
895841344 \\
898632125 \\
901428696 \\
904231063 \\
90 ; 039232 \\
909853209\end{array}$ & $\begin{array}{l}30.9838668 \\
31.0000000 \\
31.0161248 \\
31.0322413 \\
31.0483494 \\
31.0644491 \\
31.0805405 \\
31.0966236 \\
31.1126984 \\
31.1287648\end{array}$ & $\begin{array}{l}9.8648483 \\
9.8682 ; 24 \\
9.8 \% 16941 \\
9.8751135 \\
9.8785305 \\
9.8819451 \\
9.88535 r 4 \\
9.888 r 6 r 3 \\
9.8921 r 49 \\
9.8955801\end{array}$ & $\begin{array}{l}.001041667 \\
.001040583 \\
.001039501 \\
.001038422 \\
.001037344 \\
.001036269 \\
.001035197 \\
.001034126 \\
.001033058 \\
.001031992\end{array}$ \\
\hline $\begin{array}{l}970 \\
9 r 1 \\
9 r 2 \\
9 r 3 \\
9 r 4 \\
975 \\
976 \\
9 r i \\
9 r 8 \\
979\end{array}$ & $\begin{array}{l}940900 \\
942841 \\
944784 \\
946729 \\
948676 \\
950625 \\
9525 \% 6 \\
954529 \\
956484 \\
958441\end{array}$ & $\begin{array}{l}912673000 \\
915498611 \\
918330048 \\
921167317 \\
924010424 \\
926859375 \\
929714176 \\
9325 \% 4833 \\
935441352 \\
938313739\end{array}$ & $\begin{array}{l}31.1448230 \\
31.1608 \% 29 \\
31.1769145 \\
31.1929479 \\
31.2089 \% 31 \\
31.2249900 \\
31.2409987 \\
31.2569992 \\
31.2729915 \\
31.2889 \% 5 \%\end{array}$ & $\begin{array}{l}9.8989830 \\
9.9023835 \\
9.905 r 817 \\
9.90917 \% 6 \\
9.9125 r 12 \\
9.9159624 \\
9.9193513 \\
9.9227379 \\
9.9261222 \\
9.9295042\end{array}$ & $\begin{array}{l}.001030928 \\
.001029866 \\
.001028807 \\
.001027 \% 49 \\
.001026694 \\
.001025641 \\
.001024590 \\
.001023541 \\
.001022495 \\
.001021450\end{array}$ \\
\hline $\begin{array}{l}980 \\
981 \\
982 \\
983 \\
984 \\
985 \\
986 \\
987 \\
988 \\
989\end{array}$ & $\begin{array}{l}960400 \\
962361 \\
964324 \\
966289 \\
968256 \\
9 \% 0225 \\
972196 \\
974169 \\
976144 \\
978121\end{array}$ & $\begin{array}{l}941192000 \\
944076141 \\
946966168 \\
949862087 \\
952 \tau 63904 \\
955671625 \\
958585256 \\
961504803 \\
9644302 \% 2 \\
96 \% 361669\end{array}$ & $\begin{array}{l}31.3049517 \\
31.3209195 \\
31.3368792 \\
31.3528308 \\
31.368 \% 743 \\
31.384 r 097 \\
31.4006369 \\
31.4165561 \\
31.43246 \% 3 \\
31.4483 r 04\end{array}$ & $\begin{array}{l}9.9328839 \\
9.9362613 \\
9.9396363 \\
9.9430092 \\
9.9463797 \\
9.9497479 \\
9.9531138 \\
9.9564775 \\
9.9598389 \\
9.9631981\end{array}$ & $\begin{array}{l}.001020408 \\
.001019368 \\
.001018330 \\
.001017294 \\
.001016260 \\
.001015228 \\
.001014199 \\
.001013171 \\
.001012146 \\
.001011122\end{array}$ \\
\hline $\begin{array}{l}990 \\
991 \\
992\end{array}$ & $\begin{array}{l}980100 \\
982081 \\
984064\end{array}$ & $\begin{array}{l}9 \% 0299000 \\
9732422 \% 1 \\
9 ; 6191488\end{array}$ & $\begin{array}{l}31.4642654 \\
31.4801525 \\
31.4960315\end{array}$ & $\begin{array}{l}9.9665549 \\
9.9699095 \\
9.9732619\end{array}$ & $\begin{array}{l}.001010101 \\
.001009082 \\
.001008065\end{array}$ \\
\hline
\end{tabular}


CUBE ROOTS, AND RECIPROCALS.

\begin{tabular}{|c|c|c|c|c|c|}
\hline No. & Squares. & Cubes. & $\begin{array}{l}\text { Square } \\
\text { Roots. }\end{array}$ & Cube Roots. & Reciprocals. \\
\hline $\begin{array}{r}993 \\
991 \\
995 \\
996 \\
997 \\
998 \\
999 \\
1000\end{array}$ & $\begin{array}{r}986049 \\
988036 \\
990025 \\
992016 \\
994009 \\
996004 \\
998001 \\
1000000\end{array}$ & $\begin{array}{c}979146657 \\
982107784 \\
985074875 \\
988047936 \\
991026973 \\
994011992 \\
997002999 \\
1000000000\end{array}$ & $\begin{array}{l}31.5119025 \\
31.5277655 \\
31.5436206 \\
31.5594677 \\
31.5753068 \\
31.5911380 \\
31.6069613 \\
31.622766\end{array}$ & $\begin{array}{r}9.9766120 \\
9.9799599 \\
9.9833055 \\
9.9866488 \\
9.9899900 \\
9.9933289 \\
9.9966656 \\
10.0000000\end{array}$ & $\begin{array}{l}.001007049 \\
.001006036 \\
.001005025 \\
.001004016 \\
.001003009 \\
.001002004 \\
.001001001 \\
.001000000\end{array}$ \\
\hline $\begin{array}{l}1001 \\
100: 2 \\
1003 \\
1001 \\
1005 \\
1006 \\
1007 \\
1003 \\
1009 \\
1010\end{array}$ & $\begin{array}{l}1002001 \\
1004004 \\
1006009 \\
1008016 \\
1010025 \\
1012036 \\
1014049 \\
1016064 \\
1018081 \\
1020100\end{array}$ & $\begin{array}{l}1003003001 \\
1006012008 \\
1009027027 \\
1012.48064 \\
1015075125 \\
1018108216 \\
1021147343 \\
1024192512 \\
1027243729 \\
1030301 \mathrm{C} 0 J\end{array}$ & $\begin{array}{l}31.6385340 \\
31.6513836 \\
31.6701752 \\
31.6859590 \\
31.7017349 \\
31.7175030 \\
31.7382633 \\
31.7490157 \\
31.7647603 \\
31.7804972\end{array}$ & $\begin{array}{l}10.0033322 \\
10.0066622 \\
10.0099899 \\
10.0133155 \\
10.0166389 \\
10.0199601 \\
10.0232791 \\
10.0265958 \\
10.0299104 \\
10.0332228\end{array}$ & $\begin{array}{r}.0009990010 \\
.0009980040 \\
.0009970090 \\
.0009960159 \\
.0009950249 \\
.0009940358 \\
.0009930487 \\
.0009920635 \\
.0009910803 \\
.0009900990\end{array}$ \\
\hline $\begin{array}{l}1011 \\
1012 \\
1013 \\
1014 \\
1015 \\
1016 \\
1017 \\
1018 \\
1019 \\
1020\end{array}$ & $\begin{array}{l}1022121 \\
1024144 \\
1026169 \\
1028196 \\
1030225 \\
1032256 \\
1034289 \\
1036324 \\
1038361 \\
1040400\end{array}$ & $\begin{array}{l}1033364331 \\
1036433729 \\
1039509197 \\
1042590714 \\
1045678375 \\
1048772096 \\
1051871913 \\
105497839 \\
1058089859 \\
1061208000\end{array}$ & $\begin{array}{l}31.7962262 \\
31.8119474 \\
31.8276609 \\
31.8433666 \\
31.8590616 \\
31.8747549 \\
31.8904374 \\
31.9061123 \\
31.9217 \% 94 \\
31.9371389\end{array}$ & $\begin{array}{l}10.0365330 \\
10.0398410 \\
10.0431469 \\
10.0464506 \\
10.0497521 \\
10.0530514 \\
10.0563485 \\
10.0596435 \\
10.0629364 \\
10.0662271\end{array}$ & $\begin{array}{r}.0009891197 \\
.0009881423 \\
.0009871668 \\
.0009861933 \\
.0009852217 \\
.0009842520 \\
.0009832842 \\
.0009823183 \\
.0009813543 \\
.0009803922\end{array}$ \\
\hline $\begin{array}{l}1021 \\
1023 \\
1023 \\
1021 \\
1025 \\
1026 \\
1027 \\
1028 \\
1029 \\
1030\end{array}$ & $\begin{array}{l}1042441 \\
1044484 \\
1046529 \\
1048576 \\
1050625 \\
1052676 \\
1054729 \\
1056784 \\
1058841 \\
1060900\end{array}$ & $\begin{array}{l}1064332261 \\
1067462648 \\
1070599167 \\
10 \% 3741824 \\
1076890625 \\
1030045576 \\
1083206683 \\
1036373952 \\
1039547339 \\
1092727000\end{array}$ & $\begin{array}{l}31.9530906 \\
31.9637317 \\
31.9813712 \\
32.1000000 \\
32.0156212 \\
32.0312318 \\
32.0168107 \\
32.0624391 \\
32.0780298 \\
32.0936131\end{array}$ & $\begin{array}{l}10.0695156 \\
10.0728020 \\
10.0760863 \\
10.0793684 \\
10.0826484 \\
10.0859262 \\
10.0892019 \\
10.0924755 \\
10.0957469 \\
10.0990163\end{array}$ & $\begin{array}{l}.0009794319 \\
.0009781736 \\
.0009775171 \\
.0009765625 \\
.0009756098 \\
.0009746589 \\
.0009737098 \\
.0009727626 \\
.0009718173 \\
.0009708738\end{array}$ \\
\hline $\begin{array}{l}1031 \\
103: \\
1033 \\
1034 \\
1035 \\
1036 \\
1037 \\
1038 \\
1039 \\
1010\end{array}$ & $\begin{array}{l}1062961 \\
1065024 \\
1067089 \\
1069156 \\
1071225 \\
1073296 \\
1075369 \\
1077414 \\
1079521 \\
1081600\end{array}$ & $\begin{array}{l}1095912791 \\
1099104768 \\
1102302937 \\
1105507301 \\
1103717875 \\
1111931656 \\
1115157653 \\
1118386872 \\
1121623319 \\
1121861000\end{array}$ & $\begin{array}{l}32.1091837 \\
32.1217568 \\
32.1403173 \\
32.1558704 \\
32.1714159 \\
32.1869539 \\
32.2024844 \\
32.2180074 \\
32.2335229 \\
32.2490310\end{array}$ & $\begin{array}{l}10.1022835 \\
10.1055487 \\
10.1088117 \\
10.1120726 \\
10.1153314 \\
10.1185882 \\
10.1218428 \\
10.1250953 \\
10.1283457 \\
10.1315941\end{array}$ & $\begin{array}{l}.0009699321 \\
.009689922 \\
.0009680542 \\
.0009671180 \\
.0009661836 \\
.0009652510 \\
.0009643202 \\
.0009633911 \\
.0009624639 \\
.0009615385\end{array}$ \\
\hline $\begin{array}{l}1041 \\
1042 \\
1043 \\
1044 \\
1045 \\
1046 \\
1047 \\
1048 \\
1049 \\
1050\end{array}$ & $\begin{array}{l}1083681 \\
1085764 \\
1087849 \\
1089936 \\
1092025 \\
1094116 \\
1096209 \\
1098304 \\
1100401 \\
1102500\end{array}$ & $\begin{array}{l}1128111921 \\
1131366088 \\
1134626507 \\
1137893184 \\
1141166125 \\
1144445336 \\
1147730823 \\
1151022592 \\
1154320649 \\
1157625000\end{array}$ & $\begin{array}{l}32.2645316 \\
32.2800248 \\
32.2955105 \\
32.3109888 \\
32.3264598 \\
32.3419233 \\
32.3573794 \\
32.3728281 \\
32.3882695 \\
32.4037035\end{array}$ & $\begin{array}{l}10.1348403 \\
10.1380845 \\
10.1413266 \\
10.1445667 \\
10.1478047 \\
10.1510406 \\
10.1542744 \\
10.1575062 \\
10.1607359 \\
10.1639636\end{array}$ & $\begin{array}{l}.0009606148 \\
.0009596929 \\
.0009587738 \\
.0009578544 \\
.0009569378 \\
.0009560229 \\
.0009551098 \\
.0009511985 \\
.0009532888 \\
.0009523810\end{array}$ \\
\hline $\begin{array}{l}1051 \\
1052 \\
1053 \\
1054\end{array}$ & $\begin{array}{l}1104601 \\
1106704 \\
1108809 \\
1110916\end{array}$ & $\begin{array}{l}1160935651 \\
1164252608 \\
1167575877 \\
1170905464\end{array}$ & $\begin{array}{l}32.4191301 \\
32.4345495 \\
32.4499615 \\
32.4653662\end{array}$ & $\begin{array}{l}10.1671893 \\
10.1704129 \\
10.1736344 \\
10.1768539\end{array}$ & $\begin{array}{l}.0009514748 \\
.0009505703 \\
.0009496676 \\
.0009487666\end{array}$ \\
\hline
\end{tabular}



TAIBLE XI.-LOGARITHMS OF NUMBERS.

\begin{tabular}{|c|c|c|c|c|c|c|c|c|c|c|c|}
\hline \multicolumn{8}{|c|}{ No. 100 L. 000.$]$} & & \multicolumn{3}{|c|}{ No. 109 L. 040.} \\
\hline N. & 0 & 1 & 2 & 8 & 4 & 5 & 6 & 7 & 8 & 9 & Diff. \\
\hline \multirow{3}{*}{$\begin{array}{r}100 \\
1 \\
2\end{array}$} & \multirow{3}{*}{$\begin{array}{r}000000 \\
4321 \\
8600\end{array}$} & \multirow{3}{*}{$\begin{array}{l}0434 \\
4751 \\
9026 \\
\end{array}$} & \multirow{3}{*}{$\begin{array}{l}0868 \\
5181 \\
9451\end{array}$} & \multirow{3}{*}{$\begin{array}{l}1301 \\
5609 \\
98 \% 6\end{array}$} & 1734 & 2166 & 2598 & 3029 & 3461 & 3891 & 432 \\
\hline & & & & & 6038 & 6466 & 6894 & 7321 & 7748 & $81 \% 4$ & 438 \\
\hline & & & & & \multirow{3}{*}{$\begin{array}{l}0300 \\
4521 \\
8700 \\
\end{array}$} & \multirow{3}{*}{$\begin{array}{l}0724 \\
4940 \\
9116 \\
\end{array}$} & \multirow{3}{*}{$\begin{array}{r}1147 \\
5360 \\
9532 \\
\end{array}$} & \multirow{3}{*}{$\begin{array}{l}1570 \\
5779 \\
9947 \\
\end{array}$} & \multirow{2}{*}{$\begin{array}{l}1998 \\
6197 \\
\end{array}$} & \multirow{2}{*}{$\begin{array}{l}2415 \\
6616 \\
\end{array}$} & \multirow{2}{*}{$\begin{array}{l}424 \\
420\end{array}$} \\
\hline 3 & 012837 & 3259 & 3680 & 4100 & & & & & & & \\
\hline 4 & \%033 & 7451 & 7868 & 8284 & & & & & \multirow{3}{*}{$\begin{array}{l}0361 \\
4486 \\
8571\end{array}$} & \multirow{3}{*}{$\begin{array}{l}0775 \\
4896 \\
8978\end{array}$} & \multirow{3}{*}{$\begin{array}{l}416 \\
412 \\
408\end{array}$} \\
\hline \multirow{3}{*}{$\begin{array}{l}5 \\
6 \\
7\end{array}$} & \multirow{3}{*}{$\begin{array}{r}021189 \\
5306 \\
9384\end{array}$} & \multirow{3}{*}{$\begin{array}{l}1603 \\
5715 \\
9789\end{array}$} & 2016 & 2428 & 2841 & 3252 & 3664 & 4075 & & & \\
\hline & & & 6125 & 6533 & 6942 & 7350 & 7757 & 8164 & & & \\
\hline & & & \multirow{3}{*}{$\begin{array}{l}0195 \\
4227 \\
8223\end{array}$} & \multirow{3}{*}{$\begin{array}{l}0600 \\
4628 \\
8620\end{array}$} & \multirow{3}{*}{$\begin{array}{l}1004 \\
5029 \\
9017\end{array}$} & \multirow{3}{*}{$\begin{array}{l}1408 \\
5430 \\
9414\end{array}$} & \multirow{3}{*}{$\begin{array}{l}1812 \\
5830 \\
9811\end{array}$} & 2216 & 2619 & 3021 & \multirow{2}{*}{$\begin{array}{l}404 \\
400\end{array}$} \\
\hline \multirow{2}{*}{$\begin{array}{l}8 \\
9\end{array}$} & \multirow{2}{*}{$\begin{array}{l}033424 \\
04\end{array}$} & \multirow{2}{*}{$\begin{array}{l}3826 \\
7825\end{array}$} & & & & & & 6230 & 6629 & 7028 & \\
\hline & & & & & & & & 0207 & 0602 & 0998 & 397 \\
\hline
\end{tabular}

Proportional Parts.

\begin{tabular}{|c|c|c|c|c|c|c|c|c|c|}
\hline Diff. & 1 & 2 & 3 & 4 & 5 & 6 & 7 & 8 & 9 \\
\hline 434 & 3.4 & 86 & 130.2 & 173 & 0 & 4 & 303.8 & 34 & 390.6 \\
\hline & & & & & & & 30 & & 389.7 \\
\hline 43 & 43.2 & 86.4 & 129 & 172.8 & 216.0 & 2 & 02.4 & 34 & 388.8 \\
\hline 43 & 43.1 & 86.2 & 129.3 & 172.4 & 215.5 & 258.6 & 301.7 & 344.8 & 387.9 \\
\hline 43 & 43.0 & 86.0 & 129.0 & 172.0 & 215.0 & 258.0 & 301.0 & 344.0 & 387.0 \\
\hline 42 & 42. & 85.8 & 128.7 & 171.6 & 214.5 & 257.4 & 300.3 & 343.2 & 386.1 \\
\hline 42 & 42.8 & 85.6 & 128.4 & 171.2 & 214.0 & 256.8 & 299.6 & 342.4 & 385.2 \\
\hline 42 & 42.7 & 85.4 & 128.1 & 170.8 & 213.5 & 256.2 & 298.9 & 341.6 & 384.3 \\
\hline 426 & 42.6 & 85.2 & 127.8 & 170.4 & $21:$ & & 299.2 & 340.8 & 383.4 \\
\hline 425 & 42 & 85.0 & 127.5 & 17 & $21:$ & 255.0 & 297.5 & 340.0 & .5 \\
\hline 424 & 42 & 84 & 127 & 16 & 212 & 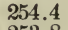 & 296.8 & 2 & 1.6 \\
\hline 4 & 42. & 84. & 126 & 169 & 211.5 & 253.8 & 296.1 & 33 & 380 \\
\hline 42 & 42.2 & 84.4 & 126 & 168 & 2110 & 253.2 & 295.4 & 6 & 379.8 \\
\hline 421 & 42. & 84.2 & 126.3 & 168 & 210.5 & 252.6 & 294.7 & 336.8 & 378.9 \\
\hline 42 & & 84.0 & 126.0 & 168 & 210 & 252.0 & 294.0 & 336.0 & $3 \approx 8.0$ \\
\hline 419 & 41.9 & 83.8 & 125.7 & 167.6 & 209.5 & 251.4 & 293.3 & 335.2 & 377.1 \\
\hline 41 & 41.8 & 83. & 125.4 & & & & 292.6 & 334.4 & $3 \pi 6.2$ \\
\hline 417 & 41.7 & 83.4 & 125.1 & 166.8 & 208 & 250 & 291.9 & 333.6 & 375.8 \\
\hline 416 & 41.6 & 83.2 & 124 & 16 & 20 & & 291.2 & 332.8 & 374.4 \\
\hline 415 & 41. & 83.0 & 124.5 & 166.0 & $20 \% .5$ & 249.0 & 290.5 & 332.0 & 373.5 \\
\hline 414 & 41. & 82 & 124.2 & 1 & 0 & & .8 & 1.2 & 372.6 \\
\hline 413 & 41.3 & 8 & 12 & & 20 & & 289.1 & 33 & 371.7 \\
\hline 412 & 41.2 & & 123.6 & 1 & 20 & & & & 370.8 \\
\hline 411 & 41.1 & 82.2 & 123.3 & 16 & 20 & 6 & 287.7 & 328.8 & 369.9 \\
\hline 410 & 41.0 & 82.0 & 123.0 & 1 & 20 & & 287.0 & 328.0 & 369.0 \\
\hline 409 & 40.9 & 81.8 & 122.7 & 16 & 204.5 & 24 & 286.3 & $32 \% .2$ & 368.1 \\
\hline 408 & 408 & 81.6 & 122.4 & $16:$ & 204.0 & 244.8 & 285.6 & 326.4 & 367.2 \\
\hline 407 & 40.7 & 81.4 & 122.1 & 16 & 203 & 244.2 & 284.9 & 325.6 & 366.8 \\
\hline 406 & 40. & 81.2 & 121.8 & 162.4 & 203.0 & 2436 & 284.2 & 324.8 & 365.4 \\
\hline 405 & 40. & 81.0 & 121.5 & 162.0 & 202.5 & 243.0 & 283.5 & 324.0 & 364.5 \\
\hline 404 & 40 & 80 & 12 & 16 & 2 & 2 & .8 & 323.2 & 36 \\
\hline 40 & & & & & & & 282.1 & & \\
\hline 402 & 40.2 & 80. & 120 & & 201.0 & 2412 & 281.4 & 321.6 & 361.8 \\
\hline 40 & 40 & & 12 & & & & 280.7 & 320.8 & 360.9 \\
\hline 400 & 40. & 80 & 120 & 16 & 2 & & 280.0 & 320.0 & 360.0 \\
\hline 39 & 39 & 79. & 119.7 & 15 & 19 & & 279.3 & 319.2 & 359.1 \\
\hline 39 & 39. & 79.6 & 119 & 159 & & & & 318.4 & 358 \\
\hline 39 & 39. & 79 & 119 & 15 & 19 & 238 & 277.9 & 317.6 & 357.3 \\
\hline 39 & 3 & 79. & 118 & 15 & 198.0 & 23 & $2 \pi 7.2$ & 316.8 & 356.4 \\
\hline 395 & 39.5 & 79.0 & 118.5 & 158.0 & 197.5 & 237.0 & 276.5 & 316.0 & 355.5 \\
\hline
\end{tabular}


TABLE XI.-LOGARITHMS OF NUMBERS.

\begin{tabular}{|c|c|c|c|c|c|c|c|c|c|c|c|}
\hline \multicolumn{9}{|c|}{ No. 110 L. 041.] } & \multicolumn{3}{|c|}{ [No. 119 L. 078.} \\
\hline N. & $\mathbf{0}$ & 1 & 2 & $\mathbf{3}$ & 4 & 5 & 6 & 7 & 8 & 9 & Diff. \\
\hline \multirow{3}{*}{$\begin{array}{r}110 \\
1 \\
2\end{array}$} & \multirow{3}{*}{$\begin{array}{r}041393 \\
5323 \\
9218\end{array}$} & \multirow{3}{*}{$\begin{array}{l}1787 \\
5714 \\
9606\end{array}$} & \multirow{3}{*}{$\begin{array}{l}2182 \\
6105 \\
9993\end{array}$} & 2576 & 2969 & 3362 & 3755 & 4148 & 4540 & 4932 & 393 \\
\hline & & & & 6495 & 6885 & $72 \% 5$ & 7664 & 8053 & 8442 & 8830 & 390 \\
\hline & & & & \multirow{3}{*}{$\begin{array}{l}\text { U380 } \\
4230 \\
8046\end{array}$} & \multirow{3}{*}{$\begin{array}{l}0766 \\
4613 \\
8426\end{array}$} & \multirow{3}{*}{$\begin{array}{l}1153 \\
4996 \\
8805\end{array}$} & \multirow{3}{*}{$\begin{array}{l}1538 \\
5378 \\
9185\end{array}$} & \multirow{3}{*}{$\begin{array}{l}1924 \\
5 \% 60 \\
9563\end{array}$} & \multirow{3}{*}{$\begin{array}{l}2309 \\
6142 \\
9942\end{array}$} & \multirow{2}{*}{$\begin{array}{l}2694 \\
6524\end{array}$} & \multirow{3}{*}{$\begin{array}{l}386 \\
383\end{array}$} \\
\hline \multirow{2}{*}{$\begin{array}{l}3 \\
4\end{array}$} & \multirow{2}{*}{$\begin{array}{r}053078 \\
6905\end{array}$} & \multirow{2}{*}{$\begin{array}{l}3463 \\
7286\end{array}$} & \multirow{2}{*}{$\begin{array}{l}3846 \\
7666\end{array}$} & & & & & & & & \\
\hline & & & & & & & & & & & \\
\hline \multirow{3}{*}{$\begin{array}{l}5 \\
6 \\
7\end{array}$} & \multirow{3}{*}{$\begin{array}{r}060698 \\
4458 \\
8186\end{array}$} & \multirow{3}{*}{$\begin{array}{l}1075 \\
4832 \\
8557\end{array}$} & \multirow{3}{*}{$\begin{array}{l}1452 \\
5206 \\
8928\end{array}$} & \multirow{3}{*}{$\begin{array}{l}1829 \\
5580 \\
9298\end{array}$} & \multirow{3}{*}{$\begin{array}{l}2206 \\
5953 \\
9668\end{array}$} & 2582 & 2958 & $33{ }^{\circ}$ & 370 & 40 & $\begin{array}{l}3, y \\
376\end{array}$ \\
\hline & & & & & & 6326 & 6699 & $70 \% 1$ & 7443 & ซะ15 & 373 \\
\hline & & & & & & 0038 & 0407 & 07 & 1145 & 1514 & $3 \pi 0$ \\
\hline 8 & 071882 & 2250 & 2617 & 2985 & 3352 & & 4085 & & 4816 & 5182 & 366 \\
\hline 9 & & 5912 & 6276 & 6640 & 7004 & 7368 & 7731 & 8094 & 8457 & 8819 & 363 \\
\hline
\end{tabular}

Proportional Parts.

\begin{tabular}{|c|c|c|c|c|c|c|c|c|c|}
\hline Diff. & 1 & 2 & 3 & 4 & 5 & 6 & 7 & 8 & 9 \\
\hline 395 & 39.5 & 79.0 & 118.5 & 158.0 & 197.5 & $23 \% .0$ & 276.5 & 316.0 & 355.5 \\
\hline 39 & 3 & & & $15^{r}$ & 197.0 & & 275.8 & 315.2 & 354.6 \\
\hline 393 & 39.3 & 78 & 117.9 & 157.2 & 196 & 235.8 & 275.1 & 314.4 & 353.7 \\
\hline 392 & 39.2 & 78.4 & 117.6 & 156.8 & 196 & 235.2 & 274.4 & 313.6 & 352.8 \\
\hline 391 & 39.1 & 78.2 & 117.3 & 156.4 & 195 & 234.6 & 273.7 & 312.8 & 351.9 \\
\hline 39 & 39.0 & 78.0 & 117.0 & 156.0 & 19 & 234 & 273.0 & 312.0 & 351.0 \\
\hline 38 & 38. & 77.8 & 116.7 & 155.6 & 194 & 233 & 272.3 & 311.2 & 350.1 \\
\hline 388 & 38.8 & 77.6 & 116.4 & 155.2 & 19 & 23 & 271.6 & 310.4 & 349.2 \\
\hline 38 & 38.7 & 77.4 & 116.1 & 154.8 & 193.5 & 232.2 & 270.9 & & 348.3 \\
\hline 38 & 38.6 & 77.2 & 115.8 & 154.4 & 19 & 231.6 & 270.2 & 308 & 347.4 \\
\hline 385 & 38.5 & 77.0 & 115.5 & 154.0 & 192.5 & 231.0 & 269.5 & 308.0 & 346.5 \\
\hline 384 & 38.4 & 6.8 & 115.2 & 153.6 & 192.0 & 230.4 & 268.8 & $30 \% .2$ & 345.6 \\
\hline 3 & 38. & 76 & 11 & 15 & & 22 & & 30 & 34 \\
\hline 38 & 38.2 & 76 & 11 & 152.8 & 19 & 22 & 26 & & 343.8 \\
\hline 381 & 38.1 & 76. & 114 & 152.4 & 19 & 22 & 26 & 30 & 342.9 \\
\hline 38 & 38.0 & 76. & 114.0 & 152.0 & 19 & 22 & 26 & 30 & 342.0 \\
\hline 379 & 37.9 & 75. & 113 & 151.6 & & 227.4 & 26 & 30 & 341.1 \\
\hline 378 & 37.8 & 75.6 & 113.4 & 151.2 & 18 & 226.8 & 26 & & 340.2 \\
\hline 377 & 37.7 & 75. & 113 & 150.8 & 18 & 22 & & 30 & 339.3 \\
\hline 376 & 37.6 & 75. & 112.8 & 150.4 & 18 & 225.6 & & 30 & 338.4 \\
\hline 375 & 37.5 & 75 & 112.5 & 150.0 & 187.5 & 225.0 & 262.5 & 300.0 & $33 \% .5$ \\
\hline 374 & 37.4 & 74. & 112 & 1 & 187.0 & & & & 3 \\
\hline 373 & 37.3 & 74 & & & & & & & \\
\hline 372 & 37.2 & 74. & 111.6 & 14 & & 2 & 26 & & 334.8 \\
\hline 371 & 37.1 & 74 & 111 & & & 22 & & & 333.9 \\
\hline 370 & 37.0 & 74 & 111.0 & 14 & & 222.0 & & & 333.0 \\
\hline 369 & 36.9 & 73 & 110 & & & 221.4 & & & 332.1 \\
\hline 368 & 36.8 & 73 & 110.4 & 14 & & 22 & & & 331.2 \\
\hline 367 & 36.7 & & 110 & & & 220 & & & 330.3 \\
\hline 366 & 36.6 & 73 & 109 & 14 & & 219.6 & & & 329.4 \\
\hline 565 & 36.5 & 73 & 109.5 & 146.0 & 182.5 & 219.0 & 255.7 & 292.0 & 388.5 \\
\hline 364 & 36.4 & 72 & 10 & 1 & 1 & 21 & 2 & 2 & 327.6 \\
\hline 363 & 36. & & & & & & & & \\
\hline 362 & 36.2 & 72 & 10 & 14 & & 21 & 25 & & 325.8 \\
\hline 361 & 36. & 72 & & & & 21 & & & 324.9 \\
\hline 360 & 36.0 & & & & & 21 & & 288.0 & 824.0 \\
\hline 359 & 35.9 & 71 & & & & & & & 323.1 \\
\hline 358 & 35.8 & 71 & 107 & 14 & & 21 & & 286.4 & 322.2 \\
\hline 357 & 35.7 & 71 & & & & 214.2 & & & 321.3 \\
\hline 356 & 35.6 & 71.2 & 106.8 & 142.4 & 178.0 & 213.6 & 249.2 & 284.8 & 320.4 \\
\hline
\end{tabular}


TABLE XI.-LOGARITHMS OF NUMBERS.

\begin{tabular}{|c|c|c|c|c|c|c|c|c|c|c|c|}
\hline \multicolumn{7}{|c|}{ No. 120 L. 0\%9.] } & \multicolumn{2}{|l|}{. } & \multicolumn{3}{|c|}{ [No. 134 L. 130.} \\
\hline N. & $\mathbf{0}$ & 1 & 2 & 3 & 4 & 5 & 6 & 7 & 8 & 9 & Diff. \\
\hline \multirow{2}{*}{120} & \multirow{2}{*}{$0 \% 9181$} & \multirow{2}{*}{9543} & \multirow{2}{*}{9904} & & & & & & & & \\
\hline & & & & 0266 & 0626 & 0987 & \multirow{3}{*}{$\begin{array}{l}1347 \\
4934 \\
8490\end{array}$} & 1707 & 2067 & 2426 & $36 n$ \\
\hline \multirow{2}{*}{$\begin{array}{l}1 \\
2 \\
3\end{array}$} & \multirow{2}{*}{$\begin{array}{r}082785 \\
6360 \\
9905\end{array}$} & & & 3861 & & & & & 5647 & \multirow{2}{*}{$\begin{array}{l}6004 \\
9552\end{array}$} & \multirow{2}{*}{$\begin{array}{l}357 \\
355\end{array}$} \\
\hline & & & & & & $81:$ & & & & & \\
\hline \multirow[t]{2}{*}{4} & \multirow{2}{*}{$\begin{array}{r}09342: 2 \\
6910 \\
\end{array}$} & & $\begin{array}{l}0611 \\
412: 2\end{array}$ & & & & $\begin{array}{l}2018 \\
5518\end{array}$ & $\begin{array}{l}23 \% 0 \\
5866\end{array}$ & $\begin{array}{l}2721 \\
6215\end{array}$ & & $\begin{array}{l}352 \\
349\end{array}$ \\
\hline & & 7257 & 7604 & 7951 & $8 *$ & 864 & $\begin{array}{l}5518 \\
8990\end{array}$ & $\begin{array}{l}5866 \\
9335\end{array}$ & 9681 & & $\begin{array}{l}346 \\
343 \\
341\end{array}$ \\
\hline \multirow{3}{*}{$\begin{array}{l}6 \\
7 \\
8\end{array}$} & \multirow{3}{*}{$\begin{array}{r}1003 \% 1 \\
3804 \\
7210 \\
\end{array}$} & \multirow{3}{*}{$\begin{array}{l}0715 \\
4146 \\
7549\end{array}$} & \multirow{3}{*}{$\begin{array}{l}10.59 \\
4487 \\
7888 \\
\end{array}$} & \multirow{3}{*}{$\begin{array}{l}1403 \\
4828 \\
8227\end{array}$} & \multirow{3}{*}{$\begin{array}{l}1747 \\
5169 \\
8565\end{array}$} & & \multirow{3}{*}{$\begin{array}{l}5851 \\
9241 \\
\end{array}$} & \multirow{3}{*}{$\begin{array}{l}27 \% \\
6191 \\
95 \% 9 \\
\end{array}$} & \multirow{3}{*}{$\begin{array}{l}3119 \\
6531 \\
9916 \\
\end{array}$} & \multirow{3}{*}{$\begin{array}{l}0026 \\
3162 \\
68 \% 1 \\
\end{array}$} & \multirow{2}{*}{$\begin{array}{l}343 \\
341\end{array}$} \\
\hline & & & & & & & & & & & \\
\hline & & & & & & & & & & & 35 \\
\hline 9 & 110590 & 0926 & 1263 & 9 & 1934 & 2270 & 2605 & 0 & $32 \% 5$ & 9 & 205 \\
\hline \multirow{2}{*}{$\begin{array}{r}130 \\
1\end{array}$} & \multirow{2}{*}{$\begin{array}{l}3943 \\
7271\end{array}$} & \multirow{2}{*}{$\begin{array}{l}4277 \\
7603\end{array}$} & & 494 & 52 & & 59 & 62 & 6608 & 6940 & 333 \\
\hline & & & 7934 & & & 8926 & & & & & \\
\hline 2 & 120574 & 09 & & & & & 25 & 28 & 3198 & & \\
\hline $\begin{array}{l}3 \\
4\end{array}$ & $\begin{array}{l}3852 \\
7105\end{array}$ & & & 8076 & $\begin{array}{l}5156 \\
8399\end{array}$ & & $\begin{array}{l}5806 \\
9045\end{array}$ & & $\begin{array}{r}6456 \\
.9690\end{array}$ & & 325 \\
\hline & & & & & & & & & & 0012 & 323 \\
\hline
\end{tabular}

Proportional Parts.

\begin{tabular}{|c|c|c|c|c|c|c|c|c|c|}
\hline Diff. & 1 & 2 & 3 & 4 & 5 & 6 & 7 & 8 & 9 \\
\hline 35.5 & 35.5 & 71.0 & 106.5 & 142.0 & 177.5 & 213.0 & 248.5 & 284.0 & 319.5 \\
\hline 354 & 35.4 & 70.8 & 106.2 & 141.6 & 177.0 & 212.4 & 247.8 & 283.2 & 318.6 \\
\hline 353 & 35.3 & 70.6 & 105.9 & 141.2 & 176.5 & 211.8 & 247.1 & 282.4 & 317.7 \\
\hline 352 & 35.2 & 70.4 & 105.6 & 140.8 & 176.0 & 211.2 & 246.4 & 281.6 & 316.8 \\
\hline 351 & 35.1 & 70.2 & 105.3 & 140.4 & 175.5 & 210.6 & 245.7 & 280.8 & 315.9 \\
\hline 350 & 35.0 & 70.0 & 105.0 & 140.0 & 175.0 & 210.0 & 245.0 & 280.0 & 315.0 \\
\hline 349 & 34.9 & 69.8 & 104.7 & 139.6 & 174.5 & 209.4 & 244.3 & 279.2 & 314.1 \\
\hline 348 & 34.8 & 69.6 & 104.4 & 139.2 & 174.0 & 208.8 & 243.6 & 278.4 & 313.2 \\
\hline 347 & 34.7 & 69.4 & 104.1 & 138.8 & 173.5 & 208.2 & 242.9 & 277.6 & 312.3 \\
\hline 316 & 34.6 & 69.2 & 103.8 & 138.4 & 173.0 & $20 \% .6$ & 242.2 & 276.8 & 311.4 \\
\hline 345 & 34.5 & 69.0 & 103.5 & 138.0 & 172.5 & 207.0 & 241.5 & $2 \pi 6.0$ & 310.5 \\
\hline 344 & 34.4 & 68.8 & 103.2 & 137.6 & 172.0 & 206.4 & 240.8 & 275.2 & 309.6 \\
\hline 343 & 34.3 & 68.6 & 102.9 & 137.2 & 171.5 & 205.8 & 240.1 & 274.4 & 308.7 \\
\hline 312 & 34.2 & 68.4 & 102.6 & 136.8 & 171.0 & 2052 & 239.4 & 273.6 & 307.8 \\
\hline 311 & 34.1 & 68.2 & 102.3 & 136.4 & 170.5 & 204.6 & 238.7 & 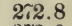 & 306.9 \\
\hline 310 & 34.0 & 68.0 & 102.0 & 136.0 & 170.0 & 204.0 & 238.0 & 272.0 & 306.0 \\
\hline 339 & 33.9 & 67.8 & 101.7 & 135.6 & 169.5 & 203.4 & 237.3 & $2 \pi 1.2$ & 305.1 \\
\hline 338 & 33.8 & 67.6 & 101.4 & 135.2 & 169.0 & 202.8 & 236.6 & $2 \pi 0.4$ & 304.2 \\
\hline 337 & 33.7 & $6 ? .4$ & 101.1 & 134.8 & 168.5 & 202.2 & 235.9 & 269.6 & 303.3 \\
\hline 336 & 33.6 & 67.2 & 100.8 & 134.4 & 168.0 & 201.6 & 235.2 & 268.8 & 302.4 \\
\hline 335 & 23.5 & 67.0 & 100.5 & 134.0 & 167.5 & 201.0 & 234.5 & 268.0 & 301.5 \\
\hline 334 & 33.4 & 66.8 & 100.2 & 133.6 & 167.0 & 200.4 & 233.8 & 267.2 & 300.6 \\
\hline 333 & 33.3 & 66.6 & 99.9 & 133.2 & 166.5 & 199.8 & 233.1 & 266.4 & 299.7 \\
\hline 332 & 33.2 & 66.4 & 99.6 & 132.8 & 166.0 & 199.2 & 232.4 & 265.6 & 298.8 \\
\hline 331 & 33.1 & 66.2 & 99.3 & 132.4 & 165.5 & 198.6 & 231.7 & 264.8 & 297.9 \\
\hline 330 & 33.0 & 66.0 & 99.0 & 132.0 & 165.0 & 198.0 & 231.0 & 264.0 & 297.0 \\
\hline 329 & 32.9 & 65.8 & 98.7 & 131.6 & 164.5 & 197.4 & 230.3 & 263.2 & 296.1 \\
\hline 328 & 32.8 & 65.6 & 98.4 & 131.2 & 164.0 & 196.8 & 229.6 & 262.4 & 295.2 \\
\hline 327 & 32.7 & 65.4 & 98.1 & 130.8 & 163.5 & 196.2 & 228.9 & 261.6 & 294.3 \\
\hline 326 & 32.6 & 65.2 & 97.8 & 130.4 & 163.0 & 195.6 & 228.2 & 260.8 & 293.4 \\
\hline 325 & 32.5 & 65.0 & 97. & 130.0 & 162.5 & 195.0 & 227.5 & 260.0 & 292.5 \\
\hline 324 & 32.4 & 64. & 97. & 129 & 162. & 194. & 226. & 259.2 & 291.6 \\
\hline 323 & 32.3 & 64.6 & 96.9 & 129.2 & 161.5 & 193.8 & 226.1 & 258.4 & 290.7 \\
\hline 322 & 32.2 & 64.4 & 96.6 & 128.8 & 161.0 & 193.2 & 225.4 & 257.6 & 289.8 \\
\hline
\end{tabular}


TABLE XI. -LOGARITHMS OF NUMBERS.

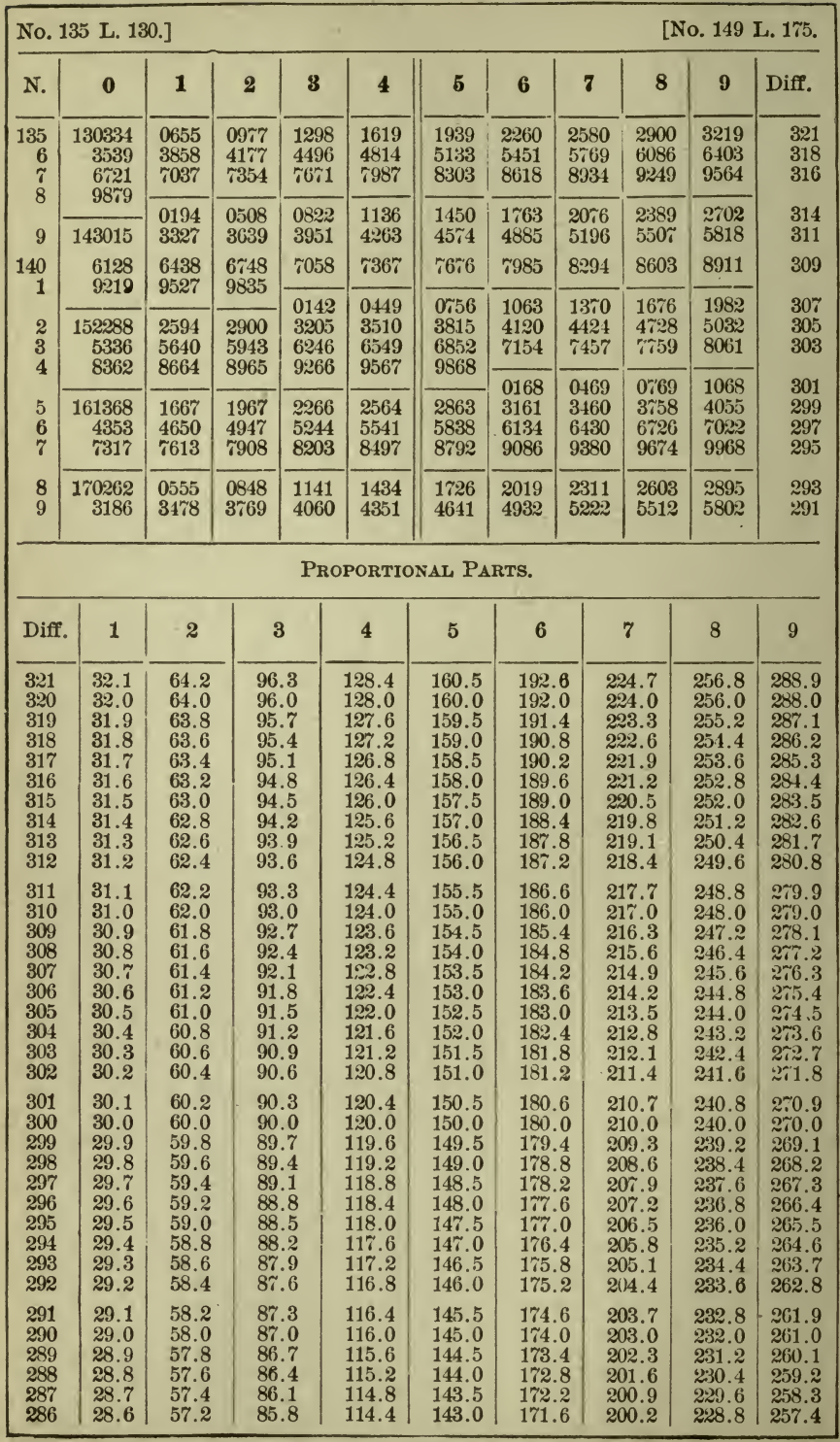


TABLE XI. -LOGARITHMS OF NUMBERS.

\begin{tabular}{|c|c|c|c|c|c|c|c|c|c|c|c|}
\hline \multicolumn{9}{|c|}{ No. 150 L. 176.] } & \multicolumn{3}{|c|}{ [No. 169 L. 230.} \\
\hline N. & 0 & 1 & 2 & 3 & 4 & 5 & 6 & 7 & 8 & 9 & Diff. \\
\hline \multirow{2}{*}{$\begin{array}{r}150 \\
1\end{array}$} & \multirow{2}{*}{$\begin{array}{r}176091 \\
897 \%\end{array}$} & \multirow{2}{*}{$\begin{array}{l}6381 \\
9264\end{array}$} & \multirow{2}{*}{$\begin{array}{l}6670 \\
9552\end{array}$} & \multirow{2}{*}{$\begin{array}{l}6959 \\
9839\end{array}$} & 7248 & 7536 & 7825 & 8113 & 8401 & 8689 & 289 \\
\hline & & & & & 0126 & 0413 & 0699 & 0986 & 1272 & 1558 & 287 \\
\hline \multirow{3}{*}{$\begin{array}{l}2 \\
3 \\
4\end{array}$} & \multirow{3}{*}{$\begin{array}{r}181844 \\
4691 \\
7521 \\
\end{array}$} & \multirow{3}{*}{$\begin{array}{l}2129 \\
4975 \\
7803\end{array}$} & \multirow{3}{*}{$\begin{array}{l}2415 \\
5259 \\
8084 \\
\end{array}$} & \multirow{3}{*}{$\begin{array}{l}2700 \\
5542 \\
8366\end{array}$} & 2985 & $\begin{array}{l}3270 \\
6108\end{array}$ & 3555 & \multirow{3}{*}{$\begin{array}{l}3839 \\
6674 \\
9490 \\
\end{array}$} & \multirow{3}{*}{\begin{tabular}{|l|}
4123 \\
6956 \\
97771
\end{tabular}} & 4407 & 285 \\
\hline & & & & & $\begin{array}{l}5825 \\
8647\end{array}$ & $\begin{array}{l}6108 \\
8928\end{array}$ & $\begin{array}{l}6391 \\
9209\end{array}$ & & & 7239 & 283 \\
\hline & & & & & & & & & & 0051 & 281 \\
\hline \multirow{3}{*}{$\begin{array}{l}5 \\
6 \\
7 \\
8\end{array}$} & \multirow{3}{*}{$\begin{array}{r}190332 \\
3125 \\
5900 \\
8657 \\
\end{array}$} & \multirow{3}{*}{$\begin{array}{l}0612 \\
3403 \\
6176 \\
8932 \\
\end{array}$} & $\begin{array}{l}0892 \\
3681\end{array}$ & $\begin{array}{l}11 \% 1 \\
3959\end{array}$ & $\begin{array}{l}1451 \\
42337\end{array}$ & $\begin{array}{l}1730 \\
4514\end{array}$ & $\begin{array}{l}2010 \\
4792\end{array}$ & 2289 & 2567 & 2846 & $\underset{279}{279}$ \\
\hline & & & 6453 & 6729 & $\tau 005$ & $\begin{array}{l}4514 \\
7281\end{array}$ & $\begin{array}{l}4792 \\
7556\end{array}$ & $\begin{array}{l}5069 \\
7832\end{array}$ & $\begin{array}{l}5346 \\
8107\end{array}$ & $\begin{array}{l}5623 \\
8382\end{array}$ & $\begin{array}{l}278 \\
216\end{array}$ \\
\hline & & & 9206 & 9481 & 9755 & & & & & & \\
\hline 9 & 201397 & $16 \% 0$ & 1943 & 2216 & 2488 & 2761 & 3033 & 3305 & $35 \% 7$ & 3848 & $\begin{array}{l}274 \\
272\end{array}$ \\
\hline 160 & $4120^{\circ}$ & 4391 & 4663 & 4934 & 5204 & 5475 & 5746 & 6016 & 6286 & 6556 & 271 \\
\hline $\begin{array}{l}1 \\
2\end{array}$ & $\begin{array}{l}6826 \\
9515\end{array}$ & $\begin{array}{l}7096 \\
9783\end{array}$ & 7365 & 7634 & 7904 & 8173 & 8441 & 8710 & 8979 & 9247 & 269 \\
\hline 3 & 212188 & 2454 & $\begin{array}{l}0051 \\
2720\end{array}$ & $\begin{array}{l}0319 \\
2986\end{array}$ & $\begin{array}{l}0586 \\
3252\end{array}$ & $\begin{array}{l}0853 \\
3518\end{array}$ & $\begin{array}{l}1121 \\
3783\end{array}$ & $\begin{array}{l}1388 \\
4049\end{array}$ & $\begin{array}{l}1654 \\
4314\end{array}$ & $\begin{array}{l}1921 \\
4579\end{array}$ & $\begin{array}{l}267 \\
266\end{array}$ \\
\hline 4 & 4844 & 5109 & 5373 & 5638 & 5902 & 6166 & 6430 & 6694 & 6957 & 7221 & 264 \\
\hline 5 & 7484 & 7747 & 8010 & 8273 & 8536 & 8798 & 9060 & 9323 & 9585 & 9846 & 262 \\
\hline 6 & 220108 & 0370 & 0631 & 0892 & 1153 & 1414 & 1675 & $1936^{\circ}$ & 2196 & 2456 & 261 \\
\hline 7 & 2716 & 2976 & 3236 & 3496 & 3755 & 4015 & 4274 & 4533 & 4792 & 5051 & 259 \\
\hline $\begin{array}{l}8 \\
9\end{array}$ & $\begin{array}{l}5309 \\
7887\end{array}$ & 5568 & 5826 & 6084 & 6342 & 6600 & 6858 & 7115 & $73 \% 2$ & 7630 & 258 \\
\hline & $23^{808}$ & & & 8657 & & & & & & 0193 & 256 \\
\hline & & & & Pro & $\pi$ & $L$ & Ts. & & & & \\
\hline Diff. & 1 & 2 & 3 & & 4 & 5 & 6 & & $\gamma$ & 8 & 9 \\
\hline 285 & 28.5 & 57.0 & 85. & & 114.0 & 142.5 & 171.0 & & 199.5 & 228.0 & 256.5 \\
\hline 284 & 28.4 & 56.8 & 85. & & 113.6 & 142.0 & 170.4 & & 198.8 & 227.2 & 255.6 \\
\hline 283 & 28.3 & 56.6 & 84. & & 113.2 & 141.5 & 169.8 & & 198.1 & 226.4 & 254.7 \\
\hline 282 & 28.2 & 56.4 & 84. & & 112.8 & 141.0 & 169.2 & & 197.4 & 225.6 & 253.8 \\
\hline 281 & 28.1 & 56.2 & 84. & & 1124 & 140.5 & 168.6 & & 196.7 & 224.8 & 252.9 \\
\hline 280 & 28.0 & 56.0 & 84. & & 112.0 & 140.0 & 168.0 & & 196.0 & 224.0 & 252.0 \\
\hline 279 & 27.9 & 55.8 & 83. & & 111.6 & 139 & 167.4 & & 195.3 & 223.2 & 251.1 \\
\hline 278 & 27.8 & 55.6 & 83. & & 111.2 & 139 & 166.8 & & 194.6 & 222.4 & 250.2 \\
\hline 277 & 27.7 & 55.4 & 83. & & 110.8 & 138.5 & 166.2 & & 193.9 & 221.6 & 249.3 \\
\hline 276 & 27.6 & 55 & 82. & & 110.4 & 13 & 165.6 & & 193.2 & 220.8 & 248.4 \\
\hline 275 & 27.5 & 55.0 & 82. & & 110.0 & 137.5 & 165.0 & & 192.5 & 220.0 & 247.5 \\
\hline 274 & 27.4 & 54.8 & & & 109.6 & 13 & 164.4 & & 191.8 & 219.2 & 246.6 \\
\hline 273 & 27.3 & 54.6 & 81. & & 109.2 & 136.5 & 163.8 & & 191.1 & 218.4 & 245.7 \\
\hline 272 & 27.2 & 54. & 81. & & 108.8 & 13 & 163.2 & & 190.4 & 217.6 & 244.8 \\
\hline 271 & 27.1 & 54.2 & 81. & & 108.4 & & 162.6 & & 189.7 & 216.8 & 243.9 \\
\hline 270 & 27.0 & 54 & 81. & & 108.0 & 13 & 162.0 & & 189.0 & 216.0 & 243.0 \\
\hline 269 & 26.9 & 53 & 80 & & 107.6 & 13 & & & 188.3 & $21:$ & 242.1 \\
\hline 268 & 26.8 & 53 & & & 107.2 & 13 & 16 & & 187.6 & & 241.2 \\
\hline 267 & 26.7 & 53. & & & 106.8 & & 16 & & 186.9 & 213.6 & 240.3 \\
\hline 266 & 26.6 & 53.2 & 79 & & 106.4 & 133 & 159.6 & & 186.2 & 212.8 & 239.4 \\
\hline 265 & 26.5 & 53.0 & 79. & & 106.0 & 132.5 & 159.0 & & 185.5 & 212.0 & 238.5 \\
\hline 264 & 26.4 & 52. & & & 105.6 & 132 & 158.4 & & 184.8 & 211.2 & 237.6 \\
\hline 263 & 26.3 & 52.6 & & & 105.2 & 131.5 & & & 184.1 & 210.4 & 236.7 \\
\hline 262 & 26.2 & 52. & & & 104.8 & 131.0 & 157.2 & & 183.4 & 209.6 & 235.8 \\
\hline 261 & 26.1 & 52. & & & 104.4 & 130 & & & 182.7 & 208.8 & 234.9 \\
\hline 260 & 26.0 & 52. & 78. & & 104.0 & 130 & 156.0 & & 182.0 & 208.0 & 234.0 \\
\hline 259 & 25.9 & 51. & 77. & & 103.6 & & & & 181.3 & 207.2 & 233.1 \\
\hline 258 & 25.8 & 51. & 77. & & 103.2 & 129.0 & 154.8 & & 180.6 & 206.4 & 232.2 \\
\hline 257 & 25. & & 87. & & 102.8 & 128.5 & 154.2 & & 179.9 & 205.6 & 231.3 \\
\hline 256 & 25.6 & 51.2 & 76. & & 102.4 & 128.0 & 153.6 & & 179.2 & 204.8 & 230.4 \\
\hline 255 & 25.5 & 51.0 & 76. & & 102.0 & $1 \approx 7.5$ & 153.0 & & 178.5 & 204.0 & 229.5 \\
\hline
\end{tabular}


TABLE XI.-LOGARITHMS OF NUMBERS.

\begin{tabular}{|c|c|c|c|c|c|c|c|c|c|c|c|}
\hline \multicolumn{9}{|c|}{ No. 170 L. 230.] } & \multicolumn{3}{|c|}{ [No. 189 L. 278} \\
\hline N. & $\mathbf{0}$ & 1 & 2 & $\mathbf{3}$ & 4 & 5 & 6 & 7 & 8 & 9 & Diff. \\
\hline \multirow{4}{*}{$\begin{array}{r}170 \\
1 \\
2 \\
3\end{array}$} & \multirow{4}{*}{$\begin{array}{r}230449 \\
2996 \\
5528 \\
8046 \\
\end{array}$} & \multirow{4}{*}{$\begin{array}{l}0 \% 04 \\
3250 \\
5781 \\
8297\end{array}$} & \multirow{4}{*}{$\begin{array}{l}0960 \\
3504 \\
6033 \\
8548\end{array}$} & \multirow{4}{*}{$\begin{array}{l}1215 \\
3757 \\
6285 \\
8799\end{array}$} & \multirow{4}{*}{$\begin{array}{l}14 \% 0 \\
4011 \\
6537 \\
9049\end{array}$} & \multirow{4}{*}{$\begin{array}{l}1724 \\
4264 \\
6789 \\
9299\end{array}$} & \multirow{4}{*}{$\begin{array}{l}1979 \\
4517 \\
7041 \\
9550\end{array}$} & \multirow{4}{*}{$\begin{array}{l}2234 \\
4770 \\
7292 \\
9800\end{array}$} & \multirow{3}{*}{$\begin{array}{r}2488 \\
5023 \\
7544 \\
\end{array}$} & \multirow{3}{*}{$\begin{array}{l}2742 \\
5276 \\
7795\end{array}$} & \multirow{3}{*}{255} \\
\hline & & & & & & & & & & & \\
\hline & & & & & & & & & & & \\
\hline & & & & & & & & & 0050 & \multirow{4}{*}{$\begin{array}{l}0300 \\
2790 \\
5266 \\
7728\end{array}$} & 250 \\
\hline \multirow{4}{*}{$\begin{array}{l}4 \\
5 \\
6 \\
7\end{array}$} & \multirow{4}{*}{$\begin{array}{r}240549 \\
3038 \\
5513 \\
7973 \\
\end{array}$} & \multirow{4}{*}{$\begin{array}{r}0799 \\
3286 \\
5759 \\
8219 \\
\end{array}$} & \multirow{4}{*}{$\begin{array}{l}1048 \\
3534 \\
6006 \\
8464\end{array}$} & \multirow{4}{*}{$\begin{array}{l}1297 \\
3782 \\
6252 \\
8709\end{array}$} & \multirow{4}{*}{$\begin{array}{l}1546 \\
4030 \\
6499 \\
8954\end{array}$} & \multirow{4}{*}{$\begin{array}{l}1795 \\
4277 \\
6745 \\
9198\end{array}$} & \multirow{4}{*}{$\begin{array}{l}2044 \\
4525 \\
6991 \\
9443\end{array}$} & \multirow{4}{*}{$\begin{array}{l}2293 \\
4772 \\
7237 \\
9687\end{array}$} & \multirow{4}{*}{$\begin{array}{l}2541 \\
5019 \\
7482 \\
9932\end{array}$} & & $\begin{array}{l}250 \\
249\end{array}$ \\
\hline & & & & & & & & & & & 248 \\
\hline & & & & & & & & & & & 246 \\
\hline & & & & & & & & & & 01 & 245 \\
\hline 8 & $\begin{array}{r}250420 \\
2853\end{array}$ & 0664 & 0908 & 1151 & 1395 & 1638 & 1881 & 2125 & 2368 & & 243 \\
\hline 180 & 5 & 5 & & 0.00 & 00 & & 4 & 45 & 4790 & 5001 & 242 \\
\hline 1 & r679 & 7918 & 8158 & 8398 & 8637 & 8877 & 9116 & 9355 & $\begin{array}{l}198 \\
9594\end{array}$ & 9833 & $\begin{array}{l}241 \\
239\end{array}$ \\
\hline 2 & 260071 & 0310 & 0548 & 0787 & 1025 & 1263 & 15 & 1739 & 1976 & 2214 & 238 \\
\hline 3 & 2451 & & 29 & 3. & 33 & & & & & 4 & 237 \\
\hline 4 & $\begin{array}{l}4818 \\
7172\end{array}$ & $\begin{array}{l}5054 \\
7406\end{array}$ & $\begin{array}{l}5290 \\
7641\end{array}$ & $\begin{array}{l}5525 \\
7875\end{array}$ & $\begin{array}{l}5761 \\
8110\end{array}$ & & $\begin{array}{l}6232 \\
8578\end{array}$ & & $\begin{array}{l}6702 \\
9046\end{array}$ & $\begin{array}{l}6937 \\
9979\end{array}$ & 235 \\
\hline 6 & 9513 & 9746 & 9980 & rore & 811 & & 80.8 & & & $\nabla \alpha$ & 25 \\
\hline & 271842 & 20 & & 0213 & 0446 & 0679 & 09 & 11 & 1377 & 1609 & 23 \\
\hline 8 & 4158 & $\begin{array}{l}2014 \\
4389\end{array}$ & 4620 & 4850 & $\begin{array}{l}21 \\
508\end{array}$ & 53 & 52 & $\begin{array}{l}37 \\
57\end{array}$ & 6002 & $\begin{array}{l}3927 \\
6232\end{array}$ & 232 \\
\hline 9 & 646 & 6692 & 6921 & 7151 & 7380 & 760 & 7838 & 8067 & 8296 & 8525 & 229 \\
\hline
\end{tabular}

Proportional Parts.

\begin{tabular}{|c|c|c|c|c|c|c|c|c|c|}
\hline Diff. & 1 & 2 & 3 & 4 & 5 & 6 & 7 & 8 & 9 \\
\hline $\begin{array}{l}255 \\
254 \\
253 \\
252 \\
251 \\
250 \\
249 \\
248 \\
247 \\
246 \\
245\end{array}$ & $\begin{array}{l}25.5 \\
25.4 \\
25.3 \\
25.2 \\
25.1 \\
250 \\
24.9 \\
24.8 \\
24.7 \\
24.6 \\
24.5\end{array}$ & $\begin{array}{l}51.0 \\
50.8 \\
50.6 \\
50.4 \\
50.2 \\
50.0 \\
49.8 \\
49.6 \\
49.4 \\
49.2 \\
49.0\end{array}$ & $\begin{array}{l}76.5 \\
76.2 \\
75.9 \\
75.6 \\
75.3 \\
75.0 \\
74.7 \\
74.4 \\
74.1 \\
73.8 \\
73.5\end{array}$ & $\begin{array}{r}102.0 \\
101.6 \\
101.2 \\
100.8 \\
100.4 \\
100.0 \\
99.6 \\
99.2 \\
98.8 \\
98.4 \\
98.0\end{array}$ & $\begin{array}{l}127.5 \\
127.0 \\
126.5 \\
126.0 \\
125.5 \\
125.0 \\
124.5 \\
124.0 \\
123.5 \\
123.0 \\
122.5\end{array}$ & $\begin{array}{l}153.0 \\
152.4 \\
151.8 \\
151.2 \\
150.6 \\
150.0 \\
149.4 \\
148.8 \\
148.2 \\
147.6 \\
147.0\end{array}$ & $\begin{array}{l}178.5 \\
177.8 \\
177.1 \\
176.4 \\
175.7 \\
175.0 \\
174.3 \\
173.6 \\
172.9 \\
172.2 \\
171.5\end{array}$ & $\begin{array}{l}204.0 \\
203.2 \\
202.4 \\
201.6 \\
200.8 \\
200.0 \\
199.2 \\
198.4 \\
197.6 \\
196.8 \\
196.0\end{array}$ & $\begin{array}{l}229.5 \\
228.6 \\
227.7 \\
226.8 \\
225.9 \\
225.0 \\
224.1 \\
223.2 \\
222.3 \\
221.4 \\
220.5\end{array}$ \\
\hline $\begin{array}{l}244 \\
243 \\
242 \\
241 \\
240 \\
239 \\
238 \\
237 \\
236 \\
235\end{array}$ & $\begin{array}{l}24.4 \\
24.3 \\
24.2 \\
24.1 \\
24.0 \\
23.9 \\
23.8 \\
23.7 \\
23.6 \\
23.5\end{array}$ & $\begin{array}{l}48.8 \\
48.6 \\
48.4 \\
48.2 \\
48.0 \\
47.8 \\
47.6 \\
47.4 \\
47.2 \\
47.0\end{array}$ & $\begin{array}{l}73.2 \\
72.9 \\
72.6 \\
72.3 \\
72.0 \\
71.7 \\
71.4 \\
71.1 \\
70.8 \\
70.5\end{array}$ & $\begin{array}{r}9 \% .6 \\
9 \% .2 \\
96.8 \\
96.4 \\
96.0 \\
95.6 \\
95.2 \\
94.8 \\
94.4 \\
94.0\end{array}$ & $\begin{array}{l}122.0 \\
121.5 \\
121.0 \\
120.5 \\
120.0 \\
119.5 \\
119.0 \\
118.5 \\
118.0 \\
117.5\end{array}$ & $\begin{array}{l}146.4 \\
145.8 \\
145.2 \\
144.6 \\
144.0 \\
143.4 \\
142.8 \\
142.2 \\
141.6 \\
141.0\end{array}$ & $\begin{array}{l}170.8 \\
170.1 \\
169.4 \\
168.7 \\
168.0 \\
16 \% .3 \\
166.6 \\
165.9 \\
165.2 \\
164.5\end{array}$ & $\begin{array}{l}195.2 \\
194.4 \\
193.6 \\
192.8 \\
192.0 \\
191.2 \\
190.4 \\
189.6 \\
188.8 \\
188.0\end{array}$ & $\begin{array}{l}219.6 \\
218.7 \\
217.8 \\
216.9 \\
216.0 \\
215.1 \\
214.2 \\
213.3 \\
212.4 \\
211.5\end{array}$ \\
\hline $\begin{array}{l}234 \\
233 \\
232 \\
231 \\
230 \\
229 \\
228 \\
227 \\
226\end{array}$ & $\begin{array}{l}23.4 \\
23.3 \\
23.2 \\
23.1 \\
23.0 \\
22.9 \\
22.8 \\
22.7 \\
22.6\end{array}$ & $\begin{array}{l}46.8 \\
46.6 \\
46.4 \\
46.2 \\
46.0 \\
45.8 \\
45.6 \\
45.4 \\
45.2\end{array}$ & $\begin{array}{l}70.2 \\
69.9 \\
69.6 \\
69.3 \\
69.0 \\
68.7 \\
68.4 \\
68.1 \\
67.8\end{array}$ & $\begin{array}{l}93.6 \\
93.2 \\
92.8 \\
92.4 \\
92.0 \\
91.6 \\
91.2 \\
90.8 \\
90.4\end{array}$ & $\begin{array}{l}117.0 \\
116.5 \\
116.0 \\
115.5 \\
115.0 \\
114.5 \\
114.0 \\
113.5 \\
113.0\end{array}$ & $\begin{array}{l}140.4 \\
139.8 \\
139.2 \\
138.6 \\
138.0 \\
137.4 \\
136.8 \\
136.2 \\
135.6\end{array}$ & $\begin{array}{l}163.8 \\
163.1 \\
162.4 \\
161.7 \\
161.0 \\
160.3 \\
159.6 \\
158.9 \\
158.2\end{array}$ & $\begin{array}{l}187.2 \\
186.4 \\
185.6 \\
184.8 \\
184.0 \\
183.2 \\
182.4 \\
181.6 \\
180.8\end{array}$ & $\begin{array}{l}210.6 \\
209.7 \\
208.8 \\
207.9 \\
207.0 \\
206.1 \\
205.2 \\
204.3 \\
203.4\end{array}$ \\
\hline
\end{tabular}


TABLE XI.-LOGARITHMS OF NUMBERS.

\begin{tabular}{|c|c|c|c|c|c|c|c|c|c|c|c|}
\hline \multicolumn{9}{|c|}{ No. 190 L. 278.] } & \multicolumn{3}{|c|}{ [No. 214 L. 332.} \\
\hline N. & $\mathbf{0}$ & 1 & 2 & 3 & 4 & 5 & 6 & 7 & 8 & $\mathbf{9}$ & Diff. \\
\hline 190 & $278 \div 54$ & 8982 & 9211 & 9439 & 9667 & 9895 & & & & & \\
\hline 1 & 281033 & 1261 & 1488 & 1715 & 194 & 216 & \multirow{4}{*}{$\begin{array}{l}0123 \\
2396 \\
4656 \\
6905 \\
9143\end{array}$} & & \multirow{4}{*}{$\begin{array}{l}0578 \\
2849 \\
5107 \\
7354 \\
9589\end{array}$} & \multirow{4}{*}{$\begin{array}{l}0806 \\
3075 \\
5332 \\
75 \% 8 \\
9812\end{array}$} & \multirow{4}{*}{$\begin{array}{l}228 \\
227 \\
226 \\
225 \\
223\end{array}$} \\
\hline 2 & 3301 & 3527 & & & & & & 488 & & & \\
\hline 3 & 5557 & 5.82 & $60 c$ & 62 & & & & \%1 & & & \\
\hline 4 & 7802 & 8026 & 82 & 8473 & 8696 & $80^{\circ}$ & & 09 & & & \\
\hline \multirow{5}{*}{$\begin{array}{l}5 \\
6 \\
7 \\
8 \\
9\end{array}$} & 290035 & $025 \%$ & 0480 & $0 \pi$ & 09 & 1 & 136 & 15 & 8 & 20 & \multirow{4}{*}{$\begin{array}{l}222 \\
221 \\
220 \\
219\end{array}$} \\
\hline & $2256^{\circ}$ & $24 \pi 8$ & & & & & & & & & \\
\hline & 4466 & 4687 & 49 & 51 & & 5 & $5 \pi$ & $f$ & 6226 & 64 & \\
\hline & $\begin{array}{l}6665 \\
8853\end{array}$ & $\begin{array}{l}6884 \\
90 \div 1\end{array}$ & & & & $\begin{array}{l}7761 \\
9943\end{array}$ & 79 & & 8416 & & \\
\hline & & & & & & & \multirow{5}{*}{$\begin{array}{l}0161 \\
2331 \\
4491 \\
6639 \\
8778\end{array}$} & 0378 & 0595 & 0813 & 218 \\
\hline \multirow{5}{*}{$\begin{array}{r}200 \\
1 \\
2 \\
3 \\
4\end{array}$} & \multirow{5}{*}{$\begin{array}{r}301030 \\
3196 \\
5351 \\
7496 \\
9630 \\
\end{array}$} & \multirow{5}{*}{$\begin{array}{l}1247 \\
3412 \\
5566 \\
7710 \\
9843\end{array}$} & 1464 & 10 & 18 & 2114 & & 25 & \multirow{4}{*}{$\begin{array}{l}2764 \\
4921 \\
7068 \\
9204\end{array}$} & 29 & \multirow{4}{*}{$\begin{array}{l}217 \\
216 \\
215 \\
213\end{array}$} \\
\hline & & & & & & & & & & & \\
\hline & & & 5 & 5 & 6 & 6 & & 68 & & 7 & \\
\hline & & & 79 & 8 & 8 & 8564 & & 89 & & 94 & \\
\hline & & & 0056 & 0268 & 0481 & 0693 & 0906 & 11 & \multirow{4}{*}{$\begin{array}{l}1330 \\
3445 \\
5551 \\
7646 \\
9730\end{array}$} & 1542 & \multirow{4}{*}{$\begin{array}{l}212 \\
211 \\
210 \\
209 \\
208\end{array}$} \\
\hline \multirow{3}{*}{$\begin{array}{c}5 \\
6 \\
5 \\
8\end{array}$} & 311754 & 1966 & & & & & \multirow{3}{*}{$\begin{array}{l}3023 \\
5130 \\
7227 \\
9314\end{array}$} & & & & \\
\hline & $\begin{array}{l}386 \% \\
59 \% 0\end{array}$ & $40 i$ & 4 & & 47 & 49 & & 53 & & & \\
\hline & 8063 & $\begin{array}{l}0180 \\
8 \% 72\end{array}$ & 8181 & 868 & 889 & 9106 & & 9522 & & 9938 & \\
\hline 9 & 320146 & 0354 & 05 & 0709 & $09^{\prime}$ & 1184 & 1391 & 1598 & 1805 & 201 & $20 \%$ \\
\hline \multirow{4}{*}{$\begin{array}{r}210 \\
1 \\
2 \\
3\end{array}$} & \multirow{4}{*}{$\begin{array}{l}2219 \\
4282 \\
6336 \\
8380\end{array}$} & \multirow{4}{*}{$\begin{array}{l}2426 \\
4488 \\
6541 \\
8583 \\
\end{array}$} & \multirow{4}{*}{$\begin{array}{l}2633 \\
4694 \\
6745 \\
8 \% 8 \pi\end{array}$} & \multirow{4}{*}{$\begin{array}{l}2839 \\
4899 \\
6950 \\
8991 \\
\end{array}$} & \multirow{4}{*}{$\begin{array}{l}3046 \\
5105 \\
7155 \\
9194 \\
\end{array}$} & \multirow{4}{*}{$\begin{array}{l}3252 \\
5310 \\
7359 \\
9398 \\
\end{array}$} & \multirow{4}{*}{$\begin{array}{l}3458 \\
5516 \\
7563 \\
9601\end{array}$} & \multirow{4}{*}{$\begin{array}{l}3665 \\
5721 \\
7767 \\
9805 \\
\end{array}$} & \multirow{5}{*}{$\begin{array}{l}3871 \\
5926 \\
7972 \\
0008 \\
2034\end{array}$} & & \multirow{3}{*}{$\begin{array}{l}206 \\
205 \\
204\end{array}$} \\
\hline & & & & & & & & & & & \\
\hline & & & & & & & & & & 8176 & \\
\hline & & & & & & & & & & & 203 \\
\hline 4 & 330414 & 0617 & 0819 & 1022 & 1225 & 1427 & 1630 & 1832 & & 223 & 202 \\
\hline
\end{tabular}

Proportional Parts.

\begin{tabular}{|c|c|c|c|c|c|c|c|c|c|}
\hline Diff. & 1 & 2 & 3 & 4 & 5 & 6 & $\tau$ & 8 & 9 \\
\hline 225 & 22.5 & 45.0 & $6 \% .5$ & 90.0 & 112.5 & 135.0 & $15 \pi .5$ & 180.0 & 202.5 \\
\hline 224 & 22.4 & 44.8 & 67.2 & 89.6 & 112.0 & 134.4 & 156.8 & 179.2 & 201.6 \\
\hline 223 & 22.3 & 44.6 & $66 . \tilde{9}$ & 89.2 & 111.5 & 133.8 & 156.1 & 178.4 & 200.7 \\
\hline 222 & 22.2 & 44.4 & 66.6 & 88.8 & 111.0 & 133.2 & 155.4 & 17.6 & 199.8 \\
\hline 221 & 22.1 & 44.2 & 66.3 & 88.4 & 110.5 & 132.6 & 154.7 & 176.8 & 198.9 \\
\hline 220 & 22.0 & 44.0 & 66.0 & 88.0 & 110.0 & 132.0 & 154.0 & 176.0 & 198.0 \\
\hline 219 & 21.9 & 43.8 & 65.7 & 87.6 & 109.5 & 131.4 & 153.3 & 175.2 & 197.1 \\
\hline 218 & 21.8 & 43.6 & 65.4 & $8 \% .2$ & 109.0 & 130.8 & 152.6 & 174.4 & 196.2 \\
\hline $21 \%$ & 21.7 & 43.4 & 65.1 & 86.8 & 108.5 & 130.2 & 151.9 & 173.6 & 195.3 \\
\hline 216 & 21.6 & 43.2 & 64.8 & 86.4 & 108.0 & 129.6 & 151.2 & 172.8 & 194.4 \\
\hline 215 & 21.5 & 43.0 & 64.5 & 86.0 & 107.5 & 129.0 & 150.5 & 172.0 & 193.5 \\
\hline 214 & 21.4 & 42.8 & 64.2 & 85.6 & 107.0 & 128.4 & 149.8 & 171.2 & 192.6 \\
\hline 213 & 21.3 & 42.6 & 63.9 & 85.2 & 106.5 & 127.8 & 149.1 & 170.4 & 191.7 \\
\hline 212 & 21.2 & 42.4 & 63.6 & 84.8 & 106.0 & 127.2 & 148.4 & 169.6 & 190.8 \\
\hline 211 & 21.1 & 42.2 & 63.3 & 84.4 & 105.5 & 126.6 & 147.7 & 168.8 & 189.9 \\
\hline 210 & 21.0 & 42.0 & 63.0 & 84. & 105.0 & 126.0 & 147.0 & 168.0 & 189.0 \\
\hline 209 & 20.9 & 41.8 & 62.7 & 83.6 & 104.5 & 125.4 & 146.3 & $16 \% .2$ & 188.1 \\
\hline 208 & 20.8 & 41.6 & 62.4 & 83 & 104.0 & 124.8 & 145.6 & 1664 & 187.2 \\
\hline 207 & 20.7 & 41.4 & 62.1 & 82.8 & 103.5 & 124.2 & 144.9 & 165.6 & 186.3 \\
\hline 206 & 20.6 & 41.2 & 61.8 & 82.4 & 103.0 & 123.6 & 144.2 & 164.8 & 185.4 \\
\hline 205 & 20.5 & 40 & C1.5 & 82.0 & 102. & 123.0 & 143.5 & 164.0 & 184.5 \\
\hline 204 & 20.4 & 40.8 & 61.2 & 81.6 & 102.0 & 122.4 & 142.8 & 163.2 & 183.6 \\
\hline 20 & 20.3 & 40.6 & 60.9 & 81.2 & 101.5 & 121.8 & 142.1 & 162.4 & 182.7 \\
\hline 202 & 20.2 & 40.4 & 60.6 & 0.8 & 101.0 & 121.2 & 141.4 & 161.6 & 181.8 \\
\hline
\end{tabular}


TABLE XI.-LOGARITHMS OF NUMBERS.

\begin{tabular}{|c|c|c|c|c|c|c|c|c|c|c|c|}
\hline \multicolumn{4}{|c|}{ No. 215 L. 332.] } & & & & & & \multicolumn{3}{|c|}{ [No. 239 L. 380.} \\
\hline N. & 0 & 1 & 2 & 8 & 4 & 5 & 6 & 7 & 8 & 9 & Diff. \\
\hline \multirow{4}{*}{$\begin{array}{r}215 \\
6 \\
7 \\
8\end{array}$} & \multirow{4}{*}{$\begin{array}{r}332438 \\
4454 \\
6460 \\
8456\end{array}$} & \multirow{4}{*}{$\begin{array}{l}2640 \\
4655 \\
6660 \\
8656\end{array}$} & \multirow{4}{*}{$\begin{array}{l}2842 \\
4856 \\
6860 \\
8855\end{array}$} & \multirow{4}{*}{$\begin{array}{l}3044 \\
505 \% \\
7060 \\
9054\end{array}$} & \multirow{4}{*}{$\begin{array}{l}3246 \\
5257 \\
7260 \\
9253\end{array}$} & \multirow{4}{*}{$\begin{array}{l}3447 \\
5458 \\
7459 \\
9451\end{array}$} & \multirow{4}{*}{$\begin{array}{l}3649 \\
5658 \\
7659 \\
9650\end{array}$} & \multirow{4}{*}{$\begin{array}{l}3850 \\
5859 \\
r 858 \\
9849\end{array}$} & 4051 & 4253 & \multirow{3}{*}{$\begin{array}{l}202 \\
201 \\
200\end{array}$} \\
\hline & & & & & & & & & & & \\
\hline & & & & & & & & & 8058 & 8257 & \\
\hline & & & & & & & & & 0047 & & \\
\hline 9 & 340444 & 0642 & 0841 & 1039 & $123 \pi$ & 1435 & 1632 & 1830 & 2028 & & 198 \\
\hline \multirow{4}{*}{$\begin{array}{r}220 \\
1 \\
2 \\
3\end{array}$} & \multirow{4}{*}{$\begin{array}{l}2423 \\
4392 \\
6353 \\
8305 \\
\end{array}$} & \multirow{4}{*}{$\begin{array}{l}2620 \\
4589 \\
6549 \\
8500\end{array}$} & \multirow{4}{*}{$\begin{array}{l}2817 \\
4785 \\
6744 \\
8694\end{array}$} & \multirow{4}{*}{$\begin{array}{l}3014 \\
4981 \\
6939 \\
8889\end{array}$} & \multirow{4}{*}{$\begin{array}{l}3212 \\
5178 \\
7135 \\
9083\end{array}$} & \multirow{4}{*}{$\begin{array}{l}3409 \\
5374 \\
r 330 \\
92 \% 8\end{array}$} & \multirow{4}{*}{$\begin{array}{l}3606 \\
55 \% 0 \\
7525 \\
94 \% 2\end{array}$} & \multirow{4}{*}{$\begin{array}{l}3802 \\
5766 \\
7720 \\
9666\end{array}$} & \multirow{4}{*}{$\begin{array}{l}3999 \\
5962 \\
7915 \\
9860\end{array}$} & 4196 & \multirow{3}{*}{$\begin{array}{l}197 \\
196 \\
195\end{array}$} \\
\hline & & & & & & & & & & & \\
\hline & & & & & & & & & & 0 & \\
\hline & & & & & & & & & & & 19 \\
\hline \multirow{5}{*}{$\begin{array}{l}4 \\
5 \\
6 \\
7 \\
8\end{array}$} & \multirow{5}{*}{$\begin{array}{r}350248 \\
2183 \\
4108 \\
6026 \\
7935 \\
9835 \\
\end{array}$} & 044 & 6 & & & & & & 696 & & \\
\hline & & & & & & & & & & & \\
\hline & & & 640 & & & & & & $\begin{array}{l}56 \\
75\end{array}$ & & 191 \\
\hline & & 8125 & 831 & 85 & 869 & . & 000 & 926 & 94 & 9646 & 190 \\
\hline & & 0025 & 0215 & 0404 & 0593 & 0783 & 0972 & 11 & 1350 & 1539 & 189 \\
\hline \multirow{5}{*}{$\begin{array}{r}230 \\
1 \\
2 \\
3 \\
4\end{array}$} & \multirow{5}{*}{$\begin{array}{r}361728 \\
3612 \\
5488 \\
7356 \\
9216\end{array}$} & \multirow{5}{*}{$\begin{array}{l}1917 \\
3800 \\
5675 \\
7542 \\
9401 \\
\end{array}$} & \multirow{5}{*}{$\begin{array}{l}2105 \\
3988 \\
5862 \\
729 \\
9587\end{array}$} & \multirow{5}{*}{$\begin{array}{l}2294 \\
4176 \\
6049 \\
7915 \\
97 \% 2 \\
\end{array}$} & & 2 & 2859 & & 3236 & & 188 \\
\hline & & & & & $4 i$ & & & & 511 & & 1 \\
\hline & & & & & & & & & 698 & & $18 \gamma$ \\
\hline & & & & & $\begin{array}{l}8101 \\
9958\end{array}$ & 8 & 84 & & 8845 & & 186 \\
\hline & & & & & & 5 & 0 & & 0698 & 08 & 1 \\
\hline 5 & $3 \% 1068$ & & 14 & 1622 & & & & & & & \\
\hline 6 & 2912 & & & & & & & & 43 & & \\
\hline 7 & 4748 & 4932 & & & & 56 & & & 6212 & & \\
\hline 8 & 6577 & $6 \pi$ & 69 & 71 & 73 & 74 & $76 \% 0$ & & 8034 & 8216 & 182 \\
\hline & $38^{8398}$ & 8580 & 8761 & 89 & 9124 & 9306 & 9487 & & 9849 & 0030 & 181 \\
\hline
\end{tabular}

Proportional Parts.

\begin{tabular}{|c|c|c|c|c|c|c|c|c|c|}
\hline Diff. & 1 & 2 & 3 & 4 & 5 & 6 & 7 & 8 & 9 \\
\hline 202 & 20.2 & 40.4 & 60.6 & 80.8 & 101.0 & 121.2 & 141.4 & 161.6 & 181.8 \\
\hline 20 & 20. & 40.2 & 60. & 80. & 100.5 & 120.6 & 140.7 & 160.8 & 180.9 \\
\hline 200 & 20.0 & 40.0 & 60.0 & 80.0 & 100.0 & 120.0 & 140.0 & 160.0 & 180.0 \\
\hline 199 & 19.9 & 39.8 & 59.7 & 79.6 & 99.5 & 119.4 & 139.3 & 159.2 & 179.1 \\
\hline 198 & 19.8 & 39.6 & 59.4 & 79.2 & 99.0 & 118.8 & 138.6 & 158.4 & 178.2 \\
\hline 197 & 19.7 & 39.4 & 59.1 & r8.8 & 98.5 & 118.2 & 137.9 & 157.6 & 177.3 \\
\hline 196 & 19.6 & 39.2 & 58.8 & 78.4 & 980 & 117.6 & 137.2 & 156.8 & $1 \% 6.4$ \\
\hline 195 & 19.5 & 39.0 & $\mathbf{5 8 . 5}$ & 78. & 97.5 & 117.0 & 136.5 & 156.0 & 175.5 \\
\hline 194 & 19.4 & 38.8 & 58.2 & 77. & 97.0 & 116.4 & 135.8 & 155.2 & 174.6 \\
\hline 193 & 19.3 & 38.6 & 57.9 & 77.2 & 96.5 & 115.8 & 135.1 & 154.4 & 173.7 \\
\hline 192 & 19.2 & 38 & 57 & 76 & 96 & 115.2 & 13 & 15 & 172.8 \\
\hline 191 & 19.1 & 38.2 & 57.3 & 76. & 95.5 & 114.6 & 133.7 & 152.8 & 171.9 \\
\hline 190 & 19.0 & 38.0 & 57.0 & 76. & 95.0 & 114.0 & 133.0 & 152.0 & 171.0 \\
\hline 189 & 18.9 & 37.8 & 56.7 & 75. & 945 & 113.4 & 132.3 & 151.2 & 170.1 \\
\hline 188 & 18.8 & 37.6 & 56.4 & 75 & 94 & 112.8 & 131.6 & 150.4 & 169.2 \\
\hline 187 & 18.7 & 374 & 56.1 & 74.8 & 93.5 & 112.2 & 130.9 & 149.6 & 168.3 \\
\hline 186 & 18.6 & 37.2 & 55.8 & 74.4 & 93.0 & 111.6 & 130.2 & 148.8 & 167.4 \\
\hline 185 & 18.5 & 37.0 & 55.5 & 74. & 92.5 & 111.0 & 129.5 & 148.0 & 166.5 \\
\hline 184 & 184 & 368 & 55. & 73 & 92.0 & 110.4 & 128.8 & 147.2 & 165.6 \\
\hline 183 & 183 & 36.6 & 54.9 & 73.2 & 91.5 & 109.8 & 128.1 & 146.4 & 164.7 \\
\hline 182 & 182 & 36.4 & 546 & 72.8 & 91.0 & 109.2 & 127.4 & 145.6 & 163.8 \\
\hline 181 & 181 & 36.2 & 54.3 & 72.4 & 90.5 & 1086 & 126.7 & 144.8 & 162.9 \\
\hline 180 & 18.0 & 36.0 & 540 & 72.0 & 900 & 108.0 & 126.0 & 144.0 & 162.0 \\
\hline 179 & 17.9 & 35.8 & 53.7 & 71.6 & 89.5 & 107.4 & 125.3 & 143.2 & 161.1 \\
\hline
\end{tabular}


TABLE XY.-LOGARITHMS OF NUMBERS.

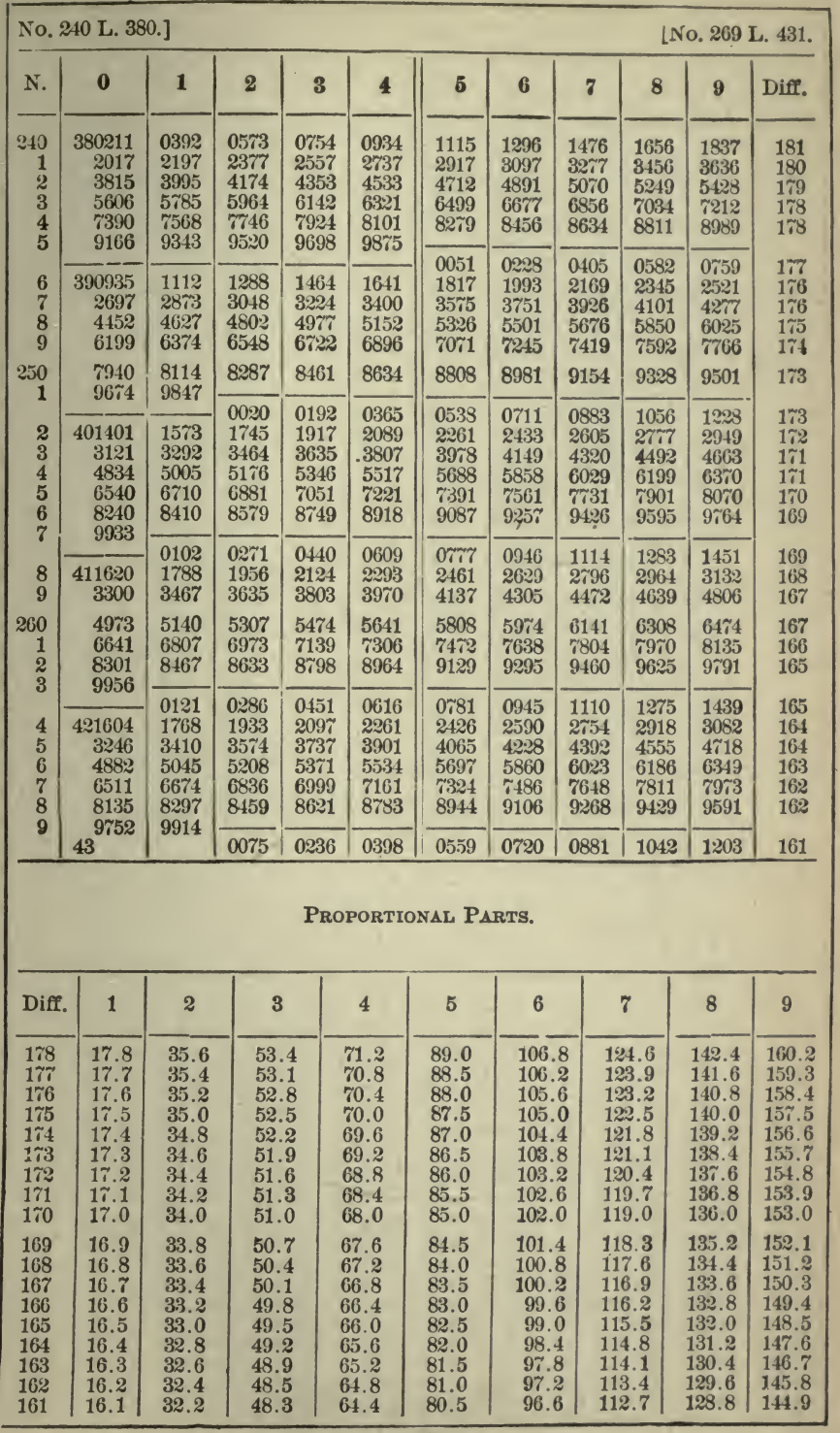


TABLE XI.-LOGARITHMS OF NUMIB RRS.

\begin{tabular}{|c|c|c|c|c|c|c|c|c|c|c|c|}
\hline \multicolumn{9}{|c|}{ No. 270 L. 431.$]$} & \multicolumn{3}{|c|}{ [No. 299 L. 476.} \\
\hline N. & $\mathbf{0}$ & 1 & 2 & 3 & 4 & 5 & 6 & 7 & 8 & 9 & Diff. \\
\hline $\begin{array}{r}270 \\
1 \\
2 \\
3 \\
4 \\
5\end{array}$ & $\begin{array}{r}431364 \\
2969 \\
4569 \\
6163 \\
7751 \\
9333\end{array}$ & $\begin{array}{l}1525 \\
8130 \\
4729 \\
6322 \\
7909 \\
9491\end{array}$ & $\begin{array}{l}1685 \\
3290 \\
4888 \\
6481 \\
8067 \\
9648\end{array}$ & $\begin{array}{l}1846 \\
3450 \\
5048 \\
6640 \\
8226 \\
9806\end{array}$ & $\begin{array}{l}2007 \\
3610 \\
5207 \\
6799 \\
8384 \\
9964\end{array}$ & $\begin{array}{l}167 \\
770 \\
367 \\
957 \\
542\end{array}$ & $\begin{array}{l}328 \\
930 \\
526 \\
116 \\
701\end{array}$ & $\begin{array}{l}488 \\
090 \\
685 \\
275 \\
8859\end{array}$ & $\begin{array}{l}2649 \\
4249 \\
5844 \\
7433 \\
9017\end{array}$ & $\begin{array}{l}2809 \\
1409 \\
3004 \\
7592 \\
9175\end{array}$ & $\begin{array}{l}161 \\
160 \\
159 \\
159 \\
158\end{array}$ \\
\hline $\begin{array}{l}6 \\
7 \\
8 \\
9\end{array}$ & $\begin{array}{r}440909 \\
2480 \\
4045 \\
5604\end{array}$ & $\begin{array}{l}2637 \\
4201 \\
5760\end{array}$ & $\begin{array}{l}1224 \\
2793 \\
4357 \\
5915\end{array}$ & $\begin{array}{l}2950 \\
4513 \\
6071\end{array}$ & $\begin{array}{l}1538 \\
3106 \\
4669 \\
6226\end{array}$ & & & & $\begin{array}{l}0594 \\
2166 \\
3732 \\
5293 \\
6848\end{array}$ & & $\begin{array}{l}158 \\
157 \\
157 \\
156 \\
155\end{array}$ \\
\hline $\begin{array}{r}280 \\
1\end{array}$ & $\begin{array}{l}7158 \\
8706\end{array}$ & $\begin{array}{l}7313 \\
8861\end{array}$ & $\begin{array}{l}7468 \\
9015\end{array}$ & $\begin{array}{l}7623 \\
91 \% 0\end{array}$ & $\begin{array}{l}7778 \\
9324\end{array}$ & $\begin{array}{l}7933 \\
9478\end{array}$ & $\begin{array}{l}8088 \\
\mathbf{9 6 3 3}\end{array}$ & $\begin{array}{l}8242 \\
9787\end{array}$ & $\begin{array}{l}8397 \\
9941\end{array}$ & 8552 & 155 \\
\hline $\begin{array}{l}2 \\
3 \\
4 \\
5 \\
6 \\
7 \\
8\end{array}$ & $\begin{array}{r}450249 \\
1786 \\
3318 \\
4845 \\
6366 \\
7882 \\
9392\end{array}$ & $\begin{array}{l}3471 \\
4997 \\
6518 \\
8053 \\
9543\end{array}$ & $\begin{array}{l}0557 \\
2093 \\
3624 \\
5150 \\
6610 \\
8184 \\
9694\end{array}$ & $\begin{array}{l}0 \div 11 \\
2247 \\
3777 \\
5302 \\
6821 \\
8336 \\
9845\end{array}$ & $\begin{array}{l}0865 \\
2400 \\
3930 \\
5454 \\
6973 \\
8487 \\
9995\end{array}$ & $\begin{array}{l}1018 \\
2553 \\
4082 \\
5606 \\
7125 \\
8638\end{array}$ & & & $\begin{array}{l}1479 \\
3012 \\
4540 \\
6062 \\
7579 \\
9091\end{array}$ & $\begin{array}{l}1633 \\
3165 \\
4692 \\
6214 \\
7731 \\
9242\end{array}$ & $\begin{array}{l}154 \\
153 \\
153 \\
152 \\
152 \\
151\end{array}$ \\
\hline 9 & 460898 & 1048 & 1198 & 1348 & 1499 & 1649 & $\begin{array}{l}0296 \\
1799\end{array}$ & & $\begin{array}{l}0597 \\
2098\end{array}$ & $\begin{array}{l}0 ; 48 \\
2248\end{array}$ & $\begin{array}{l}151 \\
150\end{array}$ \\
\hline $\begin{array}{r}290 \\
1 \\
2 \\
3 \\
4\end{array}$ & $\begin{array}{l}2398 \\
3893 \\
5383 \\
6868 \\
8347 \\
0809\end{array}$ & $\begin{array}{l}2548 \\
4042 \\
5532 \\
7016 \\
8495 \\
0060\end{array}$ & $\begin{array}{l}2697 \\
4191 \\
5680 \\
7164 \\
8643\end{array}$ & $\begin{array}{l}2847 \\
4340 \\
5829 \\
7312 \\
8790\end{array}$ & $\begin{array}{l}2997 \\
4490 \\
5977 \\
7460 \\
8938\end{array}$ & $\begin{array}{l}3146 \\
4639 \\
6126 \\
\tau 608 \\
9085\end{array}$ & $\begin{array}{l}3296 \\
4788 \\
62 \pi 4 \\
7 \% 56 \\
9233\end{array}$ & $\begin{array}{l}3445 \\
4936 \\
6423 \\
7904 \\
9380\end{array}$ & $\begin{array}{l}3594 \\
5085 \\
6571 \\
8052 \\
9527\end{array}$ & & $\begin{array}{l}150 \\
149 \\
149 \\
148 \\
148\end{array}$ \\
\hline $\begin{array}{l}6 \\
7 \\
8 \\
9\end{array}$ & $\begin{array}{r}471292 \\
2756 \\
4216 \\
5671\end{array}$ & $\begin{array}{l}1438 \\
2903 \\
4362 \\
5816\end{array}$ & $\begin{array}{l}0116 \\
1585 \\
3049 \\
4508 \\
5962\end{array}$ & $\begin{array}{l}0263 \\
1732 \\
3195 \\
4653 \\
6107\end{array}$ & $\begin{array}{l}1878 \\
3341 \\
4799 \\
6252\end{array}$ & $\begin{array}{l}2025 \\
3487 \\
4944 \\
6397\end{array}$ & $\begin{array}{l}0 \% 04 \\
2171 \\
3633 \\
5090 \\
6542\end{array}$ & $\begin{array}{l}0851 \\
2318 \\
3779 \\
5235 \\
6687\end{array}$ & $\begin{array}{l}0998 \\
2464 \\
3925 \\
5381 \\
6832\end{array}$ & $\begin{array}{l}1145 \\
2610 \\
40 \% 1 \\
5526 \\
6976\end{array}$ & $\begin{array}{l}147 \\
146 \\
146 \\
146 \\
145\end{array}$ \\
\hline
\end{tabular}

Proportional Parts.

\begin{tabular}{|c|c|c|c|c|c|c|c|c|c|}
\hline Diff. & 1 & 2 & 3 & 4 & 5 & 6 & 7 & 8 & 9 \\
\hline 161 & 16.1 & 32.2 & 48.3 & 64.4 & 80.5 & 96.6 & 112.7 & 128.8 & 144.9 \\
\hline 160 & 16.0 & 32.0 & 48.0 & 64.0 & 80.0 & 96.0 & 112.0 & 128.0 & 144.0 \\
\hline 153 & 15.9 & 31.8 & 47.7 & 63.6 & 79.5 & 95.4 & 111.3 & 127.2 & 143.1 \\
\hline 158 & 15.8 & 31.6 & 47.4 & 63.2 & 79.0 & 94.8 & 110.6 & 126.4 & 142.2 \\
\hline 157 & 15.7 & 31.4 & 47.1 & 62.8 & 78.5 & 94.2 & 109.9 & 125.6 & 141.3 \\
\hline 156 & 15.6 & 31.2 & 46.8 & 62.4 & 78.0 & 93.6 & 109.2 & 124.8 & 140.4 \\
\hline 155 & 15.5 & 31.0 & 46.5 & 62.0 & 77.5 & 93.0 & 108.5 & 124.0 & 139.5 \\
\hline 154 & 15.4 & 30.8 & 46.2 & 61.6 & 77.0 & 92.4 & 107.8 & 123.2 & 138.6 \\
\hline 153 & $15 . \overline{3}$ & 30.6 & 45.9 & 61.2 & 76.5 & 91.8 & 107.1 & 122.4 & 137.7 \\
\hline 152 & 15.2 & 30.4 & 45.6 & 60.8 & 76. & 91.2 & 106.4 & 121.6 & 136.8 \\
\hline 151 & 15.1 & 30.2 & 45.3 & 60. & 75 & 90.6 & 105.7 & 120.8 & 135.9 \\
\hline 150 & 15.0 & 30.0 & 45.0 & 60.0 & 75.0 & 90.0 & 105.0 & 120.0 & 135.0 \\
\hline 149 & 14.9 & 29. & 44.7 & 59 & 74. & 89.4 & 104.3 & 119.2 & 134.1 \\
\hline 148 & 14.8 & 29. & 44.4 & & 74 & 88 & 103 & & 133.2 \\
\hline 147 & 14.7 & 29.4 & 44.1 & 58.8 & 73.5 & 88.2 & 102.9 & 117.6 & 132.3 \\
\hline 146 & 14.6 & 29.2 & 43.8 & & 73 & 87.6 & 102.2 & 116.8 & 131.4 \\
\hline 145 & 14.5 & 29.0 & 43.5 & 58.0 & 72.5 & 87.0 & 101.5 & 116.0 & 130.5 \\
\hline 144 & 14.4 & 28.8 & 43.2 & 57 & \% & 86.4 & 100.8 & 115.2 & 129.6 \\
\hline 143 & 14.3 & 28.6 & 42.9 & 57.2 & 71.5 & 85.8 & 100.1 & 114.4 & 128.7 \\
\hline 142 & 14.2 & 28.4 & 42.6 & 56.8 & 71.0 & 85.2 & 99.4 & 113.6 & 127.8 \\
\hline 141 & 14.1 & 28.2 & 42.3 & 56 & 70. & 81. & 98.7 & 112.8 & 126.9 \\
\hline 140 & 14.0 & 28.0 & 42.0 & 56.0 & 70.0 & 84.0 & 98.0 & 112.0 & 126.0 \\
\hline
\end{tabular}


TABLE XI, - LOGARITHMS OF NUMBERS.

\begin{tabular}{|c|c|c|c|c|c|c|c|c|c|c|c|}
\hline \multicolumn{9}{|c|}{ No. 300 L. $47 \%]}$. & \multicolumn{3}{|c|}{ [No. 339 L. 531.} \\
\hline N. & 0 & 1 & 2 & 8 & 4 & 5 & 6 & 7 & 8 & 9 & Diff. \\
\hline $\begin{array}{r}300 \\
1\end{array}$ & $\begin{array}{r}477121 \\
8566\end{array}$ & $\begin{array}{l}7266 \\
8711\end{array}$ & $\begin{array}{l}7411 \\
8855\end{array}$ & $\begin{array}{l}7555 \\
8999\end{array}$ & $\begin{array}{l}7700 \\
9143\end{array}$ & $\begin{array}{l}7844 \\
9287\end{array}$ & $\begin{array}{l}7989 \\
9431\end{array}$ & $\begin{array}{l}8133 \\
9575\end{array}$ & $\begin{array}{l}8278 \\
9719\end{array}$ & $\begin{array}{l}8422 \\
9863\end{array}$ & 145 \\
\hline & 48000 & 0151 & & 38 & 0582 & 0 & 086 & 1012 & $115 t$ & & \\
\hline 3 & 1443 & 6 & & & & & & & 1100 & 731 & 144 \\
\hline 4 & 2874 & 301 & 315 & 3302 & 34 & 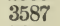 & 37 & 38 & 4015 & 4157 & 143 \\
\hline 5 & 4300 & 444 & 45 & 4727 & 486 & & 51 & 52 & 5437 & 5579 & 142 \\
\hline 6 & $5 \pi 21$ & 586 & 600 & 6147 & 62 & 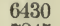 & 65 & 6714 & 6855 & 6997 & 142 \\
\hline$\hat{\imath}$ & 7138 & 8 & 7 & 8 & $\pi$ & & 79 & & 8269 & 8410 & 141 \\
\hline $\begin{array}{l}8 \\
9\end{array}$ & $\begin{array}{l}6001 \\
9958\end{array}$ & & & 8974 & 9114 & & 9390 & 9031 & 9016 & 9818 & 141 \\
\hline & & 0099 & 0239 & 0380 & 0520 & 0661 & 0801 & 0941 & 1081 & 1222 & 140 \\
\hline 310 & 491362 & 1502 & 1642 & 1782 & 1922 & 2062 & 2201 & 2341 & 2481 & 2621 & 140 \\
\hline 1 & 2760 & 290 & 3040 & 3179 & 3319 & 3 & 3597 & 3 & $38 \pi 6$ & 015 & 139 \\
\hline 2 & 4155 & 4294 & 4433 & 4572 & 4711 & 48 & 4989 & 5128 & 5267 & 5406 & 139 \\
\hline 3 & 5544 & 5683 & 5822 & 5960 & 6099 & 623 & 63 & 6515 & 6653 & 6591 & 139 \\
\hline 4 & 6930 & 7068 & 7206 & 7344 & 7483 & $76 \%$ & 7759 & 7897 & 8035 & $81 \% 3$ & 138 \\
\hline 5 & 8311 & 8448 & 8586 & 8724 & 8862 & 8999 & 9137 & 9275 & 9412 & 9550 & 138 \\
\hline & & & & 0099 & 0236 & 037 & 05 & 0648 & 0785 & 0922 & 137 \\
\hline 7 & 501059 & 1196 & 1333 & 147 & 1607 & 17 & & 2017. & 2154 & 291 & $13 \%$ \\
\hline 8 & 2427 & 2564 & 270 & 2837 & 297 & 31 & 32 & 338 & 3518 & 3655 & 136 \\
\hline 9 & 3791 & 3927 & 4063 & 4199 & 4335 & $44^{7}$ & 460 & 474 & 48.8 & 5014 & 136 \\
\hline 320 & 5150 & 5286 & 5421 & $555 i$ & 5693 & 5828 & 5964 & 6099 & 6234 & $63 \% 0$ & 136 \\
\hline 1 & 6505 & 6640 & $67 \% 6$ & 6911 & 70 & $\pi 1$ & r3 & 745 & 7586 & $7 \% 21$ & 135 \\
\hline 2 & 7856 & 7991 & 8126 & 8260 & 839 & 85 & 8664 & 8799 & 8934 & 9068 & 135 \\
\hline & & 9337 & 94 & $y$ & 9140 & 98 & 00 & 014 & $02 \%$ & 0411 & 134 \\
\hline 4 & 510545 & 0679 & 0813 & 08 & 1 & 12 & & & 1616 & 1750 & 134 \\
\hline 5 & & & & & & & & 2 & 2951 & 8 & 133 \\
\hline 6 & 3218 & 3351 & 34 & 36 & 37 & 38 & 40 & 41 & 4282 & 441 & 133 \\
\hline 7 & 4548 & 4681 & 48 & 49 & 50 & & 53 & 54 & 5609 & $5 ; 4$ & 133 \\
\hline 8 & 58 & 600 & $61:$ & 6271 & 64 & 65 & 60 & 68 & 6932 & 7064 & 132 \\
\hline 9 & 7196 & 732 & 7460 & 7592 & 7724 & 78 & 7987 & 8119 & 8251 & 8282 & 132 \\
\hline 330 & 8514 & 8646 & $8 \% 77$ & 8909 & 9040 & $91 \% 1$ & 9303 & 9434 & 9566 & 969 & 131 \\
\hline & & & 0090 & 0221 & 03. & & & $0 \sim 15$ & & 10 & 131 \\
\hline 2 & 52113 & 126 & & & & & & & & 33 & 131 \\
\hline 3 & 0 & 25 & & 28 & 29 & 30 & & & 34 & 3616 & 130 \\
\hline 4 & 374 & 38 & & 41 & 42 & & & & & 491 & 130 \\
\hline 5 & 50 & $51 \%$ & 53 & 54 & 55 & 56 & 58 & 59 & 6081 & & 129 \\
\hline 6 & & & & & & & 71 & & $73 \pi 2$ & 750 & 129 \\
\hline 7 & 763 & 759 & 7888 & 8016 & 81 & 82 & 8402 & 8531 & 8660 & 8788 & 129 \\
\hline 8 & 89 & 904 & $91 \%$ & 9302 & 943 & 95 & 368 & 98 & 994 & & 128 \\
\hline 9 & 530200 & 0328 & 0456 & 0584 & $0 \div 12$ & 0840 & 0968 & 1096 & 1223 & 1351 & 12 \\
\hline
\end{tabular}

Proportional Parts.

\begin{tabular}{|c|c|c|c|c|c|c|c|c|c|}
\hline Diff. & 1 & 2 & 3 & 4 & 5 & 6 & 7 & 8 & 9 \\
\hline 139 & 13.9 & 27 . & 41. & 55 & 69. & 83.4 & 97.3 & 111.2 & 125.1 \\
\hline 138 & 1 & 2 & & & 6 & 82 & 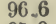 & 110.4 & 124.2 \\
\hline 137 & 13 & $2 \pi$. & 41 & 5 & 68 & 82.2 & 95 & 109.6 & 123.3 \\
\hline 136 & 13. & 27.2 & 40. & 54 & 68. & 81.6 & 95. & 108.8 & 122.4 \\
\hline 135 & 13.5 & 27.0 & 40. & 54.0 & 67.5 & 81.0 & 94 & 108.0 & 121.5 \\
\hline 134 & 13. & 26.8 & 40 & 53. & 67. & 80 & 93 & 107.2 & 120.6 \\
\hline 133 & 13.3 & 26.6 & 39. & 53.2 & 66.5 & 79 & 93 & 106.4 & 119.7 \\
\hline 132 & 13. & 26. & & 5 & 66 & 79 & 92 & 105.6 & 118.8 \\
\hline 131 & 13.1 & 26.2 & 89. & 52.4 & 65. & 78 & 91. & 104.8 & 317.9 \\
\hline 130 & 13.0 & 26. & & 52 & 65 & 78. & 91.0 & 104.0 & $\begin{array}{l}117.0 \\
116.1\end{array}$ \\
\hline 129 & 12.9 & 25.8 & 38 & 51.6 & 64.5 & 77. & 90.3 & $\begin{array}{l}103.2 \\
102.4\end{array}$ & 115.2 \\
\hline 128 & 12.8 & 25.6 & 38. & 51.2 & 64.0 & 76.8 & $\begin{array}{l}89.6 \\
88.9\end{array}$ & 101.6 & 114.3 \\
\hline 127 & & 25.4 & 38.1 & 50.8 & 63.5 & & & & \\
\hline
\end{tabular}


TABLE XI.-LOGARITHMS OF NUMBERS.

\begin{tabular}{|c|c|c|c|c|c|c|c|c|c|c|c|}
\hline \multicolumn{9}{|c|}{ No. 340 L. 531.$]$} & \multicolumn{3}{|c|}{ [No. $3 \pi 9$ L. $5 \% 9}$. \\
\hline N. & $\mathbf{0}$ & 1 & 2 & 8 & 4 & 5 & 6 & 7 & 8 & 9 & Diff. \\
\hline $\begin{array}{r}340 \\
1 \\
2 \\
3 \\
4 \\
5 \\
6\end{array}$ & $\begin{array}{r}531479 \\
2754 \\
4026 \\
5294 \\
6558 \\
7819 \\
9076\end{array}$ & $\begin{array}{l}1607 \\
2882 \\
4153 \\
5421 \\
6685 \\
7945 \\
9202\end{array}$ & $\begin{array}{l}1734 \\
3009 \\
4280 \\
5547 \\
6811 \\
8071 \\
9327\end{array}$ & $\begin{array}{l}1862 \\
3136 \\
4407 \\
5674 \\
6937 \\
8197 \\
9452\end{array}$ & $\begin{array}{l}1990 \\
3264 \\
4534 \\
5800 \\
7063 \\
8322 \\
9578\end{array}$ & $\begin{array}{l}2117 \\
3391 \\
4661 \\
5927 \\
7189 \\
8448 \\
9703\end{array}$ & $\begin{array}{l}2245 \\
3518 \\
4787 \\
6053 \\
7315 \\
8574 \\
9829\end{array}$ & $\begin{array}{l}2372 \\
3645 \\
4914 \\
6180 \\
7441 \\
8699 \\
9954\end{array}$ & $\begin{array}{l}2500 \\
3772 \\
5041 \\
6306 \\
7567 \\
8825\end{array}$ & $\begin{array}{l}2627 \\
3899 \\
5167 \\
6432 \\
7693 \\
8951\end{array}$ & $\begin{array}{l}128 \\
127 \\
127 \\
126 \\
126 \\
126\end{array}$ \\
\hline $\begin{array}{l}7 \\
8 \\
9\end{array}$ & $\begin{array}{r}510329 \\
1579 \\
2825\end{array}$ & $\begin{array}{l}0455 \\
1704 \\
2950\end{array}$ & $\begin{array}{l}0580 \\
1829 \\
30 \sim 4\end{array}$ & $\begin{array}{l}0 \% 05 \\
1953 \\
3199\end{array}$ & $\begin{array}{l}0830 \\
20 \pi 8 \\
3323\end{array}$ & $\begin{array}{l}0955 \\
2203 \\
3447\end{array}$ & & $\begin{array}{l}1205 \\
2452 \\
3696\end{array}$ & $\begin{array}{l}0079 \\
1330 \\
2576 \\
3820\end{array}$ & $\begin{array}{l}0204 \\
1454 \\
2701 \\
3944\end{array}$ & $\begin{array}{l}125 \\
125 \\
125 \\
124\end{array}$ \\
\hline $\begin{array}{r}350 \\
1 \\
2 \\
3 \\
4\end{array}$ & $\begin{array}{l}4068 \\
5307 \\
6543 \\
7775 \\
9003\end{array}$ & $\begin{array}{l}4192 \\
5431 \\
6666 \\
7898 \\
9126\end{array}$ & $\begin{array}{l}4316 \\
5555 \\
6789 \\
8021 \\
9249\end{array}$ & $\begin{array}{l}4440 \\
5678 \\
6913 \\
8144 \\
9371\end{array}$ & $\begin{array}{l}4564 \\
5802 \\
7036 \\
8267 \\
9494\end{array}$ & $\begin{array}{l}4688 \\
5925 \\
7159 \\
8389 \\
9616\end{array}$ & $\begin{array}{l}4812 \\
6049 \\
7282 \\
8512 \\
9739\end{array}$ & $\begin{array}{l}4936 \\
6172 \\
7405 \\
8635 \\
9861\end{array}$ & $\begin{array}{l}5060 \\
6296 \\
7529 \\
8758 \\
9984\end{array}$ & $\begin{array}{l}5183 \\
6419 \\
7652 \\
8881\end{array}$ & $\begin{array}{l}124 \\
124 \\
123 \\
123\end{array}$ \\
\hline $\begin{array}{l}5 \\
6 \\
7 \\
8 \\
9\end{array}$ & $\begin{array}{r}550228 \\
1450 \\
2668 \\
3883 \\
5094\end{array}$ & $\begin{array}{l}0351 \\
1572 \\
2790 \\
4004 \\
5215\end{array}$ & $\begin{array}{l}0473 \\
1694 \\
2911 \\
4126 \\
5336\end{array}$ & $\begin{array}{l}0595 \\
1816 \\
3033 \\
4247 \\
5457\end{array}$ & $\begin{array}{l}0717 \\
1938 \\
3155 \\
4368 \\
5578\end{array}$ & $\begin{array}{l}0840 \\
2060 \\
3276 \\
4489 \\
5699\end{array}$ & $\begin{array}{l}0962 \\
2181 \\
3398 \\
4610 \\
58: 0\end{array}$ & $\begin{array}{l}1084 \\
2303 \\
3519 \\
4731 \\
5940\end{array}$ & $\begin{array}{l}1206 \\
2425 \\
3640 \\
4852 \\
6061\end{array}$ & $\begin{array}{l}0106 \\
1328 \\
2547 \\
3762 \\
4973 \\
6182\end{array}$ & $\begin{array}{l}123 \\
122 \\
122 \\
121 \\
121 \\
121\end{array}$ \\
\hline $\begin{array}{r}360 \\
1 \\
2 \\
3\end{array}$ & $\begin{array}{c}6303 \\
7507 \\
8709 \\
9007\end{array}$ & $\begin{array}{l}6423 \\
7627 \\
8829\end{array}$ & $\begin{array}{l}6544 \\
7748 \\
8948 \\
\end{array}$ & $\begin{array}{r}6664 \\
7868 \\
9068 \\
\end{array}$ & $\begin{array}{l}6785 \\
7988 \\
9188\end{array}$ & $\begin{array}{l}6905 \\
8108 \\
9308 \\
\end{array}$ & $\begin{array}{l}7026 \\
8228 \\
9428\end{array}$ & $\begin{array}{l}7146 \\
8349 \\
9548 \\
\end{array}$ & $\begin{array}{l}7267 \\
8469 \\
966 \% \\
\end{array}$ & $\begin{array}{l}7387 \\
8589 \\
9 \approx 87\end{array}$ & $\begin{array}{l}120 \\
120 \\
120\end{array}$ \\
\hline $\begin{array}{l}4 \\
5 \\
6 \\
7 \\
8 \\
9\end{array}$ & $\begin{array}{r}561101 \\
2293 \\
\mathbf{3 4 8 1} \\
4666 \\
5848 \\
7026\end{array}$ & $\begin{array}{l}0026 \\
12: 1 \\
2412 \\
3600 \\
4784 \\
5966 \\
7144\end{array}$ & $\begin{array}{l}0146 \\
1340 \\
2531 \\
3718 \\
4903 \\
6084 \\
7262\end{array}$ & $\begin{array}{l}0265 \\
1459 \\
2650 \\
3837 \\
5021 \\
6202 \\
7379\end{array}$ & $\begin{array}{l}0385 \\
1578 \\
2769 \\
3955 \\
5139 \\
6320 \\
7497\end{array}$ & $\begin{array}{l}0504 \\
1698 \\
2887 \\
4074 \\
5257 \\
6437 \\
7614\end{array}$ & $\begin{array}{l}0624 \\
1817 \\
3006 \\
4192 \\
5376 \\
6555 \\
7732\end{array}$ & $\begin{array}{l}0743 \\
1936 \\
3125 \\
4311 \\
5494 \\
6673 \\
7849\end{array}$ & $\begin{array}{l}0863 \\
2055 \\
3244 \\
4429 \\
5612 \\
6791 \\
7967\end{array}$ & $\begin{array}{l}0982 \\
2174 \\
3362 \\
4548 \\
5730 \\
6909 \\
8084\end{array}$ & $\begin{array}{l}119 \\
119 \\
119 \\
119 \\
118 \\
118 \\
118\end{array}$ \\
\hline $\begin{array}{r}370 \\
1\end{array}$ & $\begin{array}{l}8202 \\
9374\end{array}$ & $\begin{array}{l}8319 \\
9491\end{array}$ & $\begin{array}{l}8436 \\
9608\end{array}$ & $\begin{array}{l}8554 \\
9725\end{array}$ & $\begin{array}{l}8671 \\
9842\end{array}$ & $\begin{array}{l}8788 \\
9959\end{array}$ & 8905 & 9023 & 9140 & 9257 & 117 \\
\hline $\begin{array}{l}2 \\
3 \\
4 \\
5 \\
6 \\
7 \\
8 \\
9\end{array}$ & $\begin{array}{r}570543 \\
1709 \\
2872 \\
4031 \\
5188 \\
6341 \\
7492 \\
8639\end{array}$ & $\begin{array}{l}0660 \\
1825 \\
2988 \\
4147 \\
5303 \\
6457 \\
7607 \\
8754\end{array}$ & $\begin{array}{l}0776 \\
1942 \\
3104 \\
4263 \\
5419 \\
6572 \\
7722 \\
8868\end{array}$ & $\begin{array}{l}0893 \\
2058 \\
3220 \\
4379 \\
5534 \\
6687 \\
7836 \\
8983\end{array}$ & $\begin{array}{l}2174 \\
3336 \\
4491 \\
5650 \\
6802 \\
7951 \\
9097\end{array}$ & $\begin{array}{l}1126 \\
2291 \\
3452 \\
4610 \\
5765 \\
6917 \\
8066 \\
9212\end{array}$ & $\begin{array}{l}0076 \\
1243 \\
2407 \\
3568 \\
4726 \\
5880 \\
7032 \\
8181 \\
9326\end{array}$ & $\begin{array}{l}0193 \\
1359 \\
2523 \\
3684 \\
4841 \\
5996 \\
7147 \\
8295 \\
9441\end{array}$ & $\begin{array}{l}0309 \\
1476 \\
2639 \\
3800 \\
4957 \\
6111 \\
7262 \\
8110 \\
9555\end{array}$ & $\begin{array}{l}0426 \\
1592 \\
2755 \\
3915 \\
5072 \\
6226 \\
7377 \\
8525 \\
9669\end{array}$ & $\begin{array}{l}717 \\
117 \\
116 \\
116 \\
116 \\
115 \\
115 \\
115 \\
114\end{array}$ \\
\hline
\end{tabular}

Proportional Parts.

\begin{tabular}{|c|c|c|c|c|c|c|c|c|c|}
\hline Diff. & 1 & 2 & 3 & 4 & 5 & 6 & 7 & 8 & 9 \\
\hline 128 & 12.8 & 25.6 & 38.4 & 51.2 & 64.0 & 76.8 & 89.6 & 102.4 & 115.2 \\
\hline 127 & 127 & 254 & 38.1 & 50.8 & 63.5 & 76.2 & 88.9 & 101.6 & 114.3 \\
\hline 126 & 126 & 25.2 & 37.8 & 50.4 & 63.0 & 75.6 & 88.2 & 100.8 & 113.4 \\
\hline 125 & 12.5 & 25.0 & 37.5 & 50.0 & 62.5 & 75.0 & $8 \pi .5$ & 100.0 & 112.5 \\
\hline 124 & 12.4 & 24.8 & 37.2 & 49.6 & 62.0 & 74.4 & 868 & 99.2 & 111.6 \\
\hline 123 & 12.3 & 24.6 & 36.9 & 49.2 & 61.5 & 73.8 & 86.1 & $98 . \tilde{4}$ & 110.7 \\
\hline 122 & 12.2 & 24.4 & 36.6 & 48.8 & 61.0 & 73.2 & 85.4 & 97.6 & 109.8 \\
\hline 121 & 12.1 & 24.2 & 36.3 & 48.4 & 60.5 & 72.6 & 84.7 & 96.8 & 108.9 \\
\hline 120 & 12.0 & 24.0 & 36.0 & 48.0 & 60.0 & 72.0 & 84.0 & 96.0 & 108.0 \\
\hline 119 & 11.9 & 23.8 & 35.7 & 47.6 & 59.5 & 71.4 & 83.3 & 95.2 & 107.1 \\
\hline
\end{tabular}


TABLE XI. - LOGARITHMS OF NUMBERS.

\begin{tabular}{|c|c|c|c|c|c|c|c|c|c|c|c|}
\hline \multicolumn{9}{|c|}{ No. 380. L. 579.] } & \multicolumn{3}{|c|}{ [No, 414 L, 617.} \\
\hline N. & 0 & 1 & 2 & 3 & 4 & 5 & 6 & 7 & 8 & 9 & Diff. \\
\hline \multirow[t]{2}{*}{380} & 579784 & 9898 & & & & & & & & & \\
\hline & & & 0012 & 0126 & 0241 & 0355 & 0469 & 0583 & 0697 & 0811 & \multirow[t]{8}{*}{114} \\
\hline 1 & 580925 & 1039 & 1153 & 1267 & 1381 & 1495 & 1608 & 1722 & 1836 & 1950 & \\
\hline 2 & $\begin{array}{l}2063 \\
3199\end{array}$ & $\begin{array}{l}2177 \\
3312\end{array}$ & 2291 & 2404 & 2518 & 2631 & & 2858 & $29 \tau^{2}$ & 3085 & \\
\hline $\begin{array}{l}3 \\
4\end{array}$ & $\begin{array}{l}\text { 819y } \\
4331\end{array}$ & $\begin{array}{l}3312 \\
4444\end{array}$ & $\begin{array}{l}3426 \\
4557\end{array}$ & $\begin{array}{l}3539 \\
4670\end{array}$ & $\begin{array}{l}3652 \\
4783\end{array}$ & $\begin{array}{l}3765 \\
4896\end{array}$ & $\begin{array}{l}3879 \\
5009\end{array}$ & 3992 & 4105 & 4218 & \\
\hline 5 & 5461 & 5574 & 5686 & 5799 & $\begin{array}{l}4.00 \\
5912\end{array}$ & 6024 & 6137 & $\begin{array}{l}5122 \\
6250\end{array}$ & $\begin{array}{l}5235 \\
6362\end{array}$ & $\begin{array}{l}5348 \\
6475\end{array}$ & \\
\hline 6 & 6587 & 6700 & 6812 & 6925 & 7037 & 7149 & ๆ 262 & 7374 & 7486 & 7599 & \\
\hline \multirow{3}{*}{$\begin{array}{l}7 \\
8 \\
9\end{array}$} & 7711 & 7823 & 7935 & 8047 & 8160 & 8272 & 8384 & 8496 & 8608 & $8 \%: 0$ & \\
\hline & \multirow{2}{*}{$\begin{array}{l}8832 \\
9950\end{array}$} & 8944 & 9056 & 9167 & $92 \% 9$ & 9391 & 9503 & 9615 & 9726 & 9838 & \\
\hline & & 0061 & 0173 & 0284 & 0396 & 0507 & 0619 & 0730 & 0842 & 0953 & \\
\hline 390 & 591065 & 1176 & 1287 & 1399 & 1510 & 1621 & 1732 & 1843 & 1955 & 2066 & \multirow{7}{*}{111} \\
\hline 1 & $21 \% 7$ & 2288 & 2399 & 2510 & 2621 & 2732 & 2843 & 2954 & 3064 & 3175 & \\
\hline 2 & 3286 & 3397 & 3508 & 3618 & 3729 & 3840 & 3950 & 4061 & 4171 & 4282 & \\
\hline 3 & 4393 & 4503 & 4614 & 4724 & 4834 & 4945 & 5055 & 5165 & $52 \pi 6$ & 5386 & \\
\hline $\begin{array}{l}4 \\
5\end{array}$ & $\begin{array}{l}5496 \\
6597\end{array}$ & $\begin{array}{l}5606 \\
6707\end{array}$ & $\begin{array}{l}5717 \\
6817\end{array}$ & $\begin{array}{l}5827 \\
6927\end{array}$ & $\begin{array}{l}5937 \\
7037\end{array}$ & $\begin{array}{l}6047 \\
7146\end{array}$ & $\begin{array}{l}6157 \\
7256\end{array}$ & $\begin{array}{l}6267 \\
7366\end{array}$ & $\begin{array}{l}6377 \\
7476\end{array}$ & $\begin{array}{l}6487 \\
7586\end{array}$ & \\
\hline 6 & 7695 & 7805 & 7914 & 8024 & 8134 & 8243 & 8353 & 8462 & 8572 & 8681 & \\
\hline \multirow{2}{*}{8} & \multirow{2}{*}{9883} & \multirow{2}{*}{9992} & 9009 & 9119 & 9228 & 9337 & 9446 & 9556 & 9665 & $9 \pi \% 4$ & \\
\hline & & & 0101 & 0210 & 0319 & $04: 8$ & 0537 & 0646 & 0755 & 0864 & \multirow{2}{*}{109} \\
\hline 9 & 600973 & 1082 & 1191 & 1299 & 1408 & 1517 & 1625 & 1734 & 1843 & 1951 & \\
\hline \multirow{7}{*}{$\begin{array}{r}400 \\
1 \\
2 \\
3 \\
4 \\
5 \\
6 \\
7\end{array}$} & 2060 & 2169 & 2277 & 2386 & 2494 & 2603 & 2711 & 2819 & 2928 & 3036 & \multirow{6}{*}{108} \\
\hline & 3144 & 3253 & 3361 & 3469 & 3577 & 3686 & 3794 & 3902 & 4010 & 4118 & \\
\hline & 4226 & 4334 & 4442 & 4550 & 4658 & 4766 & $48 \pi 4$ & 4982 & 5089 & 5197 & \\
\hline & $\begin{array}{l}5305 \\
6381\end{array}$ & $\begin{array}{l}5413 \\
6489\end{array}$ & $\begin{array}{l}5521 \\
6596\end{array}$ & $\begin{array}{l}5628 \\
6704\end{array}$ & $\begin{array}{l}5736 \\
6811\end{array}$ & $\begin{array}{l}5844 \\
6919\end{array}$ & $\begin{array}{l}5951 \\
70 \cdot 6\end{array}$ & $\begin{array}{l}6059 \\
7133\end{array}$ & 6166 & $\begin{array}{l}6274 \\
7348\end{array}$ & \\
\hline & 7455 & 7562 & 7669 & 7777 & 7884 & 7991 & 8098 & 8205 & 8312 & 8419 & \\
\hline & \multirow{2}{*}{$\begin{array}{l}8526 \\
9594\end{array}$} & \multirow{2}{*}{$\begin{array}{l}8633 \\
9701\end{array}$} & \multirow{2}{*}{$\begin{array}{l}8740 \\
9808\end{array}$} & \multirow{2}{*}{$\begin{array}{l}8847 \\
9914\end{array}$} & 8954 & 9061 & 9167 & $92 \pi 4$ & 9381 & 9488 & \\
\hline & & & & & 00 & 01 & 0234 & 03 & 0447 & & \\
\hline 8 & 610660 & $076 \pi$ & 0873 & 0979 & 1086 & & 1298 & & 1511 & & \multirow{7}{*}{100} \\
\hline 9 & $1 \tau 23$ & 1829 & 1936 & 2042 & 2148 & 2254 & 2360 & 2166 & $25 \% 2$ & $26 \pi 8$ & \\
\hline 410 & 2784 & 2890 & 2996 & 3102 & 3207 & 3313 & 3419 & 3525 & 3630 & 3736 & \\
\hline 1 & 3842 & 3947 & 4053 & 4159 & 4264 & 4370 & 4475 & 4581 & 4686 & $4 \pi 92$ & \\
\hline 2 & 4897 & 5003 & 5108 & 5213 & 5319 & 5424 & 5529 & 5634 & 5740 & & \\
\hline 3 & 5950 & 6055 & 6160 & 6265 & 6370 & 6476 & 6581 & 6686 & 6790 & 6895 & \\
\hline 4 & 7000 & 7105 & 7210 & 7315 & 7420 & 7525 & $\tau 629$ & 7734 & 7833 & 7943 & \\
\hline
\end{tabular}

Proportional Parts.

\begin{tabular}{|c|c|c|c|c|c|c|c|c|c|}
\hline Diff. & 1 & 2 & 3 & 4 & 5 & 6 & 7 & 8 & 9 \\
\hline $\begin{array}{l}118 \\
117 \\
116 \\
115 \\
114 \\
113 \\
112\end{array}$ & $\begin{array}{l}11.8 \\
11.7 \\
11.6 \\
11.5 \\
11.4 \\
11.3 \\
11.2\end{array}$ & $\begin{array}{l}23.6 \\
23.4 \\
23.2 \\
23.0 \\
22.8 \\
22.6 \\
22.4\end{array}$ & $\begin{array}{l}35.4 \\
35.1 \\
34.8 \\
34.5 \\
34.2 \\
33.9 \\
33.6\end{array}$ & $\begin{array}{l}47.2 \\
46.8 \\
46.4 \\
46.0 \\
45.6 \\
45.2 \\
44.8\end{array}$ & $\begin{array}{l}59.0 \\
58.5 \\
58.0 \\
57.5 \\
57.0 \\
56.5 \\
56.0\end{array}$ & $\begin{array}{l}70.8 \\
70.2 \\
69.6 \\
69.0 \\
68.4 \\
67.8 \\
67.2\end{array}$ & $\begin{array}{l}82.6 \\
81.9 \\
81.2 \\
80.5 \\
79.8 \\
79.1 \\
78.4\end{array}$ & $\begin{array}{l}94.4 \\
93.6 \\
92.8 \\
92.0 \\
91.2 \\
90.4 \\
89.6\end{array}$ & $\begin{array}{l}106.2 \\
105.3 \\
104.4 \\
103.5 \\
102.6 \\
101.7 \\
100.8\end{array}$ \\
\hline $\begin{array}{l}111 \\
110 \\
109 \\
108 \\
107 \\
106 \\
105 \\
105 \\
104\end{array}$ & $\begin{array}{l}11.1 \\
11.0 \\
10.9 \\
10.8 \\
10.7 \\
10.6 \\
10.5 \\
10.5 \\
10.4\end{array}$ & $\begin{array}{l}22.2 \\
22.0 \\
21.8 \\
21.6 \\
21.4 \\
21.2 \\
21.0 \\
21.0 \\
20.8\end{array}$ & $\begin{array}{l}33.3 \\
33.0 \\
32.7 \\
32.4 \\
32.1 \\
31.8 \\
31.5 \\
31.5 \\
31.2\end{array}$ & $\begin{array}{l}44.4 \\
44.0 \\
43.6 \\
43.2 \\
42.8 \\
42.4 \\
42.0 \\
42.0 \\
41.6\end{array}$ & $\begin{array}{l}55.5 \\
55.0 \\
54.5 \\
54.0 \\
53.5 \\
53.0 \\
52.5 \\
52.5 \\
52.0\end{array}$ & $\begin{array}{l}66.6 \\
66.0 \\
65.4 \\
64.8 \\
64.2 \\
63.6 \\
63.0 \\
63.0 \\
62.4\end{array}$ & $\begin{array}{l}77.7 \\
77.0 \\
76.3 \\
75.6 \\
74.9 \\
74.2 \\
73.5 \\
73.5 \\
72.8\end{array}$ & $\begin{array}{l}88.8 \\
88.0 \\
87.2 \\
86.4 \\
85.6 \\
84.8 \\
84.0 \\
84.0 \\
83.2\end{array}$ & $\begin{array}{l}99.9 \\
99.0 \\
98.1 \\
97.2 \\
96.3 \\
95.4 \\
94.5 \\
94.5 \\
93.6\end{array}$ \\
\hline
\end{tabular}


TABLE XI.-LOGARITHMS OF NUMBERS.

\begin{tabular}{|c|c|c|c|c|c|c|c|c|c|c|c|}
\hline \multicolumn{3}{|c|}{ No. 415 L. 618.$]$} & & \multicolumn{3}{|c|}{ [No. 459 L. 662 . } \\
\hline N. & $\mathbf{0}$ & 1 & 2 & 3 & 4 & 5 & 6 & 7 & 8 & 9 & Diff. \\
\hline \multirow{2}{*}{$\begin{array}{r}415 \\
6\end{array}$} & 618048 & 8153 & \multirow{2}{*}{$\begin{array}{l}8257 \\
9302\end{array}$} & 8362 & 8466 & $85 \% 1$ & $86 \hat{6} 6$ & \multirow{2}{*}{$\begin{array}{l}8780 \\
9824\end{array}$} & \multirow{2}{*}{$\begin{array}{r}8884 \\
9928 \\
\end{array}$} & 8989 & \multirow[t]{2}{*}{105} \\
\hline & 9093 & 9198 & & & & & 9719 & & & $z$ & \\
\hline$\tau$ & 620136 & 0240 & 0344 & 0448 & 0552 & 0656 & 0760 & 0864 & 0968 & $10 \% 2$ & \multirow[t]{3}{*}{104} \\
\hline 8 & 1176 & 1280 & \multirow{2}{*}{$\begin{array}{l}1384 \\
2421\end{array}$} & & 1592. & 1695 & 1799 & \multirow{2}{*}{$\begin{array}{l}1903 \\
2939\end{array}$} & 2007 & 2110 & \\
\hline 9 & 2214 & 2318 & & 2525 & 2628 & 2732 & 2835 & & 3042 & 3146 & \\
\hline 420 & 3249 & 3353 & \multirow{7}{*}{$\begin{array}{r}3456 \\
4488 \\
5518 \\
6546 \\
7571 \\
8593 \\
9613 \\
\end{array}$} & \multirow{7}{*}{$\begin{array}{l}3559 \\
4591 \\
5621 \\
6648 \\
7673 \\
8695 \\
9715\end{array}$} & \multirow{7}{*}{$\begin{array}{l}3663 \\
4695 \\
5724 \\
6751 \\
7755 \\
8797 \\
9817 \\
\end{array}$} & & 3869 & $39 \pi 3$ & 4076 & $41 \% 9$ & \\
\hline 1 & 4282 & 4385 & & & & 4798 & 49 & & 5107 & 5210 & 103 \\
\hline 2 & 5312 & 5415 & & & & $582 \%$ & 9 & 6032 & 6135 & 6238 & \\
\hline 3 & 6340 & 6443 & & & & 6853 & 6956 & 7058 & 7161 & 7263 & \\
\hline 4 & 7366 & 7468 & & & & 7878 & 0 & 8082 & 8185 & 8287 & \\
\hline 5 & 8389 & $\begin{array}{l}8491 \\
9512\end{array}$ & & & & $\begin{array}{l}8900 \\
0919\end{array}$ & 9002 & 9104 & 9206 & 9308 & 102 \\
\hline 6 & & & & & & & 0021 & 0 & $0 \approx 24$ & 052 & \\
\hline 7 & 630428 & 0530 & 0631 & 0733 & 0835 & 0936 & $10^{\circ} 8$ & & 1241 & 13 & \\
\hline 8 & 1444 & 1545 & 1647 & $1 \% 48$ & 1849 & 1951 & 2052 & & 2255 & 2356 & \\
\hline 9 & $245 \%$ & 2559 & 2660 & 27 & 8862 & 3 & 3064 & 31 & 3266 & 3367 & \\
\hline 430 & 3468 & 3569 & 3670 & $3 \pi 1$ & $38 \% 2$ & 3973 & 4074 & 4175 & $42 \pi 6$ & $43 \pi 6$ & 101 \\
\hline 1 & 4477 & 4578 & 4679 & & & & & & 5283 & & \\
\hline 2 & 5484 & 5584 & 5685 & 52 & 5886 & 5986 & $608 \%$ & & 6287 & 6388 & \\
\hline 3 & 6488 & 6588 & 6688 & 61 & 688 & 6989 & 7089 & & 7290 & 7390 & \\
\hline 4 & 7490 & 7590 & 7690 & 7790 & 7890 & 7990 & 8090 & 81 & 8290 & 8389 & 100 \\
\hline 5 & 8489 & 8589 & 8689 & 8789 & 8888 & 8988 & 9088 & 9188 & 9287 & 9387 & 200 \\
\hline 6 & 9486 & 9586 & 9686 & 9785 & D & & 0084 & 0183 & 0283 & 0382 & \\
\hline 7 & 640481 & 0581 & 0680 & $0 \% \div 9$ & 0879 & 0978 & & & 12,6 & 1375 & \\
\hline 8 & 1474 & 1573 & $16 \pi 2$ & 17 & 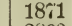 & & 20 & & 2267 & 2366 & \\
\hline 9 & 2465 & 2563 & 2662 & 2761 & 2860 & 2959 & 3058 & 3156 & 3255 & 3354 & 99 \\
\hline 440 & 3453 & 3551 & 3650 & 3749 & 3847 & 3946 & 4044 & 4143 & 4242 & 4340 & \\
\hline 1 & 4439 & 4537 & 4636 & & & & & & 5226 & 5324 & \\
\hline 2 & $54 \% 2$ & 5521 & 56 & 57 & 58 & 5 & 6 & & 08 & 6306 & \\
\hline 3 & 6404 & 6502 & 66 & 6698 & 67 & 6894 & 6992 & & 7187 & r285 & 98 \\
\hline 4 & 7383 & 7481 & 7579 & $76 \% 6$ & 7 & 7872 & 7969 & & 8165 & 8262 & 30 \\
\hline 5 & 8360 & 8458 & 8555 & 86 & 87 & 8848 & 8945 & 9 & 9140 & 923 & \\
\hline 6 & 9335 & 9432 & 9530 & 96 & $9 \%$ & 9821 & 8919 & & 3 & & \\
\hline 7 & 650308 & 0405 & 0502 & 0599 & 696 & 3 & 0 & & & & \\
\hline 8 & 1278 & 1375 & $14 \%$ & 1569 & 666 & 2 & & & 53 & 50 & 97 \\
\hline 9 & 2246 & 2343 & 2440 & 2536 & 2633 & 2730 & 2826 & 29 & 3019 & 3116 & \\
\hline 450 & 3213 & 3309 & 3405 & 3502 & 3598 & 3695 & 3791 & 3888 & 3984 & 4080 & \\
\hline & 4177 & & & & & & & & & & \\
\hline 2 & 5138 & 5235 & 5331 & 54 & 55 & 56 & 57 & & 5906 & 6002 & 96 \\
\hline$\tilde{3}$ & 6098 & 6194 & 6290 & 63 & & & 66 & & 68 & 6960 & \\
\hline 4 & 7056 & r152 & 7247 & 7343 & & & $r 6$ & & & 7916 & \\
\hline 5 & 8011 & 8107 & 82 & 82 & & & & & & & \\
\hline 6 & 8965 & 9060 & 9155 & 9250 & 9346 & 9441 & 9536 & 963 & 9726 & 9821 & \\
\hline & & 0011 & 0106 & 02 & 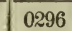 & 1 & & & 06.6 & & 95 \\
\hline 8 & 660865 & & & 11 & & & & & & & \\
\hline 9 & 813 & 1907 & 200 & 20 & F:Di & 2286 & & & 2569 & 266 & \\
\hline & & & & & RT & 4. & & & & & \\
\hline Diff & 1 & 2 & & 3 & 4 & 5 & 6 & & 7 & 8 & 9 \\
\hline & 105 & & & & & J2 & & & & & \\
\hline & & 208 & & & 6 & 52 & & & & 832 & 93.6 \\
\hline & 103 & 206 & & & & 51 & & & & & 927 \\
\hline & 102 & 20 & & & & 51 & & & & & 918 \\
\hline 1 & 101 & 20 & & & & 50 & & & & & 90.9 \\
\hline 100 & 10.0 & 200 & & & 400 & & & & & & 900 \\
\hline 99 & 99 & 198 & & & 396 & 49 & & & & & 89.1 \\
\hline
\end{tabular}


TABLE XI.-LOGARITHMS OF NUMBERS.

\begin{tabular}{|c|c|c|c|c|c|c|c|c|c|c|c|}
\hline \multicolumn{7}{|c|}{ No. 460 L. 662.$]$} & & & \multicolumn{3}{|c|}{ [No. 499 L. 698.} \\
\hline $\mathrm{N}$ & 0 & 1 & 2 & 8 & 1 & 5 & 6 & 7 & 8 & $\theta$ & Diff. \\
\hline $\begin{array}{r}460 \\
1 \\
2 \\
3 \\
4 \\
5 \\
6 \\
7 \\
7\end{array}$ & $\begin{array}{r}662758 \\
3701 \\
4642 \\
5581 \\
6518 \\
7453 \\
8386 \\
931 \%\end{array}$ & $\begin{array}{l}2852 \\
3795 \\
4736 \\
5675 \\
6612 \\
7546 \\
8479 \\
9410\end{array}$ & $\begin{array}{l}2947 \\
3889 \\
4830 \\
5769 \\
6705 \\
7640 \\
8572 \\
9503\end{array}$ & $\begin{array}{l}3041 \\
3983 \\
4924 \\
5862 \\
6799 \\
7733 \\
8665 \\
9596\end{array}$ & $\begin{array}{l}3135 \\
4078 \\
5018 \\
5956 \\
6892 \\
7826 \\
8759 \\
9689\end{array}$ & $\begin{array}{l}3230 \\
4172 \\
5112 \\
6050 \\
6986 \\
7920 \\
8852 \\
9782\end{array}$ & $\begin{array}{l}3324 \\
4266 \\
5206 \\
6143 \\
7079 \\
8013 \\
8945 \\
9875\end{array}$ & $\begin{array}{l}3418 \\
4360 \\
5299 \\
6237 \\
7173 \\
8106 \\
9038 \\
9967\end{array}$ & $\begin{array}{l}3512 \\
4454 \\
5393 \\
6331 \\
7266 \\
8199 \\
9131\end{array}$ & $\begin{array}{l}3607 \\
4548 \\
5487 \\
6424 \\
7360 \\
8293 \\
9224\end{array}$ & 94 \\
\hline $\begin{array}{l}8 \\
9\end{array}$ & $\begin{array}{r}670246 \\
-1173\end{array}$ & $\begin{array}{l}0339 \\
1265\end{array}$ & $\begin{array}{l}0431 \\
1358\end{array}$ & $\begin{array}{l}0524 \\
1451\end{array}$ & $\begin{array}{l}0617 \\
1543\end{array}$ & $\begin{array}{l}0710 \\
1636\end{array}$ & $\begin{array}{l}0802 \\
1728\end{array}$ & $\begin{array}{l}0895 \\
1821\end{array}$ & $\begin{array}{l}0060 \\
0988 \\
1913\end{array}$ & $\begin{array}{l}0153 \\
1080 \\
2005\end{array}$ & 93 \\
\hline $\begin{array}{r}470 \\
1 \\
2 \\
3 \\
4 \\
5 \\
6 \\
7 \\
8\end{array}$ & $\begin{array}{l}2098 \\
3021 \\
3942 \\
4861 \\
5778 \\
6694 \\
7607 \\
8518 \\
9428\end{array}$ & $\begin{array}{l}2190 \\
3113 \\
4034 \\
4953 \\
5870 \\
6785 \\
7698 \\
8609 \\
9519\end{array}$ & $\begin{array}{l}2283 \\
3205 \\
4126 \\
5045 \\
5962 \\
6876 \\
7789 \\
8700 \\
9610\end{array}$ & $\begin{array}{l}2375 \\
3297 \\
4218 \\
5137 \\
6053 \\
6968 \\
7881 \\
8791 \\
9700\end{array}$ & $\begin{array}{l}2167 \\
3390 \\
4310 \\
5228 \\
6145 \\
7059 \\
7972 \\
8882 \\
9791\end{array}$ & $\begin{array}{l}2560 \\
3482 \\
4402 \\
5320 \\
6236 \\
7151 \\
8063 \\
8973 \\
9882\end{array}$ & $\begin{array}{l}2652 \\
3574 \\
4494 \\
5412 \\
6328 \\
7242 \\
8154 \\
9064 \\
9973\end{array}$ & $\begin{array}{l}2744 \\
3666 \\
4586 \\
5503 \\
6419 \\
7333 \\
8215 \\
9155\end{array}$ & $\begin{array}{l}2836 \\
3758 \\
4677 \\
5595 \\
6511 \\
7424 \\
8336 \\
9246\end{array}$ & $\begin{array}{l}2929 \\
3850 \\
4769 \\
5687 \\
6602 \\
7516 \\
8427 \\
9337\end{array}$ & 92 \\
\hline 9 & 680336 & 0426 & 0517 & 0607 & 0698 & 0789 & 0879 & $\begin{array}{l}0063^{\circ} \\
0970\end{array}$ & $\begin{array}{l}0154 \\
1060\end{array}$ & $\begin{array}{l}0245 \\
1151\end{array}$ & \\
\hline $\begin{array}{r}480 \\
1 \\
2 \\
3 \\
4 \\
5 \\
6 \\
7 \\
8 \\
9\end{array}$ & $\begin{array}{l}1241 \\
2145 \\
3047 \\
3947 \\
4845 \\
5742 \\
6636 \\
7529 \\
8420 \\
9309\end{array}$ & $\begin{array}{l}1332 \\
2235 \\
3137 \\
4037 \\
4935 \\
5831 \\
6726 \\
7618 \\
8509 \\
9398\end{array}$ & $\begin{array}{l}1422 \\
2326 \\
3227 \\
4127 \\
5025 \\
5921 \\
6815 \\
7707 \\
8598 \\
9486\end{array}$ & $\begin{array}{l}1513 \\
2416 \\
3317 \\
4217 \\
5114 \\
6010 \\
6904 \\
7796 \\
8687 \\
9575\end{array}$ & $\begin{array}{l}1603 \\
2506 \\
3407 \\
4307 \\
5204 \\
6100 \\
6994 \\
7886 \\
8776 \\
9664\end{array}$ & $\begin{array}{l}1693 \\
2596 \\
3497 \\
4396 \\
5294 \\
6189 \\
7083 \\
7975 \\
8865 \\
9753\end{array}$ & $\begin{array}{l}1784 \\
2686 \\
3587 \\
4486 \\
5383 \\
6279 \\
7172 \\
8064 \\
8953 \\
9841\end{array}$ & $\begin{array}{l}1874 \\
2777 \\
3677 \\
4576 \\
5473 \\
6368 \\
7261 \\
8153 \\
9042 \\
9930\end{array}$ & $\begin{array}{l}1964 \\
2867 \\
3767 \\
4666 \\
5563 \\
6458 \\
7351 \\
8242 \\
9131\end{array}$ & $\begin{array}{l}2055 \\
2957 \\
3857 \\
4756 \\
5652 \\
6547 \\
7440 \\
8331 \\
9220 \\
\end{array}$ & 89 \\
\hline & & & & & & & & & 0019 & 0107 & \\
\hline 1 & 1081 & 1170 & 1258 & 18 & 1 & 46 & $\begin{array}{l}0728 \\
1612 \\
2491\end{array}$ & $\begin{array}{l}0816 \\
1700 \\
2583\end{array}$ & $\begin{array}{l}0905 \\
1789 \\
2671\end{array}$ & $\begin{array}{l}18 \pi 7 \\
2759\end{array}$ & \\
\hline 3 & 2847 & 2935 & $\begin{array}{l}2142 \\
3023\end{array}$ & 3111 & 31 & & 3375 & & 3551 & 3639 & 88 \\
\hline 4 & 3727 & 3815 & 3903 & 3991 & 40 & 4166 & 4254 & 4342 & 4430 & 4517 & \\
\hline 5 & 460 & 46 & 4731 & 486 & 49 & 5044 & 5131 & 5219 & 5307 & 5394 & \\
\hline $\begin{array}{l}6 \\
7\end{array}$ & $\begin{array}{l}5482 \\
6356\end{array}$ & $\begin{array}{l}5569 \\
6444\end{array}$ & $\begin{array}{l}5657 \\
6531\end{array}$ & $\begin{array}{l}5744 \\
6618\end{array}$ & $\begin{array}{l}5832 \\
6706\end{array}$ & $\begin{array}{l}5919 \\
6793\end{array}$ & $\begin{array}{l}6007 \\
6880\end{array}$ & $\begin{array}{l}6094 \\
6968\end{array}$ & $\begin{array}{l}6182 \\
7055\end{array}$ & $\begin{array}{l}6269 \\
7142\end{array}$ & \\
\hline 8 & 7229 & 731 & 7404 & 7491 & 7578 & 7665 & 7752 & 7839 & 7926 & 8014 & 87 \\
\hline 9 & 8100 & 8188 & 8275 & 8362 & 8449 & 8535 & 8622 & 8709 & & & \\
\hline
\end{tabular}

Proportional Parts.

\begin{tabular}{|c|c|c|c|c|c|c|c|c|c|}
\hline Diff. & 1 & 2 & 3 & 4 & 5 & 6 & 7 & 8 & 9 \\
\hline 98 & 9.8 & 19.6 & 29.4 & 39.2 & 49.0 & 58.8 & 68.6 & 78.4 & 88.2 \\
\hline 97 & 9.7 & 19.4 & 29.1 & 38.8 & 48.5 & 58.2 & 67.9 & 77.6 & 87.3 \\
\hline 96. & 9.6 & 19.2 & 28.8 & 38.4 & 48.0 & 57.6 & 67.2 & 76.8 & 86.4 \\
\hline 95 & 9.5 & 19.0 & 28.5 & 38.0 & 47.5 & 57.0 & 66.5 & 76.0 & 85.5 \\
\hline 04 & 9.4 & 18.8 & 28.2 & 37.6 & 47.0 & 56.4 & 65.8 & 75.2 & 84.6 \\
\hline 93 & 9.3 & 18.6 & 27.9 & 37.2 & 46.5 & 55.8 & 65.1 & 74.4 & 83.7 \\
\hline 92 & 9.2 & 18. & 27.6 & 36.8 & 46.0 & 55.2 & 64.4 & 73.6 & 82.8 \\
\hline 91 & 9.1 & 18.2 & 27.3 & 36.4 & 45.5 & 54.6 & 63.7 & 72.8 & 81.9 \\
\hline 90 & 9.0 & 18.0 & 27.0 & 36.0 & 45.0 & 54. & 63.0 & 72.0 & 81.0 \\
\hline 89 & 8.9 & 17.8 & 26.7 & 35.6 & 44.5 & 53.4 & 62.3 & 71.2 & 80.1 \\
\hline 88 & 8.8 & 17.6 & 26.4 & 35.2 & 44.0 & 52.8 & 61.6 & 70.4 & 79.2 \\
\hline $\begin{array}{l}87 \\
86\end{array}$ & $\begin{array}{l}8.7 \\
8.6\end{array}$ & $\begin{array}{l}17.4 \\
17.2\end{array}$ & $\begin{array}{l}26.1 \\
25.8\end{array}$ & $\begin{array}{l}34.8 \\
34.4\end{array}$ & $\begin{array}{l}43.5 \\
43.0\end{array}$ & $\begin{array}{l}52.2 \\
51.6\end{array}$ & 60.2 & 68.8 & $\frac{10.0}{77.4}$ \\
\hline
\end{tabular}


TABLE XI.-LOGARITHMS OF NUMBERS.

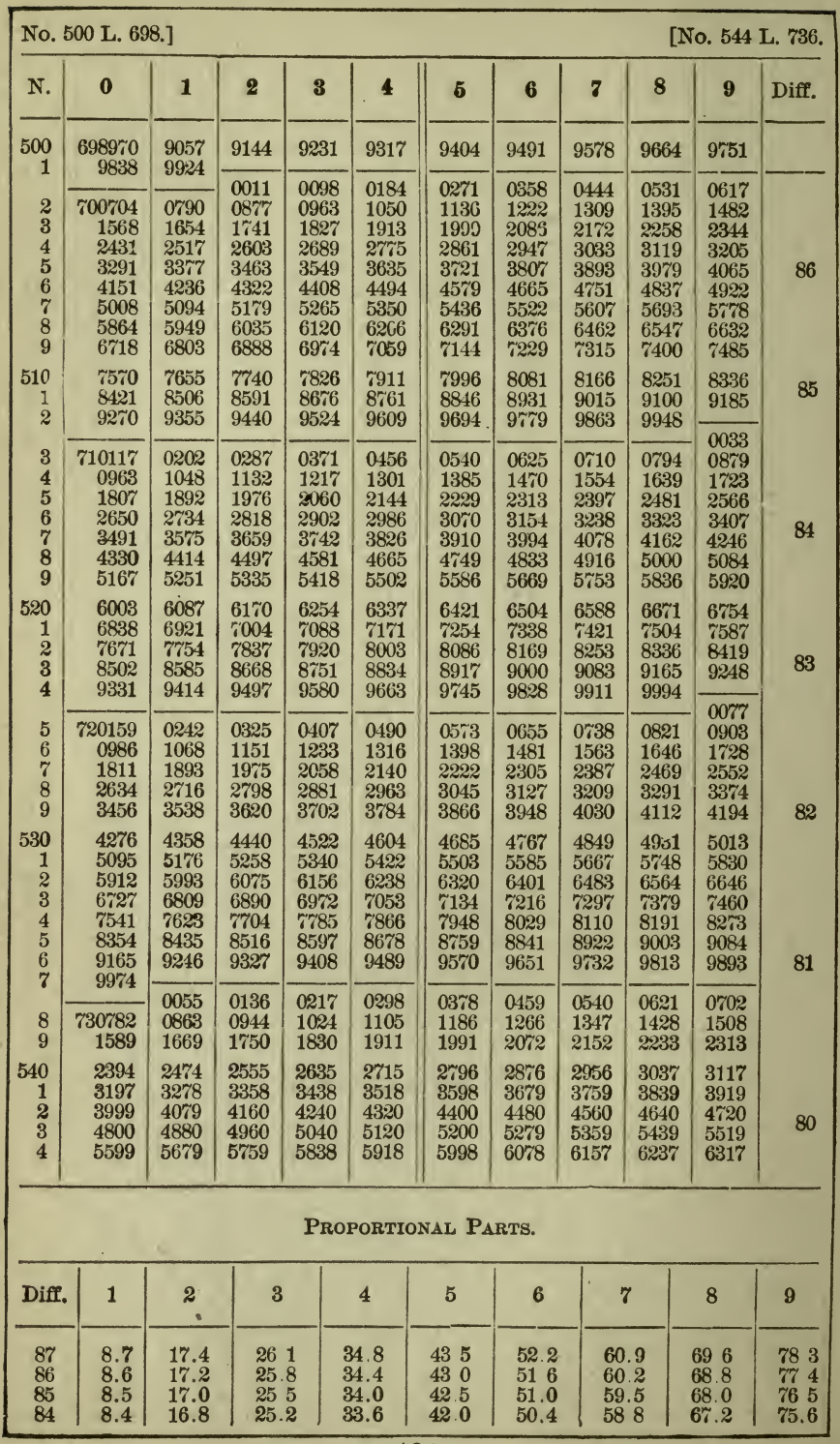


TABLE XI.-LOGARITHMS OF NUMBERS.

\begin{tabular}{|c|c|c|c|c|c|c|c|c|c|c|c|}
\hline \multicolumn{9}{|c|}{ No. 545 L. 736.] } & \multicolumn{3}{|c|}{ [No. 584 L. 767.} \\
\hline N. & 0 & 1 & 2 & 3 & 4 & 5 & c & 8 & 8 & 9 & Diff. \\
\hline $\begin{array}{r}545 \\
6 \\
7 \\
8 \\
9\end{array}$ & $\begin{array}{r}736397 \\
7193 \\
r 987 \\
8781 \\
9572\end{array}$ & $\begin{array}{l}64 \% 6 \\
72 \% 2 \\
8067 \\
8860 \\
9651\end{array}$ & $\begin{array}{l}6556 \\
7352 \\
8146 \\
8939 \\
9731\end{array}$ & $\begin{array}{l}6635 \\
7431 \\
8225 \\
9018 \\
9810\end{array}$ & $\begin{array}{l}6715 \\
7511 \\
8305 \\
9097 \\
9889\end{array}$ & $\begin{array}{l}6795 \\
7590 \\
8384 \\
9177 \\
9968\end{array}$ & $\begin{array}{l}6874 \\
7670 \\
8463 \\
9256\end{array}$ & $\begin{array}{l}6954 \\
7449 \\
8543 \\
9335\end{array}$ & $\begin{array}{l}7034 \\
7829 \\
8622 \\
9414 \\
\end{array}$ & $\begin{array}{l}7113 \\
7908 \\
8701 \\
9493\end{array}$ & \\
\hline $\begin{array}{r}550 \\
1 \\
2 \\
3 \\
4 \\
5 \\
6 \\
7 \\
8 \\
9\end{array}$ & $\begin{array}{r}740363 \\
1152 \\
1939 \\
2725 \\
3510 \\
4293 \\
5075 \\
5855 \\
6634 \\
7412\end{array}$ & $\begin{array}{l}0442 \\
1230 \\
2018 \\
2804 \\
3588 \\
4371 \\
5153 \\
5933 \\
6712 \\
r 489\end{array}$ & $\begin{array}{l}0521 \\
1309 \\
2096 \\
2882 \\
3667 \\
4449 \\
5231 \\
6011 \\
6790 \\
7567\end{array}$ & $\begin{array}{l}0600 \\
1388 \\
2175 \\
2961 \\
3745 \\
4528 \\
5309 \\
6089 \\
6868 \\
7645\end{array}$ & $\begin{array}{l}0678 \\
1467 \\
2254 \\
3039 \\
3823 \\
4606 \\
5387 \\
6167 \\
6945 \\
7722\end{array}$ & $\begin{array}{l}0757 \\
1546 \\
2332 \\
3118 \\
3902 \\
4684 \\
5465 \\
6245 \\
7023 \\
7800\end{array}$ & $\begin{array}{l}0047 \\
0836 \\
1624 \\
2411 \\
3196 \\
3980 \\
4762 \\
5543 \\
6323 \\
7101 \\
7878\end{array}$ & $\begin{array}{l}0126 \\
0915 \\
1703 \\
2489 \\
3275 \\
4058 \\
4840 \\
5621 \\
6401 \\
7179 \\
7955\end{array}$ & $\begin{array}{l}0205 \\
0934 \\
1782 \\
2568 \\
3353 \\
4136 \\
4919 \\
5699 \\
6479 \\
7256 \\
8033\end{array}$ & $\begin{array}{l}0284 \\
1073 \\
1860 \\
2647 \\
3431 \\
4215 \\
4997 \\
5777 \\
6556 \\
7334 \\
8110\end{array}$ & 78 \\
\hline $\begin{array}{r}560 \\
1 \\
2\end{array}$ & $\begin{array}{l}8188 \\
8963 \\
9736\end{array}$ & $\begin{array}{l}8266 \\
9040 \\
9814\end{array}$ & $\begin{array}{l}8343 \\
9118 \\
9891\end{array}$ & $\begin{array}{l}8421 \\
9195 \\
9968\end{array}$ & $\begin{array}{l}8498 \\
9272\end{array}$ & $\begin{array}{l}85 \% 6 \\
9350\end{array}$ & $\begin{array}{l}8653 \\
9427\end{array}$ & $\begin{array}{l}8 \% 31 \\
9504\end{array}$ & $\begin{array}{l}8808 \\
9582\end{array}$ & $\begin{array}{l}8885 \\
9659\end{array}$ & \\
\hline $\begin{array}{l}3 \\
4 \\
5 \\
6 \\
7 \\
8 \\
9\end{array}$ & $\begin{array}{r}750508 \\
1279 \\
2048 \\
2816 \\
3583 \\
4348 \\
5112\end{array}$ & $\begin{array}{l}0586 \\
1356 \\
2125 \\
2893 \\
3660 \\
4425 \\
5189\end{array}$ & $\begin{array}{l}0663 \\
1433 \\
2202 \\
2970 \\
3736 \\
4501 \\
5265\end{array}$ & $\begin{array}{l}0740 \\
1510 \\
22 \% 9 \\
3047 \\
3813 \\
45 \% 8 \\
5341\end{array}$ & $\begin{array}{l}0045 \\
0817 \\
1587 \\
2356 \\
3123 \\
3889 \\
4654 \\
\mathbf{5 4 1 7}\end{array}$ & $\begin{array}{l}0123 \\
0894 \\
1664 \\
2433 \\
3200 \\
3966 \\
4730 \\
5494\end{array}$ & $\begin{array}{l}0200 \\
0971 \\
1741 \\
2509 \\
3277 \\
4042 \\
4807 \\
5570\end{array}$ & $\begin{array}{l}02 \% 1 \\
1048 \\
1818 \\
2586 \\
3353 \\
\mathbf{4 1 1 9} \\
4883 \\
5646\end{array}$ & $\begin{array}{l}0354 \\
1125 \\
1895 \\
2663 \\
3430 \\
4195 \\
4960 \\
5722\end{array}$ & $\begin{array}{l}0431 \\
1202 \\
1972 \\
2140 \\
3506 \\
4272 \\
50 \% 6 \\
5799\end{array}$ & 77 \\
\hline $\begin{array}{r}570 \\
1 \\
2 \\
3 \\
4 \\
5\end{array}$ & $\begin{array}{l}5875 \\
6636 \\
7396 \\
8155 \\
8912 \\
9668\end{array}$ & $\begin{array}{l}5951 \\
6712 \\
7472 \\
8230 \\
8988 \\
9743\end{array}$ & $\begin{array}{l}6027 \\
6788 \\
7548 \\
8306 \\
9063 \\
9819\end{array}$ & $\begin{array}{l}6103 \\
6864 \\
7624 \\
8382 \\
9139 \\
9894\end{array}$ & $\begin{array}{l}6180 \\
6940 \\
r 700 \\
8458 \\
9214 \\
9970\end{array}$ & $\begin{array}{l}6256 \\
7016 \\
7075 \\
8533 \\
9290 \\
\end{array}$ & $\begin{array}{l}6332 \\
7092 \\
7851 \\
8609 \\
9366 \\
\end{array}$ & $\begin{array}{l}6408 \\
7168 \\
7927 \\
8685 \\
9441 \\
\end{array}$ & $\begin{array}{l}6484 \\
7244 \\
8003 \\
8 \% 61 \\
9517\end{array}$ & $\begin{array}{l}6560 \\
7320 \\
80 \pi 9 \\
8836 \\
9592 \\
\end{array}$ & 76 \\
\hline $\begin{array}{l}6 \\
7 \\
8 \\
9\end{array}$ & $\begin{array}{r}760422 \\
1176 \\
1928 \\
2679\end{array}$ & $\begin{array}{l}0498 \\
1251 \\
2003 \\
2754\end{array}$ & $\begin{array}{l}0573 \\
1326 \\
2078 \\
2829\end{array}$ & $\begin{array}{l}0649 \\
1402 \\
2153 \\
2904\end{array}$ & $\begin{array}{l}0724 \\
1477 \\
2228 \\
2978\end{array}$ & $\begin{array}{l}0045 \\
0799 \\
1552 \\
2303 \\
3053\end{array}$ & $\begin{array}{l}0121 \\
08 \% 5 \\
1627 \\
23 \% 8 \\
3128\end{array}$ & $\begin{array}{l}0196 \\
0950 \\
1702 \\
2453 \\
3203\end{array}$ & $\begin{array}{l}0272 \\
1025 \\
1778 \\
2529 \\
3278\end{array}$ & $\begin{array}{l}0347 \\
1101 \\
1853 \\
2604 \\
3353\end{array}$ & ז \\
\hline $\begin{array}{r}580 \\
1 \\
2 \\
3 \\
4\end{array}$ & $\begin{array}{l}3428 \\
4176 \\
4923 \\
5669 \\
6413\end{array}$ & $\begin{array}{l}3503 \\
4251 \\
4998 \\
5743 \\
6487\end{array}$ & $\begin{array}{l}3578 \\
4326 \\
5072 \\
5818 \\
6562\end{array}$ & $\begin{array}{l}3653 \\
4400 \\
5147 \\
5892 \\
6636\end{array}$ & $\begin{array}{l}3727 \\
4475 \\
5221 \\
5966 \\
6710\end{array}$ & $\begin{array}{l}3802 \\
4550 \\
5296 \\
6041 \\
6785\end{array}$ & $\begin{array}{l}3877 \\
4624 \\
53 \% 0 \\
6115 \\
6859\end{array}$ & $\begin{array}{l}3952 \\
4699 \\
5445 \\
6190 \\
6933\end{array}$ & $\begin{array}{l}4027 \\
4774 \\
5520 \\
6264 \\
7007\end{array}$ & $\begin{array}{l}4101 \\
4848 \\
5594 \\
6338 \\
7082\end{array}$ & \\
\hline
\end{tabular}

Proportional Parts.

\begin{tabular}{|c|c|c|c|c|c|c|c|c|c|}
\hline Diff. & 1 & 2 & 3 & 4 & 5 & 6 & 7 & 8 & 9 \\
\hline 83 & 8.3 & 16.6 & 24.9 & 33.2 & 41.5 & 49.8 & 58.1 & 66.4 & 74.7 \\
\hline 82 & 8. & 16. & 24. & 32.8 & 41.0 & 49.2 & 57.4 & 65 & 73.8 \\
\hline 81 & 8.1 & 16.2 & 24.3 & 32.4 & 40.5 & 48.6 & 56.7 & 64.8 & 72.9 \\
\hline 80 & 8.0 & 16.0 & 24.0 & 32.0 & 40.0 & 48.0 & 56.0 & 64.0 & 72.0 \\
\hline 79 & 7.9 & 15.8 & 23.7 & 31.6 & 39.5 & 47.4 & 55.3 & 63.2 & $\pi 1.1$ \\
\hline 78 & 7.8 & 15.6 & 23.4 & 31.2 & 39.0 & 46.8 & 54.6 & 62.4 & 70.2 \\
\hline$\pi$ & $7 . \%$ & 15.4 & 23.1 & 30.8 & 38.5 & 46.2 & 53.9 & 61.6 & 69.3 \\
\hline$\pi 6$ & $\tau 6$ & 15.2 & 22.8 & 30.4 & 38.0 & 45.6 & 53.2 & 60.8 & 68.4 \\
\hline 75 & 7.5 & 15.0 & 22.5 & 30.0 & 37.5 & 45.0 & 52.5 & 60.0 & 67.5 \\
\hline 74 & $\therefore$ & 14.8 & 22.2 & 29.6 & 37.0 & 44.4 & 51.8 & 59.2 & 68.6 \\
\hline
\end{tabular}


TABLE XI.-LOGARITHMS OF NUMBERS.

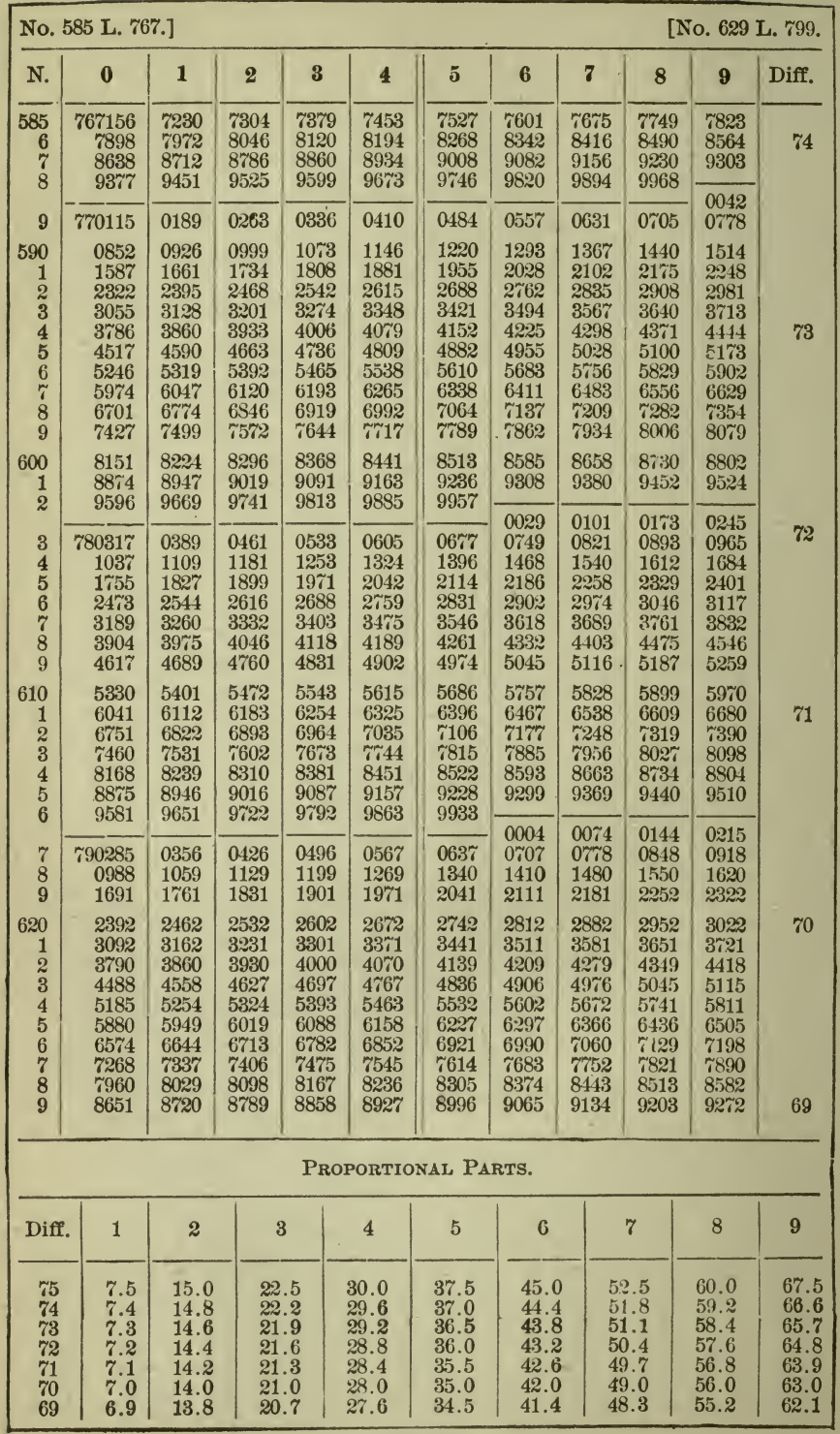


TABLE XI.-LOGARITHMS OF NUMBERS.

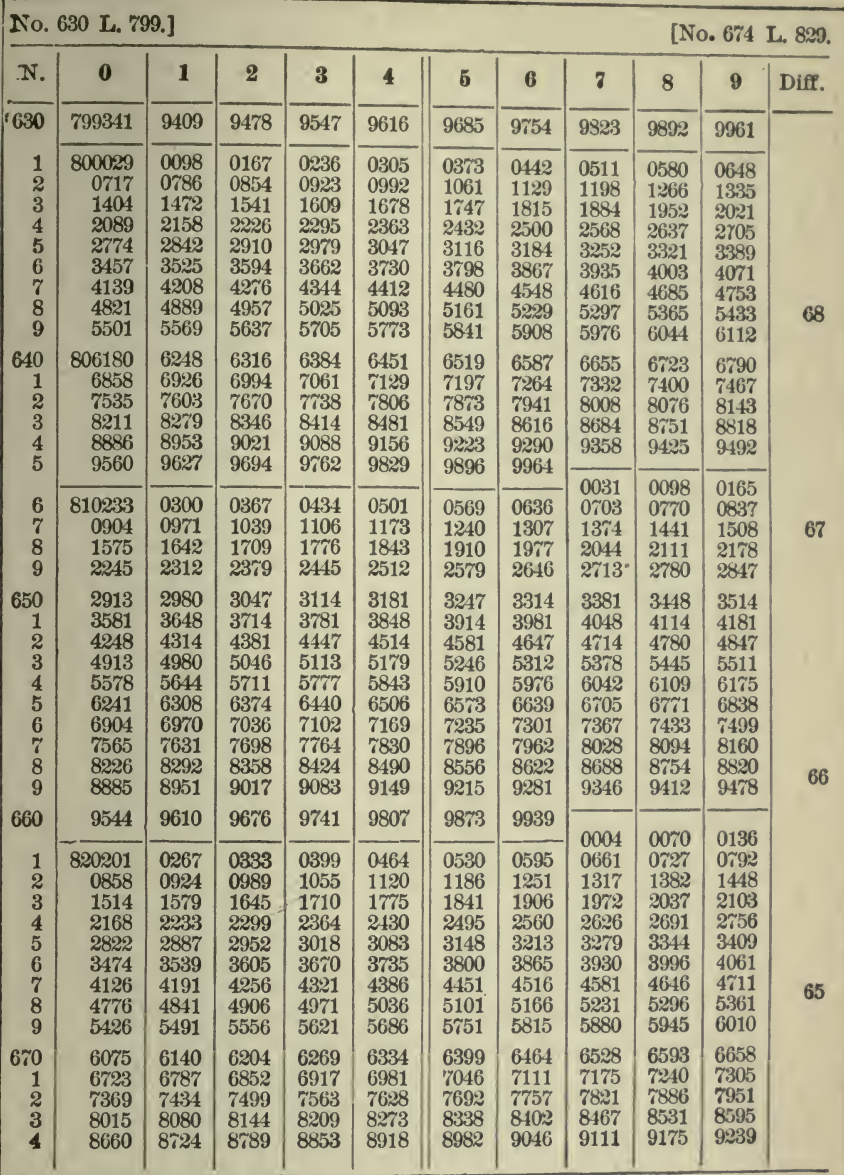

Proportional Partg.

\begin{tabular}{|c|c|c|c|c|c|c|c|c|c|}
\hline Diff & 1 & 2 & 3 & 4 & 5 & 6 & 7 & 8 & 9 \\
\hline $\begin{array}{l}68 \\
67 \\
66 \\
65 \\
64\end{array}$ & $\begin{array}{ll}6 & 8 \\
6 & 7 \\
6 & 6 \\
6 & 5 \\
6.4\end{array}$ & $\begin{array}{ll}13 & 6 \\
13 & 4 \\
13.2 \\
13 & 0 \\
15.8\end{array}$ & $\begin{array}{l}204 \\
20.1 \\
198 \\
19.5 \\
19.2\end{array}$ & $\begin{array}{ll}27 & 2 \\
26 & 8 \\
26 & 4 \\
26 & 0 \\
25 & 6\end{array}$ & $\begin{array}{ll}34 & 0 \\
33 & 5 \\
33 & 0 \\
32.5 \\
32.0\end{array}$ & $\begin{array}{ll}40 & 8 \\
40 & 2 \\
39 & 6 \\
39 & 0 \\
38.4\end{array}$ & $\begin{array}{l}476 \\
469 \\
462 \\
455 \\
448\end{array}$ & $\begin{array}{ll}54 & 4 \\
53 & 6 \\
52 & 8 \\
52 & 0 \\
51 & 2\end{array}$ & $\begin{array}{ll}61 & 2 \\
60 & 3 \\
59 & 4 \\
58 & 5 \\
57 & 6\end{array}$ \\
\hline
\end{tabular}


TABLE XI. - LOGARITHMS OF NUMBERS.

\begin{tabular}{|c|c|c|c|c|c|c|c|c|c|c|c|}
\hline \multicolumn{9}{|c|}{ No. 675 L. 829.] } & \multicolumn{3}{|c|}{ [No. 719 L. 857.} \\
\hline N. & $\mathbf{0}$ & 1 & 2 & 3 & 4 & 5 & 6 & 7 & 8 & 9 & Diff. \\
\hline $\begin{array}{r}675 \\
6\end{array}$ & \multirow{2}{*}{$\begin{array}{r}829304 \\
9947\end{array}$} & 9368 & 9432 & $949 \pi$ & 9561 & 9625 & 9690 & 9754 & 9818 & 9882 & \multirow{15}{*}{64} \\
\hline & & \multirow{4}{*}{$\begin{array}{l}0011 \\
0653 \\
1294 \\
1934\end{array}$} & \multirow{4}{*}{$\begin{array}{l}00 \pi 5 \\
0 \pi 17 \\
1358 \\
1998\end{array}$} & 0139 & 0204 & 0268 & 0332 & \multirow{2}{*}{$\begin{array}{l}0396 \\
1037\end{array}$} & 0460 & 0525 & \\
\hline 7 & 830589 & & & 0781 & 0845 & 0909 & 0973 & & 1102 & 1166 & \\
\hline 8 & 1230 & & & 1422 & 1486 & 1550 & 1614 & \multirow{2}{*}{$\begin{array}{l}1678 \\
2317\end{array}$} & 1742 & \multirow{2}{*}{$\begin{array}{l}1806 \\
2445\end{array}$} & \\
\hline 9 & 1870 & & & 2062 & 2126 & 2189 & 2253 & & 2381 & & \\
\hline 580 & 2509 & 2573 & 2637 & 2700 & 2764 & 2828 & 2892 & \multirow{2}{*}{2956} & 3020 & 3083 & \\
\hline 1 & 3147 & 3211 & 3275 & 3338 & 3402 & 3466 & 3530 & & 3657 & \multirow{2}{*}{$\begin{array}{l}3721 \\
4357\end{array}$} & \\
\hline$\overline{2}$ & 3784 & 3848 & 3912 & 3975 & 4039 & 4103 & 4166 & 4230 & 4294 & & \\
\hline 3. & 4421 & 4484 & 4548 & 4611 & 4675 & 4739 & 4802 & 4866 & 4929 & 4993 & \\
\hline 4 & 5056 & 5120 & 5183 & 5247 & 5310 & $53 \% 3$ & 5437 & 5500 & 5564 & 5627 & \\
\hline 5 & 5691 & 5754 & 5817 & 5881 & 5944 & 6007 & $60 r 1$ & 6134 & 6197 & 6261 & \\
\hline 6 & 6324 & 6387 & 6451 & 6514 & 6577 & 6641 & 6704 & $6 \pi 67$ & 6830 & 6894 & \\
\hline 7 & 6957 & 7020 & 7083 & 7146 & 7210 & 7273 & ร336 & 7399 & 7462 & 7525 & \\
\hline 8 & 7588 & 7652 & 7715 & 7778 & 7841 & 7904 & 7967 & 8030 & 8093 & 8156 & \\
\hline 9 & 8219 & 8282 & 8345 & 8408 & 8471 & 8534 & 8597 & 8660 & 8723 & 8786 & \\
\hline 690 & 8849 & 8912 & 8975 & 9038 & 9101 & 9164 & 9227 & 9289 & 9352 & 9415 & \\
\hline 1 & 9478 & 1 & 504 & 9667 & 9 & 2 & 9805 & 9918 & 1 & 0043 & \\
\hline 2 & 840106 & 0169 & 0232 & 0294 & 0357 & 0420 & 0482 & 0545 & 0608 & 0671 & \\
\hline 3 & 0733 & 0796 & 0859 & 0921 & 0984 & 1046 & 1109 & $11 \% 2$ & 1234 & 1297 & \\
\hline 4 & 1359 & 1422 & 1485 & 1547 & 1610 & $16 \% 2$ & 1735 & 1797 & 1860 & 1922 & \\
\hline 5 & 1985 & 2047 & 2110 & $21 \% 2$ & 2235 & 2297 & 2360 & 2422 & 2484 & 2547 & \\
\hline 6 & 2609 & 2672 & 2734 & 2796 & 2859 & 2921 & 2983 & 3046 & 3108 & 3170 & \\
\hline 7 & 3233 & 3295 & 3357 & 3420 & 3482 & 3544 & 3606 & 3669 & 3731 & 3793 & \\
\hline 8 & 3855 & 3918 & 3980 & 4042 & 4104 & 4166 & 4229 & 4291 & 4353 & 4415 & \\
\hline 9 & 4477 & 4539 & 4601 & 4664 & 4726 & 4788 & 4850 & 4912 & $49 \pi 4$ & 5036 & \\
\hline 700 & 5098 & 5160 & 5222 & 5284 & 5346 & 5408 & $54 \% 0$ & 5532 & 5594 & 5656 & 62 \\
\hline 1 & 5718 & 5780 & 5842 & 5904 & 5966 & 6028 & 6099 & 6151 & 6213 & 6275 & \\
\hline 2 & 6337 & 6399 & 6461 & 6523 & 6585 & 6646 & $6 \% 08$ & $6 \% 70$ & 6832 & 6894 & \\
\hline 3 & 6955 & 7017 & 7079 & 7141 & 7202 & 7264 & 7326 & 7388 & 7449 & 7511 & \\
\hline 4 & 7573 & 7634 & $\tau 696$ & 7758 & $\tau 819$ & 7881 & ๆ943 & 8004 & 8066 & 8128 & \\
\hline 5 & 8189 & 8251 & 8312 & 8374 & 8435 & 8497 & 8559 & 8620 & 8682 & 8743 & \\
\hline 6 & 8805 & 8866 & 8928 & 8989 & 9051 & 9112 & 9174 & 9235 & 9297 & 9358 & \\
\hline 7 & 9419 & 9481 & 9542 & 9604 & 9665 & 9726 & 9788 & 9849 & 9911 & 9972 & \\
\hline 8 & 850033 & 0095 & 0156 & 0217 & $02 \% 9$ & 0340 & 0401 & 0462 & 0524 & 0585 & \\
\hline 9 & 0846 & 0707 & 0769 & 0830 & 0891 & 0952 & 1014 & 1075 & 1136 & 1197 & \\
\hline 710 & 1258 & 1320 & 1381 & 1442 & 1503 & 1564 & 1625 & 1686 & 1747 & 1809 & \\
\hline 1 & 1870 & 1931 & 1992 & 2053 & 2114 & $21 \% 5$ & 2236 & 2297 & 2358 & 2419 & \\
\hline 2 & 2480 & 2541 & 2602 & 2663 & $2 \gamma 24$ & 2785 & 2846 & 2907 & 2968 & $30: 29$ & 61 \\
\hline $\mathbf{3}$ & 3090 & 3150 & 3211 & 3272 & 3333 & 3394 & 3455 & 3516 & 3577 & 3637 & \\
\hline 4 & 3698 & 3759 & 3820 & 3881 & 3941 & 4002 & 4063 & 4124 & 4185 & 4245 & \\
\hline 5 & 4306 & 4367 & 4428 & 4488 & 4549 & 4610 & $46 \% 0$ & 4731 & 4792 & 4852 & \\
\hline 6 & 4913 & 4974 & 5034 & 5095 & 5156 & 5216 & 5277 & 5337 & 5398 & 5459 & \\
\hline 7 & 5519 & 5580 & 5640 & 5701 & 5761 & 5822 & 5882 & 5943 & 6003 & 6064 & \\
\hline 8 & 6124 & 6185 & 6245 & 6306 & 6366 & 6427 & 6487 & 6548 & 6608 & 6668 & \\
\hline 9 & 6729 & 6789 & 6850 & 6910 & 6970 & 7031 & 7091 & 7152 & 7212 & 7272 & \\
\hline & & & & & & 2 & & & & & \\
\hline Diff. & 1 & 2 & & 3 & 4 & 5 & 6 & & 7 & 8 & 9 \\
\hline 65 & 6.5 & 13. & & & 26.0 & 32 & 39 & & 5 & 52.0 & 58.5 \\
\hline 64 & 6 & 12.8 & & & & 32 & & & & 51. & 57 \\
\hline 63 & 6.3 & 12.6 & & & 25.2 & 31 . & & & 4 & 50.4 & 56. \\
\hline 62 & 6.2 & 12 & & & 24.8 & 31. & & & & 49.6 & 55.8 \\
\hline 61 & 6.1 & 12. & & & 24.4 & 30 & 36 & & 2 & 48.8 & 54.9 \\
\hline 60 & 6.0 & 12.0 & & & 24.0 & 30.0 & 36 & & & 48.0 & 54.0 \\
\hline
\end{tabular}


TABLE XI.-LOGARITHMS OF NUMBERS.

\begin{tabular}{|c|c|c|c|c|c|c|c|c|c|c|c|}
\hline \multicolumn{9}{|c|}{ No. 720 L. 857.$]$} & \multicolumn{3}{|c|}{ [No. 764 L. 883.} \\
\hline N. & 0 & 1 & 2 & 8 & 4 & 5 & $\epsilon$ & 7 & 8 & 9 & Diff. \\
\hline $\begin{array}{r}720 \\
1 \\
2 \\
3 \\
4\end{array}$ & $\begin{array}{r}857332 \\
7935 \\
8537 \\
9138 \\
9739\end{array}$ & $\begin{array}{l}7393 \\
7995 \\
8597 \\
9198 \\
9799\end{array}$ & $\begin{array}{l}7453 \\
8056 \\
8657 \\
9258 \\
9859\end{array}$ & $\begin{array}{l}7513 \\
8116 \\
8718 \\
9318 \\
9918\end{array}$ & $\begin{array}{l}7574 \\
8176 \\
8778 \\
9379 \\
9978\end{array}$ & $\begin{array}{l}7634 \\
82336 \\
8838 \\
9439\end{array}$ & $\begin{array}{l}7694 \\
8297 \\
8898 \\
9499\end{array}$ & $\begin{array}{l}7755 \\
8357 \\
8958 \\
9559\end{array}$ & $\begin{array}{l}7815 \\
8117 \\
9018 \\
9619\end{array}$ & $\begin{array}{l}7875 \\
8477 \\
9078 \\
9679\end{array}$ & 60 \\
\hline $\begin{array}{l}5 \\
6 \\
7 \\
8 \\
9\end{array}$ & $\begin{array}{r}860338 \\
0937 \\
1534 \\
2131 \\
2728\end{array}$ & $\begin{array}{l}0398 \\
0996 \\
1594 \\
2191 \\
2787\end{array}$ & $\begin{array}{l}0458 \\
1056 \\
1654 \\
2251 \\
2847\end{array}$ & $\begin{array}{l}0518 \\
1116 \\
1 \hat{1} 14 \\
2310 \\
2906\end{array}$ & $\begin{array}{l}0578 \\
1176 \\
1773 \\
2370 \\
2966\end{array}$ & $\begin{array}{l}0038 \\
0637 \\
1236 \\
1833 \\
2430 \\
3025\end{array}$ & $\begin{array}{l}0098 \\
0697 \\
1295 \\
1893 \\
2439 \\
3085\end{array}$ & $\begin{array}{l}0158 \\
0757 \\
1355 \\
1952 \\
2549 \\
3114\end{array}$ & $\begin{array}{l}0218 \\
0817 \\
1415 \\
2012 \\
2608 \\
3204\end{array}$ & $\begin{array}{l}0278 \\
0877 \\
1475 \\
2072 \\
2668 \\
3263\end{array}$ & \\
\hline $\begin{array}{r}730 \\
1 \\
2 \\
3 \\
4 \\
5 \\
6 \\
7 \\
8 \\
9\end{array}$ & $\begin{array}{l}3323 \\
3917 \\
4511 \\
5104 \\
5696 \\
6287 \\
6878 \\
7467 \\
8056 \\
8644\end{array}$ & $\begin{array}{l}3382 \\
3977 \\
4570 \\
5163 \\
5755 \\
6346 \\
6937 \\
7526 \\
8115 \\
8703\end{array}$ & $\begin{array}{l}3442 \\
4036 \\
4630 \\
5222 \\
5814 \\
6405 \\
6996 \\
7585 \\
8174 \\
8 \% 62\end{array}$ & $\begin{array}{l}3501 \\
4096 \\
4689 \\
5282 \\
5874 \\
6465 \\
7055 \\
7644 \\
8233 \\
8821\end{array}$ & $\begin{array}{l}3561 \\
4155 \\
4748 \\
5341 \\
5933 \\
6521 \\
7114 \\
7703 \\
8292 \\
8879\end{array}$ & $\begin{array}{l}3620 \\
4214 \\
4808 \\
5400 \\
5992 \\
6583 \\
7173 \\
7762 \\
8350 \\
8938\end{array}$ & $\begin{array}{l}3680 \\
4274 \\
4867 \\
5459 \\
6051 \\
6642 \\
7232 \\
7821 \\
8409 \\
8997\end{array}$ & $\begin{array}{l}3739 \\
4333 \\
4926 \\
5519 \\
6110 \\
6701 \\
7291 \\
7880 \\
8168 \\
9056\end{array}$ & $\begin{array}{l}3799 \\
4392 \\
4985 \\
5578 \\
6169 \\
6760 \\
7350 \\
7939 \\
8527 \\
9114\end{array}$ & $\begin{array}{l}3858 \\
4452 \\
5045 \\
5637 \\
6228 \\
6819 \\
7409 \\
7998 \\
8586 \\
91 ، 3\end{array}$ & 59 \\
\hline 740 & $\begin{array}{l}9232 \\
9818\end{array}$ & $\begin{array}{l}9290 \\
98 \approx 7\end{array}$ & $\begin{array}{l}9349 \\
9935\end{array}$ & 9408 & 9466 & 9525 & 9584 & 9642 & 9701 & $9 \pi 60$ & \\
\hline $\begin{array}{l}2 \\
3 \\
4 \\
5 \\
6 \\
7 \\
8 \\
9\end{array}$ & $\begin{array}{r}870401 \\
0989 \\
1573 \\
2156 \\
2739 \\
3321 \\
3902 \\
4482\end{array}$ & $\begin{array}{l}0462 \\
1047 \\
1631 \\
2215 \\
2797 \\
3: 379 \\
3960 \\
4540\end{array}$ & $\begin{array}{l}0521 \\
1106 \\
1690 \\
2273 \\
2855 \\
3437 \\
4018 \\
4598\end{array}$ & $\begin{array}{l}0579 \\
1164 \\
1748 \\
2331 \\
2913 \\
3495 \\
4076 \\
4656\end{array}$ & $\begin{array}{l}0053 \\
0638 \\
1223 \\
1806 \\
2389 \\
2972 \\
3553 \\
4134 \\
4714\end{array}$ & $\begin{array}{l}0111 \\
0696 \\
1281 \\
1865 \\
2448 \\
3030 \\
3611 \\
4192 \\
4 \% 2\end{array}$ & $\begin{array}{l}0170 \\
0755 \\
1339 \\
1923 \\
2506 \\
3088 \\
3669 \\
4250 \\
4830\end{array}$ & $\begin{array}{l}0228 \\
0813 \\
1398 \\
1981 \\
2564 \\
8146 \\
3727 \\
4308 \\
4888\end{array}$ & $\begin{array}{l}0287 \\
0872 \\
1456 \\
2040 \\
2622 \\
3204 \\
3785 \\
4366 \\
4945\end{array}$ & $\begin{array}{l}0345 \\
0930 \\
1515 \\
2008 \\
2681 \\
3262 \\
3844 \\
4424 \\
5003\end{array}$ & 58 \\
\hline $\begin{array}{r}750 \\
1 \\
2 \\
3 \\
4 \\
5 \\
6 \\
7 \\
8\end{array}$ & $\begin{array}{l}5061 \\
5640 \\
6218 \\
6795 \\
7371 \\
7947 \\
8522 \\
9096 \\
9669\end{array}$ & $\begin{array}{l}5119 \\
5698 \\
6276 \\
6853 \\
7429 \\
8004 \\
8579 \\
9153 \\
9726\end{array}$ & $\begin{array}{l}5177 \\
5756 \\
6333 \\
6910 \\
7487 \\
8062 \\
8637 \\
9211 \\
9784\end{array}$ & $\begin{array}{l}5235 \\
5813 \\
6391 \\
6968 \\
7544 \\
8119 \\
8694 \\
9268 \\
9841\end{array}$ & $\begin{array}{l}5293 \\
5871 \\
6449 \\
7026 \\
7602 \\
817 \% \\
8 \% 52 \\
9825 \\
9898\end{array}$ & $\begin{array}{l}5351 \\
5929 \\
6507 \\
7083 \\
7659 \\
8234 \\
8809 \\
9383 \\
9956\end{array}$ & $\begin{array}{l}\mathbf{5 4 0 9} \\
\mathbf{5 9 8 7} \\
6564 \\
7141 \\
7717 \\
8292 \\
8866 \\
9440 \\
\end{array}$ & $\begin{array}{l}\mathbf{5 4 6 6} \\
6045 \\
6622 \\
7199 \\
77 \% 4 \\
8349 \\
8924 \\
9497 \\
\end{array}$ & $\begin{array}{l}5524 \\
6102 \\
6680 \\
7256 \\
7832 \\
8407 \\
8981 \\
9555\end{array}$ & $\begin{array}{l}5582 \\
6160 \\
6737 \\
7314 \\
7889 \\
8464 \\
9039 \\
9612\end{array}$ & \\
\hline 9 & 880242 & 0299 & 0356 & 0413 & 0471 & 0528 & $\begin{array}{l}0013 \\
0585\end{array}$ & $\begin{array}{l}0070 \\
0642\end{array}$ & $\begin{array}{l}0127 \\
0699\end{array}$ & $\begin{array}{l}0185 \\
0756\end{array}$ & \\
\hline $\begin{array}{r}760 \\
1 \\
2 \\
3 \\
4 \\
4\end{array}$ & $\begin{array}{l}0814 \\
1385 \\
1955 \\
2525 \\
3093\end{array}$ & $\begin{array}{l}0871 \\
1442 \\
2012 \\
2581 \\
3150\end{array}$ & $\begin{array}{l}0928 \\
1499 \\
2069 \\
2638 \\
3207\end{array}$ & $\begin{array}{l}0985 \\
1556 \\
2126 \\
2695 \\
3264\end{array}$ & $\begin{array}{l}1042 \\
1613 \\
2183 \\
2752 \\
3321\end{array}$ & $\begin{array}{l}1099 \\
1670 \\
2240 \\
2809 \\
3377\end{array}$ & $\begin{array}{l}1156 \\
1727 \\
2297 \\
2866 \\
3434\end{array}$ & $\begin{array}{l}1213 \\
1784 \\
2354 \\
2923 \\
3491\end{array}$ & $\begin{array}{l}1271 \\
1841 \\
2411 \\
2980 \\
3548\end{array}$ & $\begin{array}{l}1328 \\
1898 \\
2468 \\
3037 \\
3605\end{array}$ & 57 \\
\hline & & & & PR & $\mathrm{T}$ & $\Delta L \mathbf{P}$ & & & & & \\
\hline Diff. & 1 & 2 & 3 & & 4 & 5 & 6 & & 7 & 8 & 9 \\
\hline $\begin{array}{l}59 \\
58 \\
57 \\
56\end{array}$ & $\begin{array}{l}5.9 \\
5.8 \\
5.7 \\
5.6\end{array}$ & $\begin{array}{l}11.8 \\
11.6 \\
11.4 \\
11.2\end{array}$ & $\begin{array}{l}17 . \\
17 . \\
17 . \\
16 .\end{array}$ & & $\begin{array}{l}23.6 \\
23.2 \\
22.8 \\
22.4\end{array}$ & $\begin{array}{l}29.5 \\
29.0 \\
28.5 \\
28.0\end{array}$ & $\begin{array}{l}35.4 \\
34.8 \\
34.2 \\
33.6\end{array}$ & & $\begin{array}{l}.3 \\
.6 \\
.9 \\
.2\end{array}$ & $\begin{array}{l}47.2 \\
46.4 \\
45.6 \\
44.8\end{array}$ & $\begin{array}{l}53.1 \\
52.2 \\
51.3 \\
50.4\end{array}$ \\
\hline
\end{tabular}


TABLE XI.-LOGARITHMS OF NUMBERS.

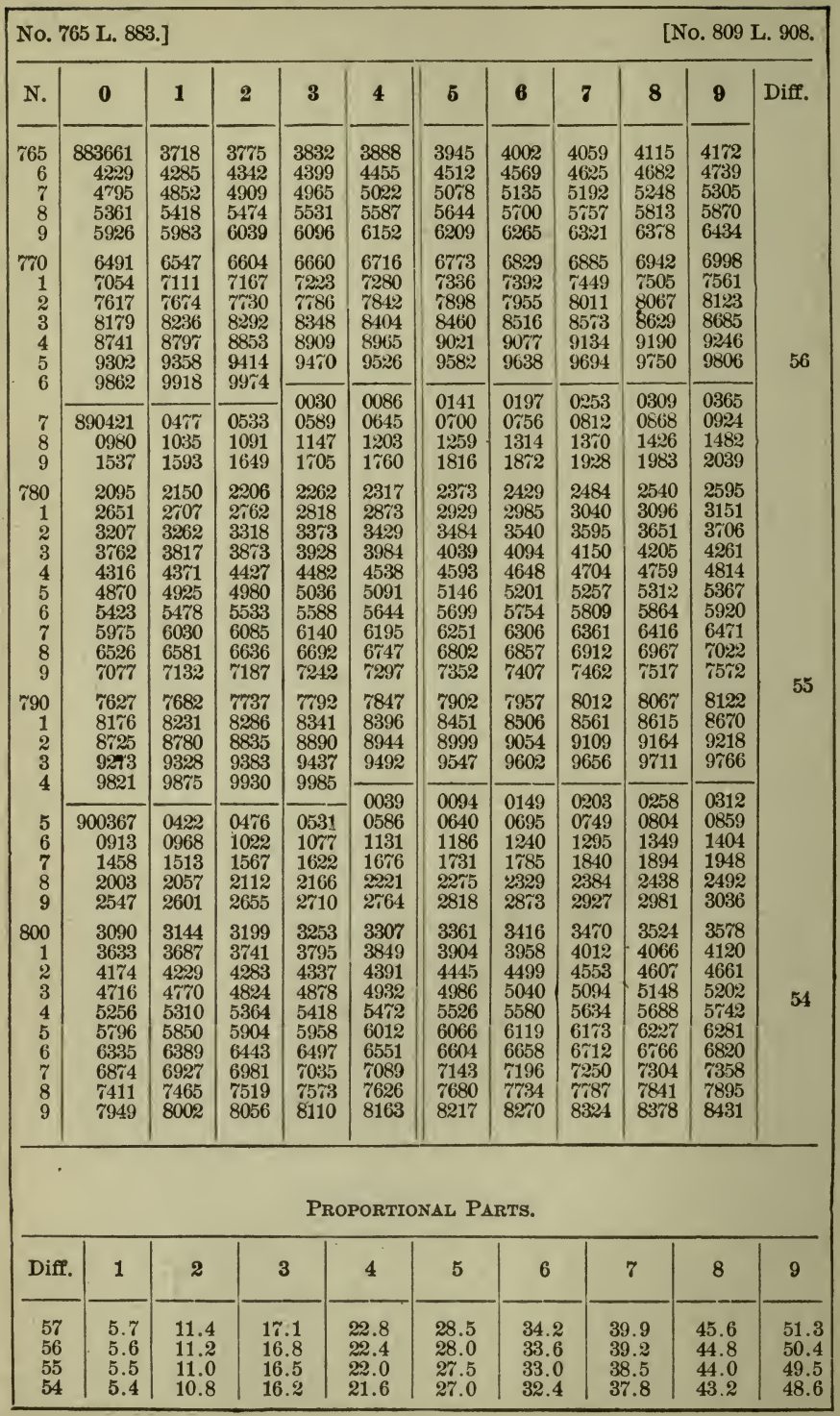


TABLE XI.-LOGARITHMS OF NUMBERS.

No. 810 L. 908.]

[No. 854 L. 931.

\begin{tabular}{|c|c|c|c|c|c|c|c|c|c|c|c|}
\hline N. & 0 & 1 & 2 & 3 & 4 & 5 & 6 & 7 & 8 & 9 & Diff. \\
\hline $\begin{array}{r}810 \\
1 \\
2\end{array}$ & $\begin{array}{r}908485 \\
9021 \\
9556\end{array}$ & $\begin{array}{l}8539 \\
9074 \\
9610\end{array}$ & $\begin{array}{l}8592 \\
9128 \\
9663\end{array}$ & $\begin{array}{l}8646 \\
9181 \\
9 \approx 16\end{array}$ & $\begin{array}{l}8699 \\
9235 \\
97 \% 0\end{array}$ & $\begin{array}{l}8 \% 53 \\
9289 \\
9823\end{array}$ & $\begin{array}{l}8807 \\
9342 \\
9877\end{array}$ & $\begin{array}{l}8860 \\
9396 \\
9930\end{array}$ & $\begin{array}{l}8914 \\
9449 \\
9984\end{array}$ & $\begin{array}{l}8967 \\
9503\end{array}$ & \\
\hline $\begin{array}{l}3 \\
4 \\
5 \\
6 \\
7 \\
8 \\
9\end{array}$ & $\begin{array}{r}910091 \\
0624 \\
1158 \\
1690 \\
2222 \\
2753 \\
3284\end{array}$ & $\begin{array}{l}0144 \\
0678 \\
1211 \\
1743 \\
2275 \\
2806 \\
3337\end{array}$ & $\begin{array}{l}0197 \\
0731 \\
1264 \\
1797 \\
2328 \\
2859 \\
3390\end{array}$ & $\begin{array}{l}0251 \\
0784 \\
1317 \\
1850 \\
2381 \\
2913 \\
3443\end{array}$ & $\begin{array}{l}0304 \\
0838 \\
1371 \\
1903 \\
2435 \\
2966 \\
3496\end{array}$ & $\begin{array}{l}0358 \\
0891 \\
1424 \\
1956 \\
2488 \\
3419 \\
3549\end{array}$ & $\begin{array}{l}0411 \\
0944 \\
1477 \\
2009 \\
2541 \\
3072 \\
3602\end{array}$ & $\begin{array}{l}0464 \\
0998 \\
1530 \\
2063 \\
2594 \\
3125 \\
3655\end{array}$ & $\begin{array}{l}0518 \\
1051 \\
1584 \\
2116 \\
2647 \\
3178 \\
3708\end{array}$ & $\begin{array}{l}0037 \\
0571 \\
1104 \\
1637 \\
2169 \\
2700 \\
3231 \\
3761\end{array}$ & 53 \\
\hline $\begin{array}{r}820 \\
1 \\
2 \\
3 \\
4 \\
5 \\
6 \\
7 \\
8 \\
9\end{array}$ & $\begin{array}{l}3814 \\
4343 \\
48 \pi 2 \\
5400 \\
5927 \\
6454 \\
6980 \\
7506 \\
8030 \\
8555\end{array}$ & $\begin{array}{l}3867 \\
4396 \\
4925 \\
5453 \\
5980 \\
6507 \\
7033 \\
7558 \\
8083 \\
8607\end{array}$ & $\begin{array}{l}3920 \\
4449 \\
4977 \\
5505 \\
6033 \\
6559 \\
7085 \\
7611 \\
8135 \\
8659\end{array}$ & $\begin{array}{l}3973 \\
4502 \\
5030 \\
5558 \\
6085 \\
6612 \\
7138 \\
7663 \\
8188 \\
8712\end{array}$ & $\begin{array}{l}4026 \\
4555 \\
5083 \\
5611 \\
6138 \\
6664 \\
7190 \\
7716 \\
8240 \\
8764\end{array}$ & $\begin{array}{l}4079 \\
4608 \\
5136 \\
5664 \\
6191 \\
6717 \\
7243 \\
7768 \\
8293 \\
8816\end{array}$ & $\begin{array}{l}4132 \\
4660 \\
5189 \\
5710 \\
6243 \\
67 \% 0 \\
7295 \\
7820 \\
8345 \\
8869\end{array}$ & $\begin{array}{l}4184 \\
4713 \\
5241 \\
5769 \\
6296 \\
6822 \\
7348 \\
7873 \\
8397 \\
8921 .\end{array}$ & $\begin{array}{l}4237 \\
4766 \\
5294 \\
5822 \\
6349 \\
6875 \\
7400 \\
7925 \\
8450 \\
8973\end{array}$ & $\begin{array}{l}4290 \\
4819 \\
5347 \\
5875 \\
6401 \\
6927 \\
7453 \\
7978 \\
8502 \\
9026\end{array}$ & \\
\hline $\begin{array}{r}830 \\
1\end{array}$ & $\begin{array}{l}9078 \\
9601\end{array}$ & $\begin{array}{l}9130 \\
9653\end{array}$ & $\begin{array}{l}9183 \\
9706\end{array}$ & $\begin{array}{l}9235 \\
9758\end{array}$ & $\begin{array}{l}9287 \\
9810\end{array}$ & $\begin{array}{l}9340 \\
9862\end{array}$ & $\begin{array}{l}9392 \\
9914\end{array}$ & $\begin{array}{l}9444 \\
996 \%\end{array}$ & 9496 & 9549 & \\
\hline $\begin{array}{l}2 \\
3 \\
4 \\
5 \\
6 \\
7 \\
8 \\
9\end{array}$ & $\begin{array}{r}920123 \\
0645 \\
1166 \\
1686 \\
2206 \\
2725 \\
3244 \\
3762\end{array}$ & $\begin{array}{l}0176 \\
0697 \\
1218 \\
1738 \\
2258 \\
2777 \\
3296 \\
3814\end{array}$ & $\begin{array}{l}0228 \\
0749 \\
1270 \\
1790 \\
2310 \\
2829 \\
3348 \\
3865\end{array}$ & $\begin{array}{l}0280 \\
0801 \\
1322 \\
1842 \\
2362 \\
2881 \\
3399 \\
3917\end{array}$ & $\begin{array}{l}0332 \\
0853 \\
1374 \\
1894 \\
2414 \\
2933 \\
3451 \\
3969\end{array}$ & $\begin{array}{l}0384 \\
0906 \\
1426 \\
1946 \\
2466 \\
2985 \\
3503 \\
4021\end{array}$ & $\begin{array}{l}0436 \\
0958 \\
1478 \\
1998 \\
2518 \\
3037 \\
3555 \\
4072\end{array}$ & $\begin{array}{l}0489 \\
1010 \\
1530 \\
2050 \\
2570 \\
3089 \\
3607 \\
4124\end{array}$ & $\begin{array}{l}0019 \\
0541 \\
1062 \\
1582 \\
2102 \\
2622 \\
3140 \\
3658 \\
4176\end{array}$ & $\begin{array}{l}0071 \\
0593 \\
1114 \\
1634 \\
2154 \\
2674 \\
3192 \\
3710 \\
4228\end{array}$ & 52 \\
\hline $\begin{array}{r}840 \\
1 \\
2 \\
3 \\
4 \\
5 \\
6 \\
7 \\
8 \\
9\end{array}$ & $\begin{array}{l}4279 \\
4796 \\
5312 \\
5828 \\
6342 \\
6857 \\
7370 \\
7883 \\
8396 \\
8908\end{array}$ & $\begin{array}{l}4331 \\
4848 \\
5364 \\
5879 \\
6394 \\
6908 \\
7422 \\
7935 \\
8447 \\
8959\end{array}$ & $\begin{array}{l}4383 \\
4899 \\
5415 \\
5931 \\
6445 \\
6959 \\
7473 \\
7986 \\
8498 \\
9010\end{array}$ & $\begin{array}{l}4434 \\
4951 \\
5467 \\
5982 \\
6497 \\
7011 \\
7524 \\
8037 \\
8549 \\
9061\end{array}$ & $\begin{array}{l}4486 \\
5003 \\
5518 \\
6034 \\
6548 \\
7062 \\
7576 \\
8088 \\
8601 \\
9112\end{array}$ & $\begin{array}{l}4538 \\
5054 \\
5570 \\
6085 \\
6600 \\
7114 \\
7627 \\
8140 \\
8652 \\
9163\end{array}$ & $\begin{array}{l}4589 \\
5106 \\
5621 \\
6137 \\
6651 \\
7165 \\
7678 \\
8191 \\
8 \% 03 \\
9215\end{array}$ & $\begin{array}{l}4641 \\
5157 \\
5673 \\
6188 \\
6702 \\
7216 \\
7730 \\
8242 \\
8754 \\
9266\end{array}$ & $\begin{array}{l}4693 \\
5209 \\
5725 \\
6240 \\
6754 \\
7268 \\
7781 \\
8293 \\
8805 \\
9317\end{array}$ & $\begin{array}{l}4744 \\
5261 \\
5 \pi ; 6 \\
6291 \\
6805 \\
7319 \\
7832 \\
8345 \\
8857 \\
9368\end{array}$ & \\
\hline 350 & $\begin{array}{l}9419 \\
9930\end{array}$ & $\begin{array}{l}9470 \\
9981\end{array}$ & 9521 & 9572 & 9623 & $96 \pi 4$ & 9725 & 9776 & 9827 & 9879 & 51 \\
\hline $\begin{array}{l}2 \\
3 \\
4\end{array}$ & $\begin{array}{r}930440 \\
0949 \\
1458\end{array}$ & $\begin{array}{l}0491 \\
1000 \\
1509\end{array}$ & $\begin{array}{l}0032 \\
0542 \\
1051 \\
1560\end{array}$ & $\begin{array}{l}0083 \\
0592 \\
1102 \\
1610\end{array}$ & $\begin{array}{l}0134 \\
0643 \\
1153 \\
1661\end{array}$ & $\begin{array}{l}0185 \\
0694 \\
1204 \\
1712\end{array}$ & $\begin{array}{l}0236 \\
0745 \\
1254 \\
1763\end{array}$ & $\begin{array}{l}0287 \\
0796 \\
1305 \\
1814\end{array}$ & $\begin{array}{l}0338 \\
0847 \\
1356 \\
1865\end{array}$ & $\begin{array}{l}0389 \\
0898 \\
1407 \\
1915\end{array}$ & \\
\hline
\end{tabular}

Proportional Parts.

\begin{tabular}{|c|c|c|c|c|c|c|c|c|c|}
\hline Diff. & 1 & 2 & 3 & 4 & 5 & 6 & 7 & 8 & 9 \\
\hline $\begin{array}{l}53 \\
52 \\
51 \\
50\end{array}$ & $\begin{array}{l}5.3 \\
5.2 \\
5.1 \\
5.0\end{array}$ & $\begin{array}{l}10.6 \\
10.4 \\
10.2 \\
10.0\end{array}$ & $\begin{array}{l}15.9 \\
15.6 \\
15.3 \\
15.0\end{array}$ & $\begin{array}{l}21.2 \\
20.8 \\
20.4 \\
20.0\end{array}$ & $\begin{array}{l}26.5 \\
26.0 \\
25.5 \\
25.0\end{array}$ & $\begin{array}{l}31.8 \\
31.2 \\
30.6 \\
30.0\end{array}$ & $\begin{array}{l}37.1 \\
36.4 \\
35.7 \\
35.0\end{array}$ & $\begin{array}{l}42.4 \\
41.6 \\
40.8 \\
40.0\end{array}$ & $\begin{array}{l}47.7 \\
46.8 \\
45.9 \\
45.0\end{array}$ \\
\hline
\end{tabular}


TABLE XI.-LOGARITHMS OF NUMBERS.

\begin{tabular}{|c|c|c|c|c|c|c|c|c|c|c|c|}
\hline \multicolumn{9}{|c|}{ No. 855 L. 931.$]$} & \multicolumn{3}{|c|}{ [No. 899 L. 954} \\
\hline N. & $\mathbf{0}$ & 1 & 2 & 3 & 4 & 5 & 6 & 7 & 8 & 9 & Diff. \\
\hline $\begin{array}{r}855 \\
6 \\
7 \\
8 \\
9\end{array}$ & $\begin{array}{r}931966 \\
24 \% 4 \\
2981 \\
3487 \\
3993\end{array}$ & $\begin{array}{l}2017 \\
2524 \\
3031 \\
3538 \\
4044\end{array}$ & $\begin{array}{l}2068 \\
25 \% 5 \\
3082 \\
3589 \\
4094\end{array}$ & $\begin{array}{l}2118 \\
2626 \\
3133 \\
3639 \\
4145\end{array}$ & $\begin{array}{l}2169 \\
2677 \\
3183 \\
3690 \\
4195\end{array}$ & $\begin{array}{l}2220 \\
2727 \\
3234 \\
3740 \\
4246\end{array}$ & $\begin{array}{l}227 \\
27.8 \\
3285 \\
3791 \\
4296\end{array}$ & $\begin{array}{l}2322 \\
2829 \\
3335 \\
3841 \\
434 \tau\end{array}$ & $\begin{array}{l}2372 \\
28 \% 9 \\
3386 \\
3892 \\
4397\end{array}$ & $\begin{array}{l}2423 \\
2930 \\
3437 \\
3943 \\
4448\end{array}$ & \multirow{7}{*}{50} \\
\hline $\begin{array}{r}860 \\
1 \\
2 \\
3 \\
4 \\
5 \\
6 \\
7 \\
8 \\
9\end{array}$ & $\begin{array}{l}4498 \\
5003 \\
5507 \\
6011 \\
6514 \\
7016 \\
7518 \\
8019 \\
8520 \\
9020\end{array}$ & $\begin{array}{l}4549 \\
5054 \\
5558 \\
6061 \\
6564 \\
7066 \\
7568 \\
8069 \\
8570 \\
9070\end{array}$ & $\begin{array}{l}4599 \\
5104 \\
5608 \\
6111 \\
6614 \\
7116 \\
7618 \\
8119 \\
8620 \\
9120\end{array}$ & $\begin{array}{l}4650 \\
5154 \\
5658 \\
6162 \\
6665 \\
7167 \\
7668 \\
8169 \\
8670 \\
91 \% 0\end{array}$ & $\begin{array}{l}4700 \\
5205 \\
5709 \\
6212 \\
6715 \\
7217 \\
718 \\
8219 \\
8720 \\
9200\end{array}$ & $\begin{array}{l}4751 \\
5255 \\
5759 \\
6262 \\
6765 \\
7267 \\
7 \% 69 \\
8269 \\
8770 \\
9270\end{array}$ & $\begin{array}{l}4801 \\
5306 \\
5809 \\
6313 \\
6815 \\
731 \tau \\
7819 \\
8320 \\
8820 \\
9320\end{array}$ & $\begin{array}{l}4852 \\
5356 \\
5860 \\
6863 \\
6865 \\
7367 \\
7869 \\
8370 \\
8870 \\
9369\end{array}$ & $\begin{array}{l}4902 \\
5406 \\
5910 \\
6413 \\
6916 \\
7418 \\
7919 \\
8420 \\
8920 \\
9419\end{array}$ & $\begin{array}{l}4953 \\
5457 \\
5960 \\
6463 \\
6966 \\
7468 \\
7969 \\
8170 \\
8970 \\
9169\end{array}$ & \\
\hline $8 \% 0$ & 9519 & 9569 & $9 \Re 15$ & 9669 & 9719 & 9769 & 9819 & $9 \mathrm{~S} 69$ & 9918 & 9968 & \\
\hline $\begin{array}{l}1 \\
2 \\
3 \\
4 \\
5 \\
6 \\
7 \\
8 \\
9\end{array}$ & $\begin{array}{r}940018 \\
0516 \\
1014 \\
1511 \\
2008 \\
2504 \\
3000 \\
3495 \\
3989\end{array}$ & $\begin{array}{l}0068 \\
0566 \\
1064 \\
1561 \\
2058 \\
2554 \\
3049 \\
3544 \\
4038\end{array}$ & $\begin{array}{l}0118 \\
0616 \\
1114 \\
1611 \\
2107 \\
2603 \\
3099 \\
3593 \\
4088\end{array}$ & $\begin{array}{l}0168 \\
0666 \\
1163 \\
1660 \\
2157 \\
2653 \\
3148 \\
3643 \\
4137\end{array}$ & $\begin{array}{l}0218 \\
0 \% 16 \\
1213 \\
1710 \\
2 \approx 07 \\
2 \% 02 \\
3198 \\
3692 \\
4186\end{array}$ & $\begin{array}{l}0267 \\
0765 \\
1263 \\
1760 \\
2256 \\
2752 \\
3247 \\
3 \% 42 \\
4236\end{array}$ & $\begin{array}{l}0317 \\
0815 \\
1313 \\
1809 \\
2306 \\
2301 \\
3297 \\
3791 \\
4285\end{array}$ & $\begin{array}{l}0367 \\
0865 \\
1362 \\
1859 \\
2355 \\
2851 \\
3346 \\
3841 \\
4335\end{array}$ & $\begin{array}{l}0417 \\
0915 \\
1412 \\
1909 \\
2405 \\
2901 \\
3396 \\
3890 \\
4384\end{array}$ & $\begin{array}{l}0467 \\
0964 \\
1462 \\
1958 \\
2455 \\
2950 \\
3445 \\
3939 \\
4433\end{array}$ & \\
\hline $\begin{array}{r}880 \\
1 \\
2 \\
3 \\
4 \\
5 \\
6 \\
7 \\
8 \\
9\end{array}$ & $\begin{array}{l}4483 \\
4976 \\
5469 \\
5961 \\
6452 \\
6943 \\
7434 \\
7924 \\
8413 \\
8902\end{array}$ & $\begin{array}{l}4532 \\
5025 \\
5518 \\
6010 \\
6501 \\
6992 \\
7483 \\
7973 \\
8462 \\
8951\end{array}$ & $\begin{array}{l}4581 \\
5074 \\
5567 \\
6059 \\
6551 \\
7041 \\
7532 \\
8022 \\
8511 \\
8999\end{array}$ & $\begin{array}{l}4631 \\
5124 \\
5616 \\
6108 \\
6600 \\
7090 \\
7581 \\
8070 \\
8560 \\
9018\end{array}$ & $\begin{array}{l}4680 \\
5173 \\
5665 \\
6157 \\
6649 \\
7139 \\
7630 \\
8119 \\
8608 \\
9097\end{array}$ & $\begin{array}{l}4729 \\
5222 \\
5715 \\
6207 \\
6698 \\
7189 \\
7679 \\
8168 \\
8657 \\
9146\end{array}$ & $\begin{array}{l}4779 \\
5272 \\
5 \% 64 \\
6256 \\
6747 \\
7238 \\
7 \% 28 \\
8217 \\
8706 \\
9195\end{array}$ & $\begin{array}{l}4828 \\
5321 \\
5813 \\
6305 \\
6796 \\
7287 \\
7767 \\
8266 \\
8755 \\
9244\end{array}$ & $\begin{array}{l}4877 \\
5370 \\
5862 \\
6354 \\
6845 \\
7336 \\
7826 \\
8315 \\
8804 \\
9292\end{array}$ & $\begin{array}{l}4927 \\
5419 \\
5912 \\
6403 \\
6894 \\
7385 \\
7875 \\
8364 \\
8853 \\
9341\end{array}$ & \\
\hline $\begin{array}{r}890 \\
1\end{array}$ & $\begin{array}{l}9390 \\
9878\end{array}$ & $\begin{array}{l}9439 \\
9926\end{array}$ & $\begin{array}{l}9488 \\
9975\end{array}$ & 9536 & 9585 & 9634 & 9683 & 9731 & 9780 & 9829 & \\
\hline $\begin{array}{l}2 \\
3 \\
4 \\
5 \\
6 \\
7 \\
8 \\
9\end{array}$ & $\begin{array}{r}950365 \\
0851 \\
1338 \\
1823 \\
2308 \\
2792 \\
3276 \\
3760\end{array}$ & $\begin{array}{l}- \\
0414 \\
0900 \\
1386 \\
1872 \\
2356 \\
2841 \\
3325 \\
3808\end{array}$ & $\begin{array}{l}0462 \\
0949 \\
1435 \\
1920 \\
2405 \\
2889 \\
3373 \\
3856\end{array}$ & $\begin{array}{l}0024 \\
0511 \\
0997 \\
1483 \\
1969 \\
2453 \\
2938 \\
3421 \\
3905\end{array}$ & $\begin{array}{l}0073 \\
0560 \\
1046 \\
1532 \\
2017 \\
2502 \\
2986 \\
3470 \\
3953\end{array}$ & $\begin{array}{l}0121 \\
0608 \\
1095 \\
1580 \\
2066 \\
2550 \\
3034 \\
3518 \\
4001\end{array}$ & $\begin{array}{l}0170 \\
0657 \\
1143 \\
1629 \\
2114 \\
2599 \\
3083 \\
3566 \\
4049\end{array}$ & $\begin{array}{l}0219 \\
0706 \\
1192 \\
1677 \\
2163 \\
2647 \\
3131 \\
3615 \\
4098\end{array}$ & $\begin{array}{l}0267 \\
0754 \\
1240 \\
1726 \\
2211 \\
2696 \\
3180 \\
3663 \\
4146\end{array}$ & $\begin{array}{l}0316 \\
0803 \\
1289 \\
1775 \\
2260 \\
2744 \\
3228 \\
3711 \\
4194\end{array}$ & \\
\hline & \multicolumn{11}{|c|}{ Proportional Parts. } \\
\hline Diff. & 1 & 2 & 3 & & 4 & 5 & 6 & & 7 & 8 & 9 \\
\hline $\begin{array}{l}51 \\
50 \\
49 \\
48\end{array}$ & $\begin{array}{l}5.1 \\
5.0 \\
4.9 \\
4.8\end{array}$ & $\begin{array}{r}10.2 \\
10.0 \\
9.8 \\
9.6\end{array}$ & $\begin{array}{l}15 . \\
15 . \\
14 . \\
14 .\end{array}$ & & $\begin{array}{l}20.4 \\
20.0 \\
19.6 \\
19.2\end{array}$ & $\begin{array}{l}25.5 \\
25.0 \\
24.5 \\
24.0\end{array}$ & $\begin{array}{l}30.6 \\
30.0 \\
29.4 \\
28.8\end{array}$ & & & $\begin{array}{l}40.8 \\
40.0 \\
39.2 \\
38.4\end{array}$ & $\begin{array}{l}45.0 \\
45.0 \\
44.1 \\
43.2\end{array}$ \\
\hline
\end{tabular}


TABLE XI.-LOGARITHMS OF NUMBERS.

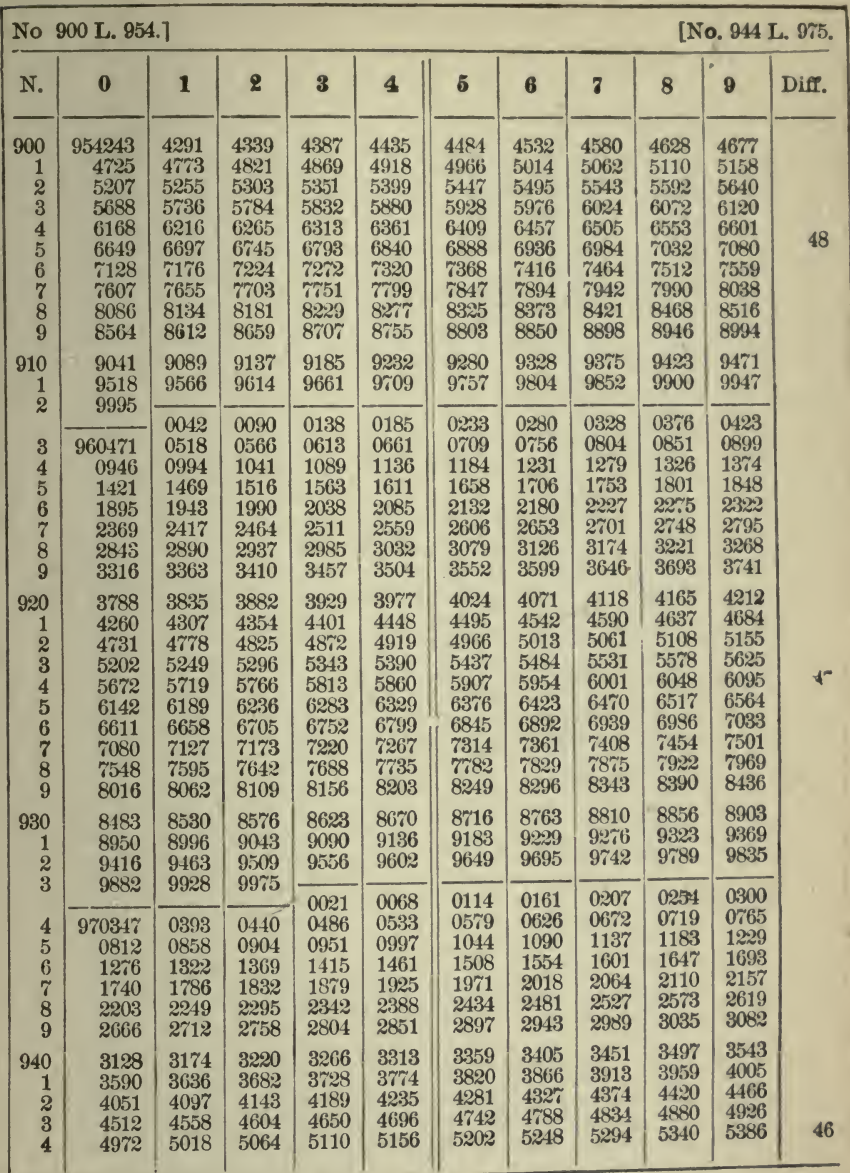

Proportional Parts.

\begin{tabular}{|c|c|c|c|c|c|c|c|c|c|}
\hline Diff. & 1 & 2 & 3 & 4 & 5 & 6 & 7 & 8 & 9 \\
\hline $\begin{array}{l}47 \\
46\end{array}$ & $\begin{array}{l}4.7 \\
4.6\end{array}$ & $\begin{array}{l}9.4 \\
9.2\end{array}$ & $\begin{array}{l}14.1 \\
13.8\end{array}$ & $\begin{array}{l}18.8 \\
18.4\end{array}$ & $\begin{array}{l}23.5 \\
23.0\end{array}$ & $\begin{array}{l}28.2 \\
27.6\end{array}$ & $\begin{array}{l}32.9 \\
32.2\end{array}$ & $\begin{array}{l}37.6 \\
36.8\end{array}$ & $\begin{array}{l}42.3 \\
41.4\end{array}$ \\
\hline
\end{tabular}


TABI.E XI.-LOGARI'TTMS OF NCMBERS.

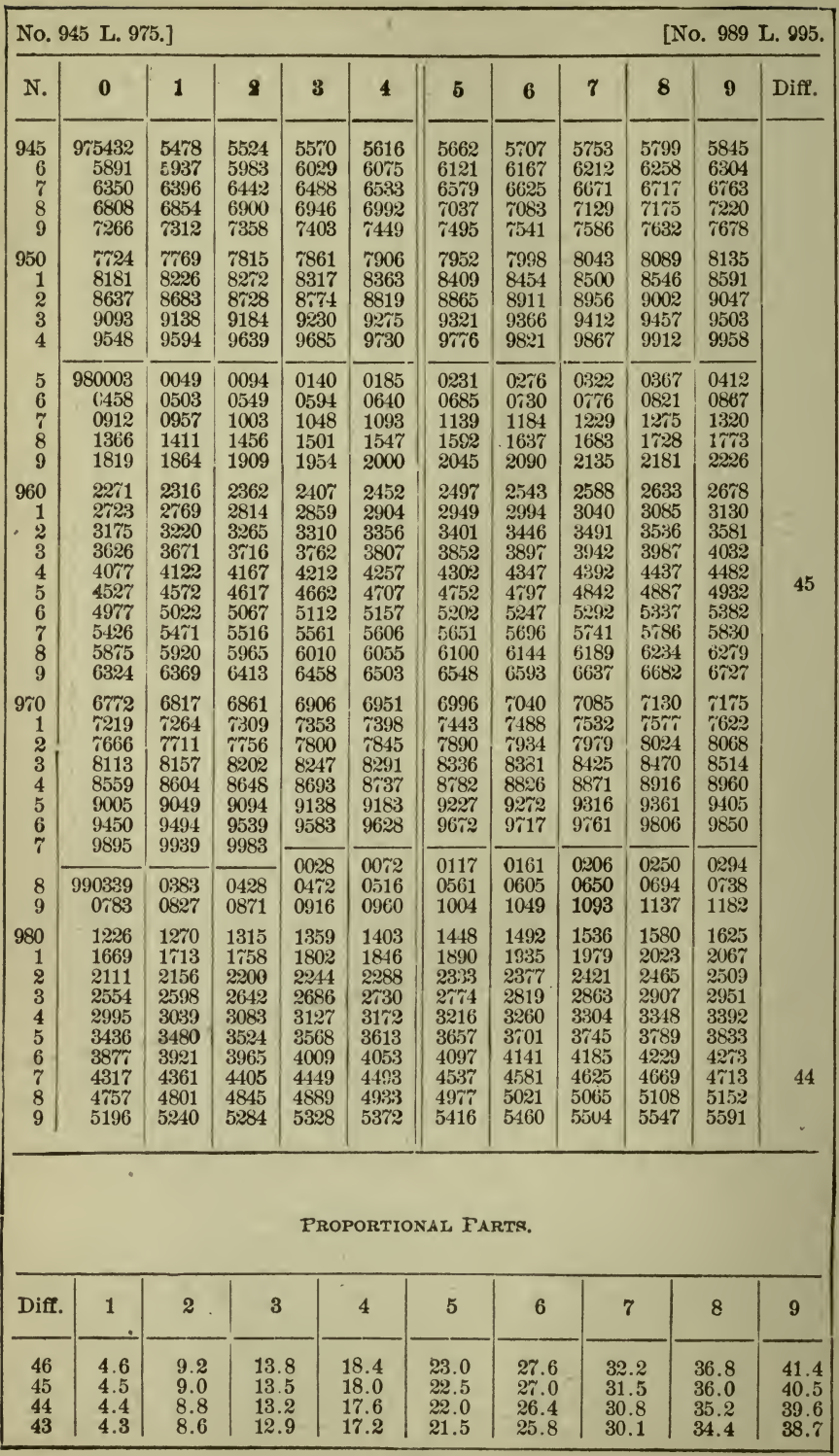


TABLE XI.-LOGARITHMS OF NUMBERS.

\begin{tabular}{|c|c|c|c|c|c|c|c|c|c|c|c|}
\hline \multicolumn{9}{|c|}{ No. 990 L. 995.] } & \multicolumn{3}{|c|}{ [No. 999 L. 999.} \\
\hline N. & 0 & 1 & 2 & 3 & 4 & 5 & 6 & 7 & 8 & 9 & Difr. \\
\hline 90 & 995635 & $56 r 9$ & $5 \% 23$ & 5767 & 5811 & 5854 & 5898 & 5942 & 5986 & 6030 & \\
\hline 1 & 60 & 6 & 61 & 62 & 62 & 62 & & & 6424 & 6468 & 44 \\
\hline 2 & 651 & 655 & 65 & 664 & 668 & 67 & $6 \pi$ & 68 & 6862 & 6906 & \\
\hline 3 & 69 & 65 & 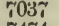 & 70 & $\pi 1$ & $\pi 1$ & 22 & 72 & ๆ299 & 7343 & \\
\hline 4 & 7386 & 74 & 74 & 751 & 75 & 76 & 76 & 76 & 7736 & 779 & \\
\hline 5 & 78 & 78 & 79 & 79 & 79 & 80 & & 81 & 8172 & 8216 & \\
\hline 6 & 825 & 8303 & 83 & 8390 & 843 & 84 & 8521 & 85 & 8608 & $865 \%$ & \\
\hline 7 & 869 & 87 & 87 & 8826 & 8869 & 89 & 8956 & 90 & 9043 & 9087 & \\
\hline 8 & 9131 & 917 & 9218 & 9261 & 9305 & 9348 & 9392 & 9435 & 9479 & 9522 & \\
\hline 9 & 9565 & 9609 & 9652 & 9696 & 9739 & 9783 & $98: 6$ & 9870 & 9913 & 9957 & 4 \\
\hline
\end{tabular}

LogartThMS OF NuMbers From 1 To 100.

\begin{tabular}{|c|c|c|c|c|c|c|c|c|c|}
\hline N. & Log. & N. & Log. & $\mathrm{N}$. & Log. & N. & Log. & N. & Log. \\
\hline 1 & 0.000000 & 21 & 1.322219 & 41 & 1.612784 & 61 & 1. 785330 & 81 & 1.908485 \\
\hline 2 & 0.301030 & 22 & 1.342423 & 42 & 1.623249 & 62 & 1. 792392 & 82 & 1. 913814 \\
\hline$\tilde{3}$ & $0.47 \div 121$ & 23 & $1.361 \% 28$ & 43 & 1.633468 & 63 & 1.799341 & 83 & 1.919078 \\
\hline 4 & 0.602060 & 24 & 1.380211 & 44 & 1.643453 & 64 & 1.806180 & 84 & $1.9242 \% 9$ \\
\hline 5 & 0.898970 & 25 & 1.397940 & 45 & 1.653213 & 65 & 1.812913 & 85 & 1.929419 \\
\hline 6 & 0.778151 & 26 & 1.414973 & 46 & 1.662758 & 66 & 1.819544 & 86 & 1.934498 \\
\hline 7 & 0.845098 & 27 & 1.431364 & $4 \pi$ & 1.6\%2098 & 67 & $1.8260 \% 5$ & 87 & 1.939519 \\
\hline 8 & 0.903090 & $\tilde{28}$ & 1.447158 & 48 & 1. 681241 & 68 & 1.832509 & 88 & 1.944483 \\
\hline 9 & 0.954243 & 29 & 1.462398 & 49 & 1.690196 & 69 & 1. 838849 & 89 & 1.049390 \\
\hline 10 & 1.000000 & 30 & 1.477121 & 50 & 1.698970 & 70 & 1.815098 & 90 & 1.954243 \\
\hline 11 & 1.041393 & 31 & 1.491362 & 51 & 1.707570 & $r 1$ & 1.851258 & 91 & 1.959041 \\
\hline 12 & 1.079181 & 32 & 1.505150 & 52 & 1.716003 & $\gamma_{2}$ & 1.857332 & 92 & 1.963788 \\
\hline 13 & 1.113943 & 33 & 1.518514 & 53 & 1.724276 & $\pi 3$ & 1.863323 & 93 & 1.968483 \\
\hline 14 & 1.146128 & 34 & 1.531479 & 54 & 1.732394 & 74 & 1.869232 & 94 & 1.973128 \\
\hline 15 & 1176091 & 35 & 1.544068 & 55 & 1.740363 & 75 & 1.8 .5061 & 95 & $1.97 \% 724$ \\
\hline 16 & 1.204120 & 36 & 1.556303 & 56 & 1. 748188 & 76 & 1.880814 & 96 & $1.9822 \pi 1$ \\
\hline 17 & 1.230449 & 37 & 1.568202 & 57 & 1.755875 & $\pi 7$ & 1.886491 & 97 & $1.986 \pi \mathrm{T}$ \\
\hline 18 & 1.255273 & 38 & $1.5 \div 9784$ & 58 & 1. 763428 & 78 & 1.892095 & 98 & $1.991 \approx 26$ \\
\hline 19 & 1.278754 & 39 & 1.591065 & 59 & 1.70852 & 79 & 1.8976:7 & 99 & 1.995635 \\
\hline 20 & 1.301030 & 40 & 1. 602060 & 60 & 1.778151 & 80 & 1.903090 & 100 & 2.000000 \\
\hline
\end{tabular}

\begin{tabular}{|c|c|c|c|c|c|c|c|c|c|}
\hline & $\begin{array}{l}\text { Value } \\
\text { at } 0^{\circ} \text {. }\end{array}$ & $\begin{array}{l}\text { Sign } \\
\text { in 1st } \\
\text { Quad. }\end{array}$ & $\begin{array}{l}\text { Value } \\
\text { at } 90^{\circ} \text {. }\end{array}$ & $\begin{array}{l}\text { Sign } \\
\text { in 2d } \\
\text { Quad. }\end{array}$ & $\begin{array}{c}\text { Value } \\
\text { at } \\
180^{\circ} \text {. }\end{array}$ & $\begin{array}{l}\text { Sign } \\
\text { in 3d } \\
\text { Quad. }\end{array}$ & $\begin{array}{l}\text { Value } \\
\text { at } \\
270^{\circ}\end{array}$ & $\begin{array}{l}\text { Sign } \\
\text { in 4th } \\
\text { Quad. }\end{array}$ & $\begin{array}{l}\text { Value } \\
\text { at } \\
360^{\circ} \text {. }\end{array}$ \\
\hline 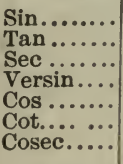 & $\begin{array}{l}\mathbf{O} \\
\mathbf{O} \\
\mathbf{R} \\
\mathbf{O} \\
\mathbf{R} \\
\infty \\
\infty\end{array}$ & \pm & $\begin{array}{l}\mathbf{R} \\
\infty \\
\infty \\
\mathbf{R} \\
0 \\
O \\
\mathrm{R}\end{array}$ & $\begin{array}{l} \pm \\
\pm \\
\pm\end{array}$ & $\begin{array}{c}\mathrm{O} \\
\mathrm{O} \\
\mathrm{R} \\
2 \mathrm{R} \\
\mathrm{R} \\
\infty \\
\infty\end{array}$ & 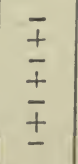 & $\begin{array}{l}\mathrm{R} \\
\infty \\
\infty \\
\mathbf{R} \\
\mathrm{O} \\
\mathrm{O} \\
\mathrm{R}\end{array}$ & $\begin{array}{l}\bar{z} \\
\pm \\
\bar{I}\end{array}$ & $\begin{array}{l}\mathrm{O} \\
\mathbf{O} \\
\mathbf{R} \\
\mathrm{O} \\
\mathbf{R} \\
\infty \\
\infty\end{array}$ \\
\hline
\end{tabular}

$R$ signifies equal to rad; $\infty$ signifies infinite; $O$ signifles evanescent. 


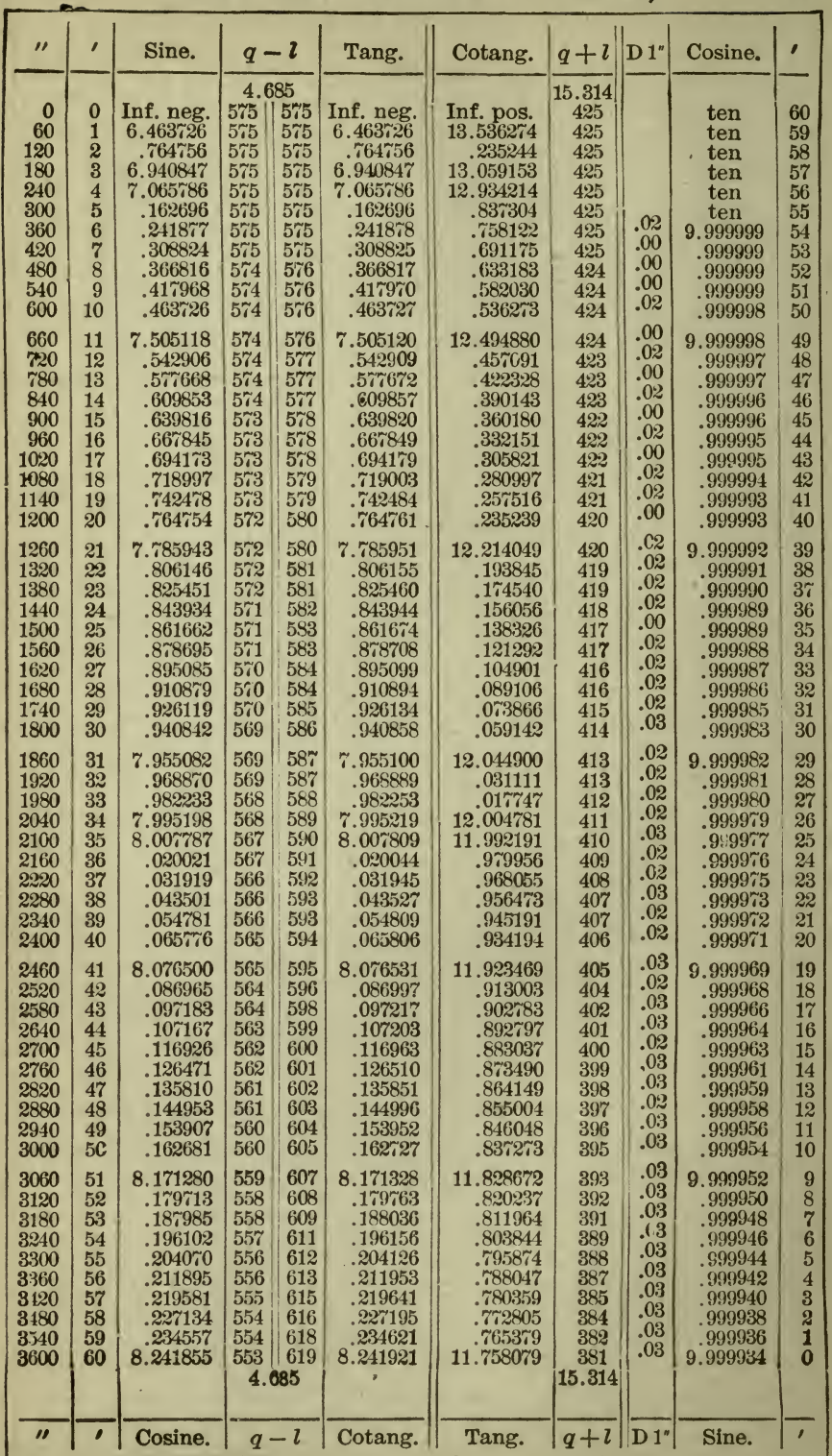




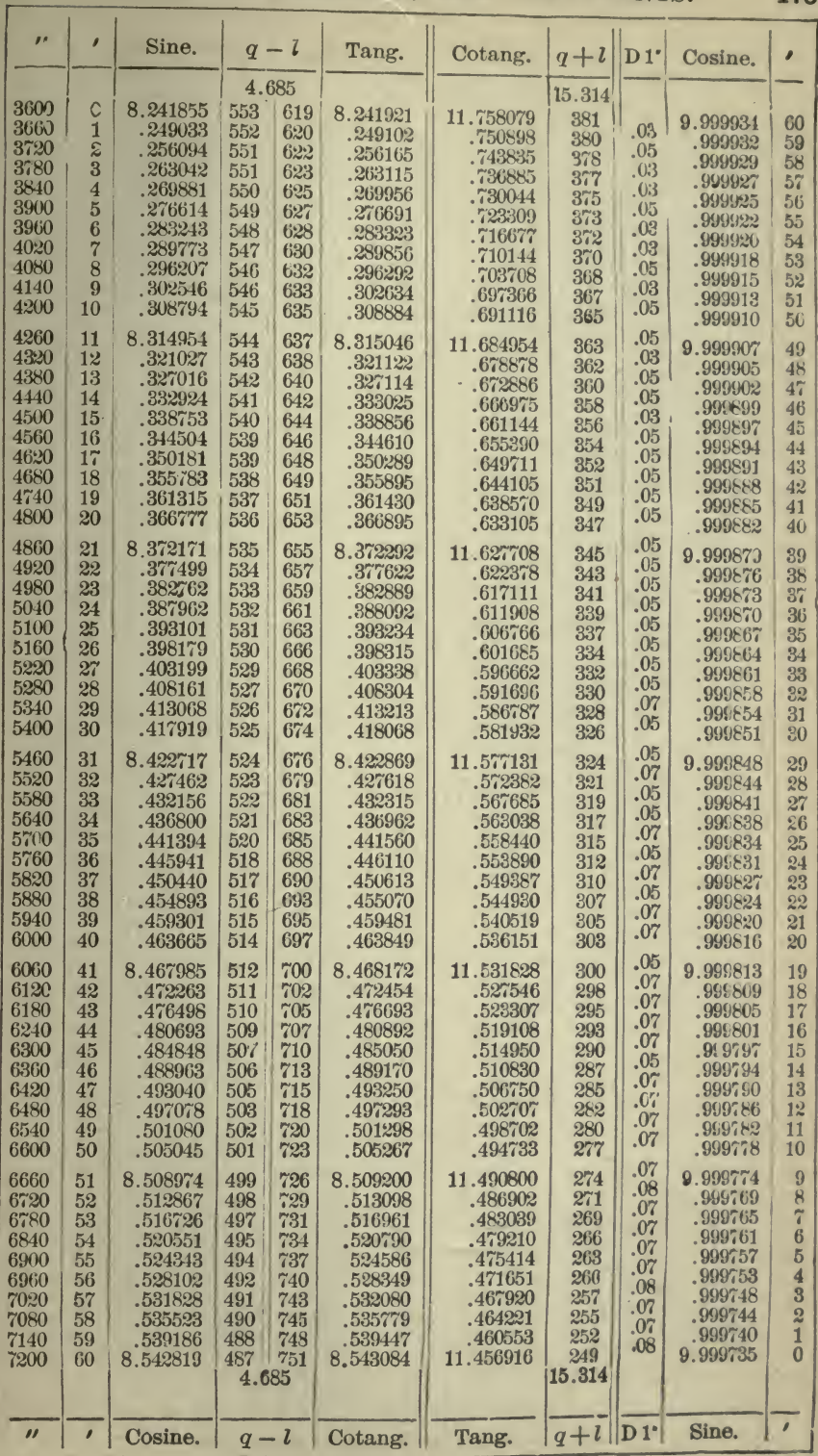




\begin{tabular}{|c|c|c|c|c|c|c|c|c|}
\hline ' & Sine. & D. $1^{\prime}$. & Cosine. & D. $1^{\circ}$. & Tang. & D. $1^{\circ}$. & Cotang. & ' \\
\hline $\begin{array}{r}0 \\
1 \\
2 \\
3 \\
4 \\
5 \\
6 \\
7 \\
8 \\
9 \\
10\end{array}$ & $\begin{array}{r}8542319 \\
.546422 \\
.549995 \\
.553539 \\
.557054 \\
.560540 \\
.563999 \\
.567431 \\
.570836 \\
.574214 \\
.577566\end{array}$ & $\begin{array}{l}60.05 \\
59.55 \\
59.07 \\
58.58 \\
58.10 \\
57.65 \\
57.20 \\
56.75 \\
56.30 \\
55.87 \\
55.43\end{array}$ & $\begin{array}{r}9.999735 \\
.999731 \\
.9997 \approx 6 \\
.999722 \\
.999 \% 1 \% \\
.999 \% 13 \\
.999708 \\
.999704 \\
.999699 \\
.999694 \\
.999689\end{array}$ & $\begin{array}{l}.07 \\
.08 \\
.07 \\
.08 \\
.07 \\
.08 \\
.07 \\
.08 \\
.08 \\
.08 \\
.07\end{array}$ & $\begin{array}{r}8.543094 \\
.546691 \\
.550268 \\
.553817 \\
.557336 \\
.560828 \\
.564291 \\
.567727 \\
.571137 \\
.574520 \\
.577877\end{array}$ & $\begin{array}{l}60.12 \\
59.62 \\
59.15 \\
58.65 \\
58.20 \\
57.72 \\
57.27 \\
56.83 \\
56.38 \\
55.95 \\
55.52\end{array}$ & $\begin{array}{r}11.456916 \\
.453309 \\
.449732 \\
.446183 \\
.442664 \\
.439172 \\
.435709 \\
.432273 \\
.428863 \\
.425480 \\
.422123\end{array}$ & $\begin{array}{l}60 \\
59 \\
58 \\
57 \\
56 \\
55 \\
54 \\
53 \\
52 \\
51 \\
50\end{array}$ \\
\hline $\begin{array}{l}11 \\
12 \\
13 \\
14 \\
15 \\
16 \\
17 \\
18 \\
19 \\
20\end{array}$ & $\begin{array}{r}8.580892 \\
.584193 \\
.58 \% 469 \\
.590721 \\
.593948 \\
.597152 \\
.600332 \\
.603489 \\
.606623 \\
.609734\end{array}$ & $\begin{array}{l}55.02 \\
54.60 \\
54.20 \\
53.78 \\
53.40 \\
53.00 \\
52.62 \\
52.23 \\
51.85 \\
51.48\end{array}$ & $\begin{array}{r}9.999685 \\
.999680 \\
.999675 \\
.9996 \% 0 \\
.999665 \\
.999660 \\
.999655 \\
.999650 \\
.999645 \\
.999640\end{array}$ & $\begin{array}{l}.08 \\
.08 \\
.08 \\
.08 \\
.08 \\
.08 \\
.08 \\
.08 \\
.08 \\
.08\end{array}$ & $\begin{array}{r}8.581208 \\
.584514 \\
.587 \% 95 \\
.591051 \\
.594283 \\
.597492 \\
.600677 \\
.603839 \\
.606978 \\
.610094\end{array}$ & $\begin{array}{l}55.10 \\
54.68 \\
54.27 \\
53.87 \\
53.48 \\
53.08 \\
52.70 \\
52.32 \\
51.93 \\
51.58\end{array}$ & $\begin{array}{r}11.418792 \\
.415486 \\
.412205 \\
.408949 \\
.405717 \\
.402508 \\
.399323 \\
.396161 \\
.393022 \\
.389906\end{array}$ & $\begin{array}{l}49 \\
48 \\
47 \\
46 \\
45 \\
44 \\
43 \\
42 \\
41 \\
40\end{array}$ \\
\hline $\begin{array}{l}21 \\
22 \\
23 \\
24 \\
25 \\
26 \\
27 \\
28 \\
29 \\
30 \\
31\end{array}$ & $\begin{array}{r}8.612823 \\
.615891 \\
.618937 \\
.621962 \\
.624965 \\
.627948 \\
.630911 \\
.633854 \\
.636776 \\
.639680\end{array}$ & $\begin{array}{l}51.13 \\
50.77 \\
50.42 \\
50.05 \\
49.72 \\
49.38 \\
49.05 \\
48.70 \\
48.40 \\
48.05\end{array}$ & $\begin{array}{r}9.999635 \\
.999629 \\
.999624 \\
.999619 \\
.999614 \\
.999608 \\
.999603 \\
.999597 \\
.999592 \\
.999586\end{array}$ & $\begin{array}{l}.10 \\
.08 \\
.08 \\
.08 \\
.10 \\
.08 \\
.10 \\
.08 \\
.10 \\
.08\end{array}$ & $\begin{array}{r}8.613189 \\
.616262 \\
.619313 \\
.622343 \\
.625352 \\
.628340 \\
.631308 \\
.634256 \\
.637184 \\
.640093\end{array}$ & $\begin{array}{l}51.22 \\
50.85 \\
50.50 \\
50.15 \\
49.80 \\
49.47 \\
49.13 \\
48.80 \\
48.48 \\
48.15\end{array}$ & $\begin{array}{r}11.386811 \\
.383738 \\
.380687 \\
.37657 \\
.344648 \\
.311660 \\
.368692 \\
.365744 \\
.362816 \\
.359907 \\
\end{array}$ & $\begin{array}{l}39 \\
38 \\
37 \\
36 \\
35 \\
34 \\
33 \\
32 \\
31 \\
30\end{array}$ \\
\hline $\begin{array}{l}31 \\
32 \\
33 \\
34 \\
35 \\
36 \\
37 \\
38 \\
39 \\
40 \\
1\end{array}$ & $\begin{array}{r}8.642563 \\
.645428 \\
.648274 \\
.651102 \\
.653911 \\
.656702 \\
.659475 \\
.662230 \\
.664968 \\
.667689\end{array}$ & $\begin{array}{l}47.75 \\
47.43 \\
47.13 \\
46.82 \\
46.52 \\
46.22 \\
45.92 \\
45.63 \\
45.35 \\
45.07\end{array}$ & $\begin{array}{r}9.999581 \\
.999575 \\
.999570 \\
.999564 \\
.999558 \\
.999553 \\
.999547 \\
.999541 \\
.999535 \\
.999529\end{array}$ & $\begin{array}{l}.10 \\
.08 \\
.10 \\
.10 \\
.08 \\
.10 \\
.10 \\
.10 \\
.10 \\
.08\end{array}$ & $\begin{array}{r}8.642982 \\
.645853 \\
.648704 \\
.651537 \\
.654352 \\
.657149 \\
.659928 \\
.662689 \\
.665433 \\
.668160\end{array}$ & $\begin{array}{l}47.85 \\
47.52 \\
47.22 \\
46.92 \\
46.62 \\
46.32 \\
46.02 \\
45.73 \\
45.45 \\
45.17\end{array}$ & $\begin{array}{r}11.357018 \\
.354147 \\
.351296 \\
.348463 \\
.345648 \\
.342851 \\
.340072 \\
.337311 \\
.334567 \\
.331840\end{array}$ & $\begin{array}{l}29 \\
23 \\
27 \\
26 \\
25 \\
24 \\
23 \\
22 \\
21 \\
20\end{array}$ \\
\hline $\begin{array}{l}41 \\
42 \\
43 \\
44 \\
45 \\
46 \\
47 \\
48 \\
49 \\
50\end{array}$ & $\begin{array}{r}8.670393 \\
.673080 \\
.675751 \\
.678405 \\
.681043 \\
.683665 \\
.686272 \\
.688863 \\
.691438 \\
.693998\end{array}$ & $\begin{array}{l}44.78 \\
44.52 \\
44.23 \\
43.97 \\
43.70 \\
43.45 \\
43.18 \\
42.92 \\
42.67 \\
42.42\end{array}$ & $\begin{array}{r}9.999524 \\
.999518 \\
.999512 \\
.999506 \\
.999500 \\
.999493 \\
.999487 \\
.999481 \\
.999475 \\
.999469\end{array}$ & $\begin{array}{l}.10 \\
.10 \\
.10 \\
.10 \\
.12 \\
.10 \\
.10 \\
.10 \\
.10 \\
.10\end{array}$ & $\begin{array}{r}8.670870 \\
.673563 \\
.676239 \\
.678900 \\
.681544 \\
.684172 \\
.686784 \\
.689381 \\
.691963 \\
.694529\end{array}$ & $\begin{array}{l}44.88 \\
44.60 \\
44.35 \\
44.07 \\
43.80 \\
43.53 \\
43.28 \\
43.03 \\
42.77 \\
42.53\end{array}$ & $\begin{array}{r}11.329130 \\
.326437 \\
.323761 \\
.321100 \\
.318456 \\
.315828 \\
.313216 \\
.310619 \\
.308031 \\
.305471\end{array}$ & $\begin{array}{l}19 \\
18 \\
17 \\
16 \\
15 \\
14 \\
13 \\
12 \\
11 \\
10\end{array}$ \\
\hline $\begin{array}{l}51 \\
52 \\
53 \\
54 \\
55 \\
56 \\
57 \\
58 \\
59 \\
60\end{array}$ & $\begin{array}{r}8.696543 \\
.699073 \\
.701589 \\
.704090 \\
.706577 \\
.709049 \\
.711507 \\
.713952 \\
.716383 \\
8.718800\end{array}$ & $\begin{array}{l}42.17 \\
41.93 \\
41.68 \\
41.45 \\
41.20 \\
40.97 \\
40.75 \\
40.52 \\
40.28\end{array}$ & $\begin{array}{r}9.999463 \\
.999456 \\
.999450 \\
.999443 \\
.999437 \\
.999431 \\
.999424 \\
.999418 \\
.999411 \\
9.999404\end{array}$ & $\begin{array}{l}.12 \\
.10 \\
.12 \\
.10 \\
.10 \\
.12 \\
.10 \\
.12 \\
.12\end{array}$ & $\begin{array}{r}8.697081 \\
.699617 \\
.702139 \\
.704646 \\
.707140 \\
.709618 \\
.712083 \\
.714534 \\
.716972 \\
8.719396\end{array}$ & $\begin{array}{l}42.27 \\
42.03 \\
41.78 \\
41.57 \\
41.30 \\
41.08 \\
40.85 \\
40.63 \\
40.40\end{array}$ & $\begin{array}{r}11.302919 \\
.300383 \\
.297861 \\
.295354 \\
.292860 \\
.290382 \\
.287917 \\
.285466 \\
.283028 \\
11.280604\end{array}$ & $\begin{array}{l}9 \\
8 \\
7 \\
6 \\
5 \\
4 \\
3 \\
2 \\
1 \\
0\end{array}$ \\
\hline ' & Cosine. & D. 1. & Sine. & D. 1". & Cotang. & D. 1". & Tang. & ' \\
\hline
\end{tabular}




\begin{tabular}{|c|c|c|c|c|c|c|c|c|}
\hline ' & Sine. & D. 1". & Cosine. & D. $1^{\prime \prime}$. & Tang. & D. 1". & Cotang. & ' \\
\hline \begin{tabular}{r|}
0 \\
1 \\
2 \\
3 \\
4 \\
5 \\
6 \\
7 \\
8 \\
9 \\
10
\end{tabular} & $\begin{array}{r}8.718800 \\
.721204 \\
.723595 \\
.7259 \% 2 \\
.728337 \\
.730688 \\
.73302 \% \\
.735354 \\
.737667 \\
.739969 \\
.742259\end{array}$ & $\begin{array}{l}40.07 \\
39.85 \\
39.62 \\
39.42 \\
39.18 \\
38.98 \\
38.78 \\
38.55 \\
38.37 \\
38.17 \\
37.95\end{array}$ & $\begin{array}{r}9.999404 \\
.999398 \\
.999391 \\
.999384 \\
.999378 \\
.999371 \\
.999364 \\
.999357 \\
.999350 \\
.999343 \\
.999336\end{array}$ & $\begin{array}{l}.10 \\
.12 \\
.12 \\
.10 \\
.12 \\
.12 \\
.12 \\
.12 \\
.12 \\
.12 \\
.12\end{array}$ & $\begin{array}{r}8.719396 \\
.721806 \\
.724204 \\
.726588 \\
.728959 \\
.731317 \\
.733663 \\
.735996 \\
.738317 \\
.740626 \\
.742922\end{array}$ & $\begin{array}{l}40.17 \\
39.97 \\
39.73 \\
39.52 \\
39.30 \\
39.10 \\
38.88 \\
38.68 \\
38.48 \\
38.27 \\
38.08\end{array}$ & $\begin{array}{r}11.280604 \\
.278194 \\
.275796 \\
.273412 \\
.271041 \\
.268683 \\
.266337 \\
.264004 \\
.261683 \\
.259374 \\
.257078\end{array}$ & $\begin{array}{l}60 \\
59 \\
58 \\
57 \\
56 \\
55 \\
54 \\
53 \\
52 \\
51 \\
50\end{array}$ \\
\hline $\begin{array}{l}11 \\
12 \\
13 \\
14 \\
15 \\
16 \\
17 \\
18 \\
19 \\
20\end{array}$ & $\begin{array}{r}8.744536 \\
.746802 \\
.749055 \\
.751297 \\
.753528 \\
.755 \% 47 \\
.75 \% 955 \\
.760151 \\
.762337 \\
.764511\end{array}$ & $\begin{array}{l}37.77 \\
37.55 \\
37.37 \\
37.18 \\
36.98 \\
36.80 \\
36.60 \\
36.43 \\
36.23 \\
36.07\end{array}$ & $\begin{array}{r}9.999329 \\
.999322 \\
.999315 \\
.999308 \\
.999301 \\
.999294 \\
.999287 \\
.999279 \\
.999272 \\
.999265\end{array}$ & $\begin{array}{l}.12 \\
.12 \\
.12 \\
.12 \\
.12 \\
.12 \\
.13 \\
.12 \\
.12 \\
.13\end{array}$ & $\begin{array}{r}8.745207 \\
.747479 \\
.749740 \\
.751989 \\
.754227 \\
.756453 \\
.758668 \\
.760872 \\
.763065 \\
.765246\end{array}$ & $\begin{array}{l}37.87 \\
37.68 \\
37.48 \\
37.30 \\
37.10 \\
36.92 \\
36.73 \\
36.55 \\
36.35 \\
36.18\end{array}$ & $\begin{array}{r}11.254793 \\
.252521 \\
.250260 \\
.248011 \\
.245773 \\
.243547 \\
.241332 \\
.239128 \\
.236935 \\
.234754\end{array}$ & $\begin{array}{l}49 \\
48 \\
47 \\
46 \\
45 \\
44 \\
43 \\
42 \\
41 \\
40\end{array}$ \\
\hline $\begin{array}{l}21 \\
22 \\
23 \\
24 \\
25 \\
26 \\
27 \\
28 \\
29 \\
30\end{array}$ & $\begin{array}{r}8.766675 \\
768828 \\
.70970 \\
.7 \% 3101 \\
.75223 \\
.77333 \\
.779434 \\
.781524 \\
.783605 \\
.785675\end{array}$ & $\begin{array}{l}35.88 \\
35.70 \\
35.52 \\
35.37 \\
35.17 \\
35.02 \\
34.83 \\
34.68 \\
34.50 \\
34.35\end{array}$ & $\begin{array}{r}9.999257 \\
.999250 \\
.999242 \\
.999235 \\
.999227 \\
.999220 \\
.999212 \\
.999205 \\
.999197 \\
.999189\end{array}$ & $\begin{array}{l}.12 \\
.13 \\
.12 \\
.13 \\
.12 \\
.13 \\
.12 \\
.13 \\
.13 \\
.13\end{array}$ & $\begin{array}{r}8.767417 \\
.769578 \\
.71727 \\
.773866 \\
.775995 \\
.778114 \\
.780222 \\
.782320 \\
.78408 \\
.786486\end{array}$ & $\begin{array}{l}36.02 \\
35.82 \\
35.65 \\
35.48 \\
35.32 \\
35.13 \\
34.97 \\
34.80 \\
34.63 \\
34.47\end{array}$ & $\begin{array}{r}11.232583 \\
.230422 \\
.228273 \\
.226134 \\
.224005 \\
.221886 \\
.219778 \\
.217680 \\
.215592 \\
.213514\end{array}$ & $\begin{array}{l}39 \\
38 \\
371 \\
36 \\
35 \\
34 \\
33 \\
32 \\
31 \\
30\end{array}$ \\
\hline $\begin{array}{l}31 \\
32 \\
33 \\
34 \\
35 \\
36 \\
37^{\prime \prime} \\
38 \\
39 \\
40\end{array}$ & $\begin{array}{r}8.787736 \\
.789787 \\
.791828 \\
.793859 \\
.795881 \\
.797894 \\
.799897 \\
.801892 \\
.803876 \\
.805852\end{array}$ & $\begin{array}{l}34.18 \\
34.02 \\
33.85 \\
33.70 \\
33.55 \\
33.38 \\
33.25 \\
33.07 \\
32.93 \\
32.78\end{array}$ & $\begin{array}{r}9.999181 \\
.999174 \\
.999166 \\
.999158 \\
.999150 \\
.999142 \\
.999134 \\
.999126 \\
.999118 \\
.999110\end{array}$ & $\begin{array}{l}.12 \\
.13 \\
.13 \\
.13 \\
.13 \\
.13 \\
.13 \\
.13 \\
.13 \\
.13\end{array}$ & $\begin{array}{r}8.788554 \\
.790613 \\
.792662 \\
.794701 \\
.796731 \\
.798752 \\
.800763 \\
.802765 \\
.804758 \\
.806742\end{array}$ & $\begin{array}{l}34.32 \\
34.15 \\
33.98 \\
33.83 \\
33.68 \\
33.52 \\
33.37 \\
33.22 \\
33.07 \\
32.92\end{array}$ & $\begin{array}{r}11.211446 \\
.209387 \\
.207338 \\
.205299 \\
.203269 \\
.201218 \\
.199237 \\
.197235 \\
.195242 \\
.193258\end{array}$ & $\begin{array}{l}29 \\
28 \\
27 \\
26 \\
25 \\
24 \\
23 \\
22 \\
21 \\
20\end{array}$ \\
\hline $\begin{array}{l}41 \\
42 \\
43 \\
44 \\
45 \\
46 \\
47 \\
48 \\
49 \\
50\end{array}$ & $\begin{array}{r}8.807819 \\
.809777 \\
.811726 \\
.813667 \\
.815599 \\
.817522 \\
.819436 \\
.821343 \\
.823240 \\
.825130\end{array}$ & $\begin{array}{l}32.63 \\
32.48 \\
32.35 \\
32.20 \\
32.05 \\
31.90 \\
31.78 \\
31.62 \\
31.50 \\
31.35\end{array}$ & $\begin{array}{r}9.999102 \\
.999094 \\
.999086 \\
.999077 \\
.999069 \\
.999061 \\
.999053 \\
.999044 \\
.999036 \\
.999027\end{array}$ & $\begin{array}{l}.13 \\
.13 \\
.15 \\
.13 \\
.13 \\
.13 \\
.15 \\
.13 \\
.15 \\
.13\end{array}$ & $\begin{array}{r}8.808717 \\
.810683 \\
.812641 \\
.814589 \\
.816529 \\
.818461 \\
.820384 \\
.822298 \\
.824205 \\
.826103\end{array}$ & $\begin{array}{l}32.67 \\
32.63 \\
32.47 \\
32.33 \\
32.20 \\
32.05 \\
31.90 \\
31.78 \\
31.63 \\
31.48\end{array}$ & $\begin{array}{r}11.191283 \\
.18931 \% \\
.187359 \\
.185411 \\
.183471 \\
.181539 \\
.179616 \\
.177702 \\
.175795 \\
.173897\end{array}$ & $\begin{array}{l}19 \\
18 \\
17 \\
16 \\
15 \\
14 \\
13 \\
12 \\
11 \\
10 \\
\end{array}$ \\
\hline $\begin{array}{l}51 \\
52 \\
53 \\
54 \\
55 \\
56 \\
57 \\
58 \\
59 \\
60\end{array}$ & $\begin{array}{r}8.827011 \\
.828881 \\
.830749 \\
.832607 \\
.834456 \\
.836297 \\
.838130 \\
.839956 \\
.841774 \\
8.843585 \\
\end{array}$ & $\begin{array}{l}31.22 \\
31.08 \\
30.97 \\
30.82 \\
30.68 \\
30.55 \\
30.43 \\
30.30 \\
30.18\end{array}$ & $\begin{array}{r}9.999019 \\
.999010 \\
.999002 \\
.998993 \\
.998984 \\
.998976 \\
.998967 \\
.998958 \\
.998950 \\
9.998941 \\
\end{array}$ & $\begin{array}{l}.15 \\
.13 \\
.15 \\
.15 \\
.13 \\
.15 \\
.15 \\
.13 \\
.15\end{array}$ & $\begin{array}{r}8.827992 \\
.8298 \pi 4 \\
.831748 \\
.833613 \\
.835471 \\
.837321 \\
.839163 \\
.840998 \\
.842825 \\
8.844644 \\
\end{array}$ & $\begin{array}{l}31.37 \\
31.23 \\
31.08 \\
30.97 \\
30.83 \\
30.70 \\
30.58 \\
30.45 \\
30.32\end{array}$ & $\begin{array}{r}11.172008 \\
.170126 \\
.168252 \\
.166387 \\
.164529 \\
.162679 \\
.160837 \\
.159002 \\
.1571 \% 5 \\
11.155356 \\
\end{array}$ & $\begin{array}{l}9 \\
8 \\
7 \\
6 \\
5 \\
4 \\
3 \\
2 \\
1 \\
0\end{array}$ \\
\hline & & & ne & $1^{\circ}$ & Cotang. & D. $1^{\circ}$. & Tang. & ' \\
\hline
\end{tabular}




\begin{tabular}{|c|c|c|c|c|c|c|c|c|}
\hline ' & Sine. & D. 1". & Cosine. & D. $1^{\prime \prime}$. & Tang. & D. $1^{\prime \prime}$ & Cotang. & ' \\
\hline $\begin{array}{r}0 \\
1 \\
2 \\
3 \\
4 \\
5 \\
6 \\
7 \\
8 \\
9 \\
10\end{array}$ & $\begin{array}{r}8.843585 \\
.845387 \\
.847183 \\
.848971 \\
.850751 \\
.852525 \\
.854291 \\
.856049 \\
.857801 \\
.859546 \\
.861283\end{array}$ & $\begin{array}{l}30.03 \\
29.93 \\
29.80 \\
29.67 \\
29.57 \\
29.43 \\
29.30 \\
29.20 \\
29.08 \\
28.95 \\
28.85\end{array}$ & $\begin{array}{r}9.998941 \\
.998932 \\
.998923 \\
.998914 \\
.998905 \\
.998896 \\
.998587 \\
.998878 \\
.998869 \\
.998860 \\
.998851\end{array}$ & $\begin{array}{l}.15 \\
.15 \\
.15 \\
.15 \\
.15 \\
.15 \\
.15 \\
.15 \\
.15 \\
.15 \\
.17\end{array}$ & $\begin{array}{r}8.844644 \\
.846455 \\
.848260 \\
.850057 \\
.851846 \\
.853628 \\
.855403 \\
.857171 \\
.858932 \\
.860686 \\
.862433\end{array}$ & $\begin{array}{l}30.18 \\
30.08 \\
29.95 \\
29.82 \\
29.70 \\
29.58 \\
29.47 \\
29.35 \\
29.23 \\
29.12 \\
29.00\end{array}$ & $\begin{array}{r}11.853556 \\
.153545 \\
.151740 \\
.149943 \\
.148154 \\
.1463 \tau 2 \\
.144597 \\
.142829 \\
.141068 \\
.139314 \\
.13756 \tau\end{array}$ & $\begin{array}{l}60 \\
59 \\
58 \\
57 \\
56 \\
55 \\
54 \\
53 \\
52 \\
51 \\
50\end{array}$ \\
\hline $\begin{array}{l}11 \\
12 \\
13 \\
14 \\
15 \\
16 \\
17 \\
18 \\
19 \\
20\end{array}$ & $\begin{array}{r}8.863014 \\
.864738 \\
.866455 \\
.868165 \\
.869868 \\
.871565 \\
.873255 \\
.874938 \\
.876615 \\
.878285\end{array}$ & $\begin{array}{l}28.73 \\
28.62 \\
28.50 \\
28.38 \\
28.28 \\
28.17 \\
28.05 \\
27.95 \\
27.83 \\
27.73\end{array}$ & $\begin{array}{r}9.998841 \\
.998832 \\
.998823 \\
.998813 \\
.998804 \\
.998795 \\
.998785 \\
.998776 \\
.998766 \\
.998757\end{array}$ & $\begin{array}{l}.15 \\
.15 \\
.17 \\
.15 \\
.15 \\
.17 \\
.15 \\
.17 \\
.15 \\
.17\end{array}$ & $\begin{array}{r}8.864173 \\
.865906 \\
.867632 \\
.869351 \\
.871064 \\
.87270 \\
.874469 \\
.876162 \\
.877849 \\
.879529\end{array}$ & $\begin{array}{l}28.88 \\
28.77 \\
28.65 \\
28.55 \\
28.43 \\
28.32 \\
28.22 \\
28.12 \\
28.00 \\
27.88\end{array}$ & $\begin{array}{r}11.13582 \\
.134094 \\
.132368 \\
.130649 \\
.128936 \\
.127230 \\
.125531 \\
.123838 \\
.122151 \\
.12047 !\end{array}$ & $\begin{array}{l}49 \\
48 \\
47 \\
46 \\
45 \\
44 \\
43 \\
42 \\
41 \\
40\end{array}$ \\
\hline $\begin{array}{l}21 \\
22 \\
23 \\
24 \\
25 \\
26 \\
27 \\
28 \\
29 \\
30\end{array}$ & $\begin{array}{r}8.879949 \\
.881607 \\
.883258 \\
.884903 \\
.886542 \\
.888174 \\
.889801 \\
.891421 \\
.893035 \\
.894643\end{array}$ & $\begin{array}{l}27.63 \\
27.52 \\
27.42 \\
27.32 \\
27.20 \\
27.12 \\
27.00 \\
26.90 \\
26.80 \\
26.72\end{array}$ & $\begin{array}{r}9.998747 \\
.998738 \\
.998728 \\
.998718 \\
.998708 \\
.998699 \\
.998689 \\
.998679 \\
.998669 \\
.998659\end{array}$ & $\begin{array}{l}.15 \\
.17 \\
.17 \\
.17 \\
.17 \\
.17 \\
.17 \\
.17 \\
.17 \\
.17\end{array}$ & $\begin{array}{r}8.881202 \\
.882869 \\
.884530 \\
.886185 \\
.887833 \\
.889476 \\
.891112 \\
.892742 \\
.894366 \\
.895984\end{array}$ & $\begin{array}{l}27.78 \\
27.68 \\
27.58 \\
27.47 \\
27.38 \\
27.27 \\
27.17 \\
27.07 \\
26.97 \\
26.87\end{array}$ & $\begin{array}{r}11.118798 \\
.117131 \\
.115470 \\
.113815 \\
.112167 \\
.110524 \\
.108888 \\
.107258 \\
.105634 \\
.104016\end{array}$ & $\begin{array}{l}39 \\
38 \\
37 \\
36 \\
35 \\
34 \\
33 \\
32 \\
31 \\
30\end{array}$ \\
\hline $\begin{array}{l}31 \\
32 \\
33 \\
34 \\
35 \\
36 \\
37 \\
38 \\
39 \\
40\end{array}$ & $\begin{array}{r}8.896246 \\
.897842 \\
.899432 \\
.901017 \\
.902596 \\
.904169 \\
.905736 \\
.907297 \\
.908853 \\
.910404\end{array}$ & $\begin{array}{l}26.60 \\
26.50 \\
26.42 \\
26.32 \\
26.22 \\
26.12 \\
26.02 \\
25.93 \\
25.85 \\
25.75\end{array}$ & $\begin{array}{r}9.998649 \\
.998639 \\
.998629 \\
.998619 \\
.998609 \\
.998599 \\
.998589 \\
.998578 \\
.998568 \\
.998558\end{array}$ & $\begin{array}{l}.17 \\
.17 \\
.17 \\
.17 \\
.17 \\
.17 \\
.18 \\
.17 \\
.17 \\
.17\end{array}$ & $\begin{array}{r}8.897596 \\
.899203 \\
.900803 \\
.902398 \\
.903987 \\
.905570 \\
.907147 \\
.908719 \\
.910285 \\
.911846\end{array}$ & $\begin{array}{l}26.78 \\
26.67 \\
26.58 \\
26.48 \\
26.88 \\
26.28 \\
26.20 \\
26.10 \\
26.02 \\
25.92\end{array}$ & $\begin{array}{r}11.102404 \\
.100797 \\
.099197 \\
.097602 \\
.096013 \\
.094430 \\
.092853 \\
.091281 \\
.089715 \\
.088154\end{array}$ & $\begin{array}{l}29 \\
28 \\
27 \\
26 \\
25 \\
24 \\
23 \\
22 \\
21 \\
20\end{array}$ \\
\hline $\begin{array}{l}41 \\
42 \\
43 \\
44 \\
45 \\
46 \\
47 \\
48 \\
49 \\
50\end{array}$ & $\begin{array}{r}8.911949 \\
.913488 \\
.915022 \\
.916550 \\
.918073 \\
.919591 \\
.921103 \\
.922610 \\
.924112 \\
.925609\end{array}$ & $\begin{array}{l}25.65 \\
25.57 \\
25.47 \\
25.38 \\
25.30 \\
25.20 \\
25.12 \\
25.03 \\
24.95 \\
24.85\end{array}$ & $\begin{array}{r}9.998548 \\
.998537 \\
.998527 \\
.998516 \\
.998506 \\
.998495 \\
.998485 \\
.998474 \\
.998464 \\
.998453\end{array}$ & $\begin{array}{l}.18 \\
.17 \\
.18 \\
.17 \\
.18 \\
.17 \\
.18 \\
.17 \\
.18 \\
.18\end{array}$ & $\begin{array}{r}8.913401 \\
.914951 \\
.916495 \\
.918034 \\
.919568 \\
.921096 \\
.922619 \\
.924136 \\
.925649 \\
.927156\end{array}$ & $\begin{array}{l}25.83 \\
25.73 \\
25.63 \\
25.57 \\
25.47 \\
25.38 \\
25.28 \\
25.22 \\
25.12 \\
25.03\end{array}$ & $\begin{array}{r}11.086599 \\
.085049 \\
.083505 \\
.081966 \\
.080432 \\
.078904 \\
.077381 \\
.075864 \\
.074351 \\
.072844\end{array}$ & $\begin{array}{l}19 \\
18 \\
17 \\
16 \\
15 \\
14 \\
13 \\
12 \\
11 \\
10\end{array}$ \\
\hline $\begin{array}{l}51 \\
52 \\
53 \\
54 \\
55 \\
56 \\
57 \\
58 \\
59 \\
60\end{array}$ & $\begin{array}{r}8.927100 \\
.928587 \\
.930068 \\
.931544 \\
.938015 \\
.934481 \\
.935942 \\
.937398 \\
.938850 \\
8.940296\end{array}$ & $\begin{array}{l}24.78 \\
24.68 \\
24.60 \\
24.52 \\
24.43 \\
24.35 \\
24.27 \\
24.20 \\
24.10\end{array}$ & $\begin{array}{r}9.998442 \\
.998431 \\
.998421 \\
.998410 \\
.998399 \\
.998388 \\
.998377 \\
.998366 \\
.998355 \\
9.998344\end{array}$ & $\begin{array}{l}.18 \\
.17 \\
.18 \\
.18 \\
.18 \\
.18 \\
.18 \\
.18 \\
.18\end{array}$ & $\begin{array}{r}8.928658 \\
.930155 \\
.931647 \\
.933134 \\
.934616 \\
.936093 \\
.937565 \\
.939032 \\
.940494 \\
8.941952\end{array}$ & $\begin{array}{l}24.95 \\
24.87 \\
24.78 \\
24.70 \\
24.62 \\
24.53 \\
24.45 \\
24.37 \\
24.30\end{array}$ & $\begin{array}{r}11.071342 \\
.069845 \\
.068353 \\
.066866 \\
.065384 \\
.063907 \\
.062435 \\
.060968 \\
.059506 \\
11.058048\end{array}$ & $\begin{array}{l}9 \\
8 \\
7 \\
6 \\
5 \\
4 \\
3 \\
2 \\
1 \\
0\end{array}$ \\
\hline ' & Cosine. & D. 1". & Sine. & D. 1". & Cotang. & D. 1". & Tang. & 1 \\
\hline
\end{tabular}




\begin{tabular}{|c|c|c|c|c|c|c|c|c|}
\hline ' & Sin & D. $1^{\prime \prime}$. & Cosine. & D. $1^{\prime \prime}$. & Tang. & D. 1". & Cotang. & 1 \\
\hline $\begin{array}{r}0 \\
1 \\
2 \\
3 \\
4 \\
5 \\
6 \\
7 \\
8 \\
9 \\
10\end{array}$ & $\begin{array}{r}8.940296 \\
.941738 \\
.943174 \\
.944606 \\
.946034 \\
.947456 \\
.948874 \\
.950287 \\
.951696 \\
.953100 \\
.954499\end{array}$ & $\begin{array}{l}24.03 \\
23.93 \\
23.87 \\
23.80 \\
23.70 \\
23.63 \\
23.55 \\
23.48 \\
23.40 \\
23.32 \\
23.25\end{array}$ & $\begin{array}{r}9.998344 \\
.998333 \\
.998322 \\
.998311 \\
.998300 \\
.998289 \\
.998277 \\
.998266 \\
.998255 \\
.998243 \\
.998232\end{array}$ & $\begin{array}{l}.18 \\
.18 \\
.18 \\
.18 \\
.18 \\
.20 \\
.18 \\
.18 \\
.20 \\
.18 \\
.20\end{array}$ & $\begin{array}{r}8.941952 \\
.943404 \\
.944852 \\
.946295 \\
.947734 \\
.949168 \\
.950597 \\
.952021 \\
.953441 \\
.954856 \\
.95626 \%\end{array}$ & $\begin{array}{l}24.2 n \\
24.13 \\
24.05 \\
23.98 \\
23.90 \\
23.82 \\
23.73 \\
23.67 \\
23.58 \\
23.52 \\
23.45\end{array}$ & $\begin{array}{r}11.058048 \\
.056596 \\
.055148 \\
.053705 \\
.0522666 \\
.050832 \\
.049103 \\
.047979 \\
.046559 \\
.045144 \\
.043733\end{array}$ & $\begin{array}{l}60 \\
59 \\
58 \\
57 \\
56 \\
55 \\
54 \\
53 \\
52 \\
51 \\
50\end{array}$ \\
\hline $\begin{array}{l}11 \\
12 \\
13 \\
14 \\
15 \\
16 \\
1 \% \\
18 \\
19 \\
20\end{array}$ & $\begin{array}{r}8.955894 \\
.957284 \\
.958670 \\
.960052 \\
.961429 \\
.962801 \\
.964170 \\
.965534 \\
.966893 \\
.968249\end{array}$ & $\begin{array}{l}23.17 \\
23.10 \\
23.03 \\
22.95 \\
22.87 \\
22.82 \\
22.73 \\
22.65 \\
22.60 \\
22.52\end{array}$ & $\begin{array}{r}9.998220 \\
.998209 \\
.998197 \\
.998186 \\
.998174 \\
.998163 \\
.998151 \\
.998139 \\
.998128 \\
.998116\end{array}$ & $\begin{array}{l}.18 \\
.20 \\
.18 \\
.20 \\
.18 \\
.20 \\
.20 \\
.18 \\
.20 \\
.20\end{array}$ & $\begin{array}{r}8.95 \% 6 \% 4 \\
.9590 \% 5 \\
.960473 \\
.961866 \\
.963255 \\
.964639 \\
.966019 \\
.967394 \\
.968 \% 66 \\
.970133\end{array}$ & $\begin{array}{l}23.35 \\
23.30 \\
23.22 \\
23.15 \\
23.07 \\
23.00 \\
22.92 \\
22.87 \\
22.78 \\
22.72\end{array}$ & $\begin{array}{r}11.042326 \\
.040925 \\
.039527 \\
.038134 \\
.036 \% 45 \\
.035361 \\
.033981 \\
.032606 \\
.031234 \\
.029867\end{array}$ & $\begin{array}{l}49 \\
48 \\
47 \\
46 \\
45 \\
44 \\
43 \\
42 \\
41 \\
40\end{array}$ \\
\hline $\begin{array}{l}21 \\
22 \\
23 \\
24 \\
25 \\
26 \\
27 \\
28 \\
29 \\
30\end{array}$ & $\begin{array}{r}8.969600 \\
.970947 \\
.972289 \\
.973628 \\
.974962 \\
.976293 \\
.977619 \\
.978941 \\
.980259 \\
.981573\end{array}$ & $\begin{array}{l}22.45 \\
22.37 \\
22.32 \\
22.23 \\
22.18 \\
22.10 \\
22.03 \\
21.97 \\
21.90 \\
21.83\end{array}$ & $\begin{array}{r}9.998104 \\
.998092 \\
.998080 \\
.998068 \\
.998056 \\
.998044 \\
.998032 \\
.998020 \\
.998008 \\
.997996\end{array}$ & $\begin{array}{l}.20 \\
.20 \\
.20 \\
.20 \\
.20 \\
.20 \\
.20 \\
.20 \\
.20 \\
.20\end{array}$ & $\begin{array}{r}8.971496 \\
.972855 \\
.974209 \\
.975560 \\
.976906 \\
.978248 \\
.979586 \\
.980921 \\
.982251 \\
.983577\end{array}$ & $\begin{array}{l}22.65 \\
22.57 \\
22.52 \\
22.43 \\
22.37 \\
22.30 \\
22.25 \\
22.17 \\
22.10 \\
22.03\end{array}$ & $\begin{array}{r}11.028504 \\
.027145 \\
.025791 \\
.024440 \\
.023094 \\
.021752 \\
.020414 \\
.019079 \\
.01749 \\
.016423\end{array}$ & $\begin{array}{l}39 \\
38 \\
37 \\
36 \\
35 \\
34 \\
33 \\
32 \\
31 \\
30\end{array}$ \\
\hline $\begin{array}{l}31 \\
32 \\
33 \\
34 \\
35 \\
36 \\
37 \\
38 \\
39 \\
40\end{array}$ & $\begin{array}{r}8.982883 \\
.984189 \\
.985491 \\
.986789 \\
.988083 \\
.989374 \\
.990660 \\
.991943 \\
.993222 \\
.994497\end{array}$ & $\begin{array}{l}21.77 \\
21.72 \\
21.63 \\
21.57 \\
21.52 \\
21.43 \\
21.38 \\
21.32 \\
21.25 \\
21.18\end{array}$ & $\begin{array}{r}9.997984 \\
.997972 \\
.997959 \\
.997947 \\
.997935 \\
.997922 \\
.997910 \\
.997897 \\
.997885 \\
.997872\end{array}$ & $\begin{array}{l}.20 \\
.22 \\
.20 \\
.20 \\
.22 \\
.20 \\
.22 \\
.20 \\
.22 \\
.20\end{array}$ & $\begin{array}{r}8.984899 \\
.986217 \\
.98753 \% \\
.988842 \\
.990149 \\
.991451 \\
.992750 \\
.994045 \\
.995337 \\
.996624\end{array}$ & $\begin{array}{l}21.97 \\
21.92 \\
21.83 \\
21.78 \\
21.70 \\
21.65 \\
21.58 \\
21.53 \\
21.45 \\
21.40\end{array}$ & $\begin{array}{r}11.015101 \\
.013783 \\
.012468 \\
.011158 \\
.009851 \\
.008549 \\
.007250 \\
.005955 \\
.004663 \\
.003376\end{array}$ & $\begin{array}{l}29 \\
28 \\
27 \\
26 \\
25 \\
24 \\
23 \\
22 \\
21 \\
20\end{array}$ \\
\hline $\begin{array}{l}41 \\
42 \\
43 \\
44 \\
45 \\
46 \\
47 \\
48 \\
49 \\
50\end{array}$ & $\begin{array}{r}8.995768 \\
.997036 \\
.998: 99 \\
8.999560 \\
9.000816 \\
.002069 \\
.003318 \\
.004563 \\
.005805 \\
.007044\end{array}$ & $\begin{array}{l}21.13 \\
21.05 \\
21.02 \\
20.93 \\
20.88 \\
20.82 \\
20.75 \\
20.70 \\
20.65 \\
20.57\end{array}$ & $\begin{array}{r}9.997860 \\
.997847 \\
.997835 \\
.997822 \\
.997809 \\
.997797 \\
.997784 \\
.997771 \\
.997758 \\
.997745\end{array}$ & $\begin{array}{l}.22 \\
.20 \\
.22 \\
.22 \\
.20 \\
.22 \\
.22 \\
.22 \\
.22 \\
.22\end{array}$ & $\begin{array}{r}8.997908 \\
8.999188 \\
9.000465 \\
.001738 \\
.003007 \\
.004272 \\
.005534 \\
.006792 \\
.008047 \\
.009298\end{array}$ & $\begin{array}{l}21.33 \\
21.28 \\
21.22 \\
21.15 \\
21.08 \\
21.03 \\
20.97 \\
20.92 \\
20.85 \\
20.80\end{array}$ & $\begin{array}{r}11.002092 \\
11.000812 \\
10.999535 \\
.998262 \\
.996993 \\
.995728 \\
.994466 \\
.993208 \\
.991953 \\
.990702\end{array}$ & $\begin{array}{l}19 \\
18 \\
17 \\
16 \\
15 \\
14 \\
13 \\
12 \\
11 \\
10\end{array}$ \\
\hline $\begin{array}{l}51 \\
52 \\
53 \\
54 \\
55 \\
56 \\
57 \\
58 \\
59 \\
60\end{array}$ & $\begin{array}{r}9.008278 \\
.009510 \\
.010737 \\
.011962 \\
.013182 \\
.014400 \\
.015613 \\
.016824 \\
.018031 \\
9.019235\end{array}$ & $\begin{array}{l}20.53 \\
20.45 \\
20.42 \\
20.33 \\
20.30 \\
20.22 \\
20.18 \\
20.12 \\
20.07\end{array}$ & $\begin{array}{r}9.997732 \\
.997719 \\
.997706 \\
.997693 \\
.997680 \\
.997667 \\
.997654 \\
.997641 \\
.997628 \\
9.997614\end{array}$ & $\begin{array}{l}.22 \\
.22 \\
.22 \\
.22 \\
.22 \\
.22 \\
.22 \\
.22 \\
.23\end{array}$ & $\begin{array}{r}9.010546 \\
.011790 \\
.013031 \\
.014268 \\
.015502 \\
.016732 \\
.017959 \\
.019183 \\
.020403 \\
9.021620\end{array}$ & $\begin{array}{l}20.73 \\
20.68 \\
20.62 \\
20.57 \\
20.50 \\
20.45 \\
20.40 \\
20.33 \\
20.28\end{array}$ & $\begin{array}{r}10.989454 \\
.988210 \\
.986969 \\
.985732 \\
.984498 \\
.989268 \\
.982041 \\
.980817 \\
.979597 \\
10.978380\end{array}$ & $\begin{array}{l}9 \\
8 \\
7 \\
6 \\
5 \\
4 \\
3 \\
2 \\
1 \\
0\end{array}$ \\
\hline 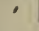 & Cosine. & D. $1^{*}$. & Sine. & D. $1^{\prime}$. & Cotang. & D. $1^{\circ}$. & Tang. & ' \\
\hline
\end{tabular}




\begin{tabular}{|c|c|c|c|c|c|c|c|c|}
\hline 1 & Sine. & D. $1^{\prime \prime}$. & Cosine. & D. $1^{\prime \prime}$. & Tang. & D. $1^{\prime}$. & Cotang. & ' \\
\hline $\begin{array}{r}0 \\
1 \\
2 \\
3 \\
4 \\
5 \\
6 \\
7 \\
8 \\
9 \\
10\end{array}$ & $\begin{array}{r}9.019235 \\
.020435 \\
.021632 \\
.022825 \\
.024016 \\
.025203 \\
.026386 \\
.027567 \\
.028744 \\
.029918 \\
.031089\end{array}$ & $\begin{array}{l}20.00 \\
19.95 \\
19.88 \\
19.85 \\
19.78 \\
19.72 \\
19.68 \\
19.62 \\
19.57 \\
1952 \\
19.47\end{array}$ & $\begin{array}{r}9.997614 \\
.997601 \\
.997588 \\
.997574 \\
.997561 \\
.997547 \\
.997534 \\
.997520 \\
.997507 \\
.997493 \\
.997480\end{array}$ & $\begin{array}{l}.22 \\
.22 \\
.23 \\
.22 \\
.23 \\
.22 \\
.23 \\
.22 \\
.23 \\
.22 \\
.23\end{array}$ & $\begin{array}{r}9.021620 \\
.022834 \\
.024044 \\
.025251 \\
.026455 \\
.027655 \\
.028852 \\
.030046 \\
.031237 \\
.032425 \\
.033609\end{array}$ & $\begin{array}{l}20.23 \\
20.17 \\
20.12 \\
20.0 \% \\
20.00 \\
19.95 \\
19.90 \\
19.85 \\
19.80 \\
19.73 \\
19.70\end{array}$ & $\begin{array}{r}10.978380 \\
.977166 \\
.975956 \\
.974749 \\
.973545 \\
.972345 \\
.971148 \\
.969954 \\
.968763 \\
.967575 \\
.966391\end{array}$ & $\begin{array}{l}60 \\
59 \\
58 \\
57 \\
56 \\
55 \\
54 \\
53 \\
52 \\
51 \\
50\end{array}$ \\
\hline $\begin{array}{l}11 \\
12 \\
13 \\
14 \\
15 \\
16 \\
17 \\
18 \\
19 \\
20\end{array}$ & $\begin{array}{r}9.032257 \\
.033421 \\
.034582 \\
.035741 \\
.036896 \\
.038048 \\
.039197 \\
.040342 \\
.041485 \\
.042625\end{array}$ & $\begin{array}{l}19.40 \\
19.35 \\
19.32 \\
19.25 \\
19.20 \\
19.15 \\
19.08 \\
19.05 \\
19.00 \\
18.95\end{array}$ & $\begin{array}{r}9.997466 \\
.997452 \\
.997439 \\
.997425 \\
.997411 \\
.997397 \\
.997383 \\
.997369 \\
.997355 \\
.997341\end{array}$ & $\begin{array}{l}.23 \\
.22 \\
.23 \\
.23 \\
.23 \\
.23 \\
.23 \\
.23 \\
.23 \\
.23\end{array}$ & $\begin{array}{r}9.034791 \\
.035969 \\
.037144 \\
.038316 \\
.039485 \\
.040651 \\
.041813 \\
.042973 \\
.044130 \\
.045284\end{array}$ & $\begin{array}{l}19.63 \\
19.58 \\
19.53 \\
19.48 \\
19.43 \\
19.37 \\
19.33 \\
19.28 \\
19.23 \\
19.17\end{array}$ & $\begin{array}{r}10.965209 \\
.964031 \\
.962856 \\
.961684 \\
.960515 \\
.959349 \\
.958187 \\
.957027 \\
.955870 \\
.954716\end{array}$ & $\begin{array}{l}49 \\
48 \\
47 \\
46 \\
45 \\
44 \\
43 \\
42 \\
41 \\
40\end{array}$ \\
\hline $\begin{array}{l}21 \\
22 \\
23 \\
24 \\
25 \\
26 \\
27 \\
28 \\
29 \\
30\end{array}$ & $\begin{array}{r}9.043762 \\
.044895 \\
.046026 \\
.047154 \\
.048279 \\
.049400 \\
.050519 \\
.051635 \\
.052749 \\
.053859\end{array}$ & $\begin{array}{l}18.88 \\
18.85 \\
18.80 \\
18.75 \\
18.68 \\
18.65 \\
18.60 \\
18.57 \\
18.50 \\
18.45\end{array}$ & $\begin{array}{r}9.997327 \\
.997313 \\
.997299 \\
.997285 \\
.997271 \\
.99725 \% \\
.997242 \\
.997228 \\
.997214 \\
.997199\end{array}$ & $\begin{array}{l}.23 \\
.23 \\
.23 \\
.23 \\
.23 \\
.25 \\
.23 \\
.23 \\
.25 \\
.23\end{array}$ & $\begin{array}{r}9.046434 \\
.047582 \\
.048727 \\
.049869 \\
.051008 \\
.052144 \\
.053277 \\
.054407 \\
.055535 \\
.056659\end{array}$ & $\begin{array}{l}19.13 \\
19.08 \\
19.03 \\
18.98 \\
18.93 \\
18.88 \\
18.83 \\
18.80 \\
18.73 \\
18.70\end{array}$ & $\begin{array}{r}10.953566 \\
.952418 \\
.951273 \\
.950131 \\
.948992 \\
.947856 \\
.946723 \\
.945593 \\
.944465 \\
.943341\end{array}$ & $\begin{array}{l}39 \\
38 \\
37 \\
36 \\
35 \\
34 \\
33 \\
32 \\
31 \\
30\end{array}$ \\
\hline $\begin{array}{l}31 \\
32 \\
33 \\
34 \\
35 \\
36 \\
37 \\
38 \\
39 \\
40\end{array}$ & $\begin{array}{r}9.054986 \\
.056071 \\
.057172 \\
.058271 \\
.059367 \\
.060460 \\
.061551 \\
.062639 \\
.063724 \\
.064806\end{array}$ & $\begin{array}{l}18.42 \\
18.35 \\
18.32 \\
18.27 \\
18.22 \\
18.18 \\
18.13 \\
18.08 \\
18.03 \\
17.98\end{array}$ & $\begin{array}{r}9.997185 \\
.9971 \% 0 \\
.997156 \\
.997141 \\
.997127 \\
.997112 \\
.997098 \\
.997083 \\
.997068 \\
.997053\end{array}$ & $\begin{array}{r}.25 \\
.23 \\
.25 \\
.23 \\
.25 \\
.23 \\
.25 \\
.25 \\
.25 \\
.23\end{array}$ & $\begin{array}{r}9.057881 \\
.058900 \\
.060016 \\
.061130 \\
.062240 \\
.063348 \\
.064453 \\
.065556 \\
.066655 \\
.067652\end{array}$ & $\begin{array}{l}18.65 \\
18.60 \\
18.57 \\
18.50 \\
18.47 \\
18.42 \\
18.38 \\
18.32 \\
18.28 \\
18.25\end{array}$ & $\begin{array}{r}10.942219 \\
.941100 \\
.939984 \\
.938870 \\
.937760 \\
.936652 \\
.935547 \\
.934444 \\
.933345 \\
.932248\end{array}$ & $\begin{array}{l}29 \\
28 \\
27 \\
26 \\
25 \\
24 \\
23 \\
22 \\
21 \\
20\end{array}$ \\
\hline $\begin{array}{l}41 \\
42 \\
43 \\
44 \\
45 \\
46 \\
47 \\
48 \\
49 \\
50\end{array}$ & $\begin{array}{r}9.065885 \\
.066962 \\
.068036 \\
.069107 \\
.070176 \\
.071242 \\
.072306 \\
.073366 \\
.074424 \\
.075480\end{array}$ & $\begin{array}{l}17.95 \\
17.90 \\
17.85 \\
17.82 \\
17.77 \\
17.73 \\
17.67 \\
17.63 \\
17.60 \\
17.55\end{array}$ & $\begin{array}{r}9.997039 \\
.997024 \\
.997009 \\
.996994 \\
.996979 \\
.996964 \\
.996949 \\
.996934 \\
.996919 \\
.996904\end{array}$ & $\begin{array}{l}.25 \\
.25 \\
.25 \\
.25 \\
.25 \\
.25 \\
.25 \\
.25 \\
.25 \\
.25\end{array}$ & $\begin{array}{r}9.068846 \\
.069938 \\
.071027 \\
.072113 \\
.073197 \\
.074278 \\
.075356 \\
.076432 \\
.077505 \\
.078576\end{array}$ & $\begin{array}{l}18.20 \\
18.15 \\
18.10 \\
18.07 \\
18.02 \\
17.97 \\
17.93 \\
17.88 \\
17.85 \\
17.80\end{array}$ & $\begin{array}{r}10.931154 \\
.930062 \\
.928973 \\
.927887 \\
.926803 \\
.925722 \\
.924644 \\
.923568 \\
.922495 \\
.921424\end{array}$ & $\begin{array}{l}19 \\
18 \\
17 \\
16 \\
15 \\
14 \\
13 \\
12 \\
11 \\
10\end{array}$ \\
\hline $\begin{array}{l}51 \\
52 \\
53 \\
54 \\
55 \\
56 \\
57 \\
58 \\
59 \\
60\end{array}$ & $\begin{array}{r}9.076533 \\
.077583 \\
.078631 \\
.079676 \\
.080719 \\
.081759 \\
.082797 \\
.083832 \\
.084864 \\
9.085894\end{array}$ & $\begin{array}{l}17.50 \\
17.47 \\
17.42 \\
17.38 \\
17.33 \\
17.30 \\
17.25 \\
17.20 \\
17.17\end{array}$ & $\begin{array}{r}9.996889 \\
.996874 \\
.996858 \\
.996843 \\
.996828 \\
.996812 \\
.996797 \\
.996782 \\
.996766 \\
9.996751\end{array}$ & $\begin{array}{l}.25 \\
.25 \\
.27 \\
.27 \\
.27 \\
.25 \\
.25 \\
.27 \\
.25\end{array}$ & $\begin{array}{r}9.079644 \\
.080710 \\
.081773 \\
.082833 \\
.083891 \\
.084947 \\
.086000 \\
.087050 \\
.088098 \\
9.089144\end{array}$ & $\begin{array}{l}17.77 \\
17.72 \\
17.67 \\
17.63 \\
17.60 \\
17.55 \\
17.50 \\
17.47 \\
17.43\end{array}$ & $\begin{array}{r}10.920356 \\
.919290 \\
.918227 \\
.917167 \\
.916109 \\
.915053 \\
.914000 \\
.912950 \\
.911902 \\
10.910856\end{array}$ & $\begin{array}{l}9 \\
8 \\
7 \\
6 \\
5 \\
4 \\
3 \\
2 \\
1 \\
0\end{array}$ \\
\hline 1 & Cosine. & D. 1". & Sine. & D. $1^{\prime \prime}$. & Cotang. & D. $1^{\prime \prime}$. & Tang. & 1 \\
\hline
\end{tabular}




\begin{tabular}{|c|c|c|c|c|c|c|c|c|}
\hline , & Sine. & D. $1^{\circ}$. & Cosine. & D. $1^{\prime \prime}$. & Tang. & D. $1^{\circ}$. & Cotang. & \\
\hline $\begin{array}{r}0 \\
1 \\
2 \\
3 \\
4 \\
5 \\
6 \\
7 \\
8 \\
9 \\
10 \\
11\end{array}$ & $\begin{array}{r}9085894 \\
.086922 \\
.087947 \\
.088970 \\
.089990 \\
.091008 \\
.092024 \\
.093037 \\
.094047 \\
.095056 \\
.096062 \\
9.097065\end{array}$ & $\begin{array}{l}17.13 \\
17.08 \\
17.05 \\
17.00 \\
16.97 \\
16.93 \\
16.88 \\
16.83 \\
16.82 \\
16.77 \\
16.72\end{array}$ & $\begin{array}{r}9.996751 \\
.996735 \\
.996720 \\
.996704 \\
.996688 \\
.996673 \\
.996657 \\
.996641 \\
.996625 \\
.996610 \\
.996594\end{array}$ & $\begin{array}{l}27 \\
.25 \\
.27 \\
.27 \\
.25 \\
.27 \\
.27 \\
.27 \\
.25 \\
.27 \\
.27\end{array}$ & $\begin{array}{r}9.089144 \\
.090187 \\
.091<28 \\
.092266 \\
.093302 \\
.094336 \\
.095367 \\
.096395 \\
.097422 \\
.098446 \\
.099468\end{array}$ & $\begin{array}{l}17.38 \\
17.35 \\
17.30 \\
17.27 \\
17.23 \\
17.18 \\
17.13 \\
17.12 \\
17.07 \\
17.03 \\
16.98\end{array}$ & $\begin{array}{r}10.910856 \\
.909813 \\
.905572 \\
.90 \div 734 \\
.906698 \\
.905664 \\
.904633 \\
.903605 \\
.902578 \\
.901554 \\
.900532\end{array}$ & $\begin{array}{l}60 \\
59 \\
58 \\
57 \\
56 \\
55 \\
54 \\
53 \\
52 \\
51 \\
50\end{array}$ \\
\hline $\begin{array}{l}11 \\
12 \\
13 \\
14 \\
15 \\
16 \\
17 \\
18 \\
19 \\
20 \\
1\end{array}$ & $\begin{array}{r}9.097065 \\
.098066 \\
.099065 \\
.100062 \\
.101056 \\
.102048 \\
.103037 \\
.104025 \\
.105010 \\
.105992\end{array}$ & $\begin{array}{l}16.68 \\
16.65 \\
16.62 \\
16.57 \\
16.53 \\
16.48 \\
16.47 \\
16.42 \\
16.37 \\
16.35\end{array}$ & $\begin{array}{r}9.9965 \% 8 \\
.996562 \\
.996546 \\
.996530 \\
.996514 \\
.996498 \\
.996482 \\
.996465 \\
.996449 \\
.996433\end{array}$ & $\begin{array}{l}.27 \\
.27 \\
.27 \\
.27 \\
.27 \\
.27 \\
.28 \\
.27 \\
.27 \\
.27\end{array}$ & $\begin{array}{r}9.100487 \\
.101504 \\
.102519 \\
.103532 \\
.104542 \\
.105550 \\
.106556 \\
.107559 \\
.108560 \\
.109559\end{array}$ & $\begin{array}{l}10.90 \\
16.95 \\
16.92 \\
16.88 \\
16.83 \\
16.80 \\
16.7 \% \\
16.72 \\
16.68 \\
16.65 \\
16.62\end{array}$ & $\begin{array}{r}10.899513 \\
.898496 \\
.89 \pi 481 \\
.896468 \\
.895458 \\
.894450 \\
.893444 \\
.892441 \\
.891440 \\
.890441\end{array}$ & $\begin{array}{l}49 \\
48 \\
47 \\
46 \\
45 \\
44 \\
43 \\
42 \\
41 \\
40\end{array}$ \\
\hline $\begin{array}{l}21 \\
22 \\
23 \\
24 \\
25 \\
26 \\
27 \\
28 \\
29 \\
30 \\
31\end{array}$ & $\begin{array}{r}9.106973 \\
.107951 \\
.108927 \\
.109901 \\
.110873 \\
.111842 \\
.112809 \\
.1137 \% 4 \\
.114737 \\
.115698 \\
9116656\end{array}$ & $\begin{array}{l}16.30 \\
16.27 \\
16.23 \\
16.20 \\
16.15 \\
16.12 \\
16.08 \\
16.05 \\
16.02 \\
15.97\end{array}$ & $\begin{array}{r}9.996417 \\
.996400 \\
.996384 \\
.996368 \\
.996351 \\
.996335 \\
.996318 \\
.996302 \\
.996285 \\
.996269\end{array}$ & $\begin{array}{l}.28 \\
.27 \\
.27 \\
.28 \\
.27 \\
.28 \\
.27 \\
.28 \\
.27 \\
.28\end{array}$ & $\begin{array}{r}9.110556 \\
.111551 \\
.112543 \\
.113533 \\
.114521 \\
.11550 \% \\
.116491 \\
.117472 \\
.118452 \\
.119429\end{array}$ & $\begin{array}{l}10.02 \\
16.58 \\
16.53 \\
16.50 \\
16.47 \\
16.43 \\
16.40 \\
16.35 \\
16.33 \\
16.28 \\
16.25\end{array}$ & $\begin{array}{r}10.889444 \\
.888449 \\
.88 \pi 457 \\
.886467 \\
.885479 \\
.884493 \\
.883509 \\
.882528 \\
.881548 \\
.880571\end{array}$ & $\begin{array}{l}39 \\
38 \\
37 \\
36 \\
35 \\
34 \\
33 \\
32 \\
31 \\
30\end{array}$ \\
\hline $\begin{array}{l}31 \\
32 \\
33 \\
34 \\
35 \\
36 \\
37 \\
38 \\
39 \\
40 \\
41\end{array}$ & $\begin{array}{r}9116656 \\
.117613 \\
118567 \\
.119519 \\
.120469 \\
.121417 \\
.122362 \\
.123306 \\
.124248 \\
125187 \\
.126125\end{array}$ & $\begin{array}{r}15.95 \\
15.90 \\
15.87 \\
15.83 \\
15.80 \\
15.75 \\
15.73 \\
15.70 \\
15.65 \\
15.63\end{array}$ & $\begin{array}{r}9.996252 \\
.996235 \\
.996219 \\
.996202 \\
.996185 \\
.996168 \\
.996151 \\
.996134 \\
.996117 \\
.996100\end{array}$ & $\begin{array}{l}.28 \\
.27 \\
.28 \\
.28 \\
.28 \\
.28 \\
.28 \\
.28 \\
.28 \\
.28\end{array}$ & $\begin{array}{r}9.120404 \\
.121377 \\
.122348 \\
.123317 \\
.124284 \\
.125249 \\
.126211 \\
.127172 \\
.128130 \\
.129087\end{array}$ & $\begin{array}{l}16.22 \\
16.18 \\
16.15 \\
16.12 \\
16.08 \\
16.03 \\
16.02 \\
15.97 \\
15.95 \\
15.90\end{array}$ & $\begin{array}{r}10.879596 \\
.878623 \\
.87652 \\
.876683 \\
.875716 \\
.874751 \\
.877789 \\
.872828 \\
.871870 \\
.870913\end{array}$ & $\begin{array}{l}29 \\
28 \\
27 \\
2 € \\
25 \\
24 \\
23 \\
22 \\
21 \\
20\end{array}$ \\
\hline $\begin{array}{l}41 \\
42 \\
43 \\
44 \\
45 \\
46 \\
47 \\
48 \\
49 \\
50\end{array}$ & $\begin{array}{r}9126125 \\
.127060 \\
.127993 \\
.128925 \\
.129854 \\
130781 \\
131706 \\
132630 \\
133551 \\
134470\end{array}$ & $\begin{array}{l}15.58 \\
15.55 \\
15.53 \\
15.48 \\
15.45 \\
15.42 \\
15.40 \\
15.35 \\
15.32 \\
15.28\end{array}$ & $\begin{array}{r}9.996083 \\
.996066 \\
.996049 \\
.996032 \\
.996015 \\
.995998 \\
.995980 \\
.995963 \\
.995946 \\
.995928\end{array}$ & $\begin{array}{l}.28 \\
.28 \\
.28 \\
.28 \\
.28 \\
.30 \\
.28 \\
28 \\
30 \\
.28\end{array}$ & $\begin{array}{r}9.130041 \\
.130994 \\
.131944 \\
.132893 \\
133839 \\
.134784 \\
.135726 \\
.136667 \\
.13 \% 605 \\
.138542\end{array}$ & $\begin{array}{l}15.88 \\
15.83 \\
15.82 \\
15.77 \\
15.75 \\
15.70 \\
15.68 \\
15.63 \\
15 \quad 62 \\
15 \quad 57\end{array}$ & $\begin{array}{r}10.869959 \\
.869006 \\
.866056 \\
.86 i 107 \\
.866161 \\
.865216 \\
.864274 \\
863333 \\
.862395 \\
.861458\end{array}$ & $\begin{array}{l}19 \\
18 \\
17 \\
16 \\
15 \\
14 \\
13 \\
12 \\
11 \\
10\end{array}$ \\
\hline \begin{tabular}{l|}
51 \\
52 \\
53 \\
54 \\
55 \\
56 \\
57 \\
58 \\
59 \\
60
\end{tabular} & $\begin{array}{r}9135387 \\
.136303 \\
137216 \\
138128 \\
139037 \\
139944 \\
140850 \\
.141754 \\
142655 \\
2143555\end{array}$ & $\begin{array}{ll}15 & 27 \\
15 & 22 \\
15 & 20 \\
15 & 15 \\
15 & 12 \\
15 & 10 \\
15 & 07 \\
15 & 02 \\
15 & 00\end{array}$ & $\begin{array}{r}7995911 \\
995894 \\
.995876 \\
.995859 \\
995841 \\
995823 \\
995806 \\
995788 \\
995 \approx 1 \\
9.995753\end{array}$ & $\begin{array}{l}28 \\
.30 \\
28 \\
30 \\
.30 \\
.28 \\
.30 \\
28 \\
.30\end{array}$ & $\begin{array}{r}91394 \% 6 \\
.140409 \\
.141340 \\
.142269 \\
143196 \\
.144121 \\
.145044 \\
.145966 \\
146885 \\
9.147503\end{array}$ & $\begin{array}{l}15.55 \\
15.52 \\
15.48 \\
15.45 \\
15.42 \\
15.38 \\
15.37 \\
15.32 \\
15.30\end{array}$ & $\begin{array}{r}10860524 \\
.859591 \\
.858660 \\
85731 \\
.856804 \\
.855879 \\
.854956 \\
854034 \\
853115 \\
10852197\end{array}$ & $\begin{array}{l}9 \\
8 \\
7 \\
6 \\
5 \\
4 \\
3 \\
2 \\
1 \\
0\end{array}$ \\
\hline ' & Cosine. & 2.20 & NAx & D. 1. & Cotang. & D. 1". & Tang. & $'$ \\
\hline
\end{tabular}




\begin{tabular}{|c|c|c|c|c|c|c|c|c|}
\hline 1 & Sine. & D. $1^{\prime \prime}$. & Cosine. & D. $1^{\prime}$. & Tang. & D. $1^{\prime \prime}$. & Cotang. & ' \\
\hline $\begin{array}{r}0 \\
1 \\
2 \\
3 \\
4 \\
5 \\
6 \\
7 \\
8 \\
9 \\
10\end{array}$ & $\begin{array}{r}9.143555 \\
.144453 \\
.145349 \\
.146243 \\
.147136 \\
.148026 \\
.148915 \\
.149802 \\
.150686 \\
.151569 \\
.152451\end{array}$ & $\begin{array}{l}14.97 \\
14.93 \\
14.90 \\
14.88 \\
14.83 \\
14.82 \\
14.78 \\
14.73 \\
14.72 \\
14.70 \\
14.65\end{array}$ & $\begin{array}{r}9.995753 \\
.995735 \\
.995717 \\
.995699 \\
.995681 \\
.995664 \\
.995646 \\
.9956288 \\
.995610 \\
.995591 \\
.995573\end{array}$ & $\begin{array}{l}.30 \\
.30 \\
.30 \\
.30 \\
.28 \\
.30 \\
.30 \\
.30 \\
.32 \\
.30 \\
.30\end{array}$ & $\begin{array}{r}9.147803 \\
.148718 \\
.149632 \\
.150544 \\
.151454 \\
.152363 \\
.153269 \\
.154174 \\
.155077 \\
.155978 \\
.156877\end{array}$ & $\begin{array}{l}15.25 \\
15.23 \\
15.20 \\
15.17 \\
15.15 \\
15.10 \\
15.08 \\
15.05 \\
15.02 \\
14.98 \\
14.97\end{array}$ & $\begin{array}{r}10.852197 \\
.851282 \\
.850368 \\
.849456 \\
.848546 \\
.847637 \\
.846731 \\
.845826 \\
.844923 \\
.844022 \\
.843123\end{array}$ & $\begin{array}{l}60 \\
59 \\
58 \\
57 \\
56 \\
55 \\
54 \\
53 \\
52 \\
51 \\
50\end{array}$ \\
\hline $\begin{array}{l}11 \\
12 \\
13 \\
14 \\
15 \\
16 \\
17 \\
18 \\
19 \\
20\end{array}$ & $\begin{array}{r}9.153330 \\
.154208 \\
.155083 \\
.155957 \\
.156830 \\
.157700 \\
.158569 \\
.159435 \\
.160301 \\
.161164\end{array}$ & $\begin{array}{l}14.63 \\
14.58 \\
14.57 \\
14.55 \\
14.50 \\
14.48 \\
14.43 \\
14.43 \\
14.38 \\
14.35\end{array}$ & $\begin{array}{r}9.995555 \\
.995537 \\
.995519 \\
.995501 \\
.995482 \\
.995464 \\
.995446 \\
.995427 \\
.995409 \\
.995390\end{array}$ & $\begin{array}{l}.30 \\
.30 \\
.30 \\
.32 \\
.30 \\
.30 \\
.32 \\
.30 \\
.32 \\
.30\end{array}$ & $\begin{array}{r}9.15775 \\
.158671 \\
.159565 \\
.160457 \\
.161347 \\
.162236 \\
.163123 \\
.164008 \\
.164892 \\
.165744\end{array}$ & $\begin{array}{l}14.93 \\
14.90 \\
14.87 \\
14.83 \\
14.82 \\
14.78 \\
14.75 \\
14.73 \\
14.70 \\
14.67\end{array}$ & $\begin{array}{r}10.842225 \\
.841329 \\
.840435 \\
.839543 \\
.838653 \\
.831764 \\
.836877 \\
.835992 \\
.835108 \\
.834226\end{array}$ & $\begin{array}{l}49 \\
48 \\
47 \\
46 \\
45 \\
44 \\
43 \\
42 \\
41 \\
40\end{array}$ \\
\hline $\begin{array}{l}21 \\
22 \\
23 \\
24 \\
25 \\
26 \\
27 \\
28 \\
29 \\
30\end{array}$ & $\begin{array}{r}9.162025 \\
.162885 \\
.163743 \\
.161600 \\
.165454 \\
.166307 \\
.167159 \\
.168008 \\
.168856 \\
.169702\end{array}$ & $\begin{array}{l}14.33 \\
14.30 \\
14.28 \\
14.23 \\
14.2 . \\
14.20 \\
14.15 \\
14.13 \\
14.10 \\
14.08\end{array}$ & $\begin{array}{r}9.995372 \\
.995353 \\
.995334 \\
.995316 \\
.995297 \\
.995278 \\
.995260 \\
.995241 \\
.995222 \\
.995203\end{array}$ & $\begin{array}{l}.32 \\
.32 \\
.30 \\
.32 \\
.32 \\
.30 \\
.32 \\
.32 \\
.32 \\
.32\end{array}$ & $\begin{array}{r}9.166654 \\
.167532 \\
.168409 \\
.169284 \\
.170157 \\
.171029 \\
.171899 \\
.172 \% 67 \\
.173634 \\
.174499\end{array}$ & $\begin{array}{l}14.63 \\
14.62 \\
14.58 \\
14.55 \\
14.53 \\
14.50 \\
14.47 \\
14.45 \\
14.42 \\
14.38\end{array}$ & $\begin{array}{r}10.833346 \\
.832468 \\
.831591 \\
.830716 \\
.829843 \\
.828971 \\
.828101 \\
.827233 \\
.826366 \\
.825501\end{array}$ & $\begin{array}{l}39 \\
38 \\
37 \\
36 \\
35 \\
34 \\
33 \\
32 \\
31 \\
30\end{array}$ \\
\hline $\begin{array}{l}31 \\
32 \\
33 \\
34 \\
35 \\
36 \\
37 \\
38 \\
39 \\
40\end{array}$ & $\begin{array}{r}9.170547 \\
.171389 \\
.172230 \\
.173070 \\
.173908 \\
.174744 \\
.175578 \\
.176411 \\
.177242 \\
.178072\end{array}$ & $\begin{array}{l}14.03 \\
14.02 \\
14.00 \\
13.97 \\
13.93 \\
13.90 \\
13.88 \\
13.85 \\
13.83 \\
13.80\end{array}$ & $\begin{array}{r}9.995184 \\
.995165 \\
.995146 \\
.995127 \\
.995108 \\
.995089 \\
.995070 \\
.995051 \\
.995032 \\
.995013\end{array}$ & $\begin{array}{l}.32 \\
.32 \\
.32 \\
.32 \\
.32 \\
.32 \\
.32 \\
.32 \\
.32 \\
.33\end{array}$ & $\begin{array}{r}9.175362 \\
.176224 \\
.177084 \\
.177942 \\
.178799 \\
.179655 \\
.180508 \\
.181360 \\
.182211 \\
.183059\end{array}$ & $\begin{array}{l}14.37 \\
14.33 \\
14.30 \\
14.28 \\
14.27 \\
14.22 \\
14.20 \\
14.18 \\
14.13 \\
14.13\end{array}$ & $\begin{array}{r}10.824638 \\
.82376 \\
.822916 \\
.822058 \\
.821201 \\
.820345 \\
.819492 \\
.818640 \\
.817 \% 89 \\
.816941\end{array}$ & $\begin{array}{l}29 \\
28 \\
27 \\
26 \\
25 \\
24 \\
23 \\
22 \\
21 \\
20\end{array}$ \\
\hline $\begin{array}{l}41 \\
42 \\
43 \\
44 \\
45 \\
46 \\
47 \\
48 \\
49 \\
50\end{array}$ & $\begin{array}{r}9178900 \\
.179726 \\
.180551 \\
.1813 \% 4 \\
.182196 \\
.183016 \\
.183834 \\
.184651 \\
.185466 \\
.186280\end{array}$ & $\begin{array}{l}13.77 \\
13.75 \\
13.72 \\
13.70 \\
13.67 \\
13.63 \\
13.62 \\
13.58 \\
13.57 \\
13.53\end{array}$ & $\begin{array}{r}9.994993 \\
.994974 \\
.994955 \\
.994935 \\
.994916 \\
.994896 \\
.994877 \\
.994857 \\
.994838 \\
.994818\end{array}$ & $\begin{array}{l}.32 \\
.32 \\
.33 \\
.32 \\
.33 \\
.32 \\
.33 \\
.32 \\
.33 \\
.33\end{array}$ & $\begin{array}{r}9.183907 \\
.184752 \\
.185597 \\
.186439 \\
.187280 \\
.188120 \\
.188958 \\
.189794 \\
.190629 \\
.191462\end{array}$ & $\begin{array}{l}14.08 \\
14.08 \\
14.03 \\
14.02 \\
14.00 \\
13.97 \\
13.93 \\
13.92 \\
13.88 \\
13.87\end{array}$ & $\begin{array}{r}10.816093 \\
.815248 \\
.814403 \\
.813561 \\
.812720 \\
.811880 \\
.811042 \\
.810206 \\
.809371 \\
.808538\end{array}$ & $\begin{array}{l}19 \\
18 \\
17 \\
16 \\
15 \\
14 \\
13 \\
12 \\
11 \\
10\end{array}$ \\
\hline $\begin{array}{l}51 \\
52 \\
53 \\
54 \\
55 \\
56 \\
57 \\
58 \\
59 \\
60\end{array}$ & $\begin{array}{r}9.187092 \\
.187903 \\
.188712 \\
.189519 \\
.190325 \\
.191130 \\
.191933 \\
.192734 \\
.193534 \\
9.194332\end{array}$ & $\begin{array}{l}13.52 \\
13.48 \\
13.45 \\
13.43 \\
13.42 \\
13.38 \\
13.35 \\
13.33 \\
13.30\end{array}$ & $\begin{array}{r}9.994798 \\
.994779 \\
.994759 \\
.994739 \\
.994720 \\
.994700 \\
.994680 \\
.994660 \\
.994640 \\
9.994620\end{array}$ & $\begin{array}{l}.32 \\
.33 \\
.33 \\
.32 \\
.33 \\
.33 \\
.33 \\
.33 \\
.33\end{array}$ & $\begin{array}{r}9.192294 \\
.193124 \\
.193953 \\
.194780 \\
.195606 \\
.196430 \\
.197253 \\
.1980 \% 4 \\
.198894 \\
9.199713\end{array}$ & $\begin{array}{l}13.83 \\
13.82 \\
13.78 \\
13.7 \% \\
13.73 \\
13.72 \\
13.68 \\
13.67 \\
13.65\end{array}$ & $\begin{array}{r}10.807706 \\
.8068 \% 6 \\
.806047 \\
.805220 \\
.804394 \\
.8035 \% 0 \\
.802747 \\
.801926 \\
.801106 \\
10.800287\end{array}$ & $\begin{array}{l}9 \\
8 \\
7 \\
6 \\
5 \\
4 \\
3 \\
2 \\
1 \\
0\end{array}$ \\
\hline ' & Cosine. & 0.1. & Sine. & D. 1 & Cotang. & D. 1". & Tang. & 1 \\
\hline
\end{tabular}




\begin{tabular}{|c|c|c|c|c|c|c|c|c|}
\hline , & Sine. & D. 1". & Cosine. & D. $1^{\circ}$. & Tang. & D. $1^{\circ}$. & Cotang. & ' \\
\hline $\begin{array}{r}0 \\
1 \\
2 \\
3 \\
4 \\
5 \\
6 \\
7 \\
8 \\
9 \\
10 \\
11\end{array}$ & $\begin{array}{r}9.194332 \\
.195129 \\
.195925 \\
.196719 \\
.197511 \\
.198302 \\
.199091 \\
.199879 \\
.200666 \\
.201451 \\
.202234 \\
9.203017\end{array}$ & $\begin{array}{l}13.28 \\
13.27 \\
13.23 \\
13.20 \\
13.18 \\
13.15 \\
13.13 \\
13.12 \\
13.08 \\
13.05 \\
13.05\end{array}$ & $\begin{array}{r}9.991620 \\
.994600 \\
.994580 \\
.994560 \\
.994540 \\
.994519 \\
.994499 \\
.994479 \\
.994459 \\
.994438 \\
.994418\end{array}$ & $\begin{array}{l}.33 \\
.33 \\
.33 \\
.33 \\
.35 \\
.33 \\
.33 \\
.33 \\
.35 \\
.33 \\
.33\end{array}$ & $\begin{array}{r}9.199713 \\
.200529 \\
.201345 \\
.202159 \\
.202971 \\
.203782 \\
.204592 \\
.205400 \\
.206207 \\
.207013 \\
.207817\end{array}$ & $\begin{array}{l}13.60 \\
13.60 \\
13.57 \\
13.53 \\
13.52 \\
13.50 \\
13.47 \\
13.45 \\
13.43 \\
13.40 \\
13.37\end{array}$ & $\begin{array}{r}10.800287 \\
.799471 \\
.798655 \\
.797841 \\
.797029 \\
.796218 \\
.795408 \\
.791600 \\
.793793 \\
.792987 \\
.792183\end{array}$ & $\begin{array}{l}60 \\
59 \\
58 \\
57 \\
56 \\
55 \\
54 \\
53 \\
53 \\
51 \\
50\end{array}$ \\
\hline $\begin{array}{l}11 \\
12 \\
13 \\
14 \\
15 \\
16 \\
17 \\
18 \\
19 \\
20 \\
91\end{array}$ & $\begin{array}{r}9.203017 \\
.203797 \\
.204577 \\
.205354 \\
.206131 \\
.206906 \\
.207679 \\
.208452 \\
.209222 \\
.209992\end{array}$ & $\begin{array}{l}13.00 \\
13.00 \\
12.95 \\
12.95 \\
12.92 \\
12.88 \\
12.88 \\
12.83 \\
12.83 \\
12.80\end{array}$ & $\begin{array}{r}9.994398 \\
.994377 \\
.994357 \\
.994336 \\
.994316 \\
.994295 \\
.994274 \\
.994254 \\
.994233 \\
.994212\end{array}$ & $\begin{array}{l}.35 \\
.33 \\
.35 \\
.33 \\
.35 \\
.35 \\
.33 \\
.35 \\
.35 \\
.35\end{array}$ & $\begin{array}{r}9.208619 \\
.209420 \\
.210220 \\
.211018 \\
.211815 \\
.212611 \\
.213405 \\
.214198 \\
.214989 \\
.215780\end{array}$ & $\begin{array}{l}13.35 \\
13.33 \\
13.30 \\
13.28 \\
13.27 \\
13.23 \\
13.22 \\
13.18 \\
13.18 \\
13.13\end{array}$ & $\begin{array}{r}10.791381 \\
.790580 \\
.789780 \\
.788982 \\
.788185 \\
.787389 \\
.786595 \\
.785802 \\
.785011 \\
.784220\end{array}$ & $\begin{array}{l}49 \\
48 \\
47 \\
46 \\
45 \\
44 \\
43 \\
42 \\
41 \\
40\end{array}$ \\
\hline $\begin{array}{l}21 \\
22 \\
23 \\
24 \\
25 \\
26 \\
27 \\
28 \\
29 \\
30\end{array}$ & $\begin{array}{r}9.210760 \\
.211526 \\
.212291 \\
.213055 \\
.213818 \\
.214579 \\
.215338 \\
.216097 \\
.216854 \\
.217609\end{array}$ & $\begin{array}{l}12.77 \\
12.75 \\
12.73 \\
12.72 \\
12.68 \\
12.65 \\
12.65 \\
12.62 \\
12.58 \\
12.57\end{array}$ & $\begin{array}{r}9.994191 \\
.994171 \\
.994150 \\
.994129 \\
.994108 \\
.994087 \\
.994066 \\
.994045 \\
.994024 \\
.994003\end{array}$ & $\begin{array}{l}.33 \\
.35 \\
.35 \\
.35 \\
.35 \\
.35 \\
.35 \\
.35 \\
.35 \\
.35\end{array}$ & $\begin{array}{r}9.216568 \\
.217356 \\
.218142 \\
.218926 \\
.219710 \\
.220492 \\
.221272 \\
.222052 \\
.222830 \\
.223607\end{array}$ & $\begin{array}{l}10.10 \\
13.13 \\
13.10 \\
13.07 \\
13.07 \\
13.03 \\
13.00 \\
13.00 \\
12.97 \\
12.95 \\
12.92\end{array}$ & $\begin{array}{r}10.783432 \\
.782644 \\
.781858 \\
.7810 \% 4 \\
.780290 \\
.79508 \\
.78729 \\
.777948 \\
.77170 \\
.76393\end{array}$ & $\begin{array}{l}39 \\
38 \\
37 \\
36 \\
35 \\
34 \\
33 \\
32 \\
31 \\
30\end{array}$ \\
\hline $\begin{array}{l}31 \\
32 \\
33 \\
34 \\
35 \\
36 \\
37 \\
38 \\
39 \\
40\end{array}$ & $\begin{array}{r}9.218363 \\
.219116 \\
.219868 \\
.220618 \\
.221367 \\
.222115 \\
.222861 \\
.223606 \\
.224349 \\
.225092\end{array}$ & $\begin{array}{l}12.55 \\
12.53 \\
12.50 \\
12.48 \\
12.47 \\
12.43 \\
12.42 \\
12.38 \\
12.38 \\
12.35\end{array}$ & $\begin{array}{r}9.993982 \\
.993960 \\
.993939 \\
.993918 \\
.993857 \\
.993875 \\
.993854 \\
.993832 \\
.993811 \\
.993789\end{array}$ & $\begin{array}{l}.37 \\
.35 \\
.35 \\
.35 \\
.37 \\
.35 \\
.37 \\
.35 \\
.37 \\
.35\end{array}$ & $\begin{array}{r}9.224382 \\
.225156 \\
.225929 \\
.226700 \\
.22 \pi 471 \\
.228239 \\
.229007 \\
.229773 \\
.230539 \\
.231302\end{array}$ & $\begin{array}{l}12.90 \\
12.88 \\
12.85 \\
12.85 \\
12.80 \\
12.80 \\
12.77 \\
12.77 \\
12.72 \\
12.72\end{array}$ & $\begin{array}{r}10.75618 \\
.774844 \\
.74071 \\
.73300 \\
.72529 \\
.771761 \\
.70993 \\
.70227 \\
.769461 \\
.768698\end{array}$ & $\begin{array}{l}29 \\
28 \\
27 \\
26 \\
25 \\
24 \\
23 \\
23 \\
21 \\
20\end{array}$ \\
\hline $\begin{array}{l}41 \\
42 \\
43 \\
44 \\
45 \\
46 \\
47 \\
48 \\
49 \\
50\end{array}$ & $\begin{array}{r}9.225833 \\
.226573 \\
.227311 \\
.228048 \\
.228784 \\
.229518 \\
.230252 \\
.230984 \\
.231715 \\
.232444\end{array}$ & $\begin{array}{l}12.33 \\
12.30 \\
12.28 \\
12.27 \\
12.23 \\
12.23 \\
12.20 \\
12.18 \\
12.15 \\
12.13\end{array}$ & $\begin{array}{r}9.993 \% 68 \\
.993746 \\
.993725 \\
.993703 \\
.993681 \\
.993660 \\
.993638 \\
.993616 \\
.993594 \\
.9935 \% 2\end{array}$ & $\begin{array}{l}.37 \\
.35 \\
.37 \\
.37 \\
.35 \\
.37 \\
.37 \\
.37 \\
.37 \\
.37\end{array}$ & $\begin{array}{r}9.232065 \\
.232826 \\
.233586 \\
.234345 \\
.235103 \\
.235859 \\
.236614 \\
.237368 \\
.238120 \\
.2388 \% 2\end{array}$ & $\begin{array}{l}12.68 \\
12.67 \\
12.65 \\
12.63 \\
12.60 \\
12.58 \\
12.57 \\
12.53 \\
12.53 \\
12.50\end{array}$ & $\begin{array}{r}10.76 r 935 \\
.767174 \\
.766414 \\
.765650 \\
.764897 \\
.764141 \\
.763386 \\
.762693 \\
.761880 \\
.761128\end{array}$ & $\begin{array}{l}19 \\
18 \\
17 \\
16 \\
15 \\
14 \\
13 \\
12 \\
11 \\
10\end{array}$ \\
\hline $\begin{array}{l}51 \\
52 \\
53 \\
54 \\
55 \\
56 \\
57 \\
58 \\
59 \\
60\end{array}$ & $\begin{array}{r}9.233172 \\
.233899 \\
.234625 \\
.235349 \\
.236073 \\
.236795 \\
.237515 \\
.238235 \\
.238953 \\
9.239670\end{array}$ & $\begin{array}{l}12.12 \\
12.10 \\
12.07 \\
12.07 \\
12.03 \\
12.00 \\
12.00 \\
11.97 \\
11.95\end{array}$ & $\begin{array}{r}9.993550 \\
.993528 \\
.993506 \\
.993484 \\
.993462 \\
.993440 \\
.993418 \\
.993396 \\
.993374 \\
9.993351\end{array}$ & $\begin{array}{l}.37 \\
.37 \\
.37 \\
.37 \\
.37 \\
.37 \\
.37 \\
.37 \\
.37 \\
.38\end{array}$ & $\begin{array}{r}9.239622 \\
.240371 \\
.241118 \\
.241865 \\
.242610 \\
.243354 \\
.244097 \\
.244839 \\
.245579 \\
9.246319\end{array}$ & $\begin{array}{l}12.00 \\
12.48 \\
12.45 \\
12.45 \\
12.42 \\
12.40 \\
12.38 \\
12.37 \\
12.33 \\
12.33\end{array}$ & $\begin{array}{r}10.760378 \\
.759629 \\
.758889 \\
.758135 \\
.757900 \\
.756646 \\
.755903 \\
.755161 \\
.754421 \\
10.753681\end{array}$ & $\begin{array}{l}9 \\
8 \\
7 \\
6 \\
5 \\
4 \\
3 \\
2 \\
1 \\
0\end{array}$ \\
\hline ' & ne. & $1^{\circ}$. & Sine. & D. $1^{\circ}$. & Cotang. & D. $1^{\circ}$. & Tang. & ' \\
\hline
\end{tabular}


TABLE XII.-LOGARITHMIC SINES,

\begin{tabular}{|c|c|c|c|c|c|c|c|c|}
\hline , & Sine. & D. $1^{\prime \prime}$. & Cosine. & D. $1^{\prime \prime}$. & Tang. & D. $1^{\prime}$. & Cotang. & ' \\
\hline $\begin{array}{r}0 \\
1 \\
2 \\
3 \\
4 \\
5 \\
6 \\
7 \\
8 \\
9 \\
10\end{array}$ & $\begin{array}{r}9.239670 \\
.240386 \\
.241101 \\
.241814 \\
.242526 \\
.243237 \\
.243947 \\
.244656 \\
.245363 \\
.246069 \\
.246775\end{array}$ & $\begin{array}{l}11.93 \\
11.92 \\
11.88 \\
11.87 \\
11.85 \\
11.83 \\
11.82 \\
11.78 \\
11.77 \\
11.77 \\
11.72\end{array}$ & $\begin{array}{r}9.993351 \\
.993329 \\
.993307 \\
.993284 \\
.993262 \\
.993240 \\
.993217 \\
.993195 \\
.993172 \\
.993149 \\
.993127\end{array}$ & $\begin{array}{l}.37 \\
.37 \\
.38 \\
.37 \\
.37 \\
.38 \\
.37 \\
.38 \\
.38 \\
.37 \\
.38\end{array}$ & $\begin{array}{r}9.246319 \\
.247057 \\
.24 \% 794 \\
.248530 \\
.249264 \\
.249998 \\
.250730 \\
.251461 \\
.252191 \\
.252920 \\
.253648\end{array}$ & $\begin{array}{l}12.30 \\
12.28 \\
12.27 \\
12.23 \\
12.23 \\
12.20 \\
12.18 \\
12.17 \\
12.15 \\
12.13 \\
12.10\end{array}$ & $\begin{array}{r}10.753681 \\
.752943 \\
.752206 \\
.751470 \\
.750736 \\
.750002 \\
.749270 \\
.748539 \\
.747809 \\
.747080 \\
.746352\end{array}$ & $\begin{array}{l}60 \\
59 \\
58 \\
5 \pi \\
56 \\
55 \\
54 \\
53 \\
52 \\
51 \\
50\end{array}$ \\
\hline $\begin{array}{l}11 \\
12 \\
13 \\
14 \\
15 \\
16 \\
17 \\
18 \\
19 \\
20\end{array}$ & $\begin{array}{r}9.247478 \\
.248181 \\
.248883 \\
.249583 \\
.250282 \\
.250980 \\
.251677 \\
.252373 \\
.253067 \\
.253761\end{array}$ & $\begin{array}{l}11.72 \\
11.70 \\
11.67 \\
11.65 \\
11.63 \\
11.62 \\
11.60 \\
11.57 \\
11.57 \\
11.53\end{array}$ & $\begin{array}{r}9.993104 \\
.993081 \\
.993059 \\
.993036 \\
.993013 \\
.992990 \\
.992967 \\
.992944 \\
.992921 \\
.992898\end{array}$ & $\begin{array}{l}.38 \\
.37 \\
.38 \\
.38 \\
.38 \\
.38 \\
.38 \\
.38 \\
.38 \\
.38\end{array}$ & $\begin{array}{r}9.254374 \\
.255100 \\
.255824 \\
.256547 \\
.257269 \\
.257990 \\
.258710 \\
.259429 \\
.260146 \\
.260863\end{array}$ & $\begin{array}{l}12.10 \\
12.10 \\
12.07 \\
12.05 \\
12.03 \\
12.02 \\
12.00 \\
11.98 \\
11.95 \\
11.95 \\
11.92\end{array}$ & $\begin{array}{r}10.745626 \\
.744900 \\
.744166 \\
.743453 \\
.742731 \\
.742010 \\
.741290 \\
.7405 \% 1 \\
.739854 \\
.739137\end{array}$ & $\begin{array}{l}49 \\
48 \\
47 \\
46 \\
45 \\
44 \\
43 \\
42 \\
41 \\
40\end{array}$ \\
\hline $\begin{array}{l}21 \\
22 \\
23 \\
24 \\
25 \\
26 \\
27 \\
28 \\
29 \\
30\end{array}$ & $\begin{array}{r}9.254453 \\
.255144 \\
.255834 \\
.256523 \\
.257211 \\
.257898 \\
.258583 \\
.259268 \\
.259951 \\
.260633\end{array}$ & $\begin{array}{l}11.52 \\
11.50 \\
11.48 \\
11.47 \\
11.45 \\
11.42 \\
11.42 \\
11.38 \\
11.37 \\
11.35\end{array}$ & $\begin{array}{r}9.992875 \\
.992852 \\
.992829 \\
.992806 \\
.992783 \\
.992759 \\
.992736 \\
.992713 \\
.992690 \\
.992666\end{array}$ & $\begin{array}{l}.00 \\
.38 \\
.38 \\
.38 \\
.38 \\
.40 \\
.38 \\
.38 \\
.38 \\
.40 \\
.38\end{array}$ & $\begin{array}{r}9.261578 \\
.262292 \\
.263005 \\
.263717 \\
.264428 \\
.265138 \\
.265847 \\
.266555 \\
.267261 \\
.267967\end{array}$ & $\begin{array}{l}11.90 \\
11.88 \\
11.87 \\
11.85 \\
11.83 \\
11.82 \\
11.80 \\
11.77 \\
11.77 \\
11.73\end{array}$ & $\begin{array}{r}10.738422 \\
.737708 \\
.736995 \\
.736283 \\
.735572 \\
.734862 \\
.734153 \\
.733445 \\
.732739 \\
.732033\end{array}$ & $\begin{array}{l}39 \\
38 \\
37 \\
36 \\
35 \\
34 \\
33 \\
32 \\
31 \\
30\end{array}$ \\
\hline $\begin{array}{l}81 \\
32 \\
33 \\
34 \\
35 \\
36 \\
37 \\
38 \\
39 \\
40\end{array}$ & $\begin{array}{r}9.261314 \\
.261994 \\
.262673 \\
.263351 \\
.264027 \\
.264703 \\
.265377 \\
.266051 \\
.266723 \\
.267395\end{array}$ & $\begin{array}{l}11.33 \\
11.32 \\
11.30 \\
11.27 \\
11.27 \\
11.23 \\
11.23 \\
11.20 \\
11.20 \\
11.17\end{array}$ & $\begin{array}{r}9.992643 \\
.992619 \\
.992596 \\
.992572 \\
.992549 \\
.992525 \\
.992501 \\
.992478 \\
.992454 \\
.992430\end{array}$ & $\begin{array}{l}.40 \\
.38 \\
.40 \\
.38 \\
.40 \\
.40 \\
.38 \\
.40 \\
.40 \\
.40\end{array}$ & $\begin{array}{r}9.2686 r 1 \\
.269375 \\
.270077 \\
.270779 \\
.271479 \\
.272178 \\
.272876 \\
.273573 \\
.274269 \\
.274964\end{array}$ & $\begin{array}{l}11.73 \\
11.70 \\
11.70 \\
11.67 \\
11.65 \\
11.63 \\
11.62 \\
11.60 \\
11.58 \\
11.57\end{array}$ & $\begin{array}{r}10.731329 \\
.730625 \\
.729923 \\
.729221 \\
.728521 \\
.727822 \\
.727124 \\
.726427 \\
.725 \% 31 \\
.725036\end{array}$ & $\begin{array}{l}29 \\
28 \\
27 \\
26 \\
25 \\
24 \\
23 \\
22 \\
21 \\
20\end{array}$ \\
\hline $\begin{array}{l}41 \\
42 \\
43 \\
44 \\
45 \\
46 \\
47 \\
48 \\
49 \\
50\end{array}$ & $\begin{array}{r}9.268065 \\
.268734 \\
.269402 \\
.270069 \\
.270735 \\
.271400 \\
.272064 \\
.272726 \\
.273388 \\
.274049\end{array}$ & $\begin{array}{l}11.15 \\
11.13 \\
11.12 \\
11.10 \\
11.08 \\
11.07 \\
11.03 \\
11.03 \\
11.02 \\
10.98\end{array}$ & $\begin{array}{r}9.992406 \\
.992382 \\
.992359 \\
.992335 \\
.992311 \\
.992287 \\
.992263 \\
.992239 \\
.992214 \\
.992190\end{array}$ & $\begin{array}{l}.40 \\
.38 \\
.40 \\
.40 \\
.40 \\
.40 \\
.40 \\
.42\end{array}$ & $\begin{array}{r}9.275658 \\
.276351 \\
.277043 \\
.277734 \\
.278424 \\
.279113 \\
.279801 \\
.280488 \\
.281174 \\
.281858\end{array}$ & $\begin{array}{l}11.55 \\
11.53 \\
11.52 \\
11.50 \\
11.48 \\
11.47 \\
11.45 \\
11.43 \\
11.40 \\
11.40\end{array}$ & $\begin{array}{r}10.724342 \\
.723649 \\
.722957 \\
.722266 \\
.721576 \\
.720887 \\
.720199 \\
.719512 \\
.718826 \\
.718142\end{array}$ & $\begin{array}{l}19 \\
18 \\
17 \\
16 \\
15 \\
14 \\
13 \\
12 \\
11 \\
10\end{array}$ \\
\hline $\begin{array}{l}51 \\
52 \\
53 \\
54 \\
55 \\
56 \\
57 \\
58 \\
59 \\
.60\end{array}$ & $\begin{array}{r}9.274708 \\
.275367 \\
.276025 \\
.276681 \\
.277337 \\
.277991 \\
.278645 \\
.279297 \\
.279948 \\
9.280599\end{array}$ & $\begin{array}{l}10.98 \\
10.97 \\
10.93 \\
10.93 \\
10.90 \\
10.90 \\
10.87 \\
10.85 \\
10.85\end{array}$ & $\begin{array}{r}9.992166 \\
.992142 \\
.992118 \\
.992093 \\
.992069 \\
.992044 \\
.992020 \\
.991996 \\
.991971 \\
9.991947\end{array}$ & $\begin{array}{l}.40 \\
.40 \\
.42 \\
.40 \\
.42 \\
.40 \\
.40 \\
.42 \\
.40\end{array}$ & $\begin{array}{r}9.282542 \\
.283225 \\
.283907 \\
.284588 \\
.285268 \\
.285947 \\
.286624 \\
.287301 \\
.287977 \\
9.288652\end{array}$ & $\begin{array}{l}11.38 \\
11.37 \\
11.35 \\
11.33 \\
11.32 \\
11.28 \\
11.28 \\
11.27 \\
11.25\end{array}$ & $\begin{array}{r}10.717458 \\
.716775 \\
.716093 \\
.715412 \\
.714732 \\
.714053 \\
.713376 \\
.712699 \\
.712023 \\
10.711348\end{array}$ & $\begin{array}{l}9 \\
8 \\
7 \\
6 \\
5 \\
4 \\
3 \\
2 \\
1 \\
0\end{array}$ \\
\hline 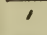 & Cosine. & D. $1^{\circ}$. & Sine. & D. $1^{\prime \prime}$. & Cotang. & D. 1". & Tang. & 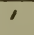 \\
\hline
\end{tabular}




\begin{tabular}{|c|c|c|c|c|c|c|c|c|}
\hline ' & Sine. & D. $1^{*}$. & Cosine. & D. 1". & Tang. & D. $1^{\prime \prime}$. & Cotang. & , \\
\hline $\begin{array}{r}0 \\
1 \\
2 \\
3 \\
4 \\
5 \\
6 \\
7 \\
8 \\
9 \\
10\end{array}$ & $\begin{array}{r}9.280599 \\
.281248 \\
.281897 \\
.282544 \\
.283190 \\
.283836 \\
.284480 \\
.285124 \\
.285766 \\
.286408 \\
.287048\end{array}$ & $\begin{array}{l}10.82 \\
10.82 \\
10.78 \\
10.77 \\
10.77 \\
10.73 \\
10.73 \\
10.70 \\
10.70 \\
10.67 \\
10.67\end{array}$ & $\begin{array}{r}9.991947 \\
.991922 \\
.991897 \\
.991873 \\
.991848 \\
.991823 \\
.991799 \\
.991774 \\
.991749 \\
.991724 \\
.991699\end{array}$ & $\begin{array}{l}.42 \\
.42 \\
.40 \\
.42 \\
.42 \\
.40 \\
.42 \\
.42 \\
.42 \\
.42 \\
.42\end{array}$ & $\begin{array}{r}9.288652 \\
.289326 \\
.289999 \\
.290671 \\
.291342 \\
.292013 \\
.292682 \\
.293350 \\
.294017 \\
.294684 \\
.295349\end{array}$ & $\begin{array}{l}11.23 \\
11.22 \\
11.20 \\
11.18 \\
11.18 \\
11.15 \\
11.13 \\
11.12 \\
11.12 \\
11.08 \\
11.07\end{array}$ & $\begin{array}{r}10.711348 \\
.7106 \pi 4 \\
.710001 \\
.709329 \\
.708658 \\
.70798 \pi \\
.707318 \\
.706650 \\
.705983 \\
.705316 \\
.704651\end{array}$ & $\begin{array}{l}60 \\
59 \\
58 \\
57 \\
56 \\
55 \\
54 \\
53 \\
52 \\
51 \\
50\end{array}$ \\
\hline $\begin{array}{l}11 \\
12 \\
13 \\
14 \\
15 \\
16 \\
17 \\
18 \\
19 \\
20\end{array}$ & $\begin{array}{r}9.287688 \\
.288326 \\
.288964 \\
.289600 \\
.290236 \\
.290870 \\
.291504 \\
.292137 \\
.292768 \\
.293399\end{array}$ & $\begin{array}{l}10.63 \\
10.63 \\
10.60 \\
10.60 \\
10.57 \\
10.57 \\
10.55 \\
10.52 \\
10.52 \\
10.50\end{array}$ & $\begin{array}{r}9.991674 \\
.991649 \\
.991624 \\
.991599 \\
.991574 \\
.991549 \\
.991524 \\
.991498 \\
.991473 \\
.991448\end{array}$ & $\begin{array}{l}.42 \\
.42 \\
.42 \\
.42 \\
.42 \\
.42 \\
.43 \\
.42 \\
.42 \\
.43\end{array}$ & $\begin{array}{r}9.296013 \\
.2966 \pi 7 \\
.297339 \\
.298001 \\
.298662 \\
.299322 \\
.299980 \\
.300638 \\
.301295 \\
.301951\end{array}$ & $\begin{array}{l}11.07 \\
11.03 \\
11.03 \\
11.02 \\
11.00 \\
10.97 \\
10.97 \\
10.95 \\
10.93 \\
10.93\end{array}$ & $\begin{array}{r}10.703987 \\
.703323 \\
.702661 \\
.701999 \\
.701338 \\
.700678 \\
.700020 \\
.699362 \\
.698705 \\
.698049\end{array}$ & $\begin{array}{l}49 \\
48 \\
47 \\
46 \\
45 \\
44 \\
43 \\
42 \\
41 \\
40\end{array}$ \\
\hline $\begin{array}{l}21 \\
22 \\
23 \\
24 \\
25 \\
26 \\
27 \\
28 \\
29 \\
30\end{array}$ & $\begin{array}{r}9.294029 \\
.294658 \\
.295286 \\
.295913 \\
.296539 \\
.297164 \\
.297788 \\
.298412 \\
.299034 \\
.299655\end{array}$ & $\begin{array}{l}10.48 \\
10.47 \\
10.45 \\
10.43 \\
10.42 \\
10.40 \\
10.40 \\
10.37 \\
10.35 \\
10.35\end{array}$ & $\begin{array}{r}9.991422 \\
.991397 \\
.991372 \\
.991346 \\
.991321 \\
.991295 \\
.991270 \\
.991244 \\
.991218 \\
.991193\end{array}$ & $\begin{array}{l}.42 \\
.42 \\
.43 \\
.42 \\
.43 \\
.42 \\
.43 \\
.43 \\
.42 \\
.43\end{array}$ & $\begin{array}{r}9.302607 \\
.303261 \\
.303914 \\
.304567 \\
.305218 \\
.305869 \\
.306519 \\
.307168 \\
.307816 \\
.308463\end{array}$ & $\begin{array}{l}10.90 \\
10.88 \\
10.88 \\
10.85 \\
10.85 \\
10.83 \\
10.82 \\
10.80 \\
10.78 \\
10.77\end{array}$ & $\begin{array}{r}10.697393 \\
.696739 \\
.696086 \\
.695433 \\
.694782 \\
.694131 \\
.693481 \\
.692832 \\
.692184 \\
.691537\end{array}$ & $\begin{array}{l}39 \\
39 \\
\mathbf{3 7} \\
36 \\
35 \\
34 \\
33 \\
32 \\
31 \\
30 \\
\end{array}$ \\
\hline $\begin{array}{l}31 \\
32 \\
33 \\
31 \\
35 \\
36 \\
37 \\
38 \\
39 \\
40\end{array}$ & $\begin{array}{r}9.3002 \% 6 \\
.300895 \\
.301514 \\
.302132 \\
.302748 \\
.303364 \\
.303979 \\
.304593 \\
.305207 \\
.305819 \\
.30\end{array}$ & $\begin{array}{l}10.32 \\
10.32 \\
10.30 \\
10.27 \\
10.27 \\
10.25 \\
10.23 \\
10.23 \\
10.20 \\
10.18\end{array}$ & $\begin{array}{r}9.991167 \\
.991141 \\
.991115 \\
.991090 \\
.991064 \\
.991038 \\
.991012 \\
.990986 \\
.990960 \\
.990934\end{array}$ & $\begin{array}{l}.43 \\
.43 \\
.42 \\
.43 \\
.43 \\
.43 \\
.43 \\
.43 \\
.43 \\
.43\end{array}$ & $\begin{array}{r}9.309109 \\
.309754 \\
.310399 \\
.311042 \\
.311685 \\
.312327 \\
.312968 \\
.313608 \\
.314247 \\
.314885\end{array}$ & $\begin{array}{l}10.75 \\
10.75 \\
10.72 \\
10.72 \\
10.70 \\
10.68 \\
10.67 \\
10.65 \\
10.63 \\
10.63\end{array}$ & $\begin{array}{r}10.690891 \\
.690246 \\
.689601 \\
.688958 \\
.688315 \\
.687673 \\
.687032 \\
.686392 \\
.685753 \\
.685115\end{array}$ & $\begin{array}{l}29 \\
28 \\
27 \\
26 \\
25 \\
24 \\
23 \\
22 \\
21 \\
20\end{array}$ \\
\hline $\begin{array}{l}41 \\
42 \\
43 \\
44 \\
45 \\
46 \\
47 \\
48 \\
49 \\
50\end{array}$ & $\begin{array}{r}9.306430 \\
.307041 \\
.307650 \\
.308259 \\
.308867 \\
.309474 \\
.310080 \\
.310685 \\
.311289 \\
.311893\end{array}$ & $\begin{array}{l}10.18 \\
10.15 \\
10.15 \\
10.13 \\
10.12 \\
10.10 \\
10.08 \\
10.07 \\
10.07 \\
10.03\end{array}$ & $\begin{array}{r}9.990908 \\
.990882 \\
.990855 \\
.990829 \\
.990803 \\
.99077 \% \\
.990750 \\
.990724 \\
.990697 \\
.990671\end{array}$ & $\begin{array}{l}.43 \\
.45 \\
.43 \\
.43 \\
.43 \\
.45 \\
.43 \\
.45 \\
.43 \\
.43\end{array}$ & $\begin{array}{r}9.315523 \\
.316159 \\
.316795 \\
.317430 \\
.318064 \\
.318697 \\
319330 \\
.319961 \\
.320592 \\
.321222\end{array}$ & $\begin{array}{l}10.60 \\
10.60 \\
10.58 \\
10.57 \\
10.55 \\
10.55 \\
10.52 \\
10.52 \\
10.50 \\
10.48\end{array}$ & $\begin{array}{r}10.684477 \\
.683841 \\
.683205 \\
.6825 \% 0 \\
.681936 \\
.681303 \\
.6806 \% 0 \\
.680039 \\
.679408 \\
.67878 \\
.679149\end{array}$ & $\begin{array}{l}17 \\
16 \\
15 \\
14 \\
13 \\
12 \\
11 \\
10\end{array}$ \\
\hline $\begin{array}{l}51 \\
52 \\
53 \\
54 \\
55 \\
56 \\
57 \\
58 \\
59 \\
60 \\
\end{array}$ & $\begin{array}{r}9.312495 \\
.313097 \\
.313698 \\
.314297 \\
.314897 \\
.315495 \\
.316092 \\
.316689 \\
.317284 \\
9.317879 \\
\end{array}$ & $\begin{array}{r}10.03 \\
10.02 \\
9.98 \\
10.00 \\
9.97 \\
9.95 \\
9.95 \\
9.92 \\
9.92\end{array}$ & $\begin{array}{r}9.990645 \\
.990618 \\
.990591 \\
.990565 \\
.990538 \\
.990511 \\
.990485 \\
.990458 \\
.990431 \\
9.990404\end{array}$ & $\begin{array}{l}.45 \\
.45 \\
.43 \\
.45 \\
.45 \\
.43 \\
.45 \\
.45 \\
.45\end{array}$ & $\begin{array}{r}9.321851 \\
.32249 \\
.323106 \\
.323733 \\
.324358 \\
.324983 \\
.325607 \\
.326231 \\
.326853 \\
9.327475 \\
\end{array}$ & $\begin{array}{l}10.47 \\
10.45 \\
10.45 \\
10.42 \\
10.42 \\
10.40 \\
10.40 \\
10.37 \\
10.37\end{array}$ & $\begin{array}{r}10.678149 \\
.677521 \\
.676894 \\
.676267 \\
.675642 \\
.675017 \\
.674393 \\
.673769 \\
.673147 \\
10.672525 \\
\end{array}$ & $\begin{array}{l}9 \\
8 \\
7 \\
6 \\
5 \\
4 \\
3 \\
2 \\
1 \\
0\end{array}$ \\
\hline 1 & Cosine. & D. $1^{\prime \prime}$. & Sine. & D. $1^{\prime \prime}$. & ( & D. 1". & Tang. & ' \\
\hline
\end{tabular}




\begin{tabular}{|c|c|c|c|c|c|c|c|c|}
\hline 1 & Sine.: & D. $1 "$. & Cosine. & D. $1^{\circ}$. & Tang. & D. $1^{n}$. & Cotang. & ' \\
\hline $\begin{array}{r}0 \\
1 \\
2 \\
3 \\
4 \\
5 \\
6 \\
7 \\
8 \\
9 \\
10\end{array}$ & $\begin{array}{r}9.317879 \\
.318473 \\
.319066 \\
.319658 \\
.320249 \\
.320840 \\
.321430 \\
.322019 \\
.322607 \\
.323194 \\
.323780\end{array}$ & $\begin{array}{l}9.90 \\
9.88 \\
9.87 \\
9.85 \\
9.85 \\
9.83 \\
9.82 \\
9.80 \\
9.78 \\
9.77 \\
9.77\end{array}$ & $\begin{array}{r}9.990404 \\
.990378 \\
.990351 \\
.990324 \\
.990297 \\
.990270 \\
.990243 \\
.990215 \\
.990188 \\
.990161 \\
.990134\end{array}$ & $\begin{array}{l}.43 \\
.45 \\
.45 \\
.45 \\
.45 \\
.45 \\
.47 \\
.45 \\
.45 \\
.45 \\
.45\end{array}$ & $\begin{array}{r}9.327475 \\
.328095 \\
.328715 \\
.329334 \\
.329953 \\
.330570 \\
.331187 \\
.331803 \\
.332418 \\
.333033 \\
.333646\end{array}$ & $\begin{array}{l}10.33 \\
10.33 \\
10.32 \\
10.32 \\
10.28 \\
10.28 \\
10.27 \\
10.25 \\
10.25 \\
10.22 \\
10.22\end{array}$ & $\begin{array}{r}10.672525 \\
.671905 \\
.671285 \\
.670666 \\
.670047 \\
.669430 \\
.668813 \\
.668197 \\
.667582 \\
.666967 \\
.666354\end{array}$ & $\begin{array}{l}60 \\
59 \\
58 \\
57 \\
56 \\
55 \\
54 \\
53 \\
52 \\
51 \\
50\end{array}$ \\
\hline $\begin{array}{l}11 \\
12 \\
13 \\
14 \\
15 \\
16 \\
17 \\
18 \\
19 \\
20\end{array}$ & $\begin{array}{r}9.324366 \\
.324950 \\
.325534 \\
.326117 \\
.326700 \\
.327281 \\
.327862 \\
.328442 \\
.329021 \\
.329599\end{array}$ & $\begin{array}{l}9.73 \\
9.73 \\
9.72 \\
9.72 \\
9.68 \\
9.68 \\
9.67 \\
9.65 \\
9.63 \\
9.62\end{array}$ & $\begin{array}{r}9.990107 \\
.990079 \\
.990052 \\
.990025 \\
.989997 \\
.989970 \\
.989942 \\
.989915 \\
.989887 \\
.989860\end{array}$ & $\begin{array}{l}.45 \\
.47 \\
.45 \\
.45 \\
.47 \\
.45 \\
.47 \\
.45 \\
.47 \\
.45 \\
.47\end{array}$ & $\begin{array}{r}9.334259 \\
.334871 \\
.335482 \\
.336093 \\
.336702 \\
.337311 \\
.337919 \\
.338527 \\
.339133 \\
.339739\end{array}$ & $\begin{array}{l}10.20 \\
10.20 \\
10.18 \\
10.18 \\
10.15 \\
10.15 \\
10.13 \\
10.13 \\
10.10 \\
10.10 \\
10.08\end{array}$ & $\begin{array}{r}10.665741 \\
.665129 \\
.664518 \\
.663907 \\
.663298 \\
.662689 \\
.662081 \\
.661473 \\
.660867 \\
.660261\end{array}$ & $\begin{array}{l}49 \\
48 \\
47 \\
46 \\
45 \\
44 \\
43 \\
42 \\
41 \\
40\end{array}$ \\
\hline $\begin{array}{l}21 \\
22 \\
23 \\
24 \\
25 \\
26 \\
27 \\
28 \\
29 \\
30\end{array}$ & $\begin{array}{r}9.330176 \\
.330753 \\
.331329 \\
.331903 \\
.332478 \\
.333051 \\
.333624 \\
.334195 \\
.334767 \\
.335337\end{array}$ & $\begin{array}{l}9.62 \\
9.60 \\
9.57 \\
9.58 \\
9.55 \\
9.55 \\
9.52 \\
9.53 \\
9.50 \\
9.48\end{array}$ & $\begin{array}{r}9.989832 \\
.989804 \\
.989777 \\
.989749 \\
.989721 \\
.989693 \\
.989665 \\
.989637 \\
.989610 \\
.989582\end{array}$ & $\begin{array}{l}.47 \\
.45 \\
.47 \\
.47 \\
.47 \\
.47 \\
.47 \\
.45 \\
.47 \\
.48\end{array}$ & $\begin{array}{r}9.340344 \\
.340948 \\
.341552 \\
.342155 \\
.342757 \\
.343358 \\
.343958 \\
.344558 \\
.345157 \\
.345755\end{array}$ & $\begin{array}{r}10.07 \\
10.07 \\
10.05 \\
10.03 \\
10.02 \\
10.00 \\
10.00 \\
9.98 \\
9.97 \\
9.97\end{array}$ & $\begin{array}{r}10.659656 \\
.659052 \\
.658448 \\
.657845 \\
.657243 \\
.656642 \\
.656042 \\
.655442 \\
.654843 \\
.654245\end{array}$ & $\begin{array}{l}39 \\
38 \\
37 \\
36 \\
35 \\
34 \\
33 \\
32 \\
31 \\
30\end{array}$ \\
\hline $\begin{array}{l}31 \\
32 \\
33 \\
34 \\
35 \\
36 \\
37 \\
38 \\
39 \\
40\end{array}$ & $\begin{array}{r}9.335906 \\
.336475 \\
.337043 \\
.337610 \\
.338176 \\
.338742 \\
.339307 \\
.339871 \\
.340434 \\
.340996\end{array}$ & $\begin{array}{l}9.48 \\
9.47 \\
9.45 \\
9.43 \\
9.43 \\
9.42 \\
9.40 \\
9.38 \\
9.37 \\
9.37\end{array}$ & $\begin{array}{r}9.989553 \\
.989525 \\
.989497 \\
.989469 \\
.989441 \\
.989413 \\
.989385 \\
.989356 \\
.989328 \\
.989300\end{array}$ & $\begin{array}{l}.47 \\
.47 \\
.47 \\
.47 \\
.47 \\
.47 \\
.48 \\
.47 \\
.47 \\
.48\end{array}$ & $\begin{array}{r}9.346353 \\
.346949 \\
.347545 \\
.348141 \\
.348735 \\
.349329 \\
.349922 \\
.350514 \\
.351106 \\
.351697\end{array}$ & $\begin{array}{l}9.93 \\
9.93 \\
9.93 \\
9.90 \\
9.90 \\
9.88 \\
9.87 \\
9.87 \\
9.85 \\
9.83\end{array}$ & $\begin{array}{r}10.653647 \\
.653051 \\
.652455 \\
.651859 \\
.651265 \\
.650671 \\
.650078 \\
.649486 \\
.648894 \\
.648303\end{array}$ & $\begin{array}{l}29 \\
28 \\
27 \\
26 \\
25 \\
24 \\
23 \\
22 \\
21 \\
20\end{array}$ \\
\hline $\begin{array}{l}41 \\
42 \\
43 \\
44 \\
45 \\
46 \\
47 \\
48 \\
49 \\
50\end{array}$ & $\begin{array}{r}9.341558 \\
.342119 \\
.342679 \\
.343239 \\
.343797 \\
.344355 \\
.344912 \\
.345469 \\
.346024 \\
.346579\end{array}$ & $\begin{array}{l}9.35 \\
9.33 \\
9.33 \\
9.30 \\
9.30 \\
9.28 \\
9.28 \\
9.25 \\
9.25 \\
9.25\end{array}$ & $\begin{array}{r}9.989271 \\
.989243 \\
.989214 \\
.989186 \\
.989157 \\
.989128 \\
.989100 \\
.989071 \\
.989042 \\
.989014\end{array}$ & $\begin{array}{l}.47 \\
.48 \\
.47 \\
.48 \\
.48 \\
.47 \\
.48 \\
.48 \\
.47 \\
.48\end{array}$ & $\begin{array}{r}9.352287 \\
.352876 \\
.353465 \\
.354053 \\
.354640 \\
.355227 \\
.355813 \\
.356398 \\
.356982 \\
.357566\end{array}$ & $\begin{array}{l}9.00 \\
9.82 \\
9.82 \\
9.80 \\
9.78 \\
9.78 \\
9.77 \\
9.75 \\
9.73 \\
9.73 \\
9.72\end{array}$ & $\begin{array}{r}10.647713 \\
.647124 \\
.646535 \\
.645947 \\
.645360 \\
.644773 \\
.644187 \\
.643602 \\
.643018 \\
.642434\end{array}$ & $\begin{array}{l}19 \\
18 \\
17 \\
16 \\
15 \\
14 \\
13 \\
12 \\
11 \\
10\end{array}$ \\
\hline $\begin{array}{l}51 \\
52 \\
53 \\
54 \\
55 \\
56 \\
57 \\
58 \\
59 \\
60\end{array}$ & $\begin{array}{r}9.347134 \\
.347687 \\
.348240 \\
.348792 \\
.349343 \\
.349893 \\
.350443 \\
.350992 \\
.351540 \\
9.352088\end{array}$ & $\begin{array}{l}9.22 \\
9.22 \\
9.20 \\
9.18 \\
9.17 \\
9.17 \\
9.15 \\
9.13 \\
9.13\end{array}$ & $\begin{array}{r}9.988985 \\
.988956 \\
.988927 \\
.988898 \\
.988869 \\
.988840 \\
.988811 \\
.988782 \\
.988753 \\
9.988724\end{array}$ & $\begin{array}{l}.48 \\
.48 \\
.48 \\
.48 \\
.48 \\
.48 \\
.48 \\
.48 \\
.48\end{array}$ & $\begin{array}{r}9.358149 \\
.358731 \\
.359313 \\
.359893 \\
.360474 \\
.361053 \\
.361632 \\
.362210 \\
.362787 \\
9.363364\end{array}$ & $\begin{array}{l}9.70 \\
9.70 \\
9.67 \\
9.68 \\
9.65 \\
9.65 \\
9.63 \\
9.62 \\
9.62\end{array}$ & $\begin{array}{r}10.641851 \\
.641269 \\
.640687 \\
.640107 \\
.639526 \\
.638947 \\
.638368 \\
.637790 \\
.637213 \\
10.636636\end{array}$ & $\begin{array}{l}9 \\
8 \\
7 \\
6 \\
5 \\
4 \\
3 \\
2 \\
1 \\
0\end{array}$ \\
\hline . & Cosine. & 1 & Sine & D. 1". & Cotang. & D. $1^{\prime \prime}$. & Tang. & ' \\
\hline
\end{tabular}




\begin{tabular}{|c|c|c|c|c|c|c|c|c|}
\hline , & Sine. & D. 1". & Cosine. & D. $1^{\prime \prime}$. & Tang. & D. $1^{\circ}$. & Cotang. & ' \\
\hline $\begin{array}{r}0 \\
1 \\
2 \\
3 \\
4 \\
5 \\
6 \\
7 \\
8 \\
9 \\
10\end{array}$ & $\begin{array}{r}9.352088 \\
.352635 \\
.353181 \\
.353726 \\
.354271 \\
.354815 \\
.355358 \\
.355901 \\
.356443 \\
.356984 \\
.357524\end{array}$ & $\begin{array}{l}9.12 \\
9.10 \\
9.08 \\
9.08 \\
9.07 \\
9.05 \\
9.05 \\
9.03 \\
9.02 \\
9.00 \\
9.00\end{array}$ & $\begin{array}{r}9.988724 \\
.988615 \\
.988666 \\
.988636 \\
.988607 \\
.988578 \\
.988548 \\
.988519 \\
.988489 \\
.988460 \\
.988430\end{array}$ & $\begin{array}{l}.48 \\
.48 \\
.50 \\
.48 \\
.48 \\
.50 \\
.48 \\
.50 \\
.48 \\
.50 \\
.48\end{array}$ & $\begin{array}{r}9.363364 \\
.363940 \\
.364515 \\
.365090 \\
.365664 \\
.366237 \\
.366810 \\
.367382 \\
.367953 \\
.368524 \\
.369094\end{array}$ & $\begin{array}{l}9.60 \\
9.58 \\
9.58 \\
9.57 \\
9.55 \\
9.55 \\
9.53 \\
9.52 \\
9.52 \\
9.50 \\
9.48\end{array}$ & $\begin{array}{r}10.636636 \\
.636060 \\
.635485 \\
.634910 \\
.634336 \\
.633763 \\
.633190 \\
.632618 \\
.632047 \\
.631476 \\
.630906\end{array}$ & $\begin{array}{l}60 \\
59 \\
58 \\
57 \\
56 \\
55 \\
54 \\
53 \\
52 \\
51 \\
50\end{array}$ \\
\hline $\begin{array}{l}11 \\
12 \\
13 \\
14 \\
15 \\
16 \\
17 \\
18 \\
19 \\
20\end{array}$ & $\begin{array}{r}9.358064 \\
.358603 \\
.359141 \\
.359678 \\
.360215 \\
.360752 \\
.361287 \\
.361822 \\
.362356 \\
.362889\end{array}$ & $\begin{array}{l}8.98 \\
8.97 \\
8.95 \\
8.95 \\
8.95 \\
8.92 \\
8.92 \\
8.90 \\
8.88 \\
8.88\end{array}$ & $\begin{array}{r}9.988401 \\
.9883 r 1 \\
.988342 \\
.988312 \\
.988282 \\
.988252 \\
.988223 \\
.988193 \\
.988163 \\
.988133\end{array}$ & $\begin{array}{l}.50 \\
.48 \\
.50 \\
.50 \\
.50 \\
.48 \\
.50 \\
.50 \\
.50 \\
.50\end{array}$ & $\begin{array}{r}9.369663 \\
.370232 \\
.370799 \\
.371367 \\
.371933 \\
.372499 \\
.373064 \\
.373629 \\
.374193 \\
.374756\end{array}$ & $\begin{array}{l}9.40 \\
9.48 \\
9.45 \\
9.47 \\
9.43 \\
9.43 \\
9.42 \\
9.42 \\
9.40 \\
9.38 \\
9.38\end{array}$ & $\begin{array}{r}10.630337 \\
.629768 \\
.629201 \\
.628633 \\
.628067 \\
.627501 \\
.626936 \\
.626371 \\
.625807 \\
.625244\end{array}$ & $\begin{array}{l}49 \\
48 \\
47 \\
46 \\
45 \\
44 \\
43 \\
42 \\
41 \\
40\end{array}$ \\
\hline $\begin{array}{l}21 \\
22 \\
23 \\
24 \\
25 \\
26 \\
27 \\
28 \\
29 \\
30\end{array}$ & $\begin{array}{r}9.363422 \\
.363954 \\
.364485 \\
.365016 \\
.365546 \\
.366075 \\
.366604 \\
.367131 \\
.367659 \\
.368185\end{array}$ & $\begin{array}{l}8.87 \\
8.85 \\
8.85 \\
8.83 \\
8.82 \\
8.82 \\
8.78 \\
8.80 \\
8.7 \% \\
8.7 \%\end{array}$ & $\begin{array}{r}9.988103 \\
.988073 \\
.988043 \\
.988013 \\
.987983 \\
.987953 \\
.987922 \\
.987892 \\
.987862 \\
.987832\end{array}$ & $\begin{array}{l}.50 \\
.50 \\
.50 \\
.50 \\
.50 \\
.52 \\
.50 \\
.50 \\
.50 \\
.52\end{array}$ & $\begin{array}{r}9.375319 \\
.375881 \\
.376442 \\
.377003 \\
.377563 \\
.378122 \\
.378681 \\
.379239 \\
.379797 \\
.380354\end{array}$ & $\begin{array}{l}9.37 \\
9.35 \\
9.35 \\
9.33 \\
9.32 \\
9.32 \\
9.30 \\
9.30 \\
9.28 \\
9.27\end{array}$ & $\begin{array}{r}10.624681 \\
.624119 \\
.623558 \\
.62299 \% \\
.622437 \\
.621878 \\
.621319 \\
.620 \pi 61 \\
.620203 \\
.619646\end{array}$ & $\begin{array}{l}39 \\
38 \\
37 \\
36 \\
35 \\
34 \\
33 \\
32 \\
31 \\
30\end{array}$ \\
\hline $\begin{array}{l}31 \\
32 \\
33 \\
34 \\
35 \\
36 \\
37 \\
38 \\
39 \\
40\end{array}$ & $\begin{array}{r}9.368711 \\
.369236 \\
.369761 \\
.370285 \\
.370808 \\
.371330 \\
.371852 \\
.372373 \\
.372894 \\
.373414\end{array}$ & $\begin{array}{l}8.75 \\
8.75 \\
8.72 \\
8.72 \\
8.70 \\
8.70 \\
8.68 \\
8.68 \\
8.67 \\
8.65\end{array}$ & $\begin{array}{r}9.987801 \\
.98771 \\
.987740 \\
.987710 \\
.987679 \\
.987649 \\
.987618 \\
.987588 \\
.987557 \\
.987526\end{array}$ & $\begin{array}{l}.0 \sim \\
.50 \\
.52 \\
.50 \\
.52 \\
.50 \\
.52 \\
.50 \\
.52 \\
.52 \\
.50\end{array}$ & $\begin{array}{r}9.380910 \\
.381466 \\
.382020 \\
.382575 \\
.383129 \\
.383682 \\
.384234 \\
.384786 \\
.385337 \\
.385888\end{array}$ & $\begin{array}{l}9.27 \\
9.23 \\
9.25 \\
9.23 \\
9.22 \\
9.20 \\
9.20 \\
9.18 \\
9.18 \\
9.17\end{array}$ & $\begin{array}{r}10.619090 \\
.618534 \\
.617980 \\
.617425 \\
.6168 \% 1 \\
.616318 \\
.615766 \\
.615214 \\
.614663 \\
.614112\end{array}$ & $\begin{array}{l}29 \\
28 \\
27 \\
26 \\
25 \\
24 \\
23 \\
22 \\
21 \\
20\end{array}$ \\
\hline $\begin{array}{l}41 \\
42 \\
43 \\
44 \\
45 \\
46 \\
47 \\
48 \\
49 \\
50\end{array}$ & $\begin{array}{r}9.373933 \\
.374452 \\
.374970 \\
.375487 \\
.376003 \\
.376519 \\
.377035 \\
.377549 \\
.378063 \\
.378577\end{array}$ & $\begin{array}{l}8.65 \\
8.63 \\
8.62 \\
8.60 \\
8.60 \\
8.60 \\
8.51 \\
8.57 \\
8.57 \\
8.53\end{array}$ & $\begin{array}{r}9.987496 \\
.987465 \\
.987434 \\
.987403 \\
.987372 \\
.987341 \\
.987310 \\
.987279 \\
.987248 \\
.987217\end{array}$ & $\begin{array}{l}.52 \\
.52 \\
.52 \\
.52 \\
.52 \\
.52 \\
.52 \\
.52 \\
.52 \\
.52\end{array}$ & $\begin{array}{r}9.386438 \\
.386987 \\
.387536 \\
.388084 \\
.388631 \\
.389178 \\
.389724 \\
.390270 \\
.390815 \\
.391360\end{array}$ & $\begin{array}{l}9.15 \\
9.15 \\
9.13 \\
9.12 \\
9.12 \\
9.10 \\
9.10 \\
9.08 \\
9.08 \\
9.05\end{array}$ & $\begin{array}{r}10.613562 \\
.613013 \\
.612464 \\
.611916 \\
.611369 \\
.610822 \\
.610276 \\
.609730 \\
.609185 \\
.608640\end{array}$ & $\begin{array}{l}19 \\
18 \\
17 \\
16 \\
15 \\
14 \\
13 \\
12 \\
11 \\
10\end{array}$ \\
\hline $\begin{array}{l}51 \\
52 \\
53 \\
54 \\
55 \\
56 \\
57 \\
58 \\
59 \\
60\end{array}$ & $\begin{array}{r}9 \cdot 379089 \\
.379601 \\
.380113 \\
.380624 \\
.381134 \\
.381643 \\
.382152 \\
.382661 \\
.383168 \\
9.383675 \\
\end{array}$ & $\begin{array}{l}8.53 \\
8.53 \\
8.52 \\
8.50 \\
8.48 \\
8.48 \\
8.48 \\
8.45 \\
8.45\end{array}$ & $\begin{array}{r}9.987186 \\
.987155 \\
.987124 \\
.987092 \\
.987061 \\
.987030 \\
.956998 \\
.986967 \\
.986936 \\
9.986904 \\
\end{array}$ & $\begin{array}{l}.52 \\
.52 \\
.52 \\
.53 \\
.52 \\
.52 \\
.53 \\
.52 \\
.52 \\
.53\end{array}$ & $\begin{array}{r}9.391903 \\
.392447 \\
.392989 \\
.393531 \\
.394073 \\
.394614 \\
.395154 \\
.395694 \\
.396233 \\
9.39671\end{array}$ & $\begin{array}{l}9.07 \\
9.03 \\
9.03 \\
9.03 \\
9.02 \\
9.00 \\
9.00 \\
8.98 \\
8.97\end{array}$ & $\begin{array}{r}10.608097 \\
.607553 \\
.607011 \\
.606469 \\
.605927 \\
.605386 \\
.604846 \\
.604306 \\
.603767 \\
10.603229\end{array}$ & $\begin{array}{l}9 \\
8 \\
7 \\
6 \\
5 \\
4 \\
3 \\
2 \\
1 \\
0\end{array}$ \\
\hline 1 & Cos & D. $1^{\circ}$. & & & Cotang. & D. $1^{\circ}$ & Tang. & ' \\
\hline
\end{tabular}




\begin{tabular}{|c|c|c|c|c|c|c|c|c|}
\hline , & Sine. & D. $1^{\prime \prime}$. & Cosine. & D. $1^{\prime \prime}$. & Tang. & D. $1^{\prime}$. & Cotang. & , \\
\hline $\begin{array}{r}0 \\
1 \\
2 \\
3 \\
4 \\
5 \\
6 \\
7 \\
8 \\
9 \\
10\end{array}$ & $\begin{array}{r}9.3836 \pi 5 \\
.38418 \% \\
.384687 \\
.385192 \\
.38569 \pi \\
.386201 \\
.386704 \\
.387207 \\
.387709 \\
.388210 \\
.388711\end{array}$ & $\begin{array}{l}8.45 \\
8.42 \\
8.42 \\
8.42 \\
8.40 \\
8.38 \\
8.38 \\
8.37 \\
8.35 \\
8.35 \\
8.33\end{array}$ & $\begin{array}{r}9.986904 \\
.986873 \\
.986841 \\
.986809 \\
.986778 \\
.986746 \\
.986714 \\
.986683 \\
.986651 \\
.986619 \\
.986587\end{array}$ & $\begin{array}{l}.52 \\
.53 \\
.53 \\
.52 \\
.53 \\
.53 \\
.52 \\
.53 \\
.53 \\
.53 \\
.53\end{array}$ & $\begin{array}{r}9.396771 \\
.397309 \\
.397846 \\
.398383 \\
.398919 \\
.399455 \\
.399990 \\
.400524 \\
.401058 \\
.401591 \\
.402124\end{array}$ & $\begin{array}{l}8.97 \\
8.95 \\
8.95 \\
8.93 \\
8.93 \\
8.92 \\
8.90 \\
8.90 \\
8.88 \\
8.88 \\
8.87\end{array}$ & $\begin{array}{r}10.603229 \\
.602691 \\
.602154 \\
.601617 \\
.601081 \\
.600545 \\
.600010 \\
.599476 \\
.598942 \\
.598409 \\
.597876\end{array}$ & $\begin{array}{l}60 \\
59 \\
58 \\
57 \\
56 \\
55 \\
54 \\
53 \\
52 \\
51 \\
50\end{array}$ \\
\hline $\begin{array}{l}11 \\
12 \\
13 \\
14 \\
15 \\
16 \\
17 \\
18 \\
19 \\
20\end{array}$ & $\begin{array}{r}9.389211 \\
.389711 \\
.390210 \\
.390708 \\
.391206 \\
.391703 \\
.392199 \\
.392695 \\
.393191 \\
.393685\end{array}$ & $\begin{array}{l}8.33 \\
8.32 \\
8.30 \\
8.30 \\
8.23 \\
8.27 \\
8.27 \\
8.27 \\
8.23 \\
8.23\end{array}$ & $\begin{array}{r}9.986555 \\
.986523 \\
.986491 \\
.986459 \\
.986427 \\
.986395 \\
.986363 \\
.986331 \\
.986299 \\
.986266\end{array}$ & $\begin{array}{l}.50 \\
.53 \\
.53 \\
.53 \\
.53 \\
.53 \\
.53 \\
.53 \\
.53 \\
.55 \\
.53\end{array}$ & $\begin{array}{r}9.402656 \\
.403187 \\
.403 \pi 18 \\
.404249 \\
.404778 \\
.405308 \\
.405836 \\
.406364 \\
.406892 \\
.407419\end{array}$ & $\begin{array}{l}8.85 \\
8.85 \\
8.85 \\
8.82 \\
8.83 \\
8.80 \\
8.80 \\
8.80 \\
8.78 \\
8.77\end{array}$ & \begin{tabular}{|r}
10.597344 \\
.596813 \\
.596282 \\
.595751 \\
.595222 \\
.594692 \\
.594164 \\
.593636 \\
.593108 \\
.592581
\end{tabular} & $\begin{array}{l}49 \\
48 \\
47 \\
46 \\
45 \\
44 \\
43 \\
42 \\
41 \\
40\end{array}$ \\
\hline $\begin{array}{l}21 \\
22 \\
23 \\
24 \\
25 \\
26 \\
27 \\
28 \\
29 \\
30\end{array}$ & $\begin{array}{r}9.394179 \\
.394673 \\
.395166 \\
.395658 \\
.396150 \\
.396641 \\
.397132 \\
.397621 \\
.398111 \\
.398600\end{array}$ & $\begin{array}{l}8.20 \\
8.23 \\
8.22 \\
8.20 \\
8.20 \\
8.18 \\
8.18 \\
8.15 \\
8.1 \% \\
8.15 \\
8.13\end{array}$ & $\begin{array}{r}9.986234 \\
.986202 \\
.986169 \\
.98613 \% \\
.986104 \\
.9860 \% 2 \\
.986039 \\
.98600 \% \\
.9859 \pi 4 \\
.985942\end{array}$ & $\begin{array}{l}.50 \\
.53 \\
.55 \\
.53 \\
.55 \\
.58 \\
.55 \\
.53 \\
.55 \\
.53 \\
.55\end{array}$ & $\begin{array}{r}9.407945 \\
.408471 \\
.408996 \\
.409521 \\
.410045 \\
.410569 \\
.411092 \\
.411615 \\
.412137 \\
.412658\end{array}$ & $\begin{array}{l}8.77 \\
8.75 \\
8.75 \\
8.73 \\
8.73 \\
8.72 \\
8.72 \\
8.70 \\
8.68 \\
8.68\end{array}$ & $\begin{array}{r}10.592055 \\
.591529 \\
.591004 \\
.590479 \\
.589955 \\
.589431 \\
.588908 \\
.588385 \\
.587863 \\
.587342\end{array}$ & $\begin{array}{l}39 \\
38 \\
37 \\
36 \\
35 \\
34 \\
33 \\
32 \\
31 \\
30\end{array}$ \\
\hline $\begin{array}{l}31 \\
32 \\
33 \\
34 \\
35 \\
36 \\
37 \\
38 \\
39 \\
40\end{array}$ & $\begin{array}{r}9.399088 \\
.399575 \\
.400062 \\
.400549 \\
.401035 \\
.401520 \\
.402005 \\
.402489 \\
.402972 \\
.403455\end{array}$ & $\begin{array}{l}8.12 \\
8.12 \\
8.12 \\
8.10 \\
8.08 \\
8.08 \\
8.07 \\
8.05 \\
8.05 \\
8.05\end{array}$ & $\begin{array}{r}9.985909 \\
.9858 \% 6 \\
.985813 \\
.985811 \\
.985 \% 7 \\
.985745 \\
.985712 \\
.9856 \pi 9 \\
.985646 \\
.985613\end{array}$ & $\begin{array}{l}.55 \\
.55 \\
.55 \\
.53 \\
.55 \\
.55 \\
.55 \\
.55 \\
.55 \\
.55 \\
.55\end{array}$ & $\begin{array}{r}9.413179 \\
.413699 \\
.414219 \\
.414738 \\
.415257 \\
.415775 \\
.416293 \\
.416810 \\
.417326 \\
.417842\end{array}$ & $\begin{array}{l}8.67 \\
8.67 \\
8.65 \\
8.65 \\
8.63 \\
8.63 \\
8.62 \\
8.60 \\
8.60 \\
8.60\end{array}$ & $\begin{array}{r}10.586821 \\
.586301 \\
.585781 \\
.585262 \\
.584743 \\
.584225 \\
.583707 \\
.583190 \\
.582674 \\
.582158\end{array}$ & $\begin{array}{l}29 \\
28 \\
27 \\
26 \\
25 \\
24 \\
23 \\
22 \\
21 \\
20\end{array}$ \\
\hline $\begin{array}{l}41 \\
42 \\
43 \\
44 \\
45 \\
46 \\
47 \\
48 \\
49 \\
50\end{array}$ & $\begin{array}{r}9.403938 \\
.404420 \\
.404901 \\
.405382 \\
.405862 \\
.406341 \\
.406820 \\
.407299 \\
.407777 \\
.408254\end{array}$ & $\begin{array}{l}8.03 \\
8.02 \\
8.02 \\
8.00 \\
7.98 \\
7.98 \\
7.98 \\
7.97 \\
7.95 \\
7.95\end{array}$ & $\begin{array}{r}9.985580 \\
.985547 \\
.985514 \\
.985480 \\
.985447 \\
.985414 \\
.985381 \\
.985347 \\
.985314 \\
.985280\end{array}$ & $\begin{array}{l}.55 \\
.55 \\
.55 \\
.57 \\
.55 \\
.55 \\
.55 \\
.57 \\
.55 \\
.57 \\
.55\end{array}$ & $\begin{array}{r}9.418358 \\
.418873 \\
.419387 \\
.419901 \\
.420415 \\
.420927 \\
.421440 \\
.421952 \\
.422463 \\
.4229 \% 4\end{array}$ & $\begin{array}{l}8.58 \\
8.57 \\
8.57 \\
8.57 \\
8.55 \\
8.55 \\
8.53 \\
8.52 \\
8.52 \\
8.50\end{array}$ & $\begin{array}{r}10.581642 \\
.581127 \\
.580613 \\
.580099 \\
.579585 \\
.579073 \\
.578560 \\
.578048 \\
.577537 \\
.577026\end{array}$ & $\begin{array}{l}19 \\
18 \\
17 \\
16 \\
15 \\
14 \\
13 \\
12 \\
11 \\
10\end{array}$ \\
\hline $\begin{array}{l}51 \\
52 \\
53 \\
54 \\
55 \\
56 \\
57 \\
58 \\
59 \\
60\end{array}$ & $\begin{array}{r}9.408731 \\
.409207 \\
.409682 \\
.410157 \\
.410632 \\
.411106 \\
.411579 \\
.412052 \\
.412524 \\
9.412996\end{array}$ & $\begin{array}{l}7.93 \\
7.93 \\
7.92 \\
7.92 \\
7.90 \\
7.88 \\
7.88 \\
7.87 \\
7.87\end{array}$ & $\begin{array}{r}9.985247 \\
.985213 \\
.985180 \\
.985146 \\
.985113 \\
.985079 \\
.985045 \\
.985011 \\
.984978 \\
9.984944\end{array}$ & $\begin{array}{l}.57 \\
.55 \\
.57 \\
.55 \\
.57 \\
.57 \\
.57 \\
.55 \\
.57\end{array}$ & $\begin{array}{r}9.423484 \\
.423993 \\
.424503 \\
.425011 \\
.425519 \\
.426027 \\
.426534 \\
.427041 \\
.427547 \\
9.428052\end{array}$ & $\begin{array}{l}8.48 \\
8.50 \\
8.47 \\
8.47 \\
8.47 \\
8.45 \\
8.45 \\
8.43 \\
8.42\end{array}$ & $\begin{array}{r}10.576516 \\
.576007 \\
.575497 \\
.574989 \\
.574481 \\
.573973 \\
.573466 \\
.572959 \\
.572453 \\
10.571948\end{array}$ & $\begin{array}{l}9 \\
8 \\
7 \\
6 \\
5 \\
4 \\
3 \\
2 \\
1 \\
0\end{array}$ \\
\hline al & Cosine. & 1. 1. & Dine & D. $1^{\prime \prime}$. & ing. & D. $1^{\circ}$. & Tang. & 1 \\
\hline
\end{tabular}




\begin{tabular}{|c|c|c|c|c|c|c|c|c|}
\hline ' & Sine. & D. $1^{\circ}$. & Cosine. & D. $1^{\circ}$. & Tang. & D. $1^{\circ}$. & Cotang. & , \\
\hline $\begin{array}{r}0 \\
1 \\
2 \\
3 \\
4 \\
5 \\
6 \\
7 \\
8 \\
9 \\
10\end{array}$ & $\begin{array}{r}9.412996 \\
.413467 \\
.413938 \\
.414408 \\
.414878 \\
.415347 \\
.415815 \\
.416283 \\
.416751 \\
.417217 \\
.417681\end{array}$ & $\begin{array}{l}7.85 \\
7.85 \\
7.83 \\
7.83 \\
7.82 \\
7.80 \\
7.80 \\
7.80 \\
7.77 \\
7.78 \\
7.77\end{array}$ & $\begin{array}{r}9.984944 \\
.984910 \\
.984876 \\
.984842 \\
.984808 \\
.984774 \\
.984740 \\
.984706 \\
.984672 \\
.984638 \\
.984603\end{array}$ & $\begin{array}{l}.57 \\
.57 \\
.57 \\
.57 \\
.57 \\
.57 \\
.57 \\
.57 \\
.57 \\
.58 \\
.57\end{array}$ & $\begin{array}{r}9.428052 \\
.428558 \\
.429062 \\
.429566 \\
.430070 \\
.430573 \\
.431075 \\
.431577 \\
.432079 \\
.432580 \\
.433080\end{array}$ & $\begin{array}{l}8.43 \\
8.40 \\
8.40 \\
8.40 \\
8.38 \\
8.37 \\
8.37 \\
8.37 \\
8.35 \\
8.33 \\
8.33\end{array}$ & $\begin{array}{r}10.571948 \\
.571442 \\
.570938 \\
.570434 \\
.569930 \\
.569427 \\
.568925 \\
.568423 \\
.567921 \\
.567420 \\
.566920\end{array}$ & $\begin{array}{l}60 \\
59 \\
58 \\
57 \\
56 \\
55 \\
54 \\
53 \\
52 \\
51 \\
50\end{array}$ \\
\hline $\begin{array}{l}11 \\
12 \\
13 \\
14 \\
15 \\
16 \\
17 \\
18 \\
19 \\
20\end{array}$ & $\begin{array}{r}9.418150 \\
.418615 \\
.419079 \\
.419544 \\
.420007 \\
.420470 \\
.420933 \\
.421395 \\
.421857 \\
.422318\end{array}$ & $\begin{array}{l}7.75 \\
7.73 \\
7.75 \\
7.72 \\
7.72 \\
7.72 \\
7.70 \\
7.70 \\
7.68 \\
7.67\end{array}$ & $\begin{array}{r}9.984569 \\
.984535 \\
.984500 \\
.984466 \\
.984432 \\
.984397 \\
.984363 \\
.984328 \\
.984294 \\
.984259\end{array}$ & $\begin{array}{l}.57 \\
.58 \\
.57 \\
.57 \\
.58 \\
.57 \\
.58 \\
.57 \\
.58 \\
.58\end{array}$ & $\begin{array}{r}9.433580 \\
. .434080 \\
.434579 \\
.435078 \\
.435576 \\
.436073 \\
.436570 \\
.437067 \\
.437563 \\
.438059\end{array}$ & $\begin{array}{l}8.33 \\
8.32 \\
8.32 \\
8.30 \\
8.28 \\
8.28 \\
8.28 \\
8.27 \\
8.27 \\
8.25\end{array}$ & $\begin{array}{r}10.566420 \\
.565920 \\
.565421 \\
.564922 \\
.564424 \\
.563927 \\
.563430 \\
.562933 \\
.562437 \\
.561941\end{array}$ & $\begin{array}{l}49 \\
48 \\
47 \\
46 \\
45 \\
44 \\
43 \\
42 \\
41 \\
40\end{array}$ \\
\hline $\begin{array}{l}21 \\
22 \\
23 \\
24 \\
25 \\
26 \\
27 \\
28 \\
29 \\
30\end{array}$ & $\begin{array}{r}9.422778 \\
.423238 \\
.423697 \\
.424156 \\
.424615 \\
.425073 \\
.425530 \\
425987 \\
.426443 \\
.426899\end{array}$ & $\begin{array}{l}7.67 \\
7.65 \\
7.65 \\
7.65 \\
7.63 \\
7.62 \\
7.62 \\
7.60 \\
7.60 \\
7.58\end{array}$ & $\begin{array}{r}9.984224 \\
.984190 \\
.984155 \\
.984120 \\
.984085 \\
.984050 \\
.984015 \\
.983981 \\
.983946 \\
.983911\end{array}$ & $\begin{array}{l}.57 \\
.58 \\
.58 \\
.58 \\
.58 \\
.58 \\
.57 \\
.58 \\
.58 \\
.60\end{array}$ & $\begin{array}{r}9.438554 \\
.439048 \\
.439543 \\
.440036 \\
.440529 \\
.441022 \\
.441514 \\
.442006 \\
.442497 \\
.442988\end{array}$ & $\begin{array}{l}8.23 \\
8.25 \\
8.22 \\
8.22 \\
8.22 \\
8.20 \\
8.20 \\
8.18 \\
8.18 \\
8.18\end{array}$ & $\begin{array}{r}10.561446 \\
.560952 \\
.560457 \\
.559964 \\
.559471 \\
.558978 \\
.558486 \\
.557994 \\
.5557503 \\
.557012\end{array}$ & $\begin{array}{l}39 \\
38 \\
37 \\
36 \\
35 \\
34 \\
33 \\
32 \\
31 \\
30\end{array}$ \\
\hline $\begin{array}{l}31 \\
32 \\
33 \\
34 \\
35 \\
36 \\
37 \\
38 \\
39 \\
40\end{array}$ & $\begin{array}{r}9.427354 \\
.427809 \\
.428263 \\
.428717 \\
.429170 \\
.429623 \\
.430075 \\
.430527 \\
.430978 \\
.431429\end{array}$ & $\begin{array}{l}7.58 \\
7.57 \\
7.57 \\
7.55 \\
7.55 \\
7.53 \\
7.53 \\
7.52 \\
7.52 \\
7.50\end{array}$ & $\begin{array}{r}9.983875 \\
.983840 \\
.983805 \\
.983770 \\
.983735 \\
.983700 \\
.983664 \\
.983629 \\
.983594 \\
.983558\end{array}$ & $\begin{array}{l}.58 \\
.58 \\
.58 \\
.58 \\
.58 \\
.60 \\
.58 \\
.58 \\
.60 \\
.58\end{array}$ & $\begin{array}{r}9.443479 \\
.443968 \\
.444458 \\
.444947 \\
.445435 \\
.445923 \\
.446411 \\
.446898 \\
.447384 \\
.447870\end{array}$ & $\begin{array}{l}8.15 \\
8.17 \\
8.15 \\
8.13 \\
8.13 \\
8.13 \\
8.12 \\
8.10 \\
8.10 \\
8.10\end{array}$ & $\begin{array}{r}10.556521 \\
.556032 \\
.555542 \\
.555053 \\
.554565 \\
.554077 \\
.553589 \\
.553102 \\
.552616 \\
.552130\end{array}$ & $\begin{array}{l}29 \\
28 \\
27 \\
26 \\
25 \\
24 \\
23 \\
22 \\
21 \\
20\end{array}$ \\
\hline $\begin{array}{l}41 \\
42 \\
43 \\
44 \\
45 \\
46 \\
47 \\
48 \\
49 \\
50\end{array}$ & $\begin{array}{r}9.431879 \\
.432329 \\
.432778 \\
.433226 \\
.433675 \\
.434122 \\
.434569 \\
.435016 \\
.435462 \\
.435908\end{array}$ & $\begin{array}{l}7.50 \\
7.48 \\
7.47 \\
7.48 \\
7.45 \\
7.45 \\
7.45 \\
7.43 \\
7.43 \\
7.42\end{array}$ & $\begin{array}{r}9.983523 \\
.983487 \\
.983452 \\
.983416 \\
.983381 \\
.983345 \\
.983309 \\
.983273 \\
.983238 \\
.983202\end{array}$ & $\begin{array}{l}.60 \\
.58 \\
.60 \\
.58 \\
.60 \\
.60 \\
.60 \\
.58 \\
.60 \\
.60\end{array}$ & $\begin{array}{r}9.448356 \\
.448841 \\
.449326 \\
.449810 \\
.450294 \\
.450777 \\
.451260 \\
.451743 \\
.452225 \\
.452706\end{array}$ & $\begin{array}{l}8.08 \\
8.08 \\
8.07 \\
8.07 \\
8.05 \\
8.05 \\
8.05 \\
8.03 \\
8.02 \\
8.02\end{array}$ & $\begin{array}{r}10.551644 \\
.551159 \\
.5506 \pi 4 \\
.550190 \\
.549706 \\
.549223 \\
.548 \% 40 \\
.548257 \\
.547775 \\
.547294\end{array}$ & $\begin{array}{l}19 \\
18 \\
17 \\
16 \\
15 \\
14 \\
13 \\
12 \\
11 \\
10\end{array}$ \\
\hline $\begin{array}{l}51 \\
52 \\
53 \\
54 \\
55 \\
56 \\
57 \\
58 \\
59 \\
60\end{array}$ & $\begin{array}{r}9.436353 \\
.436798 \\
.437242 \\
.437686 \\
.438129 \\
.438572 \\
.439014 \\
.439456 \\
.439897 \\
9.440338\end{array}$ & $\begin{array}{l}7.42 \\
7.40 \\
7.40 \\
7.38 \\
7.38 \\
7.37 \\
7.37 \\
7.35 \\
7.35\end{array}$ & $\begin{array}{r}9.983166 \\
.983130 \\
.983094 \\
.983058 \\
.983022 \\
.982986 \\
.982950 \\
.982914 \\
.982878 \\
9.982842\end{array}$ & $\begin{array}{l}.60 \\
.60 \\
.60 \\
.60 \\
.60 \\
.60 \\
.60 \\
.60 \\
.60\end{array}$ & $\begin{array}{r}9.453187 \\
.453668 \\
.454148 \\
.454628 \\
.455107 \\
.455586 \\
.456064 \\
.456542 \\
.457019 \\
9.457496\end{array}$ & $\begin{array}{l}8.02 \\
8.00 \\
8.00 \\
7.98 \\
7.98 \\
7.97 \\
7.97 \\
7.95 \\
7.95\end{array}$ & $\begin{array}{r}10.546813 \\
.546332 \\
.545852 \\
.545372 \\
.541893 \\
.544414 \\
.543936 \\
.543458 \\
.542981 \\
10.542504 \\
\end{array}$ & $\begin{array}{l}9 \\
8 \\
7 \\
6 \\
5 \\
4 \\
3 \\
2 \\
1 \\
0\end{array}$ \\
\hline ' & Cosine. & D. $1^{\prime \prime}$. & Sine. & .2. & Cc & 20 & Tang. & 1 \\
\hline
\end{tabular}




\begin{tabular}{|c|c|c|c|c|c|c|c|c|}
\hline 1 & Sine. & D. $1^{\prime \prime}$. & Cosine. & D. $1^{\prime \prime}$. & Tang. & D. $1^{\prime \prime}$. & Cotang. & , \\
\hline $\begin{array}{r}0 \\
1 \\
2 \\
3 \\
4 \\
5 \\
6 \\
7 \\
8 \\
9 \\
10\end{array}$ & $\begin{array}{r}9.440338 \\
.440778 \\
.441218 \\
.441658 \\
.442096 \\
.442535 \\
.442973 \\
.443410 \\
.443847 \\
.444284 \\
.444720\end{array}$ & $\begin{array}{l}7.33 \\
7.33 \\
7.33 \\
7.30 \\
7.32 \\
7.30 \\
7.28 \\
7.28 \\
7.28 \\
7.27 \\
7.25\end{array}$ & $\begin{array}{r}9.982842 \\
.982805 \\
.982769 \\
.982733 \\
.982696 \\
.982660 \\
.982624 \\
.982587 \\
.982551 \\
.982514 \\
.982177\end{array}$ & $\begin{array}{l}.62 \\
.60 \\
.60 \\
.62 \\
.60 \\
.60 \\
.62 \\
.60 \\
.62 \\
.62 \\
.60\end{array}$ & $\begin{array}{r}9.457496 \\
.457973 \\
.458449 \\
.458925 \\
.459400 \\
.459875 \\
.460349 \\
.460823 \\
.461297 \\
.461770 \\
.462242\end{array}$ & $\begin{array}{l}7.95 \\
7.93 \\
7.93 \\
7.92 \\
7.92 \\
7.90 \\
7.90 \\
7.90 \\
7.88 \\
7.87 \\
7.88\end{array}$ & $\begin{array}{r}10.542504 \\
.542027 \\
.541551 \\
.541075 \\
.540600 \\
.540125 \\
.539651 \\
.53917 \% \\
.538703 \\
.538230 \\
.537758\end{array}$ & $\begin{array}{l}60 \\
59 \\
58 \\
57 \\
56 \\
55 \\
54 \\
53 \\
52 \\
51 \\
50\end{array}$ \\
\hline $\begin{array}{l}11 \\
12 \\
13 \\
14 \\
15 \\
16 \\
17 \\
18 \\
19 \\
20\end{array}$ & $\begin{array}{r}9.445155 \\
.445590 \\
.446025 \\
.446459 \\
.446893 \\
.447326 \\
.447759 \\
.448191 \\
.448623 \\
.449054\end{array}$ & $\begin{array}{l}7.25 \\
7.25 \\
7.23 \\
7.23 \\
7.22 \\
7.22 \\
7.20 \\
7.20 \\
7.18 \\
7.18\end{array}$ & $\begin{array}{r}9.982441 \\
.982404 \\
.98236 \% \\
.982331 \\
.982294 \\
.982257 \\
.982220 \\
.982183 \\
.982146 \\
.982109\end{array}$ & $\begin{array}{l}.62 \\
.62 \\
.60 \\
.62 \\
.62 \\
.62 \\
.62 \\
.62 \\
.62 \\
.62\end{array}$ & $\begin{array}{r}9.462715 \\
.463186 \\
.463658 \\
.464128 \\
.464599 \\
.465069 \\
.465539 \\
.466008 \\
.466477 \\
.466945\end{array}$ & $\begin{array}{l}7.85 \\
7.87 \\
7.83 \\
7.85 \\
7.83 \\
7.83 \\
7.82 \\
7.82 \\
7.80 \\
7.80\end{array}$ & $\begin{array}{r}10.537285 \\
.536814 \\
.536342 \\
.535872 \\
.535401 \\
.534931 \\
.534461 \\
.533992 \\
.533523 \\
.533055\end{array}$ & $\begin{array}{l}49 \\
48 \\
47 \\
46 \\
45 \\
44 \\
43 \\
42 \\
41 \\
40\end{array}$ \\
\hline $\begin{array}{l}21 \\
22 \\
23 \\
24 \\
25 \\
26 \\
27 \\
28 \\
29 \\
30\end{array}$ & $\begin{array}{r}9.449485 \\
.449915 \\
.450345 \\
.450775 \\
.451204 \\
.451632 \\
.452060 \\
.452488 \\
.452915 \\
.453342\end{array}$ & $\begin{array}{l}7.17 \\
7.17 \\
7.17 \\
7.15 \\
7.13 \\
7.13 \\
7.13 \\
7.12 \\
7.12 \\
7.10\end{array}$ & $\begin{array}{r}9.982072 \\
.982035 \\
.981998 \\
.981961 \\
.981924 \\
.981886 \\
.981849 \\
.981812 \\
.981774 \\
.981737\end{array}$ & $\begin{array}{l}.62 \\
.62 \\
.62 \\
.62 \\
.63 \\
.62 \\
.62 \\
.63 \\
.62 \\
.62\end{array}$ & $\begin{array}{r}9.467413 \\
.467880 \\
.468347 \\
.468814 \\
.469280 \\
.469746 \\
.470211 \\
.470676 \\
.471141 \\
.471605\end{array}$ & $\begin{array}{l}7.00 \\
7.78 \\
7.78 \\
7.18 \\
7.77 \\
7.77 \\
7.75 \\
7.75 \\
7.75 \\
7.73 \\
7.73\end{array}$ & $\begin{array}{r}10.532587 \\
.532120 \\
.531653 \\
.531186 \\
.530720 \\
.530254 \\
.529789 \\
.529324 \\
.528859 \\
.528395\end{array}$ & $\begin{array}{l}39 \\
38 \\
37 \\
36 \\
35 \\
34 \\
33 \\
32 \\
31 \\
30\end{array}$ \\
\hline $\begin{array}{l}31 \\
32 \\
33 \\
34 \\
35 \\
36 \\
3 \% \\
38 \\
39 \\
40\end{array}$ & $\begin{array}{r}9.453768 \\
.454194 \\
.454619 \\
.455044 \\
.455469 \\
.455893 \\
.456316 \\
.456739 \\
.457162 \\
.457584\end{array}$ & $\begin{array}{l}7.10 \\
7.08 \\
7.08 \\
7.08 \\
7.07 \\
7.05 \\
7.05 \\
7.05 \\
7.03 \\
7.03\end{array}$ & $\begin{array}{r}9.981700 \\
.981662 \\
.981625 \\
.981587 \\
.981549 \\
.981512 \\
.981474 \\
.981436 \\
.981399 \\
.981361\end{array}$ & $\begin{array}{l}.63 \\
.62 \\
.63 \\
.63 \\
.62 \\
.63 \\
.63 \\
.62 \\
.63 \\
.63\end{array}$ & $\begin{array}{r}9.472069 \\
.472532 \\
.472995 \\
.473457 \\
.473919 \\
.474381 \\
.474842 \\
.475303 \\
.475763 \\
.476223\end{array}$ & $\begin{array}{l}7.72 \\
7.72 \\
7.70 \\
7.70 \\
7.70 \\
7.68 \\
7.68 \\
7.67 \\
7.67 \\
7.67\end{array}$ & $\begin{array}{r}10.527931 \\
527468 \\
.527005 \\
.526543 \\
.526081 \\
.525619 \\
.525158 \\
.524697 \\
.524237 \\
.523717\end{array}$ & $\begin{array}{l}29 \\
28 \\
27 \\
26 \\
25 \\
24 \\
23 \\
22 \\
21 \\
20\end{array}$ \\
\hline $\begin{array}{l}41 \\
42 \\
43 \\
44 \\
45 \\
46 \\
47 \\
48 \\
49 \\
50\end{array}$ & $\begin{array}{r}9.458006 \\
.458427 \\
.458848 \\
.459268 \\
.459688 \\
.460108 \\
.460527 \\
.460946 \\
.461364 \\
.461782\end{array}$ & $\begin{array}{l}7.02 \\
7.02 \\
7.00 \\
7.00 \\
7.00 \\
6.98 \\
6.98 \\
6.97 \\
6.97 \\
6.95\end{array}$ & $\begin{array}{r}9.981323 \\
.981285 \\
.981247 \\
.981209 \\
.981171 \\
.981133 \\
.981095 \\
.981057 \\
.981019 \\
.980981\end{array}$ & $\begin{array}{l}.63 \\
.63 \\
.63 \\
.63 \\
.63 \\
.63 \\
.63 \\
.63 \\
.63 \\
.65\end{array}$ & $\begin{array}{r}9.476683 \\
.477142 \\
.47601 \\
.478059 \\
.478517 \\
.478975 \\
.479432 \\
.479889 \\
.480345 \\
.480801\end{array}$ & $\begin{array}{l}7.65 \\
7.65 \\
7.63 \\
7.63 \\
7.63 \\
7.62 \\
7.62 \\
7.60 \\
7.60 \\
7.60\end{array}$ & $\begin{array}{r}10.523317 \\
.522858 \\
.522398 \\
.521941 \\
.521483 \\
.521025 \\
.520568 \\
.520111 \\
.519655 \\
.519199\end{array}$ & $\begin{array}{l}19 \\
18 \\
17 \\
16 \\
15 \\
14 \\
13 \\
12 \\
11 \\
10\end{array}$ \\
\hline $\begin{array}{l}51 \\
52 \\
53 \\
54 \\
55 \\
56 \\
57 \\
58 \\
59 \\
60\end{array}$ & $\begin{array}{r}9.462199 \\
.462616 \\
.463032 \\
.463448 \\
.463864 \\
.464279 \\
.464694 \\
.465108 \\
.465522 \\
9.465935\end{array}$ & $\begin{array}{l}6.95 \\
6.93 \\
6.93 \\
6.93 \\
6.92 \\
6.92 \\
6.90 \\
6.90 \\
6.88\end{array}$ & $\begin{array}{r}9.980942 \\
.980904 \\
.980866 \\
.980827 \\
.980789 \\
.980750 \\
.980712 \\
.980673 \\
.980635 \\
9.980596\end{array}$ & $\begin{array}{l}.63 \\
.63 \\
.65 \\
.63 \\
.65 \\
.63 \\
.65 \\
.63 \\
.65\end{array}$ & $\begin{array}{r}9.481257 \\
.481712 \\
.482167 \\
.482621 \\
.483075 \\
.483529 \\
.483982 \\
.484435 \\
.484887 \\
9.485339\end{array}$ & $\begin{array}{l}7.58 \\
7.58 \\
7.57 \\
7.57 \\
7.57 \\
7.55 \\
7.55 \\
7.53 \\
7.53\end{array}$ & $\begin{array}{r}10.518 \% 43 \\
.518288 \\
.517833 \\
.517379 \\
.516925 \\
.516471 \\
.516018 \\
.515565 \\
.515113 \\
10.514661\end{array}$ & $\begin{array}{l}9 \\
8 \\
7 \\
6 \\
5 \\
4 \\
3 \\
2 \\
1 \\
0\end{array}$ \\
\hline ' & Cosine. & D. $1^{\prime \prime}$. & Sine. & D. 1". & Cotang. & D. $1^{n}$. & Tang. & , \\
\hline
\end{tabular}




\begin{tabular}{|c|c|c|c|c|c|c|c|c|}
\hline 1 & Sine. & D. 1". & Cosine. & D. $1^{\circ}$. & Tang. & D. $1^{*}$. & Cotang. & , \\
\hline $\begin{array}{r}0 \\
1 \\
8 \\
3 \\
4 \\
5 \\
6 \\
7 \\
8 \\
9 \\
10\end{array}$ & $\begin{array}{r}9.465935 \\
.466318 \\
.466761 \\
.467173 \\
.467585 \\
.467996 \\
.468407 \\
.468817 \\
.469227 \\
.469637 \\
.470046\end{array}$ & $\begin{array}{l}6.88 \\
6.88 \\
6.87 \\
6.87 \\
6.85 \\
6.85 \\
6.83 \\
6.83 \\
6.83 \\
6.82 \\
6.82\end{array}$ & $\begin{array}{r}9.980596 \\
.980558 \\
.980519 \\
.980480 \\
.980442 \\
.980403 \\
.980364 \\
.980325 \\
.980286 \\
.980247 \\
.980208\end{array}$ & $\begin{array}{l}.63 \\
.65 \\
.65 \\
.63 \\
.65 \\
.65 \\
.65 \\
.65 \\
.65 \\
.65 \\
.65\end{array}$ & $\begin{array}{r}9.485339 \\
.485791 \\
.486242 \\
.486693 \\
.487143 \\
.487593 \\
.488043 \\
.488492 \\
.488941 \\
.489390 \\
.489838\end{array}$ & $\begin{array}{l}7.53 \\
7.52 \\
7.52 \\
7.50 \\
7.50 \\
7.50 \\
7.48 \\
7.48 \\
7.48 \\
7.47 \\
7.47\end{array}$ & $\begin{array}{r}10.514661 \\
.514209 \\
.513758 \\
.513307 \\
.512857 \\
.512407 \\
.511957 \\
.511508 \\
.511059 \\
.510610 \\
.510162\end{array}$ & $\begin{array}{l}60 \\
59 \\
58 \\
57 \\
56 \\
55 \\
54 \\
53 \\
52 \\
51 \\
50\end{array}$ \\
\hline $\begin{array}{l}11 \\
12 \\
13 \\
14 \\
15 \\
16 \\
17 \\
18 \\
19 \\
20\end{array}$ & $\begin{array}{r}9.470455 \\
.470863 \\
.471271 \\
.471679 \\
.472086 \\
.472192 \\
.472898 \\
.473304 \\
.473710 \\
.474115\end{array}$ & $\begin{array}{l}6.80 \\
6.80 \\
6.80 \\
6.78 \\
6.77 \\
6.77 \\
6.77 \\
6.77 \\
6.75 \\
6.73\end{array}$ & $\begin{array}{r}9.980169 \\
.980130 \\
.980091 \\
.980052 \\
.980012 \\
.979973 \\
.979934 \\
.979895 \\
.979855 \\
.979816\end{array}$ & $\begin{array}{l}.65 \\
.65 \\
.65 \\
.67 \\
.65 \\
.65 \\
.65 \\
.67 \\
.65 \\
.67\end{array}$ & $\begin{array}{r}9.490286 \\
.490733 \\
.491180 \\
.441627 \\
.492073 \\
.492519 \\
.492965 \\
.493410 \\
.493854 \\
.494299\end{array}$ & $\begin{array}{l}7.45 \\
7.45 \\
7.45 \\
7.43 \\
7.43 \\
7.43 \\
7.42 \\
7.40 \\
7.42 \\
7.40\end{array}$ & $\begin{array}{r}10.509714 \\
.509267 \\
.508820 \\
.508373 \\
.507927 \\
.507481 \\
.507035 \\
.506590 \\
.506146 \\
.505701\end{array}$ & $\begin{array}{l}49 \\
48 \\
47 \\
46 \\
45 \\
44 \\
43 \\
42 \\
41 \\
40\end{array}$ \\
\hline $\begin{array}{l}21 \\
22 \\
23 \\
24 \\
25 \\
26 \\
27 \\
28 \\
29 \\
30\end{array}$ & $\begin{array}{r}9.474519 \\
.474923 \\
.475327 \\
.475730 \\
.476133 \\
.476536 \\
.476938 \\
.477340 \\
.477741 \\
.478142\end{array}$ & $\begin{array}{l}6.73 \\
6.73 \\
6.72 \\
6.72 \\
6.72 \\
6.70 \\
6.70 \\
6.68 \\
6.68 \\
6.67\end{array}$ & $\begin{array}{r}9.979776 \\
.979737 \\
.979697 \\
.979658 \\
.979618 \\
.979579 \\
.979539 \\
.979499 \\
.979459 \\
.979420\end{array}$ & $\begin{array}{l}.65 \\
.67 \\
.65 \\
.67 \\
.65 \\
.67 \\
.67 \\
.67 \\
.65 \\
.67\end{array}$ & $\begin{array}{r}9.494743 \\
.495186 \\
.495630 \\
.496073 \\
.496515 \\
.496957 \\
.497399 \\
.497841 \\
.498282 \\
.498722\end{array}$ & $\begin{array}{l}7.38 \\
7.40 \\
7.38 \\
7.37 \\
7.37 \\
7.37 \\
7.37 \\
7.35 \\
7.33 \\
7.35\end{array}$ & $\begin{array}{r}10.505257 \\
.504814 \\
.504370 \\
.5039227 \\
.503485 \\
.503043 \\
.502601 \\
.502159 \\
.501718 \\
.501278\end{array}$ & $\begin{array}{l}39 \\
38 \\
37 \\
36 \\
35 \\
34 \\
33 \\
32 \\
31 \\
30\end{array}$ \\
\hline $\begin{array}{l}31 \\
32 \\
33 \\
34 \\
35 \\
36 \\
37 \\
38 \\
39 \\
40\end{array}$ & $\begin{array}{r}9.478542 \\
.478942 \\
.479342 \\
.479741 \\
.480140 \\
.480539 \\
.480937 \\
.481334 \\
.481731 \\
.482128\end{array}$ & $\begin{array}{l}6.67 \\
6.67 \\
6.65 \\
6.65 \\
6.65 \\
6.63 \\
6.62 \\
6.62 \\
6.62 \\
6.62\end{array}$ & $\begin{array}{r}9.979380 \\
.979340 \\
.979300 \\
.979260 \\
.979220 \\
.979180 \\
.979140 \\
.979100 \\
.979059 \\
.979019\end{array}$ & $\begin{array}{l}.67 \\
.67 \\
.67 \\
.67 \\
.67 \\
.67 \\
.67 \\
.68 \\
.67 \\
.67\end{array}$ & $\begin{array}{r}9.499163 \\
.499603 \\
.500042 \\
.500481 \\
.500920 \\
.501359 \\
.501797 \\
.502235 \\
.502672 \\
.503109\end{array}$ & $\begin{array}{l}7.33 \\
7.32 \\
7.32 \\
7.32 \\
7.32 \\
7.30 \\
7.30 \\
7.28 \\
7.28 \\
7.28\end{array}$ & $\begin{array}{r}10.500837 \\
.500397 \\
.499958 \\
.499519 \\
.499080 \\
.498641 \\
.498203 \\
.49765 \\
.497328 \\
.496891\end{array}$ & $\begin{array}{l}29 \\
28 \\
27 \\
26 \\
25 \\
24 \\
23 \\
22 \\
21 \\
20\end{array}$ \\
\hline $\begin{array}{l}41 \\
42 \\
43 \\
41 \\
45 \\
46 \\
47 \\
48 \\
49 \\
50\end{array}$ & $\begin{array}{r}9.482525 \\
.482921 \\
.483316 \\
.483712 \\
.484107 \\
.484501 \\
.484895 \\
.485289 \\
.485682 \\
.486075\end{array}$ & $\begin{array}{l}6.60 \\
6.58 \\
6.60 \\
6.58 \\
6.57 \\
6.57 \\
6.57 \\
6.55 \\
6.55 \\
6.53\end{array}$ & $\begin{array}{r}9.978979 \\
.978939 \\
.978898 \\
.978858 \\
.978817 \\
.978777 \\
.978737 \\
.978696 \\
.978655 \\
.978615\end{array}$ & $\begin{array}{l}.67 \\
.68 \\
.67 \\
.68 \\
.67 \\
.67 \\
.68 \\
.68 \\
.67 \\
.68\end{array}$ & $\begin{array}{r}9.503546 \\
.503982 \\
.504418 \\
.504854 \\
.505289 \\
.505724 \\
.506159 \\
.506593 \\
.507027 \\
.507460\end{array}$ & $\begin{array}{l}7.27 \\
7.27 \\
7.27 \\
7.25 \\
7.25 \\
7.25 \\
7.23 \\
7.23 \\
7.23 \\
7.22\end{array}$ & $\begin{array}{r}10.496454 \\
.496018 \\
.495582 \\
.495146 \\
.494111 \\
.494276 \\
.493841 \\
.493407 \\
.492973 \\
.492540\end{array}$ & $\begin{array}{l}19 \\
18 \\
17 \\
16 \\
15 \\
14 \\
13 \\
12 \\
11 \\
10\end{array}$ \\
\hline $\begin{array}{l}51 \\
52 \\
53 \\
54 \\
55 \\
56 \\
57 \\
58 \\
59 \\
60\end{array}$ & $\begin{array}{r}9.486467 \\
.486860 \\
.487251 \\
.487643 \\
.488034 \\
.488424 \\
.488814 \\
.489204 \\
.489593 \\
9.489982\end{array}$ & $\begin{array}{l}6.55 \\
6.52 \\
6.53 \\
6.52 \\
6.50 \\
6.50 \\
6.50 \\
6.48 \\
6.48\end{array}$ & $\begin{array}{r}9.9785 \% 4 \\
.978533 \\
.978493 \\
.978452 \\
.978411 \\
.978370 \\
978329 \\
.978288 \\
.978247 \\
9.978206\end{array}$ & $\begin{array}{l}.68 \\
.68 \\
.68 \\
.68 \\
.68 \\
.68 \\
.68 \\
.68 \\
.68 \\
.68\end{array}$ & $\begin{array}{r}9.507893 \\
.508326 \\
.508 \% 59 \\
.509191 \\
.509622 \\
.510054 \\
.510485 \\
.510916 \\
.511346 \\
9.511766\end{array}$ & $\begin{array}{l}7.22 \\
7.22 \\
7.20 \\
7.18 \\
7.20 \\
7.18 \\
7.18 \\
7.17 \\
7.17\end{array}$ & $\begin{array}{r}10.492107 \\
.4916 r 4 \\
.491211 \\
.490809 \\
.490379 \\
.489916 \\
.489515 \\
.489084 \\
.488654 \\
10.488824 \\
\end{array}$ & $\begin{array}{l}9 \\
8 \\
7 \\
6 \\
5 \\
4 \\
3 \\
2 \\
1 \\
0\end{array}$ \\
\hline , & cosine. & 01. & Sine. & D. $1^{\prime}$. & Cotang. & D. $1^{\circ}$. & Tang. & ' \\
\hline
\end{tabular}




\begin{tabular}{|c|c|c|c|c|c|c|c|c|}
\hline 1 & Sine. & D. $1^{\prime \prime}$. & Cosine. & D. 1". & Tang. & D. 1". & Cotang. & ' \\
\hline \begin{tabular}{r|}
0 \\
1 \\
2 \\
3 \\
4 \\
5 \\
6 \\
7 \\
8 \\
9 \\
10
\end{tabular} & $\begin{array}{r}9.489982 \\
.490371 \\
.490759 \\
.491147 \\
.491535 \\
.491922 \\
.492308 \\
.492695 \\
.493081 \\
.493466 \\
.493851\end{array}$ & $\begin{array}{l}6.48 \\
6.47 \\
6.47 \\
6.47 \\
6.45 \\
6.43 \\
6.45 \\
6.43 \\
6.42 \\
6.42 \\
6.42\end{array}$ & $\begin{array}{r}9.978206 \\
.978165 \\
.978124 \\
.978083 \\
.97804: \\
.978001 \\
.977959 \\
.977918 \\
.97787 \\
.977835 \\
.97 \% 94\end{array}$ & $\begin{array}{l}.68 \\
.68 \\
.68 \\
.68 \\
.68 \\
.00 \\
.68 \\
.68 \\
.70 \\
.68 \\
.70\end{array}$ & $\begin{array}{r}9.51176 \\
.512206 \\
.512635 \\
.513064 \\
.513493 \\
.513921 \\
.514349 \\
.51477 \\
.515204 \\
.515631 \\
.516057\end{array}$ & $\begin{array}{l}7.17 \\
7.15 \\
7.15 \\
7.15 \\
7.13 \\
7.13 \\
7.13 \\
7.12 \\
7.12 \\
7.10 \\
7.12\end{array}$ & $\begin{array}{r}10.488224 \\
.487994 \\
.487365 \\
.486926 \\
.486507 \\
.486079 \\
.485651 \\
.485223 \\
.484796 \\
.484369 \\
.483943\end{array}$ & $\begin{array}{l}60 \\
59 \\
58 \\
57 \\
56 \\
55 \\
54 \\
53 \\
52 \\
51 \\
50\end{array}$ \\
\hline $\begin{array}{l}11 \\
12 \\
13 \\
14 \\
15 \\
16 \\
17 \\
18 \\
19 \\
20\end{array}$ & $\begin{array}{r}9.494236 \\
.494621 \\
.495005 \\
.495388 \\
.495772 \\
.496154 \\
.496537 \\
.496919 \\
.497301 \\
.497682\end{array}$ & $\begin{array}{l}6.42 \\
6.40 \\
6.38 \\
6.40 \\
6.37 \\
6.38 \\
6.37 \\
6.37 \\
6.35 \\
6.35\end{array}$ & $\begin{array}{r}9.97 \% 52 \\
.97 \% 711 \\
.97669 \\
.977628 \\
.97 \% 586 \\
.97 \% 544 \\
.97 \% 503 \\
.97 \% 461 \\
.97 \% 419 \\
.97 \% 377\end{array}$ & $\begin{array}{l}.68 \\
.70 \\
.68 \\
.70 \\
.70 \\
.68 \\
.70 \\
.70 \\
.70 \\
.70\end{array}$ & $\begin{array}{r}9.516484 \\
.516910 \\
.517335 \\
.517617 \\
.518186 \\
.518610 \\
.519034 \\
.519458 \\
.519882 \\
.520305\end{array}$ & $\begin{array}{l}7.10 \\
7.08 \\
7.10 \\
7.08 \\
7.07 \\
7.07 \\
7.07 \\
7.07 \\
7.05 \\
7.05\end{array}$ & $\begin{array}{r}10.483516 \\
.483090 \\
.482665 \\
.482239 \\
.481814 \\
.481390 \\
.480966 \\
.480542 \\
.480118 \\
.479695\end{array}$ & $\begin{array}{l}49 \\
48 \\
47 \\
46 \\
45 \\
44 \\
43 \\
42 \\
41 \\
40\end{array}$ \\
\hline $\begin{array}{l}21 \\
22 \\
23 \\
24 \\
25 \\
26 \\
27 \\
28 \\
29 \\
30\end{array}$ & $\begin{array}{r}9.498064 \\
.498444 \\
.498825 \\
.499204 \\
.499584 \\
.499963 \\
.500342 \\
.500721 \\
.501099 \\
.501476\end{array}$ & $\begin{array}{l}6.33 \\
6.35 \\
6.32 \\
6.33 \\
6.32 \\
6.32 \\
6.32 \\
6.30 \\
6.28 \\
6.30\end{array}$ & $\begin{array}{r}9.977335 \\
.977293 \\
.97 \% 51 \\
.97209 \\
.977167 \\
.97125 \\
.977083 \\
.977041 \\
.976999 \\
.976957\end{array}$ & $\begin{array}{l}70 \\
70 \\
70 \\
70 \\
70 \\
70 \\
70 \\
70 \\
70 \\
70 \\
70 \\
70 \\
70 \\
.70\end{array}$ & $\begin{array}{r}9.520728 \\
.521151 \\
.5215 \% 3 \\
.521995 \\
.522417 \\
.522838 \\
.523259 \\
.523680 \\
.524100 \\
.524520\end{array}$ & $\begin{array}{l}7.05 \\
7.03 \\
7.03 \\
7.03 \\
7.02 \\
7.02 \\
7.02 \\
7.00 \\
7.00 \\
7.00\end{array}$ & $\begin{array}{r}10.479272 \\
.478849 \\
.47842 \% \\
.478005 \\
.475583 \\
.477162 \\
.476741 \\
.476320 \\
.475900 \\
.475480\end{array}$ & $\begin{array}{l}39 \\
38 \\
37 \\
36 \\
35 \\
34 \\
33 \\
32 \\
31 \\
30\end{array}$ \\
\hline $\begin{array}{l}31 \\
32 \\
33 \\
34 \\
35 \\
36 \\
37 \\
38 \\
39 \\
40\end{array}$ & $\begin{array}{r}9.501854 \\
.502231 \\
.502607 \\
.502984 \\
.503360 \\
.503135 \\
.504110 \\
.504485 \\
.504860 \\
.505234\end{array}$ & $\begin{array}{l}6.28 \\
6.27 \\
6.28 \\
6.27 \\
6.25 \\
6.25 \\
6.25 \\
6.25 \\
6.23 \\
6.23\end{array}$ & $\begin{array}{r}9.976914 \\
.976872 \\
.976830 \\
.976787 \\
.976745 \\
.976702 \\
.976660 \\
.976617 \\
.976574 \\
.976532\end{array}$ & $\begin{array}{l}.70 \\
.70 \\
.72 \\
.70 \\
.72 \\
.70 \\
.70 \\
.72 \\
.72 \\
.70 \\
.72\end{array}$ & $\begin{array}{r}9.524940 \\
.525359 \\
.525788 \\
.526197 \\
.526615 \\
.527033 \\
.527451 \\
.527868 \\
.528285 \\
.528702\end{array}$ & $\begin{array}{l}6.98 \\
6.98 \\
6.98 \\
6.97 \\
6.97 \\
6.97 \\
6.95 \\
6.95 \\
6.95 \\
6.95\end{array}$ & $\begin{array}{r}10.475060 \\
.474641 \\
.474222 \\
.473803 \\
.473385 \\
.472967 \\
.472549 \\
.472132 \\
.471715 \\
.471298\end{array}$ & $\begin{array}{l}29 \\
29 \\
27 \\
26 \\
25 \\
24 \\
23 \\
22 \\
21 \\
20\end{array}$ \\
\hline $\begin{array}{l}41 \\
42 \\
43 \\
44 \\
45 \\
46 \\
47 \\
48 \\
49 \\
50\end{array}$ & $\begin{array}{r}9.505608 \\
.505981 \\
.506354 \\
.506727 \\
.507099 \\
.507471 \\
.507843 \\
.508214 \\
.508585 \\
.508956\end{array}$ & $\begin{array}{l}6.22 \\
6.22 \\
6.22 \\
6.20 \\
6.20 \\
6.20 \\
6.18 \\
6.18 \\
6.18 \\
6.17\end{array}$ & $\begin{array}{r}9.976489 \\
.976446 \\
.976404 \\
.976361 \\
.976318 \\
.976275 \\
.976232 \\
.976189 \\
.976146 \\
.976103\end{array}$ & $\begin{array}{l}.72 \\
.70 \\
.72 \\
.72 \\
.72 \\
.72 \\
.72 \\
.72 \\
.72 \\
.72\end{array}$ & $\begin{array}{r}9.529119 \\
.529535 \\
.529951 \\
.530366 \\
.530781 \\
.531196 \\
.531611 \\
.532025 \\
.532439 \\
.532853\end{array}$ & $\begin{array}{l}6.93 \\
6.93 \\
6.92 \\
6.92 \\
6.92 \\
6.92 \\
6.90 \\
6.90 \\
6.90 \\
6.88\end{array}$ & $\begin{array}{r}10.470881 \\
.470465 \\
.470049 \\
.469634 \\
.469219 \\
.468804 \\
.468389 \\
.467975 \\
.467561 \\
.467147\end{array}$ & $\begin{array}{l}19 \\
18 \\
17 \\
16 \\
15 \\
14 \\
13 \\
12 \\
11 \\
10\end{array}$ \\
\hline $\begin{array}{l}51 \\
52 \\
53 \\
54 \\
55 \\
56 \\
57 \\
58 \\
59 \\
60\end{array}$ & $\begin{array}{r}9.509326 \\
.509696 \\
.510065 \\
.510434 \\
.510803 \\
.511172 \\
.511540 \\
.511907 \\
.512275 \\
9.512642\end{array}$ & $\begin{array}{l}6.17 \\
6.15 \\
6.15 \\
6.15 \\
6.15 \\
6.13 \\
6.12 \\
6.13 \\
6.12\end{array}$ & $\begin{array}{r}9.976060 \\
.976017 \\
.975974 \\
.975930 \\
.975887 \\
.975844 \\
.975800 \\
.975757 \\
.975714 \\
9.975670\end{array}$ & $\begin{array}{l}.72 \\
.72 \\
.73 \\
.72 \\
.72 \\
.73 \\
.72 \\
.72 \\
.73\end{array}$ & $\begin{array}{r}9.533266 \\
.5336 r 9 \\
.534092 \\
.534504 \\
.534916 \\
.535328 \\
.535739 \\
.536150 \\
.536561 \\
9.536972\end{array}$ & $\begin{array}{l}6.88 \\
6.88 \\
6.87 \\
6.87 \\
6.87 \\
6.85 \\
6.85 \\
6.85 \\
6.85\end{array}$ & $\begin{array}{r}10.466734 \\
.466321 \\
.465908 \\
.465496 \\
.465084 \\
.464672 \\
.464261 \\
.463850 \\
.463439 \\
10.463028\end{array}$ & $\begin{array}{l}9 \\
8 \\
7 \\
6 \\
5 \\
4 \\
3 \\
2 \\
1 \\
0\end{array}$ \\
\hline ' & Cosine. & D. $1^{\prime \prime}$. & Sine. & D. 1". & Cotang. & D. $1^{\prime \prime}$. & Tang. & 1 \\
\hline
\end{tabular}




\begin{tabular}{|c|c|c|c|c|c|c|c|c|}
\hline ' & Sine. & D. $1^{\prime \prime}$. & Cosine. & D. $1^{\prime}$. & Tang. & D. $1^{\circ}$. & Cotang. & ' \\
\hline $\begin{array}{r}0 \\
1 \\
2 \\
3 \\
4 \\
5 \\
6 \\
7 \\
8 \\
9 \\
10\end{array}$ & $\begin{array}{r}9.512642 \\
.513009 \\
.513375 \\
.513741 \\
.514107 \\
.514472 \\
.514837 \\
.515202 \\
.515566 \\
.515930 \\
.516294\end{array}$ & $\begin{array}{l}6.12 \\
6.10 \\
6.10 \\
6.10 \\
6.08 \\
6.08 \\
6.08 \\
6.07 \\
6.07 \\
6.07 \\
6.05\end{array}$ & $\begin{array}{r}9.975670 \\
.975627 \\
.975583 \\
.975539 \\
.975496 \\
.975452 \\
.975408 \\
.975365 \\
.975321 \\
.975277 \\
.975233\end{array}$ & $\begin{array}{l}.72 \\
.73 \\
.73 \\
.72 \\
.73 \\
.73 \\
.72 \\
.73 \\
.73 \\
.73 \\
.73\end{array}$ & $\begin{array}{r}9.536972 \\
.537382 \\
.537792 \\
.538202 \\
.538611 \\
.539020 \\
.539429 \\
.539837 \\
.540245 \\
.540653 \\
.541061\end{array}$ & $\begin{array}{l}6.83 \\
6.83 \\
6.83 \\
6.82 \\
6.82 \\
6.82 \\
6.80 \\
6.80 \\
6.80 \\
6.80 \\
6.78\end{array}$ & $\begin{array}{r}10.463028 \\
.462618 \\
.462208 \\
.461798 \\
.461389 \\
.460980 \\
.460571 \\
.460163 \\
.459755 \\
.459347 \\
.458939\end{array}$ & $\begin{array}{l}60 \\
59 \\
58 \\
57 \\
56 \\
55 \\
54 \\
53 \\
52 \\
51 \\
50\end{array}$ \\
\hline $\begin{array}{l}11 \\
12 \\
13 \\
14 \\
15 \\
16 \\
17 \\
18 \\
19 \\
20 \\
91\end{array}$ & $\begin{array}{r}9.5166557 \\
.517020 \\
.517382 \\
.517745 \\
.518107 \\
.518468 \\
.518829 \\
.519190 \\
.519551 \\
.519911\end{array}$ & $\begin{array}{l}6.05 \\
6.03 \\
6.05 \\
6.03 \\
6.02 \\
6.02 \\
6.02 \\
6.02 \\
6.00 \\
6.00\end{array}$ & $\begin{array}{r}9.975189 \\
.975145 \\
.975101 \\
.975057 \\
.975013 \\
.974969 \\
.974925 \\
.974880 \\
.974836 \\
.974792\end{array}$ & $\begin{array}{l}.73 \\
.73 \\
.73 \\
.73 \\
.73 \\
.73 \\
.73 \\
.75 \\
.73 \\
.73 \\
.73\end{array}$ & $\begin{array}{r}9.541468 \\
.541875 \\
.542281 \\
.542688 \\
.543094 \\
.543499 \\
.543905 \\
.544310 \\
.544715 \\
.545119\end{array}$ & $\begin{array}{l}6.78 \\
6.77 \\
6.78 \\
6.77 \\
6.75 \\
6.77 \\
6.75 \\
6.75 \\
6.73 \\
6.75\end{array}$ & $\begin{array}{r}10.458532 \\
.458125 \\
.457719 \\
.457312 \\
.456906 \\
.456501 \\
.456095 \\
.455690 \\
.455285 \\
.454881\end{array}$ & $\begin{array}{l}49 \\
48 \\
47 \\
46 \\
45 \\
44 \\
43 \\
42 \\
41 \\
40\end{array}$ \\
\hline $\begin{array}{l}21 \\
22 \\
23 \\
24 \\
25 \\
26 \\
27 \\
28 \\
29 \\
30\end{array}$ & $\begin{array}{r}9.520271 \\
.520631 \\
.520990 \\
.521349 \\
.521707 \\
.522066 \\
.522424 \\
.522781 \\
.523138 \\
.523495\end{array}$ & $\begin{array}{l}6.00 \\
5.98 \\
5.98 \\
5.97 \\
5.98 \\
5.97 \\
5.95 \\
5.95 \\
5.95 \\
5.95\end{array}$ & $\begin{array}{r}9.974748 \\
.974703 \\
.974659 \\
.974614 \\
.974570 \\
.974525 \\
.974481 \\
.974436 \\
.974391 \\
.974347\end{array}$ & $\begin{array}{l}.75 \\
.73 \\
.75 \\
.75 \\
.73 \\
.75 \\
.73 \\
.75 \\
.75 \\
.73 \\
.75\end{array}$ & $\begin{array}{r}9.545524 \\
.545928 \\
.546331 \\
.546735 \\
.547138 \\
.547540 \\
.547943 \\
.548345 \\
.548747 \\
.549149\end{array}$ & $\begin{array}{l}6.73 \\
6.72 \\
6.73 \\
6.72 \\
6.70 \\
6.72 \\
6.70 \\
6.70 \\
6.70 \\
6.68\end{array}$ & $\begin{array}{r}10.454476 \\
.454072 \\
.453669 \\
.453265 \\
.452862 \\
.452460 \\
.452057 \\
.451655 \\
.451253 \\
.450851\end{array}$ & $\begin{array}{l}39 \\
38 \\
37 \\
36 \\
35 \\
34 \\
33 \\
32 \\
31 \\
30\end{array}$ \\
\hline $\begin{array}{l}31 \\
32 \\
33 \\
34 \\
35 \\
36 \\
37 \\
38 \\
39 \\
40\end{array}$ & $\begin{array}{r}9.523852 \\
.524208 \\
.524564 \\
.524920 \\
.525275 \\
.525630 \\
.525984 \\
.526339 \\
.526693 \\
.527046\end{array}$ & $\begin{array}{l}5.93 \\
5.93 \\
5.93 \\
5.92 \\
5.92 \\
5.90 \\
5.92 \\
5.90 \\
5.88 \\
5.90\end{array}$ & $\begin{array}{r}9.974302 \\
.974257 \\
.974212 \\
.974167 \\
.974122 \\
.974077 \\
.974032 \\
.973987 \\
.973942 \\
.973897\end{array}$ & $\begin{array}{l}.75 \\
.75 \\
.75 \\
.75 \\
.75 \\
.75 \\
.75 \\
.75 \\
.75 \\
.75\end{array}$ & $\begin{array}{r}9.549550 \\
.549951 \\
.550352 \\
.550752 \\
.551153 \\
.551552 \\
.551952 \\
.552351 \\
.552750 \\
.553149\end{array}$ & $\begin{array}{l}6.68 \\
6.68 \\
6.67 \\
6.68 \\
6.65 \\
6.67 \\
6.65 \\
6.65 \\
6.65 \\
6.65\end{array}$ & $\begin{array}{r}10.450450 \\
.450049 \\
.449648 \\
.449248 \\
.448847 \\
.448448 \\
.448048 \\
.447649 \\
.447250 \\
.446851\end{array}$ & $\begin{array}{l}29 \\
28 \\
27 \\
26 \\
25 \\
24 \\
23 \\
22 \\
21 \\
20\end{array}$ \\
\hline $\begin{array}{l}41 \\
42 \\
43 \\
44 \\
45 \\
46 \\
47 \\
48 \\
49 \\
50\end{array}$ & $\begin{array}{r}9.527400 \\
.527753 \\
.528105 \\
.528458 \\
.528810 \\
.529161 \\
.529513 \\
.529864 \\
.530215 \\
.530565 \\
\end{array}$ & $\begin{array}{l}5.88 \\
5.87 \\
5.88 \\
5.87 \\
5.85 \\
5.87 \\
5.85 \\
5.85 \\
5.83 \\
5.83\end{array}$ & $\begin{array}{r}9.973852 \\
.973807 \\
.973761 \\
.973716 \\
.973671 \\
.973625 \\
.973580 \\
.973535 \\
.973489 \\
.973444\end{array}$ & $\begin{array}{l}.75 \\
.77 \\
.75 \\
.75 \\
.77 \\
.75 \\
.75 \\
.77 \\
.75 \\
.77\end{array}$ & $\begin{array}{r}9.553548 \\
.553946 \\
.554344 \\
.554741 \\
.555139 \\
.55: 536 \\
.555933 \\
.556329 \\
.556725 \\
.557121\end{array}$ & $\begin{array}{l}6.63 \\
6.63 \\
6.62 \\
6.63 \\
6.62 \\
6.62 \\
6.60 \\
6.60 \\
6.60 \\
6.60\end{array}$ & $\begin{array}{r}10.446452 \\
.446054 \\
.445656 \\
.445259 \\
.444861 \\
.444464 \\
.444067 \\
.443671 \\
.443275 \\
.442879\end{array}$ & $\begin{array}{l}19 \\
18 \\
17 \\
16 \\
15 \\
14 \\
13 \\
12 \\
11 \\
10\end{array}$ \\
\hline $\begin{array}{l}51 \\
52 \\
53 \\
54 \\
55 \\
56 \\
57 \\
58 \\
59 \\
60\end{array}$ & $\begin{array}{r}9.530915 \\
.531265 \\
.531614 \\
.531963 \\
.532312 \\
.532661 \\
.533009 \\
.533357 \\
.533704 \\
9.534052\end{array}$ & $\begin{array}{l}\mathbf{5 . 8 3} \\
5.82 \\
5.82 \\
5.82 \\
5.82 \\
5.80 \\
\mathbf{5 . 8 0} \\
\mathbf{5} .78 \\
\mathbf{5 . 8 0}\end{array}$ & $\begin{array}{r}9.973398 \\
.973352 \\
.973307 \\
.973261 \\
.973215 \\
.973169 \\
.973124 \\
.973078 \\
.973032 \\
9.972986\end{array}$ & $\begin{array}{l}.77 \\
.75 \\
.77 \\
.77 \\
.77 \\
.75 \\
.77 \\
.77 \\
.77\end{array}$ & $\begin{array}{r}9.557517 \\
.557913 \\
.558308 \\
.558703 \\
.559097 \\
.559491 \\
.559885 \\
.560279 \\
.560673 \\
9.561066\end{array}$ & $\begin{array}{l}6.60 \\
6.58 \\
6.58 \\
6.57 \\
6.57 \\
6.57 \\
6.57 \\
6.57 \\
6.55\end{array}$ & $\begin{array}{r}10.442483 \\
.442087 \\
.441692 \\
.441297 \\
.440903 \\
.440509 \\
.440115 \\
.439721 \\
.439327 \\
10.438934 \\
\end{array}$ & $\begin{array}{l}9 \\
8 \\
7 \\
6 \\
5 \\
4 \\
3 \\
2 \\
1 \\
0\end{array}$ \\
\hline 1 & Cosine. & D. $1^{\prime \prime}$. & Sine. & D. $1^{\prime \prime}$ & Cotang. & D. $1^{\prime \prime}$. & Tang. & ' \\
\hline
\end{tabular}




\begin{tabular}{|c|c|c|c|c|c|c|c|c|}
\hline , & Sine. & D. $1^{\prime \prime}$. & Cosine. & D. $1^{\prime \prime}$. & Tang. & D. $1^{\prime \prime}$. & Cotang. & , \\
\hline $\begin{array}{r}0 \\
1 \\
2 \\
3 \\
4 \\
5 \\
6 \\
7 \\
8 \\
9 \\
10\end{array}$ & $\begin{array}{r}9.534052 \\
.534399 \\
.534745 \\
.535092 \\
.535438 \\
.535783 \\
.536129 \\
.536474 \\
.536818 \\
.537163 \\
.537507\end{array}$ & $\begin{array}{l}5.78 \\
5.77 \\
5.78 \\
5.77 \\
5.75 \\
5.77 \\
5.75 \\
5.73 \\
5.75 \\
5.73 \\
5.73\end{array}$ & $\begin{array}{r}9.972986 \\
.972940 \\
.972894 \\
972848 \\
972802 \\
972755 \\
.972709 \\
.972663 \\
972617 \\
.972570 \\
.972524\end{array}$ & $\begin{array}{l}77 \\
.77 \\
77 \\
.77 \\
78 \\
77 \\
.77 \\
77 \\
.78 \\
.77 \\
.77\end{array}$ & $\begin{array}{r}9561066 \\
.561459 \\
561851 \\
562244 \\
.562636 \\
.563028 \\
563419 \\
563811 \\
.564202 \\
.564593 \\
.564983\end{array}$ & $\begin{array}{l}655 \\
655 \\
6.55 \\
6.53 \\
6.53 \\
652 \\
653 \\
652 \\
6.52 \\
650 \\
6.50\end{array}$ & $\begin{array}{r}10.438934 \\
.438541 \\
438149 \\
.437756 \\
.437364 \\
.436977 \\
.436581 \\
436189 \\
.435798 \\
.435407 \\
.435017\end{array}$ & $\begin{array}{l}60 \\
59 \\
58 \\
57 \\
56 \\
55 \\
54 \\
53 \\
52 \\
51 \\
50\end{array}$ \\
\hline $\begin{array}{l}11 \\
12 \\
13 \\
14 \\
15 \\
16 \\
17 \\
18 \\
19 \\
20\end{array}$ & $\begin{array}{r}9.537851 \\
538194 \\
538538 \\
538880 \\
.539223 \\
539565 \\
.539907 \\
.540249 \\
.540590 \\
.540931\end{array}$ & $\begin{array}{l}5.72 \\
5.73 \\
5.70 \\
5.72 \\
5.70 \\
5.70 \\
5.68 \\
5.68 \\
5.68 \\
5.68\end{array}$ & $\begin{array}{r}9.972478 \\
972431 \\
972385 \\
972338 \\
.972291 \\
.972245 \\
.972198 \\
.972151 \\
.972105 \\
.972058\end{array}$ & $\begin{array}{l}.78 \\
.77 \\
78 \\
.78 \\
78 \\
.78 \\
.78 \\
.77 \\
.78 \\
.78\end{array}$ & $\begin{array}{r}9.565373 \\
565763 \\
.566153 \\
566542 \\
.566932 \\
.567320 \\
567709 \\
.568098 \\
568486 \\
.568873\end{array}$ & $\begin{array}{l}6.50 \\
650 \\
6.48 \\
6.50 \\
6.47 \\
6.48 \\
6.48 \\
6.47 \\
6.45 \\
6.47\end{array}$ & $\begin{array}{r}10.434627 \\
.434237 \\
.433847 \\
.433458 \\
.433068 \\
.432680 \\
.432291 \\
.431902 \\
.431514 \\
.431127\end{array}$ & $\begin{array}{l}49 \\
48 \\
47 \\
46 \\
45 \\
44 \\
43 \\
42 \\
41 \\
40\end{array}$ \\
\hline $\begin{array}{l}21 \\
22 \\
23 \\
24 \\
25 \\
26 \\
27 \\
28 \\
29 \\
30\end{array}$ & $\begin{array}{r}9.5412 \% 2 \\
.541613 \\
.541953 \\
.542293 \\
.542632 \\
.542971 \\
.543310 \\
.543649 \\
.543947 \\
.544325\end{array}$ & $\begin{array}{l}5.68 \\
5.67 \\
5.67 \\
5.65 \\
5.65 \\
5.65 \\
5.65 \\
5.63 \\
5.63 \\
5.63\end{array}$ & $\begin{array}{r}9.972011 \\
.971964 \\
971917 \\
.971870 \\
.971823 \\
.971776 \\
.971729 \\
.971682 \\
.971635 \\
.971588\end{array}$ & $\begin{array}{l}.78 \\
.78 \\
.78 \\
.78 \\
.78 \\
.78 \\
.78 \\
.78 \\
.78 \\
.80\end{array}$ & $\begin{array}{r}9.569261 \\
.569648 \\
.570035 \\
.570422 \\
.570809 \\
.571195 \\
.571581 \\
.571967 \\
.572352 \\
572738\end{array}$ & $\begin{array}{l}6.45 \\
6.45 \\
6.45 \\
6.45 \\
6.43 \\
6.43 \\
6.45 \\
6.42 \\
6.43 \\
6.42\end{array}$ & $\begin{array}{r}10.430739 \\
.430352 \\
.429965 \\
.429578 \\
.429191 \\
.428805 \\
.428419 \\
.428023 \\
.427648 \\
.427262\end{array}$ & $\begin{array}{l}39 \\
38 \\
37 \\
36 \\
35 \\
34 \\
33 \\
32 \\
31 \\
30\end{array}$ \\
\hline $\begin{array}{l}31 \\
32 \\
33 \\
34 \\
35 \\
36 \\
37 \\
38 \\
39 \\
40\end{array}$ & $\begin{array}{r}9.544663 \\
.545000 \\
.545338 \\
.545614 \\
.546011 \\
.546347 \\
.546683 \\
.547019 \\
.547354 \\
.547689\end{array}$ & $\begin{array}{l}5.62 \\
5.63 \\
5.60 \\
5.62 \\
5.60 \\
5.60 \\
5.60 \\
5.58 \\
5.58 \\
5.58\end{array}$ & $\begin{array}{r}9.971540 \\
.971493 \\
.971446 \\
.971398 \\
.971351 \\
.971303 \\
.971256 \\
.971208 \\
.971161 \\
.971113\end{array}$ & $\begin{array}{l}.78 \\
.78 \\
.80 \\
.78 \\
.80 \\
.78 \\
.80 \\
.78 \\
.80 \\
.78\end{array}$ & $\begin{array}{r}9.573123 \\
.573507 \\
.573892 \\
.574276 \\
.574660 \\
.575044 \\
.575427 \\
.575810 \\
.576193 \\
.576576\end{array}$ & $\begin{array}{l}6.40 \\
6.42 \\
6.40 \\
6.40 \\
6.40 \\
6.38 \\
6.38 \\
6.38 \\
6.38 \\
6.38\end{array}$ & $\begin{array}{r}10.426877 \\
.426493 \\
.426108 \\
.425724 \\
.425340 \\
.424956 \\
.424573 \\
.424190 \\
.423807 \\
.423424\end{array}$ & $\begin{array}{l}29 \\
28 \\
27 \\
26 \\
25 \\
24 \\
23 \\
22 \\
21 \\
20\end{array}$ \\
\hline $\begin{array}{l}41 \\
42 \\
43 \\
44 \\
45 \\
46 \\
47 \\
48 \\
49 \\
50\end{array}$ & $\begin{array}{r}9.548024 \\
.548359 \\
.548693 \\
.549027 \\
.549360 \\
.549693 \\
.550026 \\
.550359 \\
.550692 \\
.551024\end{array}$ & $\begin{array}{l}5.58 \\
5.57 \\
5.57 \\
5.55 \\
5.55 \\
5.55 \\
5.55 \\
5.55 \\
5.53 \\
5.53\end{array}$ & $\begin{array}{r}9.971066 \\
.971018 \\
.970970 \\
.970922 \\
.970874 \\
.970827 \\
.970779 \\
.970731 \\
.970683 \\
.970635\end{array}$ & $\begin{array}{l}.80 \\
.80 \\
.80 \\
.80 \\
.78 \\
.80 \\
.80 \\
.80 \\
.80 \\
.82\end{array}$ & $\begin{array}{r}9.576959 \\
.577341 \\
.577723 \\
.578104 \\
.578486 \\
.578867 \\
.579248 \\
.579629 \\
.580009 \\
.580389\end{array}$ & $\begin{array}{l}6.37 \\
6.37 \\
6.35 \\
6.37 \\
6.35 \\
6.35 \\
6.35 \\
6.33 \\
6.33 \\
6.33\end{array}$ & $\begin{array}{r}10.423041 \\
.422659 \\
.422277 \\
.421896 \\
.421514 \\
.421133 \\
.420752 \\
.420371 \\
.419991 \\
.419611\end{array}$ & $\begin{array}{l}19 \\
18 \\
17 \\
16 \\
15 \\
14 \\
13 \\
12 \\
11 \\
10\end{array}$ \\
\hline $\begin{array}{l}51 \\
52 \\
53 \\
54 \\
55 \\
56 \\
57 \\
58 \\
59 \\
60\end{array}$ & $\begin{array}{r}9.551356 \\
.551687 \\
.552(118 \\
.552349 \\
.552680 \\
.553010 \\
.553341 \\
.553610 \\
.554000 \\
9.554399\end{array}$ & $\begin{array}{l}5.52 \\
5.52 \\
5.52 \\
5.52 \\
5.50 \\
5.52 \\
5.48 \\
5.50 \\
5.48\end{array}$ & $\begin{array}{r}9.970586 \\
.970538 \\
.970490 \\
.970442 \\
.970394 \\
.970345 \\
.970297 \\
.970249 \\
.970200 \\
9.970152\end{array}$ & $\begin{array}{l}.02 \\
.80 \\
.80 \\
.80 \\
.80 \\
.82 \\
.80 \\
.80 \\
.82 \\
.80\end{array}$ & $\begin{array}{r}9.580769 \\
.581149 \\
.581528 \\
581907 \\
.582286 \\
.582665 \\
.583044 \\
.583422 \\
.583800 \\
9.5811 \% 7\end{array}$ & $\begin{array}{l}6.30 \\
6.33 \\
6.32 \\
6.32 \\
6.32 \\
6.32 \\
6.32 \\
6.30 \\
6.30 \\
6.28\end{array}$ & $\begin{array}{r}10.419231 \\
.418851 \\
.418472 \\
.418093 \\
.417714 \\
.417335 \\
.416956 \\
.416578 \\
.416200 \\
10.415823\end{array}$ & $\begin{array}{l}9 \\
8 \\
7 \\
6 \\
5 \\
4 \\
3 \\
2 \\
1 \\
0\end{array}$ \\
\hline , & Cosine. & D. 1". & Sine. & D. $1^{\prime \prime}$. & Cotang. & D. $1^{\prime \prime}$. & Tang. & 1 \\
\hline
\end{tabular}




\begin{tabular}{|c|c|c|c|c|c|c|c|c|}
\hline 1 & Sine. & D. $1^{\prime \prime}$. & Cosine. & D. $1^{\circ}$. & Tang. & D. $1^{*}$. & Cotang. & ' \\
\hline $\begin{array}{r}0 \\
1 \\
2 \\
3 \\
4 \\
5 \\
6 \\
7 \\
8 \\
9 \\
10\end{array}$ & $\begin{array}{r}9.554329 \\
.554658 \\
.554987 \\
.555315 \\
.555643 \\
.5559 \% 1 \\
.556299 \\
.556626 \\
.556953 \\
.557280 \\
.55 \% 606\end{array}$ & $\begin{array}{l}5.48 \\
5.48 \\
5.47 \\
5.47 \\
5.47 \\
5.47 \\
5.45 \\
5.45 \\
5.45 \\
5.43 \\
5.43\end{array}$ & $\begin{array}{r}9.970152 \\
.970103 \\
.970055 \\
.970006 \\
.969957 \\
.969909 \\
.969860 \\
.969811 \\
.969762 \\
.969714 \\
.969665\end{array}$ & $\begin{array}{l}.82 \\
.80 \\
.82 \\
.82 \\
.80 \\
.82 \\
.82 \\
.82 \\
.80 \\
.82 \\
.82\end{array}$ & $\begin{array}{r}9.584177 \\
.584555 \\
.584932 \\
.585309 \\
.585686 \\
.586062 \\
.586439 \\
.586815 \\
.587190 \\
.587566 \\
.587941\end{array}$ & $\begin{array}{l}6.30 \\
6.28 \\
6.28 \\
6.28 \\
6.27 \\
6.28 \\
6.27 \\
6.25 \\
6.27 \\
6.25 \\
6.25\end{array}$ & $\begin{array}{r}10.415823 \\
.415445 \\
.415068 \\
.414691 \\
.414314 \\
.413938 \\
.413561 \\
.413185 \\
.412810 \\
.412434 \\
.412059\end{array}$ & $\begin{array}{l}60 \\
59 \\
58 \\
57 \\
56 \\
55 \\
54 \\
53 \\
54 \\
51 \\
50\end{array}$ \\
\hline $\begin{array}{l}11 \\
12 \\
13 \\
14 \\
15 \\
16 \\
17 \\
18 \\
19 \\
20\end{array}$ & $\begin{array}{r}9.557932 \\
.558258 \\
.558583 \\
.558909 \\
.559234 \\
.559558 \\
.559883 \\
.560207 \\
.560531 \\
.560855\end{array}$ & $\begin{array}{l}5.43 \\
5.42 \\
5.43 \\
5.42 \\
5.40 \\
5.42 \\
5.40 \\
5.40 \\
5.40 \\
5.38\end{array}$ & $\begin{array}{r}9.969616 \\
.969567 \\
.969518 \\
.969469 \\
.969420 \\
.969370 \\
.969321 \\
.969272 \\
.969223 \\
.969173\end{array}$ & $\begin{array}{l}.82 \\
.82 \\
.82 \\
.82 \\
.83 \\
.82 \\
.82 \\
.82 \\
.83 \\
.82\end{array}$ & $\begin{array}{r}9.588316 \\
.588691 \\
.589066 \\
.589410 \\
.589814 \\
.590188 \\
.590562 \\
.590935 \\
.591308 \\
.591681\end{array}$ & $\begin{array}{l}6.25 \\
6.25 \\
6.23 \\
6.23 \\
6.23 \\
6.23 \\
6.22 \\
6.22 \\
6.22 \\
6.22\end{array}$ & $\begin{array}{r}10.411684 \\
.411309 \\
.410934 \\
.410560 \\
.410186 \\
.409812 \\
.409438 \\
.409065 \\
.408692 \\
.408319\end{array}$ & $\begin{array}{l}49 \\
48 \\
47 \\
46 \\
45 \\
44 \\
43 \\
42 \\
41 \\
40\end{array}$ \\
\hline $\begin{array}{l}21 \\
22 \\
23 \\
24 \\
25 \\
26 \\
27 \\
28 \\
29 \\
30\end{array}$ & $\begin{array}{r}9.561178 \\
.561501 \\
.561824 \\
.562146 \\
.562468 \\
.562790 \\
.563112 \\
.563433 \\
.563755 \\
.5640^{\prime}{ }^{\prime} 5\end{array}$ & $\begin{array}{l}5.38 \\
5.38 \\
5.37 \\
5.37 \\
5.37 \\
5.37 \\
5.35 \\
5.37 \\
5.33 \\
5.35\end{array}$ & $\begin{array}{r}9.969124 \\
.969075 \\
.969025 \\
.968976 \\
.968926 \\
.968877 \\
.968827 \\
.968777 \\
.968728 \\
.968678\end{array}$ & $\begin{array}{l}.82 \\
.82 \\
.83 \\
.82 \\
.83 \\
.82 \\
.83 \\
.83 \\
.82 \\
.83 \\
.83\end{array}$ & $\begin{array}{r}9.592054 \\
.592426 \\
.592799 \\
.593171 \\
.593542 \\
.593914 \\
.594285 \\
.594656 \\
.595027 \\
.595398\end{array}$ & $\begin{array}{l}6.20 \\
6.22 \\
6.20 \\
6.18 \\
6.20 \\
6.18 \\
6.18 \\
6.18 \\
6.18 \\
6.17\end{array}$ & $\begin{array}{r}10.407946 \\
.407574 \\
.407201 \\
.406829 \\
.406458 \\
.406086 \\
.405 \pi 15 \\
.405344 \\
.404973 \\
.404602\end{array}$ & $\begin{array}{l}29 \\
38 \\
37 \\
36 \\
35 \\
34 \\
33 \\
32 \\
31 \\
30\end{array}$ \\
\hline $\begin{array}{l}31 \\
32 \\
33 \\
34 \\
35 \\
36 \\
37 \\
38 \\
39 \\
40\end{array}$ & $\begin{array}{r}9.564396 \\
.564716 \\
.565036 \\
.565356 \\
.565676 \\
.565995 \\
.566314 \\
.566632 \\
.566951 \\
.567269\end{array}$ & $\begin{array}{l}5.33 \\
5.33 \\
5.33 \\
5.33 \\
5.32 \\
5.32 \\
5.30 \\
5.32 \\
5.30 \\
5.30\end{array}$ & $\begin{array}{r}9.968628 \\
.968578 \\
.968528 \\
.968479 \\
.968429 \\
.968379 \\
.968329 \\
.968278 \\
.968228 \\
.968178\end{array}$ & $\begin{array}{l}.83 \\
.83 \\
.83 \\
.82 \\
.83 \\
.83 \\
.83 \\
.85 \\
.83 \\
.83 \\
.83\end{array}$ & $\begin{array}{r}9.595768 \\
.596138 \\
.596508 \\
.596878 \\
.597247 \\
.597616 \\
.597985 \\
.598354 \\
.598722 \\
.599 C 91\end{array}$ & $\begin{array}{l}6.17 \\
6.17 \\
6.17 \\
6.15 \\
6.15 \\
6.15 \\
6.15 \\
6.13 \\
6.15 \\
6.13\end{array}$ & $\begin{array}{r}10.404232 \\
.403862 \\
.40349 \% \\
.403122 \\
.402753 \\
.402384 \\
.402015 \\
.401646 \\
.401278 \\
.400909\end{array}$ & $\begin{array}{l}29 \\
28 \\
27 \\
28 \\
25 \\
21 \\
24 \\
22 \\
21 \\
20\end{array}$ \\
\hline $\begin{array}{l}41 \\
42 \\
43 \\
44 \\
45 \\
46 \\
47 \\
48 \\
49 \\
50\end{array}$ & $\begin{array}{r}9.567587 \\
.567904 \\
.568222 \\
.568539 \\
.568856 \\
.569172 \\
.569488 \\
.569804 \\
.570120 \\
.570435\end{array}$ & $\begin{array}{l}5.28 \\
5.30 \\
5.28 \\
5.28 \\
5.27 \\
5.27 \\
5.27 \\
5.27 \\
5.25 \\
5.27\end{array}$ & $\begin{array}{r}9.968128 \\
.968078 \\
.968027 \\
.967977 \\
.967927 \\
.967876 \\
.967826 \\
.967775 \\
.967725 \\
.967674\end{array}$ & $\begin{array}{l}.80 \\
.83 \\
.85 \\
.83 \\
.83 \\
.85 \\
.83 \\
.85 \\
.83 \\
.85 \\
.83\end{array}$ & $\begin{array}{r}9.599459 \\
.599827 \\
.600194 \\
.600562 \\
.600929 \\
.601296 \\
.601663 \\
.602029 \\
.602395 \\
.602761\end{array}$ & $\begin{array}{l}6.13 \\
6.12 \\
6.13 \\
6.12 \\
6.12 \\
6.12 \\
6.10 \\
6.10 \\
6.10 \\
6.10\end{array}$ & $\begin{array}{r}10.400541 \\
.4001 \% 3 \\
.399806 \\
.399438 \\
.399071 \\
.398704 \\
.398327 \\
.397971 \\
.397605 \\
.397239\end{array}$ & $\begin{array}{l}19 \\
18 \\
17 \\
16 \\
15 \\
14 \\
13 \\
12 \\
11 \\
10\end{array}$ \\
\hline $\begin{array}{l}51 \\
52 \\
53 \\
54 \\
55 \\
56 \\
57 \\
58 \\
59 \\
60\end{array}$ & $\begin{array}{r}9.570751 \\
.571066 \\
.571380 \\
.571695 \\
.572009 \\
.572323 \\
.572636 \\
.572950 \\
.573263 \\
9.573575\end{array}$ & $\begin{array}{l}5.25 \\
5.23 \\
5.25 \\
5.23 \\
5.23 \\
5.22 \\
5.23 \\
5.22 \\
5.20\end{array}$ & $\begin{array}{r}9.967624 \\
.967573 \\
.967522 \\
.967471 \\
.967421 \\
.967370 \\
.967319 \\
.967268 \\
.967217 \\
9.967166\end{array}$ & $\begin{array}{l}.05 \\
.85 \\
.85 \\
.85 \\
.83 \\
.85 \\
.85 \\
.85 \\
.85 \\
.85\end{array}$ & $\begin{array}{r}9.60312 \% \\
.603493 \\
.603858 \\
.604223 \\
.604588 \\
.604953 \\
.605317 \\
.605682 \\
.606046 \\
9.606410\end{array}$ & $\begin{array}{l}6.10 \\
6.08 \\
6.08 \\
6.08 \\
6.08 \\
6.07 \\
6.08 \\
6.07 \\
6.07\end{array}$ & $\begin{array}{r}10.396873 \\
.396507 \\
.396142 \\
.395777 \\
.395112 \\
.395047 \\
.394683 \\
.394318 \\
.393954 \\
10.393590 \\
\end{array}$ & $\begin{array}{l}9 \\
8 \\
7 \\
6 \\
5 \\
4 \\
3 \\
2 \\
1 \\
0\end{array}$ \\
\hline , & Cosine. & D. $1^{\circ}$. & Sine. & D. $1^{\prime \prime}$. & Cotang. & D. $1^{\prime \prime}$. & Tang. & , \\
\hline
\end{tabular}




\begin{tabular}{|c|c|c|c|c|c|c|c|c|}
\hline , & Sine. & D. 1". & Cosine. & D. $1^{\prime}$. & Tang. & D. $1^{\prime \prime}$. & Cotang. & ' \\
\hline $\begin{array}{r}0 \\
1 \\
2 \\
3 \\
4 \\
5 \\
6 \\
7 \\
8 \\
9 \\
10\end{array}$ & $\begin{array}{r}9.573575 \\
.573888 \\
.574200 \\
.574512 \\
.574824 \\
.575136 \\
.575447 \\
.575758 \\
.576069 \\
.576379 \\
.576689\end{array}$ & $\begin{array}{l}5.22 \\
5.20 \\
5.20 \\
5.20 \\
5.20 \\
5.18 \\
5.18 \\
5.18 \\
5.17 \\
5.17 \\
5.17\end{array}$ & $\begin{array}{r}9.967166 \\
.967115 \\
.967064 \\
.967013 \\
.966961 \\
.966910 \\
.966859 \\
.966808 \\
.966756 \\
.966705 \\
.966653\end{array}$ & $\begin{array}{l}.85 \\
.85 \\
.85 \\
.87 \\
.85 \\
.85 \\
.85 \\
.87 \\
.85 \\
.87 \\
.85\end{array}$ & $\begin{array}{r}9.606410 \\
.606773 \\
.607137 \\
.607500 \\
.607863 \\
.608225 \\
.608588 \\
.608950 \\
.609312 \\
.609674 \\
.610036\end{array}$ & $\begin{array}{l}6.05 \\
6.07 \\
6.05 \\
6.05 \\
6.03 \\
6.05 \\
6.03 \\
6.03 \\
6.03 \\
6.03 \\
6.02\end{array}$ & $\begin{array}{r}10.393590 \\
.393227 \\
.392863 \\
.392500 \\
.392137 \\
.391775 \\
.391412 \\
.391050 \\
.390688 \\
.390326 \\
.389964\end{array}$ & $\begin{array}{l}60 \\
59 \\
58 \\
57 \\
56 \\
55 \\
54 \\
53 \\
52 \\
51 \\
50\end{array}$ \\
\hline $\begin{array}{l}11 \\
12 \\
13 \\
14 \\
15 \\
16 \\
17 \\
18 \\
19 \\
20\end{array}$ & $\begin{array}{r}9.576999 \\
.577309 \\
.577618 \\
577927 \\
.578236 \\
.578545 \\
.578853 \\
.579162 \\
.579470 \\
.579777\end{array}$ & $\begin{array}{l}5.17 \\
5.15 \\
5.15 \\
5.15 \\
5.15 \\
5.13 \\
5.15 \\
5.13 \\
5.12 \\
5.13\end{array}$ & $\begin{array}{r}9.966602 \\
.966550 \\
.966499 \\
.966447 \\
.966395 \\
.966344 \\
.966292 \\
.966240 \\
.966188 \\
.966136\end{array}$ & $\begin{array}{l}.07 \\
.87 \\
.85 \\
.87 \\
.87 \\
.85 \\
.87 \\
.87 \\
.87 \\
.87 \\
.85\end{array}$ & $\begin{array}{r}9.610397 \\
.610759 \\
.611120 \\
.611480 \\
611841 \\
.612201 \\
.612561 \\
.612921 \\
.613281 \\
.613641\end{array}$ & $\begin{array}{l}0.02 \\
6.03 \\
6.02 \\
6.00 \\
6.02 \\
6.00 \\
6.00 \\
6.00 \\
6.10 \\
6.00 \\
5.98\end{array}$ & $\begin{array}{r}10.389603 \\
.389241 \\
.388880 \\
.388520 \\
.388159 \\
.387799 \\
.387439 \\
.387079 \\
.386719 \\
.386359\end{array}$ & $\begin{array}{l}49 \\
48 \\
47 \\
46 \\
45 \\
44 \\
43 \\
42 \\
41 \\
40\end{array}$ \\
\hline $\begin{array}{l}21 \\
22 \\
23 \\
24 \\
25 \\
26 \\
27 \\
28 \\
29 \\
30\end{array}$ & $\begin{array}{r}9.580085 \\
.580392 \\
.580699 \\
.581005 \\
.581312 \\
581618 \\
.581924 \\
.582229 \\
.582535 \\
.582840\end{array}$ & $\begin{array}{l}5.12 \\
5.12 \\
5.10 \\
5.12 \\
5.10 \\
5.10 \\
5.08 \\
5.10 \\
5.08 \\
5.08\end{array}$ & $\begin{array}{r}9.966085 \\
.966033 \\
.965981 \\
.965929 \\
.965876 \\
.965824 \\
.965772 \\
.965720 \\
.965668 \\
.965615\end{array}$ & $\begin{array}{l}.87 \\
.87 \\
.87 \\
.87 \\
.88 \\
.87 \\
.87 \\
.87 \\
.87 \\
.88 \\
.87\end{array}$ & $\begin{array}{r}9.614000 \\
.614359 \\
.614718 \\
.615077 \\
.615435 \\
.615793 \\
.616151 \\
.616509 \\
.616867 \\
.617224\end{array}$ & $\begin{array}{l}5.98 \\
5.98 \\
5.98 \\
5.97 \\
5.97 \\
5.97 \\
5.97 \\
5.97 \\
5.95 \\
5.97\end{array}$ & $\begin{array}{r}10.386000 \\
.385641 \\
.385282 \\
.384923 \\
.384565 \\
.384207 \\
.383849 \\
.383491 \\
.383133 \\
.382776\end{array}$ & $\begin{array}{l}39 \\
38 \\
37 \\
36 \\
35 \\
34 \\
33 \\
32 \\
31 \\
30\end{array}$ \\
\hline $\begin{array}{l}31 \\
32 \\
33 \\
34 \\
35 \\
36 \\
37 \\
38 \\
39 \\
40\end{array}$ & $\begin{array}{r}9.583145 \\
.583449 \\
583754 \\
.584058 \\
.584361 \\
.584665 \\
.584968 \\
.585272 \\
.585574 \\
.585877\end{array}$ & $\begin{array}{l}5.07 \\
5.08 \\
5.07 \\
5.05 \\
5.07 \\
5.05 \\
5.07 \\
5.03 \\
5.05 \\
5.03\end{array}$ & $\begin{array}{r}9.965563 \\
.965511 \\
.965458 \\
.965406 \\
.965353 \\
.965301 \\
.965248 \\
.965195 \\
.965143 \\
.965090\end{array}$ & $\begin{array}{l}.07 \\
.87 \\
.88 \\
.87 \\
.88 \\
.87 \\
.88 \\
.88 \\
.87 \\
.88 \\
.88\end{array}$ & $\begin{array}{r}9.617582 \\
617939 \\
.618295 \\
.618652 \\
.619008 \\
.619364 \\
.619720 \\
.620076 \\
.620432 \\
.620787\end{array}$ & $\begin{array}{l}5.95 \\
5.93 \\
5.95 \\
5.93 \\
5.93 \\
5.93 \\
5.93 \\
5.93 \\
5.92 \\
5.92\end{array}$ & $\begin{array}{r}.0382418 \\
.382061 \\
.381705 \\
.381348 \\
.380992 \\
.380636 \\
.380280 \\
.379924 \\
.379568 \\
.379213\end{array}$ & $\begin{array}{l}29 \\
28 \\
27 \\
26 \\
25 \\
24 \\
23 \\
22 \\
21 \\
20\end{array}$ \\
\hline $\begin{array}{l}41 \\
42 \\
43 \\
44 \\
45 \\
46 \\
47 \\
48 \\
49 \\
50\end{array}$ & $\begin{array}{r}9.586179 \\
.586482 \\
586783 \\
.587085 \\
.587386 \\
.587688 \\
.587989 \\
.588289 \\
.588590 \\
.588890^{\circ}\end{array}$ & $\begin{array}{l}5.05 \\
5.02 \\
5.03 \\
5.02 \\
5.03 \\
5.02 \\
5.00 \\
5.02 \\
5.00 \\
5.00\end{array}$ & $\begin{array}{r}9.965037 \\
.964984 \\
.964931 \\
.964879 \\
.964826 \\
.964773 \\
.964720 \\
.964666 \\
.964613 \\
.964560\end{array}$ & $\begin{array}{l}.00 \\
.88 \\
.88 \\
.87 \\
.88 \\
.88 \\
.88 \\
.90 \\
.88 \\
.88 \\
.88\end{array}$ & $\begin{array}{r}9.621142 \\
.621497 \\
.621852 \\
.622207 \\
.622561 \\
.622915 \\
.623269 \\
.623623 \\
.623976 \\
.624330\end{array}$ & $\begin{array}{l}5.92 \\
5.92 \\
5.92 \\
5.90 \\
5.90 \\
5.90 \\
5.90 \\
5.88 \\
5.90 \\
5.88\end{array}$ & $\begin{array}{r}10.378858 \\
.378503 \\
.378148 \\
.377793 \\
.377439 \\
.377085 \\
.376731 \\
.376377 \\
.376024 \\
.375670\end{array}$ & $\begin{array}{l}19 \\
18 \\
17 \\
16 \\
15 \\
14 \\
13 \\
12 \\
11 \\
10\end{array}$ \\
\hline $\begin{array}{l}51 \\
52 \\
53 \\
54 \\
55 \\
56 \\
57 \\
58 \\
59 \\
60\end{array}$ & $\begin{array}{r}9.589190 \\
.589489 \\
.589789 \\
.590088 \\
.590387 \\
.590686 \\
590984 \\
591282 \\
.591580 \\
9.591878\end{array}$ & $\begin{array}{l}4.98 \\
5.00 \\
4.98 \\
4.98 \\
4.98 \\
4.97 \\
4.97 \\
4.97 \\
4.97\end{array}$ & $\begin{array}{r}9.964507 \\
.964454 \\
.964400 \\
.964347 \\
.964294 \\
.964240 \\
.964187 \\
.964133 \\
.964080 \\
9.964026\end{array}$ & $\begin{array}{l}.00 \\
.88 \\
.90 \\
.88 \\
.88 \\
.90 \\
.88 \\
.90 \\
.88 \\
.90\end{array}$ & $\begin{array}{r}9.624683 \\
.625036 \\
.625388 \\
.625741 \\
.626093 \\
.626445 \\
.626797 \\
.627149 \\
.627501 \\
9.627852\end{array}$ & $\begin{array}{l}\mathbf{5 . 8 8} \\
\mathbf{5 . 8 7} \\
\mathbf{5 . 8 8} \\
5.87 \\
\mathbf{5} .87 \\
\mathbf{5 . 8 7} \\
\mathbf{5 . 8 7} \\
\mathbf{5 . 8 7} \\
\mathbf{5 . 8 5}\end{array}$ & $\begin{array}{r}10.375317 \\
.374964 \\
.374612 \\
.374259 \\
.373907 \\
.373555 \\
.373203 \\
.372851 \\
.372499 \\
10.372148\end{array}$ & $\begin{array}{l}9 \\
8 \\
7 \\
6 \\
5 \\
4 \\
8 \\
2 \\
1 \\
0\end{array}$ \\
\hline ' & e & D. $1^{\prime \prime}$. & Sine. & D. 1. & C & D. 1. & g. & 1 \\
\hline
\end{tabular}




\begin{tabular}{|c|c|c|c|c|c|c|c|c|}
\hline , & Sine. & D. $1^{\prime \prime}$. & Cosine. & D. $1^{\prime \prime}$. & Tang. & D. $1^{\circ}$ & Cotang. & ' \\
\hline $\begin{array}{r}0 \\
1 \\
2 \\
3 \\
4 \\
5 \\
6 \\
7 \\
8 \\
9 \\
10\end{array}$ & $\begin{array}{r}9.591878 \\
.592176 \\
.592473 \\
.592770 \\
.593067 \\
.593363 \\
.593659 \\
.593955 \\
.591251 \\
.594517 \\
.591812\end{array}$ & $\begin{array}{l}4.97 \\
4.95 \\
4.95 \\
4.95 \\
4.93 \\
4.93 \\
4.93 \\
4.93 \\
4.93 \\
4.92 \\
4.92\end{array}$ & $\begin{array}{r}9.964026 \\
.963972 \\
.963919 \\
.963865 \\
.963811 \\
.963757 \\
.963704 \\
.963650 \\
.963596 \\
.963542 \\
.963488\end{array}$ & $\begin{array}{l}.90 \\
.88 \\
.90 \\
.90 \\
.90 \\
.88 \\
.90 \\
.90 \\
.90 \\
.90 \\
.90\end{array}$ & $\begin{array}{r}9.627852 \\
.628203 \\
.628554 \\
.628905 \\
.629255 \\
.629606 \\
.629956 \\
.630306 \\
.630656 \\
.631005 \\
.631355\end{array}$ & $\begin{array}{l}5.85 \\
5.85 \\
5.85 \\
5.83 \\
5.85 \\
5.83 \\
5.83 \\
5.83 \\
5.82 \\
5.83 \\
5.82\end{array}$ & $\begin{array}{r}10.372148 \\
.371797 \\
.371446 \\
.371095 \\
.370745 \\
.370394 \\
.370044 \\
.369694 \\
.369344 \\
.368995 \\
.368645\end{array}$ & $\begin{array}{l}60 \\
59 \\
58 \\
57 \\
56 \\
55 \\
54 \\
53 \\
52 \\
51 \\
50\end{array}$ \\
\hline $\begin{array}{l}11 \\
12 \\
13 \\
14 \\
15 \\
16 \\
17 \\
18 \\
19 \\
20\end{array}$ & $\begin{array}{r}9.595137 \\
.595432 \\
.595727 \\
.596021 \\
.596315 \\
.596609 \\
.596903 \\
.597196 \\
.597490 \\
.597783\end{array}$ & $\begin{array}{l}4.92 \\
4.92 \\
4.90 \\
4.90 \\
4.90 \\
4.90 \\
4.88 \\
4.90 \\
4.88 \\
4.87\end{array}$ & $\begin{array}{r}9.963134 \\
.963379 \\
.963325 \\
.963271 \\
.963217 \\
.963163 \\
.963108 \\
.963054 \\
.962999 \\
.962945\end{array}$ & $\begin{array}{l}.92 \\
.90 \\
.90 \\
.90 \\
.90 \\
.92 \\
.90 \\
.92 \\
.90 \\
.92\end{array}$ & $\begin{array}{r}9.631704 \\
.632053 \\
.632402 \\
.632750 \\
.633099 \\
.633447 \\
.633795 \\
.634143 \\
.634490 \\
.634838\end{array}$ & $\begin{array}{l}5.82 \\
\mathbf{5 . 8 2} \\
\mathbf{5 . 8 0} \\
5.82 \\
\mathbf{5 . 8 0} \\
\mathbf{5 . 8 0} \\
\mathbf{5 . 8 0} \\
\mathbf{5 . 7 8} \\
\mathbf{5 . 8 0} \\
\mathbf{5 . 7 8}\end{array}$ & $\begin{array}{r}10.368296 \\
.367947 \\
.367598 \\
.367250 \\
.366901 \\
.366553 \\
.366205 \\
.365857 \\
.365510 \\
.365162\end{array}$ & $\begin{array}{l}49 \\
48 \\
47 \\
46 \\
45 \\
44 \\
43 \\
42 \\
41 \\
40\end{array}$ \\
\hline $\begin{array}{l}21 \\
22 \\
23 \\
21 \\
25 \\
26 \\
27 \\
28 \\
29 \\
30\end{array}$ & $\begin{array}{r}9.598075 \\
.598368 \\
.598660 \\
.598952 \\
.599244 \\
.599536 \\
.599827 \\
.600118 \\
.600409 \\
.600700\end{array}$ & $\begin{array}{l}4.88 \\
4.87 \\
4.87 \\
4.87 \\
4.87 \\
4.85 \\
4.85 \\
4.85 \\
4.85 \\
4.83\end{array}$ & $\begin{array}{r}9.962890 \\
.962836 \\
.962781 \\
.962727 \\
.962672 \\
.962617 \\
.962562 \\
.962508 \\
.962153 \\
.962398\end{array}$ & $\begin{array}{l}.92 \\
.90 \\
.92 \\
.90 \\
.92 \\
.92 \\
.92 \\
.90 \\
.92 \\
.92 \\
.92\end{array}$ & $\begin{array}{r}9.635185 \\
.635532 \\
.635879 \\
.636226 \\
.636572 \\
.636919 \\
.637265 \\
.637611 \\
.637956 \\
.638302\end{array}$ & $\begin{array}{l}5.18 \\
\mathbf{5 . 7 8} \\
\mathbf{5 . 7 8} \\
\mathbf{5 . 7 8} \\
\mathbf{5} .77 \\
\mathbf{5} .78 \\
\mathbf{5 . 7 7} \\
\mathbf{5 . 7 7} \\
\mathbf{5 . 7 5} \\
\mathbf{5 . 7 7} \\
\mathbf{5 . 7 5}\end{array}$ & $\begin{array}{r}10.364815 \\
.364468 \\
.364121 \\
.363774 \\
.363428 \\
.363081 \\
.362735 \\
.362389 \\
.362044 \\
.361698\end{array}$ & $\begin{array}{l}39 \\
38 \\
37 \\
36 \\
35 \\
34 \\
33 \\
32 \\
31 \\
30\end{array}$ \\
\hline $\begin{array}{l}31 \\
32 \\
33 \\
31 \\
35 \\
36 \\
37 \\
38 \\
39 \\
40\end{array}$ & $\begin{array}{r}9.600990 \\
.601280 \\
.601570 \\
.601860 \\
.602150 \\
.602439 \\
.602728 \\
.603017 \\
.603305 \\
.603594\end{array}$ & $\begin{array}{l}4.83 \\
4.83 \\
4.83 \\
4.83 \\
4.82 \\
4.82 \\
4.82 \\
4.80 \\
4.82 \\
4.80\end{array}$ & $\begin{array}{r}9.962343 \\
.962288 \\
.962233 \\
.962178 \\
.962123 \\
.962067 \\
.962012 \\
.961957 \\
.961902 \\
.961846\end{array}$ & $\begin{array}{l}.92 \\
.92 \\
.92 \\
.92 \\
.93 \\
.92 \\
.92 \\
.92 \\
.93 \\
.92\end{array}$ & $\begin{array}{r}9.638647 \\
.638992 \\
.639337 \\
.639682 \\
.640027 \\
.640371 \\
.640716 \\
.641060 \\
.641404 \\
.641747\end{array}$ & $\begin{array}{l}5.75 \\
5.75 \\
5.75 \\
5.75 \\
5.73 \\
5.75 \\
5.73 \\
5.73 \\
5.72 \\
5.73\end{array}$ & $\begin{array}{r}10.361353 \\
.361008 \\
.360663 \\
.360318 \\
.359973 \\
.359629 \\
.359284 \\
.358940 \\
.358596 \\
.358253\end{array}$ & $\begin{array}{l}29 \\
28 \\
27 \\
26 \\
25 \\
24 \\
23 \\
22 \\
21 \\
20\end{array}$ \\
\hline $\begin{array}{l}41 \\
42 \\
43 \\
44 \\
45 \\
46 \\
47 \\
48 \\
49 \\
50\end{array}$ & $\begin{array}{r}9.603882 \\
.604170 \\
.604157 \\
.604745 \\
.605032 \\
.605319 \\
.605606 \\
.605892 \\
.606179 \\
.606465\end{array}$ & $\begin{array}{l}4.80 \\
4.78 \\
4.80 \\
4.78 \\
4.78 \\
4.78 \\
4.77 \\
4.78 \\
4.77 \\
4.77\end{array}$ & $\begin{array}{r}9.961791 \\
.961735 \\
.961680 \\
.961624 \\
.961569 \\
.961513 \\
.961458 \\
.961402 \\
.961346 \\
.961290\end{array}$ & $\begin{array}{l}.93 \\
.93 \\
.93 \\
.92 \\
.93 \\
.92 \\
.93 \\
.93 \\
.93 \\
.92\end{array}$ & $\begin{array}{r}9.642091 \\
.642434 \\
.642777 \\
.643120 \\
.643468 \\
.643806 \\
.644148 \\
.644490 \\
.644832 \\
.645174\end{array}$ & $\begin{array}{l}5.72 \\
5.72 \\
5.72 \\
5.72 \\
5.72 \\
5.70 \\
5.70 \\
5.70 \\
5.70 \\
5.70\end{array}$ & $\begin{array}{r}10.357909 \\
.357566 \\
.357223 \\
.356880 \\
.356537 \\
.356194 \\
.355852 \\
.355510 \\
.355168 \\
.351820\end{array}$ & $\begin{array}{l}19 \\
18 \\
17 \\
16 \\
15 \\
14 \\
13 \\
13 \\
11 \\
10\end{array}$ \\
\hline $\begin{array}{l}51 \\
52 \\
53 \\
54 \\
55 \\
56 \\
57 \\
58 \\
59 \\
60\end{array}$ & $\begin{array}{r}9.606751 \\
.607036 \\
.607322 \\
.607607 \\
.607892 \\
.608177 \\
.608461 \\
.608745 \\
.609029 \\
9.609313\end{array}$ & $\begin{array}{l}4.75 \\
4.77 \\
4.75 \\
4.75 \\
4.75 \\
4.73 \\
4.73 \\
4.73 \\
4.73\end{array}$ & $\begin{array}{r}9.961235 \\
.961179 \\
.961123 \\
.961067 \\
.961011 \\
.960955 \\
.960899 \\
.960843 \\
.960786 \\
9.960730\end{array}$ & $\begin{array}{l}.03 \\
.93 \\
.93 \\
.93 \\
.93 \\
.93 \\
.93 \\
.95 \\
.93\end{array}$ & $\begin{array}{r}9.645516 \\
.645857 \\
.646199 \\
.646540 \\
.646881 \\
.647222 \\
.647562 \\
.647903 \\
.648243 \\
9.648583\end{array}$ & $\begin{array}{l}\mathbf{5 . 6 8} \\
\mathbf{5 . 7 0} \\
5.68 \\
5.68 \\
5.68 \\
5.67 \\
\mathbf{5} .68 \\
\mathbf{5} .67 \\
\mathbf{5 . 6 7}\end{array}$ & \begin{tabular}{|r}
10.354184 \\
.354143 \\
.353801 \\
.353460 \\
.353119 \\
.352778 \\
.352438 \\
.352007 \\
.351757 \\
10.351417 \\
\end{tabular} & $\begin{array}{l}9 \\
8 \\
7 \\
6 \\
5 \\
4 \\
3 \\
2 \\
1 \\
0\end{array}$ \\
\hline ' & Cosine. & D. 1". & Sine. & D. $1^{\prime \prime}$. & Cotang. & D. $1^{\circ}$. & Tang. & ' \\
\hline
\end{tabular}




\begin{tabular}{|c|c|c|c|c|c|c|c|c|}
\hline , & Sine. & D. $1^{\prime \prime}$. & Cosine. & D. 1". & Tang. & D. $1^{\circ}$. & Cotang. & ' \\
\hline $\begin{array}{r}0 \\
1 \\
2 \\
3 \\
4 \\
5 \\
6 \\
7 \\
8 \\
9 \\
10\end{array}$ & $\begin{array}{r}9.609313 \\
.609597 \\
.609880 \\
.610164 \\
.610447 \\
.610729 \\
.611012 \\
.611294 \\
.611576 \\
.611858 \\
.612140\end{array}$ & $\begin{array}{l}4.73 \\
4.72 \\
4.73 \\
4.72 \\
4.70 \\
4.72 \\
4.70 \\
4.70 \\
4.70 \\
4.70 \\
4.68\end{array}$ & $\begin{array}{r}9.960730 \\
.960674 \\
.960618 \\
.960561 \\
.960505 \\
.960448 \\
.960392 \\
.960335 \\
.960279 \\
.96022 z \\
.960165\end{array}$ & $\begin{array}{l}.93 \\
.93 \\
.95 \\
.93 \\
.95 \\
.93 \\
.95 \\
.93 \\
.95 \\
.95 \\
.93\end{array}$ & $\begin{array}{r}9.648583 \\
.648923 \\
.649263 \\
.649602 \\
.649942 \\
.650281 \\
.650620 \\
.650959 \\
.651297 \\
.651636 \\
.651274\end{array}$ & $\begin{array}{l}\mathbf{5 . 6 7} \\
\mathbf{5 . 6 7} \\
\mathbf{5} .65 \\
\mathbf{5 . 6 7} \\
\mathbf{5 . 6 5} \\
\mathbf{5 . 6 5} \\
\mathbf{5 . 6 5} \\
\mathbf{5 . 6 3} \\
\mathbf{5 . 6 5} \\
\mathbf{5 . 6 3} \\
\mathbf{5 . 6 3}\end{array}$ & $\begin{array}{r}10.351417 \\
.351077 \\
.350737 \\
.350398 \\
.350058 \\
.349719 \\
.349380 \\
.349041 \\
.348703 \\
.348364 \\
.348026\end{array}$ & $\begin{array}{l}60 \\
59 \\
58 \\
57 \\
56 \\
55 \\
54 \\
53 \\
52 \\
51 \\
50\end{array}$ \\
\hline $\begin{array}{l}11 \\
12 \\
13 \\
14 \\
15 \\
16 \\
17 \\
18 \\
19 \\
20\end{array}$ & $\begin{array}{r}9.612421 \\
.612702 \\
.612983 \\
.613264 \\
.613545 \\
.613825 \\
.614105 \\
.614385 \\
.614665 \\
.614944\end{array}$ & $\begin{array}{l}4.68 \\
4.68 \\
4.68 \\
4.68 \\
4.67 \\
4.67 \\
4.67 \\
4.67 \\
4.65 \\
4.65\end{array}$ & $\begin{array}{r}9.960109 \\
.960052 \\
.959995 \\
.959938 \\
.959882 \\
.959825 \\
.959768 \\
.959711 \\
.959654 \\
.959596\end{array}$ & $\begin{array}{l}.95 \\
.95 \\
.95 \\
.93 \\
.95 \\
.95 \\
.95 \\
.95 \\
.97 \\
.95\end{array}$ & $\begin{array}{r}9.652312 \\
.652650 \\
.652988 \\
.653326 \\
.653663 \\
.654000 \\
.654337 \\
.654674 \\
.655011 \\
.655348\end{array}$ & $\begin{array}{l}5.63 \\
5.63 \\
5.63 \\
5.62 \\
5.62 \\
5.62 \\
5.62 \\
5.62 \\
5.62 \\
5.60\end{array}$ & $\begin{array}{r}10.347688 \\
.347350 \\
.347012 \\
.346674 \\
.346337 \\
.346000 \\
.345663 \\
.345326 \\
.344989 \\
.344652\end{array}$ & $\begin{array}{l}49 \\
48 \\
47 \\
46 \\
45 \\
44 \\
43 \\
42 \\
41 \\
40\end{array}$ \\
\hline $\begin{array}{l}21 \\
22 \\
23 \\
24 \\
25 \\
26 \\
27 \\
28 \\
29 \\
30\end{array}$ & $\begin{array}{r}9.615223 \\
.615502 \\
.615781 \\
.616060 \\
.616338 \\
.616616 \\
.616894 \\
.617172 \\
.617450 \\
.617727\end{array}$ & $\begin{array}{l}4.65 \\
4.65 \\
4.65 \\
4.63 \\
4.63 \\
4.63 \\
4.63 \\
4.63 \\
4.62 \\
4.62\end{array}$ & $\begin{array}{r}9.959539 \\
.959482 \\
.959425 \\
.959368 \\
.959310 \\
.959253 \\
.959195 \\
.959138 \\
.959080 \\
.959023\end{array}$ & $\begin{array}{l}.95 \\
.95 \\
.95 \\
.95 \\
.97 \\
.95 \\
.97 \\
.95 \\
.97 \\
.95 \\
.97\end{array}$ & $\begin{array}{r}9.655684 \\
.656020 \\
.656356 \\
.656692 \\
.657028 \\
.657364 \\
.657699 \\
.658034 \\
.658369 \\
.658704\end{array}$ & $\begin{array}{l}5.60 \\
5.60 \\
5.60 \\
5.60 \\
5.60 \\
5.58 \\
5.58 \\
5.58 \\
5.58 \\
5.58\end{array}$ & $\begin{array}{r}10.344316 \\
.343980 \\
.343644 \\
.343308 \\
.342972 \\
.342636 \\
.342301 \\
.341966 \\
.341631 \\
.341296\end{array}$ & $\begin{array}{l}39 \\
38 \\
37 \\
36 \\
35 \\
\mathbf{3 4} \\
33 \\
32 \\
31 \\
30\end{array}$ \\
\hline $\begin{array}{l}31 \\
32 \\
33 \\
34 \\
35 \\
36 \\
37 \\
38 \\
39 \\
40\end{array}$ & $\begin{array}{r}9.618004 \\
.618 \kappa 81 \\
.618558 \\
.618834 \\
.619110 \\
.619386 \\
.619662 \\
.619938 \\
.620213 \\
.620488\end{array}$ & $\begin{array}{l}4.62 \\
4.62 \\
4.60 \\
4.60 \\
4.60 \\
4.60 \\
4.60 \\
4.58 \\
4.58 \\
4.58\end{array}$ & $\begin{array}{r}9.958965 \\
.958908 \\
.958850 \\
.958792 \\
.958734 \\
.958677 \\
.958619 \\
.958561 \\
.958503 \\
.958445\end{array}$ & $\begin{array}{l}.95 \\
.97 \\
.97 \\
.97 \\
.95 \\
.97 \\
.97 \\
.97 \\
.97 \\
.97\end{array}$ & $\begin{array}{r}9.659039 \\
.659373 \\
.659708 \\
.660042 \\
.660376 \\
.660710 \\
.661043 \\
.661377 \\
.661710 \\
.662043\end{array}$ & $\begin{array}{l}5.57 \\
5.58 \\
5.57 \\
5.57 \\
5.57 \\
5.55 \\
5.57 \\
5.55 \\
5.55 \\
5.55\end{array}$ & $\begin{array}{r}10.340961 \\
.340627 \\
.340292 \\
.339958 \\
.339624 \\
.339290 \\
.338957 \\
.338623 \\
.338290 \\
.337957\end{array}$ & $\begin{array}{l}29 \\
28 \\
27 \\
26 \\
25 \\
24 \\
23 \\
22 \\
21 \\
20\end{array}$ \\
\hline $\begin{array}{l}41 \\
42 \\
43 \\
44 \\
45 \\
46 \\
47 \\
48 \\
49 \\
50\end{array}$ & $\begin{array}{r}9.620763 \\
.621038 \\
.621313 \\
.621587 \\
.621861 \\
.622135 \\
.622409 \\
.622682 \\
.622956 \\
.623229\end{array}$ & $\begin{array}{l}4.58 \\
4.58 \\
4.57 \\
4.57 \\
4.57 \\
4.57 \\
4.55 \\
4.57 \\
4.55 \\
4.55\end{array}$ & $\begin{array}{r}9.958387 \\
.958329 \\
.958271 \\
.958213 \\
.958154 \\
.958096 \\
.958038 \\
.957979 \\
.957921 \\
.957863\end{array}$ & $\begin{array}{l}.97 \\
.97 \\
.97 \\
.98 \\
.97 \\
.97 \\
.98 \\
.97 \\
.97 \\
.98\end{array}$ & $\begin{array}{r}9.662376 \\
.662709 \\
.663042 \\
.663375 \\
.663707 \\
.664039 \\
.664371 \\
.664703 \\
.665035 \\
.665366\end{array}$ & $\begin{array}{l}5.55 \\
5.55 \\
5.55 \\
5.53 \\
5.53 \\
5.53 \\
5.53 \\
5.53 \\
5.52 \\
5.53\end{array}$ & $\begin{array}{r}10.337624 \\
.337291 \\
.336958 \\
.336625 \\
.336293 \\
.335961 \\
.335629 \\
.335297 \\
.334965 \\
.334634\end{array}$ & $\begin{array}{l}19 \\
18 \\
17 \\
16 \\
15 \\
14 \\
13 \\
12 \\
11 \\
10\end{array}$ \\
\hline $\begin{array}{l}51 \\
52 \\
53 \\
54 \\
55 \\
56 \\
57 \\
58 \\
59 \\
60\end{array}$ & $\begin{array}{r}9.623502 \\
.623774 \\
.624047 \\
.624319 \\
.624591 \\
.624863 \\
.625135 \\
.625406 \\
.625677 \\
\mathbf{9 . 6 2 5 9 4 8}\end{array}$ & $\begin{array}{l}4.53 \\
4.55 \\
4.53 \\
4.53 \\
4.53 \\
4.53 \\
4.52 \\
4.52 \\
4.52\end{array}$ & $\begin{array}{r}9.957804 \\
.957746 \\
.957687 \\
.957628 \\
.957570 \\
.9577,11 \\
.957452 \\
.957393 \\
.957335 \\
9.957276\end{array}$ & $\begin{array}{l}.90 \\
.97 \\
.98 \\
.98 \\
.97 \\
.98 \\
.98 \\
.98 \\
.97 \\
.98\end{array}$ & $\begin{array}{r}9.665698 \\
.666029 \\
.666360 \\
.666691 \\
.667021 \\
.667352 \\
.667682 \\
.668013 \\
.668343 \\
9.668673\end{array}$ & $\begin{array}{l}5.03 \\
5.52 \\
5.52 \\
5.52 \\
5.50 \\
5.52 \\
5.50 \\
5.52 \\
5.50 \\
5.50\end{array}$ & $\begin{array}{r}10.334302 \\
.333971 \\
.333640 \\
.333309 \\
.332979 \\
.332648 \\
.332318 \\
.331987 \\
.331657 \\
10.331327\end{array}$ & $\begin{array}{l}9 \\
8 \\
7 \\
6 \\
5 \\
4 \\
3 \\
2 \\
1 \\
0\end{array}$ \\
\hline ' & Cosine. & D. $1^{\prime \prime}$. & Sine. & 2.2. & Cotang. & 2.2. & Tang. & ' \\
\hline
\end{tabular}




\begin{tabular}{|c|c|c|c|c|c|c|c|c|}
\hline , & Sine. & D. 1". & Cosine. & D. $1^{\prime \prime}$. & Tang. & D. $1^{\circ}$. & Cotang. & , \\
\hline $\begin{array}{r}0 \\
1 \\
2 \\
3 \\
4 \\
5 \\
6 \\
7 \\
8 \\
9 \\
10\end{array}$ & $\begin{array}{r}9.625948 \\
.626219 \\
.626190 \\
.626760 \\
.627030 \\
.627300 \\
.627570 \\
.627840 \\
.628109 \\
.628378 \\
.628647\end{array}$ & $\begin{array}{l}4.52 \\
4.52 \\
4.50 \\
4.50 \\
4.50 \\
4.50 \\
4.50 \\
4.48 \\
4.48 \\
4.48 \\
4.48\end{array}$ & $\begin{array}{r}9.957276 \\
.957217 \\
.957158 \\
.957099 \\
.957040 \\
.956981 \\
.956921 \\
.956862 \\
.956803 \\
.956744 \\
.956681\end{array}$ & $\begin{array}{r}.98 \\
.98 \\
.98 \\
.98 \\
.98 \\
1.00 \\
.98 \\
.98 \\
.98 \\
1.00 \\
.98\end{array}$ & $\begin{array}{r}9.668673 \\
.669002 \\
.669332 \\
.669661 \\
.669991 \\
.670320 \\
.670649 \\
.670977 \\
.671306 \\
.671635 \\
.671963\end{array}$ & $\begin{array}{l}5.48 \\
5.50 \\
5.48 \\
5.50 \\
5.48 \\
5.48 \\
5.47 \\
5.48 \\
5.48 \\
5.47 \\
5.47\end{array}$ & $\begin{array}{r}10.331327 \\
.330998 \\
.330668 \\
.330839 \\
.330009 \\
.329680 \\
.3298351 \\
.329083 \\
.328694 \\
.328365 \\
.328037\end{array}$ & $\begin{array}{l}60 \\
59 \\
58 \\
57 \\
56 \\
55 \\
54 \\
53 \\
52 \\
51 \\
50\end{array}$ \\
\hline $\begin{array}{l}11 \\
12 \\
13 \\
14 \\
15 \\
15 \\
16 \\
17 \\
18 \\
19 \\
20 \\
\end{array}$ & $\begin{array}{r}9.628916 \\
.629185 \\
.629153 \\
.629721 \\
.629989 \\
.630257 \\
.630524 \\
.630792 \\
.631059 \\
.631326\end{array}$ & $\begin{array}{l}4.48 \\
4.47 \\
4.47 \\
4.47 \\
4.47 \\
4.45 \\
4.47 \\
4.45 \\
4.45 \\
4.45\end{array}$ & $\begin{array}{r}9.956625 \\
.956566 \\
.956506 \\
.956447 \\
.956387 \\
.956327 \\
.956268 \\
.956208 \\
.956148 \\
.956089\end{array}$ & $\begin{array}{r}.98 \\
1.00 \\
.98 \\
1.00 \\
1.00 \\
.98 \\
1.00 \\
1.00 \\
.98 \\
1.00\end{array}$ & $\begin{array}{r}9.672291 \\
.672619 \\
.672947 \\
.673274 \\
.673602 \\
.673929 \\
.674257 \\
.674584 \\
.674911 \\
.675237\end{array}$ & $\begin{array}{l}5.47 \\
5.47 \\
5.45 \\
5.47 \\
5.45 \\
5.47 \\
5.45 \\
5.45 \\
5.43 \\
5.45\end{array}$ & $\begin{array}{r}10.327 r 09 \\
.327381 \\
.327053 \\
.326726 \\
.326398 \\
.326071 \\
.325743 \\
.325416 \\
.325089 \\
.324763\end{array}$ & $\begin{array}{l}49 \\
48 \\
47 \\
46 \\
45 \\
44 \\
43 \\
42 \\
41 \\
40\end{array}$ \\
\hline $\begin{array}{l}21 \\
22 \\
23 \\
24 \\
25 \\
26 \\
27 \\
28 \\
23 \\
30\end{array}$ & $\begin{array}{r}9.631593 \\
631859 \\
.632125 \\
.632392 \\
.632658 \\
.632923 \\
.633189 \\
.633454 \\
.633719 \\
.633984\end{array}$ & $\begin{array}{l}4.43 \\
4.43 \\
4.45 \\
4.43 \\
4.42 \\
4.43 \\
4.42 \\
4.42 \\
4.42 \\
4.42\end{array}$ & $\begin{array}{r}9.956029 \\
.955969 \\
.955909 \\
.955849 \\
.955789 \\
.955729 \\
.955669 \\
.955609 \\
.955548 \\
.955488\end{array}$ & $\begin{array}{l}1.00 \\
1.00 \\
1.00 \\
1.00 \\
1.00 \\
1.00 \\
1.00 \\
.98 \\
100 \\
1.00\end{array}$ & $\begin{array}{r}9.675564 \\
.675890 \\
.676217 \\
.676543 \\
.676869 \\
.677194 \\
.677520 \\
.677846 \\
.678171 \\
.678496\end{array}$ & $\begin{array}{l}5.43 \\
5.45 \\
5.43 \\
5.43 \\
5.42 \\
5.43 \\
5.43 \\
5.42 \\
5.42 \\
5.42\end{array}$ & $\begin{array}{r}10.324436 \\
.324110 \\
.323783 \\
.323457 \\
.323131 \\
.322806 \\
.322480 \\
.322154 \\
.321829 \\
.321504\end{array}$ & $\begin{array}{l}39 \\
38 \\
37 \\
36 \\
35 \\
34 \\
33 \\
32 \\
31 \\
30\end{array}$ \\
\hline $\begin{array}{l}31 \\
32 \\
33 \\
34 \\
35 \\
36 \\
37 \\
38 \\
39 \\
40\end{array}$ & $\begin{array}{r}9.634249 \\
.634514 \\
.634778 \\
.635042 \\
.635306 \\
.635570 \\
.635834 \\
.636097 \\
636360 \\
.636623\end{array}$ & $\begin{array}{l}4.42 \\
4.40 \\
4.40 \\
4.40 \\
4.40 \\
4.40 \\
4.38 \\
4.38 \\
4.38 \\
4.38\end{array}$ & $\begin{array}{r}9.955428 \\
.955368 \\
.955307 \\
.955247 \\
.955186 \\
.955126 \\
.955065 \\
.955005 \\
.954944 \\
.954883\end{array}$ & $\begin{array}{l}1.00 \\
1.02 \\
1.00 \\
1.02 \\
1.00 \\
1.02 \\
1.00 \\
1.02 \\
1.02 \\
1.00\end{array}$ & $\begin{array}{r}9.678821 \\
.679146 \\
.679471 \\
.679795 \\
.680120 \\
.680444 \\
.680768 \\
.681092 \\
.681416 \\
.681740\end{array}$ & $\begin{array}{l}\mathbf{5 . 4 2} \\
5.42 \\
5.40 \\
5.42 \\
\mathbf{5} .40 \\
\mathbf{5 . 4 0} \\
5.40 \\
\mathbf{5 . 4 0} \\
\mathbf{5 . 4 0} \\
\mathbf{5 . 3 8}\end{array}$ & $\begin{array}{r}10.321179 \\
.320854 \\
.320529 \\
.320205 \\
.319880 \\
.319556 \\
.319232 \\
.318908 \\
.318584 \\
.318260\end{array}$ & $\begin{array}{l}29 \\
28 \\
27 \\
26 \\
25 \\
24 \\
23 \\
22 \\
21 \\
20\end{array}$ \\
\hline $\begin{array}{l}41 \\
42 \\
43 \\
44 \\
45 \\
46 \\
47 \\
48 \\
49 \\
50\end{array}$ & $\begin{array}{r}9.636886 \\
637148 \\
.637411 \\
.637673 \\
.637935 \\
.638197 \\
.638458 \\
.638720 \\
.638981 \\
.639242\end{array}$ & $\begin{array}{l}4.37 \\
4.38 \\
4.37 \\
4.37 \\
4.37 \\
4.35 \\
4.37 \\
4.35 \\
4.35 \\
4.35\end{array}$ & $\begin{array}{r}9.954883 \\
.954762 \\
.954701 \\
.954640 \\
.954579 \\
.954518 \\
.954457 \\
.954396 \\
.954335 \\
.954274\end{array}$ & $\begin{array}{l}102 \\
1.02 \\
1.02 \\
1.02 \\
1.02 \\
1.02 \\
1.02 \\
1.02 \\
1.02 \\
1.02\end{array}$ & $\begin{array}{r}9.682063 \\
.682387 \\
.682710 \\
.683033 \\
.683356 \\
.683679 \\
.684001 \\
.684324 \\
.684646 \\
.681968\end{array}$ & $\begin{array}{l}5.40 \\
5.38 \\
5.38 \\
5.38 \\
5.38 \\
5.37 \\
5.38 \\
5.37 \\
5.37 \\
5.37\end{array}$ & $\begin{array}{r}10317937 \\
.317613 \\
.317290 \\
.316967 \\
.316644 \\
.316321 \\
.315999 \\
.3156 \% 6 \\
.315354 \\
.315052\end{array}$ & $\begin{array}{r}19 \\
18 \\
17 \\
16 \\
15 \\
14 \\
13 \\
12 \\
11 \\
10 \\
9\end{array}$ \\
\hline $\begin{array}{l}51 \\
52 \\
53 \\
54 \\
55 \\
56 \\
57 \\
58 \\
59 \\
60\end{array}$ & $\begin{array}{r}9.639503 \\
.639764 \\
.640024 \\
.640284 \\
.640544 \\
.640804 \\
.641064 \\
.641324 \\
.641583 \\
9.641842\end{array}$ & $\begin{array}{l}4.35 \\
4.33 \\
4.33 \\
4.33 \\
4.33 \\
4.33 \\
4.33 \\
4.32 \\
4.32\end{array}$ & $\begin{array}{r}9.954213 \\
.954152 \\
.954090 \\
.954029 \\
.953968 \\
.953906 \\
.953845 \\
.953783 \\
.953722 \\
9.953660\end{array}$ & $\begin{array}{l}1.02 \\
1.03 \\
1.02 \\
1.02 \\
1.03 \\
1.02 \\
1.03 \\
1.02 \\
1.03\end{array}$ & $\begin{array}{r}9.685290 \\
.685612 \\
.685934 \\
686255 \\
.686577 \\
.686898 \\
.687219 \\
.687540 \\
.687861 \\
9.688182\end{array}$ & $\begin{array}{l}5.37 \\
5.37 \\
5.35 \\
5.37 \\
5.35 \\
5.35 \\
5.35 \\
5.35 \\
5.35\end{array}$ & $\begin{array}{r}10314710 \\
.314388 \\
314066 \\
313745 \\
.313423 \\
.313102 \\
.312781 \\
.312460 \\
.312139 \\
10.311818\end{array}$ & $\begin{array}{l}9 \\
8 \\
7 \\
6 \\
5 \\
4 \\
3 \\
2 \\
1 \\
0\end{array}$ \\
\hline , & Cosine. & D. $1^{\circ}$. & Sine. & D. $1^{\prime \prime}$. & Cotang. & D. $1^{\circ}$. & Tang. & 1 \\
\hline
\end{tabular}




\begin{tabular}{|c|c|c|c|c|c|c|c|c|}
\hline 1 & Sine. & D. $1^{\prime}$. & Cosine. & D. $1^{\prime \prime}$. & Tang. & D. $1^{\prime}$. & Cotang. & , \\
\hline $\begin{array}{r}0 \\
1 \\
2 \\
3 \\
4 \\
5 \\
6 \\
7 \\
8 \\
9 \\
10\end{array}$ & $\begin{array}{r}9.641842 \\
.642101 \\
.642360 \\
.642618 \\
.642877 \\
.643135 \\
.643393 \\
.643650 \\
.643908 \\
.644165 \\
.644423\end{array}$ & $\begin{array}{l}4.32 \\
4.32 \\
4.30 \\
4.32 \\
4.30 \\
4.30 \\
4.28 \\
4.30 \\
4.28 \\
4.30 \\
4.28\end{array}$ & $\begin{array}{r}9.953660 \\
.953599 \\
.953537 \\
.953475 \\
.953413 \\
.953352 \\
.953290 \\
.953228 \\
.953166 \\
.953104 \\
.953042\end{array}$ & $\begin{array}{l}1.02 \\
1.03 \\
1.03 \\
1.03 \\
1.02 \\
1.03 \\
1.03 \\
1.03 \\
1.03 \\
1.03 \\
1.03\end{array}$ & $\begin{array}{r}9.688182 \\
.688502 \\
.688823 \\
.689143 \\
.689463 \\
.689783 \\
.690103 \\
.690423 \\
.690742 \\
.691062 \\
.691391\end{array}$ & $\begin{array}{l}\mathbf{5 . 3 3} \\
5.32 \\
5.33 \\
\mathbf{5 . 3 3} \\
\mathbf{5 . 3 3} \\
\mathbf{5 . 3 3} \\
5.33 \\
\mathbf{5 . 3 2} \\
\mathbf{5 . 3 3} \\
\mathbf{5 . 3 2} \\
\mathbf{5 . 3 2}\end{array}$ & $\begin{array}{r}10.311818 \\
.311498 \\
.311177 \\
.310857 \\
.310537 \\
.310217 \\
.309897 \\
.309577 \\
.309258 \\
.308938 \\
.308619\end{array}$ & $\begin{array}{l}60 \\
59 \\
\mathbf{5 8} \\
\mathbf{5 7} \\
\mathbf{5 6} \\
\mathbf{5 5} \\
\mathbf{5 4} \\
53 \\
52 \\
\mathbf{5 1} \\
\mathbf{5 0}\end{array}$ \\
\hline $\begin{array}{l}11 \\
12 \\
13 \\
14 \\
15 \\
16 \\
17 \\
18 \\
19 \\
20\end{array}$ & $\begin{array}{r}9.644680 \\
.644936 \\
.645193 \\
.645450 \\
.645706 \\
.645962 \\
.646218 \\
.6464 \pi 4 \\
.646729 \\
.646984\end{array}$ & $\begin{array}{l}4.27 \\
4.28 \\
4.28 \\
4.27 \\
4.27 \\
4.27 \\
4.27 \\
4.25 \\
4.25 \\
4.27\end{array}$ & $\begin{array}{r}9.952980 \\
.952918 \\
.952855 \\
.952793 \\
.952731 \\
.952669 \\
.952606 \\
.952544 \\
.952481 \\
.952419\end{array}$ & $\begin{array}{l}1.03 \\
1.05 \\
1.03 \\
1.03 \\
1.03 \\
1.05 \\
1.03 \\
1.05 \\
1.03 \\
1.05\end{array}$ & $\begin{array}{r}9.691700 \\
.692019 \\
.692358 \\
.692656 \\
.692975 \\
.693293 \\
.693612 \\
.693930 \\
.694248 \\
.694566\end{array}$ & $\begin{array}{l}5.32 \\
5.32 \\
5.30 \\
5.32 \\
5.30 \\
5.32 \\
5.30 \\
5.30 \\
5.30 \\
5.28\end{array}$ & $\begin{array}{r}10.308300 \\
.30 \% 981 \\
.30 \% 6662 \\
.30 \% 744 \\
.30 \% 025 \\
.306707 \\
.306388 \\
.306070 \\
.305752 \\
.305434\end{array}$ & $\begin{array}{l}49 \\
48 \\
47 \\
46 \\
45 \\
44 \\
43 \\
42 \\
41 \\
40\end{array}$ \\
\hline $\begin{array}{l}21 \\
22 \\
23 \\
24 \\
25 \\
26 \\
27 \\
28 \\
29 \\
30\end{array}$ & $\begin{array}{r}9.647240 \\
.647494 \\
.647749 \\
.648004 \\
.648258 \\
.648512 \\
.648766 \\
.649020 \\
.649274 \\
.649527\end{array}$ & $\begin{array}{l}4.23 \\
4.25 \\
4.25 \\
4.23 \\
4.23 \\
4.23 \\
4.23 \\
4.23 \\
4.22 \\
4.23\end{array}$ & $\begin{array}{r}9.952356 \\
.952294 \\
.952231 \\
.952168 \\
.952106 \\
.952043 \\
.951980 \\
.951917 \\
.951854 \\
.951791\end{array}$ & $\begin{array}{l}1.03 \\
1.05 \\
1.05 \\
1.03 \\
1.05 \\
1.05 \\
1.05 \\
1.05 \\
1.05 \\
1.05\end{array}$ & $\begin{array}{r}9.694883 \\
.695201 \\
.695518 \\
.695836 \\
.696153 \\
.696470 \\
.696787 \\
.697103 \\
.697420 \\
.697736\end{array}$ & $\begin{array}{l}5.30 \\
5.28 \\
\mathbf{5} .30 \\
5.28 \\
5.28 \\
5.28 \\
5.27 \\
5.28 \\
5.27 \\
5.28\end{array}$ & $\begin{array}{r}10.305117 \\
.304799 \\
.304482 \\
.304164 \\
.303847 \\
.303530 \\
.303213 \\
.302897 \\
.302580 \\
.302264\end{array}$ & $\begin{array}{l}39 \\
38 \\
37 \\
36 \\
35 \\
34 \\
33 \\
32 \\
31 \\
30\end{array}$ \\
\hline $\begin{array}{l}31 \\
32 \\
33 \\
34 \\
35 \\
36 \\
37 \\
38 \\
39 \\
40\end{array}$ & $\begin{array}{r}9.649781 \\
.650034 \\
.650287 \\
.650539 \\
.650792 \\
.651044 \\
.651297 \\
.651549 \\
.651800 \\
.652052\end{array}$ & $\begin{array}{l}4.22 \\
4.22 \\
4.20 \\
4.22 \\
4.20 \\
4.22 \\
4.20 \\
4.18 \\
4.20 \\
4.20\end{array}$ & $\begin{array}{r}9.951728 \\
.951665 \\
.951602 \\
.951539 \\
.951476 \\
.951412 \\
.951349 \\
.951286 \\
.951222 \\
.951159\end{array}$ & $\begin{array}{l}1.05 \\
1.05 \\
1.05 \\
1.05 \\
1.07 \\
1.05 \\
1.05 \\
1.07 \\
1.05 \\
1.05\end{array}$ & $\begin{array}{r}9.698053 \\
.698369 \\
.698685 \\
.699001 \\
.699316 \\
.699632 \\
.699947 \\
.700263 \\
.700578 \\
.700893\end{array}$ & $\begin{array}{l}5.27 \\
5.27 \\
5.27 \\
5.25 \\
5.27 \\
5.25 \\
5.27 \\
5.25 \\
5.25 \\
5.25\end{array}$ & $\begin{array}{r}10.301947 \\
.301631 \\
.301315 \\
.300999 \\
.300681 \\
.300368 \\
.300053 \\
.299737 \\
.299422 \\
.299107\end{array}$ & $\begin{array}{l}29 \\
28 \\
27 \\
26 \\
25 \\
24 \\
23 \\
22 \\
21 \\
20\end{array}$ \\
\hline $\begin{array}{l}41 \\
42 \\
43 \\
44 \\
45 \\
46 \\
47 \\
48 \\
49 \\
50\end{array}$ & $\begin{array}{r}9.652304 \\
.652555 \\
.652806 \\
.653057 \\
653308 \\
.653558 \\
.653808 \\
.654059 \\
.654309 \\
.654558\end{array}$ & $\begin{array}{l}4.18 \\
4.18 \\
4.18 \\
4.18 \\
4.17 \\
4.17 \\
4.18 \\
4.17 \\
4.15 \\
4.17\end{array}$ & $\begin{array}{r}9.951096 \\
.951032 \\
.950968 \\
.950905 \\
.950841 \\
.950778 \\
.950714 \\
.950650 \\
.950586 \\
.950522\end{array}$ & $\begin{array}{l}1.07 \\
1.07 \\
1.05 \\
1.07 \\
1.05 \\
1.07 \\
1.07 \\
1.07 \\
1.07 \\
1.07\end{array}$ & $\begin{array}{r}9.701208 \\
.701523 \\
.701837 \\
.702152 \\
.702166 \\
.702781 \\
.703095 \\
.703409 \\
.703722 \\
.704036\end{array}$ & $\begin{array}{l}5.25 \\
5.23 \\
5.25 \\
5.23 \\
5.25 \\
5.23 \\
5.23 \\
5.22 \\
5.23 \\
5.23\end{array}$ & $\begin{array}{r}10.298792 \\
.298477 \\
.298163 \\
.297848 \\
.297534 \\
.297219 \\
.296905 \\
.296591 \\
.296278 \\
.295964\end{array}$ & $\begin{array}{l}19 \\
18 \\
17 \\
16 \\
15 \\
14 \\
13 \\
12 \\
11 \\
10\end{array}$ \\
\hline $\begin{array}{l}51 \\
52 \\
53 \\
54 \\
55 \\
56 \\
57 \\
58 \\
59 \\
60\end{array}$ & $\begin{array}{r}9.654808 \\
.655058 \\
.655307 \\
.655556 \\
.655805 \\
.656054 \\
656302 \\
.656551 \\
.656799 \\
9.657047\end{array}$ & $\begin{array}{l}4.17 \\
4.15 \\
4.15 \\
4.15 \\
4.15 \\
4.13 \\
4.15 \\
4.13 \\
4.13\end{array}$ & $\begin{array}{r}9.950458 \\
.950394 \\
.950330 \\
.950266 \\
.950202 \\
.950138 \\
.950074 \\
.950010 \\
.949945 \\
9.949881\end{array}$ & $\begin{array}{l}1.07 \\
1.07 \\
1.07 \\
1.07 \\
1.07 \\
1.07 \\
1.07 \\
1.08 \\
1.07\end{array}$ & $\begin{array}{r}9.704350 \\
.704663 \\
.704976 \\
.705290 \\
.705603 \\
.705916 \\
.706228 \\
.706541 \\
.706854 \\
9.707166\end{array}$ & $\begin{array}{l}5.22 \\
5.22 \\
5.23 \\
5.22 \\
5.22 \\
5.20 \\
5.22 \\
5.22 \\
5.20\end{array}$ & $\begin{array}{r}10.295650 \\
.29533 \% \\
.295024 \\
.294710 \\
.294397 \\
.294084 \\
.293772 \\
.293459 \\
.293146 \\
10.292834\end{array}$ & $\begin{array}{l}9 \\
8 \\
7 \\
6 \\
5 \\
4 \\
3 \\
2 \\
1 \\
0\end{array}$ \\
\hline 1 & osine. & D. $1^{\prime \prime}$ & Sine. & D. 1". & Cotang. & D. 1". & Tang. & I \\
\hline
\end{tabular}




\begin{tabular}{|c|c|c|c|c|c|c|c|c|}
\hline ' & Sine. & D. $1^{\prime \prime}$. & Cosine. & D. $1^{\circ}$. & Tang. & D. $1^{\prime \prime}$. & Cotang. & ' \\
\hline $\begin{array}{r}0 \\
1 \\
2 \\
3 \\
4 \\
5 \\
6 \\
7 \\
8 \\
9 \\
10\end{array}$ & $\begin{array}{r}9.65 \% 047 \\
.657295 \\
.65 \% 542 \\
.657790 \\
.658037 \\
.658284 \\
.658531 \\
.658778 \\
.659025 \\
.659271 \\
.659517\end{array}$ & $\begin{array}{l}4.13 \\
4.12 \\
4.13 \\
4.12 \\
4.12 \\
4.12 \\
4.12 \\
4.12 \\
4.10 \\
4.10 \\
4.10\end{array}$ & $\begin{array}{r}9.949881 \\
.949816 \\
.949752 \\
.949688 \\
.949623 \\
.949558 \\
.949494 \\
.949429 \\
.949364 \\
.949300 \\
.949235\end{array}$ & $\begin{array}{l}1.08 \\
1.07 \\
1.07 \\
1.08 \\
1.08 \\
1.07 \\
1.08 \\
1.08 \\
1.07 \\
1.08 \\
1.08\end{array}$ & $\begin{array}{r}9.707166 \\
.70 \% 478 \\
.76790 \\
.708102 \\
.708414 \\
.708726 \\
.709037 \\
.709349 \\
.709660 \\
.709971 \\
.710282 \\
.710503\end{array}$ & $\begin{array}{l}5.20 \\
5.20 \\
5.20 \\
5.20 \\
5.20 \\
5.18 \\
5.20 \\
5.18 \\
5.18 \\
5.18 \\
5.18\end{array}$ & $\begin{array}{r}10.292834 \\
.2925222 \\
.292210 \\
.291898 \\
.291586 \\
.291274 \\
.290963 \\
.290651 \\
.290340 \\
.290029 \\
.289718 \\
1090407\end{array}$ & $\begin{array}{l}60 \\
59 \\
58 \\
57 \\
56 \\
55 \\
54 \\
53 \\
52 \\
51 \\
50 \\
49\end{array}$ \\
\hline \begin{tabular}{l|l}
11 & \\
12 & 13 \\
14 \\
15 \\
16 \\
17 \\
18 \\
19 \\
20
\end{tabular} & $\begin{array}{r}9.659763 \\
.660009 \\
.660255 \\
.660501 \\
660 \% 46 \\
.660991 \\
.661236 \\
.661481 \\
.661726 \\
.661970\end{array}$ & $\begin{array}{l}4.10 \\
4.10 \\
4.10 \\
4.08 \\
4.08 \\
4.08 \\
4.08 \\
4.08 \\
4.07 \\
4.07\end{array}$ & $\begin{array}{r}9.949170 \\
.949105 \\
.949040 \\
.948975 \\
.948910 \\
.948845 \\
.948780 \\
.948715 \\
.948650 \\
.948581\end{array}$ & $\begin{array}{l}1.08 \\
1.08 \\
1.08 \\
1.08 \\
1.08 \\
1.08 \\
1.08 \\
1.08 \\
1.10 \\
1.08\end{array}$ & $\begin{array}{r}9.710593 \\
.710904 \\
.711215 \\
.711525 \\
.711836 \\
.712146 \\
.712456 \\
.712766 \\
.713076 \\
.713386\end{array}$ & $\begin{array}{l}5.18 \\
5.18 \\
5.17 \\
5.18 \\
5.17 \\
5.17 \\
5.17 \\
5.17 \\
5.17 \\
5.17\end{array}$ & $\begin{array}{r}10.289407 \\
.289096 \\
.288785 \\
.288475 \\
.288164 \\
.287854 \\
.287544 \\
.287234 \\
.286924 \\
.286614\end{array}$ & $\begin{array}{l}49 \\
48 \\
47 \\
46 \\
45 \\
44 \\
43 \\
42 \\
41 \\
40\end{array}$ \\
\hline $\begin{array}{l}21 \\
22 \\
23 \\
24 \\
25 \\
26 \\
27 \\
28 \\
29 \\
30\end{array}$ & $\begin{array}{r}9.662214 \\
.662459 \\
.662703 \\
.662946 \\
.663190 \\
.663433 \\
.663677 \\
.663920 \\
.664163 \\
.664406\end{array}$ & $\begin{array}{l}4.08 \\
4.07 \\
4.05 \\
4.07 \\
4.05 \\
4.07 \\
4.05 \\
4.05 \\
4.05 \\
4.03\end{array}$ & $\begin{array}{r}9.948519 \\
.948454 \\
.948388 \\
.948323 \\
.948257 \\
.948192 \\
.948126 \\
.948060 \\
.947995 \\
.947929\end{array}$ & $\begin{array}{l}1.08 \\
1.10 \\
1.08 \\
1.10 \\
1.08 \\
1.10 \\
1.10 \\
1.08 \\
1.10 \\
1.10\end{array}$ & $\begin{array}{r}9.713696 \\
.714005 \\
.714314 \\
.714624 \\
.714933 \\
.715242 \\
.715551 \\
.715860 \\
.716168 \\
.716477\end{array}$ & $\begin{array}{l}5.15 \\
5.15 \\
5.17 \\
5.15 \\
5.15 \\
5.15 \\
5.15 \\
5.13 \\
5.15 \\
5.13\end{array}$ & $\begin{array}{r}10.286304 \\
.285995 \\
.285686 \\
.285376 \\
.285067 \\
.284758 \\
.284449 \\
.284140 \\
.283839 \\
.283593\end{array}$ & $\begin{array}{l}39 \\
38 \\
37 \\
36 \\
35 \\
31 \\
33 \\
32 \\
31 \\
30 \\
0\end{array}$ \\
\hline $\begin{array}{l}31 \\
32 \\
33 \\
34 \\
35 \\
36 \\
37 \\
38 \\
39 \\
40\end{array}$ & $\begin{array}{r}9.664648 \\
.664891 \\
.665133 \\
.665375 \\
.665617 \\
.665859 \\
.666100 \\
.666312 \\
.666583 \\
.666824\end{array}$ & $\begin{array}{l}4.00 \\
4.05 \\
4.03 \\
4.03 \\
4.03 \\
4.03 \\
4.02 \\
4.03 \\
4.02 \\
4.02 \\
4.02\end{array}$ & $\begin{array}{r}9.947863 \\
.947797 \\
.947731 \\
.947665 \\
.947600 \\
.947533 \\
.947467 \\
.947401 \\
.947335 \\
.947269\end{array}$ & $\begin{array}{l}1.10 \\
1.10 \\
1.10 \\
1.08 \\
1.12 \\
1.10 \\
1.10 \\
1.10 \\
1.10 \\
1.10\end{array}$ & $\begin{array}{r}9.716785 \\
.717093 \\
.717401 \\
.717709 \\
.718017 \\
.718325 \\
.718633 \\
.718940 \\
.719248 \\
.719555\end{array}$ & $\begin{array}{l}5.13 \\
5.13 \\
5.13 \\
5.13 \\
5.13 \\
5.13 \\
5.12 \\
5.13 \\
5.12 \\
5.12\end{array}$ & $\begin{array}{r}10.283215 \\
.282907 \\
.282599 \\
.282291 \\
281983 \\
.281675 \\
.281367 \\
.281060 \\
.280752 \\
.280445\end{array}$ & $\begin{array}{l}29 \\
28 \\
27 \\
26 \\
25 \\
24 \\
23 \\
22 \\
21 \\
20 \\
19\end{array}$ \\
\hline $\begin{array}{l}41 \\
42 \\
43 \\
44 \\
45 \\
46 \\
47 \\
48 \\
49 \\
50\end{array}$ & $\begin{array}{r}9.667065 \\
.667305 \\
.667546 \\
.66 r 786 \\
.668027 \\
.668267 \\
.668506 \\
.668746 \\
.668986 \\
.669225\end{array}$ & $\begin{array}{l}4.00 \\
4.02 \\
4.00 \\
4.02 \\
4.00 \\
3.98 \\
4.00 \\
4.00 \\
3.98 \\
3.98\end{array}$ & $\begin{array}{r}9.947203 \\
.947136 \\
.947070 \\
.947004 \\
.946937 \\
.9468 \% 1 \\
946804 \\
.946738 \\
.946671 \\
.946604\end{array}$ & $\begin{array}{l}1.12 \\
1.10 \\
1.10 \\
1.12 \\
1.10 \\
1.12 \\
1.10 \\
1.12 \\
1.12 \\
1.10\end{array}$ & $\begin{array}{r}9.719862 \\
.720169 \\
.720476 \\
.720783 \\
.721089 \\
.721396 \\
.721702 \\
.722009 \\
.722315 \\
.722621\end{array}$ & $\begin{array}{l}5.12 \\
5.12 \\
5.12 \\
5.10 \\
5.12 \\
5.10 \\
5.12 \\
5.10 \\
5.10 \\
5.10\end{array}$ & 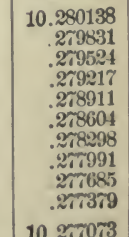 & $\begin{array}{r}19 \\
18 \\
17 \\
16 \\
15 \\
14 \\
13 \\
12 \\
11 \\
10 \\
0\end{array}$ \\
\hline $\begin{array}{l}51 \\
52 \\
53 \\
54 \\
55 \\
56 \\
57 \\
58 \\
59 \\
60\end{array}$ & $\begin{array}{r}9.669464 \\
669703 \\
.669942 \\
670181 \\
670419 \\
.670658 \\
670896 \\
.671134 \\
.671372 \\
9.671609 \\
\end{array}$ & $\begin{array}{l}3.98 \\
3.98 \\
3.98 \\
3.97 \\
3.98 \\
3.97 \\
3.97 \\
3.97 \\
3.95\end{array}$ & $\begin{array}{r}9.946538 \\
.946471 \\
.946404 \\
946337 \\
.946270 \\
.946203 \\
.946136 \\
.946069 \\
.946002 \\
9.945935 \\
\end{array}$ & $\begin{array}{l}1.12 \\
1.12 \\
1.12 \\
1.12 \\
1.12 \\
1.12 \\
1.12 \\
1.12 \\
1.12\end{array}$ & $\begin{array}{r}9.722927 \\
723232 \\
723538 \\
.723844 \\
.724149 \\
.721454 \\
724760 \\
725065 \\
725370 \\
\text { 9.725674 } \\
\end{array}$ & $\begin{array}{l}5.08 \\
5.10 \\
5.10 \\
5.08 \\
5.08 \\
5.10 \\
5.08 \\
5.08 \\
5.07\end{array}$ & $\begin{array}{r}10.27073 \\
.276768 \\
276462 \\
.276156 \\
.275851 \\
.275546 \\
275240 \\
274335 \\
274630 \\
10.274326 \\
\end{array}$ & $\begin{array}{l}9 \\
8 \\
7 \\
6 \\
5 \\
4 \\
3 \\
2 \\
1 \\
0\end{array}$ \\
\hline & & & Sine. & D. $1^{\prime \prime}$. & Conang. & D. $1^{\circ}$. & Tang. & ' \\
\hline
\end{tabular}




\begin{tabular}{|c|c|c|c|c|c|c|c|c|}
\hline 1 & Sine. & D. $1^{*}$. & Cosine. & D. 1". & Tang. & D. $1^{\prime \prime}$. & Cotang. & , \\
\hline $\begin{array}{r}0 \\
1 \\
2 \\
3 \\
4 \\
5 \\
6 \\
7 \\
8 \\
9 \\
10\end{array}$ & $\begin{array}{r}9.671609 \\
.671847 \\
.672084 \\
.672321 \\
.672558 \\
.672795 \\
.673032 \\
.673268 \\
.673505 \\
.673741 \\
.673977\end{array}$ & $\begin{array}{l}3.97 \\
3.95 \\
3.95 \\
3.95 \\
3.95 \\
3.95 \\
3.93 \\
3.95 \\
3.93 \\
3.93 \\
3.93\end{array}$ & $\begin{array}{r}9.945935 \\
.945868 \\
.945800 \\
.945733 \\
.945666 \\
.945598 \\
.945531 \\
.945464 \\
.945396 \\
.945328 \\
.945261\end{array}$ & $\begin{array}{l}1.12 \\
1.13 \\
1.12 \\
1.12 \\
1.13 \\
1.12 \\
1.12 \\
1.13 \\
1.13 \\
1.12 \\
1.13\end{array}$ & $\begin{array}{r}9.725674 \\
.725979 \\
.726284 \\
.726588 \\
.726892 \\
.727197 \\
.727501 \\
.727805 \\
.728109 \\
.728412 \\
.728716\end{array}$ & $\begin{array}{l}5.08 \\
5.08 \\
5.07 \\
5.07 \\
5.05 \\
5.07 \\
5.07 \\
5.07 \\
5.05 \\
5.07 \\
5.07\end{array}$ & $\begin{array}{r}10.274326 \\
.274021 \\
.273716 \\
.273412 \\
.273108 \\
.272803 \\
.272499 \\
.272195 \\
.271891 \\
.271588 \\
.271284\end{array}$ & $\begin{array}{l}60 \\
59 \\
58 \\
57 \\
56 \\
55 \\
54 \\
53 \\
52 \\
51 \\
50\end{array}$ \\
\hline $\begin{array}{l}11 \\
12 \\
13 \\
14 \\
15 \\
16 \\
17 \\
18 \\
19 \\
20\end{array}$ & $\begin{array}{r}9.674213 \\
.674448 \\
.674684 \\
.674919 \\
.675155 \\
.675390 \\
.675624 \\
.675859 \\
.676094 \\
.676328\end{array}$ & $\begin{array}{l}3.93 \\
3.92 \\
3.93 \\
3.92 \\
3.93 \\
3.92 \\
3.90 \\
3.92 \\
3.92 \\
3.90 \\
3.90\end{array}$ & $\begin{array}{r}9.945193 \\
.945125 \\
.945058 \\
.944990 \\
.944922 \\
.944854 \\
.944786 \\
.944718 \\
.944650 \\
.944582\end{array}$ & $\begin{array}{l}1.10 \\
1.13 \\
1.12 \\
1.13 \\
1.13 \\
1.13 \\
1.13 \\
1.13 \\
1.13 \\
1.13 \\
1.13\end{array}$ & $\begin{array}{r}9.729020 \\
.729323 \\
.729626 \\
.729929 \\
.730233 \\
.730535 \\
.730838 \\
.731141 \\
.731444 \\
.731746\end{array}$ & $\begin{array}{l}5.07 \\
5.05 \\
5.05 \\
5.05 \\
5.07 \\
5.03 \\
5.05 \\
5.05 \\
5.05 \\
5.03 \\
5.03\end{array}$ & $\begin{array}{r}10.270980 \\
.270677 \\
.270374 \\
.270071 \\
.269767 \\
.269465 \\
.269162 \\
.268859 \\
.268556 \\
.268254\end{array}$ & $\begin{array}{l}49 \\
48 \\
47 \\
46 \\
45 \\
44 \\
43 \\
42 \\
41 \\
40\end{array}$ \\
\hline $\begin{array}{l}21 \\
22 \\
23 \\
24 \\
25 \\
26 \\
27 \\
28 \\
29 \\
30\end{array}$ & $\begin{array}{r}9.676562 \\
.676796 \\
.677030 \\
.677264 \\
.67498 \\
.67731 \\
.677964 \\
.678197 \\
.678430 \\
.678663\end{array}$ & $\begin{array}{l}3.90 \\
3.90 \\
3.90 \\
3.90 \\
3.88 \\
3.88 \\
3.88 \\
3.88 \\
3.88 \\
3.87\end{array}$ & $\begin{array}{r}9.944514 \\
.944446 \\
.944377 \\
.944309 \\
.944241 \\
.944172 \\
.944104 \\
.944036 \\
.943967 \\
.943899\end{array}$ & $\begin{array}{l}1.13 \\
1.15 \\
1.13 \\
1.13 \\
1.15 \\
1.13 \\
1.13 \\
1.15 \\
1.13 \\
1.15\end{array}$ & $\begin{array}{r}9.732048 \\
.732351 \\
.732653 \\
.732955 \\
.733257 \\
.733558 \\
.733860 \\
.734162 \\
.734463 \\
.734764\end{array}$ & $\begin{array}{l}5.05 \\
5.03 \\
5.03 \\
5.03 \\
5.02 \\
5.03 \\
5.03 \\
5.02 \\
5.02 \\
5.03\end{array}$ & $\begin{array}{r}10.267952 \\
.26 \% 649 \\
.267347 \\
.267045 \\
.266743 \\
.266442 \\
.266140 \\
.265838 \\
.265537 \\
.265236\end{array}$ & $\begin{array}{l}39 \\
38 \\
37 \\
36 \\
35 \\
34 \\
33 \\
32 \\
31 \\
30\end{array}$ \\
\hline $\begin{array}{l}31 \\
32 \\
33 \\
34 \\
35 \\
36 \\
37 \\
38 \\
39 \\
40\end{array}$ & $\begin{array}{r}9.678895 \\
.679128 \\
.679360 \\
.679592 \\
.679824 \\
.680056 \\
.680288 \\
.680519 \\
.680750 \\
.680982\end{array}$ & $\begin{array}{l}3.88 \\
3.87 \\
3.87 \\
3.87 \\
3.87 \\
3.87 \\
3.85 \\
3.85 \\
3.87 \\
3.85\end{array}$ & $\begin{array}{r}9.943830 \\
.943761 \\
.943693 \\
.943624 \\
.943555 \\
.943486 \\
.943417 \\
.943348 \\
.943279 \\
.943210\end{array}$ & $\begin{array}{l}1.15 \\
1.13 \\
1.15 \\
1.15 \\
1.15 \\
1.15 \\
1.15 \\
1.15 \\
1.15 \\
1.15\end{array}$ & $\begin{array}{r}9.735066 \\
.735367 \\
.735668 \\
.735969 \\
.736269 \\
.7365 \% 0 \\
.736870 \\
.737171 \\
.737471 \\
.737771\end{array}$ & $\begin{array}{l}5.02 \\
5.02 \\
5.02 \\
5.00 \\
5.02 \\
5.00 \\
5.02 \\
5.00 \\
5.00 \\
5.00\end{array}$ & $\begin{array}{r}10.264934 \\
.264633 \\
.264332 \\
.264031 \\
.263731 \\
.263430 \\
.263130 \\
.262829 \\
.262529 \\
.262229\end{array}$ & $\begin{array}{l}29 \\
28 \\
27 \\
26 \\
25 \\
24 \\
23 \\
22 \\
21 \\
20\end{array}$ \\
\hline $\begin{array}{l}41 \\
42 \\
43 \\
44 \\
45 \\
46 \\
47 \\
48 \\
49 \\
50\end{array}$ & $\begin{array}{r}9.681213 \\
.681443 \\
.6816 r 4 \\
.681905 \\
.682135 \\
.682365 \\
.682595 \\
.682825 \\
.683055 \\
.683284\end{array}$ & $\begin{array}{l}3.83 \\
3.85 \\
3.85 \\
3.83 \\
3.83 \\
3.83 \\
3.83 \\
3.83 \\
3.82 \\
3.83\end{array}$ & $\begin{array}{r}9.943141 \\
.94,072 \\
.943003 \\
.942934 \\
.942864 \\
.942795 \\
.942726 \\
.942656 \\
.942587 \\
.942517\end{array}$ & $\begin{array}{l}1.15 \\
1.15 \\
1.15 \\
1.17 \\
1.15 \\
1.15 \\
1.17 \\
1.15 \\
1.17 \\
1.15\end{array}$ & $\begin{array}{r}9.738071 \\
.738371 \\
.738671 \\
.738971 \\
.739271 \\
.739570 \\
.739870 \\
.740169 \\
.740468 \\
.740767\end{array}$ & $\begin{array}{l}5.00 \\
5.00 \\
5.00 \\
5.00 \\
4.98 \\
5.00 \\
4.98 \\
4.98 \\
4.98 \\
4.98\end{array}$ & $\begin{array}{r}10.261929 \\
.261629 \\
.261329 \\
.261029 \\
.260729 \\
.260430 \\
.260130 \\
.259831 \\
.259532 \\
.259233\end{array}$ & $\begin{array}{l}19 \\
18 \\
17 \\
16 \\
15 \\
14 \\
13 \\
12 \\
11 \\
10\end{array}$ \\
\hline $\begin{array}{l}51 \\
52 \\
53 \\
54 \\
55 \\
56 \\
57 \\
58 \\
59 \\
60\end{array}$ & $\begin{array}{r}9.683514 \\
.683743 \\
.683972 \\
.684201 \\
.684430 \\
.684658 \\
.684887 \\
.685115 \\
.685343 \\
9.685571\end{array}$ & $\begin{array}{l}3.82 \\
3.82 \\
3.82 \\
3.82 \\
3.80 \\
3.82 \\
3.80 \\
3.80 \\
3.80\end{array}$ & $\begin{array}{r}9.942448 \\
.942378 \\
.942308 \\
.942239 \\
.942169 \\
.942099 \\
.942029 \\
.941959 \\
.941889 \\
9.941819\end{array}$ & $\begin{array}{l}1.17 \\
1.17 \\
1.15 \\
1.17 \\
1.17 \\
1.17 \\
1.17 \\
1.17 \\
1.17\end{array}$ & $\begin{array}{r}9.741066 \\
.741365 \\
.741664 \\
.741962 \\
.742261 \\
.742559 \\
.742858 \\
.743156 \\
.743454 \\
9.743752\end{array}$ & $\begin{array}{l}4.98 \\
4.98 \\
4.97 \\
4.98 \\
4.97 \\
4.98 \\
4.97 \\
4.97 \\
4.97\end{array}$ & $\begin{array}{r}10.258934 \\
.258635 \\
.258336 \\
.258038 \\
.257739 \\
.25 \% 441 \\
.257142 \\
.256844 \\
.256546 \\
10.256248\end{array}$ & $\begin{array}{l}9 \\
8 \\
7 \\
6 \\
5 \\
4 \\
3 \\
2 \\
1 \\
0\end{array}$ \\
\hline 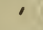 & Cosine. & D. $1^{\prime \prime}$. & Sine. & D. $1^{n}$. & Cotang. & D. $1^{\prime \prime}$. & Tang. & ' \\
\hline
\end{tabular}




\begin{tabular}{|c|c|c|c|c|c|c|c|c|}
\hline ' & Sine. & D. $1^{\prime \prime}$. & Cosine. & D. $1^{\circ}$. & Tang. & D. $1^{*}$. & Cotang. & ' \\
\hline $\begin{array}{r}0 \\
1 \\
2 \\
3 \\
4 \\
5 \\
6 \\
7 \\
8 \\
9 \\
10\end{array}$ & $\begin{array}{r}9.655 \% \pi 1 \\
.685793 \\
.686027 \\
.686254 \\
.686482 \\
.686709 \\
.686936 \\
.687163 \\
.687389 \\
.687616 \\
.687813\end{array}$ & $\begin{array}{l}3.80 \\
3.80 \\
3.78 \\
3.80 \\
3.78 \\
3.78 \\
3.78 \\
3.77 \\
3.78 \\
3.78 \\
3.77\end{array}$ & $\begin{array}{r}9.941819 \\
.941749 \\
.9416 \% 9 \\
.941609 \\
.941539 \\
.941469 \\
.941398 \\
.941328 \\
.941258 \\
.941187 \\
.941117\end{array}$ & $\begin{array}{l}1.17 \\
1.17 \\
1.17 \\
1.17 \\
1.17 \\
1.18 \\
1.17 \\
1.17 \\
1.18 \\
1.17 \\
1.18\end{array}$ & $\begin{array}{r}9.743 \pi 52 \\
.74050 \\
.74348 \\
.74645 \\
.744943 \\
.745240 \\
.745538 \\
.745835 \\
.741132 \\
.746429 \\
.746726\end{array}$ & $\begin{array}{l}4.97 \\
4.97 \\
4.95 \\
4.97 \\
4.95 \\
4.97 \\
4.95 \\
4.95 \\
4.95 \\
4.95 \\
4.95\end{array}$ & $\begin{array}{r}10.256248 \\
.255950 \\
.255652 \\
.255355 \\
.25505 \pi \\
.254760 \\
.254462 \\
.254165 \\
.253868 \\
.2535 \pi 1 \\
.253274\end{array}$ & $\begin{array}{l}60 \\
59 \\
58 \\
57 \\
56 \\
55 \\
54 \\
53 \\
52 \\
51 \\
50\end{array}$ \\
\hline $\begin{array}{l}11 \\
12 \\
13 \\
14 \\
15 \\
16 \\
17 \\
18 \\
19 \\
20\end{array}$ & $\begin{array}{r}9.688069 \\
.688295 \\
.688521 \\
.688 \% 47 \\
.688972 \\
.689198 \\
.689423 \\
.689648 \\
.689873 \\
.690098\end{array}$ & $\begin{array}{l}3.77 \\
3.77 \\
3.77 \\
3.75 \\
3.77 \\
3.75 \\
3.75 \\
3.75 \\
3.75 \\
3.75\end{array}$ & $\begin{array}{r}9.941040 \\
.940975 \\
.940905 \\
.940834 \\
.940763 \\
.940693 \\
.940622 \\
.940551 \\
.940480 \\
.940409\end{array}$ & $\begin{array}{l}1.18 \\
1.17 \\
1.18 \\
1.18 \\
1.17 \\
1.18 \\
1.18 \\
1.18 \\
1.18 \\
1.18\end{array}$ & $\begin{array}{r}9.747023 \\
.747319 \\
.74616 \\
.747913 \\
.748209 \\
.748505 \\
.748801 \\
.749097 \\
.749393 \\
.749689\end{array}$ & $\begin{array}{l}4.93 \\
4.95 \\
4.95 \\
4.93 \\
4.93 \\
4.93 \\
4.93 \\
4.93 \\
4.93 \\
4.93\end{array}$ & $\begin{array}{r}10.252977 \\
.252681 \\
.252384 \\
.252067 \\
.251791 \\
.251495 \\
.251199 \\
.250903 \\
.250607 \\
.250311\end{array}$ & $\begin{array}{l}49 \\
48 \\
47 \\
46 \\
45 \\
44 \\
43 \\
42 \\
41 \\
40\end{array}$ \\
\hline $\begin{array}{l}21 \\
22 \\
23 \\
24 \\
25 \\
26 \\
27 \\
28 \\
29 \\
30\end{array}$ & $\begin{array}{r}9.690323 \\
.690548 \\
.6907 \tau 2 \\
.690996 \\
.691220 \\
.691444 \\
.691668 \\
.691892 \\
.692115 \\
.692339\end{array}$ & $\begin{array}{l}3.75 \\
3.73 \\
3.73 \\
3.73 \\
3.73 \\
3.73 \\
3.73 \\
3.72 \\
3.73 \\
3.72\end{array}$ & $\begin{array}{r}9.940338 \\
.940267 \\
.940196 \\
.940125 \\
.940054 \\
.939982 \\
.939911 \\
.939840 \\
.939768 \\
.939697\end{array}$ & $\begin{array}{l}1.18 \\
1.18 \\
1.18 \\
1.18 \\
1.20 \\
1.18 \\
1.18 \\
1.20 \\
1.18 \\
1.20\end{array}$ & $\begin{array}{r}9.749985 \\
.750281 \\
.750576 \\
.7508 \pi 2 \\
.751167 \\
.751462 \\
.751757 \\
.752052 \\
.752347 \\
.752642\end{array}$ & $\begin{array}{l}4.93 \\
4.92 \\
4.93 \\
4.92 \\
4.92 \\
4.92 \\
4.92 \\
4.92 \\
4.92 \\
4.92\end{array}$ & $\begin{array}{r}10.250015 \\
.249719 \\
.249424 \\
.249128 \\
.248833 \\
.248538 \\
.248243 \\
.247948 \\
.247653 \\
.247358\end{array}$ & $\begin{array}{l}39 \\
38 \\
37 \\
36 \\
35 \\
34 \\
33 \\
32 \\
31 \\
30\end{array}$ \\
\hline $\begin{array}{l}31 \\
32 \\
33 \\
34 \\
35 \\
36 \\
37 \\
38 \\
39 \\
40\end{array}$ & $\begin{array}{r}9.692562 \\
.692785 \\
.693008 \\
.693231 \\
.693453 \\
.693676 \\
.693898 \\
.694120 \\
.694342 \\
.694564\end{array}$ & $\begin{array}{l}3.72 \\
3.72 \\
3.72 \\
3.70 \\
3.72 \\
3.70 \\
3.70 \\
3.70 \\
3.70 \\
3.70\end{array}$ & $\begin{array}{r}9.939625 \\
.939554 \\
.939482 \\
.939410 \\
.939339 \\
.939267 \\
.939195 \\
.939123 \\
.939052 \\
.938980\end{array}$ & $\begin{array}{l}1.18 \\
1.20 \\
1.20 \\
1.18 \\
1.20 \\
1.20 \\
1.20 \\
1.18 \\
1.20 \\
1.20\end{array}$ & $\begin{array}{r}9.752937 \\
.753231 \\
.753526 \\
.753820 \\
.754115 \\
.754409 \\
.754703 \\
.754997 \\
.755291 \\
.755585\end{array}$ & $\begin{array}{l}4.90 \\
4.92 \\
4.90 \\
4.92 \\
4.90 \\
4.90 \\
4.90 \\
4.90 \\
4.90 \\
4.88\end{array}$ & $\begin{array}{r}10.247063 \\
.246769 \\
.246474 \\
.246180 \\
.245885 \\
.245591 \\
245297 \\
.245003 \\
.24409 \\
.24415\end{array}$ & $\begin{array}{l}29 \\
28 \\
27 \\
26 \\
25 \\
24 \\
23 \\
22 \\
21 \\
20\end{array}$ \\
\hline $\begin{array}{l}41 \\
42 \\
43 \\
44 \\
45 \\
46 \\
47 \\
48 \\
49 \\
50\end{array}$ & $\begin{array}{r}9.694786 \\
.695007 \\
.695229 \\
.695450 \\
.695671 \\
.695892 \\
.696113 \\
.696331 \\
.696554 \\
.6967 \% 5\end{array}$ & $\begin{array}{l}3.68 \\
3.70 \\
3.68 \\
3.68 \\
3.68 \\
3.68 \\
3.68 \\
3.67 \\
3.68 \\
3.67\end{array}$ & $\begin{array}{r}9.938908 \\
.938836 \\
.938763 \\
.938691 \\
.938619 \\
.938547 \\
.938475 \\
.938402 \\
.938330 \\
.938258\end{array}$ & $\begin{array}{l}1.20 \\
1.22 \\
1.20 \\
1.20 \\
1.20 \\
1.20 \\
1.22 \\
1.20 \\
1.20 \\
1.22\end{array}$ & $\begin{array}{r}9.755878 \\
.756172 \\
.756165 \\
.756759 \\
.757052 \\
.757345 \\
.757638 \\
.757931 \\
.758221 \\
.758517\end{array}$ & $\begin{array}{l}4.90 \\
4.88 \\
4.90 \\
4.88 \\
4.88 \\
4.88 \\
4.88 \\
4.88 \\
4.88 \\
4.88\end{array}$ & $\begin{array}{r}10.244122 \\
.243 \times 28 \\
.243525 \\
.243241 \\
.242948 \\
.242655 \\
.242362 \\
.242069 \\
.241776 \\
.241483\end{array}$ & $\begin{array}{l}19 \\
18 \\
17 \\
16 \\
15 \\
14 \\
13 \\
13 \\
11 \\
10\end{array}$ \\
\hline $\begin{array}{l}51 \\
52 \\
53 \\
54 \\
55 \\
56 \\
57 \\
58 \\
59 \\
60\end{array}$ & $\begin{array}{r}9.696995 \\
.697215 \\
.697435 \\
.697654 \\
.697874 \\
.698094 \\
.698313 \\
.698532 \\
.698751 \\
9.698970 \\
\end{array}$ & $\begin{array}{l}3.67 \\
3.67 \\
3.65 \\
3.67 \\
3.67 \\
3.65 \\
3.65 \\
3.65 \\
3.65\end{array}$ & $\begin{array}{r}9.938185 \\
.938113 \\
.938040 \\
.937967 \\
.937895 \\
.937822 \\
.937749 \\
.937676 \\
.937604 \\
9.937531\end{array}$ & $\begin{array}{l}1.20 \\
1.22 \\
1.22 \\
1.20 \\
1.22 \\
1.22 \\
1.22 \\
1.20 \\
1.22\end{array}$ & $\begin{array}{r}9.758810 \\
.759102 \\
.759395 \\
.759687 \\
.759979 \\
.760272 \\
.760564 \\
.760856 \\
.761148 \\
9.761439\end{array}$ & $\begin{array}{l}4.87 \\
4.88 \\
4.87 \\
4.87 \\
4.88 \\
4.87 \\
4.87 \\
4.87 \\
4.85\end{array}$ & $\begin{array}{r}10.241190 \\
.240898 \\
.240605 \\
240313 \\
.240021 \\
.239728 \\
.239436 \\
.239144 \\
.238852 \\
10.238561\end{array}$ & $\begin{array}{l}9 \\
8 \\
7 \\
6 \\
5 \\
4 \\
3 \\
2 \\
1 \\
0\end{array}$ \\
\hline ' & Cos & 1 & Sine. & D. $1^{\prime \prime}$. & Cotang. & D. $1^{\circ}$. & Tang. & 1 \\
\hline
\end{tabular}




\begin{tabular}{|c|c|c|c|c|c|c|c|c|}
\hline 1 & Sine. & D. $1^{\prime \prime}$. & Cosine. & D. 1". & Tang. & D. 1". & Cotang. & ' \\
\hline $\begin{array}{r}0 \\
1 \\
2 \\
3 \\
4 \\
5 \\
6 \\
7 \\
8 \\
9 \\
10\end{array}$ & $\begin{array}{r}9.698970 \\
.699189 \\
.699407 \\
.699626 \\
.699844 \\
.700062 \\
.700280 \\
.700498 \\
.700716 \\
.700433 \\
.701151\end{array}$ & $\begin{array}{l}3.65 \\
3.63 \\
3.65 \\
3.63 \\
3.63 \\
3.63 \\
3.63 \\
3.63 \\
3.62 \\
3.63 \\
3.62\end{array}$ & $\begin{array}{r}9.937531 \\
.937458 \\
.937385 \\
.937312 \\
.937238 \\
.937165 \\
.937092 \\
.937019 \\
.936946 \\
.936872 \\
.936799\end{array}$ & $\begin{array}{l}1.22 \\
1.22 \\
1.22 \\
1.23 \\
1.22 \\
1.22 \\
1.22 \\
1.22 \\
1.22 \\
1.22 \\
1.23\end{array}$ & $\begin{array}{r}9.761439 \\
.761731 \\
.762023 \\
.762314 \\
.762606 \\
.762897 \\
.763188 \\
.763479 \\
.76370 \\
.764061 \\
.764352\end{array}$ & $\begin{array}{l}4.87 \\
4.87 \\
4.85 \\
4.87 \\
4.85 \\
4.85 \\
4.85 \\
4.85 \\
4.85 \\
4.85 \\
4.85\end{array}$ & $\begin{array}{r}10.238561 \\
.238269 \\
.237977 \\
.237686 \\
.237394 \\
.237103 \\
.236812 \\
.236521 \\
.236230 \\
.235939 \\
.235648\end{array}$ & $\begin{array}{l}60 \\
59 \\
58 \\
57 \\
56 \\
55 \\
54 \\
53 \\
52 \\
51 \\
50\end{array}$ \\
\hline $\begin{array}{l}11 \\
12 \\
13 \\
14 \\
15 \\
16 \\
17 \\
18 \\
19 \\
20\end{array}$ & $\begin{array}{r}9.701368 \\
.7 J 1585 \\
.701802 \\
.702019 \\
.702236 \\
.702452 \\
.702669 \\
.702885 \\
.703101 \\
.703317\end{array}$ & $\begin{array}{l}3.62 \\
3.62 \\
3.62 \\
3.62 \\
3.60 \\
3.62 \\
3.60 \\
3.60 \\
3.60 \\
3.60\end{array}$ & $\begin{array}{r}9.936725 \\
.936652 \\
.936578 \\
.936505 \\
.936431 \\
.936357 \\
.936284 \\
.936210 \\
.936136 \\
.936062\end{array}$ & $\begin{array}{l}1.22 \\
1.23 \\
1.22 \\
1.23 \\
1.23 \\
1.22 \\
1.23 \\
1.23 \\
1.23 \\
1.23\end{array}$ & $\begin{array}{r}9.764643 \\
.764933 \\
.765224 \\
.765514 \\
.765805 \\
.766095 \\
.766285 \\
.766675 \\
.766965 \\
.767255\end{array}$ & $\begin{array}{l}4.83 \\
4.85 \\
4.83 \\
4.85 \\
4.83 \\
4.83 \\
4.83 \\
4.83 \\
4.83 \\
4.83\end{array}$ & $\begin{array}{r}10.235357 \\
.235067 \\
.234776 \\
.234486 \\
.234195 \\
.233905 \\
.233615 \\
.233325 \\
.233035 \\
.232745\end{array}$ & $\begin{array}{l}49 \\
48 \\
47 \\
46 \\
45 \\
44 \\
43 \\
42 \\
41 \\
40\end{array}$ \\
\hline $\begin{array}{l}21 \\
22 \\
23 \\
24 \\
25 \\
26 \\
27 \\
28 \\
29 \\
30\end{array}$ & $\begin{array}{r}9.703533 \\
.703749 \\
.703964 \\
.704179 \\
.704395 \\
.704610 \\
.704825 \\
.705040 \\
.705254 \\
.705469\end{array}$ & $\begin{array}{l}3.60 \\
3.58 \\
3.58 \\
3.60 \\
3.58 \\
3.58 \\
3.58 \\
3.57 \\
3.58 \\
3.57\end{array}$ & $\begin{array}{r}9.935988 \\
.935914 \\
.935840 \\
.935766 \\
.935692 \\
.935618 \\
.935543 \\
.935469 \\
.935395 \\
.935320\end{array}$ & $\begin{array}{l}1.23 \\
1.23 \\
1.23 \\
1.23 \\
1.23 \\
1.25 \\
1.23 \\
1.23 \\
1.25 \\
1.23\end{array}$ & $\begin{array}{r}9.767545 \\
.767834 \\
.768124 \\
.768414 \\
.768703 \\
.768992 \\
.769281 \\
.769571 \\
.769860 \\
.760148\end{array}$ & $\begin{array}{l}4.82 \\
4.83 \\
4.83 \\
4.82 \\
4.82 \\
4.82 \\
4.83 \\
4.82 \\
4.80 \\
4.82\end{array}$ & $\begin{array}{r}10.232455 \\
.232166 \\
.231876 \\
.231586 \\
.231297 \\
.231008 \\
.230719 \\
.230429 \\
.230140 \\
.229852\end{array}$ & $\begin{array}{l}39 \\
38 \\
37 \\
36 \\
35 \\
34 \\
33 \\
32 \\
31 \\
30\end{array}$ \\
\hline $\begin{array}{l}31 \\
32 \\
33 \\
34 \\
35 \\
36 \\
37 \\
38 \\
39 \\
40\end{array}$ & $\begin{array}{r}9.705683 \\
.705898 \\
.706112 \\
.706326 \\
.706539 \\
.706753 \\
.706967 \\
.707180 \\
.707393 \\
.707606\end{array}$ & $\begin{array}{l}3.58 \\
3.57 \\
3.57 \\
3.55 \\
3.57 \\
3.57 \\
3.55 \\
3.55 \\
3.55 \\
3.55\end{array}$ & $\begin{array}{r}9.935246 \\
.935171 \\
.935097 \\
.935022 \\
.934948 \\
.934873 \\
.934798 \\
.934723 \\
.934649 \\
.934574\end{array}$ & $\begin{array}{l}1.25 \\
1.23 \\
1.25 \\
1.23 \\
1.25 \\
1.25 \\
1.25 \\
1.23 \\
1.25 \\
1.25\end{array}$ & $\begin{array}{r}9.770437 \\
.770726 \\
.771015 \\
.771303 \\
.771592 \\
.771880 \\
.772168 \\
.772457 \\
.772745 \\
.773033\end{array}$ & $\begin{array}{l}4.82 \\
4.82 \\
4.80 \\
4.82 \\
4.80 \\
4.80 \\
4.82 \\
4.80 \\
4.80 \\
4.80\end{array}$ & $\begin{array}{r}10.229563 \\
.229274 \\
.228985 \\
.228697 \\
.228408 \\
.228120 \\
.227832 \\
.227543 \\
.227255 \\
.226967\end{array}$ & $\begin{array}{l}29 \\
28 \\
27 \\
26 \\
25 \\
24 \\
23 \\
22 \\
21 \\
20\end{array}$ \\
\hline $\begin{array}{l}41 \\
42 \\
43 \\
44 \\
45 \\
46 \\
47 \\
48 \\
49 \\
50\end{array}$ & $\begin{array}{r}9.707819 \\
.708032 \\
.708245 \\
.708458 \\
.708670 \\
.708882 \\
.709094 \\
.709306 \\
.709518 \\
.709730\end{array}$ & $\begin{array}{l}3.55 \\
3.55 \\
3.55\end{array}$ & $\begin{array}{r}9.934499 \\
.934424 \\
.934349 \\
.934274 \\
.934199 \\
.934123 \\
.934048 \\
.933973 \\
.933898 \\
.933822\end{array}$ & $\begin{array}{l}1.25 \\
1.25 \\
1.25 \\
1.25 \\
1.27 \\
1.25 \\
1.25 \\
1.25 \\
1.27 \\
1.25\end{array}$ & $\begin{array}{r}9.773321 \\
.773608 \\
.773896 \\
.774184 \\
.774471 \\
.774759 \\
.775046 \\
.775333 \\
.775621 \\
.775908\end{array}$ & $\begin{array}{l}4.78 \\
4.80 \\
4.80 \\
4.78 \\
4.80 \\
4.78 \\
4.78 \\
4.80 \\
4.78 \\
4.78\end{array}$ & $\begin{array}{r}10.226679 \\
.226392 \\
.226104 \\
.225816 \\
.225529 \\
.225241 \\
.224954 \\
.224667 \\
.224379 \\
.224092\end{array}$ & $\begin{array}{l}19 \\
18 \\
17 \\
16 \\
15 \\
14 \\
13 \\
12 \\
11 \\
10\end{array}$ \\
\hline $\begin{array}{l}51 \\
52 \\
53 \\
54 \\
55 \\
56 \\
57 \\
58 \\
59 \\
60\end{array}$ & $\begin{array}{r}9.709941 \\
.710153 \\
.710364 \\
.710575 \\
.710786 \\
.710997 \\
.711208 \\
.711419 \\
.711629 \\
9.711839\end{array}$ & $\begin{array}{l}3.53 \\
3.52 \\
3.52 \\
3.52 \\
3.52 \\
3.52 \\
3.52 \\
3.50 \\
3.50\end{array}$ & $\begin{array}{r}9.933747 \\
.933671 \\
.933596 \\
.933520 \\
.933445 \\
.933369 \\
.933293 \\
.933217 \\
.933141 \\
9.933066\end{array}$ & $\begin{array}{l}1.27 \\
1.25 \\
1.27 \\
1.25 \\
1.27 \\
1.27 \\
1.27 \\
1.27 \\
1.25\end{array}$ & $\begin{array}{r}9.776195 \\
.776482 \\
.776768 \\
.777055 \\
.777342 \\
.777628 \\
.777915 \\
.778201 \\
.778488 \\
9.778774\end{array}$ & $\begin{array}{l}4.78 \\
4.77 \\
4.78 \\
4.78 \\
4.77 \\
4.78 \\
4.77 \\
4.78 \\
4.77\end{array}$ & $\begin{array}{r}10.223805 \\
.223518 \\
.223232 \\
.222945 \\
.222658 \\
.222372 \\
.222085 \\
.221790 \\
.221512 \\
10.221226\end{array}$ & $\begin{array}{l}9 \\
8 \\
7 \\
6 \\
5 \\
4 \\
3 \\
2 \\
1 \\
0\end{array}$ \\
\hline 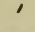 & Cosine. & D. $1^{\prime \prime}$ & Sine. & D. 1". & Cotang. & D. $1^{\prime \prime}$. & Tang. & 1 \\
\hline
\end{tabular}




\begin{tabular}{|c|c|c|c|c|c|c|c|c|}
\hline ' & Sine. & D. $1^{\circ}$ & Cosine. & D. $1^{\prime \prime}$. & Tang. & D. $1^{\prime \prime}$ & Cotang. & ' \\
\hline $\begin{array}{r}0 \\
1 \\
2 \\
3 \\
4 \\
5 \\
6 \\
7 \\
8 \\
9 \\
10 \\
11\end{array}$ & $\begin{array}{r}9.711839 \\
.712050 \\
.712260 \\
.712469 \\
.712679 \\
.712889 \\
.713098 \\
.713308 \\
.713517 \\
.713726 \\
.713935 \\
.714144\end{array}$ & $\begin{array}{l}3.52 \\
3.50 \\
3.48 \\
3.50 \\
3.50 \\
3.48 \\
3.50 \\
3.48 \\
3.48 \\
3.48 \\
3.48\end{array}$ & $\begin{array}{r}9.933066 \\
.9329990 \\
.532914 \\
.932838 \\
.93260 \\
.932685 \\
.932609 \\
.932533 \\
.932457 \\
.9332380 \\
.932304 \\
.939098\end{array}$ & $\begin{array}{l}1.27 \\
1.27 \\
1.27 \\
1.27 \\
1.28 \\
1.27 \\
1.27 \\
1.27 \\
1.27 \\
1.27 \\
1.27\end{array}$ & $\begin{array}{r}9.77874 \\
.779060 \\
.779346 \\
.796332 \\
.79918 \\
.780203 \\
.780489 \\
.780775 \\
.781060 \\
.781346 \\
.781631 \\
.781916\end{array}$ & $\begin{array}{l}4.77 \\
4.77 \\
4.77 \\
4.77 \\
4.75 \\
4.77 \\
4.77 \\
4.75 \\
4.77 \\
4.75 \\
4.75\end{array}$ & $\begin{array}{r}10.221226 \\
.220940 \\
.220654 \\
.220368 \\
.220082 \\
.219797 \\
.219511 \\
.219225 \\
.218940 \\
.218654 \\
.218369 \\
.021809\end{array}$ & $\begin{array}{l}60 \\
59 \\
58 \\
57 \\
56 \\
55 \\
54 \\
53 \\
52 \\
51 \\
50\end{array}$ \\
\hline $\begin{array}{l}11 \\
12 \\
13 \\
14 \\
15 \\
16 \\
17 \\
18 \\
19 \\
20\end{array}$ & $\begin{array}{r}9.714144 \\
.714352 \\
.714561 \\
.714769 \\
.714978 \\
.715186 \\
.715394 \\
.715602 \\
.715809 \\
.716017\end{array}$ & $\begin{array}{l}3.47 \\
3.48 \\
3.47 \\
3.48 \\
3.47 \\
3.47 \\
3.47 \\
3.45 \\
3.47 \\
3.45\end{array}$ & $\begin{array}{r}9.932228 \\
.932151 \\
.932075 \\
.931998 \\
.931921 \\
.931815 \\
.931 \% 68 \\
.931691 \\
.931614 \\
.931537\end{array}$ & $\begin{array}{l}1.28 \\
1.27 \\
1.28 \\
1.28 \\
1.27 \\
1.28 \\
1.28 \\
1.28 \\
1.28 \\
1.28\end{array}$ & $\begin{array}{r}9.781916 \\
.782201 \\
.782486 \\
.782771 \\
.783056 \\
.783341 \\
.783626 \\
.783910 \\
.784195 \\
.784479\end{array}$ & $\begin{array}{l}4.75 \\
4.75 \\
4.75 \\
4.75 \\
4.75 \\
4.75 \\
4.73 \\
4.75 \\
4.77 \\
4.75\end{array}$ & $\begin{array}{r}10.218084 \\
.217799 \\
.217514 \\
.217229 \\
.216944 \\
.216659 \\
.216374 \\
.216090 \\
.215805 \\
.215521\end{array}$ & $\begin{array}{l}49 \\
48 \\
47 \\
46 \\
45 \\
44 \\
43 \\
42 \\
41 \\
40\end{array}$ \\
\hline $\begin{array}{l}21 \\
22 \\
23 \\
24 \\
25 \\
26 \\
27 \\
28 \\
29 \\
30\end{array}$ & $\begin{array}{r}9.716224 \\
.716432 \\
.716639 \\
.716846 \\
.717053 \\
.717259 \\
.717466 \\
.717673 \\
.717879 \\
.718085\end{array}$ & $\begin{array}{l}3.47 \\
3.45 \\
3.45 \\
3.45 \\
3.43 \\
3.45 \\
3.45 \\
3.43 \\
3.43 \\
3.43\end{array}$ & $\begin{array}{r}9.931460 \\
.931383 \\
.931306 \\
.931229 \\
.931152 \\
.9310 \% 5 \\
.930998 \\
.930921 \\
.930843 \\
.930 \% 66\end{array}$ & $\begin{array}{l}1.28 \\
1.28 \\
1.28 \\
1.28 \\
1.28 \\
1.28 \\
1.28 \\
1.30 \\
1.28 \\
1.30\end{array}$ & $\begin{array}{r}9.784764 \\
.785048 \\
.785332 \\
.785616 \\
.785900 \\
.786184 \\
.786468 \\
.786752 \\
.787036 \\
.787319\end{array}$ & $\begin{array}{l}4.73 \\
4.73 \\
4.73 \\
4.73 \\
4.73 \\
4.73 \\
4.73 \\
4.73 \\
4.72 \\
4.73\end{array}$ & $\begin{array}{r}10.215236 \\
.214952 \\
.214668 \\
.214384 \\
.214100 \\
.213816 \\
.213532 \\
.213248 \\
.212964 \\
.212681\end{array}$ & $\begin{array}{l}39 \\
38 \\
37 \\
36 \\
35 \\
34 \\
33 \\
32 \\
31 \\
30 \\
\end{array}$ \\
\hline $\begin{array}{l}31 \\
32 \\
33 \\
34 \\
35 \\
36 \\
37 \\
38 \\
39 \\
40\end{array}$ & $\begin{array}{r}9.718291 \\
.718497 \\
.718703 \\
.718909 \\
.719114 \\
.719320 \\
.719525 \\
.719730 \\
.719935 \\
.720140\end{array}$ & $\begin{array}{l}3.43 \\
3.43 \\
3.43 \\
3.42 \\
3.43 \\
3.42 \\
3.42 \\
3.42 \\
3.42 \\
3.42\end{array}$ & $\begin{array}{r}9.930688 \\
.930611 \\
.930533 \\
.930456 \\
.930378 \\
.930300 \\
.930223 \\
.930145 \\
.930067 \\
.929989\end{array}$ & $\begin{array}{l}1.28 \\
1.30 \\
1.28 \\
1.30 \\
1.30 \\
1.28 \\
1.30 \\
1.30 \\
1.30 \\
1.30\end{array}$ & $\begin{array}{r}9.787603 \\
.787886 \\
.788170 \\
.788453 \\
.788736 \\
.789019 \\
.789302 \\
.789585 \\
.789868 \\
.790151\end{array}$ & $\begin{array}{l}4.72 \\
4.73 \\
4.72 \\
4.72 \\
4.72 \\
4.72 \\
4.72 \\
4.72 \\
4.72 \\
4.72\end{array}$ & $\begin{array}{r}10.212397 \\
.212114 \\
.211830 \\
.211547 \\
.211264 \\
.210981 \\
.210698 \\
.210415 \\
.210132 \\
.200849\end{array}$ & $\begin{array}{l}29 \\
28 \\
27 \\
26 \\
25 \\
24 \\
23 \\
22 \\
21 \\
20 \\
10\end{array}$ \\
\hline $\begin{array}{l}41 \\
42 \\
43 \\
44 \\
45 \\
46 \\
47 \\
48 \\
49 \\
50\end{array}$ & $\begin{array}{r}9.720345 \\
.720549 \\
.720754 \\
.720958 \\
.721162 \\
.721366 \\
.721570 \\
.721774 \\
.721978 \\
.722181\end{array}$ & $\begin{array}{l}3.40 \\
3.42 \\
3.40 \\
3.40 \\
3.40 \\
3.40 \\
3.40 \\
3.40 \\
3.38 \\
3.40\end{array}$ & $\begin{array}{r}9.929911 \\
.929833 \\
.929755 \\
.929677 \\
.929599 \\
.929521 \\
.929442 \\
.929364 \\
.929286 \\
.929207\end{array}$ & $\begin{array}{l}1.30 \\
1.30 \\
1.30 \\
1.30 \\
1.30 \\
1.32 \\
1.30 \\
1.30 \\
1.32 \\
1.30\end{array}$ & $\begin{array}{r}9.790434 \\
.790716 \\
.790999 \\
.791281 \\
.791563 \\
.791846 \\
.792128 \\
.792410 \\
.792692 \\
.792974\end{array}$ & $\begin{array}{l}4.70 \\
4.72 \\
4.70 \\
4.70 \\
4.72 \\
4.70 \\
4.70 \\
4.70 \\
4.70 \\
4.70\end{array}$ & $\begin{array}{r}10.209566 \\
.209284 \\
.209001 \\
.208719 \\
.20843 \pi \\
.208154 \\
.207872 \\
.207590 \\
.207308 \\
.207026\end{array}$ & $\begin{array}{l}19 \\
18 \\
17 \\
16 \\
15 \\
14 \\
13 \\
12 \\
11 \\
10\end{array}$ \\
\hline $\begin{array}{l}51 \\
52 \\
53 \\
54 \\
55 \\
56 \\
57 \\
58 \\
59 \\
60\end{array}$ & $\begin{array}{r}9.722385 \\
.722588 \\
.722791 \\
.722994 \\
.723197 \\
.723400 \\
.723603 \\
.723805 \\
.724007 \\
9.724210 \\
\end{array}$ & $\begin{array}{l}3.38 \\
3.38 \\
3.38 \\
3.38 \\
3.38 \\
3.38 \\
3.37 \\
3.37 \\
3.38\end{array}$ & $\begin{array}{r}9.929129 \\
.929050 \\
.928972 \\
.928893 \\
.928815 \\
.928736 \\
.928657 \\
.928578 \\
.928499 \\
9.928420 \\
\end{array}$ & $\begin{array}{l}1.32 \\
1.30 \\
1.32 \\
1.30 \\
1.32 \\
1.32 \\
1.32 \\
1.32 \\
1.32\end{array}$ & $\begin{array}{r}9.793256 \\
.793538 \\
.793819 \\
.794101 \\
.794383 \\
.794664 \\
.794916 \\
.795227 \\
.795508 \\
9.795783 \\
\end{array}$ & $\begin{array}{l}4.70 \\
4.68 \\
4.70 \\
4.70 \\
4.68 \\
4.70 \\
4.68 \\
4.68 \\
4.68\end{array}$ & $\begin{array}{r}10.206 \pi 44 \\
.206462 \\
.206181 \\
.205899 \\
.205617 \\
.205336 \\
.205054 \\
.2047 .3 \\
.204492 \\
10.204211\end{array}$ & $\begin{array}{l}9 \\
8 \\
7 \\
6 \\
5 \\
4 \\
3 \\
2 \\
1 \\
0\end{array}$ \\
\hline ' & e. & $1 \%$ & Sine. & $1^{\circ}$ & ing. & .1. & ng. & ' \\
\hline
\end{tabular}




\begin{tabular}{|c|c|c|c|c|c|c|c|c|}
\hline ' & Sine. & D. $1^{\prime \prime}$. & Cosine. & D. $1^{\circ}$. & Tang. & D. $1^{\circ}$. & Cotang. & , \\
\hline $\begin{array}{r}0 \\
1 \\
2 \\
3 \\
4 \\
5 \\
6 \\
7 \\
8 \\
9 \\
10\end{array}$ & $\begin{array}{r}9.724210 \\
.724412 \\
.724614 \\
.724816 \\
.725017 \\
.725219 \\
.725420 \\
.725622 \\
.725823 \\
.726024 \\
.726225\end{array}$ & $\begin{array}{l}3.37 \\
3.37 \\
3.37 \\
3.35 \\
3.37 \\
3.35 \\
3.37 \\
3.35 \\
3.35 \\
3.35 \\
3.35\end{array}$ & $\begin{array}{r}9.928420 \\
.928342 \\
.928263 \\
.928183 \\
.928104 \\
.928025 \\
.927946 \\
.927867 \\
.927787 \\
.92708 \\
.927629\end{array}$ & $\begin{array}{l}1.30 \\
1.32 \\
1.33 \\
1.32 \\
1.32 \\
1.32 \\
1.32 \\
1.33 \\
1.32 \\
1.32 \\
1.33\end{array}$ & $\begin{array}{r}9.795789 \\
.796070 \\
.796351 \\
.796632 \\
.796913 \\
.797194 \\
.797474 \\
.797755 \\
.798036 \\
.798316 \\
.798596\end{array}$ & $\begin{array}{l}4.68 \\
4.68 \\
4.68 \\
4.68 \\
4.68 \\
4.67 \\
4.68 \\
4.68 \\
4.67 \\
4.67 \\
4.68\end{array}$ & $\begin{array}{r}10.204211 \\
.203930 \\
.203649 \\
.203368 \\
.203087 \\
.202806 \\
.202526 \\
.202245 \\
.201961 \\
.201681 \\
.201404\end{array}$ & $\begin{array}{l}c 0 \\
59 \\
58 \\
57 \\
56 \\
55 \\
54 \\
53 \\
59 \\
51 \\
50\end{array}$ \\
\hline $\begin{array}{l}11 \\
12 \\
13 \\
14 \\
15 \\
16 \\
17 \\
18 \\
19 \\
20\end{array}$ & $\begin{array}{r}9.726426 \\
.726626 \\
.726827 \\
.727027 \\
.727228 \\
.727428 \\
.727628 \\
.727828 \\
.728027 \\
.728227\end{array}$ & $\begin{array}{l}3.33 \\
3.35 \\
3.33 \\
3.35 \\
3.33 \\
3.33 \\
3.33 \\
3.32 \\
3.33 \\
3.33\end{array}$ & $\begin{array}{r}9.927549 \\
.927470 \\
.927390 \\
.927310 \\
.927231 \\
.927151 \\
.927071 \\
.926991 \\
.926911 \\
.926831\end{array}$ & $\begin{array}{l}1.32 \\
1.33 \\
1.33 \\
1.32 \\
1.33 \\
1.33 \\
1.33 \\
1.33 \\
1.33 \\
1.33\end{array}$ & $\begin{array}{r}9.798877 \\
.799157 \\
.799437 \\
.799717 \\
.799997 \\
.800277 \\
.800557 \\
.800836 \\
.801116 \\
.801396\end{array}$ & $\begin{array}{l}4.67 \\
4.67 \\
4.67 \\
4.67 \\
4.67 \\
4.67 \\
4.65 \\
4.67 \\
4.67 \\
4.65\end{array}$ & $\begin{array}{r}10.201123 \\
.200813 \\
.200563 \\
.200283 \\
.200003 \\
.199723 \\
.199443 \\
.199164 \\
.198884 \\
.198604\end{array}$ & $\begin{array}{l}49 \\
48 \\
47 \\
46 \\
45 \\
41 \\
43 \\
42 \\
41 \\
40\end{array}$ \\
\hline $\begin{array}{l}21 \\
22 \\
23 \\
24 \\
25 \\
26 \\
27 \\
28 \\
29 \\
30\end{array}$ & $\begin{array}{r}9.728427 \\
.728626 \\
.728825 \\
.729024 \\
.729223 \\
.729122 \\
.729621 \\
.729820 \\
.730018 \\
.730217\end{array}$ & $\begin{array}{l}3.32 \\
3.32 \\
3.32 \\
3.32 \\
3.32 \\
3.32 \\
3.32 \\
3.30 \\
3.32 \\
3.30\end{array}$ & $\begin{array}{r}9.926751 \\
.926671 \\
.926591 \\
.926511 \\
.926431 \\
.926351 \\
.926270 \\
.926190 \\
.926110 \\
.926029\end{array}$ & $\begin{array}{l}1.33 \\
1.33 \\
1.33 \\
1.33 \\
1.33 \\
1.35 \\
1.33 \\
1.33 \\
1.35 \\
1.33\end{array}$ & $\begin{array}{r}9.801675 \\
.801955 \\
.802234 \\
.802513 \\
.802792 \\
.803072 \\
.803351 \\
.803630 \\
.803909 \\
.804187\end{array}$ & $\begin{array}{l}4.67 \\
4.65 \\
4.65 \\
4.65 \\
4.67 \\
4.65 \\
4.65 \\
4.65 \\
4.63 \\
4.65\end{array}$ & $\begin{array}{r}10.198325 \\
.198045 \\
.197766 \\
.197487 \\
.197208 \\
.196928 \\
.196649 \\
.196370 \\
.196091 \\
.195813\end{array}$ & $\begin{array}{l}39 \\
38 \\
37 \\
36 \\
35 \\
34 \\
33 \\
32 \\
31 \\
30\end{array}$ \\
\hline $\begin{array}{l}31 \\
32 \\
33 \\
34 \\
35 \\
36 \\
37 \\
38 \\
39 \\
40\end{array}$ & $\begin{array}{r}9.730415 \\
.730613 \\
.730811 \\
.731009 \\
.731206 \\
.731404 \\
.731602 \\
.731799 \\
.731996 \\
.732193\end{array}$ & $\begin{array}{l}3.30 \\
3.30 \\
3.30 \\
3.28 \\
3.30 \\
3.30 \\
3.28 \\
3.28 \\
3.28 \\
3.28\end{array}$ & $\begin{array}{r}9.925949 \\
.925868 \\
.925788 \\
.925707 \\
.925626 \\
.925545 \\
.925465 \\
.925384 \\
.925303 \\
.925222\end{array}$ & $\begin{array}{l}1.35 \\
1.33 \\
1.35 \\
1.35 \\
1.35 \\
1.33 \\
1.35 \\
1.35 \\
1.35 \\
1.35\end{array}$ & $\begin{array}{r}9.80+466 \\
.804745 \\
.805023 \\
.805302 \\
.805580 \\
.805859 \\
.806137 \\
.806415 \\
.806693 \\
.806971\end{array}$ & $\begin{array}{l}4.65 \\
4.63 \\
4.65 \\
4.63 \\
4.65 \\
4.63 \\
4.63 \\
4.63 \\
4.63 \\
4.63\end{array}$ & $\begin{array}{r}10.195534 \\
.195255 \\
.19497 \\
.194698 \\
.194420 \\
.194141 \\
.193863 \\
.193585 \\
.193307 \\
.193029\end{array}$ & $\begin{array}{l}29 \\
28 \\
27 \\
26 \\
25 \\
24 \\
23 \\
22 \\
21 \\
20\end{array}$ \\
\hline $\begin{array}{l}41 \\
42 \\
43 \\
44 \\
45 \\
46 \\
47 \\
48 \\
49 \\
50\end{array}$ & $\begin{array}{r}9.732390 \\
.732587 \\
.732784 \\
.732980 \\
.733177 \\
.733373 \\
.733569 \\
.733765 \\
.733961 \\
.734157\end{array}$ & $\begin{array}{l}3.28 \\
3.28 \\
3.27 \\
3.28 \\
3.27 \\
3.27 \\
3.27 \\
3.27 \\
3.27 \\
3.27\end{array}$ & $\begin{array}{r}9.925141 \\
.925060 \\
.924979 \\
.924897 \\
.924816 \\
.924735 \\
.924654 \\
.924572 \\
.924491 \\
.924409\end{array}$ & $\begin{array}{l}1.35 \\
1.35 \\
1.37 \\
1.35 \\
1.35 \\
1.35 \\
1.37 \\
1.35 \\
1.37 \\
1.35\end{array}$ & $\begin{array}{r}9.8072 f 9 \\
.807527 \\
.807805 \\
.808083 \\
.808361 \\
.808638 \\
.808916 \\
.809193 \\
.809171 \\
.809748\end{array}$ & $\begin{array}{l}4.63 \\
4.63 \\
4.63 \\
4.63 \\
4.62 \\
4.63 \\
4.62 \\
4.63 \\
4.62 \\
4.62\end{array}$ & $\begin{array}{r}10.192 \% 51 \\
.192473 \\
.192195 \\
.191917 \\
.191639 \\
.191362 \\
.191081 \\
.190807 \\
.190529 \\
.190252\end{array}$ & $\begin{array}{l}19 \\
18 \\
17 \\
16 \\
15 \\
14 \\
13 \\
12 \\
11 \\
10\end{array}$ \\
\hline $\begin{array}{l}51 \\
52 \\
53 \\
54 \\
55 \\
56 \\
57 \\
58 \\
59 \\
60\end{array}$ & $\begin{array}{r}9.734353 \\
.734549 \\
.734744 \\
.734939 \\
.735135 \\
.735330 \\
.735525 \\
.735719 \\
.735914 \\
9.736109\end{array}$ & $\begin{array}{l}3.27 \\
3.25 \\
3.25 \\
3.27 \\
3.25 \\
3.25 \\
3.23 \\
3.25 \\
3.25\end{array}$ & $\begin{array}{r}9.924328 \\
.924246 \\
.924164 \\
.924083 \\
.924001 \\
.923919 \\
.923837 \\
.923755 \\
.923673 \\
9.923591\end{array}$ & $\begin{array}{l}1.37 \\
1.37 \\
1.35 \\
1.37 \\
1.37 \\
1.37 \\
1.37 \\
1.37 \\
1.37\end{array}$ & $\begin{array}{r}9.810025 \\
.810302 \\
.810580 \\
.810857 \\
.811134 \\
.811410 \\
.811687 \\
.811964 \\
.812211 \\
9.812517\end{array}$ & $\begin{array}{l}4.62 \\
4.63 \\
4.62 \\
4.62 \\
4.60 \\
4.62 \\
4.62 \\
4.62 \\
4.60\end{array}$ & $\begin{array}{r}10.189975 \\
.189698 \\
.189420 \\
.189143 \\
.188866 \\
.188590 \\
.188313 \\
.188036 \\
.187759 \\
10.187483\end{array}$ & $\begin{array}{l}9 \\
8 \\
7 \\
6 \\
5 \\
4 \\
3 \\
2 \\
1 \\
0\end{array}$ \\
\hline 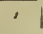 & cosine. & D. 1 . & sime. & 1.1. & voling. & 1.1. & 1ang. & ' \\
\hline
\end{tabular}




\begin{tabular}{|c|c|c|c|c|c|c|c|c|}
\hline ' & Sine. & D. $1^{\prime}$. & Cosine. & D. $i^{\prime}$. & Tang. & D. $1^{\circ}$. & Cotang. & ' \\
\hline $\begin{array}{r}0 \\
1 \\
2 \\
3 \\
4 \\
5 \\
6 \\
7 \\
8 \\
9 \\
10\end{array}$ & $\begin{array}{r}9.736109 \\
.736303 \\
.736498 \\
.736692 \\
.736886 \\
.737080 \\
.737274 \\
.737467 \\
.737661 \\
.737855 \\
.738048\end{array}$ & $\begin{array}{l}3.23 \\
3.25 \\
3.23 \\
3.23 \\
3.23 \\
3.23 \\
3.22 \\
3.23 \\
3.23 \\
3.22 \\
3.22\end{array}$ & $\begin{array}{r}9.923591 \\
.923509 \\
.923427 \\
.923345 \\
.923263 \\
.923111 \\
.923098 \\
.923016 \\
.922933 \\
.922851 \\
.922768\end{array}$ & $\begin{array}{l}1.37 \\
1.37 \\
1.37 \\
1.37 \\
1.37 \\
1.38 \\
1.37 \\
1.38 \\
1.37 \\
1.38 \\
1.37\end{array}$ & $\begin{array}{r}9.812517 \\
.812794 \\
.8130 \% 0 \\
.813347 \\
.813623 \\
.813899 \\
.814176 \\
.814452 \\
.814728 \\
.815004 \\
.815280\end{array}$ & $\begin{array}{l}4.62 \\
4.60 \\
4.62 \\
4.60 \\
4.60 \\
4.62 \\
4.60 \\
4.60 \\
4.60 \\
4.60 \\
4.58\end{array}$ & $\begin{array}{r}10.187483 \\
.1872,6 \\
.186930 \\
.186653 \\
.186377 \\
.186101 \\
.185824 \\
.185548 \\
.185272 \\
.181996 \\
.181720\end{array}$ & $\begin{array}{l}60 \\
59 \\
58 \\
57 \\
56 \\
55 \\
54 \\
53 \\
52 \\
51 \\
50\end{array}$ \\
\hline $\begin{array}{l}11 \\
12 \\
13 \\
14 \\
15 \\
16 \\
17 \\
18 \\
19 \\
19 \\
20\end{array}$ & $\begin{array}{r}9.738241 \\
.738434 \\
.738627 \\
.738820 \\
.739013 \\
.739206 \\
.739398 \\
.739590 \\
.739783 \\
.739975\end{array}$ & $\begin{array}{l}3.22 \\
3.22 \\
3.22 \\
3.22 \\
3.22 \\
3.20 \\
3.20 \\
3.22 \\
3.20 \\
3.20\end{array}$ & $\begin{array}{r}9.922686 \\
.922603 \\
.922520 \\
.922438 \\
.922355 \\
.922272 \\
.922189 \\
.922106 \\
.922023 \\
.921940\end{array}$ & $\begin{array}{l}1.38 \\
1.38 \\
1.37 \\
1.38 \\
1.38 \\
1.38 \\
1.38 \\
1.38 \\
1.38 \\
1.38\end{array}$ & $\begin{array}{r}9.815555 \\
.815831 \\
.816107 \\
.816382 \\
.816658 \\
.816933 \\
.817209 \\
.817481 \\
.817759 \\
.818035\end{array}$ & $\begin{array}{l}4.60 \\
4.60 \\
4.58 \\
4.60 \\
4.58 \\
4.60 \\
4.58 \\
4.58 \\
4.60 \\
4.58\end{array}$ & $\begin{array}{r}10.184445 \\
.184169 \\
.183893 \\
.183618 \\
.183342 \\
.183067 \\
.182791 \\
.182516 \\
.182411 \\
.181965\end{array}$ & $\begin{array}{l}49 \\
48 \\
47 \\
46 \\
45 \\
44 \\
43 \\
42 \\
41 \\
40\end{array}$ \\
\hline $\begin{array}{l}21 \\
22 \\
23 \\
24 \\
25 \\
26 \\
27 \\
28 \\
29 \\
30\end{array}$ & $\begin{array}{r}9.740167 \\
.740359 \\
.740550 \\
.740742 \\
.740934 \\
.741125 \\
.741316 \\
.741508 \\
.741699 \\
.741889\end{array}$ & $\begin{array}{l}3.20 \\
3.18 \\
3.20 \\
3.20 \\
3.18 \\
3.18 \\
3.20 \\
3.18 \\
3.17 \\
3.18\end{array}$ & $\begin{array}{r}9.921857 \\
.921774 \\
.921691 \\
.921607 \\
.921524 \\
.921441 \\
.921357 \\
.921274 \\
.921190 \\
.921107\end{array}$ & $\begin{array}{l}1.38 \\
1.38 \\
1.40 \\
1.38 \\
1.38 \\
1.40 \\
1.38 \\
1.40 \\
1.38 \\
1.40\end{array}$ & $\begin{array}{r}9.818310 \\
.818585 \\
.818860 \\
.819135 \\
.819410 \\
.819681 \\
.819959 \\
.820231 \\
.820508 \\
.820783\end{array}$ & $\begin{array}{l}4.58 \\
4.58 \\
4.58 \\
4.58 \\
4.57 \\
4.58 \\
4.58 \\
4.57 \\
4.58 \\
4.57\end{array}$ & $\begin{array}{r}10.181690 \\
.181415 \\
.181140 \\
.180865 \\
.180590 \\
.180316 \\
.180041 \\
.179766 \\
.179492 \\
.179217\end{array}$ & $\begin{array}{l}39 \\
38 \\
37 \\
36 \\
35 \\
34 \\
33 \\
32 \\
31 \\
30\end{array}$ \\
\hline $\begin{array}{l}31 \\
32 \\
33 \\
34 \\
35 \\
36 \\
37 \\
38 \\
39 \\
40\end{array}$ & $\begin{array}{r}9.742080 \\
.742271 \\
.742462 \\
.742652 \\
.742842 \\
.743033 \\
.743223 \\
.743413 \\
.743602 \\
.743792\end{array}$ & $\begin{array}{l}3.18 \\
3.18 \\
3.18 \\
3.17 \\
3.17 \\
3.18 \\
3.17 \\
3.17 \\
3.15 \\
3.17 \\
3.17\end{array}$ & $\begin{array}{r}9.921023 \\
.920939 \\
.920856 \\
.920772 \\
.920688 \\
.920604 \\
.920520 \\
.920436 \\
.920352 \\
.920268\end{array}$ & $\begin{array}{l}1.40 \\
1.40 \\
1.38 \\
1.40 \\
1.40 \\
1.40 \\
1.40 \\
1.40 \\
1.40 \\
1.40 \\
1.40\end{array}$ & $\begin{array}{r}9.821057 \\
.821332 \\
.821606 \\
.821880 \\
.822154 \\
.822429 \\
.822703 \\
.822977 \\
.823251 \\
.823524\end{array}$ & $\begin{array}{l}4.58 \\
4.57 \\
4.57 \\
4.57 \\
4.58 \\
4.57 \\
4.57 \\
4.57 \\
4.55 \\
4.57\end{array}$ & $\begin{array}{r}10.178943 \\
.178668 \\
.178394 \\
.178120 \\
.177846 \\
.17571 \\
.177297 \\
.17023 \\
.176749 \\
.176476\end{array}$ & $\begin{array}{l}29 \\
28 \\
27 \\
26 \\
25 \\
24 \\
23 \\
22 \\
21 \\
20\end{array}$ \\
\hline $\begin{array}{l}41 \\
42 \\
43 \\
44 \\
45 \\
46 \\
47 \\
48 \\
49 \\
50\end{array}$ & $\begin{array}{r}9.743982 \\
.744171 \\
.744361 \\
.744550 \\
.744739 \\
.744928 \\
.745117 \\
.745306 \\
.745494 \\
.745683\end{array}$ & $\begin{array}{l}3.15 \\
3.17 \\
3.15 \\
3.15 \\
3.15 \\
3.15 \\
3.15 \\
3.15 \\
3.13 \\
3.15 \\
3.13\end{array}$ & $\begin{array}{r}9.920184 \\
.920099 \\
.920015 \\
.919931 \\
.919846 \\
.919762 \\
.919677 \\
.919593 \\
.919508 \\
.919424\end{array}$ & $\begin{array}{l}1.40 \\
1.42 \\
1.40 \\
1.40 \\
1.42 \\
1.40 \\
1.42 \\
1.40 \\
1.42 \\
1.40 \\
1.42\end{array}$ & $\begin{array}{r}9.823798 \\
.824072 \\
.824345 \\
.824619 \\
.824893 \\
.825166 \\
.825439 \\
.825713 \\
.825986 \\
.826259\end{array}$ & $\begin{array}{l}4.57 \\
4.55 \\
4.57 \\
4.57 \\
4.55 \\
4.55 \\
4.57 \\
4.55 \\
4.55 \\
4.55\end{array}$ & $\begin{array}{r}10.176202 \\
.175928 \\
.175655 \\
.175381 \\
.175107 \\
.174834 \\
.174561 \\
.174287 \\
.174014 \\
.173741\end{array}$ & $\begin{array}{l}19 \\
18 \\
17 \\
16 \\
15 \\
14 \\
13 \\
12 \\
11 \\
10\end{array}$ \\
\hline $\begin{array}{l}51 \\
52 \\
53 \\
54 \\
55 \\
56 \\
57 \\
58 \\
59 \\
60\end{array}$ & $\begin{array}{r}9.745871 \\
.746060 \\
.746248 \\
.746436 \\
.746624 \\
.746812 \\
.746999 \\
.747187 \\
.747374 \\
9.747562\end{array}$ & $\begin{array}{l}3.10 \\
3.15 \\
3.13 \\
3.13 \\
3.13 \\
3.13 \\
3.12 \\
3.13 \\
3.12 \\
3.13\end{array}$ & $\begin{array}{r}9.919339 \\
.919254 \\
.919169 \\
.919085 \\
.919000 \\
.918915 \\
.918830 \\
.918 \% 45 \\
.918659 \\
9.9185 \pi 4\end{array}$ & $\begin{array}{l}1.4 \sim \\
1.42 \\
1.42 \\
1.40 \\
1.42 \\
1.42 \\
1.42 \\
1.42 \\
1.43 \\
1.42\end{array}$ & $\begin{array}{r}9.826532 \\
.826805 \\
.827078 \\
.827351 \\
.827624 \\
.827897 \\
.828170 \\
.828142 \\
.828715 \\
9.828987\end{array}$ & $\begin{array}{l}4.55 \\
4.55 \\
4.55 \\
4.55 \\
4.55 \\
4.55 \\
4.53 \\
4.55 \\
4.53\end{array}$ & $\begin{array}{r}10.173468 \\
.173195 \\
.172922 \\
.172649 \\
.172376 \\
.172103 \\
.171830 \\
.171558 \\
.171205 \\
10.171013 \\
\end{array}$ & $\begin{array}{l}9 \\
8 \\
7 \\
6 \\
5 \\
4 \\
3 \\
2 \\
1 \\
0\end{array}$ \\
\hline 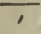 & Cosine. & D. $1^{\prime \prime}$. & Sine. & D. $1^{\circ}$. & Cotang. & D. $1^{\circ}$. & Tang. & ' \\
\hline
\end{tabular}




\begin{tabular}{|c|c|c|c|c|c|c|c|c|}
\hline , & Sine. & D. 1". & Cosine. & D. $1^{\prime \prime}$. & Tang. & D. 1". & Cotang. & I \\
\hline $\begin{array}{r}0 \\
1 \\
2 \\
3 \\
4 \\
5 \\
6 \\
7 \\
8 \\
9 \\
10\end{array}$ & $\begin{array}{r}9.747562 \\
.747749 \\
.747936 \\
.748123 \\
.748310 \\
.748497 \\
.748683 \\
.748870 \\
.749056 \\
.749243 \\
.749429\end{array}$ & $\begin{array}{l}3.12 \\
3.12 \\
3.12 \\
3.12 \\
3.12 \\
3.10 \\
3.12 \\
3.10 \\
3.12 \\
3.10 \\
3.10\end{array}$ & $\begin{array}{r}9.918574 \\
.918489 \\
.918404 \\
.918318 \\
.918233 \\
.918147 \\
.918062 \\
.917976 \\
.917891 \\
.917805 \\
.917719\end{array}$ & $\begin{array}{l}1.42 \\
1.42 \\
1.43 \\
1.42 \\
1.43 \\
1.42 \\
1.43 \\
1.42 \\
1.43 \\
1.43 \\
1.42\end{array}$ & $\begin{array}{r}9.828987 \\
.829260 \\
.829532 \\
.829805 \\
.830077 \\
.830349 \\
.830621 \\
.830893 \\
.831165 \\
.831437 \\
.831 \% 09\end{array}$ & $\begin{array}{l}4.55 \\
4.53 \\
4.55 \\
4.53 \\
4.53 \\
4.53 \\
4.53 \\
4.53 \\
4.53 \\
4.53 \\
4.53\end{array}$ & $\begin{array}{r}10.171013 \\
.170740 \\
.170468 \\
.170195 \\
.169923 \\
.169651 \\
.169379 \\
.169107 \\
.168835 \\
.168563 \\
.168291\end{array}$ & $\begin{array}{l}60 \\
59 \\
58 \\
57 \\
56 \\
55 \\
54 \\
53 \\
52 \\
51 \\
50\end{array}$ \\
\hline $\begin{array}{l}11 \\
12 \\
13 \\
14 \\
15 \\
16 \\
17 \\
18 \\
19 \\
20\end{array}$ & $\begin{array}{r}9.749615 \\
.749801 \\
.749987 \\
.750172 \\
.750358 \\
.750543 \\
.750729 \\
.750914 \\
.751099 \\
.751284\end{array}$ & $\begin{array}{l}3.10 \\
3.10 \\
3.08 \\
3.10 \\
3.08 \\
3.10 \\
3.08 \\
3.08 \\
3.08 \\
3.08\end{array}$ & $\begin{array}{r}9.917634 \\
.917548 \\
.917462 \\
.917376 \\
.917290 \\
.917204 \\
.917118 \\
.917032 \\
.916946 \\
.916859\end{array}$ & $\begin{array}{l}1.40 \\
1.43 \\
1.43 \\
1.43 \\
1.43 \\
1.43 \\
1.43 \\
1.43 \\
1.43 \\
1.45 \\
1.43\end{array}$ & $\begin{array}{r}9.831981 \\
.832253 \\
.832525 \\
.832796 \\
.833068 \\
.833339 \\
.833611 \\
.833882 \\
.834154 \\
.834425\end{array}$ & $\begin{array}{l}4.53 \\
4.53 \\
4.53 \\
4.52 \\
4.53 \\
4.52 \\
4.53 \\
4.52 \\
4.53 \\
4.52 \\
4.52\end{array}$ & $\begin{array}{r}10.168019 \\
.167747 \\
.167475 \\
.167204 \\
.166932 \\
.166661 \\
.166389 \\
.166118 \\
.165846 \\
.165575\end{array}$ & $\begin{array}{l}49 \\
48 \\
47 \\
46 \\
45 \\
44 \\
43 \\
42 \\
41 \\
40\end{array}$ \\
\hline $\begin{array}{l}21 \\
22 \\
23 \\
24 \\
25 \\
26 \\
27 \\
28 \\
29 \\
30\end{array}$ & $\begin{array}{r}9.751469 \\
.751654 \\
.751839 \\
.752023 \\
.752208 \\
.752392 \\
.752576 \\
.752760 \\
.752944 \\
.753128\end{array}$ & $\begin{array}{l}3.08 \\
3.08 \\
3.07 \\
3.08 \\
3.07 \\
3.07 \\
3.07 \\
3.07 \\
3.07 \\
3.07\end{array}$ & $\begin{array}{r}9.916 r 73 \\
.916687 \\
.916600 \\
.916514 \\
.916427 \\
.916341 \\
.916254 \\
.916167 \\
.916081 \\
.915994\end{array}$ & $\begin{array}{l}1.40 \\
1.43 \\
1.45 \\
1.43 \\
1.45 \\
1.43 \\
1.45 \\
1.45 \\
1.43 \\
1.45 \\
1.45\end{array}$ & $\begin{array}{r}9.834696 \\
.834967 \\
.835238 \\
.835509 \\
.835780 \\
.836051 \\
.836322 \\
.836593 \\
.836864 \\
.837131\end{array}$ & $\begin{array}{l}4.52 \\
4.52 \\
4.52 \\
4.52 \\
4.52 \\
4.52 \\
4.52 \\
4.52 \\
4.52 \\
4.50 \\
4.52\end{array}$ & $\begin{array}{r}10.165304 \\
.165033 \\
.164762 \\
.164491 \\
.164220 \\
.163949 \\
.163678 \\
.163407 \\
.163136 \\
.162866\end{array}$ & $\begin{array}{l}39 \\
38 \\
37 \\
36 \\
35 \\
34 \\
33 \\
32 \\
31 \\
30\end{array}$ \\
\hline $\begin{array}{l}31 \\
32 \\
33 \\
34 \\
35 \\
36 \\
37 \\
38 \\
39 \\
40\end{array}$ & $\begin{array}{r}9.753312 \\
.753495 \\
.753679 \\
.753862 \\
.754046 \\
.754229 \\
.754412 \\
.754595 \\
.754778 \\
.754960\end{array}$ & $\begin{array}{l}3.05 \\
3.07 \\
3.07 \\
3.07 \\
3.05 \\
3.05 \\
3.05 \\
3.05 \\
3.03 \\
3.05\end{array}$ & $\begin{array}{r}9.915907 \\
.915820 \\
.915733 \\
.915646 \\
.915559 \\
.915472 \\
.915385 \\
.915297 \\
.915210 \\
.915123\end{array}$ & $\begin{array}{l}1.45 \\
1.45 \\
1.45 \\
1.45 \\
1.45 \\
1.45 \\
1.45 \\
1.47 \\
1.45 \\
1.45 \\
1.47\end{array}$ & $\begin{array}{r}9.837405 \\
.837675 \\
.837946 \\
.838216 \\
.838487 \\
.838757 \\
.839027 \\
.839297 \\
.839568 \\
.839838\end{array}$ & $\begin{array}{l}4.50 \\
4.50 \\
4.50 \\
4.52 \\
4.50 \\
4.50 \\
4.50 \\
4.52 \\
4.50 \\
4.50\end{array}$ & $\begin{array}{r}10.162595 \\
.162325 \\
.162054 \\
.161784 \\
.161513 \\
.161243 \\
.160973 \\
.160703 \\
.160432 \\
.160162\end{array}$ & $\begin{array}{l}29 \\
28 \\
27 \\
26 \\
25 \\
24 \\
23 \\
22 \\
21 \\
20\end{array}$ \\
\hline $\begin{array}{l}41 \\
42 \\
43 \\
44 \\
45 \\
46 \\
47 \\
48 \\
49 \\
50\end{array}$ & $\begin{array}{r}9.755143 \\
.755326 \\
.755508 \\
.755690 \\
.755872 \\
.756054 \\
.756236 \\
.756418 \\
.756600 \\
.756782\end{array}$ & $\begin{array}{l}3.05 \\
3.03 \\
3.03 \\
3.03 \\
3.03 \\
3.03 \\
3.03 \\
3.03 \\
3.03 \\
3.02\end{array}$ & $\begin{array}{r}9.915035 \\
.914948 \\
.914860 \\
.914773 \\
.914685 \\
.914598 \\
.914510 \\
.914422 \\
.914334 \\
.914246\end{array}$ & $\begin{array}{l}1.46 \\
1.45 \\
1.47 \\
1.45 \\
1.47 \\
1.45 \\
1.47 \\
1.47 \\
1.47 \\
1.47 \\
1.47\end{array}$ & $\begin{array}{r}9.840108 \\
.840378 \\
.840648 \\
.840917 \\
.841187 \\
.841457 \\
.841727 \\
.841996 \\
.842266 \\
.842535\end{array}$ & $\begin{array}{r}4.50 \\
4.50 \\
4.50 \\
4.48 \\
4.50 \\
4.50 \\
4.50 \\
4.48 \\
4.50 \\
4.48 \\
4.50\end{array}$ & $\begin{array}{r}10.159892 \\
.159622 \\
.159352 \\
.159083 \\
.158813 \\
.158543 \\
.158273 \\
.158004 \\
.157734 \\
.15 i 465\end{array}$ & $\begin{array}{l}19 \\
18 \\
17 \\
16 \\
15 \\
14 \\
13 \\
12 \\
11 \\
10\end{array}$ \\
\hline $\begin{array}{l}51 \\
52 \\
53 \\
54 \\
5 \\
56 \\
57 \\
58 \\
59 \\
60\end{array}$ & $\begin{array}{r}9.756963 \\
.757144 \\
.757326 \\
.757507 \\
.757688 \\
.757869 \\
.758050 \\
.758230 \\
.758411 \\
9.758591\end{array}$ & $\begin{array}{l}3.02 \\
3.03 \\
3.02 \\
3.02 \\
3.02 \\
3.02 \\
3.00 \\
3.02 \\
3.00\end{array}$ & $\begin{array}{r}9.914158 \\
.914070 \\
.913982 \\
.913894 \\
.913806 \\
.913718 \\
.913630 \\
913541 \\
.913453 \\
9.913365\end{array}$ & $\begin{array}{l}1.47 \\
1.47 \\
1.47 \\
1.47 \\
1.47 \\
1.47 \\
1.48 \\
1.47 \\
1.47\end{array}$ & $\begin{array}{r}9.842805 \\
.843074 \\
.843343 \\
.813612 \\
.843882 \\
.844151 \\
.844420 \\
.844689 \\
.844958 \\
9.845227\end{array}$ & $\begin{array}{l}4.48 \\
4.48 \\
4.48 \\
4.50 \\
4.48 \\
4.48 \\
4.48 \\
4.48 \\
4.48\end{array}$ & $\begin{array}{r}10.157195 \\
156926 \\
.156657 \\
.156388 \\
.156118 \\
.155849 \\
.155580 \\
.155311 \\
.155042 \\
10.154773\end{array}$ & $\begin{array}{l}9 \\
8 \\
7 \\
6 \\
5 \\
4 \\
3 \\
2 \\
1 \\
0\end{array}$ \\
\hline 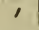 & Cosine. & D. $1^{\prime \prime}$. & Sine. & D. $1^{\prime \prime}$. & Cotang. & D. 1". & Tang. & r \\
\hline
\end{tabular}




\begin{tabular}{|c|c|c|c|c|c|c|c|c|}
\hline ' & Sine. & D. $1^{\circ}$. & Cosine. & D. $1^{\circ}$. & Tang. & D. $1^{\circ}$. & Cotang. & , \\
\hline $\begin{array}{r}0 \\
1 \\
2 \\
3 \\
4 \\
5 \\
6 \\
7 \\
8 \\
9 \\
10\end{array}$ & $\begin{array}{r}9.758591 \\
.758772 \\
.758952 \\
.759132 \\
.759312 \\
.759492 \\
.759672 \\
.759852 \\
.760031 \\
.760211 \\
.760390\end{array}$ & $\begin{array}{l}3.02 \\
3.00 \\
3.00 \\
3.00 \\
3.00 \\
3.00 \\
3.00 \\
2.98 \\
3.00 \\
2.98 \\
2.98\end{array}$ & $\begin{array}{r}9.913365 \\
.913276 \\
.913187 \\
.913099 \\
.913010 \\
.912922 \\
.912833 \\
.912744 \\
.912655 \\
.912566 \\
.91247 \%\end{array}$ & $\begin{array}{l}1.48 \\
1.48 \\
1.47 \\
1.48 \\
1.47 \\
1.48 \\
1.48 \\
1.48 \\
1.48 \\
1.48 \\
1.48\end{array}$ & $\begin{array}{r}9.845227 \\
.845496 \\
.815764 \\
.816033 \\
.846302 \\
.846570 \\
.846839 \\
.847108 \\
.847376 \\
.847644 \\
.847913\end{array}$ & $\begin{array}{l}4.48 \\
4.47 \\
4.48 \\
4.48 \\
4.47 \\
4.48 \\
4.48 \\
4.47 \\
4.47 \\
4.48 \\
4.47\end{array}$ & $\begin{array}{r}10.154773 \\
.154504 \\
.154936 \\
.153967 \\
.153698 \\
.153430 \\
.153161 \\
.152892 \\
.152624 \\
.152356 \\
.152087\end{array}$ & $\begin{array}{l}60 \\
59 \\
58 \\
57 \\
56 \\
55 \\
54 \\
53 \\
52 \\
51 \\
50\end{array}$ \\
\hline $\begin{array}{l}11 \\
12 \\
13 \\
14 \\
15 \\
16 \\
17 \\
18 \\
19 \\
20\end{array}$ & $\begin{array}{r}9.760569 \\
.760748 \\
.760927 \\
.61106 \\
.761285 \\
.761464 \\
.761642 \\
.761821 \\
.761999 \\
.762177\end{array}$ & $\begin{array}{l}2.98 \\
2.98 \\
2.98 \\
2.98 \\
2.98 \\
2.97 \\
2.98 \\
2.97 \\
2.97 \\
2.98\end{array}$ & $\begin{array}{r}9.912388 \\
.912299 \\
.912210 \\
.912121 \\
.912031 \\
.911942 \\
.911853 \\
.911763 \\
.9116 \% 4 \\
.911584\end{array}$ & $\begin{array}{l}1.48 \\
1.48 \\
1.48 \\
1.50 \\
1.48 \\
1.48 \\
1.50 \\
1.48 \\
1.50 \\
1.48\end{array}$ & $\begin{array}{r}9.848181 \\
.818449 \\
.848717 \\
.818986 \\
.849254 \\
.849522 \\
.819790 \\
.850057 \\
.850325 \\
.850593\end{array}$ & $\begin{array}{l}4.47 \\
4.47 \\
4.48 \\
4.47 \\
4.47 \\
4.47 \\
4.45 \\
4.47 \\
4.47 \\
4.47\end{array}$ & $\begin{array}{r}10.151819 \\
.151551 \\
.151283 \\
.151014 \\
.150 \pi 46 \\
.150478 \\
.150210 \\
.149943 \\
.149675 \\
.14940 \%\end{array}$ & $\begin{array}{l}49 \\
48 \\
47 \\
46 \\
45 \\
44 \\
43 \\
42 \\
41 \\
40\end{array}$ \\
\hline $\begin{array}{l}21 \\
22 \\
23 \\
24 \\
25 \\
26 \\
27 \\
28 \\
29 \\
30\end{array}$ & $\begin{array}{r}9.762356 \\
.762534 \\
.762712 \\
.762889 \\
.763067 \\
.763245 \\
.763422 \\
.763600 \\
.763 \% 77 \\
.763954\end{array}$ & $\begin{array}{l}2.97 \\
2.97 \\
2.95 \\
2.97 \\
2.97 \\
2.95 \\
2.97 \\
2.95 \\
2.95 \\
2.95\end{array}$ & $\begin{array}{r}9.911495 \\
.911405 \\
.911315 \\
.911226 \\
.911136 \\
.911046 \\
.910956 \\
.910866 \\
.910776 \\
.910686\end{array}$ & $\begin{array}{l}1.50 \\
1.50 \\
1.48 \\
1.50 \\
1.50 \\
1.50 \\
1.50 \\
1.50 \\
1.50 \\
1.50\end{array}$ & $\begin{array}{r}9.850861 \\
.851129 \\
.851396 \\
.851664 \\
.851931 \\
.852199 \\
.852466 \\
.852733 \\
.853001 \\
.853268\end{array}$ & $\begin{array}{l}4.47 \\
4.45 \\
4.47 \\
4.45 \\
4.47 \\
4.45 \\
4.45 \\
4.47 \\
4.45 \\
4.45\end{array}$ & $\begin{array}{r}10.149139 \\
.148871 \\
.148604 \\
.148336 \\
.148069 \\
.147801 \\
.147534 \\
.147267 \\
.146999 \\
.146732\end{array}$ & $\begin{array}{l}39 \\
38 \\
37 \\
36 \\
35 \\
34 \\
33 \\
32 \\
31 \\
30\end{array}$ \\
\hline $\begin{array}{l}31 \\
32 \\
33 \\
34 \\
35 \\
36 \\
37 \\
38 \\
39 \\
40\end{array}$ & $\begin{array}{r}9.764131 \\
.764308 \\
.764485 \\
.764662 \\
.764838 \\
.765015 \\
.765191 \\
.765367 \\
.765544 \\
.765720\end{array}$ & $\begin{array}{l}2.95 \\
2.95 \\
2.95 \\
2.93 \\
2.95 \\
2.93 \\
2.93 \\
2.95 \\
2.93 \\
2.93\end{array}$ & $\begin{array}{r}9.910596 \\
.910506 \\
.910415 \\
.910325 \\
.910235 \\
.910144 \\
.910054 \\
.909963 \\
.909873 \\
.909782\end{array}$ & $\begin{array}{l}1.50 \\
1.52 \\
1.50 \\
1.50 \\
1.52 \\
1.50 \\
1.52 \\
1.50 \\
1.52 \\
1.52\end{array}$ & $\begin{array}{r}9.853535 \\
.853802 \\
.854069 \\
.854336 \\
.854603 \\
.854870 \\
.855137 \\
.855404 \\
.855671 \\
.855938\end{array}$ & $\begin{array}{l}4.45 \\
4.45 \\
4.45 \\
4.45 \\
4.45 \\
4.45 \\
4.45 \\
4.45 \\
4.45 \\
4.43\end{array}$ & $\begin{array}{r}10.146465 \\
.146198 \\
.145931 \\
.145664 \\
.145397 \\
.145130 \\
.144863 \\
.144596 \\
.144329 \\
.144062\end{array}$ & $\begin{array}{l}29 \\
28 \\
27 \\
26 \\
25 \\
24 \\
23 \\
22 \\
21 \\
20\end{array}$ \\
\hline $\begin{array}{l}41 \\
42 \\
43 \\
44 \\
45 \\
46 \\
47 \\
48 \\
49 \\
50\end{array}$ & $\begin{array}{r}9.765896 \\
.766072 \\
.766247 \\
.766423 \\
.766598 \\
.766774 \\
.766949 \\
.767124 \\
.767300 \\
.767475\end{array}$ & $\begin{array}{l}2.93 \\
2.92 \\
2.93 \\
2.92 \\
2.93 \\
2.92 \\
2.92 \\
2.93 \\
2.92 \\
2.90\end{array}$ & $\begin{array}{r}9.909691 \\
.909601 \\
.909510 \\
.909419 \\
.909328 \\
.909237 \\
.909146 \\
.909055 \\
.908961 \\
.908873\end{array}$ & $\begin{array}{l}1.50 \\
1.52 \\
1.52 \\
1.52 \\
1.52 \\
1.52 \\
1.52 \\
1.52 \\
1.52 \\
1.53\end{array}$ & $\begin{array}{r}9.856204 \\
.856471 \\
.856737 \\
.857004 \\
.857270 \\
.857537 \\
.857803 \\
.858069 \\
.858336 \\
.858602\end{array}$ & $\begin{array}{l}4.45 \\
4.43 \\
4.45 \\
4.43 \\
4.45 \\
4.43 \\
4.43 \\
4.45 \\
4.43 \\
4.43\end{array}$ & $\begin{array}{r}10.143796 \\
.143529 \\
.143263 \\
.142996 \\
.142730 \\
.142463 \\
.142197 \\
.141931 \\
.141664 \\
.141398\end{array}$ & $\begin{array}{l}19 \\
18 \\
17 \\
16 \\
15 \\
14 \\
13 \\
12 \\
11 \\
10\end{array}$ \\
\hline $\begin{array}{l}51 \\
52 \\
53 \\
54 \\
55 \\
56 \\
57 \\
58 \\
59 \\
60\end{array}$ & $\begin{array}{r}9.767649 \\
.767824 \\
.767999 \\
.768173 \\
.768348 \\
.768522 \\
.768697 \\
.768871 \\
.769045 \\
9.769219\end{array}$ & $\begin{array}{l}2.92 \\
2.92 \\
2.90 \\
2.92 \\
2.90 \\
2.92 \\
2.90 \\
2.90 \\
2.90\end{array}$ & $\begin{array}{r}9.908781 \\
.908690 \\
.908599 \\
.908507 \\
.908416 \\
.908324 \\
.908233 \\
.908141 \\
.908049 \\
9.907958\end{array}$ & $\begin{array}{l}1.52 \\
1.52 \\
1.53 \\
1.52 \\
1.53 \\
1.52 \\
1.53 \\
1.53 \\
1.52\end{array}$ & $\begin{array}{r}9.858868 \\
.859134 \\
.859400 \\
.859666 \\
.859932 \\
.860198 \\
.860464 \\
.860730 \\
.860995 \\
9.861261\end{array}$ & $\begin{array}{l}4.43 \\
4.43 \\
4.43 \\
4.43 \\
4.43 \\
4.43 \\
4.43 \\
4.42 \\
4.43\end{array}$ & $\begin{array}{r}10.141132 \\
.140866 \\
.140600 \\
.140334 \\
.140069 \\
.139802 \\
.139536 \\
.139270 \\
.139005 \\
10.139739 \\
\end{array}$ & $\begin{array}{l}9 \\
8 \\
7 \\
6 \\
5 \\
4 \\
3 \\
2 \\
1 \\
0\end{array}$ \\
\hline & Cosine. & D. $1^{\prime \prime}$. & Sine. & D. $1^{\circ}$. & Cotang. & D. 1 & Tang. & ' \\
\hline
\end{tabular}


TABLE XII.-LOGARITHMIC SINES,

\begin{tabular}{|c|c|c|c|c|c|c|c|c|}
\hline , & Sine. & D. $1^{\prime \prime}$. & Cosine. & D. $1^{\prime \prime}$. & Tang. & D. $1^{\prime \prime}$. & Cotang. & , \\
\hline $\begin{array}{r}0 \\
1 \\
2 \\
3 \\
4 \\
5 \\
6 \\
7 \\
8 \\
9 \\
10\end{array}$ & $\begin{array}{r}9.769219 \\
.769393 \\
.769566 \\
.769740 \\
.769913 \\
.770087 \\
.770260 \\
.770433 \\
.770606 \\
.770779 \\
.770952\end{array}$ & $\begin{array}{l}2.90 \\
2.88 \\
2.90 \\
2.88 \\
2.90 \\
2.88 \\
2.88 \\
2.88 \\
2.88 \\
2.88 \\
2.88\end{array}$ & $\begin{array}{r}9.907658 \\
.907866 \\
.907744 \\
.907682 \\
.907590 \\
.907498 \\
.907406 \\
.907314 \\
.907222 \\
.907129 \\
.907037\end{array}$ & $\begin{array}{l}1.53 \\
1.53 \\
1.53 \\
1.53 \\
1.53 \\
1.53 \\
1.53 \\
1.53 \\
1.55 \\
1.53 \\
1.53\end{array}$ & $\begin{array}{r}9.861261 \\
.861527 \\
.861792 \\
.862058 \\
.862323 \\
.862589 \\
.862854 \\
.863119 \\
.863385 \\
.863650 \\
.863915\end{array}$ & $\begin{array}{l}4.43 \\
4.42 \\
4.43 \\
4.42 \\
4.43 \\
4.42 \\
4.42 \\
4.43 \\
4.42 \\
4.42 \\
4.42\end{array}$ & $\begin{array}{r}10.138739 \\
.138473 \\
.138208 \\
.137942 \\
.137677 \\
.137411 \\
.137146 \\
.136881 \\
.136615 \\
.136350 \\
.136085\end{array}$ & $\begin{array}{l}60 \\
59 \\
58 \\
57 \\
56 \\
55 \\
54 \\
53 \\
52 \\
51 \\
50\end{array}$ \\
\hline $\begin{array}{l}11 \\
12 \\
13 \\
14 \\
15 \\
16 \\
17 \\
18 \\
19 \\
20\end{array}$ & $\begin{array}{r}9.771125 \\
.771298 \\
.771470 \\
.771643 \\
.771815 \\
.771987 \\
.772159 \\
.772331 \\
.772503 \\
.772675\end{array}$ & $\begin{array}{l}2.88 \\
2.87 \\
2.88 \\
2.87 \\
2.87 \\
2.87 \\
2.87 \\
2.87 \\
2.87 \\
2.87\end{array}$ & $\begin{array}{r}9.906945 \\
.906852 \\
.906760 \\
.906667 \\
.906575 \\
.906482 \\
.906389 \\
.906296 \\
.906204 \\
.906111\end{array}$ & $\begin{array}{l}1.55 \\
1.53 \\
1.55 \\
1.53 \\
1.55 \\
1.55 \\
1.55 \\
1.53 \\
1.55 \\
1.55\end{array}$ & $\begin{array}{r}9.864180 \\
.864445 \\
.864710 \\
.864975 \\
.865240 \\
.865505 \\
.865770 \\
.866035 \\
.866300 \\
.866564\end{array}$ & $\begin{array}{l}4.42 \\
4.42 \\
4.42 \\
4.42 \\
4.42 \\
4.42 \\
4.42 \\
4.42 \\
4.40 \\
4.42\end{array}$ & $\begin{array}{r}10.135820 \\
.135555 \\
.135290 \\
.135025 \\
.134760 \\
.134495 \\
.134230 \\
.133965 \\
.133700 \\
.133436\end{array}$ & $\begin{array}{l}49 \\
48 \\
47 \\
46 \\
45 \\
44 \\
43 \\
42 \\
41 \\
40\end{array}$ \\
\hline $\begin{array}{l}21 \\
22 \\
23 \\
24 \\
25 \\
26 \\
27 \\
28 \\
29 \\
30\end{array}$ & $\begin{array}{r}9.772847 \\
.773018 \\
.773190 \\
.773361 \\
.773533 \\
.773704 \\
.773875 \\
.774046 \\
.744217 \\
.774388\end{array}$ & $\begin{array}{l}2.85 \\
2.87 \\
2.85 \\
2.87 \\
2.85 \\
2.85 \\
2.85 \\
2.85 \\
2.85 \\
2.83\end{array}$ & $\begin{array}{r}9.906018 \\
.905925 \\
.905832 \\
.905739 \\
.905645 \\
.905552 \\
.905459 \\
.905366 \\
.905272 \\
.905179\end{array}$ & $\begin{array}{l}1.55 \\
1.55 \\
1.55 \\
1.55 \\
1.57 \\
1.55 \\
1.55 \\
1.55 \\
1.57 \\
1.55 \\
1.57\end{array}$ & $\begin{array}{r}9.866829 \\
.867094 \\
.867358 \\
.867623 \\
.867887 \\
.868152 \\
.868416 \\
.868680 \\
.868945 \\
.869209\end{array}$ & $\begin{array}{l}4.42 \\
4.40 \\
4.42 \\
4.40 \\
4.42 \\
4.40 \\
4.40 \\
4.42 \\
4.40 \\
4.40\end{array}$ & $\begin{array}{r}10.133171 \\
.132906 \\
.132642 \\
.1323 \% \\
.132113 \\
.131848 \\
.131584 \\
.131320 \\
.131055 \\
.130791\end{array}$ & $\begin{array}{l}39 \\
38 \\
37 \\
36 \\
35 \\
34 \\
33 \\
33 \\
31 \\
30\end{array}$ \\
\hline $\begin{array}{l}31 \\
32 \\
33 \\
34 \\
35 \\
36 \\
37 \\
38 \\
39 \\
40\end{array}$ & $\begin{array}{r}9.774558 \\
.774729 \\
.774899 \\
.775070 \\
.775240 \\
.775410 \\
.775580 \\
.775750 \\
.775920 \\
.776090\end{array}$ & $\begin{array}{l}2.85 \\
2.83 \\
2.85 \\
2.83 \\
2.83 \\
2.83 \\
2.83 \\
2.83 \\
2.83 \\
2.82\end{array}$ & $\begin{array}{r}9.905085 \\
.904992 \\
.904898 \\
.904804 \\
.904711 \\
.904617 \\
.904523 \\
.9044 \% 9 \\
.904335 \\
.904241\end{array}$ & $\begin{array}{l}1.55 \\
1.57 \\
1.57 \\
1.55 \\
1.57 \\
1.57 \\
1.57 \\
1.57 \\
1.57 \\
1.57\end{array}$ & $\begin{array}{r}9.869473 \\
.869737 \\
.870001 \\
.870265 \\
.870529 \\
.870793 \\
.871057 \\
.871321 \\
.871585 \\
.871849\end{array}$ & $\begin{array}{l}4.40 \\
4.40 \\
4.40 \\
4.40 \\
4.40 \\
4.40 \\
4.40 \\
4.40 \\
4.40 \\
4.38\end{array}$ & $\begin{array}{r}10.130527 \\
.130263 \\
.129999 \\
.129 \% 35 \\
.129471 \\
.129207 \\
.128943 \\
.128679 \\
.128415 \\
.128151\end{array}$ & $\begin{array}{l}29 \\
28 \\
27 \\
26 \\
25 \\
24 \\
23 \\
22 \\
21 \\
20\end{array}$ \\
\hline $\begin{array}{l}41 \\
42 \\
43 \\
44 \\
45 \\
46 \\
47 \\
48 \\
49 \\
50\end{array}$ & $\begin{array}{r}9.776259 \\
.776429 \\
.776598 \\
.776768 \\
.776937 \\
.777106 \\
.777275 \\
.777444 \\
.777613 \\
.777781\end{array}$ & $\begin{array}{l}2.83 \\
2.82 \\
2.83 \\
2.82 \\
2.82 \\
2.82 \\
2.82 \\
2.82 \\
2.80 \\
2.82\end{array}$ & $\begin{array}{r}9.904147 \\
.904053 \\
.903959 \\
.903864 \\
.903770 \\
.903676 \\
.903581 \\
.903487 \\
.903392 \\
.903298\end{array}$ & $\begin{array}{l}1.57 \\
1.57 \\
1.58 \\
1.57 \\
1.57 \\
1.58 \\
1.57 \\
1.58 \\
1.57 \\
1.58\end{array}$ & $\begin{array}{r}9.872112 \\
.872376 \\
.872640 \\
.872903 \\
.873167 \\
.873430 \\
.873694 \\
.873957 \\
.874220 \\
.874484\end{array}$ & $\begin{array}{l}4.40 \\
4.40 \\
4.38 \\
4.40 \\
4.38 \\
4.40 \\
4.38 \\
4.38 \\
4.40\end{array}$ & $\begin{array}{r}10.127888 \\
.127624 \\
.127360 \\
.127097 \\
.126833 \\
.126570 \\
.126306 \\
.126043 \\
.125780 \\
.125516\end{array}$ & $\begin{array}{l}19 \\
18 \\
17 \\
16 \\
15 \\
14 \\
13 \\
12 \\
11 \\
10\end{array}$ \\
\hline $\begin{array}{l}51 \\
52 \\
53 \\
54 \\
55 \\
56 \\
57 \\
58 \\
59 \\
60\end{array}$ & $\begin{array}{r}9.777950 \\
.778119 \\
.778287 \\
.778455 \\
.778624 \\
.778792 \\
.778960 \\
.779128 \\
.779295 \\
9.779463\end{array}$ & $\begin{array}{l}2.82 \\
2.80 \\
2.80 \\
2.82 \\
2.80 \\
2.80 \\
2.80 \\
2.78 \\
2.80\end{array}$ & $\begin{array}{r}9.903203 \\
.903108 \\
.903014 \\
.902919 \\
.902824 \\
.902729 \\
.902634 \\
.902539 \\
.902444 \\
9.902349\end{array}$ & $\begin{array}{l}1.58 \\
1.57 \\
1.58 \\
1.58 \\
1.58 \\
1.58 \\
1.58 \\
1.58 \\
1.58\end{array}$ & $\begin{array}{r}9.874747 \\
.875010 \\
.875273 \\
.875537 \\
.875800 \\
.876063 \\
.876326 \\
.876589 \\
.876852 \\
9.877114\end{array}$ & $\begin{array}{l}4.38 \\
4.38 \\
4.40 \\
4.38 \\
4.38 \\
4.38 \\
4.38 \\
4.38 \\
4.37\end{array}$ & $\begin{array}{r}10.125253 \\
.124990 \\
.124727 \\
.124463 \\
.124200 \\
.123937 \\
.123674 \\
.123411 \\
.123148 \\
10.122886\end{array}$ & $\begin{array}{l}9 \\
8 \\
7 \\
6 \\
5 \\
4 \\
3 \\
2 \\
1 \\
0\end{array}$ \\
\hline 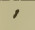 & Cosine. & D. $1^{\prime \prime}$ & Sine. & D. $1^{\circ}$. & Cotang. & D. $1^{\circ}$. & Tang. & 1 \\
\hline
\end{tabular}




\begin{tabular}{|c|c|c|c|c|c|c|c|c|}
\hline , & Sine. & D. $1^{\circ}$. & Cosine. & D. $1^{\circ}$. & Tang. & D. $1^{\circ}$. & Cotang. & , \\
\hline $\begin{array}{r}0 \\
1 \\
2 \\
3 \\
4 \\
5 \\
6 \\
7 \\
5 \\
9 \\
10\end{array}$ & $\begin{array}{r}9.779463 \\
.79631 \\
.779798 \\
.779966 \\
.780133 \\
.780300 \\
.780467 \\
780634 \\
.780801 \\
.780968 \\
.781134\end{array}$ & $\begin{array}{l}2.80 \\
2.78 \\
2.80 \\
2.78 \\
2.78 \\
2.78 \\
2.78 \\
2.78 \\
2.78 \\
2.77 \\
2.78\end{array}$ & $\begin{array}{r}9.902349 \\
.902253 \\
.902158 \\
.902063 \\
.901967 \\
.901872 \\
.9017 \% 6 \\
.901681 \\
.901585 \\
.901490 \\
.901394\end{array}$ & $\begin{array}{l}1.60 \\
1.58 \\
1.58 \\
1.60 \\
1.58 \\
1.60 \\
1.58 \\
1.60 \\
1.58 \\
1.60 \\
1.60\end{array}$ & $\begin{array}{r}9.871114 \\
.871377 \\
.87640 \\
.877903 \\
.878165 \\
.878428 \\
.878691 \\
.878953 \\
.879216 \\
.879478 \\
.879741\end{array}$ & $\begin{array}{l}4.38 \\
4.38 \\
4.38 \\
4.37 \\
4.38 \\
4.38 \\
4.37 \\
4.38 \\
4.37 \\
4.38 \\
4.37\end{array}$ & $\begin{array}{r}10.122886 \\
.122623 \\
.122360 \\
.122097 \\
.121835 \\
.121572 \\
.121309 \\
.121047 \\
.120784 \\
.120522 \\
.120259\end{array}$ & $\begin{array}{l}60 \\
59 \\
58 \\
57 \\
56 \\
55 \\
54 \\
53 \\
52 \\
51 \\
50\end{array}$ \\
\hline $\begin{array}{l}11 \\
12 \\
13 \\
14 \\
15 \\
16 \\
17 \\
18 \\
19 \\
20\end{array}$ & $\begin{array}{r}9.781301 \\
.781468 \\
.781634 \\
.781800 \\
.781966 \\
.782132 \\
.782298 \\
.782461 \\
.782630 \\
.782796\end{array}$ & $\begin{array}{l}2.78 \\
2.77 \\
2.77 \\
2.77 \\
2.77 \\
2.77 \\
2.77 \\
2.77 \\
2.77 \\
2.75\end{array}$ & $\begin{array}{r}9.901298 \\
.901202 \\
.901106 \\
.901010 \\
.900914 \\
.900818 \\
.900722 \\
.900626 \\
.900529 \\
.900433\end{array}$ & $\begin{array}{l}1.60 \\
1.60 \\
1.60 \\
1.60 \\
1.60 \\
1.60 \\
1.60 \\
1.62 \\
1.60 \\
1.60\end{array}$ & $\begin{array}{r}9.880003 \\
.880265 \\
.880528 \\
.880190 \\
.881052 \\
.881314 \\
.881577 \\
.881839 \\
.882101 \\
.882363\end{array}$ & $\begin{array}{l}4.37 \\
4.38 \\
4.37 \\
4.37 \\
4.37 \\
4.38 \\
4.37 \\
4.37 \\
4.37 \\
4.37\end{array}$ & $\begin{array}{r}10.119997 \\
.119735 \\
.119472 \\
.119210 \\
.118948 \\
.118686 \\
.118423 \\
.118761 \\
.117899 \\
.117637\end{array}$ & $\begin{array}{l}49 \\
48 \\
47 \\
46 \\
45 \\
44 \\
43 \\
42 \\
41 \\
40\end{array}$ \\
\hline $\begin{array}{l}21 \\
22 \\
23 \\
24 \\
25 \\
26 \\
27 \\
29 \\
29 \\
30\end{array}$ & $\begin{array}{r}9.782961 \\
.783127 \\
.783292 \\
.783458 \\
.783623 \\
.783788 \\
.783953 \\
.784118 \\
.781282 \\
.784447\end{array}$ & $\begin{array}{l}2.77 \\
2.75 \\
2.77 \\
2.75 \\
.2 .75 \\
2.75 \\
2.75 \\
2.73 \\
2.75 \\
2.75\end{array}$ & $\begin{array}{r}9.900337 \\
.900240 \\
.900144 \\
.900047 \\
.899951 \\
.899854 \\
.899757 \\
.899660 \\
.899564 \\
.899467\end{array}$ & $\begin{array}{l}1.62 \\
1.60 \\
1.62 \\
1.60 \\
1.62 \\
1.62 \\
1.62 \\
1.60 \\
1.62 \\
1.62\end{array}$ & $\begin{array}{r}9.882625 \\
.882887 \\
.883143 \\
.883410 \\
.883672 \\
.883931 \\
.884196 \\
.881457 \\
.884719 \\
.884980\end{array}$ & $\begin{array}{l}4.37 \\
4.35 \\
4.37 \\
4.37 \\
4.37 \\
4.37 \\
4.35 \\
4.37 \\
4.35 \\
4.37\end{array}$ & $\begin{array}{r}10.117375 \\
.117113 \\
.116852 \\
.116590 \\
.116328 \\
.116066 \\
.115804 \\
.115543 \\
.115281 \\
.115020\end{array}$ & $\begin{array}{l}39 \\
38 \\
37 \\
36 \\
35 \\
34 \\
33 \\
32 \\
31 \\
30\end{array}$ \\
\hline $\begin{array}{l}31 \\
32 \\
33 \\
34 \\
35 \\
36 \\
37 \\
38 \\
39 \\
40\end{array}$ & $\begin{array}{r}9.784612 \\
.784776 \\
.784941 \\
.785105 \\
.785269 \\
.785433 \\
.785597 \\
.785761 \\
.785925 \\
.786089\end{array}$ & $\begin{array}{l}2.73 \\
2.75 \\
2.73 \\
2.73 \\
2.73 \\
2.73 \\
2.73 \\
2.73 \\
2.73 \\
2.72\end{array}$ & $\begin{array}{r}9.899370 \\
.899273 \\
.899176 \\
.899078 \\
.898981 \\
.898884 \\
.898787 \\
.898689 \\
.898592 \\
.898494\end{array}$ & $\begin{array}{l}1.62 \\
1.62 \\
1.63 \\
1.62 \\
1.62 \\
1.62 \\
1.63 \\
1.62 \\
1.63 \\
1.62\end{array}$ & $\begin{array}{r}9.885242 \\
.885501 \\
.885765 \\
.886026 \\
.886288 \\
.886549 \\
.886811 \\
.887072 \\
.887333 \\
.887594\end{array}$ & $\begin{array}{l}4.31 \\
4.35 \\
4.35 \\
4.37 \\
4.35 \\
4.37 \\
4.35 \\
4.35 \\
4.35 \\
4.35\end{array}$ & $\begin{array}{r}10.114758 \\
.114496 \\
.114235 \\
.113974 \\
.113712 \\
.113451 \\
.113189 \\
.112928 \\
.112667 \\
.112406\end{array}$ & $\begin{array}{l}29 \\
28 \\
2 \pi \\
26 \\
25 \\
24 \\
23 \\
22 \\
21 \\
20\end{array}$ \\
\hline $\begin{array}{l}41 \\
42 \\
43 \\
44 \\
45 \\
46 \\
47 \\
48 \\
49 \\
50\end{array}$ & $\begin{array}{r}9.786252 \\
.786416 \\
.786579 \\
.786742 \\
.786906 \\
.787069 \\
.787232 \\
.787395 \\
.787557 \\
.787720\end{array}$ & $\begin{array}{l}2.73 \\
2.72 \\
2.72 \\
2.73 \\
2.72 \\
2.72 \\
2.72 \\
2.70 \\
2.72 \\
2.72\end{array}$ & $\begin{array}{r}9.898397 \\
.898299 \\
.898202 \\
.898104 \\
.898006 \\
.897908 \\
.897810 \\
.897712 \\
.897614 \\
.897516\end{array}$ & $\begin{array}{l}1.63 \\
1.62 \\
1.63 \\
1.63 \\
1.63 \\
1.63 \\
1.63 \\
1.63 \\
1.63 \\
1.63\end{array}$ & $\begin{array}{r}9.887855 \\
.888116 \\
.888378 \\
.888639 \\
.888900 \\
.889161 \\
.889421 \\
.869682 \\
.889343 \\
.890204\end{array}$ & $\begin{array}{l}4.35 \\
4.37 \\
4.35 \\
4.35 \\
4.35 \\
4.33 \\
4.35 \\
4.35 \\
4.35 \\
4.35\end{array}$ & $\begin{array}{r}10.112145 \\
.111884 \\
.111622 \\
.111361 \\
.111100 \\
.110839 \\
.110579 \\
.110318 \\
.110057 \\
.109796\end{array}$ & $\begin{array}{l}19 \\
18 \\
17 \\
16 \\
15 \\
14 \\
13 \\
12 \\
11 \\
10\end{array}$ \\
\hline $\begin{array}{l}51 \\
52 \\
53 \\
54 \\
55 \\
56 \\
57 \\
58 \\
59 \\
60\end{array}$ & $\begin{array}{r}9.787883 \\
.788045 \\
.788208 \\
.788370 \\
.788532 \\
.788694 \\
.788856 \\
.789018 \\
.789180 \\
9.789342 \\
\end{array}$ & $\begin{array}{l}2.70 \\
2.72 \\
2.70 \\
2.70 \\
2.70 \\
2.70 \\
2.70 \\
2.70 \\
2.70\end{array}$ & $\begin{array}{r}9.897418 \\
.897320 \\
.897222 \\
.897123 \\
.897025 \\
.896926 \\
.896828 \\
.896729 \\
.896631 \\
9.896532 \\
\end{array}$ & $\begin{array}{l}1.63 \\
1.63 \\
1.65 \\
1.63 \\
1.65 \\
1.63 \\
1.65 \\
1.63 \\
1.65\end{array}$ & $\begin{array}{r}9.890465 \\
.890725 \\
.890986 \\
.891247 \\
.891507 \\
.891766 \\
.892028 \\
.892289 \\
.892549 \\
9.892810 \\
\end{array}$ & $\begin{array}{l}4.33 \\
4.35 \\
4.35 \\
4.33 \\
4.35 \\
4.33 \\
4.35 \\
4.33 \\
4.35\end{array}$ & $\begin{array}{r}10.109535 \\
.109275 \\
.109014 \\
.108753 \\
.108493 \\
.108932 \\
.107972 \\
.107711 \\
.107451 \\
10.107190\end{array}$ & $\begin{array}{l}9 \\
8 \\
7 \\
6 \\
5 \\
4 \\
3 \\
2 \\
1 \\
0\end{array}$ \\
\hline & Cosine. & D. $1^{\circ}$. & Sine. & D. 1". & Cotang. & D. 1 & Tang. & ' \\
\hline
\end{tabular}




\begin{tabular}{|c|c|c|c|c|c|c|c|c|}
\hline ' & Sine. & D. $1^{\circ}$. & Cosine. & D. 1". & Tang. & D. 1". & Cotang. & . \\
\hline $\begin{array}{r}0 \\
1 \\
2 \\
3 \\
4 \\
5 \\
6 \\
7 \\
8 \\
9 \\
10\end{array}$ & $\begin{array}{r}9.789342 \\
.789504 \\
.789665 \\
.789827 \\
.789988 \\
.790149 \\
.790310 \\
.790471 \\
.790632 \\
.790793 \\
.790954\end{array}$ & $\begin{array}{l}2.70 \\
2.68 \\
2.70 \\
2.68 \\
2.68 \\
2.68 \\
2.68 \\
2.68 \\
2.68 \\
2.68 \\
2.68\end{array}$ & $\begin{array}{r}9.896532 \\
.896433 \\
.8963335 \\
.896236 \\
.896137 \\
.896038 \\
.895939 \\
.895840 \\
.895741 \\
.895641 \\
.895542\end{array}$ & $\begin{array}{l}1.65 \\
1.63 \\
1.65 \\
1.65 \\
1.65 \\
1.65 \\
1.65 \\
1.65 \\
1.67 \\
1.65 \\
1.65\end{array}$ & $\begin{array}{r}9.892810 \\
.893070 \\
.893331 \\
.893591 \\
.893851 \\
.894111 \\
.894372 \\
.894632 \\
.894892 \\
.895152 \\
.895412\end{array}$ & $\begin{array}{l}4.33 \\
4.35 \\
4.33 \\
4.33 \\
4.33 \\
4.35 \\
4.33 \\
4.33 \\
4.33 \\
4.33 \\
4.33\end{array}$ & $\begin{array}{r}10.107190 \\
.106930 \\
.106669 \\
.106409 \\
.106149 \\
.105889 \\
.105628 \\
.105368 \\
.105108 \\
.104848 \\
.104588\end{array}$ & $\begin{array}{l}60 \\
59 \\
58 \\
57 \\
56 \\
55 \\
54 \\
53 \\
52 \\
51 \\
50\end{array}$ \\
\hline $\begin{array}{l}11 \\
12 \\
13 \\
14 \\
15 \\
16 \\
17 \\
18 \\
19 \\
20\end{array}$ & $\begin{array}{r}9.791115 \\
.791275 \\
.791436 \\
.791596 \\
.791757 \\
.791917 \\
.792077 \\
.792237 \\
.792397 \\
.792557\end{array}$ & $\begin{array}{l}2.67 \\
2.68 \\
2.67 \\
2.68 \\
2.67 \\
2.67 \\
2.67 \\
2.67 \\
2.67 \\
2.65\end{array}$ & $\begin{array}{r}9.895443 \\
.895343 \\
.895244 \\
.895145 \\
.895045 \\
.894945 \\
.894846 \\
.894746 \\
.894646 \\
.894546\end{array}$ & $\begin{array}{l}1.67 \\
1.65 \\
1.65 \\
1.67 \\
1.67 \\
1.65 \\
1.67 \\
1.67 \\
1.67 \\
1.67\end{array}$ & $\begin{array}{r}9.895672 \\
.895932 \\
.896192 \\
.896452 \\
.896712 \\
.896971 \\
.897231 \\
.897491 \\
.897751 \\
.898010\end{array}$ & $\begin{array}{l}4.30 \\
4.33 \\
4.33 \\
4.33 \\
4.33 \\
4.32 \\
4.33 \\
4.33 \\
4.33 \\
4.32 \\
4.33\end{array}$ & $\begin{array}{r}10.104328 \\
.104068 \\
.103808 \\
.103548 \\
.103288 \\
.103029 \\
.102669 \\
.102509 \\
.102249 \\
.101990\end{array}$ & $\begin{array}{l}49 \\
48 \\
47 \\
46 \\
45 \\
44 \\
43 \\
42 \\
41 \\
40\end{array}$ \\
\hline $\begin{array}{l}21 \\
22 \\
23 \\
24 \\
25 \\
26 \\
27 \\
28 \\
29 \\
30\end{array}$ & $\begin{array}{r}9.792716 \\
.792876 \\
.793035 \\
.793195 \\
.793354 \\
.793514 \\
.793673 \\
.793832 \\
.793991 \\
.794150\end{array}$ & $\begin{array}{l}2.67 \\
2.65 \\
2.67 \\
2.65 \\
2.67 \\
2.65 \\
2.65 \\
2.65 \\
2.65 \\
2.63\end{array}$ & $\begin{array}{r}9.891446 \\
.894346 \\
.891246 \\
.894146 \\
.891046 \\
.893946 \\
.893846 \\
.893745 \\
.893645 \\
.893544\end{array}$ & $\begin{array}{l}1.67 \\
1.67 \\
1.67 \\
1.67 \\
1.67 \\
1.67 \\
1.68 \\
1.67 \\
1.68 \\
1.67\end{array}$ & $\begin{array}{r}9.898270 \\
.898530 \\
.898789 \\
.899049 \\
.899308 \\
.899568 \\
.899827 \\
.900087 \\
.900346 \\
.900605\end{array}$ & $\begin{array}{l}4.33 \\
4.32 \\
4.33 \\
4.32 \\
4.33 \\
4.32 \\
4.33 \\
4.32 \\
4.32 \\
4.32\end{array}$ & $\begin{array}{r}10.101730 \\
.1014 \% \mathrm{C} \\
.101211 \\
.100951 \\
.100692 \\
.100432 \\
.100173 \\
.099913 \\
.099654 \\
.099395\end{array}$ & $\begin{array}{l}39 \\
38 \\
37 \\
36 \\
35 \\
34 \\
33 \\
32 \\
31 \\
30\end{array}$ \\
\hline $\begin{array}{l}31 \\
32 \\
33 \\
34 \\
35 \\
36 \\
37 \\
38 \\
39 \\
40\end{array}$ & $\begin{array}{r}9.794308 \\
.794467 \\
.794626 \\
.794784 \\
.794942 \\
.795101 \\
.795259 \\
.795417 \\
.795575 \\
.795733\end{array}$ & $\begin{array}{l}2.65 \\
2.65 \\
2.63 \\
2.63 \\
2.65 \\
2.63 \\
2.63 \\
2.63 \\
2.63 \\
2.63\end{array}$ & $\begin{array}{r}9.893444 \\
.893343 \\
.893243 \\
.893142 \\
.893041 \\
.892940 \\
.892839 \\
.892739 \\
.892638 \\
.892536\end{array}$ & $\begin{array}{l}1.68 \\
1.67 \\
1.68 \\
1.68 \\
1.68 \\
1.68 \\
1.67 \\
1.68 \\
1.70 \\
1.68\end{array}$ & $\begin{array}{r}9.900864 \\
.901124 \\
.901383 \\
.901642 \\
.901901 \\
.902160 \\
.902420 \\
.902679 \\
.902938 \\
.903197\end{array}$ & $\begin{array}{l}4.32 \\
4.33 \\
4.32 \\
4.32 \\
4.32 \\
4.32 \\
4.33 \\
4.32 \\
4.32 \\
4.32 \\
4.32\end{array}$ & $\begin{array}{r}10.099136 \\
.098876 \\
.098617 \\
.098358 \\
.098099 \\
.097840 \\
.097580 \\
.097321 \\
.097062 \\
.096803\end{array}$ & $\begin{array}{l}29 \\
23 \\
27 \\
26 \\
25 \\
24 \\
23 \\
22 \\
21 \\
20\end{array}$ \\
\hline $\begin{array}{l}41 \\
42 \\
43 \\
44 \\
45 \\
46 \\
47 \\
48 \\
49 \\
50\end{array}$ & $\begin{array}{r}9.795891 \\
.796049 \\
.796206 \\
.796364 \\
.796521 \\
.796679 \\
.796836 \\
.796993 \\
.797150 \\
.797307\end{array}$ & $\begin{array}{l}2.63 \\
2.62 \\
2.63 \\
2.62 \\
2.63 \\
2.62 \\
2.62 \\
2.62 \\
2.62 \\
2.62\end{array}$ & $\begin{array}{r}9.892435 \\
.892334 \\
.892233 \\
.892132 \\
.892030 \\
.891929 \\
.891827 \\
.891726 \\
.891621 \\
.891523\end{array}$ & $\begin{array}{l}1.68 \\
1.68 \\
1.68 \\
1.70 \\
1.68 \\
1.70 \\
1.68 \\
1.70 \\
1.68 \\
1.70\end{array}$ & $\begin{array}{r}9.903456 \\
.903714 \\
.903973 \\
.904232 \\
.904491 \\
.904750 \\
.905008 \\
.905267 \\
.905526 \\
.905785\end{array}$ & $\begin{array}{l}4.30 \\
4.32 \\
4.32 \\
4.32 \\
4.32 \\
4.30 \\
4.32 \\
4.32 \\
4.32 \\
4.30\end{array}$ & $\begin{array}{r}10.096544 \\
.096286 \\
.096027 \\
.095769 \\
.095509 \\
.095250 \\
.094992 \\
.094733 \\
.094474 \\
.094215\end{array}$ & $\begin{array}{l}19 \\
18 \\
17 \\
16 \\
15 \\
14 \\
13 \\
12 \\
11 \\
10\end{array}$ \\
\hline $\begin{array}{l}51 \\
52 \\
53 \\
54 \\
55 \\
56 \\
57 \\
58 \\
59 \\
60\end{array}$ & $\begin{array}{r}9.797464 \\
.797621 \\
.797777 \\
.797934 \\
.798091 \\
.798247 \\
.798403 \\
.798560 \\
.798716 \\
9.798872\end{array}$ & $\begin{array}{l}2.62 \\
2.60 \\
2.62 \\
2.62 \\
2.60 \\
2.60 \\
2.62 \\
2.60 \\
2.60\end{array}$ & $\begin{array}{r}9.891421 \\
.891319 \\
.891217 \\
.891115 \\
.891013 \\
.890911 \\
.890809 \\
.890707 \\
.890605 \\
9.890503\end{array}$ & $\begin{array}{l}1.70 \\
1.70 \\
1.70 \\
1.70 \\
1.70 \\
1.70 \\
1.70 \\
1.70 \\
1.70\end{array}$ & $\begin{array}{r}9.906043 \\
.906302 \\
.906560 \\
.906819 \\
.907077 \\
.907336 \\
.907594 \\
.907853 \\
.908111 \\
9.908369\end{array}$ & $\begin{array}{l}4.32 \\
4.30 \\
4.32 \\
4.30 \\
4.32 \\
4.30 \\
4.32 \\
4.30 \\
4.30\end{array}$ & $\begin{array}{r}10.093957 \\
.093698 \\
.093440 \\
.093181 \\
.092923 \\
.092664 \\
.092406 \\
.092147 \\
.091889 \\
10.091631\end{array}$ & $\begin{array}{l}9 \\
8 \\
7 \\
6 \\
5 \\
4 \\
3 \\
2 \\
1 \\
0\end{array}$ \\
\hline${ }^{\prime}$ & Cosine. & D. 1". & Sine. & D. $\overline{1 "}$. & Cotang. & D. $1^{\prime \prime}$. & Tang. & ' \\
\hline
\end{tabular}




\begin{tabular}{|c|c|c|c|c|c|c|c|c|}
\hline , & Sine. & D. $1^{\prime \prime}$. & Cosine. & D. 1". & Tang. & D. $1^{\prime \prime}$. & Cotang. & ' \\
\hline $\begin{array}{r}0 \\
1 \\
2 \\
3 \\
4 \\
5 \\
6 \\
7 \\
8 \\
9 \\
10\end{array}$ & $\begin{array}{r}9.798872 \\
.799028 \\
.799181 \\
.799339 \\
.799495 \\
.799651 \\
.799806 \\
.799962 \\
.800117 \\
.800272 \\
.800427\end{array}$ & $\begin{array}{l}2.60 \\
2.60 \\
2.58 \\
2.60 \\
2.60 \\
2.58 \\
2.60 \\
2.58 \\
2.58 \\
2.58 \\
2.58\end{array}$ & $\begin{array}{r}9.890503 \\
.890400 \\
.890298 \\
.890195 \\
.890093 \\
.889990 \\
.889888 \\
.889785 \\
.889682 \\
.889579 \\
.889477\end{array}$ & $\begin{array}{l}1.72 \\
1.70 \\
1.72 \\
1.70 \\
1.72 \\
1.70 \\
1.72 \\
1 . \% 2 \\
1.72 \\
1.70 \\
1.72\end{array}$ & $\begin{array}{r}9.908369 \\
.908628 \\
.908986 \\
.909144 \\
.909402 \\
.909660 \\
.909918 \\
.910177 \\
.910435 \\
.910693 \\
.910951\end{array}$ & $\begin{array}{l}4.32 \\
4.30 \\
4.30 \\
4.30 \\
4.30 \\
4.30 \\
4.32 \\
4.30 \\
4.30 \\
4.30 \\
4.30\end{array}$ & $\begin{array}{r}10.091631 \\
.091372 \\
.091114 \\
.090856 \\
.090598 \\
.090340 \\
.090082 \\
.089883 \\
.089565 \\
.089307 \\
.089049\end{array}$ & $\begin{array}{l}60 \\
59 \\
58 \\
57 \\
56 \\
55 \\
54 \\
53 \\
52 \\
51 \\
50\end{array}$ \\
\hline $\begin{array}{l}11 \\
12 \\
13 \\
14 \\
15 \\
16 \\
17 \\
18 \\
19 \\
20\end{array}$ & $\begin{array}{r}9.800582 \\
.800737 \\
.800892 \\
.801047 \\
.801201 \\
.801356 \\
.801511 \\
.801665 \\
.801819 \\
.801973\end{array}$ & $\begin{array}{l}2.58 \\
2.58 \\
2.58 \\
2.57 \\
2.58 \\
2.58 \\
2.57 \\
2.57 \\
2.57 \\
2.58\end{array}$ & $\begin{array}{r}9.889314 \\
.889271 \\
.889168 \\
.889064 \\
.888961 \\
.888858 \\
.888755 \\
.888651 \\
.888548 \\
.888444\end{array}$ & $\begin{array}{l}1.72 \\
1.72 \\
1.73 \\
1.72 \\
1.72 \\
1.72 \\
1.73 \\
1.72 \\
1.73 \\
1.72\end{array}$ & $\begin{array}{r}9.911209 \\
.911467 \\
.911725 \\
.911982 \\
.912240 \\
.912498 \\
.912756 \\
.913014 \\
.9132 \pi 1 \\
.913529\end{array}$ & $\begin{array}{l}4.30 \\
4.30 \\
4.28 \\
4.30 \\
4.30 \\
4.30 \\
4.30 \\
4.28 \\
4.30 \\
4.30\end{array}$ & $\begin{array}{r}10.088791 \\
.088533 \\
.088275 \\
.088018 \\
.087760 \\
.087502 \\
.087244 \\
.086986 \\
.086729 \\
.086471\end{array}$ & $\begin{array}{l}49 \\
48 \\
47 \\
46 \\
45 \\
44 \\
43 \\
42 \\
41 \\
40\end{array}$ \\
\hline $\begin{array}{l}21 \\
22 \\
23 \\
24 \\
25 \\
26 \\
27 \\
28 \\
29 \\
30\end{array}$ & $\begin{array}{r}9.802128 \\
.802282 \\
.802436 \\
.802589 \\
.802743 \\
.802897 \\
.803050 \\
.803204 \\
.803357 \\
.803511\end{array}$ & $\begin{array}{l}2.57 \\
2.57 \\
2.55 \\
2.57 \\
2.57 \\
2.55 \\
2.57 \\
2.55 \\
2.57 \\
2.55\end{array}$ & $\begin{array}{r}9.888341 \\
.888237 \\
.888134 \\
.888030 \\
.887926 \\
.887822 \\
.887718 \\
.887614 \\
.887510 \\
.887406\end{array}$ & $\begin{array}{l}1.73 \\
1.72 \\
1.73 \\
1.73 \\
1.73 \\
1.73 \\
1.73 \\
1.73 \\
1.73 \\
1.73\end{array}$ & $\begin{array}{r}9.913787 \\
.914044 \\
.914302 \\
.914560 \\
.914817 \\
.915075 \\
.915332 \\
.915590 \\
.915847 \\
.916104\end{array}$ & $\begin{array}{l}4.28 \\
4.30 \\
4.30 \\
4.28 \\
4.30 \\
4.28 \\
4.30 \\
4.28 \\
4.28 \\
4.30\end{array}$ & $\begin{array}{r}10.086213 \\
.085956 \\
.085698 \\
.085440 \\
.085183 \\
.084925 \\
.084668 \\
.084410 \\
.084153 \\
.083896\end{array}$ & $\begin{array}{l}39 \\
38 \\
37 \\
36 \\
35 \\
34 \\
33 \\
32 \\
31 \\
30\end{array}$ \\
\hline $\begin{array}{l}31 \\
32 \\
33 \\
34 \\
35 \\
36 \\
37 \\
38 \\
39 \\
40\end{array}$ & $\begin{array}{r}9.803664 \\
.803817 \\
.803970 \\
.804123 \\
.804276 \\
.804428 \\
.804581 \\
.804734 \\
.804886 \\
.805039\end{array}$ & $\begin{array}{l}2.55 \\
2.55 \\
2.55 \\
2.55 \\
2.55 \\
2.55 \\
2.55 \\
2.53 \\
2.55 \\
2.53\end{array}$ & $\begin{array}{r}9.887302 \\
.887198 \\
.887093 \\
.886989 \\
.886885 \\
.886780 \\
.886676 \\
.886571 \\
.886466 \\
.886362\end{array}$ & $\begin{array}{l}1.73 \\
1.75 \\
1.73 \\
1.73 \\
1.75 \\
1.73 \\
1.75 \\
1.75 \\
1.73 \\
1.75\end{array}$ & $\begin{array}{r}9.916362 \\
.916619 \\
.916877 \\
.917134 \\
.917391 \\
.917648 \\
.917906 \\
.918163 \\
.918420 \\
.918677\end{array}$ & $\begin{array}{l}4.28 \\
4.30 \\
4.28 \\
4.28 \\
4.28 \\
4.30 \\
4.28 \\
4.28 \\
4.28 \\
4.28\end{array}$ & $\begin{array}{r}10.083638 \\
.083381 \\
.083123 \\
.082566 \\
.082609 \\
.082352 \\
.083094 \\
.081837 \\
.081580 \\
.081323\end{array}$ & $\begin{array}{l}29 \\
28 \\
27 \\
26 \\
25 \\
24 \\
23 \\
22 \\
21 \\
20\end{array}$ \\
\hline $\begin{array}{l}41 \\
42 \\
43 \\
44 \\
45 \\
46 \\
47 \\
48 \\
49 \\
50\end{array}$ & $\begin{array}{r}9.805191 \\
.805343 \\
.805495 \\
.805647 \\
.805799 \\
.805951 \\
.806103 \\
.806254 \\
.806406 \\
.806557\end{array}$ & $\begin{array}{l}2.50 \\
2.53 \\
2.53 \\
2.53 \\
2.53 \\
2.53 \\
2.52 \\
2.53 \\
2.52 \\
2.53\end{array}$ & $\begin{array}{r}9.886257 \\
.886152 \\
.886047 \\
.885942 \\
.885837 \\
.885732 \\
.885627 \\
.885522 \\
.885416 \\
.885311\end{array}$ & $\begin{array}{l}1.75 \\
1.75 \\
1.75 \\
1.75 \\
1.75 \\
1.75 \\
1.75 \\
1.77 \\
1.75 \\
1.77\end{array}$ & $\begin{array}{r}9.918934 \\
.919191 \\
.919448 \\
.919705 \\
.919962 \\
.920219 \\
.920476 \\
.920733 \\
.920990 \\
.921247\end{array}$ & $\begin{array}{l}4.20 \\
4.28 \\
4.28 \\
4.28 \\
4.28 \\
4.28 \\
4.28 \\
4.28 \\
4.28 \\
4.28 \\
4.27\end{array}$ & $\begin{array}{r}10.081066 \\
.080809 \\
.080552 \\
.080295 \\
.080038 \\
.079781 \\
.079524 \\
.079267 \\
.079010 \\
.078753\end{array}$ & $\begin{array}{l}19 \\
18 \\
17 \\
16 \\
15 \\
14 \\
13 \\
12 \\
11 \\
10\end{array}$ \\
\hline $\begin{array}{l}51 \\
52 \\
53 \\
54 \\
55 \\
56 \\
57 \\
58 \\
59 \\
60\end{array}$ & $\begin{array}{r}9.806709 \\
.806860 \\
.807011 \\
.807163 \\
.807314 \\
.807465 \\
.807615 \\
.807666 \\
.807917 \\
9.808067\end{array}$ & $\begin{array}{l}2.50 \\
2.52 \\
2.52 \\
2.53 \\
2.52 \\
2.52 \\
2.50 \\
2.52 \\
2.52 \\
2.50\end{array}$ & $\begin{array}{r}9.885205 \\
.885100 \\
.884994 \\
.884889 \\
.884783 \\
.884677 \\
.884572 \\
.884466 \\
.884360 \\
9.884254\end{array}$ & $\begin{array}{l}1.75 \\
1.77 \\
1.75 \\
1.77 \\
1.77 \\
1.75 \\
1.77 \\
1.77 \\
1.77\end{array}$ & $\begin{array}{r}9.921503 \\
.921760 \\
.922017 \\
.922274 \\
.922530 \\
.922787 \\
.923044 \\
.923300 \\
.923557 \\
9.923814\end{array}$ & $\begin{array}{l}4.28 \\
4.28 \\
4.28 \\
4.27 \\
4.28 \\
4.28 \\
4.27 \\
4.28 \\
4.28\end{array}$ & $\begin{array}{r}10.078497 \\
.078240 \\
.067953 \\
.06726 \\
.067470 \\
.067213 \\
.076956 \\
.076700 \\
.076413 \\
10.076186\end{array}$ & $\begin{array}{l}9 \\
8 \\
7 \\
6 \\
5 \\
4 \\
3 \\
2 \\
1 \\
0\end{array}$ \\
\hline & & D. $1^{\circ}$. & Sine. & D. 1". & Cotang. & D. $1^{\circ}$ 。 & Tang. & \\
\hline
\end{tabular}




\begin{tabular}{|c|c|c|c|c|c|c|c|c|}
\hline ' & Sine. & D. $1^{\prime \prime}$. & Cosine. & D. $1^{\prime \prime}$. & Tang. & D. $1^{\prime \prime}$. & Cotang. & , \\
\hline \begin{tabular}{r|}
0 \\
1 \\
2 \\
3 \\
4 \\
5 \\
6 \\
7 \\
8 \\
9 \\
10
\end{tabular} & $\begin{array}{r}9.808067 \\
.808218 \\
.808368 \\
.808519 \\
.808669 \\
.808819 \\
.808969 \\
.809119 \\
.809269 \\
.809419 \\
.809569\end{array}$ & $\begin{array}{l}2.52 \\
2.50 \\
2.52 \\
2.50 \\
2.50 \\
2.50 \\
2.50 \\
2.50 \\
2.50 \\
2.50 \\
2.48\end{array}$ & $\begin{array}{r}9.884254 \\
.884148 \\
.884042 \\
.883936 \\
.883829 \\
.883723 \\
.883617 \\
.883510 \\
.883404 \\
.883297 \\
.883191\end{array}$ & $\begin{array}{l}1.77 \\
1.77 \\
1.77 \\
1.78 \\
1.77 \\
1.77 \\
1.78 \\
1.77 \\
1.78 \\
1.77 \\
1.78\end{array}$ & $\begin{array}{r}9.923814 \\
.924070 \\
.924327 \\
.924583 \\
.924840 \\
.925096 \\
.925352 \\
.925609 \\
.925865 \\
.926122 \\
.926378\end{array}$ & $\begin{array}{l}4.27 \\
4.28 \\
4.27 \\
4.28 \\
4.27 \\
4.27 \\
4.28 \\
4.27 \\
4.28 \\
4.27 \\
4.27\end{array}$ & $\begin{array}{r}10.076186 \\
.075930 \\
.0756 \% 3 \\
.075417 \\
.075160 \\
.074904 \\
.074648 \\
.074391 \\
.074135 \\
.073878 \\
.073622\end{array}$ & $\begin{array}{l}60 \\
59 \\
58 \\
57 \\
56 \\
55 \\
54 \\
53 \\
52 \\
51 \\
50\end{array}$ \\
\hline $\begin{array}{l}11 \\
12 \\
13 \\
14 \\
15 \\
16 \\
17 \\
18 \\
19 \\
20\end{array}$ & $\begin{array}{r}9.809718 \\
.809868 \\
.810017 \\
.810107 \\
.810316 \\
.810465 \\
.810614 \\
.810763 \\
.810912 \\
.811061\end{array}$ & $\begin{array}{l}2.50 \\
2.48 \\
2.50 \\
2.48 \\
2.48 \\
2.48 \\
2.48 \\
2.48 \\
2.48 \\
2.48\end{array}$ & $\begin{array}{r}9.883084 \\
.882977 \\
.882871 \\
.882 \% 64 \\
.88265 \% \\
.882550 \\
.882443 \\
.882336 \\
.882229 \\
.882121\end{array}$ & $\begin{array}{l}1.78 \\
1.77 \\
1.78 \\
1.78 \\
1.78 \\
1.78 \\
1.78 \\
1.78 \\
1.80 \\
1.78\end{array}$ & $\begin{array}{r}9.926634 \\
.926890 \\
.927147 \\
.927403 \\
.927659 \\
.927915 \\
.928171 \\
.928427 \\
.928684 \\
.928940\end{array}$ & $\begin{array}{l}4.27 \\
4.28 \\
4.27 \\
4.27 \\
4.27 \\
4.27 \\
4.27 \\
4.28 \\
4.27 \\
4.27\end{array}$ & $\begin{array}{r}10.073366 \\
.073110 \\
.072853 \\
.072597 \\
.072341 \\
.072085 \\
.071829 \\
.071573 \\
.071316 \\
.071060\end{array}$ & $\begin{array}{l}49 \\
48 \\
47 \\
46 \\
45 \\
44 \\
43 \\
42 \\
41 \\
40\end{array}$ \\
\hline $\begin{array}{l}21 \\
22 \\
23 \\
24 \\
25 \\
26 \\
27 \\
28 \\
29 \\
30\end{array}$ & $\begin{array}{r}9.811210 \\
.811358 \\
.811507 \\
.811655 \\
.811804 \\
.811952 \\
.812100 \\
.812248 \\
.812396 \\
.812544\end{array}$ & $\begin{array}{l}2.47 \\
2.48 \\
2.47 \\
2.48 \\
2.47 \\
2.47 \\
2.47 \\
2.47 \\
2.47 \\
2.47\end{array}$ & $\begin{array}{r}9.882014 \\
.881907 \\
.881799 \\
.881692 \\
.881584 \\
.881477 \\
.881369 \\
.881261 \\
.881153 \\
.881046\end{array}$ & $\begin{array}{l}1.78 \\
1.80 \\
1.78 \\
1.80 \\
1.78 \\
1.80 \\
1.80 \\
1.80 \\
1.78 \\
1.80\end{array}$ & $\begin{array}{r}9.929196 \\
.929452 \\
.929708 \\
.929964 \\
.930220 \\
.930475 \\
.930731 \\
.930987 \\
.931243 \\
.931499\end{array}$ & $\begin{array}{l}4.27 \\
4.27 \\
4.27 \\
4.27 \\
4.25 \\
4.27 \\
4.27 \\
4.27 \\
4.27 \\
4.27\end{array}$ & $\begin{array}{r}10.070804 \\
.070548 \\
.070202 \\
.070036 \\
.069780 \\
.069525 \\
.069269 \\
.069013 \\
.068757 \\
.068501\end{array}$ & $\begin{array}{l}39 \\
38 \\
3 \pi \\
36 \\
35 \\
34 \\
33 \\
32 \\
31 \\
30\end{array}$ \\
\hline $\begin{array}{l}31 \\
32 \\
33 \\
34 \\
35 \\
36 \\
37 \\
38 \\
39 \\
40\end{array}$ & $\begin{array}{r}9.812692 \\
.812840 \\
.812988 \\
.813135 \\
.813283 \\
.813430 \\
.813578 \\
.813725 \\
.813872 \\
.814019\end{array}$ & $\begin{array}{l}2.47 \\
2.47 \\
2.45 \\
2.47 \\
2.45 \\
2.47 \\
2.45 \\
2.45 \\
2.45 \\
2.45\end{array}$ & $\begin{array}{r}9.880938 \\
.880830 \\
.880722 \\
.880613 \\
.880505 \\
.880397 \\
.880289 \\
.880180 \\
.880072 \\
.879963\end{array}$ & $\begin{array}{l}1.80 \\
1.80 \\
1.82 \\
1.80 \\
1.80 \\
1.80 \\
1.82 \\
1.80 \\
1.82 \\
1.80\end{array}$ & $\begin{array}{r}9.931755 \\
.932010 \\
.932266 \\
.932522 \\
.932778 \\
.933033 \\
.933289 \\
.933545 \\
.933800 \\
.934056\end{array}$ & $\begin{array}{l}4.25 \\
4.27 \\
4.27 \\
4.27 \\
4.25 \\
4.27 \\
4.27 \\
4.25 \\
4.27 \\
4.25\end{array}$ & $\begin{array}{r}10.068245 \\
.067990 \\
.067734 \\
.067478 \\
.067222 \\
.066967 \\
.066711 \\
.066455 \\
.066200 \\
.065944\end{array}$ & $\begin{array}{l}29 \\
28 \\
27 \\
26 \\
25 \\
24 \\
23 \\
22 \\
21 \\
20\end{array}$ \\
\hline $\begin{array}{l}41 \\
42 \\
43 \\
44 \\
45 \\
46 \\
47 \\
48 \\
49 \\
50\end{array}$ & $\begin{array}{r}9.814166 \\
.814313 \\
.814460 \\
.814607 \\
.814753 \\
.814900 \\
.815046 \\
.815193 \\
.815339 \\
.815485\end{array}$ & $\begin{array}{l}2.45 \\
2.45 \\
2.45 \\
2.43 \\
2.45 \\
2.43 \\
2.45 \\
2.43 \\
2.43 \\
2.45\end{array}$ & $\begin{array}{r}9.879855 \\
.879746 \\
.879637 \\
.879529 \\
.879420 \\
.879311 \\
.879202 \\
.879093 \\
.878984 \\
.878875\end{array}$ & $\begin{array}{l}1.82 \\
1.82 \\
1.80 \\
1.82 \\
1.82 \\
1.82 \\
1.82 \\
1.82 \\
1.82 \\
1.82\end{array}$ & $\begin{array}{r}9.934311 \\
.93456 \pi \\
.934822 \\
.935078 \\
.935333 \\
.935589 \\
.935844 \\
.936100 \\
.936355 \\
.936611\end{array}$ & $\begin{array}{l}4.27 \\
4.25 \\
4.27 \\
4.25 \\
4.27 \\
4.25 \\
4.27 \\
4.25 \\
4.27 \\
4.25\end{array}$ & $\begin{array}{r}10.065689 \\
.065433 \\
.065178 \\
.064922 \\
.064667 \\
.064411 \\
.064156 \\
.063900 \\
.063645 \\
.063389\end{array}$ & $\begin{array}{l}19 \\
18 \\
17 \\
16 \\
15 \\
14 \\
13 \\
12 \\
11 \\
10\end{array}$ \\
\hline $\begin{array}{l}51 \\
52 \\
53 \\
54 \\
55 \\
56 \\
57 \\
58 \\
59 \\
60\end{array}$ & $\begin{array}{r}9.815632 \\
.81578 \\
.815924 \\
.816069 \\
.816215 \\
.816361 \\
.816507 \\
.816652 \\
.816798 \\
9.816943\end{array}$ & $\begin{array}{l}2.43 \\
2.43 \\
2.42 \\
2.43 \\
2.43 \\
2.43 \\
2.42 \\
2.43 \\
2.42\end{array}$ & $\begin{array}{r}9.878766 \\
.878656 \\
.878547 \\
.878438 \\
.878328 \\
.878219 \\
.878109 \\
.877999 \\
.877890 \\
9.877780\end{array}$ & $\begin{array}{l}1.83 \\
1.82 \\
1.82 \\
1.83 \\
1.82 \\
1.83 \\
1.83 \\
1.82 \\
1.83\end{array}$ & $\begin{array}{r}9.936866 \\
.937121 \\
.937377 \\
.937632 \\
.937887 \\
.938142 \\
.938398 \\
.938653 \\
.938908 \\
9.939163\end{array}$ & $\begin{array}{l}4.25 \\
4.27 \\
4.25 \\
4.25 \\
4.25 \\
4.27 \\
4.25 \\
4.25 \\
4.25\end{array}$ & $\begin{array}{r}10.063134 \\
.062879 \\
.062623 \\
.062368 \\
.062113 \\
.061858 \\
.061602 \\
.061347 \\
.061092 \\
10.060837\end{array}$ & $\begin{array}{l}9 \\
8 \\
7 \\
6 \\
5 \\
4 \\
3 \\
2 \\
1 \\
0\end{array}$ \\
\hline$\prime$ & Cosine. & D. 1". & Sine. & D. $1^{\prime \prime}$. & ng. & D. 1". & Tang. & ' \\
\hline
\end{tabular}




\begin{tabular}{|c|c|c|c|c|c|c|c|c|}
\hline , & Sine. & D. $1^{\prime \prime}$. & Cosine. & D. $1^{\circ}$. & Tang. & D. $1^{\circ}$. & Cotang. & , \\
\hline $\begin{array}{r}0 \\
1 \\
2 \\
3 \\
4 \\
5 \\
6 \\
7 \\
8 \\
9 \\
10\end{array}$ & $\begin{array}{r}9.816913 \\
.817089 \\
.817233 \\
.817379 \\
.817524 \\
.817663 \\
.817813 \\
.8179 .9 \\
.818103 \\
.818247 \\
.818392\end{array}$ & $\begin{array}{l}2.42 \\
2.42 \\
2.43 \\
2.42 \\
2.40 \\
2.42 \\
2.42 \\
2.42 \\
2.40 \\
2.42 \\
2.40\end{array}$ & $\begin{array}{r}9.8 \% 780 \\
.87670 \\
.8 \% 760 \\
.87450 \\
.87 \% 340 \\
.87 \% 230 \\
.87 \% 120 \\
.87010 \\
.876899 \\
.876789 \\
.876678\end{array}$ & $\begin{array}{l}1.83 \\
1.83 \\
1.83 \\
1.83 \\
1.83 \\
1.83 \\
1.83 \\
1.85 \\
1.83 \\
1.85 \\
1.83\end{array}$ & $\begin{array}{r}9.939163 \\
.939118 \\
.9396 \pi 3 \\
.939928 \\
.940183 \\
.940439 \\
.940694 \\
.940949 \\
.941204 \\
.941459 \\
.941713\end{array}$ & $\begin{array}{l}4.25 \\
4.25 \\
4.25 \\
4.25 \\
4.27 \\
4.25 \\
4.25 \\
4.25 \\
4.25 \\
4.23 \\
4.25\end{array}$ & $\begin{array}{r}10.06089 \pi \\
.060582 \\
.06032 i \\
.060072 \\
.05981 \% \\
.059561 \\
.059306 \\
.059051 \\
.058796 \\
.058541 \\
.05828 \%\end{array}$ & $\begin{array}{l}60 \\
59 \\
58 \\
57 \\
56 \\
55 \\
51 \\
53 \\
52 \\
51 \\
50\end{array}$ \\
\hline $\begin{array}{l}11 \\
12 \\
13 \\
14 \\
15 \\
16 \\
1 \% \\
18 \\
19 \\
20\end{array}$ & $\begin{array}{r}9.818536 \\
.818681 \\
.818825 \\
.818989 \\
.819113 \\
.819251 \\
.819401 \\
.819545 \\
.819689 \\
.819832\end{array}$ & $\begin{array}{l}2.42 \\
2.40 \\
2.40 \\
2.40 \\
2.40 \\
2.40 \\
2.40 \\
2.40 \\
2.39 \\
2.40\end{array}$ & $\begin{array}{c}9.876568 \\
.876457 \\
.876347 \\
.876236 \\
.876125 \\
.876014 \\
.875901 \\
.875793 \\
.875682 \\
.875571\end{array}$ & $\begin{array}{l}1.85 \\
1.83 \\
1.85 \\
1.85 \\
1.85 \\
1.83 \\
1.85 \\
1.85 \\
1.85 \\
1.8 \%\end{array}$ & $\begin{array}{r}9.941968 \\
.942223 \\
.942478 \\
.942733 \\
.942988 \\
.943213 \\
.943498 \\
.943752 \\
.944007 \\
.941262\end{array}$ & $\begin{array}{l}4.25 \\
4.25 \\
4.25 \\
4.25 \\
4.25 \\
4.25 \\
4.23 \\
4.25 \\
4.25 \\
4.25\end{array}$ & $\begin{array}{r}10.058032 \\
.05777 \\
.057522 \\
.057261 \\
.057012 \\
.056757 \\
.056502 \\
.056218 \\
.055993 \\
.055738\end{array}$ & $\begin{array}{l}49 \\
48 \\
47 \\
46 \\
45 \\
44 \\
43 \\
42 \\
41 \\
40\end{array}$ \\
\hline $\begin{array}{l}21 \\
22 \\
23 \\
21 \\
25 \\
26 \\
27 \\
23 \\
29 \\
30\end{array}$ & $\begin{array}{r}9.819976 \\
.820120 \\
.820263 \\
.820406 \\
.820550 \\
.820693 \\
.820836 \\
.820979 \\
.821122 \\
.821265\end{array}$ & $\begin{array}{l}2.40 \\
2.38 \\
2.38 \\
2.40 \\
2.38 \\
2.38 \\
2.38 \\
2.38 \\
2.38 \\
2.37\end{array}$ & $\begin{array}{r}9.875459 \\
.875348 \\
.875237 \\
.875126 \\
.875014 \\
.874903 \\
.874791 \\
.874680 \\
.874568 \\
.874456\end{array}$ & $\begin{array}{l}1.07 \\
1.85 \\
1.85 \\
1.85 \\
1.87 \\
1.85 \\
1.87 \\
1.85 \\
1.87 \\
1.87 \\
1.87\end{array}$ & $\begin{array}{r}9.944517 \\
.94471 \\
.945026 \\
.945281 \\
.945535 \\
.945790 \\
.946045 \\
.946299 \\
.946554 \\
.946808\end{array}$ & $\begin{array}{l}4.23 \\
4.25 \\
4.25 \\
4.23 \\
4.25 \\
4.25 \\
4.23 \\
4.25 \\
4.23 \\
4.25\end{array}$ & $\begin{array}{r}10.055483 \\
.055229 \\
.054974 \\
.054719 \\
.054465 \\
.054210 \\
.053955 \\
.053701 \\
.053446 \\
.053192\end{array}$ & $\begin{array}{l}39 \\
39 \\
37 \\
36 \\
35 \\
34 \\
33 \\
32 \\
31 \\
50\end{array}$ \\
\hline $\begin{array}{l}31 \\
32 \\
33 \\
34 \\
35 \\
36 \\
37 \\
38 \\
39 \\
40\end{array}$ & $\begin{array}{r}9.821407 \\
.821550 \\
.821693 \\
.821835 \\
.821977 \\
.822120 \\
.822262 \\
.822404 \\
.822546 \\
.8222688\end{array}$ & $\begin{array}{l}2.38 \\
2.38 \\
2.37 \\
2.37 \\
2.38 \\
2.37 \\
2.37 \\
2.37 \\
2.37 \\
2.37\end{array}$ & $\begin{array}{r}9.874341 \\
.874232 \\
.874121 \\
.874009 \\
.873896 \\
.873781 \\
.873672 \\
.873560 \\
.873448 \\
.873335\end{array}$ & $\begin{array}{l}1.87 \\
1.85 \\
1.87 \\
1.88 \\
1.87 \\
1.87 \\
1.87 \\
1.87 \\
1.88 \\
1.8 \%\end{array}$ & $\begin{array}{r}9.947063 \\
.947318 \\
.9475 \% 2 \\
.947827 \\
.948081 \\
.948335 \\
.948590 \\
.948844 \\
.949099 \\
.949353\end{array}$ & $\begin{array}{l}4.25 \\
4.23 \\
4.25 \\
4.23 \\
4.33 \\
4.25 \\
4.23 \\
4.25 \\
4.23 \\
4.25\end{array}$ & $\begin{array}{r}10.05293 \% \\
.052682 \\
.052428 \\
.052173 \\
.051919 \\
.051665 \\
.051410 \\
.051156 \\
.050901 \\
.050647\end{array}$ & $\begin{array}{l}29 \\
28 \\
27 \\
26 \\
25 \\
24 \\
23 \\
22 \\
21 \\
20\end{array}$ \\
\hline $\begin{array}{l}41 \\
42 \\
43 \\
44 \\
45 \\
46 \\
47 \\
48 \\
49 \\
50\end{array}$ & $\begin{array}{r}9.822830 \\
.822972 \\
.823114 \\
.823255 \\
.823397 \\
.823539 \\
.823680 \\
.823821 \\
.823963 \\
.821104\end{array}$ & $\begin{array}{l}2.37 \\
2.37 \\
2.35 \\
2.37 \\
2.37 \\
2.35 \\
2.35 \\
2.37 \\
2.35 \\
2.35\end{array}$ & $\begin{array}{r}9.873223 \\
.873110 \\
.872998 \\
.872885 \\
.872772 \\
.872659 \\
.872547 \\
.872434 \\
.872321 \\
.872208\end{array}$ & $\begin{array}{l}1.88 \\
1.87 \\
1.88 \\
1.88 \\
1.88 \\
1.87 \\
1.88 \\
1.88 \\
1.88 \\
1.88\end{array}$ & $\begin{array}{r}9.949608 \\
.949862 \\
.950116 \\
.950371 \\
.950625 \\
.950879 \\
.951133 \\
.951388 \\
.951642 \\
.951896\end{array}$ & $\begin{array}{l}4.23 \\
4.23 \\
4.25 \\
4.23 \\
4.23 \\
4.23 \\
4.25 \\
4.23 \\
4.23 \\
4.23\end{array}$ & $\begin{array}{r}10.050392 \\
.050138 \\
.049884 \\
.049629 \\
.049375 \\
.049121 \\
.04886 \\
.048612 \\
.048358 \\
.048104 \\
10.047850\end{array}$ & $\begin{array}{l}1 y \\
18 \\
17 \\
16 \\
15 \\
14 \\
13 \\
12 \\
11 \\
10\end{array}$ \\
\hline $\begin{array}{l}51 \\
52 \\
53 \\
54 \\
55 \\
56 \\
57 \\
58 \\
59 \\
60\end{array}$ & $\begin{array}{r}9.824245 \\
.824386 \\
.824527 \\
.824668 \\
.821808 \\
.824949 \\
.825090 \\
.825230 \\
.8253 \% 1 \\
\mathbf{9 . 8 2 5 5 1 1} \\
\end{array}$ & $\begin{array}{l}2.35 \\
2.35 \\
2.35 \\
2.35 \\
2.33 \\
2.35 \\
2.35 \\
2.33 \\
2.35 \\
2.33\end{array}$ & $\begin{array}{r}9.872095 \\
.871981 \\
.871868 \\
.871755 \\
.871641 \\
.871528 \\
.871414 \\
.871301 \\
.871187 \\
9.871073 \\
\end{array}$ & $\begin{array}{l}1.00 \\
1.90 \\
1.88 \\
1.88 \\
1.90 \\
1.88 \\
1.90 \\
1.88 \\
1.90 \\
1.90\end{array}$ & $\begin{array}{r}9.952150 \\
.952405 \\
.952659 \\
.952913 \\
.953167 \\
.953421 \\
.953675 \\
.953929 \\
.954183 \\
9.954437\end{array}$ & $\begin{array}{l}4.25 \\
4.23 \\
4.23 \\
4.23 \\
4.23 \\
4.23 \\
4.23 \\
4.23 \\
4.23\end{array}$ & $\begin{array}{r}10.047850 \\
.047595 \\
.047341 \\
.047087 \\
.046833 \\
.046579 \\
.046325 \\
.046071 \\
.045817 \\
10.045563\end{array}$ & $\begin{array}{l}9 \\
8 \\
7 \\
6 \\
5 \\
4 \\
3 \\
2 \\
1 \\
0\end{array}$ \\
\hline & & D. 1". & Sine. & D. $1^{\circ}$ & Cotang. & .1. & ang. & ' \\
\hline
\end{tabular}




\begin{tabular}{|c|c|c|c|c|c|c|c|c|}
\hline , & Sine. & D. $1^{\circ}$. & Cosine. & D. $1^{*}$. & Tang. & D. $1^{\prime \prime}$. & Cotang. & , \\
\hline $\begin{array}{r}0 \\
1 \\
2 \\
3 \\
4 \\
5 \\
6 \\
7 \\
8 \\
9 \\
10\end{array}$ & $\begin{array}{r}9.825511 \\
.825651 \\
.825791 \\
.825931 \\
.8260 \% 1 \\
.826211 \\
.826351 \\
.826491 \\
.826631 \\
.826770 \\
.826910\end{array}$ & $\begin{array}{l}2.33 \\
2.33 \\
2.33 \\
2.33 \\
2.33 \\
2.33 \\
2.33 \\
2.33 \\
2.32 \\
2.33 \\
2.32\end{array}$ & $\begin{array}{r}9.8710 \% 3 \\
.870960 \\
.870846 \\
.870732 \\
.870618 \\
.870504 \\
.870390 \\
.870276 \\
.870161 \\
.870047 \\
.869983\end{array}$ & $\begin{array}{l}1.83 \\
1.90 \\
1.90 \\
1.90 \\
1.90 \\
1.90 \\
1.90 \\
1.92 \\
1.90 \\
1.90 \\
1.92\end{array}$ & $\begin{array}{r}9.954437 \\
.954691 \\
.954946 \\
.955200 \\
.955454 \\
.955708 \\
.955961 \\
.956215 \\
.956469 \\
.956723 \\
.956977\end{array}$ & $\begin{array}{l}4.23 \\
4.25 \\
4.23 \\
4.23 \\
4.23 \\
4.22 \\
4.23 \\
4.23 \\
4.23 \\
4.23 \\
4.23\end{array}$ & $\begin{array}{r}10.045563 \\
.045309 \\
.045054 \\
.044800 \\
.044546 \\
.044292 \\
.044039 \\
.043785 \\
.043531 \\
.0432 \% \\
.043023\end{array}$ & $\begin{array}{l}60 \\
59 \\
58 \\
57 \\
56 \\
55 \\
54 \\
53 \\
52 \\
51 \\
50\end{array}$ \\
\hline $\begin{array}{l}11 \\
12 \\
13 \\
14 \\
15 \\
16 \\
17 \\
18 \\
19 \\
20\end{array}$ & $\begin{array}{r}9.827049 \\
.827189 \\
.827328 \\
.827467 \\
.827606 \\
.827745 \\
.827881 \\
.828023 \\
.828162 \\
.828301\end{array}$ & $\begin{array}{l}2.33 \\
2.32 \\
2.32 \\
2.32 \\
2.32 \\
2.32 \\
2.32 \\
2.32 \\
2.32 \\
2.30\end{array}$ & $\begin{array}{r}9.869818 \\
.869704 \\
.869589 \\
.869474 \\
.869360 \\
.869245 \\
.869130 \\
.869015 \\
.868900 \\
.868785\end{array}$ & $\begin{array}{l}1.92 \\
1.90 \\
1.92 \\
1.90 \\
1.92 \\
1.92 \\
1.92 \\
1.92 \\
1.92 \\
1.92\end{array}$ & $\begin{array}{r}9.957231 \\
.957485 \\
.957739 \\
.957993 \\
.958247 \\
.958500 \\
.958754 \\
.959008 \\
.959262 \\
.959516\end{array}$ & $\begin{array}{l}4.20 \\
4.23 \\
4.23 \\
4.23 \\
4.23 \\
4.22 \\
4.23 \\
4.23 \\
4.23 \\
4.23 \\
4.22\end{array}$ & $\begin{array}{r}10.042769 \\
.042515 \\
.042261 \\
.042007 \\
.041753 \\
.041500 \\
.041246 \\
.040992 \\
.0407 .8 \\
.040484\end{array}$ & $\begin{array}{l}49 \\
48 \\
47 \\
46 \\
45 \\
44 \\
43 \\
42 \\
41 \\
40\end{array}$ \\
\hline $\begin{array}{l}21 \\
22 \\
23 \\
24 \\
25 \\
26 \\
27 \\
28 \\
29 \\
30\end{array}$ & $\begin{array}{r}9.828439 \\
.828578 \\
.828716 \\
.828855 \\
.828993 \\
.829131 \\
.829269 \\
.829407 \\
.829545 \\
.829683\end{array}$ & $\begin{array}{l}2.32 \\
2.30 \\
2.32 \\
2.30 \\
2.30 \\
2.30 \\
2.30 \\
2.30 \\
2.30 \\
2.30\end{array}$ & $\begin{array}{r}9.8686 \% 0 \\
.868555 \\
.868440 \\
.868321 \\
.868209 \\
.868093 \\
.867978 \\
.86 \% 862 \\
.86 \% 747 \\
.86 \% 631\end{array}$ & $\begin{array}{l}1.92 \\
1.92 \\
1.93 \\
1.92 \\
1.93 \\
1.92 \\
1.93 \\
1.92 \\
1.93 \\
1.93\end{array}$ & $\begin{array}{r}9.959769 \\
.960023 \\
.960277 \\
.960530 \\
.960784 \\
.961038 \\
.961292 \\
.961545 \\
.961799 \\
.962052\end{array}$ & $\begin{array}{l}4.23 \\
4.23 \\
4.22 \\
4.23 \\
4.23 \\
4.23 \\
4.22 \\
4.23 \\
4.22 \\
4.23\end{array}$ & $\begin{array}{r}10.040231 \\
.039977 \\
.039723 \\
.039470 \\
.039216 \\
.038962 \\
.038708 \\
.038455 \\
.038 \% 01 \\
.037948\end{array}$ & $\begin{array}{l}39 \\
38 \\
37 \\
36 \\
35 \\
34 \\
33 \\
32 \\
31 \\
30\end{array}$ \\
\hline $\begin{array}{l}31 \\
32 \\
33 \\
34 \\
35 \\
36 \\
37 \\
38 \\
39 \\
40\end{array}$ & $\begin{array}{r}.829821 \\
.829959 \\
.830097 \\
.830234 \\
.830372 \\
.830509 \\
.830646 \\
.830784 \\
.830921 \\
.831058\end{array}$ & $\begin{array}{l}2.30 \\
2.30 \\
2.28 \\
2.30 \\
2.28 \\
2.28 \\
2.30 \\
2.28 \\
2.28 \\
2.28\end{array}$ & $\begin{array}{r}9.867515 \\
.867399 \\
.867283 \\
.867167 \\
.867051 \\
.866935 \\
.866819 \\
.866 \% 03 \\
.866586 \\
.866470\end{array}$ & $\begin{array}{l}1.93 \\
1.93 \\
1.93 \\
1.93 \\
1.93 \\
1.93 \\
1.93 \\
1.95 \\
1.93 \\
1.95\end{array}$ & $\begin{array}{r}9.962306 \\
.962560 \\
.962813 \\
.96306 \% \\
.963320 \\
.9635 \% 4 \\
.963828 \\
.964081 \\
.964335 \\
.964588\end{array}$ & $\begin{array}{l}4.20 \\
4.23 \\
4.22 \\
4.23 \\
4.22 \\
4.23 \\
4.23 \\
4.22 \\
4.23 \\
4.22 \\
4.23\end{array}$ & $\begin{array}{r}10.037694 \\
.037440 \\
.037187 \\
.036933 \\
.036680 \\
.036426 \\
.036172 \\
.035919 \\
.035665 \\
.035412\end{array}$ & $\begin{array}{l}29 \\
28 \\
27 \\
26 \\
25 \\
24 \\
23 \\
22 \\
21 \\
20\end{array}$ \\
\hline $\begin{array}{l}41 \\
42 \\
43 \\
44 \\
45 \\
46 \\
47 \\
48 \\
49 \\
50\end{array}$ & $\begin{array}{r}9.831195 \\
.831332 \\
.831469 \\
.831606 \\
.831742 \\
.831879 \\
.832015 \\
.832152 \\
.832288 \\
.832425\end{array}$ & $\begin{array}{l}2.28 \\
2.28 \\
2.28 \\
2.27 \\
2.28 \\
2.27 \\
2.28 \\
2.27 \\
2.28 \\
2.27\end{array}$ & $\begin{array}{r}9.866353 \\
.866237 \\
.866120 \\
.866004 \\
.865887 \\
.865 \% 0 \\
.865653 \\
.865536 \\
.865419 \\
.865302\end{array}$ & $\begin{array}{l}1.93 \\
1.95 \\
1.93 \\
1.95 \\
1.95 \\
1.95 \\
1.95 \\
1.95 \\
1.95 \\
1.95\end{array}$ & $\begin{array}{r}9.964842 \\
.965095 \\
.965349 \\
.965602 \\
.965855 \\
.966109 \\
.966362 \\
.966616 \\
.966869 \\
.967123\end{array}$ & $\begin{array}{l}4.20 \\
4.22 \\
4.23 \\
4.22 \\
4.22 \\
4.23 \\
4.22 \\
4.23 \\
4.22 \\
4.23 \\
4.22\end{array}$ & $\begin{array}{r}10.035158 \\
.034905 \\
.034651 \\
.034398 \\
.034145 \\
.033891 \\
.033638 \\
.033384 \\
.033131 \\
.032877\end{array}$ & $\begin{array}{l}19 \\
18 \\
17 \\
16 \\
15 \\
14 \\
13 \\
12 \\
11 \\
10\end{array}$ \\
\hline $\begin{array}{l}51 \\
52 \\
53 \\
54 \\
55 \\
56 \\
57 \\
58 \\
59 \\
60\end{array}$ & $\begin{array}{r}9.832561 \\
.832697 \\
.832833 \\
.832969 \\
.833105 \\
.833241 \\
.833377 \\
.833512 \\
.833648 \\
9.833783\end{array}$ & $\begin{array}{l}2.27 \\
2.27 \\
2.27 \\
2.27 \\
2.27 \\
2.27 \\
2.25 \\
2.27 \\
2.25\end{array}$ & $\begin{array}{r}9.865185 \\
.865068 \\
.864950 \\
.864833 \\
.864716 \\
.864598 \\
.864481 \\
.864363 \\
.864245 \\
9.86412 \gamma\end{array}$ & $\begin{array}{l}1.95 \\
1.97 \\
1.95 \\
1.95 \\
1.97 \\
1.95 \\
1.97 \\
1.97 \\
1.97\end{array}$ & $\begin{array}{r}9.9673 r 6 \\
.967629 \\
.967883 \\
.968136 \\
.968389 \\
.968643 \\
.968896 \\
.969149 \\
.969403 \\
9.969656\end{array}$ & $\begin{array}{l}4.22 \\
4.23 \\
4.22 \\
4.22 \\
4.23 \\
4.22 \\
4.22 \\
4.23 \\
4.22\end{array}$ & $\begin{array}{r}10.032624 \\
.032311 \\
.03211 \\
.031864 \\
.031611 \\
.031357 \\
.031104 \\
.030851 \\
.030597 \\
10.030344\end{array}$ & 0 \\
\hline ' & Cosine. & $1^{\prime \prime}$ & Sine. & D. $1^{\prime \prime}$. & Cotang. & D. $1^{\prime \prime}$. & Tang. & ' \\
\hline
\end{tabular}




\begin{tabular}{|c|c|c|c|c|c|c|c|c|}
\hline ' & Sine. & D. $1^{\prime \prime}$. & Cosine. & D. 1". & Tang. & D. $1^{\prime}$. & Cotang. & , \\
\hline $\begin{array}{r}0 \\
1 \\
2 \\
3 \\
4 \\
5 \\
6 \\
7 \\
8 \\
9 \\
10\end{array}$ & $\begin{array}{r}9.833783 \\
.833919 \\
.834054 \\
.834189 \\
.834325 \\
.834160 \\
.834595 \\
.834730 \\
.834865 \\
.834999 \\
.835134\end{array}$ & $\begin{array}{l}2.2 \% \\
2.25 \\
2.25 \\
2.27 \\
2.25 \\
2.25 \\
2.25 \\
2.25 \\
2.23 \\
2.25 \\
2.25\end{array}$ & $\begin{array}{r}9.864127 \\
.864010 \\
.863892 \\
.863114 \\
.863656 \\
.863538 \\
.863419 \\
.863301 \\
.863183 \\
.863064 \\
.862946\end{array}$ & $\begin{array}{l}1.95 \\
1.97 \\
1.97 \\
1.97 \\
1.97 \\
1.98 \\
1.97 \\
1.97 \\
1.98 \\
1.97 \\
1.98\end{array}$ & $\begin{array}{r}9.969656 \\
.969909 \\
.970162 \\
.970416 \\
.970669 \\
.970922 \\
.971175 \\
.971429 \\
.971682 \\
.971935 \\
.972188\end{array}$ & $\begin{array}{l}4.22 \\
4.22 \\
4.23 \\
4.22 \\
4.22 \\
4.22 \\
4.23 \\
4.22 \\
4.22 \\
4.22 \\
4.22\end{array}$ & $\begin{array}{r}10.030344 \\
.030091 \\
.029838 \\
.029584 \\
.029331 \\
.029078 \\
.028825 \\
.028571 \\
.028318 \\
.028065 \\
.027812\end{array}$ & $\begin{array}{l}60 \\
59 \\
58 \\
57 \\
56 \\
55 \\
54 \\
53 \\
52 \\
51 \\
50\end{array}$ \\
\hline $\begin{array}{l}11 \\
12 \\
13 \\
14 \\
15 \\
16 \\
17 \\
18 \\
19 \\
20\end{array}$ & $\begin{array}{r}9.835269 \\
.835403 \\
.835538 \\
.835672 \\
.835807 \\
.835941 \\
.836075 \\
.836209 \\
.836343 \\
.836477\end{array}$ & $\begin{array}{l}2.23 \\
2.25 \\
2.23 \\
2.25 \\
2.23 \\
2.23 \\
2.23 \\
2.23 \\
2.23 \\
2.23\end{array}$ & $\begin{array}{r}9.862827 \\
.862709 \\
.862590 \\
.8624 \pi 1 \\
.862353 \\
.862234 \\
.862115 \\
.861996 \\
.8618 \% 7 \\
.861758\end{array}$ & $\begin{array}{l}1.97 \\
1.98 \\
1.98 \\
1.97 \\
1.98 \\
1.98 \\
1.98 \\
1.98 \\
1.98 \\
2.00\end{array}$ & $\begin{array}{r}9.972441 \\
.972695 \\
.972948 \\
.973201 \\
.973454 \\
.973707 \\
.973960 \\
.974213 \\
.974466 \\
.974 \% 20\end{array}$ & $\begin{array}{l}4.23 \\
4.22 \\
4.22 \\
4.22 \\
4.22 \\
4.22 \\
4.22 \\
4.22 \\
4.23 \\
4.22\end{array}$ & $\begin{array}{r}10.027559 \\
.027305 \\
.027052 \\
.026799 \\
.026546 \\
.026293 \\
.026040 \\
.025787 \\
.025534 \\
.025280\end{array}$ & $\begin{array}{l}49 \\
48 \\
47 \\
46 \\
45 \\
44 \\
43 \\
42 \\
41 \\
40\end{array}$ \\
\hline $\begin{array}{l}21 \\
22 \\
23 \\
24 \\
25 \\
26 \\
27 \\
28 \\
29 \\
30\end{array}$ & $\begin{array}{r}9.836611 \\
.836745 \\
.836878 \\
.837012 \\
.837146 \\
.837279 \\
.837412 \\
.837546 \\
.837679 \\
.837812\end{array}$ & $\begin{array}{l}2.23 \\
2.22 \\
2.23 \\
2.23 \\
2.22 \\
2.22 \\
2.23 \\
2.22 \\
2.22 \\
2.22\end{array}$ & $\begin{array}{r}9.861638 \\
.861519 \\
.861400 \\
.861280 \\
.861161 \\
.861041 \\
.860922 \\
.860802 \\
.860682 \\
.860562\end{array}$ & $\begin{array}{l}1.98 \\
1.98 \\
2.00 \\
1.98 \\
2.00 \\
1.98 \\
2.00 \\
2.00 \\
2.00 \\
2.00\end{array}$ & $\begin{array}{r}9.974973 \\
.975226 \\
.975479 \\
.975 \% 32 \\
.975985 \\
.976238 \\
.976491 \\
.976 \% 44 \\
.976997 \\
.977250\end{array}$ & $\begin{array}{l}4.22 \\
4.22 \\
4.22 \\
4.22 \\
4.22 \\
4.22 \\
4.22 \\
4.22 \\
4.22 \\
4.22\end{array}$ & $\begin{array}{r}10.025027 \\
.024774 \\
.024521 \\
.024268 \\
.024015 \\
.023 \% 62 \\
.023509 \\
.023256 \\
.023003 \\
.022750\end{array}$ & $\begin{array}{l}39 \\
38 \\
37 \\
36 \\
35 \\
34 \\
33 \\
32 \\
31 \\
30\end{array}$ \\
\hline $\begin{array}{l}31 \\
32 \\
33 \\
34 \\
35 \\
36 \\
37 \\
38 \\
39 \\
40\end{array}$ & $\begin{array}{r}9.837945 \\
.838078 \\
.838211 \\
.838344 \\
.838477 \\
.838610 \\
.838742 \\
.838875 \\
.839007 \\
.839140\end{array}$ & $\begin{array}{l}2.22 \\
2.22 \\
2.22 \\
2.22 \\
2.22 \\
2.20 \\
2.22 \\
2.20 \\
2.22 \\
2.20\end{array}$ & $\begin{array}{r}9.860442 \\
.860322 \\
.860202 \\
.860082 \\
.859962 \\
.859842 \\
.859721 \\
.859601 \\
.859480 \\
.859360\end{array}$ & $\begin{array}{l}2.00 \\
2.00 \\
2.00 \\
2.00 \\
2.00 \\
2.02 \\
2.00 \\
2.02 \\
2.00 \\
2.02\end{array}$ & $\begin{array}{r}9.97 \% 503 \\
.97756 \\
.978009 \\
.978262 \\
.978515 \\
.978768 \\
.979021 \\
.979274 \\
.979527 \\
.979780\end{array}$ & $\begin{array}{l}4.22 \\
4.22 \\
4.22 \\
4.22 \\
4.22 \\
4.22 \\
4.22 \\
4.22 \\
4.22 \\
4.22\end{array}$ & $\begin{array}{r}10.022497 \\
.022244 \\
.021991 \\
.021738 \\
.021485 \\
.021232 \\
.020979 \\
.020726 \\
.020473 \\
.0202220\end{array}$ & $\begin{array}{l}29 \\
28 \\
27 \\
26 \\
25 \\
24 \\
23 \\
22 \\
21 \\
20\end{array}$ \\
\hline $\begin{array}{l}41 \\
42 \\
43 \\
44 \\
45 \\
46 \\
47 \\
48 \\
49 \\
50\end{array}$ & $\begin{array}{r}9.8392 \pi 2 \\
.839404 \\
.839536 \\
.839668 \\
.839800 \\
.839932 \\
.840064 \\
.840196 \\
.840328 \\
.840459\end{array}$ & $\begin{array}{l}2.20 \\
2.20 \\
2.20 \\
2.20 \\
2.20 \\
2.20 \\
2.20 \\
2.20 \\
2.18 \\
2.20\end{array}$ & $\begin{array}{r}9.859239 \\
.859119 \\
.858998 \\
.858877 \\
.858756 \\
.858635 \\
.858514 \\
.858393 \\
.858272 \\
.858151\end{array}$ & $\begin{array}{l}2.00 \\
2.02 \\
2.02 \\
2.02 \\
2.02 \\
2.02 \\
2.02 \\
2.02 \\
2.02 \\
2.03\end{array}$ & $\begin{array}{r}9.980033 \\
.980286 \\
.980538 \\
.980791 \\
.981044 \\
.981297 \\
.981550 \\
.981 \times 03 \\
.982056 \\
.982309\end{array}$ & $\begin{array}{l}4.22 \\
4.20 \\
4.22 \\
4.22 \\
4.22 \\
4.22 \\
4.22 \\
4.22 \\
4.22 \\
4.22\end{array}$ & $\begin{array}{r}10.019967 \\
.019714 \\
.019462 \\
.019209 \\
.018956 \\
.018703 \\
.018450 \\
.018197 \\
.017944 \\
.017691\end{array}$ & $\begin{array}{r}19 \\
18 \\
17 \\
16 \\
15 \\
14 \\
13 \\
12 \\
11 \\
10\end{array}$ \\
\hline $\begin{array}{l}51 \\
52 \\
53 \\
54 \\
55 \\
56 \\
57 \\
58 \\
59 \\
60\end{array}$ & $\begin{array}{r}9.840591 \\
.840722 \\
.840854 \\
.840985 \\
.811116 \\
.811247 \\
.841378 \\
.841509 \\
.841640 \\
9.841771 \\
\end{array}$ & $\begin{array}{l}2.18 \\
2.20 \\
2.18 \\
2.18 \\
2.18 \\
2.18 \\
2.18 \\
2.18 \\
2.18\end{array}$ & $\begin{array}{r}9.858029 \\
.857908 \\
.857786 \\
.857665 \\
.857543 \\
.857422 \\
.857300 \\
.857178 \\
.857056 \\
9.856934 \\
\end{array}$ & $\begin{array}{l}2.00 \\
2.02 \\
2.03 \\
2.02 \\
2.03 \\
2.02 \\
2.03 \\
2.03 \\
2.03 \\
2.03\end{array}$ & $\begin{array}{r}9.982562 \\
.982814 \\
.983067 \\
.983320 \\
.983573 \\
.983826 \\
.984079 \\
.984332 \\
.984584 \\
9.981837 \\
\end{array}$ & $\begin{array}{l}4.20 \\
4.22 \\
4.22 \\
4.22 \\
4.22 \\
4.22 \\
4.22 \\
4.20 \\
4.22\end{array}$ & $\begin{array}{r}10.017438 \\
.017186 \\
.016933 \\
.016680 \\
.016427 \\
.016174 \\
.015921 \\
.015668 \\
.015416 \\
10.015163 \\
\end{array}$ & $\begin{array}{l}9 \\
8 \\
7 \\
6 \\
5 \\
4 \\
3 \\
2 \\
1 \\
0\end{array}$ \\
\hline & Cosine & 1 & $\sin \theta$. & D. $1^{\prime \prime}$. & Cotang. & D. 1 . & Tang. & 1 \\
\hline
\end{tabular}




\begin{tabular}{|c|c|c|c|c|c|c|c|c|}
\hline , & Sine. & D. $1^{\prime \prime}$. & Cosine. & D. $1^{\circ}$. & Tang. & D. $1^{\prime \prime}$. & Cotang. & ' \\
\hline $\begin{array}{r}0 \\
1 \\
2 \\
3 \\
4 \\
5 \\
6 \\
7 \\
8 \\
9 \\
10\end{array}$ & $\begin{array}{r}9.84171 \\
.841902 \\
.842033 \\
.842163 \\
.842294 \\
.842424 \\
.842555 \\
.842685 \\
.842815 \\
.842946 \\
.843076\end{array}$ & $\begin{array}{l}2.18 \\
2.18 \\
2.17 \\
2.18 \\
2.17 \\
2.18 \\
2.17 \\
2.17 \\
2.18 \\
2.17 \\
2.17\end{array}$ & $\begin{array}{r}9.856934 \\
.856812 \\
.856690 \\
.856568 \\
.856446 \\
.856323 \\
.856201 \\
.856078 \\
.855956 \\
.855833 \\
.855711\end{array}$ & $\begin{array}{l}2.03 \\
2.03 \\
2.03 \\
2.03 \\
2.05 \\
2.03 \\
2.05 \\
2.03 \\
2.05 \\
2.03 \\
2.05\end{array}$ & $\begin{array}{r}9.984837 \\
.985090 \\
.985543 \\
.985596 \\
.985848 \\
.986101 \\
.986354 \\
.986607 \\
.986860 \\
.987112 \\
.987365\end{array}$ & $\begin{array}{l}4.22 \\
4.22 \\
4.22 \\
4.20 \\
4.22 \\
4.22 \\
4.22 \\
4.22 \\
4.20 \\
4.22 \\
4.22\end{array}$ & $\begin{array}{r}10.015163 \\
.014910 \\
.014657 \\
.014404 \\
.014152 \\
.013899 \\
.013646 \\
.013393 \\
.013140 \\
.012888 \\
.012635\end{array}$ & $\begin{array}{l}60 \\
59 \\
58 \\
57 \\
56 \\
55 \\
54 \\
53 \\
52 \\
51 \\
50\end{array}$ \\
\hline $\begin{array}{l}11 \\
12 \\
13 \\
14 \\
15 \\
16 \\
17 \\
18 \\
19 \\
20\end{array}$ & $\begin{array}{r}9.843206 \\
.843336 \\
.843466 \\
.843595 \\
.843725 \\
.843855 \\
.843984 \\
.844114 \\
.844243 \\
.814372\end{array}$ & $\begin{array}{l}2.17 \\
2.17 \\
2.15 \\
2.17 \\
2.17 \\
2.15 \\
2.17 \\
2.15 \\
2.15 \\
2.17\end{array}$ & $\begin{array}{r}9.855588 \\
.855465 \\
.855342 \\
.855219 \\
.855096 \\
.854973 \\
.854850 \\
.854727 \\
.854603 \\
.854480\end{array}$ & $\begin{array}{l}2.05 \\
2.05 \\
2.05 \\
2.05 \\
2.05 \\
2.05 \\
2.05 \\
2.07 \\
2.05 \\
2.07\end{array}$ & $\begin{array}{r}9.987618 \\
.987871 \\
.988123 \\
.988376 \\
.988629 \\
.988882 \\
.989134 \\
.989387 \\
.989640 \\
.989893\end{array}$ & $\begin{array}{l}4.22 \\
4.20 \\
4.22 \\
4.22 \\
4.22 \\
4.20 \\
4.22 \\
4.22 \\
4.22 \\
4.20\end{array}$ & $\begin{array}{r}10.012382 \\
.012129 \\
.0118 \% 7 \\
.011624 \\
.0113 \% 1 \\
.011118 \\
.010866 \\
.010613 \\
.010360 \\
.010107\end{array}$ & $\begin{array}{l}49 \\
48 \\
47 \\
46 \\
45 \\
44 \\
43 \\
42 \\
41 \\
40\end{array}$ \\
\hline $\begin{array}{l}21 \\
22 \\
23 \\
24 \\
25 \\
26 \\
27 \\
28 \\
29 \\
30\end{array}$ & $\begin{array}{r}9.844502 \\
.814631 \\
.844660 \\
.844889 \\
.845018 \\
.815147 \\
.845276 \\
.815405 \\
.845533 \\
.845662\end{array}$ & $\begin{array}{l}2.15 \\
2.15 \\
2.15 \\
2.15 \\
2.15 \\
2.15 \\
2.15 \\
2.13 \\
2.15 \\
2.13\end{array}$ & $\begin{array}{r}9.854356 \\
.854233 \\
.854109 \\
.853986 \\
.853862 \\
.853738 \\
.853614 \\
.853490 \\
.853366 \\
.853242\end{array}$ & $\begin{array}{l}2.05 \\
2.07 \\
2.05 \\
2.07 \\
2.07 \\
2.07 \\
2.07 \\
2.07 \\
2.07 \\
2.07\end{array}$ & $\begin{array}{r}9.990145 \\
.990398 \\
.990651 \\
.990903 \\
.991156 \\
.991409 \\
.991662 \\
.991914 \\
.992167 \\
.992420\end{array}$ & $\begin{array}{l}4.22 \\
4.22 \\
4.20 \\
4.22 \\
4.22 \\
4.22 \\
4.20 \\
4.22 \\
4.22 \\
4.20\end{array}$ & $\begin{array}{r}10.009855 \\
.009602 \\
.009349 \\
.00909 \\
.008844 \\
.008591 \\
.008338 \\
.008086 \\
.007833 \\
.007580\end{array}$ & $\begin{array}{l}38 \\
37 \\
36 \\
35 \\
34 \\
33 \\
32 \\
31\end{array}$ \\
\hline $\begin{array}{l}31 \\
32 \\
33 \\
34 \\
35 \\
36 \\
37 \\
38 \\
39 \\
40\end{array}$ & $\begin{array}{r}9.845790 \\
.845919 \\
.846047 \\
.846175 \\
.846304 \\
.846432 \\
.846560 \\
.846688 \\
.846816 \\
.846944\end{array}$ & $\begin{array}{l}2.15 \\
2.13 \\
2.13 \\
2.15 \\
2.13 \\
2.13 \\
2.13 \\
2.13 \\
2.13 \\
2.12\end{array}$ & $\begin{array}{r}9.853118 \\
.852994 \\
.852869 \\
.852745 \\
.852620 \\
.852496 \\
.852371 \\
.852247 \\
.852122 \\
.851997\end{array}$ & $\begin{array}{l}2.07 \\
2.08 \\
2.07 \\
2.08 \\
2.07 \\
2.08 \\
2.08 \\
2.08 \\
2.08 \\
2.08\end{array}$ & $\begin{array}{r}9.992612 \\
.992925 \\
.993178 \\
.993431 \\
.993683 \\
.993936 \\
.994189 \\
.994441 \\
.994694 \\
.994947\end{array}$ & $\begin{array}{l}4.22 \\
4.22 \\
4.22 \\
4.20 \\
4.22 \\
4.22 \\
4.20 \\
4.22 \\
4.22 \\
4.20\end{array}$ & $\begin{array}{r}10.007328 \\
.007075 \\
.006822 \\
.006569 \\
.006317 \\
.006064 \\
.005811 \\
.005559 \\
.005306 \\
.005053\end{array}$ & $\begin{array}{l}29 \\
28 \\
27 \\
26 \\
25 \\
24 \\
23 \\
22 \\
21 \\
20\end{array}$ \\
\hline $\begin{array}{l}41 \\
42 \\
43 \\
44 \\
45 \\
46 \\
47 \\
48 \\
49 \\
50\end{array}$ & $\begin{array}{r}9.847071 \\
.847199 \\
.847327 \\
.847454 \\
.847582 \\
.847709 \\
.847836 \\
.847964 \\
.848091 \\
.848218\end{array}$ & $\begin{array}{l}2.13 \\
2.13 \\
2.12 \\
2.13 \\
2.12 \\
2.12 \\
2.13 \\
2.12 \\
2.12 \\
2.12\end{array}$ & $\begin{array}{r}9.851872 \\
.851747 \\
.851622 \\
.851497 \\
.851372 \\
.851246 \\
.851121 \\
.850996 \\
.850870 \\
.850745\end{array}$ & $\begin{array}{l}2.08 \\
2.08 \\
2.08 \\
2.08 \\
2.10 \\
2.08 \\
2.08 \\
2.10 \\
2.08 \\
2.10\end{array}$ & $\begin{array}{r}9.995199 \\
.995452 \\
.995705 \\
.995957 \\
.996210 \\
.996463 \\
.996715 \\
.996968 \\
.997221 \\
.997473\end{array}$ & $\begin{array}{l}4.20 \\
4.22 \\
4.20 \\
4.22 \\
4.22 \\
4.20 \\
4.22 \\
4.22 \\
4.20 \\
4.22\end{array}$ & $\begin{array}{r}10.004801 \\
.004548 \\
.004295 \\
.004043 \\
.003790 \\
.003537 \\
.003285 \\
.003032 \\
.002779 \\
.002527\end{array}$ & $\begin{array}{l}19 \\
18 \\
17 \\
16 \\
15 \\
14 \\
13 \\
12 \\
11 \\
10\end{array}$ \\
\hline $\begin{array}{l}51 \\
52 \\
53 \\
54 \\
55 \\
56 \\
57 \\
58 \\
59 \\
60\end{array}$ & $\begin{array}{r}9.848345 \\
.848472 \\
.848599 \\
.848726 \\
.848852 \\
.848979 \\
.849106 \\
.849232 \\
.849359 \\
9.849485\end{array}$ & $\begin{array}{l}2.12 \\
2.12 \\
2.12 \\
2.10 \\
2.12 \\
2.12 \\
2.10 \\
2.12 \\
2.10\end{array}$ & $\begin{array}{r}9.850619 \\
.850493 \\
.850368 \\
.850242 \\
.850116 \\
.849990 \\
.849864 \\
.849738 \\
.849611 \\
9849485\end{array}$ & $\begin{array}{l}2.10 \\
2.08 \\
2.10 \\
2.10 \\
2.10 \\
2.10 \\
2.10 \\
2.12 \\
2.10\end{array}$ & $\begin{array}{r}9.997726 \\
.997979 \\
.998231 \\
.998484 \\
.998737 \\
.998989 \\
.999242 \\
.999495 \\
.999747 \\
10.000000\end{array}$ & $\begin{array}{l}4.22 \\
4.20 \\
4.22 \\
4.22 \\
4.20 \\
4.22 \\
4.22 \\
4.20 \\
4.22\end{array}$ & $\begin{array}{r}10.002274 \\
.002021 \\
.001769 \\
.001516 \\
.001263 \\
.001011 \\
.000758 \\
.000505 \\
.000253 \\
10.000000\end{array}$ & $\begin{array}{l}9 \\
8 \\
7 \\
6 \\
5 \\
4 \\
3 \\
2 \\
1 \\
0\end{array}$ \\
\hline , & Cosine. & D. $1 "$. & Sine. & D. $1^{\prime \prime}$. & Cotang. & D. $1^{\prime \prime}$. & Tang. & ' \\
\hline
\end{tabular}




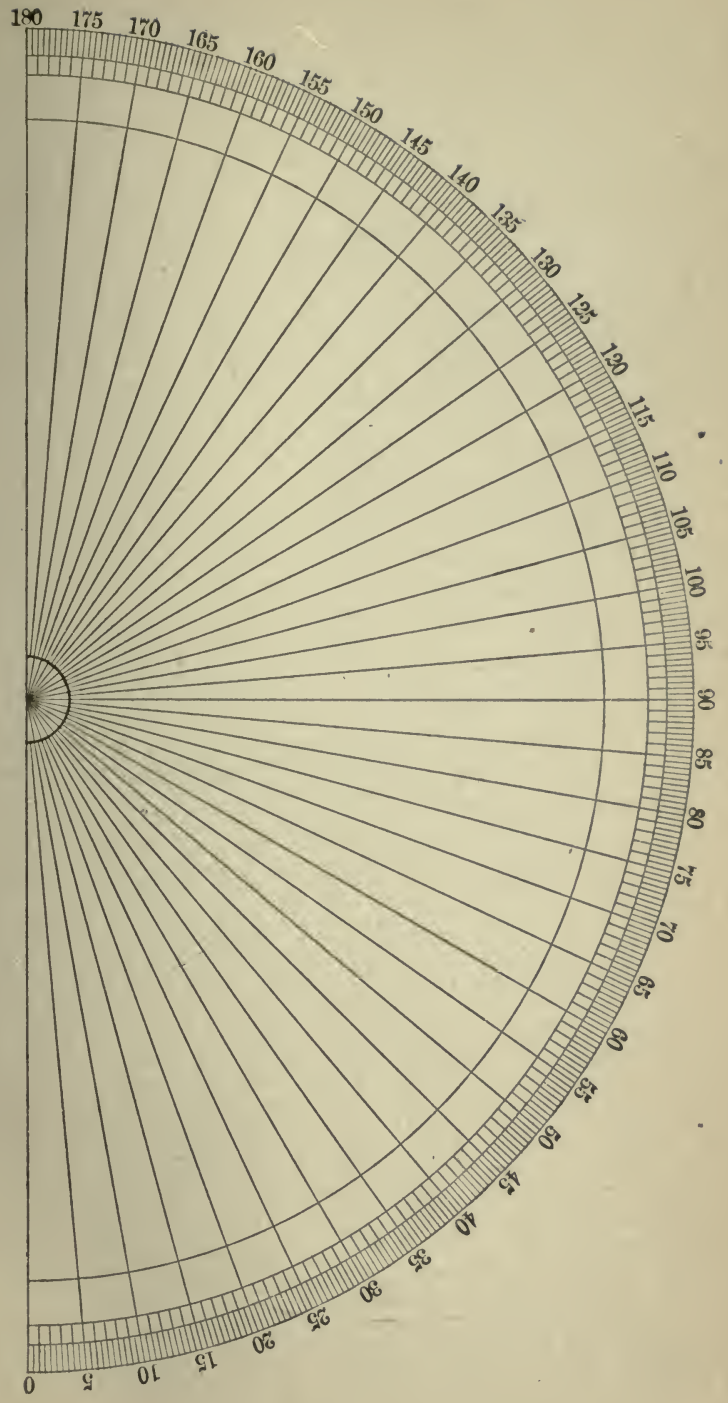





\section{INDEX.}

(Names of animals are to be looked for under their class name.)

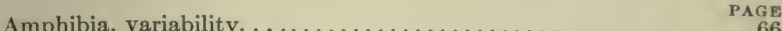

Amphipoda, see Crustacea. ....................... 66

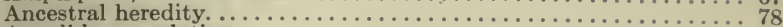

Annelida, correlation. ............................. 76

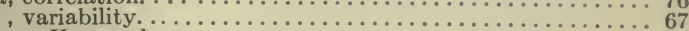

Aphidæ, see Hexapoda . . . . . . . . . . . . . . . . . . 66

Area, measurement of. . . . .

Arithmetical work, precautions in. . . . . . . . . . .

Arithometer. . . . . . . . . . . . . . . . . . . 7

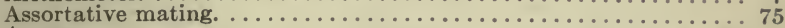

Average. .............................. 17

deviation. . . . . . . . . . . . .

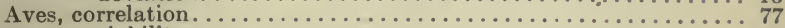

, variability . . . . . . . . . . . . . . . . . . 65

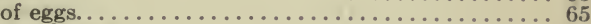

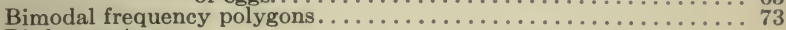

Birds, see Aves.

Brachiopoda, variability. . . . . . . . . . . . . . . . 67

Brunsviga calculator. ...................... 8

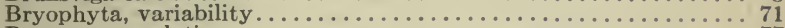

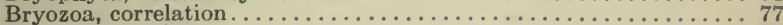

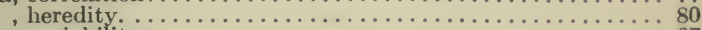

, variability.............................. 67

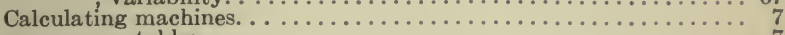

tables. . . . . . . . . . . . . .

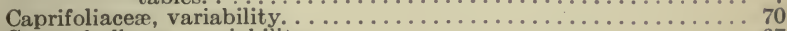

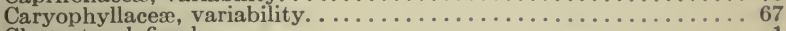

Character defined. ...................... 1

Chauvenet's criterion. . . . . . . . . . . . . . . . . 12

Class, defined . . . . . . . . . . . . . . . . . . . 1

range. . . . . . . . .

Closeness of fit. . . . . . . . . . . . . . . . . .

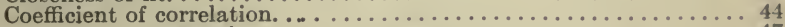

regression. . . . . . . . . . .

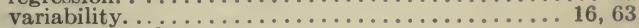

Cœelenterata, see Hydromedusa.

Color, measurement of. ....................... 6

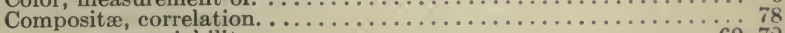

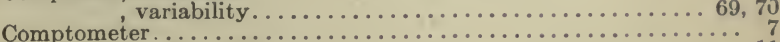

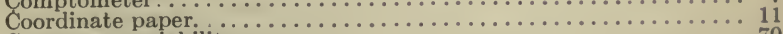

Cornaceæ, variability. . . . . . . . . . . . . . . . . 70

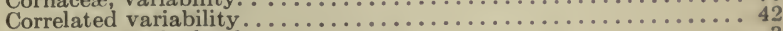

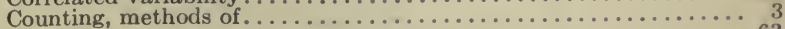

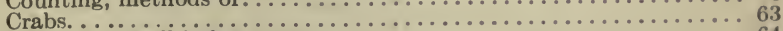

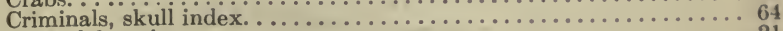

Critical function.

Cruciferæ, variability............................... 
PAGE Amphipoda, variability ....................67

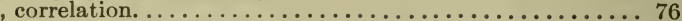

, Daphnia, correlation............................. 77

, heredity. ........................ 80

, Eupagurus, correlation................... 77

, local races. . . . . . . . . . . . . . . . . 84

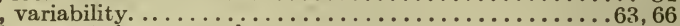

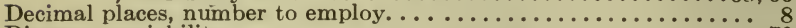

Dipsacæ, variability. . . . . . . . . . . . . . . . . 70

Discontinuous variates. . . . ....................... 1

Dissymmetrical animals, bilateral correlation of $\ldots \ldots \ldots \ldots \ldots \ldots \ldots 76$

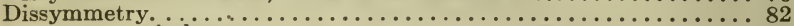

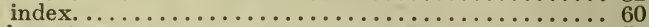

Dominating characters. . . . . . . . . . . . . . . .

Echinodermata, correlation. . . . . . . . . . . . . . 76

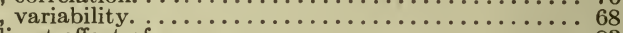

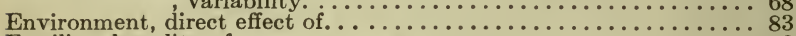

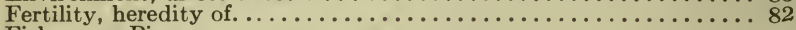

Fishes, see Pisces.

Frequency polygon . . . . . . . . . . . . . . . . . . 62

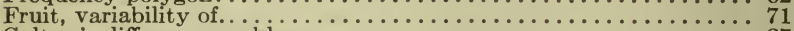

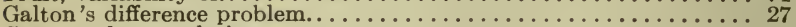

Gastropoda, correlation. . . . . . . . . . . . . . . . 77

Geometric , variability. ............................. 67

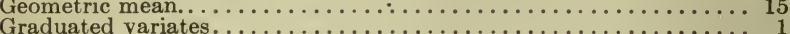

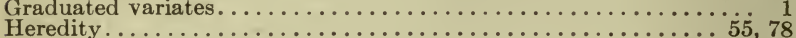

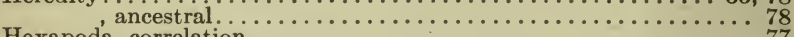

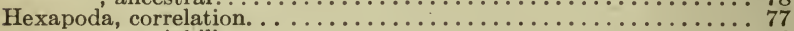

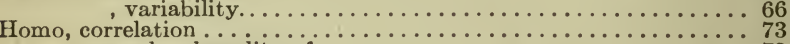

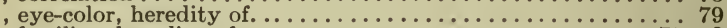

, fertility, heredity of. . . . . . . . . .

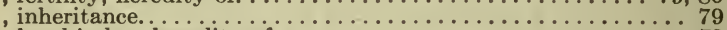

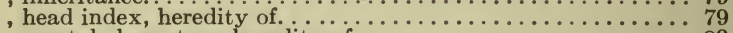

, mental characters, heredity of. .........................

, skeletal, correlation. .................................. 74

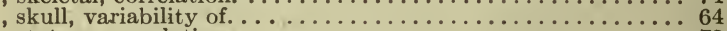

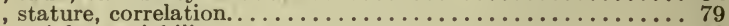

, weight, variability. . . . . . . . . . . . . . .

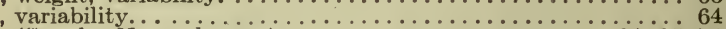

(See also Naquada race). . . . . . . .

Homotyposis . . . . . . . . . . . . . . . . . . . 81

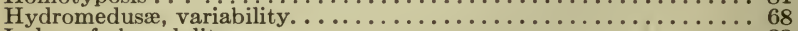

Index of abmodality. ... . . . . . . . .

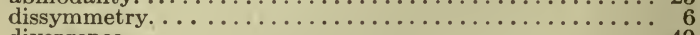

divergence. . . . . . . . . . . .

isolation. . . . . . . . .

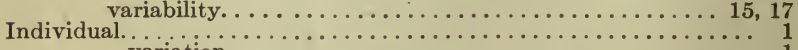

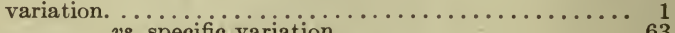

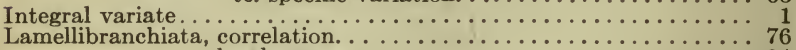

, local races. .................. 84

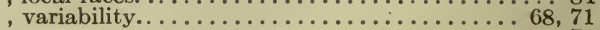

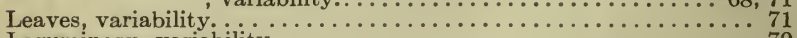

Leguminosæ, variability. ......................... 70

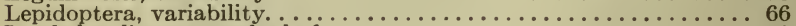

Loaded ordinates, method of....................... 12

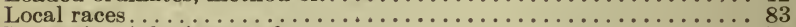

Longevity, inheritance of. . . . . . . . . . . . . .

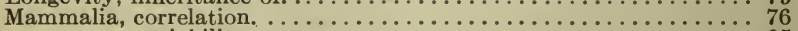

Mean variability. . . . . . . . . . . . . . . . . . . 65

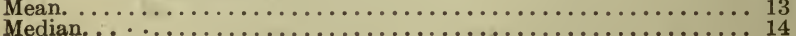




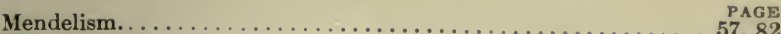

Mid-departure . . . . . . . . .

Mode. . . . . . . . . . . . . . . . . . .

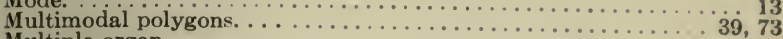

Multiple organ $\ldots \ldots \ldots \ldots \ldots \ldots \ldots \ldots \ldots \ldots \ldots \ldots \ldots \ldots \ldots,{ }_{1}$

Mutations. . . . . . . .

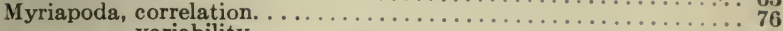

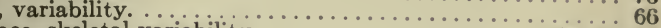

Naquada race, skeletal variability. . . .

Normal curve of frequency. . . . . . . . . . . . . . . . . . 22

Number of variates to employ. . . . . . . . . . . . . . .

Orchidace

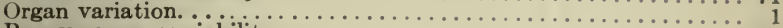

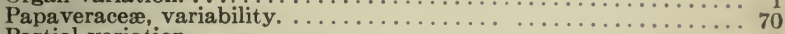

Partial variation. . . . . . . . . . . . . . . . . . . 1

Person. . . . . . . . . . . . . . . . . . . .

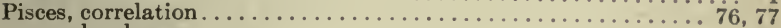
, local races ........................... 83

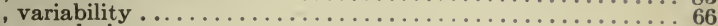

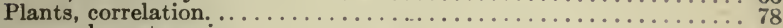

, homotyposis. .................................... 81

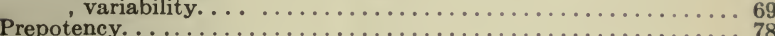

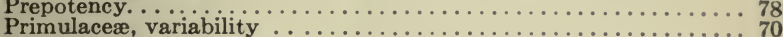

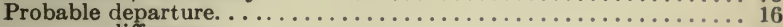

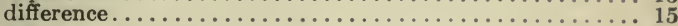

error. ................................. 14

in uniparental heredity............................. 55

of coefficient of correlation. . . . . . . . . . . . . . 44

of variability................ 16

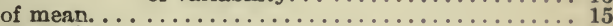

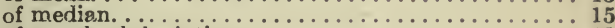

of standard deviation. ....................... 16

Probability of normality of a given distribution. ............ 24

Protista, correlation. . . . . . . . . . . . . . . . . 77

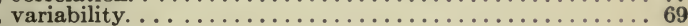

Range of variability. . . . . . . . . . . . . . . . . . . 25

Ranunculaceæ, variability. . . . . . . . . . . . . . . . . 69

Recessive characters. . ............................. 58

Rectangles, method of, in platting frequency distributions. . . . . . 11

Rejection of extreme variates. . . . . . . . . . . . . . . . . 12

Relative variability of the sexes. . . . . . . . . . . . . . . . . . . 63

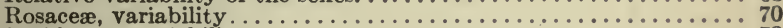

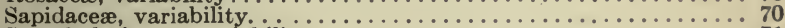

Scrophulariaceæ, variability. . . . . . . . . . . . . . 71

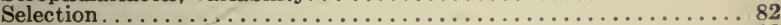

Sex, relative variability. . . . . . . . . . . . . . . . . 63

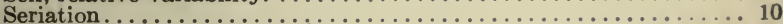

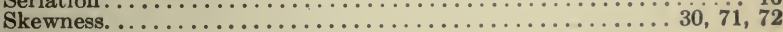

Skull, see Homo.

Spurious correlation. . . . . . . . . . . . . . . . . . . . . . . . 54

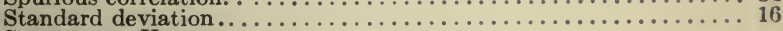

Stature, see Homo.

Symmetry in frequency distribution. . . . . . . . . . . . . 19

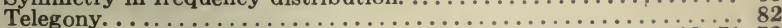

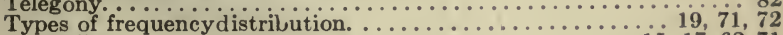

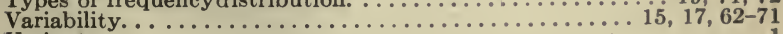

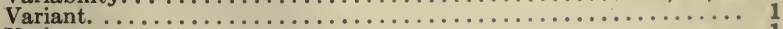

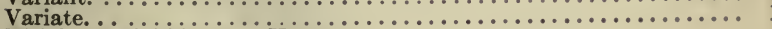

Weight, variability, see Homo. 



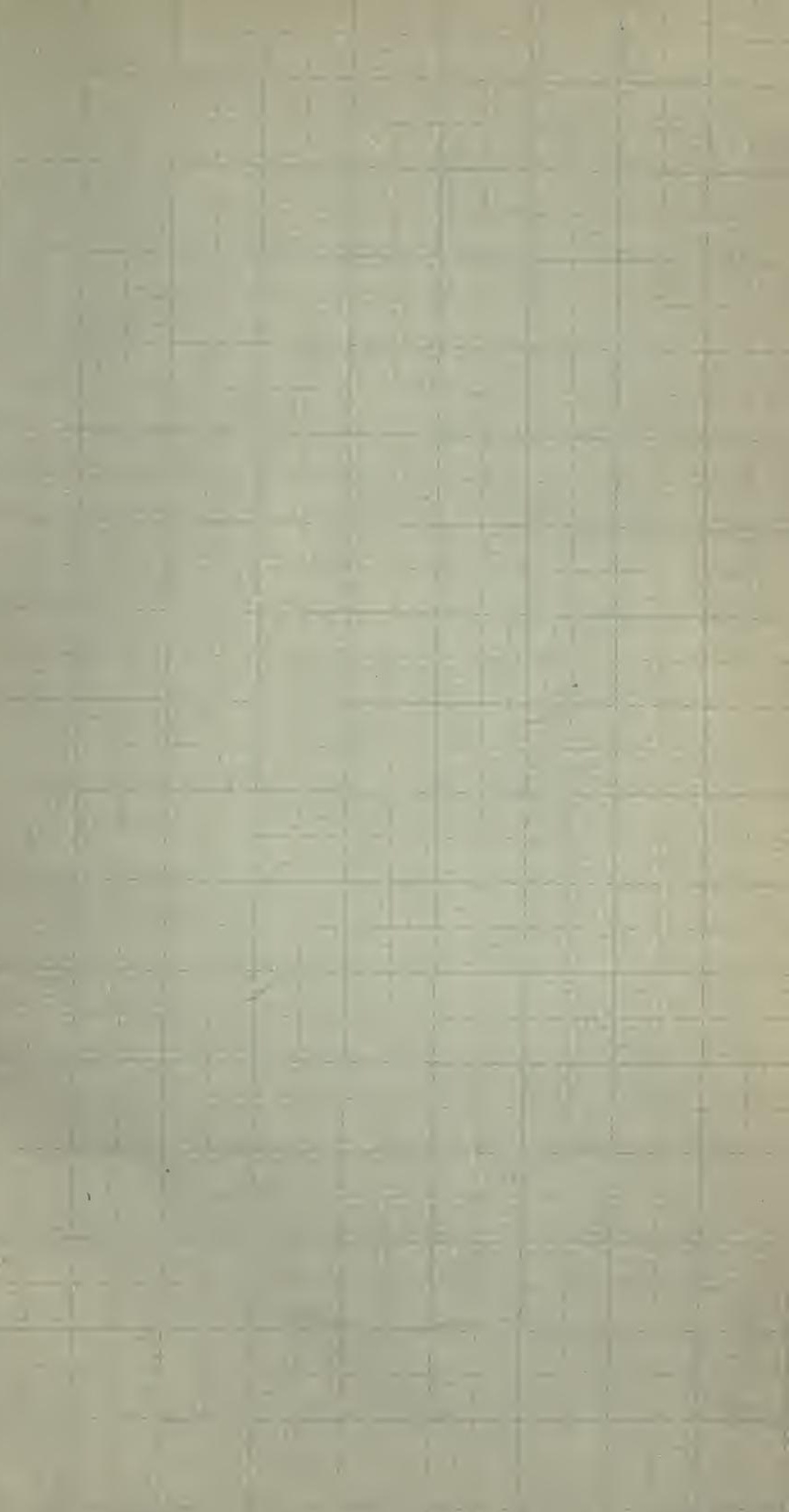








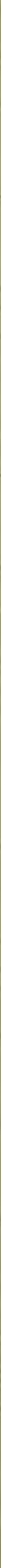






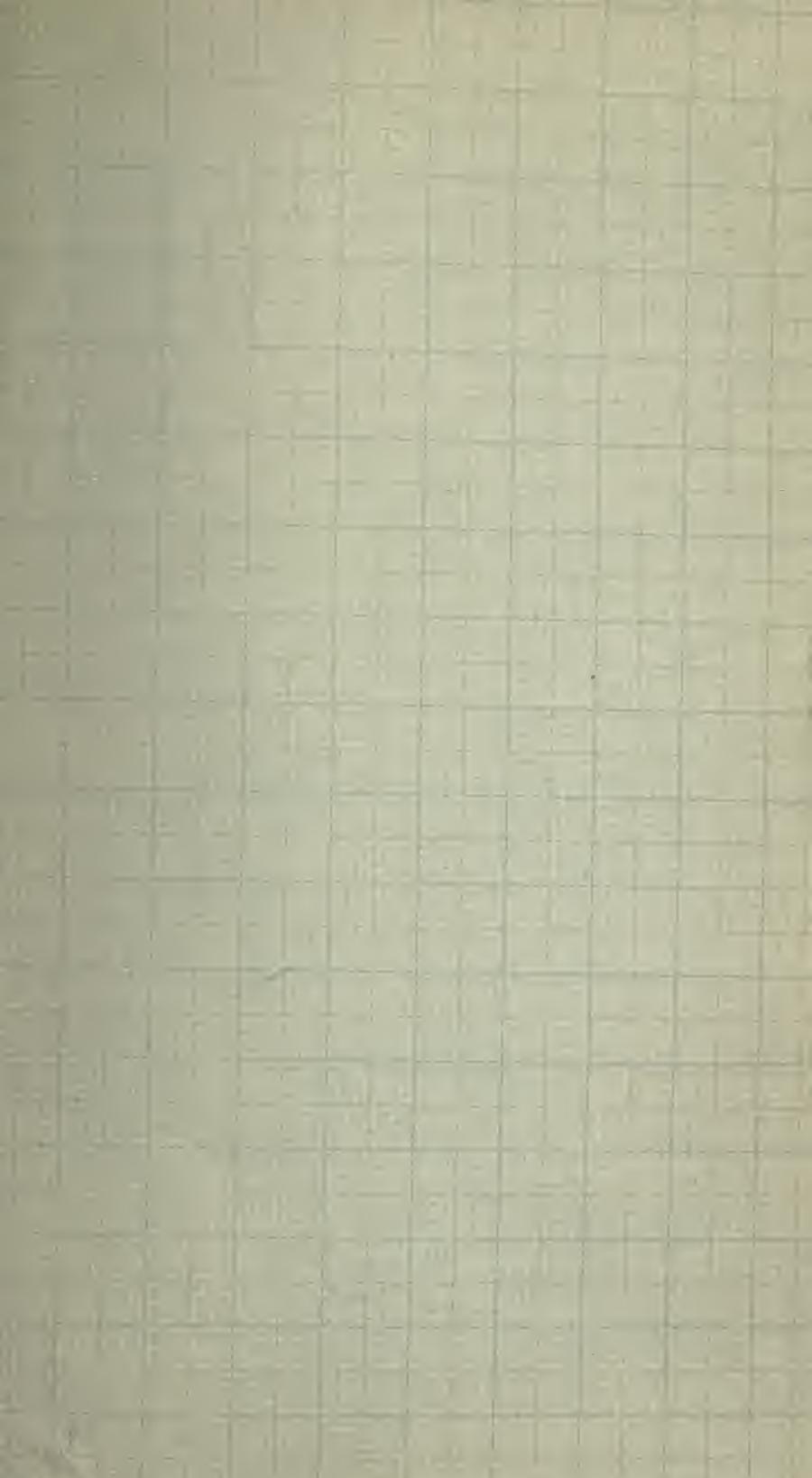






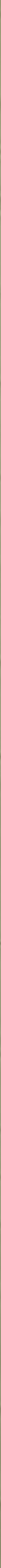




UNIVERSITY OF CALIFORNIA

BRANCH OF THE COLLEGE OF AGRICULTURE

THIS BOOK IS DUE ON THE LAST DATE STAMPED BELOW

\section{FEg 1 [83]}

MAP $2 B$ B TH81

SFP : 2501

SWAR ह- kब3?

APR $6 \quad 293 \%$

APR \& $\quad 293$ ?

AAY 261837

FLY

FEB 551946

EEB 281947

MMT ? 61987

8 NoV oft L 18 


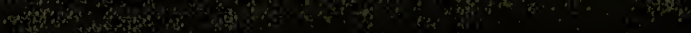

